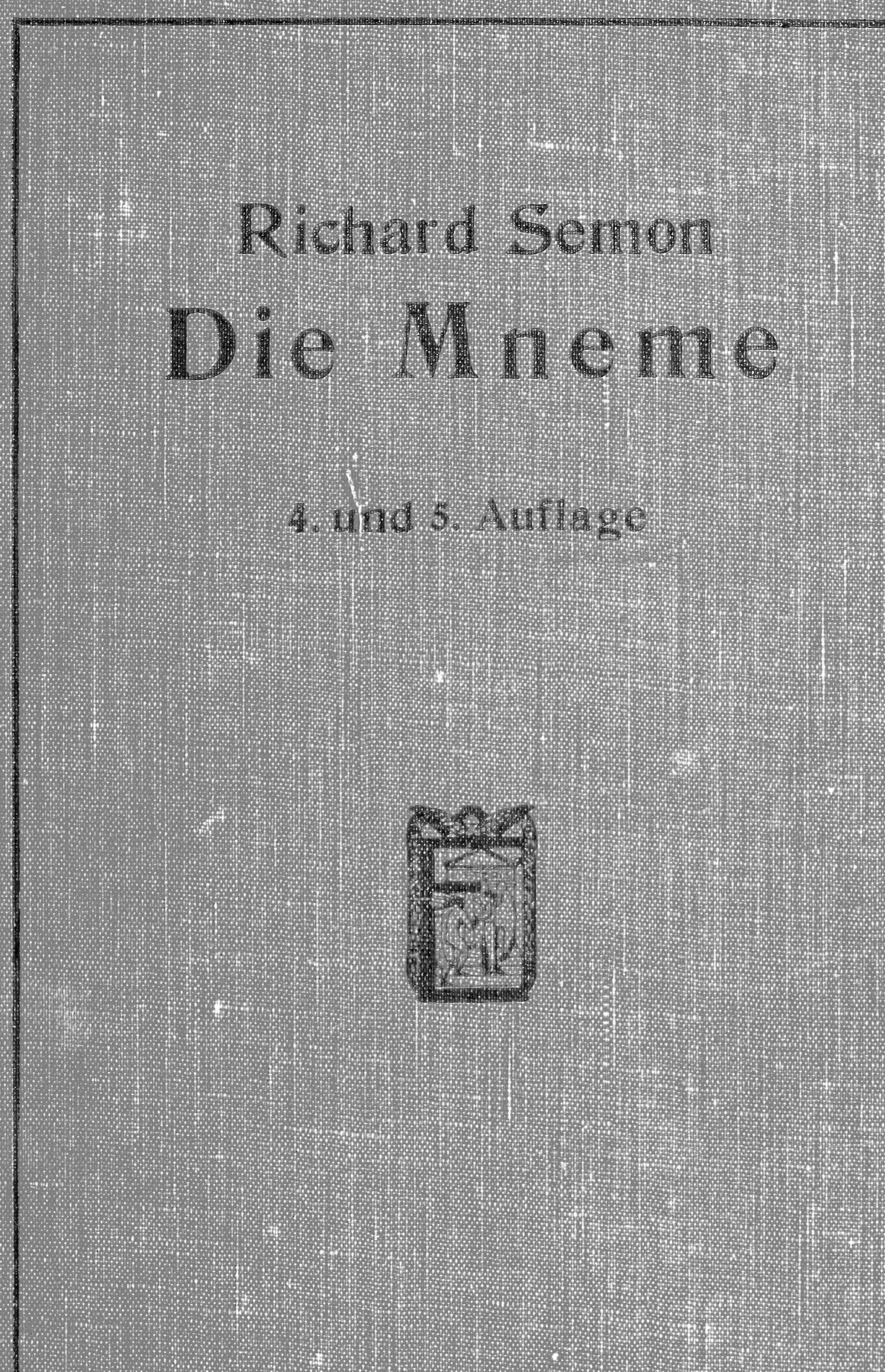





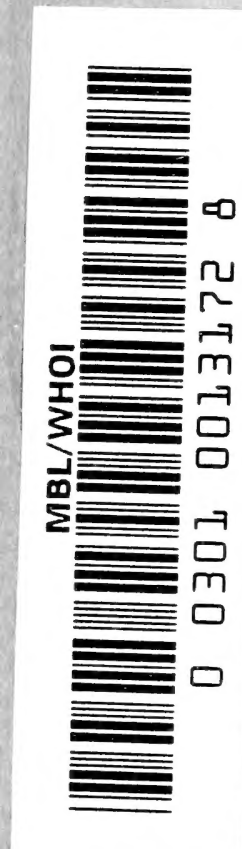





\section{DIE MNEME}




\section{Von demselben Verfasser:}

Die Inemischen Empfindungen in ihren Beziehungen zu den Originalempfindungen. Erste Fortsetzung der Mneme. Leipzig 1909. 80. Geh. M. 9.-

Im australischen Busch und an den Küsten des Korallenmeeres. - Reiseerlebnisse und Beobachtungen eines Naturforschers in Australien, Neu-Guinea und den Molukken. 2. verbesserte Auflage, Leipzig 1903. Mit 86 Abbildungen und 4 Karten. gr, $8^{\circ}$. Geh. M. 15.- 


\section{DIE MNEME}

ALS ERHALTENDES PRINZIP

\section{WECHSEL DES ORGANISCHEN GESCHEHENS}

VON

\section{RICHARD SEMON}

VIERTE UND FÜNFTE UNVERÄNDERTE AUFLAGE

\section{LEIPZIG}

VERLAG VON WILHELM ENGELMANN 


\section{Copyright 1911 by Wilhelm Engelmann, Leipzig.}




\section{Aus dem Vorwort zur ersten Auflage.}

Der Gedanke, alle diejenigen Erscheinungen in der Welt 1 des Organisehen, bei denen es sich um Reproduktionen irgendwelcher Art handelt, unter einem einheitlichen Gesichtspunkt zusammenzufassen, ist kein neuer. Es liegt so nahe, die Fähigkeit der Organismen, auf dem Wege der Keimbildung ihr körperliches Bild und ihre dynamischen Eigentimlichkeiten wieder aufleben zn lassen, mit dem Reproduktionsvermögen zu vergleichen, das wir bei Menschen und höheren Tieren als Gedächtnis bezeichnen, daß es ein Wunder wäre, wenn diese Übereinstimmung nicht Philosophen und Naturforschern wiederholt aufgefallen wäre. Sollte mir oder einem anderen der Beweis gelingen, daß mehr in diesem Gedanken steckt als ein spielender Vergleich, so werden höchstwahrscheinlich Kenner der menschlichen Geistesentwicklung nachweisen, daß vom Altertum bis in unsere Tage dieser oder jener Denker gelegentlich eine verwandte Vorstellung zum Ausdruck gebracht hat'. Aussprüchen, daB »die Erblichkeit eine Art spezifisches Gedächtnis der Gattung sei ${ }^{2}$, begegnen wir durchaus nicht selten in der Literatur des vorigen Jahrhunderts.

1 Vgl. z. B. den 39. Abschnitt in Erasmus Darwin, Zoonomia or the laws of organic life, London 1794-1798. 1876.

2 Th. Ribot, Die Erblichkeit. Übersetzt von 0 . Hotzen. Leipzig 
Die erste nähere Begründung dieses Gedankens stammt meines Wissens aus dem Jahre 1870 und hat zu ihrem Verfasser keinen Geringeren als den berühmten Physiologen Ewald Hering. In einem am 30. Mai vor der Wiener Akademie gehaltenen Vortrag * Über das Gedächtnis als eine allgemeine Funktion der organischen Materie (Wien 1870) hat Hering auf dem Raum von 20 Druckseiten mit bewunderungswürdiger Schärfe und Klarheit alles das zusammengefaßt, was uns bei einer allgemein gehaltenen Betrachtungsweise an augenfälligen Übereinstimmungen zwischen dem Reproduktionsvermögen der Vererbung, dem der Gewohnheit und Übung und dem des bewußten Gedächtnisses entgegentritt, und hat diese Zusammenstellung in künstlerischer Weise zur Schaffung eines einheitlichen Bildes verwertet. Was aber Hering in diesem meisterhaften Aufsatz nicht unternommen hat, und was offenbar außerhalb seiner Absicht lag, weil er es für gentigend hielt, im allgemeinen den Weg zu zeigen, war eine analytische Durchführung des Beweises, daß es sich hier um eine Identität der verschiedenen Reproduktionsvermögen, nicht um eine bloße Analogie handelt, und eine Verfolgung dieses Ergebnisses in alle seine Konsequenzen.

Herings Versuch scheint seinerzeit von einem großen Teil der Naturforscher freudig begrißt worden zu sein. Vor allem schloß sich ihm Ernst Haeckel in seinem Vortrag uber die Perigenesis der Plastidule (Jena 1875) fast unbedingt an ${ }^{1}$.

1 Wie ich neuerdings in Erfahrung gebracht habe, hat zwei Jahre nach Hering und unabhängig von ihm der Kliniker F. Laycock ähnliche Gedankengänge verfolgt und sie später in seinem interessanten Aufsatz: A Chapter on some Organic Laws of Personal and Ancestral Memory, Jeurn. of Mental Science Vol. XXI, 1875 zum Ausdruck gebracht. Ebenso möchte ich hier Henry B. Orr anführen, der denselben Grundgedanken, zu dem er ebenfalls ganz selbständig gelangt 
Eine ansfuhriichere Behandlung erfuhr unser Problem in dem 1878 erschienenen Buche von Samuel Butler "Life and Habit «. In vielen Beziehungen ging Butler den Übereinstimmungen der verschiedenartigen organischen Reproduktionen mehr in ihre Einzelheiten nach, als es Hering getan hatte, dessen Schrift Butler erst nach Erscheinen seiner srsten Pablikation kennen gelernt hat (vgl. Butler, Unconscions Memory, 1880). Neben sehr vielem Unhaltbaren enthalten die Butlerschen Schriften manche geistreiche Gedanken, bedeuten aber im ganzen gegen Hering viel mehr einen Rückschritt als einen Fortschritt. Einen merklichen Einfluf auf die zeitgenössische Literatur haben sie augenscheinlich nicht ausgeüht.

Überhaupt schwindet von Beginn der achtziger Jahre, also gerade von der Zeit an, in der man den Vererbungsfragen besondere Aufmerksamkeit zuzuwenden begann, mehr und mehr der Einfluß der Heringschen Gedanken. Je tiefer man in die Feinheiten der Karyokinese und der morphologischen Vorgänge bei der Reifung und Befruchtung der Keimprodukte eindrang, umsomehr strebte man danach, auch die Anschauungen uber Vererbung auf eine morphologische Basis zu stellen, ein an sich berechtigtes, vorläufig aber meiner Ansicht nach noch durchaus verfribtes Bestreben. So kam es, daß, tiberwuchët von einem Dickicht zahlreicher morphologischer Vererbungshynothesen, der von Hering gewiesene Weg mehr und mehr in Vergessenheit geriet. In der Fachliteratur der letzten 20 Jahre tuber Vererbung, Entwicklungsphysio-

ist, in seinem Buch. $\Lambda$ Theory of Development and Heredity, New York 185:3, vertreten hat. Auf die historische Seite desfegenstandes einzugehen wird erst asnn an der Zeit sein, wenn es gelun ${ }^{2}, n$ ist der Crundanschauung diejenige Geltung in der biologischen Wissenschaft 2:1 verschaffeu, die ihr meinor Ansicht nach aukommt (Anmerkung zur 3. Aurlage). 
logie und Regulationsprobleme wird in der Mehrzahl der Originalaufsätze und Zusammenfassungen der Heringschen Anschauung keinerlei Erwähnung getan, nur von wenigen wird sie zitiert und dann gewöhnlich mit der Erklärung abgetan, es handle sich um nichts weiter als entfernte Analogien.

Freilich finden wir, daß die Heringsche Anregung auf die Anschauungen gerade der hervorragendsten naturwissenschaftlichen Denker unserer Zeit, wie Forel ${ }^{1}$, Haeckel ${ }^{2}$, Mach ${ }^{3}$ und Andere, einen unverkennbaren EinfluB ausgeübt hat. Aber diese Männer geben im Gegensatz zu der jetzt herrschenden Zeitströmung wobl zu erkennen, daß sie die Grund̄anschauung für richtig halten; sie haben es jedoch nicht als ihre Aufgabe betrachtet, die eigentliche Durcharbeitung des Problems vorzunehmen und so einen genialen Gedanken zu einer naturwissenschaftlichen Theorie umzugestalten.

Was der bisherigen Behandlung des Gegenstandes fehlt, ist der Nachweis, daß die verschiedenen Erscheinungen der mnemischen Reproduktion etwas Gemeinsames haben, das uber die bloße Tatsache der Wiederholung hinausgebt. Sich wiederholenden Erscheinungen begegnen wir auch in größter Mannigfaltigkeit in der anorganischen Natur, ohne sie deshalb in die Reihe der mnemischen Phänomene aufzunehmen. Sie treten uberall da auf, wo die gleichen Bedingungen in annähernder Vollständigkeit wiederkehren. Wenn wir die mnemischen Erscheinungen auf eine besondere Eigentümlichkeit der organischen Substanz zurückfüren wollen, haben wir vor allen Dingen zu zeigen, daß diese Wiederholnngen

1 A. Forel, Das Gedächtnis und seine Abnormitäten. Zürich 1885, S. $12-14$.

2 Ernst Haeckel, Die Perigenesis der Plastidule. Jena 1875. Die Lebenswunder. Stuttgart 1904, S. 481.

3 E. Mach, Analyse der Empfindungen. 3. Auf. Jena 1902, S. 58. 
oder Reproduktionen auch ohne vollständige Wiederkehr der gleichen Bedingungen eintreten. Diesen Nachweis aber können wir nur führen mittels einer gründlichen, auf alle Hauptzusammenhänge eingehenden Analyse der ganzen Erıcheinung.

Die Vornahme dieser Analyse der mnemischen Reproduktionserscheinangen anf rein physiologischer Grundlage und den damit verbundenen Ausbau eines bisher immer nur fluchtig gestreiften Kapitels der Reizphysiologie betrachte ich ale die eigentliche Aufgabe des vorliegenden Buches. An sie schiieBt sich eine Prüfung des erklärenden Wertes dieser analytisch gewonnenen Regultate durch ihre Anwendung auf die Haupterscheinungen der Ontogenese und der Regulation. Daß ich bei dieser Arbeit jeder Auseinandersetzung mit Ansichten, die von ganz anderen Gesichtspunkten aus dieselben Erscheinungen zu deuten suchten, unterlassen habe, ist bei der Fulle der zu behandelnden Einzelprobleme selbstverständlich. Einmal wäre sonst der Umfang dieses Buches um ein Vielfaches angeschwollen. Ferner, wenn es mir gelungen sein sollte, die Erscheinungen auf meine Weise einfacher und vollständiger zu beschreiben, als dies auf anderem Wege bisher möglich war, wlurde dieser tatsächliche Erfolg sicherer als jede kritische Auseinandersetzung den Widerstreit erledigen.

Prinz-Ladwigshöhe bei München, August 1904. 


\section{Vorwort zur dritten Auflage.}

Tn den drei Jahren, die seit dem Erscheinen der zweiten Auflage der Mneme verflossen sind, habe ish die Durcharbeitung der mnemischen Probleme weiter fortgesetzt. Die Ergebnisse dieser Fortfubrung, die ich in verschiedenen anderen Schriften niedergelegt habe, sind naturgemäß auch dem Inhalt und der Fassung vieler Darlegungen des vorliegenden Buchs za gute gekommen.

Das erste, einleitende Kapitel ist auf der Grundlage meiner Árbeit tuber den Keizbegriff ${ }^{1}$ einer vollständigen Umarbeitung unterzogen worden. Nicht ganz so umfangreich aber sachlich noch wichtiger sind äie Veränderungen, die durch die schärfere Fassung der mnemischen Grundgesetzlichkeit sowie das tiefere Eindringen in das Wesen der Homophonie bedingt sind, zu welchen ich in der ersten Fortsetzung der Mneme, den Mnemischen Empfindungen gelangt bin. Da ich mich ferner an vielen Stelien auf die äußerst zahlreichen neuen Tatsachen stutzen konnte, die inzwischen von der unermuldlich arbeitenden experimentellen Forschung unserer

1 Der Reizbegriff. Biologisches Centralblatt, 30. Bd., Nr. 5 und 6, 1910.

2 Die mnemischen Empfindungen, Erste Fortsetzung der Mneme. Leipzig 1909 . 
Zeit' sowohl tiber den individuellen als auch den erblichen ${ }^{1}$ Erwerb von Engrammen ermittelt worden sind, so konnte ich die Grundlagen meiner Ausfubrungen in dieser Beziebung in sehr erfreulicher Weise verstärken.

Auf einer ebenfalls viel ausgedehnteren Grundlage ist diesmal die Auseinandersetzang mit den Ergebnissen der modernen Variations- and Bastardforschung erfolgt. Ich konnte zeigen, daß die im vorliegenden Buche eingeschlagenen Wege eine notwendige Ergänzang zu letzteren Forschungen liefern, daß sie von ihnen eine Brticke zu den Ermittlungen der Entwicklungsphysiologie und verwandter Forschungsgebiete bilden, daß sie sich aber in keinerlei Gegensalz zu ibnen befinden. So ist $€$ zu einer vollständigen Neubearbeitung des zwölften und dreizehnten Kapitels gekommen, während das vierzehnte Kapitel überhaupt neu eingefügt worden ist.

Ich habe diesmal die mir gemachten Einwände, soweit sie sich auf irgendwie wesentliche Punkte beziehen, einer näheren Prufung unterzogen (Kap. XVI). Leider halten sich alle bisherigen Einwände an der Oberfläche und sind deshalb nur allzu leicht za widerlegen. Der Feuerprobe einer tiefer eindringenden fachmännischen Kritik sind die vorliegenden Untersuchungen bisher noch nicht anterzogen worden, was ich selbst am meisten bedaure, weil ein solcher Kampf nur zum Vater nener Erkenntnisse werden würde.

Munchen, Mårz 1911.

\section{Richard Semon.}

1 Letzteres Problem habe ich monographisch bebandelt in der Schrift: Der Stand der Frage nach der Vererbung erworbener Eigenschaften. Fortschritte der naturwissenschaftlichen Forschung. 2. Bd. Berlin uno Wien 1911. 



\section{In halt.}

Erster Teil. Einfuihrung in den Begriff der Mneme.

Frstes Kapitel. Einleitendes über Reiz und Reizwirkung

Reizbegriff S. 1. Erfolg als Kriterium S.2. Reaktionen S. 2. Erregung S. 5. Erregungsenergie S. 6. Energetische Situation und ihre Einteilung S. 8. Definition des Reizes S. 10. Synchrone Reizwirkung S. 11. Akoluthe Reizwirkung S. 12. Primärer nnd sekundärer Indifferenzzustand S. 14.

Zweites Kapitel. Engraphische Wirkung der Reize auf das Individuum . . . . . . . . . . . . . .

Engraphische Reizwirkung S. 15. Engraphische Empfïnglichkeit und Nervensystem S. 16. Beispiele engraphischer Reizwirkung bei höheren Tieren S. 17, bei niederen Tieren, Pflanzen und Protisten S. 21. Primärer Indifferenzzustand S. 24. Engraphisch wirkender Reiz S. 27. Schwellenwert S. 28. Reizsummation S. 29. Wirkung verschiedener gleichzeitiger Reize S. 32. Assoziationen S. 33. Sekundärer Indifferenzzustand S. 35. Ekphorische Einflüsse S. 38. Introspektive und objektive Methode S.40. Wiedererkennen S. 44. Feststellung ekphorischer Wirkang mittels der objektiven Methode S. 44. Ekphorie und Assoziation S. 48. Chronogene Ekphorie S. 52. Phasogene Ekphorie S. 61.

Drittes Kapitel. Engraphische Wirkung der Reize auf die Deszendenz . . . . . . . . . . . . . . . . .

Begriff der Vererbung S. 63. Stellung des Individuums in der Generationsreihe S. 61. Beispiele für die Vererbung engraphischer Einwirkungen: Vererbung von erzwungener Fortpflanzungsveränderung bei Salamandra (Kammerer) S. 69. Erbliche Färbungsveränderungen bei Schmetterlingen (Standfuß, Fischer) 
S. 74. Erbliche Wirkungen der Akklimatisation (Schübeler und seine Gegner; Bordage) S. 78. Analogieschluisse S. 82. Wiederholbare und nicht wiederholbare Vorgänge S. 83. Wahrscheinlichkeitsbeweis, daß die große Mehrzahl der ererbten Dispositonen Engramme sind S. 86. Latenzstadium S. 86. Ekphorischer Charakter der Auslösung: vikariierende Ekphorie S. 88. Sukzessiv assoziierte Ekphorie S. 90. Chronogene Ekphorie S. 91. Jahresperiode der Pflanzen S. 92. Tagesperiode S. 93. Pfeffers ansdrückliche Bestätigung S. 94. Periodizitä bei Tieren S. 95. Phasogene Ekphorie S. 97. Speziell anslösende Momente bei derselben S. 100. Bildung der Augenlinse S. 101. Zusammenfassende Schlußfolgerungen S. 103. Nachschrift bei Gelegenheit der dritten Auflage S. 111.

\section{Zweiter Teil. Systematische Darstellung der mnemischen Grundphänomene.}

Viertes Kapitel. Die gegenseitigen Beziehungen der Engramme, simultane und sukzessive Assoziation. . .

Dem Nebeneinander der verschiedenen Originalerregungen entspricht ein Nebeneinander von Engrammen S. 116. Simultaner Erregungskomplex und simultaner Engrammkomplex S. 118. Hieraus erklärt sich die simultane Assoziation S. 119. Anordnung der verschiedenen Simultankomplexe in zeitlich determinierter Reihe S. 123. Nähere ond fernere Beziehungen der Engramme S. 125. Sukzessive Assoziation und ihre Ableitung aus der simultanen S. 129. Polare Ungleichwertigkeit der sukzessiven Verknïpfung S. 133. Simultan ekphorierbare und alternativ ekphorierbare Engrammdichotomien S. 144. Assoziation von komponenten verschiedener Engrammschichten S. 147.

Fünftes Kapitel. Die Lokalisation der Engramme . .

Einleitende Betrachtungen über das Problem der Lokalisation ererbter Engramme S. 149. Teilstïcke und Keimzellen im Besitz des gesamten ererbten Engrammschatzes S. 151. Begriff des mnemischen Protomers S. 152. Lokalisation der individuell erworbenen Engramme S. 154. Keimzellen nicht im Besitz der Mehrzahl der individuell erworbenen Engramme S. 154. Sensibie Perioden der Keimzellen S. 155 . Lokalisation der Engramme im Gehirn S. 156. Eigenbezirk der Erregung S. 159. 
Übergreifen über den Eigenbezirk: Reflexkrïmpfe S. 160. Mitbewegungen S. 161. Irradiationen S. 161. Graduell verschiedene synchrone und engraphische Wirksamkeit der Reize auf die verschiedenen Protomeren je nach deren Lage S. 164. (Ungleichartigkeit des Erregungsprozesses in den verschiedenen Neuronen S. 164 Anm.). Illustration durch einen Vergleich S.165. Die Erregungen erreichen ihre maximale Stärke in der Großhirnrinde und wirken infolgedessen dort am stärksten engraphisch S. 168. >Lokalisation der Symptomes: Graduelle Lokalisation der Engramme S. 171. Lokalisation der Ekphorie S. 171. Ausstrahlung nervöser Erregungen bis zu den Keimzellen: Experiment M. v. Chauvins an Ambiystoma S. 173. Experimente Kammerers S. 177 und Schröders 178. Von Generation zu Generation zunehmende Zahmbeit der Gottesanbeterin S. 178. Somatische Induktion und Parallelinduktion S. 179. Physikalische und physiologische Undurcbführbarkeit der Parallelinduktion S. 180. Experimente von Przibram und Sumner S. 181. SchluBfolgerungen S. 183.

Sechstes Kapitel. Die Ekphorie der Engramme. Die beiden mnemischen Hauptsätze . . . . . . . . . 187

Schema eines originalen Ablaufs S. 188. Schema eines mnemischen Ablaufs S. 189. Zurückführung aller im dritten Kapitel aufgeführter Arten von Ekphorie auf partielle Wiederkehr einer energetischen Situation S. 193. Die meisten Amnesien beruhen nicht auf Verlust von Engrammen, sondern auf der Unmöglichkeit die noch vollkommen intakten Engramme zur Zeit zu ekphorieren S. 194. Skala der ekphorischen Wirkung S. 197. Chronogene Ekphorie S. 197. Phasogene Ekphorie S. 200. Die beiden mnemischen Hauptsätze S. 200. Assoziation S. 201.

Siebentes Kapitel. Der mnemische Erregungszustand und die Homophonie . . . . . . . . . . . 202

Der mnemische Erregungszustand eine Wiederholung des originalen in allen seinen Wertverhältnissen, auch seinen zeitlichen S. 202. Das Zustandekommen der Bomophonie S. 206. Reaktion des Wiedererkennens und Unterschiedempfindens S. 207. Homophonie von Originalerregungen S. 209 Anm. Nachweis von Homophonie mittels der objektiven Methode: Beobachtungsvermögen beim Hunde S. 212. Reagieren des Wildes auf ihm bekannte Töne S. 213. Bauinstinkt der Vögel und Bienen 
S. 214. Homophonie und Bewußtsein S. 217. Natur der Reaktionen, aus denen wir auf Bomophonie schließen können S. 219. Reaktionen zur Beseitigung einer Inkongruenz der Homophonie S. 221. Wirkung wieaerholter engraphischer Einwirkung durch identische oder einander sehr ähnliche Reizkomplexe S. 223. Abstraktion durch Homophonie S. 224. Synthetische Konstruktion der wiederholten engraphischen Einwirkung S. 226. Alternativ ekphorierbare Dichotomien S. 228. Mischreaktionen S. 229. Entscheidung der Alternative S. 230. Wesentlicher Unterschied zwischen einmaliger starker und mehrmaliger schwächerer engraphischer Einwirkung S. 231.

\section{Dritter Teil. Die Wirksamkeit mnemischer Prozesse bei der Ontogenese.}

Achtes Kapitel. Nachweis des mnemischen Faktors bei den ontogenetischen Reproduktionen . . . . . . . 235

Wiederholung eines Ablaufs bei völliger Wiederkehr der Voraussetzungen ohne Heranziehung des mnemischen Prinzips orklärbar S. 235. Wiederholung eines Ablaufs bei nur teilweiser Wiederkehr der Voraussetzungen S. 237. Experimentelle Änderungen der Voraussetzungen S. 238. Dadurch eventuell bewirkte Modifikation des Ablaufs S. 241. Zurückführung der Regulationen anf Homophonie: Morphogener Teil der Erregungskomplexe S. 242. Seine originale Komponente S. 244. Seine mnemische Komponente S. 245. Doppelte Quelle der Ekphorie morphogener Engramme bei der Ontogenese S. 249. Darstellung der Abläufe bei der normalen S. 252 und bei der gestörten Ontogenese S. 253. Schema einer adäqualen Eifurchung S. 254. Ekphorisches Übergewicht der sukzessiven über die simultanen Assoziationen in diesen Fïllen S. 255. Schwankungen in den Abläufen S. 256. Keine strenge Lokalisation der morphogenen Erregangen S. 257.

Neuntes Kapitel. Das ontogenetische Initialengramm und der ontogenetische Ablauf . . . . . . . . . 258

Einteilung der kontinuierlichen Entwicklungsreihe in Individualitätsphasen S. 258. Sekundäre Trennung, Ruhezustand S. 259. Initialengramm und seine Ekphorie S. 259. Vikariierende Ekphorie bei der künstlichen Parthenogenese S. 260. Zytolytische 
Wirkungen S. 261. Loebs Versuch in das Wesen des Erregungsvorgangs einzudringen S. 261. Resultat desselben S. 263. DSpontane: Parthenogenese S. 264. Ontogenetischer Ablauf S. 265. Gewisse Engramme nur durch Einwirkung äußerer Originalreize ekphorierbar S. 266. Metamorphosen der Salamandrinen S. 266. Ergänzung der früheren Schemata S. 269, 270. Vorteile der Einführung des mnemischen Gesichtpunkts S. 271.

Zehntes Eapitel. Vorhandensein und Wirksamkeit morphogener mnemischer Erregungen im ausgebildeten Organismus . . . . . . . . . . . . . . .

Was ist unter sausgebildeter Zustand su verstehen? S. 274. Übergangszeit S. 275. Homophonie im ausgebildeten Organismus S. 276. Zykliche Abläufe S. 278.

Elftes Kapitel. Spricht die Einschränkung des Regenerationsvermögens für eine Lokalisation des ererbten Engrammschatzes? Lokalisation der \$kphorie . . .

Verschiedengradige Einschränkung des Regenerationsvermügens bei verschiedenen Tieren S. 281. Lokalisation des Baumaterials, keine Lokalisation des ererbten Engrammschatzes S. 285. Erlöschen des Regenerationsvermögens verlänft nicht in gleichem Schritt mit der Differenzierung der Organe: Anuren S. 289. Salmoniden S. 290. Urodelen S. 291. Abnahme der Fühigkeit zu neoplastischen Leistungen S. 292. Angeblicher formativer Einfln B des Zentralnervensystems S. 293. Zentralnervensystem and Regeneration S. 294. Untersuchungen Rubins und ihre Deutung S. 294. Herbstsche Experimente beweisen nichts für einen spezifisch formativen Einfluß des Zentralnervensystems S. 296. Heteromorphosen S. 298. Schlußzusammenfassung S. 299. Lokalisation der Ekphorie S. 300.

Zwölftes Kapitel. Die Bedeutung der alternativ ekphorierbaren Dichotomien auf ontogenetischem Gebiet .

Fall, bei dem die Entscheidung der Alternative durch änßere Einflüsse erfolgt: Königin und Arbeiterin der Honigbiene S. 303. Experimente Kleins Arbeiterfutter and Königinfutter S. 304. Mischreaktionen (Übergangstiere) S. 306. Chemische Beschaffenheit des Reizstoffs S. 307. Pseudogyne Ameisen S. 307. Wasmanns Lomechusa-Theorie S. 308. Keine Ausschaltung der Arbeiter bei Hymenopteren und Termiten aus dem Zeugungs- 
Inbalt.

kreis der Art S. 309. Nicht äquilibre Dichotomien S. 311. Begriff des Atavismus S. 312. Neotenisch-atavistische Dichotomie bei Ambiystoma nach Experimenten M. v. Chauvins S. 315. Verhältnisse bei Salamandrinen und Tritonen S. 320. Fortpflanzungs- und Brutplege-Eigentümlichkeiten bei der Geburtshelferkröte S. 322. Zwangsweise Veränderung derselben bei den Versuchen Kammerers S. 323. Vererbung der Veränderungen S. 324. Atavistisches Auftreten der Brunstschwielen usw. S. 324 .

Dreizehntes Kapitel. Der Bau der ontogenetischen Engrammsukzessionen und seine verschiedenen Entstehüngsweisen $\quad \ldots \quad \ldots \ldots \ldots$

Entstehung von alternativen Dichotomien durch Reizwirkung S. 327. Entstehung von alternativen Dichotomien durch Kreuzung S. 331. Schicksal der $F_{1}$-Generation S. 332. Dominanz S. 333. Intermediäre Merkınale (Mischreaktionen) S. 334. Dominanzverschiebung S. 335. Schicksal der späteren Generationen: Mendelsche Spaltung S. 337. Ausschaltung des einen Faktors bei der Gametenbildung S. 340. Richtigkeit der Mendelschen Erklärung für das zahlenmäßige Verhalten S. 341. Segregation S. 344. Stellungnahme zu derselben S. 345. Intermediäre Vererbung bei Artbastarden S. 347. Die Towerschen konstanten Rassenbastarde S. 348. Schlußzusammenfassung S. 349.

\section{Vierzehntes Kapitel. Engraphische Herkunft der deter-} minierenden Faktoren $, \cdots, \cdots$

Die neuerzeugten Determinanten entstehen auf engraphischem Wege S. 352. Somatische Induktion und Parallelinduktion S. 353. Alternative Vererbung der neuerzeugten Determinanten S. 353. Sensible Periode der Keimzellen S. 354. Scheinbar spontanes Auftreten nener Potenzen (spontane Mutationen); Experimente Towers S. 355. Kooperation einer größeren Anzahl qualitativ gleicher Determinanten nach Nilsson-Ehle S. $359 . \quad$ Entsprechende Befunde in bezug auf die individuell erworbenen Engramme S. 360. Unsere Betrachtungsweise als Ergänzung der Variations- und Bastard-Forschung S. 361. Brücke zur Entwicklungsphysiologie S. 362. Frage nach der strukturellen Beschaffenheit der Determinanten: ihre Isolierbarkeit S. 362. Brechung von Korrelationen S. 363 . Beweist nichts gegen einen vorherigen Zusammenhang S. 364. Entsprechendes Verhalten der individuell erworbenen Engramme S. 365. Die mnemischen Gesetze als skoordinierender Hechánismus s: S: 366. 
Fünfzehntes Kapitel. Die proportionale Veränderbarkeit der mnemischen Erregungen

Proportionale Veränderbarkeit der Wertverhältnisse S. 367. Verschiebbarer Rahmen der räumlichen Projektion S. 368. Veränderbarkeit des Tempos der Abläufe S. 368. Ontogenetische proportionale Verkleinerung und Vergrößerung S. 370 . Einschmelzen inkongraenter Teile S. 371. Engraphische Merkzeichen für die absoluten Werte S. 372. Homophonie als regulierendes Moment S. 373.

\section{Vierter Teil. SchlaBbetrachtungen.}

Sechzehntes Kapitel. Rückblick. Einwände. . . . .

Rückblick S. 377. Einwand, die mnemische Betrachtungsweise bedeute nur eine Umschreibung alter Rätsel S. 379. Das Wesen der Engramme S. 380. Das Engramra, eine materielle Veränderung; Lokalisation S. 381. Ausschaltung verschiedener Unbekannter und Ersatz durch eine einzige S. 3S2. Fortschritt in der Auffassung der Regulation: Nachweis des Vorhandenseins zweier real vorhandener Erregungen S. 383. Dadurch Ausschaltung vitalistischer Auffassungen S. 384. Einwand der Nichtvererbung erworbener Eigenschaften S. 385. Somatische und parallele Induktion S. 385. Identität und Analogie S. 387. Das Fundament der Mnemetheorie ein physiologisches S. 389. Beziehung der Erregung zu ihrer Empfindungsmanifestation S. 390. Der Terminus > Gedächtnis und meine eigene Terminologie S. 390. Unmöglichkeit einer absoluten Scheidung der objektiven von der subjektiven Methode S. 391. Speziellere Einwände: Angebliche Schwierigkeit der Vorstellung von somatischer Induktion S. 392. Einwand, der sich auf veraltete Vorstellangen von der Lokalisation der Gehirnengramme stiitzt S. 394. Angebliche Grundverschiedenheit der materiellen Grundlagen S. 395. Nur eine Verschiedenheit der Komplikation S. 396. Fiktive Darstellungen der strukturellen Beschaffenheit von Hirnengrammeu S. 396. Pfeffers Bestätigung meiner Experimente über die Schlaf bewegungen S. 398. Die Mnemelehre als Ergänzung zur Arbeit der Variations- und Bastardforschung S. 399.

\section{Siebzehntes Kapitel. Die Mneme als erhaltendes Prinzip} im Wechsel des organischen Geschehens. . . . . . 402

Die Anßenwelt als Umgestalterin, die Mneme als Erhalterin dieser Umgestaltang S. 402. Teleologische Prinzipien S. 403. 
Inhalt.

Darwins Zuchtwahlprinzip S. 404. Seine Auffassung der Variationen und ihre genauere Analyse durch die neuere Forschung S. 405. Grenzen der Zuchtwahl, die im Gegensatz zu der Weismannschen Auffassung nicht allmächtig ist S. 405. Nicht alles, was wir als szweckmäßig • bezeichnen, ist auf Zuchtwahl zurückzaführen S. 406. Mneme und biogenetisches Grandgesetz S. 407. Vermeidung des Rückschritts mum Vitalismus S. 408. Erweiterte Aufgaben der Reizphysiologie S. 409.

\section{Sachregister . . . . 411}

Autorenregister . . . . . . 418 
Erster Teil

\section{Einführung in den Begriff der Mneme}




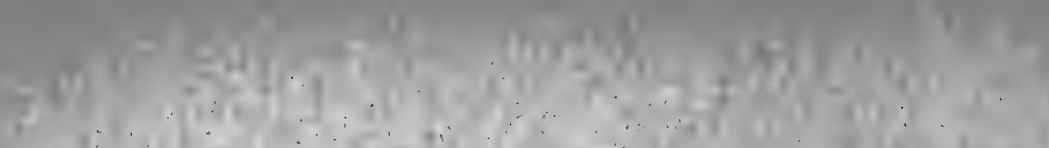

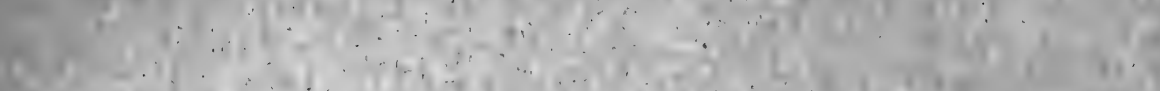
$\therefore \quad+\cdots+\cdots+\cdots$

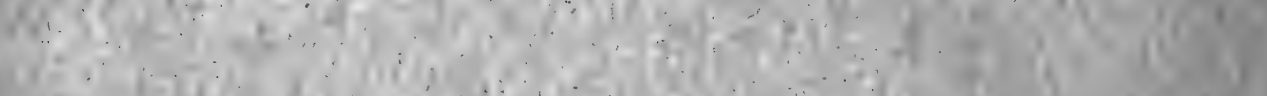

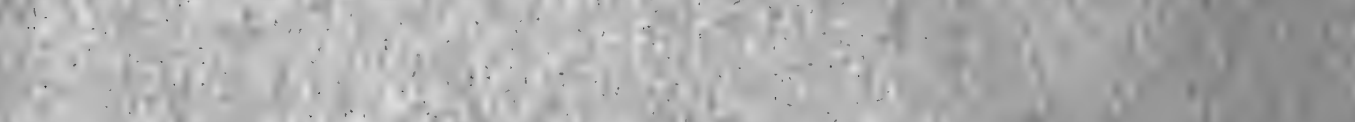

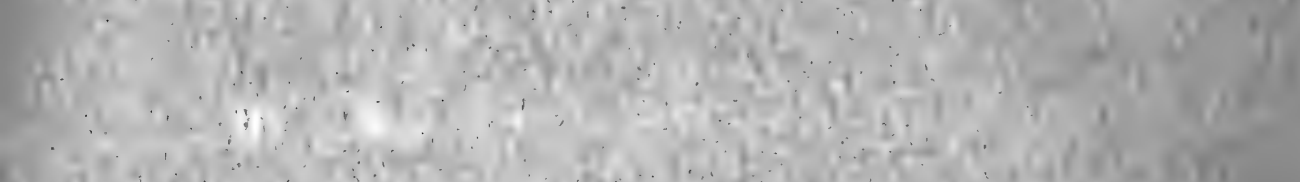

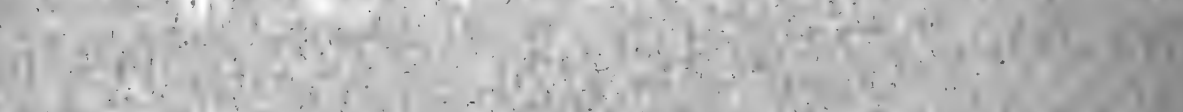

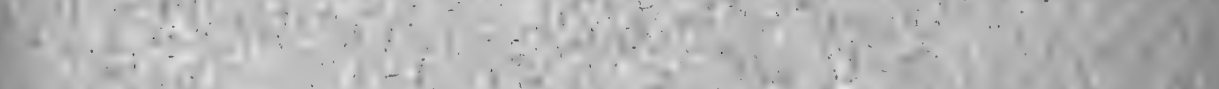

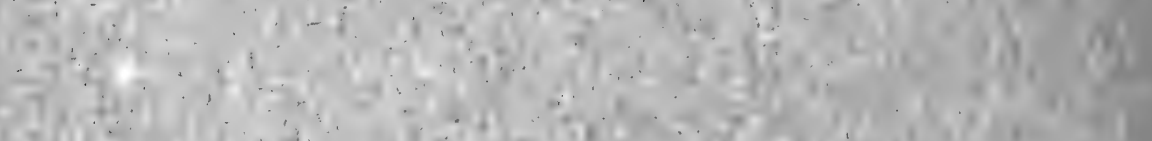

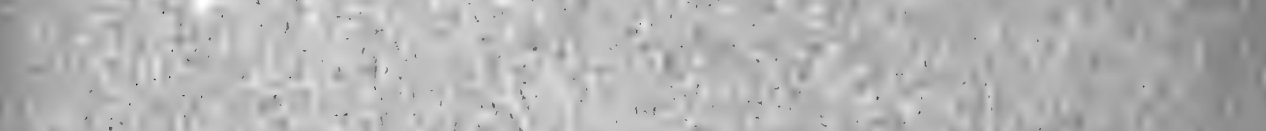
$\therefore$
$\therefore$

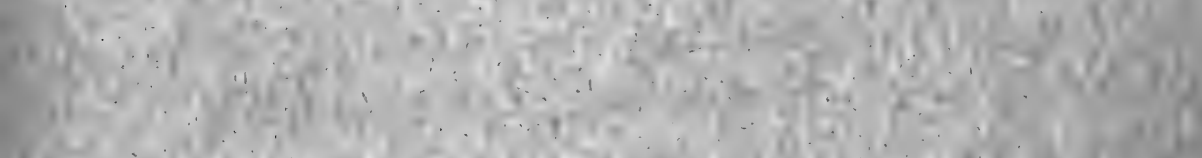

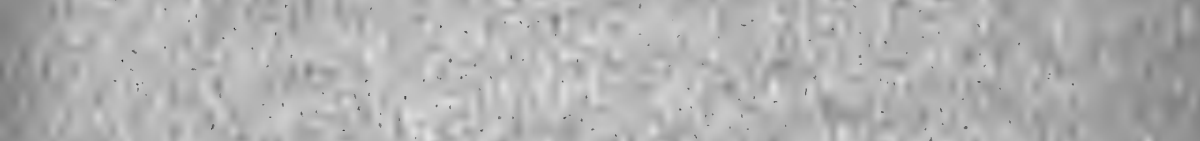

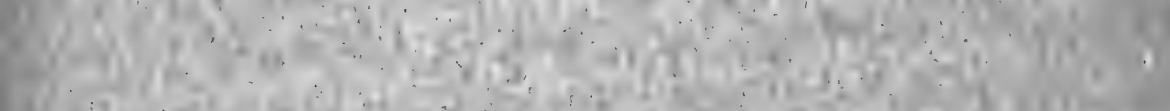

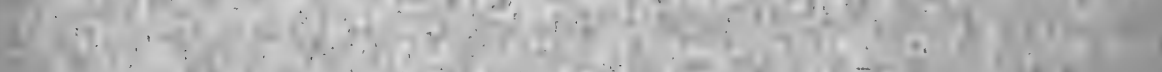

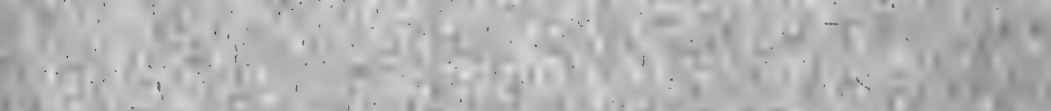

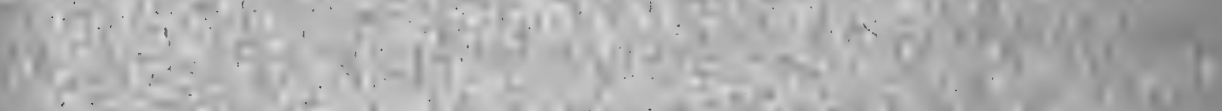

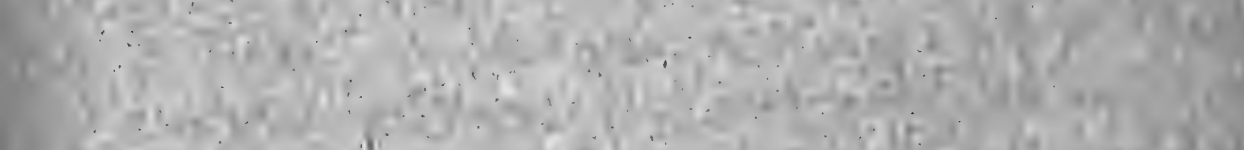

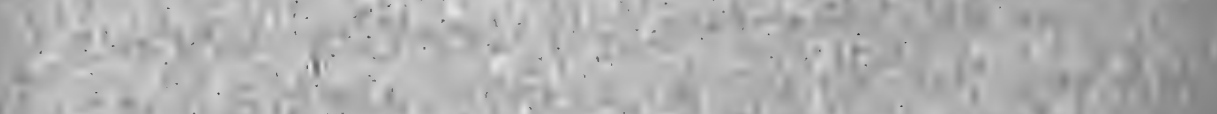

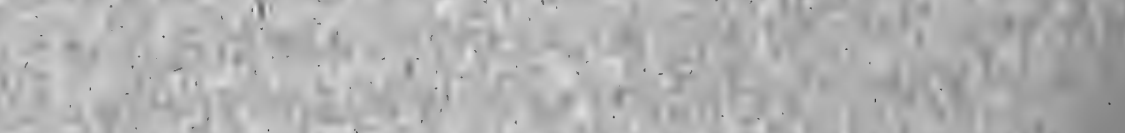

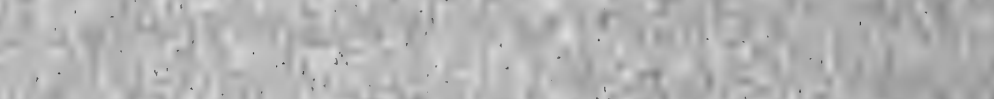

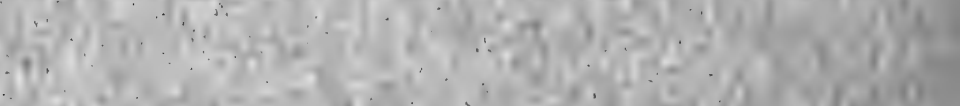

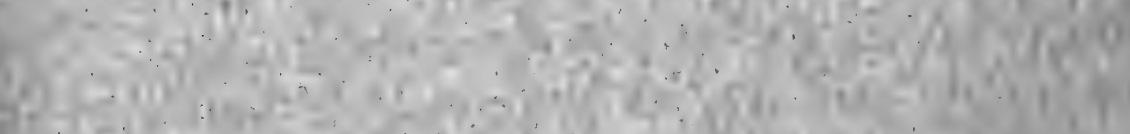

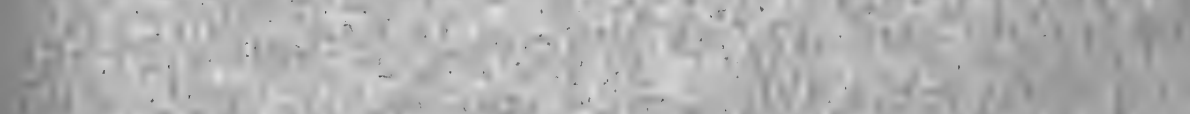

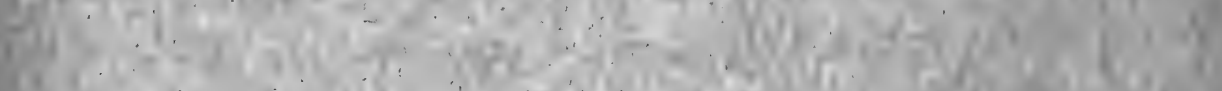

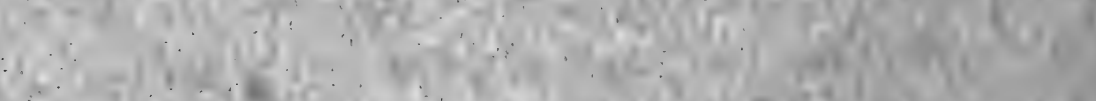

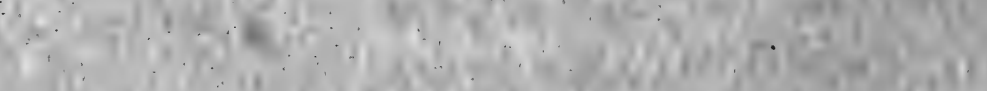

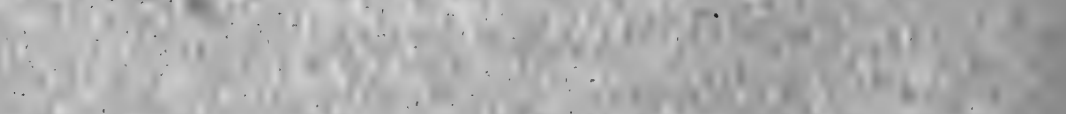

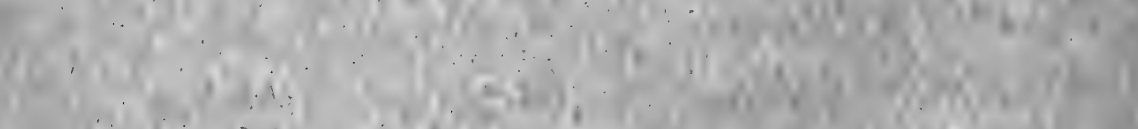

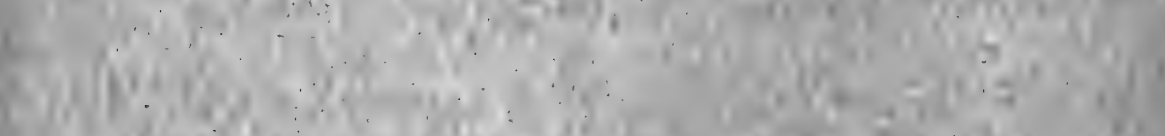

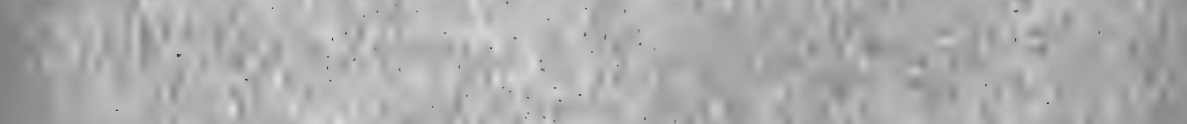

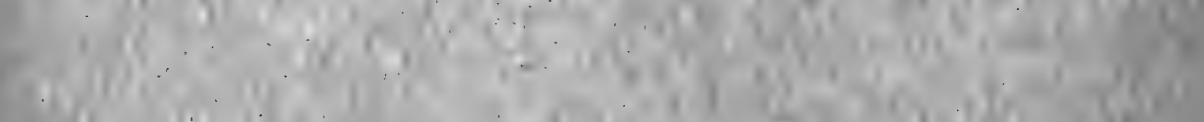
1.

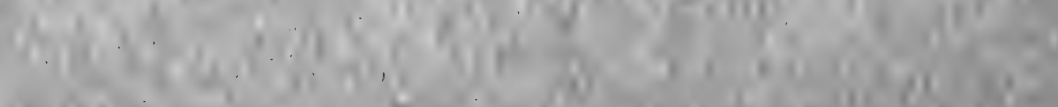

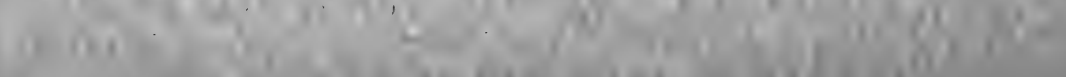




\section{Erstes Kapitel.}

Einleitendes über Reiz und Reizwirkung.

Die Aufgabe des vorliegenden Buchs ist es, eine besondere Art der Reiz- oder, vielleicht noch besser ausgedrickt, der Erregungswirkung zu untersuchen. Es ist deshalb ein unumgängliches Erfordernis, auf der Grundlage einer möglichst präzisen Definition der Begriffe Reiz und Erregung zu fußen. Nun ist es eine bemerkenswerte Tatsache, daß die reizphysiologische Forschnng auf dem Gebiet des Tier-, Pflanzen- und Protistenreichs ihre zahlreichen und bewunderungswürdigen Erfolge errungen hat, ohne daß es bisher zu einer schärferen Prägung und allgemein verwendbaren Fassung dieser Grundbegriffe gekommen wäre. Ich habe dieser Aufgabe deshalb in den beiden ersten Auflagen des vorliegenden Werkes den größten Teil des ersten Kapitels gewidmet. Dann aber habe ich, um dieser Frage die selbständige, von keinen anderen Ruicksichten beengte Behandlung zu Teil werden zu lassen, die sie verdient, and um das vorliegende Buch $\mathrm{za}$ entlasten, den Gegenstand in einer selbständigen Arbeit behandelt1. Ich darf mich deshalb jetzt hier darauf beschränken, die wesentlichen Ergeb-

1 R. Semon. Der Reizbegriff. Biologisches Centralblatt, 30. Bd., No. 5 und 6, 1. und 15. Mairz 1910. 
Erstes Kapitel.

nisse jener Arbeit wiederzugeben, and kann diejenigen, die sich für die näheren Belege and die sich ankntipfenden Unterfragen interessieren, auf die Lektüre der ausfuhrlichen Abhandlung verweisen.

Wir gehen, um einen Ausgangspunkt zu haben, von einer mit dem gewöhnlichen Sprachgebrauch übereinstimmenden und dabei so allgemein gefaßten Definition aus, daß ein Widerspruch gegen dieselbe wohl kaum denkbar ist, und sagen: Unter Reizen verstehen wir gewisse, ron bestimmten Erfolgen begleitete Einwirkungen auf lebende Organismen. Damit ist bereits ausgedruckt, daß wir den Einwirkungen auf die Organismen nur dann Reizcharakter zuschreiben, wenn sie von ganz bestimmten Erfolgen begleitet sind. Der Erfolg charakterisiert also den Reiz als solchen.

Wie beschaffen muissen nun die Erfolge von Einwirkungen auf Organismen sein, um sie im Unterschied von anderen Einwirkungen zu Reizen zu stempeln? Wir können hierbei ein negatives Kriterium in den Vordergrund stellen und sagen, der Erfolg einer Einwirkung stempelt die letztere dann zum Reiz, wenn er in einer Veränderung besteht, wie er gegenüber der entsprechenden Einwirkung bei einem anorganischen Körper oder bei dem betreffenden oder auch anderen Organismen nach Erlöschen des Lebens nicht auftreten würde. Wir pflegen derartige Veränderungen als Reaktionen des lebenden Organismus auf die Einwirkung zu bezeichnen.

Unter diesen Reaktionen können wir nun, je nach der Art, wie der Untersucher sie wabrnimmt, zwei Hauptgruppen unterscheiden.

Die eine Grappe pflegen wir als die der Empfindungsreaktionen zu bezeichnen. Sie beruhen darauf, daß der Erfolg gewisser Einwirkungen, die unseren eigenen Körper 
treffen, sich uns in unmittelbarer Empfindung: Licht oder Ton oder Druck oder Schmerz offenbart. Diesen Erfolg kann jeder nur an sich selbst wahrnehmen, und wir bezeichnen diese Reaktionen deshalb auch als subjektive. Aus den betreffenden Empfindungen schließen wir dann auf Grund ausgedehnter physiologischer Erfahrungen und Versuche auf ganz bestimmte Erregungsvorgänge in bestimmten Teilen unserer reizbaren Substanz.

$\mathrm{Zu}$ diesen nur subjektiv wahrnehmbaren Empfindungsreaktionen gesellen sich als zweite Hauptgruppe die objektiv wahrnehmbaren Reaktionen, die dadurch charakterisiert sind, daB ein Organismus auf eine bestimmte Einwirkung mit einer den Sinnen des Beobachters wahrnehmbar zu machenden, d. h. also physikalisch-chemisch nachweisbaren Veränderung antwortet; diese Veränderung kann eine Mnskelzuckung oder ein WachstumsprozeB oder irgendein Stoffwechselvorgang; z. B. eine Ausscheidung oder ein chemischer Umsatz sein.

Ein groBer Teil dieser objektir wahrnehmbaren Reaktionen ist dadurch ausgezeichnet, daß der Erfolg der Einwirkung nicht an derjenigen Stelle der reizbaren Substanz, an der die Einwirkung stattfindet, sondern an ganz entfernten Stellen des Organismus zur Manifestation gelangt. Das markanteste Beispiel dafür liefert dasjenige Gewebe, in dem das Vermögen der Reizbarkeit die höchste Spezialisation erlangt hat, das Nervengewebe der Tiere. Doch ließen sich auch Beispiele aus dem Pflanzenreich anfuhren. Was das Nervengewebe anlangt, so nimmt man bekanntlich weder an bloßgelegten Gehirn oder Rückenmark, noch an den ron ihnen ausgehenden Nerven unmittelbar irgendwelche Veränderung wahr, wenn man diese Teile elektrisch, mechanisch, chemisch oder anf irgendeine andere Weise reizt. Dafür aber sieht 
man je nach der Stelle des Nervensystems, die der Einwirkung als Angriffspunkt dient, einmal diese, einmal jene Muskelgruppe zucken, die Atmung sich beschleuhigen oder verlangsamen, den Herzschlag sich ändern, Speichel oder Tränendrtisen sezernieren usw. Wir beobachten den Erfolg der Einwirkung dann also nicht an der in erster Linie gereizten reizbaren Substanz, der Nervensubstanz, an der wir weder morphologisch noch chemisch eine Veränderung nachweisen können, sondern an entfernten ${ }^{2}$ Erfolgsorganen *.

Freilich schließen wir mit gutem Recht auf einen Erfolg der Einwirkung auch auf die zunächst gereizte Substanz, und man ist ubereingekommen, diesen Erfolg, diese primäre Veränderung, an die sich die allein wahrnehmbare Reaktion am Erfolgsorgan nur als sekundäre Folge anschließt, als Erregung zu bezeichnen. Erst lange, nachdem man sich tiber diese Sachlage völlig klar geworden war, fand Du Bois-Reymond in dem elektromotorischen Verhalten der Nerven ein Mittel, den Erregungszustand der nervösen Substanz an dieser selbst nachzuweisen. Durch das veränderte elektromotorische Verhalten der Nervenströme bei der Reizung (negative Schwankung) können wir den Erfolg der Reizung auf die nervöse Substanz selbst nachweisen, und auf demselben Wege können wir den direkten Nachweis des Reizerfolgs für die reizbare Substanz der Drüsen durch die negative Schwankung des Drüsenstroms, des Reizerfolgs für die reizbare Substanz der pflanzlichen Parenchymzellen durch die Reizschwankung des pflanzlichen »Ruhestroms * erbringen.

Wir können nunmelr sagen: Wenn wir die spezifischen Erfolge der von uns als Reize bezeichneten Einwirkungen auf den Organismus als Reaktionen auf den Reiz zusammenfassen, so begreift diese Zusammenfassung sehr heterogene 
Dinge in sich: erstens unmittelbare Empfindungen; zweitens Beobachtungen, die wir an Erfolgsorganen oft ganz fern vom Angriffspunkt der Einwirkung machen; endlich Beobachtungen an derjenigen reizbaren Substanz, die von der Einwirkung direkt betroffen ist. In diesem heterogenen Gemisch gibt es aber ein einigendes Moment. Es ist das, worauf wir aus allen diesen drei Arten von Reaktionen s chlieBen: der Vorgang der Erregung in der reizbaren Substanz. Wir können demnach auf die Frage nach den charakteristischen Erfolgen einer Einwirkung, die wir als Reiz bezeichnen, die zusammenfassende Antwort geben: der Erfolg einer Reizung äußert sich in allen Fällen im Auftreten einer Erregung in der reizbaren organischen Substanz.

Erregung ist, wie wir betont haben, immer etwas Erschlossenes, und zwar bewegt sich das betreffende Schlußverfahren in einer Richtung, die wir als energetische Betrachtungsweise kennzeichnen können, ganz gleich, ob der Schluß auf Grund unmittelbarer Bewußtseinsreaktionen oder auf Grund der Wahrnehmung solcher Erscheinungen, wie es die negative Schwankung der Ruheströme ist, oder endlich auf noch weiteren Umwegen auf Grund der Wahrnehmung von allerlei Bewegungen, von plastischen Reaktionen, von Stoffwechseländerungen erfolgt. Was wir auf diesem Wege erschließen, ist ein energetischer Vorgang in der reizbaren Substanz, and somit können wir ganz allgemein die Erregung: als einen energetischen Vorgang in der reizbaren organischen Substanz bezeichnen. Über die Form oder die Formen der Energie, die den Erregungsvorgang bedingen, ist es zurzeit unmöglich, bestimmte Aussagen zu machen. Manche Autoren glauben, daß es sich dabei wesentlich um chemische Energie handelt. Andere ziehen es vor, vorläufig einen summarischen 
Ausdruck fur diese bisher nicht mit Sicherheit bestimmte Energieform zu gebrauchen and sprechen von physiologischer Energie oder (entschieden zu eng gefaßt) von Nervenenergie, wobei sie alle allerdings die Wahrscheinlichkeit betonen, daß eine Zurtickführung bzw. Zerlegung dieser Energieform in die anderen durch Physik und Chemie genauer bekannten Energien, wie mechanische, thermische, elektrische, strahlende, chemische, die ich hier als elementare Energi en bezeichnen will, möglich sein wird. Wir lassen diese Frage auf sich beruhen und sprechen einfach von dem energetischen Vorgang der Erregung oder von Erregungsenergie, die je nach der Reizpforte, durch die sie im Organismus ausgelöst wird, sich außerordentlich verschiedenartig manifestieren kann. Auch hierauf gehen wir an dieser Stelle nicht näher ein.

Wenn wir nun sagen, daß eine bestimmte Einwirkung auf den Organismus sich dadurch als Reiz ausweist, daß sie gesetzmäßig von dem Auftreten einer Erregung in der reizbaren Substanz gefolgt ist, so ergibt sich hieraus als eine zwar nicht notwendige, aber doch sehr naheliegende Folgerung, daß der gewöhnliche Zustand der reizbaren Substanz ein Zustand der Erregungslosigkeit, der Abwesenheit von Erregung sei. In der Tat wird bei reizphysiologischen Untersuchungen fast immer stillschweigend von dieser Vorăussetzung ausgegangen. Für den praktischen Gebrauch läßt sich auch in den meisten Fällen hiergegen nichts einwenden. An sich ist aber diese Voraussetzung nicht vollkommen zutreffend, sie enthält eine willkürliche Vereinfachung, die dem tieferen Verständnis schädlich werden kann und sich dieser Schädlichkeit nur dadurch entkleiden läßt, daß mar sich der vorgenommenen Schematisierung immer bewußt bleibt. Wie ich in der oben zitierten Abhandlung tiber den Reizbegriff 
näher auseinander gesetzt habe, ist die Annahme einer zeitweiligen absoluten Erregungslosigkeit der reizbaren Substanz oder einzelner Abschnitte derselben eine Fiktion, die man in erster Linie als solche anzuerkennen hat.

Es hat jedoch, dies rorausgeschickt, meiner Ansicht nach nichts Bedenisliches, bei der Untersuchung der Reizwirkangen einen zwar wivat im strengsten Wortsinn zu verstehenden, aber für den praktischen Gebrauch doch bestimmbaren Indifferenz zustand, einen Zustand zwar nicht absolnter, aber relativer Erregranglosigkeit anzunehmen. In diesem Sinne bitte ich es zu verstehen, wenn ich oben gesagt habe, die Reizwirkung charakterisiere sich als solche durch das Auftreten einer Erregung. Das Korrektere aber bleibt es immer, zu sagen, der veränderte Zustand der e nergetis ch en Situation - so bezeichne ich den Inbegriff der Faktoren und Bedingungen, die im gegebenen Augenblick fir den Organismus von Bedeutung sind - bedinge einen in bestimmter Hinsicht veränderten Erregungszustand, und an diese Formulierung wollen wir auch zunächst weiter anknüpfen und sie schärfer analysieren.

$\mathrm{Zu}$ den Komplexen ron Komponenten der gesamten energetischen Situation, die fur einen Organismus jeweilig von Bedeutung ist, gehört auch sein eigener Zustand. Wenn also in dem obigen Satz eine Beziehung festgestellt wird zwischen energetischer Situation des Organismus und Erregungszustand. des Organismus, so kann es sich bei dieser Beziehung logischerweise nur handeln um: einerseits die ganze ubrige energetische Situation ausschließlich des Erregungszustandes und andererseits eben diesen Erregungszustand.

Wir können uns dieses Verhältnis durch folgende Einteilung noch klarer machen. Wir teilen die gesamte ener- 
getische Situation, die fur einen Organismus jeweilig von Bedentung ist, und in der er selbst als ein Teil figuriert, ein in:

1. Seine äußere energetische Situation. (Die energetische Situation anBerhalb der Körperoberfläche des Organismus, soweit sie fur ihn von Bedeutung ist.)

2. Seine innere energetische Situation.

Diese letztere wiederum muß geteilt werden in

a) die innere elementarenergetische Situation,

b) die innere erregungsenergetische Situation.

Unter der inneren elementarenergetischen Sitaation ist die gesamte innere energetische Situation zu verstehen, soweit ihre Komponenten nicht aus Erregungsenergien bestehen, sondern aus den elementaren Energien, die bisher anssehließlich den energetischen Studien der Physik und Chemie zum Gegenstand gedient haben. Man denke an den gegenseitigen Drack, den die Teile des sich entwickelnden wie des fertigen Organismus aufeinander austiben, an die Wärme, die durch die Funktion der Organe (z. B. Drïsen, Muskeln) erzeugt wird und sich als solche als energetischer Faktor bemerklich machen kann, an die chemische Wirkung eines im Organismus produzierten Enzyms, einer Säure, karz an die unzähligen elementarenergetischen Faktoren, die im Getriebe des Stoff- und Formwechsels des Organismus frei werden und dadurch in die Lage kommen, auf die reizbare Substanz einzuwirken.

Unter derinneren erregungsenergetischen Situation wollen wir, wie dies auch der von uns gewählte Name ausdrückt, denjengen Teil der inneren energetischen Situation verstehen, der aus Erregungszuständen der reizbaren Substanz des Organismus besteht.

Wir können nun die äußere energetische Situation in ihrer 
Beziehnng zum Organismus mit dessen innerer elementarenergetischer Situation zusammenfassen als elementarenergetische Situation schlechthin und sie der inneren erregungsenergetischen Situation, die wir dann schlechthin als erregungseneregtische bezeichnen können, gegentiberstellen.

Wir können danach den Satz, von dem wir oben ansgegangen sind, jetzt noch schärfer formulieren und sagen: Veränderte Zustände der elementarenergetischen Situation bedingen veränderte Zustände der erregungsenergetischen Situation. In dieser Fassung ist der Satz allerdings noch nicht brauchbar, da wir mit der Methode induktiver Forschung nicht die Gesamtheit der Abhängigkeiten auf einmal erfassen können, sondern zunächst die speziellen Abhängigkeiten, diejenigen eines Einzelfaktors von einem anderen Einzelfaktor, ermitteln müssen. Wir müssen dazu analysieren, müssen Trennungen vornehmen und gegebene, also nattüliche Zusammenhänge lösen.

In einer von mir näher in der Abhandlung über den Reizbegriff charakterisierten Weise tun wir dies, indem wir ein besonderes Abhängigkeitsverhältnis von je einer freilich nur mittelst eines gewissen Willkirakts zu isolierenden Komponente der erregungsenergetischen Situation zu je einer besonderen, ans der elementarenergetischen Situation resultierenden Bedingung feststellen. Die aus der elementarenergetischen Situation resultierende Bedingung, die wir als Reiz zu bezeichnen pflegen, kann sowohl in dem Vorhandensein als auch in der Abwesenheit eines bestimmten elementarenergetischen Faktors bestehen und dieser Faktor kann im ersteren Fall entweder ein aktuell-energetischer oder ein potentiell-energetischer sein. Die näheren Belege hierfür wird man in der zitierten Arbeit (S. 200-203) finden. 
Das Wesen des speziellen Abhängigkeitsverhältnisses einer Komponente der erregungsenergetischen Situation von einer besonderen aus der elementarenergetischen Situation resultierenden Bedingung besteht darin, daß das Auftreten, die Dauer bzw. das Verschwinden der elementarenergetischen Bedingung das Auftreten, die Dauer bzw. das Verschwinden der erregungsenergetischen Komponente nach sich zieht.

Die erstere Komponente bezeichnen wir dann als Reiz, die letztere als Erregung. Ein solches Abhängigkeitsverhältnis pflegen wir im Sprachgebrauch als das Verhältnis von Ursache und Wirkung zu bezeichnen. Nun hängt aber in allen Fällen, in denen wir die Kausalzusammenhänge ver. folgen, das als Wirkung Bezeichnete von einer Mehrheit von Bedingungen $a b$, so daB von einem schlichten Hervorbringen und Bewirken von seiten eines einzigen Etwas keine Rede sein kann «. Dies gilt auch, wie unsere obigen Ausführungen gezeigt haben, in besonders augentälliger Weise fur die $\mathrm{Be}$ ziehung zwischen dem einzelnen Reiz und dem, was man als seine *Wirkung* bezeichnet, der Einzelerregung. Wir haben, wenn wir diese Beziehung als die von Ursache und Wirkung bezeichnen, daher immer ausdrucklich oder stillschweigend den Zusatz zu machen: bei Erfüllung der allgemeinen Bedingungen. Reiz nennen wir somit diejenige elementarenergetische Bedingung, deren Auftreten, Dauer bzw. Verschwinden bei Erfuilung der allgemeinen Bedingungen das Auftreten, die Dauer bezw. das Verschwinden einer Einzelkomponenteder erregungsenergetischen Situation, einer Einzelerregung, im Gefolge hat, oderwiewirdieszubezeichnen pflegen,

1 Vgl: W. Schuppe, Grundriß der Erkenntnistheorie nnd Logik, Berlin 1894, S 61. 
bewirkt. Durch sie wird also jone Komponente, d. h. die einzelne Originalerregung nicht nur »ausgelöst *, sondern während ihrer Dauer auch aufrecht erhalten, und zu ihren Größenverhältnissen steht die Intensität der durch sie bedingten Erregung in einem bestimmten Abhängigkeitsverhältnis.

Die Formulierung des Abhängigkeitsverhältnisses von Reiz und Erregung, wie sie in dem obigen Satze gegeben ist, rückt durchaus den zeitlichen Zusammenhang in den Vordergrand, sie beschreibt die zeitliche Abhängigkeit der Erregungskomponente von der elementarenergetischen Bedingung durch die Tatsache, daß anmittelbar nach dem Auftreten des Reizes die entsprechende Erregung auftritt, daß sie andauert, 'solange jener andanert und daß sie unmittelbar nach dem Verschwinden des Reizes zwar nicht immer gleich spurlos verschwindet, aber doch sofort rapide abfällt und daß nach einem kurzen Zeitraum sich auch nicht mehr Spuren ron ihr nachweisen lassen.

Dieser zeitliche Zusammenhang zwischen Reiz und Erregung ist dasjenige, was uns als gesicherte eindeutige Beobachtungstatsache vorliegt nnd hierauf hat sich meiner Ansicht nach die nähere analytische Beschreibung der Reizwirkung in erster Linie zu stützen. Ich habe eben bereits erwähnt, daß unmittelbar nach dem Verschwinden des Reizes zwar kein völliges Verschwinden, aber ein rapider Niveauabfall der Erregung stattfindet. Nur während des Vorhandenseins des Reizes, unmittelbar nach ihm auftretend und unmittelbar nach seinem Verschwinden rapid abfallend, besteht also die Erregung in ihrer vollen Ausbildung. Ich bezeichne diese Phase, in der man die Hauptphase der Reizwirkung zu erblicken hat, als die synchrone, und die durch sie bedingte Erregung als synchrone Erregung. 
Nach dem Verschwinden des Reizes erfolgt der rapide Abfall der Erregnng, aber es dauert wohl in allen Fällen Sekunden, zuweilen (vielleicht sogar immer?) Minuten, bis die letzten anf irgendwelche Weise nachweisbaren Spuren der betreffenden Erregungen völlig abgeklungen sind, und in dieser Hinsicht derselbe Zustand der erregungsenergetischen Situation eingetreten ist, der vor Auftreten des Reizes bestanden hat. Ich bezeichne diese abklingende Phase der Erregung vom Verschwinden des Reizes und dem entsprechenden rapiden Niveauabfall der Erregung an bis zu deren gänzlichen Ausklingen als die akoluthe Phase der Erregung. Auch diese Phase kann als das Produkt der Reizwirkung aufgefaßt werden; allerdings mehr als das mittelbare Produkt, denn das unmittelbare ist die synchrone Erregung, und deren Hinterlassenschaft ist die akoluthe Erregung. Wenn wir diese letztere als mittelbares Produkt des Reizes auffassen, können wir von einer akoluthen Reizwirkung, einer $\gg$ Nachwirkung* des Reizes sprechen.

Das Stadium der akolnthen Erregungen ist bisher nur in änßerst sporadischer Weise betriebøen worden. Auf dem Gebiet der durch Sinnesempfindungen manifestierten Erregungen haben bis jetzt nur die optischen akoluthen Empfindungen und die Nachbilder e eine intensive Bearbeitung erfahren. In viel geringerem Maße ist dies bei den akustisehen akoluthen Empfindungen der Fall gewesen, und, was die utbrigen Sinnesgebiete anlangt, so bleibt für sie in dieser Beziehung noch fast alles zu tun tubrig.

Auf dem Gebiet der zentrifugalen, speziell der motorischen Erregungen sind besonders die akolnthen Erregungserscheinungen, die sich bei elektrischer Reizung der Muskeln und Nerven bemerklich machen, genauer studiert worden(Öffnungs- 
zuckung, Öffnungskontraktion, Öffnungstetanus, Öffnungserregung, Öffnungshemmung). Auch sei erwähnt, daß das im nächsten Kapitel zu besprechende Phänomen der Reizsummation anf einer Summation von akoluthen und synchronen Erregungen beruht, indem neue synchrone Erregungen zu bereits vorhandenen akoluthen hinzakommen, sich zu ihnen hinzu addieren.

Auch auf pflanzenphysiologischem Gebiet sind verschiedene Fälle von »Nachwirkungen « zur Beobachtung gelangt. Leider hat man aber auf diesem Gebiet fast durchweg nicht die akoluthe Reizwirkang von der gleich zu besprechenden engraphischen, die akoluthe Erregung von der mnemischen in ausreichender Weise unterschieden, und meines Wissens haben nur Francis Darwin und D. F. M. Pertz ${ }^{1}$ auf den fundamentalen Unterschied zwischen diesen beiden Begriffen und auf die Unzulässigkeit, den Terminus »after effect $\star$, „Nachwirkung", unterschiedslos auf beide anzuwenden, mit der nötigen Schärfe hingewiesen.

Die akoluthe Erregung ist dadurch charakterisiert, daß sie die unmittelbare Fortsetzung der synchronen Erregung ist, der sie sich unter rapidem Niveauabfall anschließt. In manchen Fällen, vielleicht immer, besitzt sie einen oszillierenden Charakter; doch scheinen die Tiefpunkte der Oszillationen immer nur Abschwächnngen, nicht Nollpunkte der betreffenden akoluthen Erregungen darzustellen. Einige Sekunden, höchstens Minuten nach Aufhören des Reizes ist endlich die akoluthe Erregung vollständig sausgeklungen * und von ihr als solcher, d. h. als sich in irgendeiner Weise manifestierender Erregung ist durchaus nichts mehr nachweisbar. Die erregungsenerge-

1 Fr. Darwin and D. F. M. Pertz, On the artificial Production of Rhythm in Planty. Annals of Botany, Vol. XVII, 1903, S. 104. 
tische Situation befindet sich alsdann in bezug auf die nunmehr abgelaufene besondere Erregung in demselben Zustand, in dem sie sich vor Auftreten des betreffenden Reizes befunden hat. Ich bezeichne den somit wieder eingetretenen Indifferenzzustand - der Ausdrack ist im oben S. 7 gekennzeichneten Sinne aufzufassen - als den sekundären im Gegensatz zum primären Indifferenzzustand, d. h. dem Zustand, der vor Einfall des Reizes geherrscht hat.

Es scheint fast allgemein die stillschweigende Annahme gemacht zu werden, daß primärer und sekundärer Indifferenzzustand identisch oder so gut wie identisch sind. Sie sind es ja auch in bezug anf die gerade manifesten Reaktionen. Es wird nun unsere Aufgabe sein, zu zeigen, daß sie es nicht sind in bezug auf die Reaktionsfähigkeit. Bei den Pflanzenphysiologen hat diese Tatsache mehr Beachtung gefunden als bei den Tierphysiologen, doch finde ich auch bei ersteren keine schärfere Formulierung und systematische Durcharbeitung dieses Problems, dessen Bedentung für Reizphysiologie und Abstammungslehre meiner Ansicht nach grundlegend ist. 


\section{Zweites Kapitel.}

Engraphische Wirkung der Reize anf das Individnum.

In sehr viel Fällen läßt sich nachweisen, daß die reizbare Substanz des Organismus, gehöre er nun dem Protisten-, Pflanzen- oder Tierreich an, nach Einwirkung und Wiederauf'hören eines Reizes und nach Wiedereintritt in den sekundären Indifferenzzustand dauernd verändert ist. Ich bezeichne diese Wirkung der Reize als ihre engraphische Wirkung, weil sie sich in die organische Substanz sozusagen eingräbt oder einschreibt. Die so bewirkte Veränderung der organischen Substanz bezeichne ich als das Engramm des betreffenden Reizes, und die Summe der Engramme, die ein Organismus besitzt, als seinen Engrammschatz, wobei ein ererbter von einem individuell erworbenen Engrammschatz zu unterscheiden ist. Die Erscheinungen, die am Organismus aus dem Vorhandensein eines bestimmten Engramms oder einer Summe von solchen resultieren, bezeichne ich als mnemische Erscheinungen. Den Inbegriff der mnemischen Fähigkeiten eines Organismus bezeichne ich als 'seine Mnemé ${ }^{1}$.

${ }^{1}$ Ich wähle für die so von mir definierten Begriffe eigene Ausdrücke. Zahlreiche Gründe bestimmen mich, von den guten deutschen Worten Gedächtnis und Erinnerungsbild keinen Gebrauch zu machen. $\mathrm{Za}$ den hauptsächlichsten dieser Gründe gehört in erster Linie der, $\mathrm{da} B$ ich für meine $\mathrm{Z}_{\text {wecke }}$ die vorhandenen deutschen Worte in einem 
Wenn ich mich jetzt anschicke, einige experimentelle Beispiele von engraphischen Reizwirkungen bei höheren und niederen Organismen zu geben, so muß ich von vornherein auf einen Umstand aufmerksam machen. Die Fähigkeit, die engraphischen Reizwirkungen festzuhalten, die engraphische Empfänglichkeit, ist nicht bei allen reizbaren organischen Substanzen die gleiche, wie ja anch die Reizbarkeit in bezug auf synchrone Erregung bei den verschiedenen Organismen und innerhalb eines Organismus bei den verschiedenen Geweben und Zellarten sehr verschieden ist. Bei den Tieren hat sich im Laufe der Stammesgeschichte ein Organsystem sozusagen zu einem Spezialisten für Aufnahme und Fortleitung von Reizen ausgebildet. Es ist das Nervensystem. Aus dieser Spezialisation ergibt sich allerdings noch kein Monopol des Nervensystems für diese Funktion, selbst nicht bei so hoher Ausbildung desselben, wie wir sie beim Menschen finden. Ist doch, um nur ein recht deutliches Beispiel heranszugreifen, durch einwandfreie Beobachtungen und Versuche nachgewiesen, $\mathrm{da} B$ die Muskeln auch bei vollkommener Ausschaltung jeden Nerveneinflusses erregbar sind.

In gleichem Maße, wie sich die synchrone Erregbarkeit des Nervensystems stammesgeschichtlich schrittweise vergrößert hat, hat auch seine engraphische Empfänglichkeit zugenommen; ebensowenig jedoch wie die Erregbarkeit durch synchrone Reize ist diese Empfänglichkeit dabei zu einem

viel weiteren Sinne fassen müßte, als sie gewöhnlich gebraucht werden, und dadurch zahllosen Mißverständnissen und zwecklosen Polemiken Tür und Tor öffnen würde. Es wäre auch sachlich ein Fehler, den weiteren Begriff mit einer Bezeichnung zu belegen, die für gewöhnlich in einem engeren Sinne gebrancht oder gar, wie die Bezeichnung Erinnerungsbild, fast immer mit Bewußtseinsphänomenen verbunden gedacht wird. 
Monopol des Nervensystems geworden. Sie ist anch bei den höheren und höchsten Organismen eine Eigenschaft jeder reizbaren Substanz geblieben und scheint mir mit der Erregbarkeit als solcher untrennbar verbunden zu sein. Unsere Beobachtungen am Nervensystem fuhren uns also nur zu dem Schlusse, daß mit der Steigerung der Erregbarkeit sich auch die engraphische Empfänglichkeit steigert. So sehen wir denn, daß Reize, die zu schwach oder zu kurz sind, um auf nicht nervös differenzierte organische Substanz merklich engraphisch za wirken, in dieser Richtung auf nervöse Substanzen eine sehr starke Wirkung austiben.

Ich habe diese Auseinandersetzung vorausgeschickt, um den Leser darauf vorzubereiten, daß der Nachweis von engraphischer Wirkung der Reize, besonders dann, wenn es sich um eine experimentelle Erzeugung solcher Wirkung handelt, bei nervösen Substanzen sehr viel leichter und deutlicher ist, als bei nicht nervös differenzierten. Bei letzteren müssen die Reize in der Regel sehr viel länger wirken, oder sich sehr viel häufiger wiederbolen, um engraphische Wirkungen hervorzubringen, während bei nervösen Substanzen höherer Tiere häufig ein einziger kurzer Reiz genugt, um ein leicht nachweisbares, lange Zeit haftendes Engramm zu erzengen. So wenig prinzipielle Bedentung dieser Unterschied hat, um so fülbarer macht er sich bei der experimentellen Behandlung und bei derAnführang von Beispielen geltend, die in dem Maße schlagender und in ihrer Darlegung anch einfacher ausfallen, je höher differenzierte nervöse Sabstanzen man wählt.

Aus diesem Grunde bringe ich als erstes Beispiel einer engraphischen Reizwirkung eine solche auf nerröse Substanz, und zwar nervöse Snbstanz eines höheren Tieres. Die An- 
nahme, daß man die physiologischen Eigenschaften und Fähigkeiten der organischen Substanzen am besten bei den einzelligen Lebewesen studieren könne, ist ein Trugschluß, freilich ein neuerdings oft proklamierter. Wo die Arbeitsteilung unter den Zellen und Geweben weit fortgeschritten ist, wo ein Organsystem eine besondere Funktion als Spezialität ausuibt, ist das Studium dieser Funktion gewöhnlich einfacher, die Antwort, die uns das Experiment auf unsere Fragen gibt, unzweideutiger als da, wo sich die betreffende Funktion weniger vorherrschend und weniger sauber herausgearbeitet findet, mehr mit anderen Funktionen vergesellschaftet ist.

Obwohl wir natürlich beim Studium der engraphischen Reizwirkungen die nicht nervösen organischen Substanzen genau ebenso berücksichtigen müssen wie die nervösen, erscheint mir also als Einführung in das speziellere Studium der Weg vom Differenzierteren zum weniger Differenzierten zweckmäßiger als der umgekehrte.

Wir betrachten also zanächst folgenden Fall. Ein junger Hund, der bis dahin noch keine ubeln Erfahrungen mit dem Herrn der Schöpfung gemacht hat, wird anf einem unbeaufsichtigten Spaziergang ron Knaben mit Steinen geworfen. Zwei Gruppen von Reizen wirken auf ihn: die optischen Reize der sich nach den Steinen buckenden und dieselben werfenden Menschen (Reizgruppe a) und die sensibeln, mit Schmerz verbandenen Hautreize, die die ihn treffenden Steine verursachen (Reizgruppe b). Beide Reizgruppen wirken engraphisch; denn nach dem Aufhören der synchronen sowie anch der akoluthen Reizwirkungen zeigt sich der Organismus von nun an in bezug auf gewisse Reize dauernd verändert. Während zuvor der optische Reiz eines sich rasch buckenden 
Menschen von keiner besonderen und vor allem von keiner konstanten Reaktion begleitet war, wirkt dieser Reiz jetzt regelmäßig - meist bis an das Lebensende des Tieres - wie ein schmerzerregender Reiz. Das Tier klemmt den Schwanz zwischen die Beine und flieht, oft unter lautem Schmerzgeheul. Wir können dies so ausdrücken, daB die zur Reizgruppe $b$ gehörigen Reaktionen von jetzt an nicht nur durch diese Reize selbst, sondern auch durch die Reizgrippe $a$ ausgelöst werden.

Hier erhalten wir von einer Seite aus einen weiteren Einblick in das Wesen der engraphischen Reizwirkungen. Dasselbe beruht anf einer bleibenden Veränderung der organischen Substanz von der Beschaffenheit, daß der zu Reiz $b$ gehörige synchrone Erregungszustand nicht nur, wie im primären Indifferenzzustand, durch Eintritt von Reiz $b$, sondern auch durch andere Einflusse, in unserem Falle durch Reiz $a$, nea hervorgerufen, wieder erweckt werden kann. Ich bezeichne die Einflusse, die das vermögen, als ekphorische Einflusse, und, wenn sie Reizcharakter tragen, als ekphorische Reize. Nicht alle ekphorischen Einflusse kann man ohne weiteres als Reize bezeichnen, wie wir im weiteren Verlauf unserer Betrachtungen noch erkennen werden.

Nach Ablauf der unmittelbaren Wirkungen, d. b. der synchronen und akoluthen Wirkungen eines Reizes, und nach Eintritt des sekundären Indifferenzzustandes können wir nur auf folgende Weise erkennen, ob der Reiz eine engraphische Veränderung hinterlassen hat: wir mussen herausfinden, $o b$ der jenem Reize zugehörige Erregungszustand, der fur uns durch bestimmte Reaktionen manifest wird, nunmehr auch durch Einflusse hervorgerufen werden kann, die quantitativ und qualitativ von dem engraphisch wirksamen Reize ver- 
schieden sind. Einen Reiz, der, zum ersten Male auftretend, engraphisch wirkt, bezeichne ich als Originalreiz, die ihn begleitende synchrone Erregung zusammen mit ihrer akoluthen Nachfolgerin nenne ich in bezug anf diesen Reiz und seine weiteren Folgen Originalerregung.

Daß der Reiz selbst bei jeder Einwirkung den ihm zugehörigen synchronen Erregungszustand hervorruft, ist ja selbstrerständlich, und deshalb unbeweisend für den Nachweis einer vorhergegangenen engraphischen Veränderung. Ein Reiz muß deshalb quantitativ oder qualitativ vom Originalreiz verschieden sein, wenn von ihm auf Grund objektiver Untersuchung behauptet werden soll, daß er ekphorisch wirkt, d. h. daB der von ihm hervorgerufene Erregungszustand Produkt der Ekphorie eines Engramms, nicht einfach ein synchroner Erregungszustand ist. Um diesen Beweis voll zu erbringen, ist es sogar notwendig, durch den Versuch zu zeigen, daß dieser ekphorische Einfluß an sich quantitativ oder qualitativ nicht ausreichend ist, ohne vorhergegangene Einwirkung des Originalreizes die letzterem zugehörige Reaktion auszulösen. In dem vorliegenden Falle hat man es leicht, diesen Beweis zu erbringen, indem man das Verhalten des Tieres vor der schmerzhaften Erfahrung mit dem nach derselben vergleicht.

Die Quintessenz des angeftuhrten Beispiels, dem sich noch hundert andere von Säugetieren, Vögeln, Reptilien, gewissen Insekten und Cephalopoden anreihen ließen, läßt sich in folgenden Sätzen ausdrlicken:

1. Reiz $a$ löst als Originalreiz nur Erregung $\alpha$ aus.

2. Reiz $b$ löst als Originalreiz nur Erregung $\beta$ aus.

3. Erregung $(\alpha+\beta)$ wird als Originalerregung nur durch Reiz $(a+b)$ ausgelöst. 
Engraphische Wirkung der Reize auf das Individuum.

Dagegen kann

4. Erregung $(\alpha+\beta)$ als mnemische Erregung, d. h. nach fruherer Einwirkung von Reiz $(a+b)$ und Erzeugang des Engramms $(A+B)$, schon allein durch Reiz $a$ als ekphorischem Reiz ausgelöst werden.

Bei niederen Tieren, Pflanzen und Protisten ist es in der Regel nicht möglich, durch Einwirkung eines einmaligen, kürzer andauernden Reizes eine engraphische Wirkung zu erzielen. Es bedarf dort längerer $3: w$. häufiger wiederholter Reizung. Doch hat sich meine schon in der ersten Auflage des vorliegenden Werkes (S. 26) groäußerte Ansicht vollständig bestätigt, daß es durch weiteres Studium gelingen werde, sprechende experimentelle Beispiele von engraphischer Reizwirkung jeder Art bei niederen Formen ans Licht za ziehen. So haben die im letzten Jahrzehnt angestellten Beobachtungen von Bohn, Jennings, van der Ghinst a. a. bei niederen wirbellosen Tieren (niederen Mollusken, Echinodermen, Coelenteraten - von den höher organisierten Krebstieren ganz zu schweigen -) den Nachweis deutlich zutage tretender und lange Zeit haftender engraphischer Reizwirkung gefuhrt ${ }^{1}$. Bei Infusorien (Vorticella) wurden solche Wirkungen, deren Spuren sich immerhin mehrere Stunden erhalten, schon im Jahre 1895 von Hodge und Aikins ${ }^{2}$ nachgewiesen.

Seit dem Erscheinen der ersten Auflage der Mneme hat Francis Darwin in Verfolgung der dort eingeschlagenen Ge-

1 Vgl. die Zusammenstellungen bei G. Bohn, La Naissance de l'Intelligence, Paris 1909, Deutsche Übersetzung von R. Thesing unter dem Titel: Die Entstehung des Denkvermögens, Leipzig 1910. Ferner H. S. Jennings, Das Verhalten der niederen Organismen, Leipzig und Berlin 1910.

2 C. F. Hodge and H. A. Aikins, The daily Life of a Protozoon. Amer. Journ. of Psychology VI, 1895. 
dankengänge verschiedene Beispiele von vereinigten (assoziierten) Engrammen auf pflanzenphysiologischem Gebiet beigebracht ${ }^{1}$. Schon fruher ${ }^{2}$ war es demselben Forscher zasammen mit D. Pertz gelungen, bei Pflanzen zwei verschiedenartige Engramme, nämlich photische bzw. geotropische mit Stoffwechselengrammen (Zeitengrammen) $\mathrm{zu}$ assoziieren.

Engraphische Wirkung läßt sich übrigens experimentell schon bei Anwendung von einer Reizqualität allein nachweisen, und zwar dadurch, daß man zeigt, daß nach wiederholter oder längerer Einwirkung eines Reizes und nach Ruckkehr des Organismus in den sekundären Indifferenzzustand eine quantitativ kleinere energetische Einwirkung derselben Art genügt, um denselben Erregungszustand bzw. dieselben Reaktionen hervorzurufen, die vorher als Originalerregungen nur auf stärkeren Reiz hin auftraten. Solche Wirkungen treten vei Tieren mit mäßig hoch differenziertem Nervensystem schon auf wenige, kurze Reize hin auf. So fanden Davenport und Cannon ${ }^{3}$ bei ihren auf andere Fragen gerichteten Experimenten mit Daphnien ganz beiläufig, daß sich die Reaktion ihrer Objekte auf den Lichtreiz, auf den sie positiv heliotropisch reagieren, nach wenigen kurzen Reizen merklich ändert. Es bedurfte, um dieselbe oder selbst eine stärkere Reaktion auszulösen, alsdann nur eines Viertels von dem Lichtreiz, der am Anfang der Versuche für dieselbe Reaktion erforderlich war. Das Resultat war ein konstantes.

${ }^{1}$ Francis Darwin, Lectures on the physiology of movement in plants. 1. Associated stimuli. The New Phytologist. Vol. V, No. 9, 1906.

${ }^{2}$ Francis Darwin and D. Pertz, On the articifial production of rhythm in plants. Annals of Botany Vol. VI, $1892 \mathrm{u}$. Vol. XVII, 1903.

3 C. B. Davenport and W. B. Cannon, $O n$ the determination of the direction and rate of movement of organisms by light. Journ. of Physiol. Vol. XXI, 1897, S. 32. 
Engraphische Wirkung der Reize auf das Individunm.

Ganz ähnlich zu beurteilen sind gewisse von Botanikern und Protistenforschern häufig gemachte Beobachtungen uber die Änderung der sogenannten sLichtstimmung * ${ }^{1}$ unter dem Einfluß photischer Reize. Die Reaktionen, durch die diese den Eintritt des sekundären Indifferenzzustandes überdauernden Veränderungen manifest werden, können sowohl motorische wie Wachstumsreaktionen sein. In bezug auf letztere fand z. B. Oltmanns ${ }^{2}$ folgendes bei Pilzen, die 10 Stunden lang einer äußerst intensiven Beleuchtung durch elektrisches Bogenlicht auggesetzt worden waren, dann 15 Stunden verdunkelt und darauf wieder intensi Einflaß dieser erneuten Belenchtung machten die Fruchtkörper »anfänglich starke negative Krummungen, dann aber wurden dieselben bald ausgeglichen, und in relativ kurzer Zeit setzten positive Bewegungen ein, die nun mit viel gröBerer Energie dauernder anhielten als am Tage zuror und auch schärfere Krimmungen herbeifubrten. Daß diese letzteren durch die vorangehende intensive Beleuchtung bedingt waren, d. h. daß infolge gesteigerter Lichtstimmung die Bewegungen energischer ausfielen, ist einigermaßen klar. «

Drucken wir das Wesentliche dieser und der vorher angefuhrten Beobachtung in Sätzen aus, die denen entsprechen, welche das Resultat unseres ersten Beispiels zogen (vgl. S. 20). so ergibt sich folgendes:

1 Der Ausdruck > Stimmung e wird außerdem noch bei vielen andern Gruppen von Erscheinungen angewendet, bei denen es sich nicht um mnemische Phänomene handelt. Ich vermeide ihn deshalb ganz, ebenso wie den Ausdruck sNachwirkunge, der von den Physiologen in der Regel unterschiedlos für akoluthe und engraphische Reizwirkungen gebraucht wird (vgl. oben S. 13).

2 F. Oltmanns, Über positiven nnd negativen Heliotropismus. Flora oder Allg. Bot. Zeit. 83. Bd. 1897. 
1. Reiz $\frac{a}{2}$ löst als Originalreiz nur Erregung $\frac{\alpha}{2}$ aus.

2. Reiz $a$ löst als Originalreiz nur Erregung $\alpha$ aus, oder anders ausgedrickt:

3. Erregung $\alpha$ wird als Originalerregung nur durch Reiz $a$ ansgelöst.

\section{Dagegen kann}

4. Erregung $\alpha$ als mnemische Erregung, d.h. nach friherer Einwirkung von Reiz $a$ und Erzeugung eines Engramms $A$, schon allein durch Reiz $\frac{a}{2}$ als ekphorischem Reiz ausgelöst werden.

Weitere Beispiele für die engraphische Wirksamkeit der Reize bzw. Erregungen sowohl im Individuum selbst als in seiner Deszendenz werden im Lanfe dieser Untersuchung noch in größerer Zahl vorgefuhrt werden. Im gegenwärtigen Augenblick halte ich es, statt weitere Beispiele zu bringen, für angemessener, in die genauere Analyse der engraphischen Reizwirkang und ihrer Manifestationen einzutreten, eine Analyse, die in diesem einfuihrenden Teil unserer Arbeit freilich nur einen provisorischen Charakter tragen wird, and die erst im zweiten Teil ihren Abschluß finden kann.

Bei unserer jetzigen Untersuchung gehen wir aus von dem Zastande des Organismus, den ich oben als primären Indifferenzustand bezeichnet habe.

Primärer Indifferenzzustand: unter dieser Bezeichnung haben wir einfach den Zustand des betreffenden Organismus bei Beginn unserer jeweiligen Beobachtungen und Versuche zu verstehen. Diese Definition hat den Vorzag, durchaus klar und unzweideutig zu sein. Wir sehen uns aber durch sie selbstverständlich vor die Aufgabe gestellt, 
jedesmal den Zastand des Objekts bei Beginn der Beobachtnngen oder Versuche möglichst genau zu erforschen. Große Schwierigkeiten erwachsen dieser Erforschung nach zwei Richtungen. Einmal besitzen die Objekte, die wir zur Untersuchung heranziehen, wenn sie nicht gerade soeben ron den elterlichen Organismen losgelöste Keime sind, schon eine Summe von individuell erworbenen Engrammen, und zwar von Engrammen, die sich vielleicht mit denen, deren Entstehung wir beobachten oder die wir ktinstlich erzengen wollen, nahe beruhren. Nehmen wir z. B. ein einjähriges Individuum der Sinnpflanze, Mimosa pudica, und suchen es engraphisch durch Lichtreize zu beeinflussen, so gentigt es durchaus nicht, seine Lichtreaktionen in den letzten 24 Stunden vor Anfang der Versuche zu konstatieren. Diese Reaktionen können Ende September in Christiania bei einer dort gezogenen und bei einer direkt vom Äquator importierten einjährigen Pflanze fast identisch sein. Man hat aber die Möglichkeit im Auge za behalten, daß vielleicht wenige Monate später Verschiedenheiten manifest werden können, die ohne Berucksichtigung der Engramme, die beide Pflanzen anf ihren verschiedenen Standorten erwarben, ganz unerklärlich sein wlirden. Der beste Answeg dürfte es da sein, die Versuchsobjekte, wenn irgend möglich, direkt ans Samen oder Eiern zu ziehen und unter Bedingungen zu halten, bei denen wir die betreffenden Reize, deren engraphische Wirkung studiert werden soll, einigermaßen kontrollieren können. Eine Mimosa, die das Jahr tuber täglich genan 12 Stunden in einem klinstlich erhellten und 12 Stunden in einem klinstlich verdunkelten, gleich temperierten Raum verbracht hat, ist ein besser uberschaubares Objekt als eine, die der nattirlichen Beleuchtang ausgesetzt war. Am besten aber, man nimmt Objekte, anf 
die in ihrem individuellen Leben noch keine oder doch verhältnismäßig nor sebr wenige Reize eingewirkt haben, die Keimpflanze im Moment, wo sie, sich aus dem Boden erhebend das Licht des Tages erblickt, das junge Huhnchen, wenn es die Eierschale verläßt, oder man sucht doch, wenn dies nicht angeht, möglichst Individuen ans, die wenigstens demjenigen Reize, dessen engraphische Wirkung man studieren will, bisher entzogen gewesen waren.

Unsere bisherige Methode, engraphische Verändernngen durch objektive Beobachtung, also ohne Anwendung von Introspektion festzustellen, war die, die Veränderung der Reaktionsfähigkeit zwischen primären und sekundärem Indifferenzzustand nachzuweisen. Je weniger individuell erworbene Engramme im Primärzustand vorhanden sind, um so unkomplizierter die Aufgabe.

Nun ist aber das Individuum, das sich im einzelligen Stadium als Ei soeben von dem elterlichen Organismus abgelöst hat, zwar in bezug anf seine individuelle Mneme noch jungfräulicher Boden. Wie wir aber später ausfuhrlich erörtern werden, besitzt auch dieses schon ererbte Engramme, und zwar einen ungehenern Reichtum von solchen. Im Hinblick darauf ist heutzutage, wo frisch durch Urzeugung geschaffenes organisches Material anf unserem Planeten nicht mehr erhältlich ist, kein einziger Organismus, ob Ei, ob ausgewachsenes Geschöpf, den wir der Beobachtung unterwerfen, mnemisch als ein unbeschriebenes Blatt zu betrachten. Die Keimzelle, die eben noch ein Teil der Matter war und an deren Mneme teilhatte, schafft, wie a priori anzunehmen wäre und wie sich durch beliebig viele Tatsachen erweisen läßt, durch den Akt der Ablösung von der Mutter und den Eintritt in eine neue Individualitätsphase in bezug auf ihre 
Engraphische Wirkung der Reize auf das Individuum.

Mneme nicht tabula rasa. Es wird später unsere Aufgabe sein, zu untersuchen, inwieweit die Keimzellen an den individuellen und an den ererbten Engrammen des Gesamtorganismus teilhaben, und inwieweit sie ibren Anteil nach ibrer $\mathrm{Ab}$ lösung bewahren.

Engraphisch wirkender Reiz: energetische Einflisse aus allen den Energiegruppen, von denen wir wissen, daß sie bei Organismen synchrone Erregungen auslösen, können eben durch Vermittlung dieser Erregungen engraphisch wirken, also: mechanische, geotropische, akustische, photische, thermische, elektrische und ehemische Einflüsse. Magnetische Einflusse scheinen uberhaupt unvermögend zu sein, bei Organismen als Reize zu wirken; ist diese Annahme richtig, so können solche Einflisse natürlich auch nicht engraphisch wirken. Außerdem ist es wohl möglich, daß Energien, die sich bisher unserer Kenntnis entzogen haben, bei den Organismen synchrone Erregungen anslösen und dadurch anch engraphisch wirken können. Erst klurzlich ist ja eine bis dahin unbekannte Art von strahlender Energie, die sogenannten X-Strablen, entdeckt und bald darauf auch ihre Fähigkeit, organische Körper als Reiz zu beeinflussen, erkannt worden. Dasselbe gilt von der Radiumstrahlung ${ }^{1}$. Obwohl ich deshalb die Liste der Energien, die als Originalreize und in zwe:ter Lin'a als engraphische Reize wirken, durch obenstehende Aufzählung keineswegs erschöpft zu haben glaube, gibt sie uns in der gegenwärtigen Phase unserer Untersuchung eine ausreichende Orientierung.

Die nächste Frage, die an uns herantritt, ist diese: Wann

10 . Hertwig, Neue Untersuchungen über die Wirkung der Radiumstrahlung auf die Entwicklung tierischer Eier. Sitzungsber. d. Kgl. Pr. Akad. d. Wissenseh. 39. Bd., 1910. 
wirkt ein Reiz, der fähig ist, im Organismus eine synchrone Wirkung hervorzurufen, engraphisch, und wann tat er es nicht? Um diese Frage zu beantworten, haben wir uns zunächst uber einige allgemeine Gesetze der Reizwirkungen zu orientieren. Auch um eine synchrone Wirkung anszuttben, bedarf jede energetische Einwirkung einer bestimmten Stärke und Dauer, die je nach Art und Zustand des beeinflußten Organismus verschieden ist. In diesem Sinne spricht man von einem Schwellenwerte des Reizes. Eine anfmerksame Betrachtung ergibt nun, daß dieser Schwellenwert nicht allein von den beiden schon genannten Faktoren abhängig ist, nämlich der Stärke und der Dauer der energetischen Einwirkung, sondern auch von einem dritten Faktor: ihrer Kontinuität oder Diskontinuität. Während die beiden ersten Faktoren in ibrer Bedeutung für synchrone Reizwirkungen hier keiner weiteren Erörterung bedurfen, maß auf den dritten etwas näher eingegangen werden. Es ist bekannt, daß elektrische (sowie auch mechanische) Einwirkungen anf kontraktile Substanzen, die an sich unter dem Schwellenwert liegen, wie man sagt, ssubliminal sind, bei wiederholter Einwirkung wirksam werden. Man stellt sich vor, daß bei solcher Anwendung der Reize die Erregbarkeit der organischen Substanz durch *addition latente (Richet) so weit gesteigert wird, daB sich der Schwellenwert der für sie wirksamen Reizintensität nach unten verschiebt, so daß eine zunächst subliminale Intensität $z \mathfrak{u}$ einer liminalen wird.

Wie Biedermann ${ }^{1}$ bei Erörterung der Reizsummation bei glatten Maskeln ansfuhrt, släßt sich sehr oft zeigen, daß selbst unter den günstigsten Bedingungen durch die stärksten einzelnen Induktionsschläge ein sichtbarer Reizerfolg (Kon-

1 W. Biedermann, Elektrophysiologie. Jena 1895. S. 101. 
traktion) kaum erzielt werden kann, während dieselben $\mathrm{Ob}-$ jekte (Darm, Ureter, Muschelmuskel) bei schwingendem Neffschen Hammer durch die in rascher Folge wirkenden Reize schon bei verhältnismäßig geringem Rollenabstande in Tetanus geraten. Auch bei Anwendung von Kettenströmen hat man oft Gelegenheit, zu beobachten, wie bei mehrmals in nicht zu großen Pausen wiederholter Schließung eines an sich unwirksamen Stromes allmählich eine wirksame Erregung eintritt (Engelmann). Es scheint tubrigens das Vermögen der Reizsummation, wenn auch in einer gradweise verschiedenen Ausbildung, jedem irritabeln Plasma zuzukommen (Flimmerzellen, Nervenzellen, pflanzliches Plasma wie z.B. Dionaea usw.), so daß die gesehilderten Erscheinungen am Maskel nur einen speziellen Fall eines allgemeinen Gesetzes darstellen. Ob man dabei den Vorgang als eine wirkliche *Summierung * an sich unwirksamer Reize zu einem wirksamen oder als eine durch dieselben bedingte Erregbarkeitssteigerung auffassen will, scheint ziemlich unwesentlich, wenn man die schon friher betonten Beziehungen zwischen einer darch den Reiz bedingten Erhöhnng der Erregbarkeit und dem Vorgang der Erregung selbst berlicksichtigt. \& - Neuerdings von Steinach ${ }^{1}$ vorgenommene Untersuchungen an Protisten (Flagellaten, Infusorien), Pflanzen und tierischen Geweben haben die Richtigkeit der Biedermannschen Auffassung, daß jedes irritable Plasma zur Reizsummation befähigt sei, auf das glänzenste bestätigt. So ist z. B. das Summationsvermögen der Pflanzenzellen und in noch höherem Grade dasjenige der Leuchtzellen von Lampyris geradezu als enorm zu bezeichnen.

1 E. Steinach, Die Summation einzeln unwirksamer Reize als allgemeine Lebenserscheinung. Pflïgers Archiv f. Physiologie, 125. Bd. Heft 5-7, 1908. 
Was nun die engraphische Wirkung diskontinuierlicher Reize anlangt, so haben wir hier auf das schärfste zwei verschiedene Wirkungsweisen auseinanderzuhalten. Unmittelbar engraphisch wirkt ja in keinem, Falle der Reiz selbst, sondern dies tnt nur die durch ihn ausgelöste Erregung. Ruft nun ein diskontinuierlicher Reiz eine kontinuierliche Erregung hervor, was regelmäßig dann geschieht, wenn die trennenden Zeitintervalle bei der Reizung hinreichend klein sind, hierher gehören alle die von Biedermann und Steinach ins Auge gefaßten Fälle - so unterscheidet sich die so hervorgerufene Erregung in ihrer engraphischen Wirkung nicht von einer solchen, die durch kontinuierliche Reizung hervorgerufen wird. Sie ist vielleicht infolge der Reizsummation quantitativ stärker, im ubrigen aber von gleicher Beschaffenheit.

Ganz anders aber ist die engraphische Wirkung beschaffen, wenn zwischen den einzelnen Phasen der Wiederholung des Reizes längere Zeitintervalle liegen, Intervalle von Minuten, Stunden usw., die lang genug sind, daß vor Wiedereintritt des neuen Reizes die von seinem Vorgänger hervorgerufene Erregung völlig ausgeklungen ist, so daß inzwischen die reizbare Substanz Zeit gehabt hat, in ihren entsprechenden Indifferenzzustand zurtickzukehren. Dann sind natürlich nicht nur die Reize, sondern auch die von ihnen hervorgerufenen Erregungen diskontinuierlich, und jede Wiederkehr des Reizes erzeugt dann ein neues qualitativ gleiches aber von seinen entsprechenden Vorgängern getrenntes Engramm. Diese Diskontinuität und Selbständigkeit von Engrammen, die der Wiederholung desselben Reizes ihre Entstehung verdanken, ist von großer Bedeutung, wie noch näher im 7. Kapitel bei Besprechung der Homophonie and der Be- 
deutung der Reizwiederholung auseinandergesetzt werden wird 1 .

Bisher war immer nur von der engraphischen Wirkung eines kontinuierlichen oder diskontinuierlichen Reizes die Rede. Jeder Organismus befindet sich aber dauernd unter dem Einfluß von allen möglichen Energiearten, wie Distanz-, Volum-, Bewegungs-, Wärmeenergie, strahlender Energie usw. Wir haben dies als seine jeweilige äußere energetische Situation bezeichnet. Nun wird es kaum im Laboratorium unter den bestausgedachten Bedingungen möglich sein, die energetische Situation bloß in bezug auf eine einzige Energie zn verändern, und unter natülichen Bedingungen wird dies überhanpt so gut wie nie vorkommen. Bricht die Sonne aus den Wolken hervor und bescheint sie eine Pflanze, so ist damit keine einfache, sondern eine höchst zusammengesetzte Veränderung der energetischen Situation geschaffen, da verschiedene Arten strahlender Energie, ultrarote Wärmestrahlen, verschiedene Arten Lichtstrahlen, chemisch wirksame ultraviolette Strahlen als ebensoviele Reize auf den Organismus wirken.

Nur im Laboratorium wird es mir einigermaßen gelingen, rein photische Einflusse auf den Organismus wirken zu lassen, indem ich mich z. B. gewisser roter Strahlen von einer bestimmten Wellenlänge, deren chemische Wirkung annähernd gleich Null ist, bediene und thermische Einflusse durch eingeschaltete Eisschichten ebenfalls anf annähernd Null reduziere.

Eine einzige Ursache, das durch Wegziehen eines Vorhangs veranlaßte Einlassen der Sonnenstrahlen, bewirkt also

1 Noch ausfuihrlicher bin ich hierauf in den ninemischen Empfindungen eingegangen und zwar besonders im 15. Kapitel: Die Wiederholung der Erregungen als Schöpferin der Vorbedingung für mnemische Homophonie. 
zum Beispiel bei einer im dunkeln Zimmer stehenden Mimosa die gleichzeitige Einwirkung mindestens dreier Reize, deren synchrone Wirkung wir durch den Eintritt dreier verschiedener Reaktionen nachweisen können. Anf den photischen Reiz antwortet die Pflanze durch Entfalten ihrer Blätter, auf den chemischen durch Reaktionen in ihrem Stoffwechsel (sogenannte Assimilation: Aufnahme von Kohlensäure, Ausscheidung von Sauerstoff), auf den thermischen durch Beschleunigung in ihrem Wachstum. Man kann sich also in diesem Falle leicht durch geeignete Versuchsanordnung (Ausschaltung der thermischen, oder Ausschaltung der photischen, oder Ausschaltung der chemischen Strahlen) davon uberzengen, daß eine scheinbar so einfache und einheitliche Veränderung der energetischen Situation die Quelle verschiedener gleichzeitiger Reize furr den Organismus gewesen ist.

Es ist aber ferner die energetische Situation der Organismen auf unserem Planeten so beschaffen, daß sie fortdauernd nicht in einer, sondern in vielen Beziehungen Veränderungen unterliegt. Diese Veränderungen können in einem erkennbaren Zusammenhange untereinander stehen: ein Gewitter bringt z. B. gleichzeitig photische, thermische, akustische, mechanische und noch viele andere Reize fuir die Organismen, in deren energetische Situation es eingreift. Ebenso häufig aber beeinflussen verschiedene Reize gleichzeitig denselben Organismas, ohne daß ihre Entstehung in einer für uns erkennbaren Weise verknüpft wäre. Ein solches Zusammentreffen bezeichnen wir als zufällig.

Als Gesamtresultat ergibt sich, daß jeder Organismus fortgesetzt Reizwirkungen unterworfen ist, und zwar gewöhnlich gleichzeitig den Einwirkungen verschiedener Reize.

Die Frage erhebt sich nun : können zwei oder mehr Reize, 
Engraphische Wirkung der Reize auf das Individuum.

die einen Organismus gleichzeitig treffen und synchrone Wirkungen zur Folge haben, ihn auch nebeneinander engraphisch beeinflussen? Und wenn dies der Fall ist: treten die durch gleichzeitige Reizwirkungen erzeugten engraphischen Veränderungen in bestimmte Beziehungen zaeinander?

Die experimentelle Entscheidung dieser Fragen ist naturlich leichter zu erzielen bei Organismen, bei denen überhaupt engraphische Wirkungen von Reizen unschwer zu erzeugen sind, als bei solchen, bei denen dies nicht der Fall ist. Ist der betreffende Organismus ein Mensch oder Affe, ein Hund, ein Pferd, ein Vogel, so ist es ganz leicht, bei ihm die engraphische Wirkung zweier gleichzeitiger Reize zu zeigen. Ich schlage einen jungen Hund, der noch nie gezuichtigt worden ist, mit einer Peitsche. Der optische Reiz (Anblick der Peitsche) und der mechanische Reiz, der eine Schmerzempfindang auslöst, wirken beide engraphisch, und, was besonders wichtig ist, die beiden durch diese gleichzeitigen Reize erzeugten Engramme sind von uun an in gewisse unlösliche Beziehungen zueinander getreten. Diese Beziehungen lassen sich kurz dahin definieren, daß von nun an die Wiederkehr bloB des einen Reizes genligt, um in einer später noch näher zu analysierenden Weise auf das gleichzeitig erzeugte Engramm des anderen ekphorisch zu wirken. Der bloße Anblick der Peitsche in der Hand des Herrn genügt, um bei diesem Hunde die mnemische Erregung der bestimmten Schmerzempfindung zu ekphorieren und die betreffende Reaktion. Einklemmen des Schwanzes, Aufheulen, schleunige Flucht, hervorzurufen. Derartig zusammengekoppelte Engramme, bei denen die Wiederkehr des engraphischen Reizes des einen zum eĭkphorischen des 
anderen dienen kann, bezeichnen wir als assoziierte Eng ramme.

Eine Regel, von der es keine Ausnahme gibt, ist die, daß alle gleichzeitig erzeugten Engramme assoziiert sind, auch wenn die Reize, die sie erzeugt haben, den verschiedensten Reizqualitäten angehören und in bezug auf die Kansalität ihres Auftretens keinerlei Beziehungen zeigen. Auf mich haben einstmals gleichzeitig zwei Reize eingewirkt, die ganz verschiedenen Energiearten angehören und ohne erkennbare Beziehungen zueinander stehen: der Anblick Capris von Neapel aus und die Wahrnehmung eines bestimmten Ölgeruchs. Seitdem genügt die Wiederkehr dieses oder eines ähnlichen Ölgeruchs, um bei mir unweigerlich auf jenes photogene Engramm *Capri ekphorisch zu wirken. Außer dieser Assoziation von Engrammen, die durch die Gleichzeitigkeit des Auftretens ihrer engraphischen Reize geschaffen wird, und die wir im Anschluß an schon eingefuhrte Kunstansdrícke als Assoziation der simultan erzengten Engramme bezeichnen wollen, läßt sich noch eine zweite, ebenso wichtige Assoziation beobachten, die ebenfalls ron dem Zeitverhältnis beim Einwirken der engraphischen Reize abhängig ist. Nicht nur die gleichzeitig, sondern auch die in unmittelbarer zeitlicher Aufeinanderfolge erzeugten Engramme sind derart assoziiert, daß die Wiederholung des Originalreizes der einen als ekphorischer Reiz für die anderen dienen kann, und auch in diesem Fall ergibt sich die Assoziation ebenfalls dann, wenn die betreffenden Engramme den verschiedensten Reizqualitäten ihre Entstehung verdanken, und wenn ein kausaler Zusammenhang im Auftreten dieser engraphischen Reize nicht erkennbar ist. Wir bezeichnen die soeben besprochene Erscheinung als Assoziation der sukzessiv erzeugten Engramme. 
Auf die Ableitung der sukzessiven Assoziation von der simultanen werden wir im zweiten Teil dieses Buches noch ausfuhrlicher einzugehen haben.

Sekundärer Indifferenzustand (Latenzustand des Engramms). Nach Ablauf des durch den Originalreiz bewirkten synchronen Erregungszustandes, dem ein rasch voribergehender akoluther Erregangszustand folgt, gelangt der Organismus in einen Zustand, den wir als sekundären Indifferenzzustand bezeichnet haben. Vom Primärzastande, von dem wir ausgingen, ist dieser Sekundärzustand durch nichts als durch das Vorhandensein des neuen Engramms (oder nach Einwirkung verschiedener engraphischer Reize: der neuen Engramme) unterschieden. Aber diese sind im Sekundärzustande unserem Wahrnehmungsvermögen verborgen, sie sind latent. Zu ihrer Manifestation ist der Eintritt ekphorischer Einflüsse erforderlich.

Die Einschaltung einer Latenzphase zwischen dem synchronen und mnemischen Erregungszustand könnte auf den ersten Blick als eine merkwürdige Eigentlimlichkeit der mnemischen $\mathrm{Phänomene} \mathrm{erscheinen.} \mathrm{Charakteristisch} \mathrm{ist} \mathrm{sie} \mathrm{in}$ der Tat in hohem Grade, und durch sie erst erscheint uns die mnemische Erregung im Licht einer "Reproduktion*. Als Reproduktionen stellen sich aber Äußerungen der Mneme gewöhnlich unserem Geiste dar.

Die Resultate unserer bisherigen Untersuchungen können wir folgendermaßen ausdricken: Ein Reiz versetzt einen Organismus in einen bestimmten Erregungszustand, dessen Vorhandensein wir an bestimmten Reaktionen erkennen. Mit dem Aufhören des Reizes schwindet der Erregungszustand entweder sofort (synchrone Erregung) oder gewöhnlich - richtiger wohl: immer - eine kurze Zeit nachher (akolnthe Er- 
regung). Die reizbare Substanz des Organismus kehrt damit im Hinblick auf den betreffenden Reiz in den Zustand zurtick, in dem sie sich vor Eintritt des Reizes befand (Indifferenzzustand). Dennoch sind die beiden Indifferenzzustände, derjenige vor und derjenige nach Eingreifen des Reizes, der primäre und sekundäre Indifferenzzustand, nicht identisch, sondern dadurch unterschieden, daß die reizbare Substanz im Sekundärzustand durch gewisse ekphorische Einflusse in den dazwischenliegenden Erregungszustand versetzt werden kann, was im Primärzustand nicht der Fall war.

Es erhebt sich aber nun die Frage, ob es nicht auch Fälle gibt, in denen die reizbare Substanz nach Aufhören des Reizes gar nicht in den sekundären Indifferenzzustand zuricktritt, sondern dauernd in dem durch den Reiz einmal geschaffenen Erregungszastand verharrt. Ich glaube, wir sind schon heute, obwohl unsere Kenntnisse noch keineswegs abgeschlossene sind, berechtigt, diese Frage uneingeschränkt mit nein zu beantworten. Natlirlich können manche sekundäre Produkte der Erregungen von der Art sein, daß sie durch das Aufhören der Erregung nicht ohne weiteres rückgängig gemacht werden. So können z. B. alle solche Produkte, die sich als Wachstumserscheinungen darstellen, nach Aufhören des Reizes und Verschwinden der Erregung überhaupt nicht mehr ruckgängig gemacht werden, sondern sind dauernd fixiert.

Etwas schwieriger zu beurteilen sind manche Fälle, die Pfeffer (Pflanzenphysiologie, II, S. 167) als fortwirkende (stabile, inhärente) Induktion bezeichnet. Alle diese Fälle, in denen ein voribergehender Reiz eine fortwirkende Induktion schafft, sind aber wohl so zu erklären, daß auch bei ihnen die Reizwirkung Produkte schafft (Wachstumsprodukte), deren 
Vorhandensein nun ihrerseits den neuen Zuwachs als Reiz (Positionsreiz) beeinflußt, auf ihn determinierend wirkt. In allen diesen Fällen ist natülich nicht vom Verharren der reizbaren Substanz im primären Erregungszustand zu reden. Am meisten Schwierigkeit scheint mir der Fall von Marchantia zu machen. Die Brutkörbchen dieses Lebermooses lassen sich durch eine wenige Tage währende einseitige Beleuchtung so beeinflussen, daß, ehe noch in dem kleinen Sproß die anatomische Differenzierung deutlich hervorgetreten ist, dasjenige, was an dem zukünftigen Pflänzchen Oberseite, und das, was Unterseite werden wird, unverrückbar bestimmt ist. Auch dieser vereinzelte Fall wird sich aber aller Wahrscheinlichkeit nach bei weiterer Untersuchung so erklären lassen, daß durch den Reiz während seines Einwirkens in der morphologischen Struktur des wachsenden Pflänzchens bleibende Zustände geschaffen werden, die ibrerseits als Positionsreize fortwirkend das Neuhinzukommende beeinflussen. Bis eine solche Struktur durch die Beobachtung nachgewiesen iśt, bleibt dies freilich nur Vermutung. Jedenfalls aber brauchen wir, da noch andere Erklärungen denkbar sind, diesen Fall nicht als eine bewiesene Ausnahme von unserer Regel und nicht als ein Beispiel dafür zu betrachten, daß unter Umständen ein durch einen Reiz geschaffener Erregungszustand der organischen Substanz nach Aufhören des Reizes als solcher bestehen bleibt, statt schließlich dem sekundären Indifferenzzustand Platz zu machen. Wir dürfen vielmehr als Regel aussprechen: nach Aufhören eines Reizes kehrt der Organismus stets iiber kurz oder lang in den Indifferenzzustand zurück. Eine dauernde Wirkung ubbt ein Reiz auf die reizbare Substanz nur insofern aus, als er ein Engramm zurückläßt. Er verändert also die reizbare Sub- 
stanz nur in der Beziehung, daß nunmehr der dem Reiz eigentümliche synchrone Erregungszustand nicht nur durch diesen selbst, sondern auch durch andere Einflissse, dio wir ekphorische nennen, neu hervorgerufen werden kann.

Ekphorische Einflusse. Aus unseren bisherigen Ausführangen geht hervor, daß das Engramm eines Reizes oder, besser gesagt, des durch diesen Reiz hervorgerufenen Erregungszustandes, nichts anderes ist als eine veränderte Disposition der reizbaren Substanz in bezug auf die Wiederholung dieses Erregungszustandes. Die organische Substanz zeigt sich alsdann gegen fruher in eigentimlicher und durchaus gesetzmäßiger Weise dafür prädisponiert, auch durch andersartige Einflusse als durch den Originalreiz wieder in jenen Erregungszustand versetzt zu werden. Den anf Grund der Ekphorie eines Engramms entstandenen Erregungszustand bezeichne ich als mnemischen Erregungsustand. Insofern sich eine mnemische Erregung durch eine Empfindung manifestiert, bezeichne ich eine solche Empfindung als mnemische Empfin dung1.

Überblicken wir die mnemischen Phänomene in den drei organischen Reichen, so finden wir, daß folgende Gruppen von Einflitissen ekphorisch auf ein Engramm wirken können: Erstens die Wiederkehr des Originalreizes, and zwar sowohl in qualitativ und quantitativ identischer orler nahezu identischer Gestaltung, als auch in zwar ähnlicher, aber qualitativ oder quantitativ etwas verschiedener Gestaltung. Zweitens wirkt ekphorisch auf ein Engramm die Ekphorie aller

1 Über das Verhältnis einer Erregung zu ihrer Empfindungsmanifestation vgl. die Erörterung im Einleitungskapitel zu meinen Mnemischen Empfindungen, ferner das Übersichtsschema ebenda im 7. Kap. S. 141. 
gleichzeitig mit ihm oder unmittelbar vor ihm erzengter Engramme (aller simultan und sukzessiv assoziierter Engramme). Drittens wirken ekphorisch gewisse Einflttsse, die sich für uns scheinbar zunächst bloß als Abläufe bestimmter Zeit- oder Entwicklungsperioden darstellen, die sich aber, wie wir später sehen werden, im Grunde anch alle auf dasselbe, sämtlichen drei Gruppen zugrunde liegende Prinzip zurückführen lassen : dieses Prinzip ist die partielle Wiederkehr einer bestimmten energetischen Situation.

Von den angefuhrten Fällen ist scheinbar der einfachste der, in welchem ein Reiz, der qualitativ und quantitativ mit dem Originalreiz identisch ist, ekphorisch wirkt. Gerade in diesem Falle ist aber die ekphorische Wirkung dieses Reizes auf objektivem Wege kaum beweisbar. Denn, wenn ein Reiz bei seiner Wiederholung genau dieselben Wirkungen äußert wie bei seinem ersten Auftreten, hat man kein Recht, zwischen seiner Wirksamkeit bei seiner ersten und bei seiner späteren Einwirkung einen Unterschied zu machen.

Dennoch gibt es Grinde, die uns, wie ich glaube, das Recht geben, auch bei bloßer Wiederholung des Originalreizes von ekphorischer Wirkung zu sprechen. Diese Gründe stutzen sich in erster Linie auf die subjektive Beobachtung oder Introspektion, und da dieses sehr wesentliche Hilfsmittel bei vielen Naturforschern, die als ausschlieBliche Morphologen sich mit Arbeitsweise und Methoden physiologischer, besonders sinnesphysiologischer Forschung nicht vertrant gemacht haben, in MiBkredit steht, von uns aber noch öfters herangezogen werden $m u B$, so kann ich nicht umhin, uber seinen methodischen Wert bei naturwissenschaftlichen Untersuchungen einige Worte zu sagen.

Es bedarf keines weiteren Beweises, daß alles das, was 
wir Außenwelt nennen, nur auf Grund von subjektiven Vorgängen, das heißt von Vorgängen, die sich in unserem eigenen Organismus abspielen, unserer Kenntnis und Erkenntnis zugänglich wird. Eine Summe von Vorgängen z. B., .die sich in unserer Netzhaut and unserem Gehirn abspielen, empfinden wir als außerhalb von uns, und nennen sie „Baum ", andere Vorgänge in unserem Riechepithel und unserem Gebirn bezeichnen wir, indem wir sie ebenfalls nach außen verlegen, als $\gg$ Rosenduft . Wir nehmen unmittelbar in unserem Bewußtsein nur die Reizwirkungen wahr. Durch Erfahrung lernen wir allmählich, von diesen Wirkungen auf die sie verursachenden Reize zu schließen, wir suchen die Quelle der Reize auf, die uns treffen, und das sich entwickelnde Kind baut sich so schrittweise ein Bild der Außenwelt auf, das es ebenso wie der naive erwachsene Mensch dann fur ein objektiv gegebenes ansiebt, und dessen subjektives Fundament ihm gewöhnlich ganz und gar nicht bewußt ist. Demgegenüber durfen wir nicht aus den Augen verlieren, daß gerade die subjektiven Bewaßtseinszustände für uns das Gegebene, Primäre sind; die Bilder der Außenwelt aber, die wir uns aus jenen subjektiven Zuständen allmählich formen, die wir uns in vielen Fällen erst langsam und mühsam durch Vergleichung zurechtkonstruieren, und die wir als objektiv bezeichnen, das Sekundäre, Abgeleitete. Dies muB vorangeschickt werden, auch dann, wenn die Realität derjenigen Außenwelt, die wir uns aus unseren Bewußtseinszuständen konstruiert haben, nicht weiter kritisch untersucht, sondern hingenommen werden soll, wie wir es im folgenden tun wollen.

Die Unentbehrlichkeit der subjektiven (introspektiven) Methode bei der Untersuchung vieler biologischer und physio- 
logischer Grundfragen beruht nun in folgendem. Sie allein gibt uns Auskunft, ja überhaupt eine Vorstellung von den verschiedenen Empfindungen. Die Erkenntnis und Erforschung letzterer ist der objektiven Methode so gut wie verschlossen. Auf Empfindungen bei anderen Organismen als dem eigenen Ich, also bei Objekten, können wir nur indirekte und meist sehr unsichere Schlüsse machen. Selbst da, wo zu den tibrigen Reaktionen noch die Reaktionsgruppe, die wir als menschliche Sprache bezeichnen, hinzukommt, sind die Vorstellungen, die wir uns auf objektivem Wege von den Empfindungen unserer Mitgeschöpfe bilden, unscharf und wohl nur ganz ausnahmsweise, vielleicht niemals, absolut zutreffend.

Die Anwendung der subjektiven Methode ist deshalb an sich durchaus einwandfrei und ist auch von den besten und kritischsten Physiologen, z. B. von Johannes Müller, Helmholtz, Hering und vielen Anderen, da, wo sie hingehürte, in ansgiebiger Weise verwertet worden. Die wertvollsten Errungenschaften der Sinnesphysiologie verdankeu wir dieser Methode; ohne dieselbe wäre der Ausbau dieser Wissenschaft, wie sie als eine imposante und in ibren Grundlagen durchaus gesicherte vor uns steht, undenkbar gewesen. Mißtrauen verdient nur eine unkritische Vermischung der objektiven mit der subjektiven Methode.

Die letztere kann jeder einzig und allein nur am eigenen Ich anwenden, während er mit Hilfe der objektiven Methode Reizwirkungen sowohl am eigenen Ich als auch bei allen andern Geschöpfen untersuchen kann. Sobald man es aber unternimmt, aus den motorischen, sekretorischen und auderen derartigen Reaktionen auf Empfindungen bei anderen Geschöpfen als dem eigenen Ich Rückschlissse zu machen, begibt man sich in das Gebiet der Hypothese. Zunächst 
meist in das Gebiet der durchaus berechtigten Hypothese, solange es sich um Geschöpíe handelt, die uns morphologisch and physiologisch nahe stehen, und deren motorische und andere periphere Reaktionen eine fur uns kaum mißzudeutende Sprache reden. Vor allen Dingen, wenn dies die menschliche Sprache ist.

Die Schmerzempfindung, die ein Nadelstich bei mir erzeugt, kenne nur ich selbst qualitativ und quantitativ genau. Aber es hieße die Skepsis tubertreiben, wollte ich den Schluß zurtickweisen, daß dieser Reiz bei meinen Mitmenschen, die auf ihn in ähnlicher Weise mit Zusammenzucken und einem leisen Aufschrei reagieren, die mir das dabei empfundene Gefühl mit Worten ausführlich beschreiben können, eine sehr ähnliche, ja qualitativ, wenn auch nicht quantitativ fast identische Empfindung auslöst, wie bei mir. Daß auch ein Affe, oder ein Hund, der auf diesen Reiz mit Zusammenzucken und einem bestimmten Laut seiner Sprache reagiert, dabei etwas sehr ähnliches empfindet, wie ich selbst, ist äußerst wahrscheinlich. Die Ähnlichkeit der Empfindungsreaktion auf den gleichen Reiz bei einem Frosche oder Fische ist schon zweifelhafter, wenn sie auch immer noch wahrscheinlich erscheinen mag.

Noch unsicherer werden unsere Schlüsse, wenn wir uns zu den wirbellosen Tieren wenden, zu Würmern, Cölenteraten und ähnlichen Geschöpfen, auch wenn dieselben auf den Stich mit raschem Zurickziehen des betroffenen Körperteils reagieren. Gänzlich außerhalb des Bereichs wissenschaftlicher Diskussion würde es liegen, weil es vorläufig nicht einmal durch einleuchtende Analogieschltisse wahrscheinlich zu machen wäre, wollte jemand behaupten, eine Mimose empfände bei brüsker Beruhrung ihrer Zweige, auf die sie bekanntlich mit 
raschem Zusammenlegen der Blätter reagiert, etwas anserem Schmerze ähnliches.

Wie wir sehen, ergibt die subjektive Methode der Untersuchung am eigenen Ich Resultate, die zum großen Teil der objektiven Methode uberhanpt nicht zugänglich sind. Hier darf sie also in uneingeschränkter Weise als eine der wichtigsten und reinsten Quellen des Naturerkennens angewandt werden. Die Übertragung ihrer Resultate durch Analogieschltisse auf die Empfindungsreaktionen anderer Geschöpfe ist zwar nicht $\mathrm{za}$ verwerfen - wie wäre das menschliche Zusammenleben ohne dieselbe denkbar - aber sie trägt die Unsicherheit aller derartiger Schliusse an sich, und zwar verringert sich die Wahrscheinlichkeit solcher Schlüsse um so mehr, je.weiter wir sie von unseren Mitmenschen auf die übrigen Warmblutter, von diesen auf die Kaltbluter, von den Wirbeltieren auf die Wirbellosen, von diesen etwa gar auf Pflanzen und Protozoen ausdehnen.

Im augenblicklichen Verlaufe unserer Untersuchung sind wir aber in der glicklichen Lage, von einer derartigen Übertragung der subjektiven Methode ganz absehen zu können. Wir wenden sie zunächst nur für das eigene Ich an, damit jeder Leser sich fur sich selbst eine Vorstellung von der Ekphorie eines Engramms durch einen Reiz, der qualitativ and quantitatir dem Originalreiz gleicht, machen kann.

Jeder kann leicht bei sich selbst beobachten, daß, wenn ein Reiz, der schon einmal auf ihn eingewirkt hat, sagen wir einmal der optische Reiz einer eigentlimlich geschlungenen Linie oder die charakteristische Zeichnung eines Teppichoder Tapetenmusters, wieder auftritt, der Empfindungszustand, der bei der erstmaligen Einwirkung dieses Reizes eingetreten war, sich nicht einfach wiederholt, sondern daß zu der Wieder- 
holung ein neaes Bewußtseinselement hinzukommt: die Empfindung, dieser speziellen Reizwirkung schon einmal unterworfen gewesen za sein, diesen charakteristischen Erregungszustand schon einmal durchgemacht zu haben. Diesen Bewußtseinszustand, der sich Reizen jeder Qualität gegenüber änßert, und den wir nicht weiter andlysieren wollen ${ }^{1}$, bezeichnen wir als Wiedererkennen. Er ist ein Beweis dafur, daß die reizbare Substanz im sekundären Indifferenzzustand, verglichen mit ihrer Beschaffenheit im primären Indifferenzzustand, eine Veränderung erlitten hatte, engraphisch beeinflußt worden war. Wenn nun die Wiederholung des Originalreizes nicht nur dieselbe synchrone Wirkung hervorbringt wie bei seinem ersten Auftreten, sondern unser Bewußtsein noch außerdem uns mit größter Deutlichkeit sagt: mein Organismus hat Spuren davon bewahrt, daß er diesen Erregungsuastand bereits einmal durchgemacht hat, daß er ein Engramm dieser Reizwirkung besitzt, so ist das, zumal bei der Konstanz des Ergebnisses, ein Beweis aus erster Hand, daß der wiederholte Reiz nicht einfach eine synchrone, sondern auch eine ekphorische Wirkung ausübt, indem er uns von dem Vorhandensein einesEngramms durch eine besondere Reaktion, und zwar eine Bewußtseinsreaktion, Kunde gibt.

Auch mittels der objektiven Methode läßt sich in ziemlich überzeugender, wenn auch freilich nicht ganz so eindeutiger Weise zeigen, daß sich schon durch bloße Wiederholung des Originalreizes das Vorhandensein eines Engramms nachweisen läßt. Dieser mehr indirekte Beweis stützt sich auf die Tatsache, daß die objektiv nachweisbaren Reaktionen häufig bei Wiederholung des Originalreizes rascher oder ener-

1 Eine genauere Analyse des Wiederkennenshabeich im siebzehnten Kapitel der Mnemischen Empfindungen S. 313-320 vorgenommen. 
gischer auftreten als bei seiner erstmaligen Einwirkung. Ich erinnere an die bereits oben (S. 22) besprochenen Beobachtungen von Davenport und Cannon, aus denen hervorgeht, daß Daphnien bei ihren heliotropischen Bewegungen nach der Lichtquelle za bei dreimaliger Anwendung eines starken Lichtreizes beim dritten Male nur etwa die Hälfte der zuerst erforderlichen Zeit (28 statt 48 Sekunden) gebrauchen, um die Strecke von $16 \mathrm{~cm}$ zu durchschwimmen. Zu ganz ähnlichen Schluissen fuhren auch die ebenfalls oben zitierten Oltmannsschen Beobachtungen an Pilzen.

Durch die eben erwähnten Experimente werden wir bereits za Fällen hinübergeleitet, in denen ein Reiz als ekphorischer zu bezeichnen ist, der zwar noch qualitativ mit dem Originalreiz ubereinstimmt, von ihm aber quantitativ verschieden ist. Durch wiederholte Einwirkang eines Reizes läßt sich das Resultat erzielen, daß dieselben Reaktionen, die bei erster Einwirknng des Reizes nur bei einer bestimmten Größe oder Daner des Reizes eintreten, bei wiederholter Einwirkung unter wesentlicher Herabsetzung der Reizgröße oder der Dauer des Reizes erzielt werden können (Herabsetzang des Schwellenwertes des Reizes). Beweisend, daß es sich hierbei um Ekphorie von Engrammen handelt, sind natürlich nur solche Fälle, in denen die Wiederholung in nicht za raschem Tempo eintritt, so daß dem Organismus Zeit gegeben wird, auch wirklich vollständig in den sekundären Indifferenzzustand zurlickzutreten und die synchronen und akoluthen Erregungszustände ausklingen zu lassen. Das Phänomen der Reizsummation darf deshalb hier anch nicht mit herangezogen werden; denn es handelt sich dabei, wie bereits oben (S. 30) angedeutet, nicht um eine Ekphorie von mnemischen Erregungen durch die in rascher Wieder- 
holnng wiederkehrenden Reize, sondern darum, daß die durch diese Reize ausgelösten synchronen Erregungen sich zu bereits vorhandenen, noch nicht ausgeklungenen akoluthen Erregungen hinzuaddieren. Wohl aber kann bei den Versuchen von Davenport und Cannon an Daphnien von engraphischer und ekphorischer Wirkung gesprochen werden, bei denen es durch in längeren Zeitintervallen wiederholte Reizung gelang, den Erfolg zu erzielen, daß schon nach wenigen Wiederholungen ein Reiz, der nur ein Viertel der Stärke des Originalreizes besaß, dieselben und schließlich sogar promptere Reaktionen hervorrief, als der Originalreiz bei seiner ersten Einwirkung.

Ähnliche Beobachtungen lassen sich bei höheren Tieren und dem Menschen in großer Zahl und in bezug auf alle möglichen Reize anstellen. Beim Zureiten eines Pferdes kann man z. B. beim Reiten der sogenannten Seitengänge mit der Stärke der Drackreize, die bestimmte Stellungen und Bewegungen des Pferdes auslösen, allmählich so weit heruntergehen, daß am Ende Reize von einer Schwäche wirksam sind, die im Anfang tiberhaupt keine Beachtung fanden.

Bei derartiger wiederholter Einwirkung von Reizen ist es möglich, die Schwellenwerte für alle Reizqualitäten herabzusetzen, wobei aber in den meisten Fällen bewiesen werden kann, daß es sich am eine ekphorische Wirkung auf Engramme, nicht aber oder nur in untergeordnetem Maße um eine allgemeine Steigerang der Empfindlichkeit in den betreffenden Sinnesgebieten handelt. Ein Experte im Weinschmecken ist deshalb noch kein solcher im Teeschmecken und bedarf, obwohl natturlich besser vorbereitet als ein anderer Mensch, erst hundertfacher neuer Engramme durch 
letzteren chemischen Reiz, um auch hier auf minimale Reizstärken in einer Weise zu reagieren, die dem Laien fast zauberhaft erscheint.

Ähnliche Beispiele lassen sich auch für die engraphische „Übung * des Gesichts- und Gehörssinns beibringen. Doch lassen sich bei ihnen die Mitwirkung komplizierter Nebenprozesse im Gehirn nicht so gut ansschließen wie bei den von weniger Beiwerk begleiteten Reaktionen des Tastsinns, des Geschmacks und der Riechempfindung.

Geringe qualitative Abweichungen vom Originalreiz machen einen Reiz noch nicht ungeeignet, ekphorisch auf das zu jenem Originalreiz zugehörige Engramm zu wirken. So gentigt es, das Bild einer Landschaft zu sehen, statt dieser selbst, um das ihr zugehörige Engramm zu ekphorieren, eine Melodie gesungen zu hören, um das Engramm zu ekphorieren, das dem Anhören einer Orchesterproduktion seine Entstehung verdankt. Wenn der Geruch von Selengas bei uns das Geruchsengramm des faulen Rettichs ekphoriert, so ist es klar, daß hier ein Reiz als ekphorischer vikariierend an die Stelle eines anderen getreten ist, der vom chemischen Standpunkt aus von ihm grundverschieden ist. Wie weit diese Abweichungen gehen dtrfen, ohne die ekphorische Wirkung zu beeinträchtigen oder ganz zu verhindern, ist von Fall zu Fall verschieden und läßt sich nicht allgemein definieren.

Wir kommen nun zu denjenigen Einflitssen, deren ekphorische Wirkung man in gewissem Sinne als eine nur mittelbare bezeichnen könnte, weil sie nicht anf das Engramm $(A)$ selbst, das ins Auge gefaßt wird, ekphorisch wirken, sondern auf ein anderes mit ersterem assoziiertes Engramm $(B)$. Die Ekphorie von $B$, also die mnemische Erregung $\beta$, wirkt dann ekphorisch auf Engramm $A$. 
Schon in dem Abschnitt uber die Originalreize mit engraphischer Wirkang ist eine besondere Eigentümlichkeit der gleichzeitig oder in unmittelbarer Aufeinanderfolge bei einem Organismus erzeugten Engramme (der simultan oder sukzessiv erzeugten Engramme) erwähnt worden. Dieselben wurden als assoziiert bezeichnet. Diese Assoziation oder Verkntipfung ist im latenten Zustande der Engramme natülich auch latent. Nur bei der Ekphorie wird sie manifest, dergestalt, daß die Ekphorie des einen Engramms in Fällen von gut ausgeprägter Assoziation unweigerlich die Ekphorie des anderen zur Folge hat. Eine gute Ausprägung der Assoziation wird durch häufige Wiederholung der simultanen oder sukzessiven engraphischen Reizwirkung erreicht.

Was die experimentelle Erzeugung von assoziierten Engrammen anlangt, deren Vorhandensein zur Demonstration solcher mittelbarer Ekphorie Vorbedingung ist, so haben wir bereits darauf hingewiesen, daß es bei Organismen, bei denen noch keine höhere Differenzierung der reizbaren Substanz als solcher eingetreten ist, schon Schwierigkeiten macht, durch individuelle Beeinflussung ein einziges, sich dentlich manifestierendes Engramm, noch mehr aber zwei verschiedene, simultan oder sukzessiv assoziierte Engramme zu erzengen. Ich verweise anf das Seite 21 gesagte. In den späteren Kapiteln dieses Buches, besonders dem Teil uber die Wirksamkeit mnemischer Prozesse bei der Ontogenese, werden wir noch viele Beispiele von simultan und sukzessiv assoziierten Engrammen bei niederen Organismen kennen lernen. Augenblicklich wählen wir unsere Beispiele lieber aus dem Kreise der höheren Tiere, bei denen im Verhältnis zur höheren Spezialisierung ihrer reizbaren Substanz in Gestalt eines Nervensystems die Erzeugung von Engrammen überhaupt, 
Engraphische Wirkung der Reize auf das Individuum.

und damit anch die simultane oder sukzessive Erzeugung verschiedener Engramme viel leichter ist.

Schon oben wurde erwähnt, daß bei einem jungen Hunde das einmalige simultane Auftreten folgender beider Reize: erstens des photischen Reizes sich rasch nach Steinen bückender Menschen; zweitens des sensibeln Reizes, verursacht durch Steine, welche die Haut des Tieres treffen, genügt, um für Lebenszeit zwei Engramme zu erzeugen, die dergestalt assoziiert sind, daß die Wiederkehr des dem einen Engramm zugehörigen Originalreizes, hier des photischen, die Ekphorie auch des anderen Engramms bewirkt.

Der Bruder dieses Hundes, der eine solche Erfahrung nicht gemacht hat, reagiert ebenso wie das Tier selbst vor Erzengung der beiden assoziierten Engramme ganz anders auf den Anblick des sich bückenden Menschen: entweder indifferent, oder, wenn er in der Richtung des Spielens mit Steinen vorher engraphisch beeinflußt worden war, mit den entsprechenden Reaktionen, z. B. Spannung der Maskeln zu sprungbereiter Stellung, genaues Fixieren der werfenden Hand mit den Augen, um den fortspringenden Stein sofort zu erhaschen.

Um ein Beispiel von assoziativer Ekphorie bei Wirbeltieren zu geben, die nicht so hoch organisiert sind wie der Hund, wende ich mich zunächst zn den auch noch recht hoch organisierten Vögeln.

Durch die Beobachtungen von Lloyd Morgan ${ }^{1}$ wissen wir; daß junge Vögel (Küken von Hühnern, Fasanen, Perlhühnern, Wasserhühnern), wenn erst kürzlich aus dem Ei geschlipft,

1 C. Lloyd Morgan, Habit and Instinct. London, New York 1896. Ins Deutsche ubersetzt unter dem Titel: Instinkt und Gewohnheit. Leipzig 1909. 
\bei Abwesenheit elterlicher Leitung zunächst nach jedem Dinge von passender Größe vollkommen wahllos picken, also nach Körnern, kleinen Steinen, Brotkrumen, zerhackten Wachsziundhölzern, Papierschnitzeln, Perlen, Zigarettenasche and -enden, ihren und ihrer Gefährten Zehen, Maden, Fäden, Flecken auf dem Boden, den Augen ihrer Geschwister usw. usw. * Bald aber wird das optische Engramm eines Gegenstandes mit dem entsprechenden Geschmacksengramm assoziiert, und die Tiere hören auf, nach uneßbaren oder schlecht schmeckenden Dingen zu picken. Warf ihnen Morgan die ekelhaft schmeckenden, schwarz und goldgelb geringelten Raupen der Motte Euchelia jacobiae vor, so wurden sie zunächst ohne weiteres aufgepickt aber sofort wieder fallen gelassen. Meistens genügte dieser einmalige Reizversuch, um ein optisches und ein chemisches assoziiertes Engramm zn erzeugen, dessen Vorhandensein sich dadurch manifestierte, da $B$ bei Wiederholung des Experiments der optische Reiz allein ausreichte, um durch Ekphorie des optischen Engramms mittelbar auch auf das chemische Engramm ekphorisch zu wirken and ein Aufpicken der so gezeichneten Raupen zu verhindern, obwohl anders gefärbte (braune und grine) Raupen nach wie vor anfgepickt und verzehrt wurden. Nach zwei- oder dreimaliger Wiederholung waren in allen Fällen die beiden Engramme so gut fixiert und assoziiert, daß die schwarz und goldgelb geringelte Raupe gar nicht mehr beachtet oder auf ihren Anblick mit Flucht- oder Vorsichtsreaktionen (Warnungsruf) geantwortet wurde.

Viel hänfigerer Wiederholungen der Reize bedarf es bei Fischen um deutlich wahrnehmbare und gut fixierte Engramme zu erzeugen, aber die Ergebnisse der umfassenden 
Engraphische Wirkung der Reize auf das Individunm.

Edingerschen Sammelforschung ${ }^{1}$ zeigen auf das deutlichste, daß es durch häufige Wiederholung der Reize gelingt, gleichzeitig mehrere Engramme zu erzeugen, und daß bei solchen simultan oder sukzessiv erzengten Engrammen die Ekphorie des einen ekphorisch auf das andere wirkt, also eine Assoziation vorliegt. Das Engramm, das der wiederholte optische Reiz des futternden Menschen erzeugt, ist assoziiert mit dem optisch-chemischen der Nahrung, die er ansstreut, nnd seine Ekphorie allein wirkt dann ekphorisch auch auf das assoziierte Engramm und löst die letzterem zugehörigen Reaktionen (Heranschwimmen usw.) aus, auch wenn das Nahrungstreuen unterbleibt. Auch ließ sich feststellen, da $B$ diese Engramme eine Latenzzeit von vier Monaten uberdauerten, ohne za verschwinden oder bei der Ekphorie ihre assoziativ ekphorische Wirkung einzubtißen (a. a. 0. S. 20). Daß aber derartige Engramme auch durch einmaligen Reiz bei gewissen Fischen erzeugt und wenigstens stunden- oder tagelang fixiert bleiben können, habe ich selbst an dem eigentumlichen Schildfisch oder Schiffshalter (Echeneis) in der Torresstraße beobachtet, wo es gentigte, einen einzigen Fisch aus einer großen Zahl arglos die zugeworfene Nahrung anfnehmender Tiere mit der Angel herauszufangen, um seine Genossen auf Tage von dieser Nahrung zu vergrämen. Der Versuch wurde mehrfach wiederholt, immer mit demselben Erfolg. Ähnliches wurde Edinger tiber den Blei (Abramis brama) und den Aland (Idus melanotus) berichtet. Ferner teilt Edinger noch eine Anzahl gat verbtirgter Beobachtungen mit,

1 L. Edinger, Haben die Fische ein Gedächtnis? München 1899, Buchdruckerei der $\triangleright$ Allgemeinen Zeitung $\ll$. Interessante Beobachtungen über Gedächtniserscheinungen bei Fischen teilt W. Köhler in den Blättern für Aquarienkunde 1905, Nr. 51, in dem Anfsatz über Osphromenus trichopteras mit: 
aus denen hervorgeht, daß mehrere assoziierte und fur Tage und Wochen fixierte Engramme durch einmalige Reizung bei Fischen erzeugt werden können. Noch leichter als bei diesen niederen Wirbeltieren gelingt es bei den höchstentwickelten Wirbellosen, besonders gewissen Insekten, wie den Wespen, Bienen und Ameisen, sowie bei manchen Tintenfischen Engramme, deren Vorhandensein sich mit wünschenswerter Bestimmtheit feststellen läßt, durch einmalige Reizwirkung hervorzurufen. Immerhin ist ein solcher Reizerfolg auch bei diesen Formen stets nur auf bestimmte von Gruppe zu Gruppe verschiedene Reize beschränkt, und je tiefer wir in dem Tierreiche hinabsteigen, umsomehr bedarf es der Wiederholung der Reizung, um deutlich nachweisbare Engramme zu erzeugen.

Wir haben das vorliegende Kapitel nicht ekphorische Reize , sondern *ekphorische Einflüsse uberschrieben. Was wir bisher als ekphorisch wirkend aufgezählt haben, hätte anstandslos das Prädikat $»$ Reiz« verdient. Wir muissen uns aber nun zu Einflissen wenden, deren ekphorischer Charakter zwar ein durchaus unweidentiger ist, die man aber nicht ohne weiteres als Reize bezeichnen kann.

Ich will mit einem allbekannten Beispiel beginnen, das jeder von sich selbst kennt, oder doch leicht an sich selbst versuchen kann. Angenommen, ich bin gewohnt, um $8 \mathrm{Uhr}$ früh meine erste Mahlzeit am Tage zu mir zu nehmen, um 1 Uhr meine zweite, um $8 \mathrm{Uhr}$ abends meine dritte, so erzeugen die komplexen Reize, die mit jeder Nahrungsaufnahme verbunden sind und auf die hier nicht weiter eingegangen zu werden braucht, außer anderen Reaktionen auch die, daß Anblick und Geschmack der Speisen von einer eigentumlichen Reaktion unserer Empfindungssphäre begleitet sind, die wir 
als Hunger oder Appetit bezeichnen, und die bei einem reichlich ernährten Menschen unter gewöhnlichen Umständen in den Pausen zwischen den Mahlzeiten fehlt: Angenommen nun, ich beginne aus irgendwelchen Gründen zwischen die erwähnten drei Mahlzeiten noch um 11 Uhr und um 5 Uhr je eine weitere kleine Mahlzeit einzuschieben, so wird mir das anfangs gar nicht leicht fallen. Aber ich zwinge mich daza, vielleicht weil der Arzt es verordnet hat, und fuhre es ein halbes Jahr lang durch. Versuche ich dann wieder die Mahlzeiten um 11 und o Uhr ausfallen zu lassen, so stellt sich jetzt der Hunger um die betreffende Zeit mit großer Stärke und Deutlichkeit in. Scheinbar wirkt also jetzt die Zeit oder der Ablauf eines bestimmten Zeitabschnittes ekphorisch auf diese Reaktion meiner Empfindungṣsphäre.

Ekphorisch wirkt ja auch scheinbar die «Zeit a auf andere Reaktionen unseres Körpers. Ich will dabei von Atmung und Herzschlag abseken, weil hier die Pausen zwischen den einzelnen Reaktionen so kurz sind, daß es sehr fraglich erscheint, ob in denselben tiberhaupt eine Rückkehr der reizbaren Substanzen in den indifferenten Zustand stattfindet, und ob daher diese $\mathrm{Phänomene} \mathrm{als} \mathrm{mnemische} \mathrm{aufzufassen} \mathrm{sind.}$ Das Wesen dieser Rhythmik läßt sich auf andere Weise ebensogut und besser erklären, obwohl die Art und Weise, wie sie sich änßert, in den verschiedenen Tiergruppen höchstwahrscheinlich durch ererbte Engramme beeinflußt wird. Auf diese ganze Frage will ich aber in der vorliegenden Untersuchung tiberhaupt nicht näher eingehen.

Deutlich den Charakter einer Ekphorie trägt dagegen der ^Zeitablauf e bei der periodischen Eireifung und den Umwandlungsprozessen der Uterusschleimhant, die wir als Menstrua- 
tion bezei hnen. Bei fast allen speriodischen Erscheinungen a im Tier- nnd Pflanzenreich, ererbten wie erworbenen, scheint fur die naive Auffassung die Zeit schwinden der Reaktionen zu bestimmen und zu regeln.

Ich werde dies an einem jedermann geläufigen Beispiel erläutern, bei dem es sich allerdings um ererbte Engramme handelt. Da es uns aber im gegenwärtigen Augenblick nicht auf die Herkunft der Engramme, sondern lediglich auf die Natur des ekphorischen Einflusses ankommt, sei dieses Vorgreifen erlaubt.

Die meisten Gewächse der gemäßigten und kalten Zone besitzen bekanntlich eine Jahresperiode $*$ d. h. einen periodischen Wechsel von Vegetationsruhe and Vegetationsfortschritt, deren Wendepunkte z. B. bei unseren Laubbäumen darch den Laubfall während des Herbstes und durch das Ansschlagen neuer Triebe und Blätter im Frühling sehr deutlich bezeichnet werden. Diese Periode hängt in ganz unzweideutiger Weise mit den klimatischen Perioden, die wir als Jahreszeiten bezeichnen, zusammen, und ist naturlich in erster Linie von der geographischen Breite, in zweiter von lokalen Bedingangen (Höhe uber dem Meeresspiegel, Nachbarschaft des Gebirges oder Meeres, vorherrschender Wind- richtung, Eigenart des Standortes usw. usw.) abhängig. Es ist unnötig, hier auszufuhren, daß das Bestimmende in der Abhängigkeit der Vegetationsperioden von den Jahreszeiten in den kalten und gemäßigten Zonen der periodische Wechsel von Warm und Kalt ist. In den Tropen sind dagegen die Beziehungen zwischen den Jahreszeiten und den Vegetationsperioden von dem Wechsel von Feucht und Trocken abhångig.

Untersuchen wir nun die Pflañen unserer Zone, so finden 
wir bei einer kleinen Anzahl derselben, daß bei ihnen der Wechsel von Kalt zu Warm in jedem gegebenen Falle direkt den Übergang von Vegetationsruhe zu Vegetationsfortschritt auslöst. Ein Teil unserer Büsche vermag schon im Winter auszuschlagen, wenn im Januar oder Februar einmal einige Wochen lang sehr mildes Wetter mit reichlichem Sonnenschein herrscht. Dann beginnen auch Schneeglöckchen, Krokus, Scilla, Aurikeln and Daphne zu bluhen, das Geißblatt entfaltet seine Blätter, die Syringensträuche zeigen frthzeitig den ersten Schimmer von Grün. Es sind das dieselben Pflanzen, die sich auch im geheizten Zimmer oder im Treibhaus vorzeitig zum Wachsen und Blthen bringen lassen, die sicb, wie die Gärtner sagen, streiben lassen. Ein aufmerksamer Beobachter, auch wenn er naturwissenschaftlich Laie ist, wird nun bald herausfinden, $\mathrm{da} B$ die verschiedenen Pflanzen sich dem Treiben gegenuber sehr verschiedenartig verhalten. Während eine große Anzahl der verschiedenartigsten Pflanzen - meistens sind es die schon an und fur sich zeitig im Fruhjahr ansschlagenden - sich leicht treiben lassen, setzen andere dem Treiben mehr Widerstand entgegen, und auf eine Anzahl hat es nar sehr schwachen EinfluB. Dasselbe ergibt sich aus Beobachtungen, die mehrere Jahre hindurch an freilebenden Pflanzen fortgesetzt werden.

Der Winter 1899-1900 war in Muthchen sehr kalt and langdanernd; noch im März und Anfang April traten bedeutende Schneefälle und starke Fröste (Anfang April in einer Nacht bis $-15^{\circ} \mathrm{C}$ ) auf, und erst von Mitte April an trat allmähliche Erwärmung ein. Die Vegetation war infolgedessen im April im Isartal bei München noch sehr zaruck. Märzglöckchen (Leucojum vernum) und Krokus bluhten in unserem schattig gelegenen Garten erst von Mitte April an, der be- 
kannte grüne Schleier zeigte sich an den meisten Büschen erst sehr spät, bei Lonicera tatarica erst Mitte April, beim spanischen Flieder erst gegen Ende April. An einer bestimmten Rotbuche unseres Gartens öffneten sich die Blattknospen an den meisten Ästen am 1. Mai.

Winter und Frihjahr 1901-1902 standen fast in jeder Beziehung im Gegensatz zu den entsprechenden Jahreszeiten von 1899-1900. Der Winter durchweg milde, das Frthjahr ohne stärkere Kälterückfälle, ohne Schneebedeckung, fast immer mäßig temperiert, zeitweilig auch sonnig. In diesem Jahre blühten die ersten Märzglöckchen in unserem Garten schon am 17, die ersten Krokus schon am 20. März auf, also fast 4 Wochen früher als im Jahre 1900. Die ersten grünen Blätter an den Lonicerabiischen sah ich ebenfalls am 20. März, die Syringen begannen am 10. April ihre Blätter zu entfalten. Das erste Griin an der obenerwähnten Buche sah ich in diesem Jahre am 23. April, also nur eine Woche fruber als im Jahre 1900. Und dies in einem Jahre, in dem die Mehrzahl der übrigen unter gleichen Verhältnissen befindlichen Pflanzen in ihrem Vegetationszastand gegen das Jahr 1900 um 3-4 Wochen voraus waren.

Ein ganz ähnliches Resultat ergab die sich durch mehrere Jahre erstreckende Fortsetzung dieser Beobachtungen, die übrigens nur angestellt wurden, um ein den Botanikern und Gärtnern schon lange bekanntes Faktum recht einleuchtend za illustrieren. Wie die folgende kleine Tabelle zeigt, schwankte die Blattentfaltung bei der betreffenden Buche während der Jahre 1900-1905 zeitlich nurin den engen Grenzen zwischen 22. April und 4. Mai, zeigte also einen viel höheren Grad von Unabhängigkeit gegen die von Jahr zu Jahr wechselnden klimatischen Einfliisse als die meisten übrigen Pflanzen. 
Engraphische Wirkung der Reize auf das Individuum.

\begin{tabular}{|c|c|c|c|c|c|}
\hline Jahr & $\begin{array}{l}\text { Beginn } \\
\text { der Blate von } \\
\text { Leucojum ver- } \\
\text { num }\end{array}$ & $\begin{array}{l}\text { Beginn der } \\
\text { Krokusblate }\end{array}$ & $\begin{array}{l}\text { Blattentfaltung } \\
\text { bei Lonicera } \\
\text { tatarica }\end{array}$ & $\begin{array}{l}\text { Blattentfaltung } \\
\text { bei Syringa } \\
\text { vulgaris }\end{array}$ & $\begin{array}{l}\text { Blattentfaltung } \\
\text { bei einem be- } \\
\text { stimmten Exem. } \\
\text { plar von } \\
\text { Fagus silvatica }\end{array}$ \\
\hline $\begin{array}{l}1900 \\
1901\end{array}$ & 15. April & 17. April & 17. April & 17. April & 1. Mai \\
\hline 1902 & 17. März & 20. März & 20. März & 10. April & 23. April \\
\hline 1903 & 25. Februar & 20. März & 8. März & 26. März & 4. Mai \\
\hline 1904 & 13. März & 19. März & 25. Mårz & 8. April & 22. April \\
\hline 1905 & 9. März & 11. März & & 17. April & 23. April \\
\hline
\end{tabular}

Aus dem Angeführten geht hervor, daß für eine Anzahl von Pflanzen die Jahresperiode nicht in einer unmittelbaren and vorwiegenden Abhängigkeit von dem Plus oder Minus von zugefuhrter Wärme steht, sondern daß ein zweiter Faktor uberwiegenden EinfluB hat: der zeitliche Faktor. Dieser spielt tibrigens auch bei den Pflanzen eine Rolle, die sich treiben lassen. Sein Einfluß kann allerdings bei letzteren leichter $\mathfrak{u b e r w u n d e n}$ werden, was nur bei relativ wenigen Pflanzen ganz ohne Schwierigkeiten möglich ist. Wie nämlich aus pflanzenphysiologischen Untersuchungen ${ }^{1}$ und aus den Experimenten der Praktiker hervorgeht, widerstehen auch diejenigen Pflanzen, die sich verhältnismäßig leicht treiben lassen, im ersten Teil ihrer Ruheperiode dem Temperaturreiz, überhaupt äußeren Einflissen, und gelangen erst nach Ablauf eines bestimmten, nach Spezies und geographischer Rasse wechselnden Zeitabschnittes in einen Zustand, in dem ein Treiben bei ihnen möglich wird ${ }^{2}$.

1 Vgl. bes. E. Askenasy, Über die jährliche Periode der Knospen. Bot. Zeit. 1877.

2 Auf die interessante Tatsache, daß man durch allerlei außergewöhnliche Beeinflussungen, wie chemische Reize (Narkotisierung 
Um die Wirksamkeit des zeitlichen Faktors in seiner vollen Reinheit za beobachten, kann man die Wirksamkeit des Temperaturreizes ganz ausschalten. Ich habe dies getan, indem ich eine einjährige Buche eintopfte und nebst $z w e i$ aus Samen gezogenen, ebenfalls eingetopften Buchenkeimlingen vom Fruhjahr 1903 an in einer möglichst gleichmäßigen Temperatur kultivierte. Vom 1. September an wurden die Pflanzen ganz im Zimmer gehalten, um sie der Nachtkühle und der Berührung durch kalte Niederschläge zu entziehen. Dennoch begann der Blattfall bei diesen Pflanzen am 22. September und war am 15. November vollendet. Den ganzen Winter uber standen diese drei Buchen im temperierten, bei Tag und bei Nacht gleichmäßig geheizten Zimmer und wurden nur mit uberschlagenem Wasser begossen. Bis zum 1. Mai erfolgte keinerlei Blattentfaltung bei einem der drei Exemplare, dann begann sie bei der nunmehr zweijährigen Buche am 1. Mai, bei einer der beiden nunmehr einjährigen am 25. Mai, bei der dritten erst Mitte Juni. Diese Verspätung erklärt sich aus der Schädigung, die die Pflanzen dadurch erlitten haben, daß sie der winterlichen Abkuhlung gänzlich entzogen worden sind. Es ist bekannt, daß gerade dieser Eingriff nur von den wenigsten Pflanzen der temperierten Zone ohne Schaden ertragen wird. Übrigens ist es von Interesse, daß aus dem Einhalten der Periodizität seitens der beiden Keimpllanzen, die doch in ihrem individuellen Leben noch keiner periodischen Beeinflussung unterworfen ge-

durch Ätherdïmpfe, Einspritzung von diastasehaltiger Flüssigkeit), ungewöhnliche Kälte- und Wärmereize, Austrocknung der ausgegrabenen Pflanzen, schwache galvanische Reize, diesen mnemischen Faktor noch weiter beeinflussen kann, werde ich erst in einer späteren Fortsetzung der Mneme näher eingehen. 
wesen waren, der erbliche Charakter der in Frage kommenden Dispositionen hervorgeht.

Was bedeutet nun der Ausdruck ,zeitlicher Faktora, oder, da wir uns hier nicht in erkenntnistheoretische Betrachtungen einlassen wollen: wie haben wir uns den zeitlichen Einfluß, also den Ablauf eines Zeitabschnitts in seiner Wirksamkeit, die der eines Reizes ähnelt, oder ihn vertritt, vorzustellen?

Alle Lebensvorgänge erscheinen uns in unserer Erfahrung zeitlich geordnet. Wir finden, daß bei einem bestimmten Organismus der Erregungszustand einer genan bestimmten Zeit bedarf, um sich durch eine gleiche Strecke reizbarer Substanz fortzupflanzen. Ebenso ist Eintritt und Ablauf aller anderen Reaktionen unter den jedesmal gegebenen Umständen zeitlich genau determiniert. Dieser Erfahrungssatz gibt uns den Schlussel zu dem Wesen der scheinbar etwas mystischen zeitlichen Einflisse. Der Ablauf eines Zeitabschnittes bedeutet für eine Pflanze oder ein Tier den Ablauf einer bestimmten Anzahl von Lebensprozessen in seinem Innern. Auch ohne eine Uhr kann ein Mensch, der seine durchschnittliche Pals- und Atemfrequenz kennt, den Ablauf von Minuten und, wenn er sich der Muhe des langen Zählens unterzieht, anch von Stunden mit ziemlicher Genauigkeit angeben.

Ein Gefangener in einem unterirdischen, kunstlich beleuchteten, künstlich erwärmten Gefängnis, der keinerlei Kommunikation mit der Außenwelt hätte, und dem selbst die Nahrung in ganz unregelmäßigen Intervallen zugeführt würde, könnte doch mit den erwähnten Hilfsmitteln, mit denen er dann ferner die Wachstumsgeschwindigkeit seiner Nägel und Haare za bestimmen imstande wäre, seinen eigenen Körper als Minuten-, Stunden-, Tages- und Monatsuhr benutzen und 
mittels dieser Uhr den Ablauf der Jahre mit annähernder Genanigkeit registrieren.

Das Chronometer des Organismus, das man seine $>$ Körperuhr* nennen könnte, ist also das Tempo seiner Lebensvorgänge. Wie aber liest der Organismus ohne bewußte Zählarbeit an diesem Chronometer den Ablauf einer Zeitperiode ab, oder, um mich weniger bildlich auszudrucken, wie kommt es, daB nach Ablauf einer bestimmten Reihe von Lebensprozessen eine ganz bestimmte Reaktion eintritt? Einfach dadurch, daß nach Ablauf einer bestimmten Reihe von Stoffwechsel- oder anderen Lebensprozessen jedesmal ein Zustand des Organismus gegeben ist, der total oder partiell dem Zustande entspricht, der zur Zeit der Entstehung eines bestimmten Engramms herrschte, und durch dessen Wiederkehr jenes Engramm jetzt ekpheriert wird. Eine mitteleuropäische Buche, die rom Mai bis September in lebhafter Vegetation gestanden hat, hat im September einen Zustand ihrer organischen Substanz erreicht, der auf das Engramm ekphorisch wirkt, dessen sukzessive Reaktionen in Stoffwanderung von den Blättern in die Zweige und Wurzelstöcke und Blattabwurf bestehen. Diese Ekphorie tritt bei der Buche im Herbste auch ein, wenn die ebenfalls auf dieses Engramm ekphorisch wirkenden Temperatureinflisse einmal ganz ausbleiben.

Wir kommen also zu dem Resultat: ekphorisch wirkt selbstverständlich nicht der Zeitverlauf an sich, sondern der Eintritt eines bestimmten, mit dem betreffenden Engramm assoziierten Zustandes, und dieser Eintritt ist insofern zeitlich determiniert, als er nach Ablauf einer ganz bestimmten Summe von Lebensprozessen von dem Zeitpunkt an gerechnet erfolgt, den wir als Ausgangspunkt wählen. 
Engraphische Wirkung der Reize auf das Individuum.

$\mathrm{Da}$ es sich aber bei diesen Vorgängen um nichts anderes als um Ekphorie von Engrammen handelt, läßt sich dadurch beweisen, daß man durch wiederholte Einwirkung engraphisch wirkender Reize das Engramm des Blattabwurfs einer Pflanze mit einem anderen Engramm des Stoffwechselablaufs - ich will diese Engramme chronogene Engramme, die Ekphorie, durch die sie manifest werden, chronogene Ekphorie nennen - assoziieren kann. Bei der Buche gelingt dies aus uns unbekannten Gründen nur sehr schwer'1. Bei den meisten anderen Pflanzen genügt es, eine Anzahl von Jahreǹ hindurch veränderte Temperatur- und Lichteinflüsse wirken zu lassen, um z. B. das Engramm des Blattabwurfs oder des Austreibens mit einem anderen chronogenen Engramm zu assoziieren. Die Lehre von der Akklimatisation der Pflanzen liefert für diese Erscheinung zahlreiche Belege?

Ähnlich zu beurteilen wie die eben besprochene chronogene Ekphorie ist der ekphorische Einfluß, den der Eintritt eines bestimmten Entwicklungsstadiums in dem Lebensgange eines Organismus auf ein bestimmtes Engramm anslibt. Anch hier handelt es sich um Assoziation des betreffenden Engramms mit dem in dem betreffenden Stadium eintretenden Allgemeinzustand. Bei dieser Ekphorie, die ihrem Wesen nach ebenfalls auf der Assoziation verschiedener Engramme beruht, ein Begriff, den wir im zweiten Teil noch genauer analysieren werden, tritt meistens der zeitliche Faktor mehr in den Hintergrund als bei den vorher besprochenen Fällen chronogener Ekphorie. Ich bezeichne sie als phaso-

1 Auch die Gleditschien und Robinien sind, wenn man sie aus ihrer Heimat in kühlere Klimate versetzt, nicht imstande, den Beginn der Vegetationsperiode hinauszuschieben. Vgl. H. Mayr, Die Waldungen in Nordamerika. München 1890.

2 Vgl. z. B. dariber unten S. 80. 
$62 \mathrm{Z}$ weites Kapitel. Engraphische Wirkung der Reize etc.

gene Ekphorie, um auszudricken, daß mit Erreichung einer bestimmten Entwicklungsphase ein Zustand der erregbaren Substanz geschaffen ist, der auf ein bestimmtes Engramm ekphorisch wirkt.

Bezeichnungen wie chronogene oder phasogene Ekphorie benutze ich nur um der raschen und bequemen Verständigung willen, nicht um auszudrücken, daß sie ganz eigenartige, von anderen Ekphorien wohl abzugrenzende Kategorien darstellen. Das Charakteristische ist für sie wie für jede andere Ekphorie, daß die partielle Wiederkehr einer energetischen Situation auf den Engrammkomplex der Gesamtsituation ekphorisch wirkt. Ausftuhrlicher und eindringender werden diese Fragen im zweiten Teil des vorliegenden Werkes behandelt werden. 


\section{Drittes Kapitel.}

\section{Engraphische Wirkung der Reize anf die Deszendenz.}

Bei unserer bisherigen Analyse der mnemischen Phänomene haben wir uns möglichst an solche Engramme gehalten, die im individuellen Leben des untersuchten Organismus erworben worden waren, und haben Engramme, die der Organismus schon von seinen Vorfahrengenerationen geerbt hatte, nur ausnahmsweise berïcksichtigt. Sie ganz bei der Betrachtung anszuschalten, war nicht möglich, weil sie in jedem Organismus vom Ei-Stadium an vorhanden sind und in tausendfältiger Weise in den Gang aller unserer Versuche eingreifen.

$\mathrm{Zu}$ ihrer näheren Untersuchung wenden wir uns jetzt. Bevor wir aber in unser eigentliches Thema eintreten, erscheint es angebracht, den Begriff der Vererbung etwas näher zu analysieren, der ja jedem gebildeten Menschen, auch wenn er kein Biologe ist, durchaus geläufig ist, über den sich aber wohl mancher gerade wegen seiner scheinbaren Einfachheit keine wirklich klare Vorstellung gebildet hat.

Zur Erleichterung der Anseinandersetzung diene das umstehende Schema. Dasselbe verfolgt die Generationsfolge eines vielzelligen Organismus. Jedes Individunm enthält in seinem Körper eine Anzahl von Keim- oder Geschlechtszellen . 
(Germinalzellen) und von somatischen Zellen wie Nervenzellen, Muskelzellen, Bindegewebszellen usw. bei Tieren; Hautgewebszellen, Gefäßbündelzellen, Grundgewebszellen bei Pflanzen). Auf dem Schema sind in jedem Individuum die Keimzellen durch Schraffierung von den somatischen Zellen unterschieden. Keimzellen sowohl als auch somatische Zellen sind in jedem Individuum Abkömmlinge der Eizelle, die im Schema durch vollkommene Schwärzung gekennzeichnet ist. Die Abszisse des Schemas $A-I$ stellt einen Zeitabschnitt dar, der in $B, C, D-H$ in kleinere (der Einfachheit halber gleiche) Abschnitte geteilt ist.

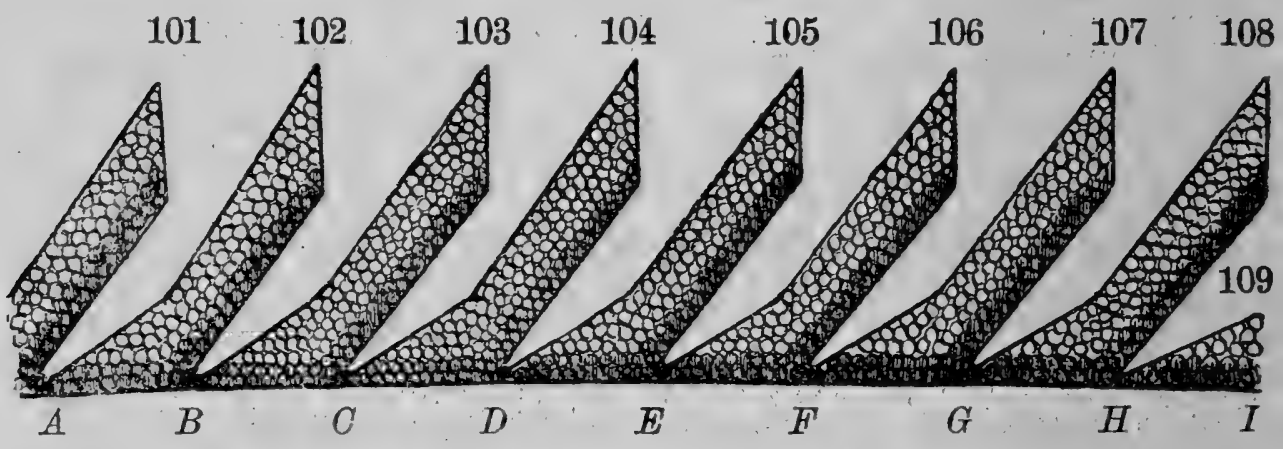

Aus Gründen der Einfachheit ist das Schema so angelegt, daß die Eizelle, die dem Tochterorganismus das Leben gibt, mitten im Dasein des Mutterorganismus sich von letzterem trennt. Da bei vielen Organismen eine parthenogenetische Fortpflanzung (durch unbefruchtete Eier) vorkommt und durch Generationen hindurch fortgeführt wird, im Pflanzenreich z. B. bei Chara crinita, im Tierreich bei Branchiopoden, Aphididen, Phylloxeren, Rotatorien, so ist wiederum der Einfachheit wegen diese Form der Generationsfolge gewählt und von einer Berïcksichtigung der Befruchtung, weil nicht unerläßliche Bedingung und für die folgenden Betrachtungen zunächst unwesentlich, Abstand genommen worden. 
Unser Schema könnte auch dergestalt in ein solches für eine Generationsfolge mit ungeschlechtlicher Fortpflanzung durch Teilung oder Knospung umgewandelt werden, wie sie bei niederen Tieren and besonders bei Pflanzen so hänfig ist, $\mathrm{da} B$ wir die Verbindung $\mathrm{z}$ wischen elterlichem Individuum und Nachkommen nicht durch eine Keimzelle, sondern durch einen Komplex von somatischen Zellen fubrten. In allen Fällen ist das Resultat das gleiche: eine absolute Kontinuität der Generationen. Hierans ergibt sich nattirlich, seit der Satz >omnis cellula e cellula « feststeht, weder für den Naturforscher noch für den Laien eine neue Wahrheit. Und dennoch wird sich bei Betrachtung unseres Schemas vielleicht manchem eine Anschaungsweise aufdrängen, die zwar, seit die Vererbungsfragen in der Naturwissenschaft ein besonderes Interesse gewonnen haben, in der einen oder der anderen Form von rerschiedenen Forschern ausgesprochen wurde, die aber dadurch doch keineswegs Gemeingut geworden ist. Die Entwicklung jedes Organismus, nach rückwärts verfolgt, stellt sich als ein Kontinuum dar, das zeitlich und räumlich in Phasen verläuft. Jeder Zeitphase entspricht als räumliche Phase ein Individuum. Während die zeitliche Kontinuität eine absolut ununterbrochene ist, kann die räumliche Kontinuität insofern unterbrochen sein, als sich bei $A, B, C, D$ usw. eine räumliche Kontinuitätstrennung auszubilden pflegt. Ich sage auszubilden pflegt, weil diese Trennung nur bei geschlechtlicher Fortpflanzung die Regel ist; bei vegetativer Fortpflanzung kann sie ganz ansbleiben oder doch erst sehr spät eintreten.

Diese räumliche Kontinuitätstrennung ist nun allerdings, wie wir später sehen werden, in mancher Beziehung von großer Bedeutang. Sie darf aber nicht za sehr in unserer 
Anschauung der Entwicklungsfolge vorherrschen und uns, wenn auch nur zeitweilig, vergessen machen, daß die eigentliche Entwicklung sich ausnahmslos als eine fortlanfende Linie darstellt, deren Unterbrechungen durchweg sekundärer Natur sind, d. h. an einem Punkte stattfinden, der von der Ftihrungslinie bereits durchlaufen ist.

Diese Auffassungen ergeben sich von selbst, wenn wir die Entwicklung des Individuums 109 auf das Vorfahrenindividuum zuriuckverfolgen. Etwas anders stellt sich die Sache aber scheinbar dar, wenn wir von 101 auf 109 vorwärtsschreiten. Dann ergibt sich freilich auch eine kontinuierliche Verbindung von 101 bis 109. Gleichzeitig aber tritt bei weiterer Überlegung die Tatsache hervor, daß von 101 nicht eine, sondern gewöhnlich mehrere, bei manchen Organismen viele Tausende derartiger Deszendenzlinien ausgehen können, die sich entweder gleichzeitig oder früher oder später als 102 von 101 trennen. Dasselbe ist der Fall bei Individunm 102 103 usw., und angesichts der vielleicht millionenfachen Linien, die wir bei Verfolgung der gesamten Deszendenz sich strahlenförmig in 101 vereinigen sehen, könnte die Auffassung des Individuums 101 als bloßer Phase in der Entwicklung einer einzigen Generationsreihe als eine schiefe erscheinen. Darauf aber läßt sich erwidern: der Umstand, daß ein Individuum sich als Phase in einer bestimmten Generationsreihe darstellt, schließt keineswegs aus, daß es auch als $P$ hase in anderen Generationsreihen eine Rolle spielt, ebenso wie man einen Eisenring unbedenklich als Glied einer Kette anffassen und als solchen, von seinen übrigen Beziehungen abstrahierend, charakterisieren kann, obwohl er gleichzeitig anch ein Glied einer zweiten und dritten, in die erste einlaufenden Kette ist. 
Vielleicht könnte man glauben, es wäre zweckmäßiger gewesen, von den Individuen in unserem Schema ganz abzusehen und lediglich die kontinuierlichen Zellfolgen von Ei zu Ei zu berlicksichtigen. Dann hätte aber unser Schema ein in einem wesentlichen Punkte unvollständiges Bild gegeben. Denn es hätte nicht die fundamentale Tatsache enthalten, daß bei mehrzelligen Organismen jene kontinuierliche Zellenfolge einen Teil der Individualitätsphase durchlanfen $\mathrm{muB}$, um wieder zum einzelligen Stadium zurückzagelangen.

Nun pflegen wir als ererbt im weiteren Sinne alles das zu bezeichnen, was sich in der Generationsfolge mit Regelmäßigkeit wiederholt. Unter »alles * ist jegliche Lebensänßerung zu verstehen, mag sie nun als Wachstumserscheinung, Kontraktion oder Stoffwechselphänomen zutage treten.

Diese Regelmäßigkeit, die sich natïlich immer auf korrespondierende Punkte der Phasen bezieht, ist aber selbst in asexuellen (parthenogenetischen oder vegetativen) Generationsreihen keine absolute. Abweichungen von der Regelmäßigkeit, mögen sie sich nun auf morphologische oder funktionelle Charaktere beziehen, bezeichnen wir als individuelle Eigentumlichkeiten. Soweit dieselben auf äußere Einflusse zurtickgeführt werden können, die während der vorliegenden individuellen Phase auf das Untersuchungsobjekt eingewirkt haben, bezeichnen wir sie als individuell erworben.

Bisher haben wir nur Individualitäten ins Auge gefaßt, die aus asexuellen (parthenogenetischen oder vegetativen) Generationsreihen hervorgegangen sind. Bei sexueller Fortpflanzung komplizieren sich die Verhältnisse dadurch, daß jedes Individuum nicht als ein Durchgangspankt einer Generationsreihe, sondern als ein Vereinigungspunkt außerordentlich vieler Generationsreihen sich darstellt. Bei streng exogamer 
Vermischang finden sich in der 5 . Ahnengeneration bereits 32 Generationsreihen, die im Urururenkel zusammenlaufen. Da nun diese Reihen in ihren morphologischen und physiologischen Charakteren an korrespondierenden Punkten der Phasen zwar untereinander sehr ähnlich, aber nicht völlig gleich sind, ist es hier besonders schwierig, zu entscheiden, ob diese oder jene Abweichung vielleicht durch Mischung der abweichenden Charaktere der sich vereinigenden Reihen entstanden, also ob sie ererbt ist, oder ob sie individuell, $d$. $h$. in der zur Untersuchung vorliegenden Individualitätsphase selbst erworben ist.

Die obenstehenden Erörterangen werden uns noch in verschiedener Beziehung für unsere Untersuchungen tiber die Vererbung der Engramme von Bedeutung sein. Die Frage, an die wir zunächst heranzutreten haben, und deren Beantwortang einen fundamentalen Punkt entscheidet, lautet: Erhalten sich Engramme tiber die Individualitätsphase, in der sie erzeugt (individuell erworben) sind, hinaus, in die nächste and unter Umständen noch fernere Phasen hinein? Ich bringe zur Beantwortung dieser Frage Stichproben ${ }^{1}$ aus vier verschiedenen Gruppen von Beobachtungen, aus denen die Vererbung engraphischer Einwirkungen anf das deutlichste hervorgeht.

Bei der ersten von mir zu behandelnden Gruppe manifestiert sich das ererbte Engramm oder besser der ererbte Engrammkomplex durch Reaktionen, die in erster Linie, wenn

1 Stichproben aus einem reichen experimentellen Material! Seit Erscheinen der ersten Auflage der Mneme, also in den letzten sieben Jahren hat sich dasselbe noch ganz außerordentlich vermehrt. Eine zusammenfassende Darstellung habe ich kürzlich in Abderhaldens Fortschritten der naturwissenschaftlichen Forschung Bd. 2, 1911 in der Abhandlung über den Stand der Frage nach der Vererbung emoorbenev. Eigensehaften gegeben. 
auch keineswegs ausschließlich, die Instinktsphäre betreffen, und ich wähle hier als ausfuhrlicher darzustellendes Beispiel die Experimente, durch die P. Kammerer ${ }^{1}$ folgenden Nachweis geführt hat.

Der bekannte Fenersalamander, Salamandra maculosa bringt normalerweise zahlreiche (14-72) Junge als kiementragende, durchschnittlich $25 \mathrm{~mm}$ lange Larven zar Welt, die ins Wasser abgesetzt werden und dort noch einen längeren Entwicklungsgang durchmachen, bis sie nach Monaten ihre Kiemen verlieren, das Wasser verlassen und sich völlig $\mathrm{zu}$ Landmolchen umwandeln. Kammerer glückte es nun zunächst, die Weibchen durch äußere Einwirkungen zu zwingen, ihre Nachkommen länger im Uterus zu behalteu, sodann durch Wiederholung dieses Zwanges, die Spätgeburten zu habituellen zu machen. Um die bisher normal gebärenden Weibchen zu veranlassen, ihre Jungen tiber die normale Zeit im Uterus zu behalten, wandte Kammerer vor allen Dingen Wasserentziehung an, indem er den Tieren kein Wasserbecken zur Verfugung stellte, in das sie die Larven hätten absetzen können. Daneben erwies sich das Halten der Tiere bei niedriger Temperatur (für gewöhnlich bei $12^{\circ}$, Winterschlaf bei $2-4^{\circ}$ ) als Hilfsfaktor.

Der Werdegang der Anpassung von Salamandra maculosa zum habituellen Vollmolchgebären vollzog sich sodann in vier Stufen, die vom Larvengebären ins Wasser, wie es bei Salamandra maculosa normalerweise Brauch ist zum Vollmolchgebären auf trocknem Lande, und zwar in der Art, wie es beim Alpensalamander, Salamandra atra, Brauch ist, hinführen: 1. Viele Larven von 25- $30 \mathrm{~mm}$ Länge werden statt

1 P. Kammerer, Vererbung erzwungener Fortpflanzungsanpassungen. I. u. II. Mitt. in Arch. f. Entwicklungsmech., 25. Bd., 1907. 
ins Wasser auf dem Lande abgesetzt. 2. Ebenda wird eine geringere Anzabl ron Larven aber innerhalb ein und desselben Wurfes gleichen Stadinms geboren. Zugleich mit den wohlausgebildeten Embryonen gehen ziemlich viele teratologische, nicht lebensfähige Abortivembryonen ab. 3. Eine noch geringere Anzahl von (höchstens 7) Larven mit reduzierten Kiemen die knapp vor der Metamorphose stehen, oder von bereits frisch verwandelten Vollsalamandern wird abgesetzt. 4. Auch diese geringe Individuenzahl des Wurfes vermindert sich noch yon einer Gravidationsperiode zur anderen, bis wie bei Salamandra atra die Zahl der Nachkommen konstant auf zwei (ein Fötus in jedem Uterus) stehen bleibt.

Kammerer zog nun eine Anzahl von Jungen auf, die geboren waren, als ihre Mutter die höchste Stufe habituellen Spätgebärens erreicht hatten, und paarte sie untereinander. Brachte er dann die befruchteten Weibchen dieser zweiten Generation während ihrer Trächtigkeit in durchaus normale Verhältnisse, also gab er ihnen Wasserbecken, genugende Feuchtigkeit, hielt er sie bei mäßig hohen Temperaturen, so gebaren sie, trotzdem jeder äußere Zwang zum Spätgebären jetzt fortfiel, doch nicht in der fur ihre Spezies normalen Art und Weise, sondern lieferten ohne Ausnahme von Anfang an Spät- und Spärlichgeburten.

Es waren zwar noch keine metamorphosierten Vollmolche, die sie zur Welt brachten, aber in allen Fällen standen sie der Metamorphose außerordentlich viel näher als die normalen Larven. Auch war die Zahl der Jungen von normalerweise 14-72 auf 5, 4 und 2 Junge bei je einem Wurf zurückgegangen 1.

1 Für die näheren Details, die in dissem Falle überaus interessant und lehrreich sind, muß ich den Leser auf die Kammerersche Arbeit selbst verweisen. Vor allem sind auch wichtig die vererbten morphologischen und Instinktsänderungen der Neugeborenen. 
Analysieren wir diesen Fall einer von einer Generation auf die andere vererbten äußeren Einwirkung auf Grund unserer bisherigen Betrachtungen, so ergibt sich folgendes:

Primärer Indifferenzzustand: Unter dieser Bezeichnung verstanden wir einfach den Zustand des betreffenden Organismus bei Beginn unserer jeweiligen Betrachtungen und Versuche. Im vorliegenden Fall bedentet es den Zustand der Muttergeneration, bevor von ihren Vertreterinnen jeweilig die erste Spätgeburt erzwungen worden ist, die dann durch Wiederholung stufenweise gesteigert und habituell gemacht wird.

Reiz, der auf seine engraphische Wirkung geprüft werden soll: Dieser ist hier komplexer Natur und kann zusammenfassend als der Zwang bezeichnet werden, die Jungen nach Ablauf der normalen Tragezeit im Uterus zu behalten. Dieser Zwang wurde ausgeübt durch Halten der Tiere in verhältnismäBiger Trockenheit und Ktible und besonders durch Entziehung des Wasserbeckens. Wurde er bei jeder folgenden Trächtigkeit wiederholt, so steigerte sich seine Wirkung von Fall zu Fall ${ }^{1}$, und die Spätgeburten gelangten schließlich auf Stufe 4. Hieraus ergibt sich, daß der komplexe Reiz jenes Zwanges auf die Individuen der ersten Generation eine greifbare engraphische Wirkung ausgetibt hat. Diese engraphische Wirkung läßt sich aber bis zu diesem Punkt unserer Betrachtung nur für die Individaen, die dem Reize direkt unterworfen gewesen waren, nachweisen, und bei ihnen handelt es sich damit um ein individuell erworbenes, kein ererbtes 'Engramm.

1 Auf die Steigerung der engraphischen Reizwirkung durch Wiederholung, die, wie bei diesen, bei allen muemischen Phänomenen hervortritt, werden wir unten noch öfters, am ausführlichsten im siebenten Kapitel zurückkommen. 
Um den Nachweis der Vererbung des Engramms za erbringen, muissen wir uns also von dieser Generation, auf die der Reiz direkt als Originalreiz gewirkt hat, zu der folgenden Generation wenden, und die Tiere unter Bedingangen halten, unter denen sie den Einwirkangen, die engraphisch anf ihre Matter gewirkt haben, entzogen sind.

Sekundärer Indifferenzzastand: In diesem Zustand befindet sich die zweite Generation, die von den habituell spätgebärenden Müttern abstammt, während ihrer ersten Schwangerschaft bis zu dem Zeitpunkt, der der normalen Ablage der Jungen von Salamandra maculosa entspricht. In dieser Zeit unterscheidet sie sich in nichts von solchen Salamandern, die von normalgebärenden Müttern abstammen.

Ekphorischer Einfluß: Der Beweis, daß der wiederholt auf die Mtutter geübte $\mathrm{Zwang}$, die Jungen länger and länger im Uterus zu behalten, nicht nur auf sie selbst, sondern auch auf ihre Nachkommen engraphisch gewirkt hat, wird dadurch geführt, daß beiletzteren, wenn sie die Trächtigkeitsphase der normalen Geburt erreichen, diese sich verzögert, und statt dessen regelmäßig Spätgeburt auftritt, obwohl die Mütter dieser zweiten Generation unter normalen Bedingungen gehalten werden, das heißt ihre Trächtigkeit bei gewöhnlicher Feuchtigkeit und Temperatur und unter Verftigung eines Wasserbeckens durchzumachen haben. Der auf die erste Generation geubte äußere Zwang, die Jungen im Uterus zu behalten, fällt mithin fort. Das durch Erreichung der betreffenden Trächtigkeitsphase ekphorierte Engramm oder, anders ausgedrickt, die phasogen ekphorierte mnemische Erregang manifestiert sich in diesem Falle darch die Verzögerung eines normalerweise anftretenden Vorganges, des um diese Zeit auftretenden Geburtsakts. 
Dagegen manifestiert sich in dem parallelen aber entgegengesetzt gerichteten Fall des Alpensalamanders, Salamandra atra, das ebenfalls ererbte Engramm bei seiner phasogenen Ekphorie durch eine positive Reaktion, keine Hemmung. Salamandra atra setzt normalerweise seine zwei Junge als vollentwickelte Landmolche ins Trockne ab. Durch Anwendung entgegengesetzter Mittel wie die beim Feuersalamander verwendeten, nämlich durch reichliche Wasserdarreichung und daneben verhältnismäßig hohe Temperaturen, vermochte Kammerer beim Alpensalamander Frtihgeburten einzuleiten und diese stufenweise za steigern und habituell zu machen. Auch diese Eigentumlichkeit vererbte sich auf die Jungen, die, auch wenn man sie unter den fur ihre Art normalen Verhältnissen hielt und alle jene äußeren Beeinflussungen fortließ, doch ausnahmslos Fruhgeburten durchmachten, das heißt zahlreichere und unentwickeltere Junge warfen. In diesem Fall manifestierte sich also das phasogen ekphorierte Engramm nicht durch die Hemmung eines Vorganges, der normalerweise eintreten sollte, sondern durch den Eintritt eines sonst ausbleibenden Ereignisses: die Frühgeburt.

Ebenso äußert sich die Ekphorie des ererbten Engramms durch eine positive Manifestation in dem sehr ähnlichen Fall der ererbten Enwicklungs- und Instinktsänderung beim Axolotl, den Frl. v. Chauvin ${ }^{1}$ beschrieben hat und auf den ich unten noch zurickkomme, sowie in den rerschiedenartigen von Pictet ${ }^{2}$

1 M. v. Chauvin, Über die Verwandlungsfähigkeit der mexikanischen Axolotl. Zeitschr. f. wiss. Zoologie, Bd. 41, 1885.

2 A Pictet. Influence d'Alimentation et de l'Humidité sur la Variation des Papillons. Mém. Soc. de Phys. et de l'Hist. nat. de Genève, V.ol. 35, 1905. 
und von Schröder ${ }^{1}$ experimentell hervorgerufenen Instinktsänderungen bei Schmetterlingsraupen und bei Käfern (Ocneria, Gracilaria, Phratora). Auf die ebenso erfolgreichen Vererbangsexperimente, die Kammerer ${ }^{2}$ an der Geburtshelferkröte, Alytes obstetricans, vorgenommen hat, werde ich an einer späteren Stelle noch ausfuihrlicher eingehen.

An diese Fälle der Vererbung von Engrammen, die sich bei ihrer Ekphorie vornehmlich durch Instinktreaktionen, daneben auch in einigen morphologischen und psychologischen Charakteren der Neugeborenen, manifestieren, schließe ich den Bericht ebenso beweisender Untersuchungen, bei denen das vererbte Engramm sich durch Reaktionen in der körperlichen Entwicklung (plastische Reaktionen) der Nachkommen zu erkennen gibt. Ich wähle dazu als ein Beispiel von vielen die Versuche von E. Fischer ${ }^{3}$ an einem allbekannten Schmetterling, dem »braunen Bär *, Arctia caja, die an Eindeutigkeit und Beweiskraft nichts zu wünschen übriglassen. Vor Fischer hatte schon Standfuß ${ }^{4}$ an Schmetterlingen ähnliche Versuche mit ähnlichem Erfolge angestellt und später haben viele andere, von denen ich hier nur Schröder, Pictet und Tower nennen will, bei Schmetterlingen und bei Käfern durchaus

$1 \mathrm{Chr}$. Schröder, Über experimentell erzeugte Instinktvariationen. Verhandl. d. D. zool? Gesellschaft, 1903.

2 P. Kammerer, Vererbung erzwungener Fortpflanzungsanpassungen. III. Mitt. Archiv f. Entwicklungsmechanik, 28. Bd., 1909.

3 E. Fischer, Experimentelle Untersuchungen ïber die Vererbung erworbener Eigenschaften. Allgemeine Zeitschrift für Entomologie, Bd. 6, 1901.

4 M. Standfuß, Experimentelle zoologische Studien mit Lepidopteren. Neue Denkschr. d. allg. Schweiz. Naturf. Ges. Bd. 36, 1898, sowie: Zur Frage der Gestaltung und Vererbung auf Grund 28jähriger Experimente. Vortrag, Zürich 1905. 
analoge Resultate erzielt ${ }^{1}$. Reize verschiedener Art wurden dabei zur Anwendung gebracht. Bei den Fischerschen Versuchen handelt es sich um Temperaturreize (Abktihlung der Puppen auf $-8^{\circ} \mathrm{C}$ ). Die durch diesen Reiz ausgelöste Reaktion änßert sich auf plastischem Gebiete (Änderungen in der Pigmentierung der Fltigel des ans der Puppe ausschlüpfenden Falters).

Der primäre Indifferenzunstand wurde in dem vorliegenden Versuch von Fischer mit ausreichender Genanigkeit derart ermittelt, daß die Hälfte der für die Versuche gesammelten Brut (54 Puppen) dauernd bei normaler Temperatur belassen wurde. Diese Puppen (mit Ausnahme von 5, die nicht ausschltipften) »ergaben Schmetterlinge, die keine nennenswerte Veränderung der Färbang and Zeichnung zeigten; weder die braunen Flecken der Vorderflügel noch auch die schwarzen der Hinterflugel zeigten eine Abweichung gegenüber der Normalform*. Wir wollen also in unserem Falle die Ausbildung solcher normal gefärbten Falter als den primären Indifferenzzustand bezeichnen.

Als Reiz, der auf seine engraphische Wirkang gepruft werden soll, diente bei den Fischerschen Versuchen eine intermittierende Abklihlung auf $-8^{\circ} \mathrm{C}$. Dieser Reiz wirkte auf die Generation, die ihm im Puppenstadium ausgesetzt wurde, derart, $d a B$ fast alle ausschlupfenden Falter (von 48 starben 7) »in verschiedenen Abstufungen, die einen mehr in dieser, die anderen mehr in

1 Eine Darstellung des Entwicklungsganges dieser denkwïrdigen Forschungen und eine kritische Würdigung der wichtigen Towerschen Experimente an Leptinotarsa (Carnegie Institution Publ. 48 Washington 1906), Experimente, deren Bedentung vielfach ganz unrichtig eingeschätzt worden ist, findet man in meiner oben (S. 68) zitierten $\mathrm{Ab}$ handlung über den Stand der Frage, S. 39-41, 57-64. 
jener Flügelpartie, aberrativ verändert waren. Es bestand diese aberrative Bildung in einer Verbreiterung der dunkeln also auf den Vorderfltigeln der braunen, auf den Hinterflugeln der schwarzen Flecken, so daß diese teilweise, bei einigen (männlichen) Exemplaren sogar vollständig miteinander zusammenflossen. - - Auf der Unterseite waren diese Falter ebenfalls entsprechend verändert. « Es war mit einem Wort eine ansgesprochen melanotische Aberration aufgetreten.

Sekundärer Indifferenzzustand: Als sekundären Indifferenzzustand haben wir denjenigen Zustand bezeichnet, in dem die durch den Reiz ausgelöste Erregung der organischen Substanz abgeklungen und nur eine latente Veränderang (Engramm) zurückgeblieben ist. Wann dieser Zustand bei der Generation von Arctia caja, die dem Kältereiz ausgesetzt worden war, eingetreten ist, brauchen wir hier nicht näher zu untersuchen. Im sekundären Indifferenzzustand befinden sich aber die Deszendenten so lange, bis bei ihnen die durch jenen frtheren Reiz bedingte Reaktion wieder eintritt, also vom Ei bis zum Puppenstadium, da während dieser Entwicklungsphasen keine von der Norm abweichende Reaktionen im Wachstum oder in anderen biologischen $\mathrm{Phänomenen}$ zu erkennen sind.

Was diese Deszendenten anlangt, so handelt es sich um die Nachkommen zweier von Fischer durch Kältereiz veränderter Falter, eines sehr stark veränderten Männchens und eines weniger stark veränderten Weibchens, beide von ihm in der zitierten Publikation abgebildet. Ans der Paarung dieser beiden abnormen Individuen gingen 173 Puppen hervor, diebei gewöhnlicher Zimmertemperatur $\left(+18^{\circ}\right.$ bis $+25^{\circ} \mathrm{C}$ ) gehalten w urden.

Ekphorie des Engramms: Auch in diesem Falle han- 
delt es sich um eine phasogene Ekphorie unter Fortfall des Kältereizes, der bei der Elterngeneration engraphisch gewirkt hatte. Als nämlich die Verpuppung beendigt war, zeigten sich von den 173 Exemplaren 17 aberrativ verändert, und zwar ganz im Sinne der Eltern, das heißt im Sinne einer melanotischen Aberration. Wie ein Vergleich der Deszendenten mit den Eltern lehrt, »stellen erstere im allgemeinen eine Kombination der beiden elterlichen Individuen derart dar, daß bei einigen mehr die Zeichnung des elterlichen Männchens, bei anderen mehr die des Weibchens uberwiegt. Bemerkenswert ist auch, $\mathrm{da} B$ die aberrative Entwicklung fast nur bei männlichen Faltern sich eingestellt hatte. Auch bei diesen Nachkommen ist die Unterseite der Flügel ähnlich verändert wie die Oberseite.e

Daß übrigens der Kältereiz in der Elterngeneration nicht nur Engramme erzengt hatte, die sich bei den Deszendenten in morphogenetischen Reaktionen äußerten, sondern auch solche, die in andersartigen Realitionen zum Ausdruck kommen, geht daraus hervor, daß die aberranten 17 Exemplare sich unter den zuletzt ausschliupfenden Faltern befanden, während die im Anfang ausgeschlüpften vollkommen normal waren. Schon in der ersten Auflage (S. 82) habe ich die Vermutung ausgesprochen, daß sich also auch ein durch den Kältereiz erzengtes Engramm: Verlangsamung des Entwicklungstempos, vererbt hätte. Diese Vermatung hat sich in der Folgezeit bestätigt; denn wie Pictet (a. a. 0.S. 85) gefunden hat, geht regelmäßig eine Verlängerung des Puppenstadiums mit der hier vorliegenden melanotischen Aberration Hand in Hand, während mit albinotischer Aberration eine Verkürzung des Puppenstadiums verknuipit ist.

Wir haben soeben zwei vollkommen klare und jederzeit 
einer erneuten Nachprüfung zugångliche Fälle von Vererbung engraphischer Einwirknngen kennen gelernt, deren jeder nur ein Musterbeispiel aus einer großen Reihe verwandter Fälle darstellt. Ich wende mich jetzt noch kurz zu einer dritten Versuohsgruppe, die uns die erbliche engraphische Veränderung bei Pflanzen vor Angen führt und zwar wähle ich aus dem vorliegenden Material die Gruppe der Akklimatisationsphänomene. Auf diesem Gebiet sind uberhaupt die ersten für unsere Frage wichtigen Beobachtungen gemacht und vor allem die ersten systematischen Kulturversuche unternommen worden. Der norwegische Forscher F. C. Schlibeler ${ }^{1}$ war es, der hier vor 60 Jahren als der erste von allen den experimentellen Weg beschritten und damit eine neue Ära der Forschung inauguriert hat. Durch Anban von Getreidearten in verschiedenen geographischen Breiten (in Christiania unter $60^{\circ}$ n. Br. and in Deutschland unter $50^{\circ}$ n. Br.) gelang es ihm; die Vegetationsdauer von der Zeit der Aussaat bis zur Reife einerseits unter den sommerlichen Besonnungsverhältnissen des Nordens von Generation zu Generation zu verkürzen und sie andererseits unter der kürzeren sommerlichen Besonnung der stadlicheren Breite von Generation zu Generation zu verlängern, so daß sich schließlich erblich fixierte Differenzen der Vegetationsdaner von uber 4 Wochen ergaben.

Ein Angriff auf diese bedeutungsvollen Ergebnisse Schübelers, der vor einiger Zeit von $\mathrm{N}$. Wille unternommen worden ist, erwies sich deshalb als bedeutungslos, weil dieser Kritiker die Hauptsache, auf die es im Grunde einzig und allein ankommt, vollkommen ubbersehen hat, nämlich die Schübeler-

1 F. C. Schübeler, Die Pflanzenwelt Norwegens, Christiania, 1873, S. $52 \mathrm{ff}$. and $80 \mathrm{ff}$, Die Kulturpflanzen Norwegens, Christiania 1862; Viridarium Norwegicum, Christiania 1885. 
schen Experimentaluntersuchungen. Sie sind ihm bei seiner Lektlire der Schübelerschen Schriften durch irgend einen Zufall ganz entgangen, und er glaubt irrtumlicherweise, Schtibeler grunde seine Schlisse nur auf Hörensagen und die Angaben eines alten schwedischen Journals. Ich bin hierauf in der zweiten Auflage des vorliegenden Buchs (S. 86) ausführlich eingegangen, wiederhole aber meine Ausfuhrungen jetzt hier nicht, weil die Angelegenheit wohl nunmehr erledigt ist.

Einen berechtigten Einwand kann man allerdings gegen die volle Beweiskraft der Schübelerschen Experimente ebenso wie gegen die verwandten von Hoffmann, Cieslar und Wettstein erheben; sie sind nicht an Reinzachten elementarer Arten, nicht an reinen Linien angestellt worden, sondern an den nur scheinbar einheitlichen Beständen, die ein Gemenge solcher elementarer Arten darstellen. Zur Zeit, als Schibeler arbeitete, war man auf solche Gemenge oder »Populationen*, wie Johannsen sie nennt, angewiesen, und deshalb erscheint vom modernen Standpunkt aus eine Nachprüfung seiner Experimente durch entsprechende Kulturversuche mit reinen Linien als ein unumgängliches Erfordernis, und dürfen seine Ergebnisse bis dahin nicht ohne Vorbehalt angenommen werden. Glücklicherweise besitzen wir aber in einer neueren Arbeit ${ }^{1}$ uber Akklimatisation insofern eine sehr reine und von diesem Einwand nicht getroffene Ergänzung, als sie nicht an einer Massen- sondern an einer Einzelkultur angestellt worden ist und es sich bei ihr um einen neuen, durch den Einfluß der Außenwelt anf das Einzelindividuam ganz allmählich herangebildeten Charakter handelt.

1 E. Bordage. A propos de l'hérédité des caractères acquis. Bulletin scientifique, 7. Série, T. 44, Paris 1910. 
Schon seit langer Zeit ist es bekannt, daß manche Bäume, die man aus der gemäßigten Zone in feuchte Tropengegenden versetzt, allmählich ihren periodischen Blattabwurf aufgeben und von sommergrỉnen zu immergrünen Gewächsen werden. Bordage ist nun während seines 12jährigen Aufenthalts auf Réunion der Frage nachgegangen, ob sich diese durch den Klimawechsel bedingte Veränderung bei Fortpflanzung durch Aussaat (nicht durch Firopfung) auf die Nachkommen vererbt, und er fand dafur im Pfirsichbaum ein geeignetes Versuchsobjekt. Sät man aus Europa bezogene Pfirsichkerne auf Réunion aus, so werfen die daraus gezogenen Pflanzen selbst bei Kultur in den heißen Küstengegenden noch 10 Jahre lang regelmäßig jahresperiodisch ihr gesamtes Laub ab und bleiben, zunächst für etwa $1 \frac{1}{2}$ Monate, später für immer kürzere Zeit vollständig kahl. Nach 10 Jahren sind einige Exemplare so weit, daß eine Phase vollkommener Blattlosigkeit bei ihnen nicht mehr eintritt; aber erst nach 20 Jahren ist ein Zustand erreicht, daß man sie als nahezu immergrtine Gewächse (subpersistance du feuillage) bezeichnen kann.

Sät man nun die Samen solcher immergrün gewordener Bäume aus, so gehen aus ihnen Nachkommen hervor, die sofort in demselben Maße immergrün sind wie ibre Eltern, und zwar geschieht dies selbst dann, wenn diese Aussaat nicht in den heißen Niederungen der Küste, sondern bei 1000 Meter Meereshöhe erfolgt, wo solche Pfirsichbäume, die von Eltern stammen, welche nicht durch das Klima abgeändert sind, dauernd einen periodischen totalen Blattabwurf beibehalten.

Mit diesen Stichproben können wir es uns hier unter Hinweis auf die ausfuhrliche Zusammenstellung im stand der Frage gentigen lassen. Wir kommen nanmehr za. 
folgendem Schluß: Wenn, wie gezeigt worden ist, die zahlreichen Reize, die fort und fort jeden Organismus treffen, nicht nur synchrone und akoluthe, sondern sehr häufig auch engraphische Wirkungen haben, wenn ferner diese engraphischen Wirkungen, wie ebenfalls gezeigt worden ist, zuweilen über die Individualitätsphase hinaus auf spätere Phasen der kontinuierlichen Entwicklungsreihe sich erstrecken, sich vererben a, so folgt daraus mit Notwendigkeit, daß in jedem lebenden Organismus, der ja eine Geschichte von Jahrmillionen hinter sich hat, der die millionste oder billionste Phase einer kontinuierlichen Entwicklungsreihe darstellt, sich sehr viel derartige Engramme befinden müssen, die von seinen Ahnengenerationen anf ihn übertragen sind.

Finden wir nun, wenn wir daraufhin die Organismen untersuchen, in ihrer reizbaren Substanz Eigenschaften, die den Charakter ererbter Engramme besitzen? Ob ererbt oder nicht, wird sich natürlich bei fortgesetzter Untersuchnng mehrerer Generationen leicht ausmachen lassen. Ob aber Engramm, d. h. latenter Rest einer früheren Reizwirkung, wird schwerer zu entscheiden sein.

Das ererbte Engramm ist das Produkt einer Reizwirkung, die die Vorfahrengeneration getroffen hat.

Wir haben es also mit einem historischen Vorgang zu tun, und diesem können wir in der Regel nicht mit experimentellen Methoden za Leibe gehen. Wenn wir auch in tausend Fällen zeigen, daß wir imstande sind, bei den Organismen Engramme zu erzeugen, die sich vererben, so wird dadurch keineswegs ohne weiteres bewiesen, daß alle oder doch die meisten ererbten Dispositionen, die wir bei den Organismen finden, nun auch Engramme, d. h. latente Reste fruherer Reizwirkungen sind. 
Wir stehen hier bei der Frage nach dem Wesen der erblich von Generation zu Generation übermittelten Dispositionen an einem kritischen Punkte unserer Untersuchung. Bisher hatten wir immer den festen Boden der unmittelbaren experimentellen Erfahrung unter den Füßen. Sollen wir ihn jetzt verlassen und uns in das Reich der Vermutungen begeben? Diese Frage ist so wichtig, daß wir nicht umhin können, ihrer Beantwortung einen kleinen Exkurs zu widmen.

Wir haben von der Tatsache anszugehen, daß jeder Schluß, der uns wirklich etwas neues sagt, der unserer Erkenntnis etwas zuerobert, ein AnalogieschIuß ist. Alles, was man als notwendige Schlisse bezeichnet, die mathematischen und rein logischen Schlüsse sind nur Umformungen dessen, was bereits in den Voraussetzungen enthalten ist. Sie sagen uns faktisch nichts neues. Nenes sagt uns nur die Erfahrung, und alles, was diese uns lehrt, lehrt sie uns auf dem Wege des Analogieschlusses. Aus dieser Quelle stammen alle unsere Raum- und Zeitvorstellungen, die mathematischen > Grundsätze* ebensowohl wie die physikalischen Fundamentalsätze. Daß ein Stein, den wir in die Luft werfen, zur Erde fallen wird, wissen wir einzig und allein per analogiam. Denn die Kenntnis vom Vorhandensein der Schwerkraft oder Distanzenergie ist für den menschlichen Geist nichts primär Gegebenes. Sie ist nur das Ergebnis einer großen Menge analoger Erfahrungen, ein großer, zusammenfassender Analogieschluß. Ebenso verhält es sich mit dem Gesetz von der Erhaltung der Energie, kurz mit jeder naturwissenschaftlichen Erkenntnis.

Nun können wir die Vorgänge, die sich als Objekte dem menschlichen Schlußvermögen darbieten, in zwei Gruppen 
einteilen: solche, die sich wiederholen (oder wiederholen lassen), und solche, die nur einmal anftreten und nicht wiederholbar sind.

Nur die wiederholbaren Vorgänge sind strenggenommen einer experimentellen Prtfung zugänglich. Die Fallgesetze werden uns fort und fort durch neue Erfahrung bestätigt. Ich kann die Voraussetzungen und Bedingungen der sie beweisenden Experimente nach allen Richtungen hin variieren: stets ergibt sich dasselbe Resultat. Schlusse, die derart fort und fort durch neue unmittelbare Erfahrungen bestätigt werden können, erlangen für uns den Charakter nicht der Wahrscheinlichkeit, sondern der Unumstößlichkeit.

Nicht wiederholbare Erscheinungen entziehen sich der Kontrolle durch neue unmittelbare Erfahrung, wenigstens der direkten Kontrolle. Daß sich die Schichten des Muschelkalks durch Niederschlag fester Bestandteile aus einem wässerigen Medium gebildet haben, kann ich durch neue unmittelbare Erfahrung nicht beweisen. Eine experimentelle Nachahmung des Vorgangs ist eben nur Nachahmung, nicht Nachprüfung. Das weitere Argument, daß sich Geschöpfe in dieser Ablagerung vorfinden, die wir gegenwärtig ausschließlich als Bewohner des Wassers kennen, wie die Echinodermen, während Landbewohner fehlen, vermehrt zwar außerordentlich die Sicherheit dieses Wahrscheinlichkeitsbeweises. Aber ein professioneller Skeptiker wird immer leichter durch unmittelbaren Experimentalnachweis widerlegt werden als durch die schönste indirekte Beweisfuhrung. In diesem Falle wird er vielleicht einwenden: daß die heatigen Echinodermen Bewohner des Wassers seien, beweise noch nichts für die Echinodermen der Trias. Daß aber auch nicht wiederholbare Erscheinungen in Wissenschaft and Leben Schlußfolgerungen 
unterliegen können, die wenigstens jedem unverbildeten Menschen absolut zwingend erscheinen, ist leicht an beliebig vielen Beispielen zu zeigen. Wird irgendein denkender Mensch im Ernst daran zweifeln, daß die fossilen Tere und Pflanzen einst wirklich gelebt haben und nicht bloße Naturspiele sind, oder da $B$ die fossilen Wirbeltiere auch Nerven besessen haben? zweifeln, weil sich alles dieses durch unmittelbaren Experimentalbeweis nicht mehr nachweisen läßt?

Wenn es neuerdings in einem gewissen Kreise von Biologen Mode geworden ist, die historische, auf indirekten Schlüssen basierende Methode, die für alle historischen, $d . h$. nicht wiederholbaren Erscheinungen notgedrungen die allein anwendbare ist, herabzusetzen und ihr jeden wissenschaftlichen Wert abzusprechen, so kann man den betreffenden Gelehrten ihr sonderbares Vergnůgen ja lassen. Die ubrige Menschheit, gelehrte wie ungelehrte, wird deshalb nicht darauf verzichten, den historischen, nicht wiederholbaren Erscheinungen Aufmerksamkeit und Nachdenken zazuwenden.

Die Frage, inwieweit überhaupt Erscheinungen in der Welt im strengsten Sinne genau wiederholbar sind, soll hier nicht erörtert werden. Es muß zugegeben werden, daß sich viele Geschehnisse in der Welt des Anorganischen mit solcher Gleichförmigkeit wiederholen lassen, daß die Abweichnngen im Hinblick auf das zu prüfende Resultat uberhaupt keinen erkennbaren Ausschlag zu geben vermögen und nicht in Betracht kommen.

In der Welt des Organischen sind die Abweichnngen bei jeder Wiederholung eines Geschehnisses meist größer. Dient derselbe Organismus zum Objekt, so hat er sich von Versuch za Versuch bereits geändert; handelt es sich um verschiedene Organismen, etwa zwei Individuen derselben Spezies, so sind 
sie ron Anfang an relativ stark ungleich. Immerhin kann man auch in der Welt des Organischen von wiederholbaren Erscheinungen sprechen, wenn man nämlich diejenigen Grundzüge der Erscheinungen ins Ange faßt, denen gegenüber die sich bei jeder Wiederholung ergebenden Abweichungen als verschwindend klein nicht in Betracht kommen. Doch ist es gut, sich zu erinnern, daß die Wiederholbarkeit organischer Vorgänge strenggenommen nur eine Fiktion ist.

Indem wir die Überlegenheit der unmittelbaren Experimentalschlnßfolgerung gegenüber der mittelbaren historischen Schlußfolgerung voll anerkennen, verzichten wir dennoch nicht anf letztere, weil sie das einzige Mittel zur Erschließung der Zusammenhänge nicht wiederholbarer, historischer Vorgänge darstellt, und weil ihre Resultate in günstigen Fällen eine Sicherheit besitzen können, die den durch unmittelbaren Experimentalbeweis gewonnenen Resultaten an zwingender Beweiskraft so wenig nachsteht, daß die Differenz eine unmeßbar kleine wird. Das Resultat der historischen Schlaßfolgerung: die Fossilien sind Reste von Tieren und Pflanzen, die fruher gelebt haben, und nicht $\gg$ Naturspiele , läßt sich so zwingend begründen, daß die Behauptung, die Schlußfolgerungen der Mechanik seien aber noch sicherer beweisbar, obwohl an sich richtig, praktisch bedeutungslos wird.

Wenden wir die Resultate der vorstehenden Erwägungen auf die Frage von der Vererbung der Engramme an, so ist es klar, daß es sich, was die erste Entstehnng dieser Engramme anbetrifft, in der Mehrzahl der Fälle um nicht wiederholbare Vorgänge handelt. Immer dann nämlich, wenn die Engramme von Ahnengenerationen erworben wurden, die sich von den jetzt lebenden Tier- und Pflanzengenerationen erheblich unterschieden haben. Alle solche sehr alten Erwerbungen sind der 
unmittelbaren Experimentalbeweisfuhrung entzogen; siekönnen nur mit Hilfe der indirekten Schlußfolgerung ergründet werden.

Wenn wir uns nun anschicken, den Wahrscheinlichkeitsbeweis zu fuhren, daß die große Mehrzahl der von den Organismen ererbten Dispositionen * als Engramme aufzufassen ist, so haben wir zunächst zu untersuchen: woran erkennen wir ein Engramm?

Das sicherste Kriterium für ein Engramm ist die Beobachtung der Phasen seiner Entstehung: 1. Beobachtung des Organismus vor dem Vorhandensein des Engramms (primärer Indifferenzzustand), 2. Eintreten des engraphischen Reizes, 3. sekundärer Indifferenzzustand (Latenzphase), 4. Manifestationsphase (Ekphorie).

Bei den uns jetzt beschäftigenden historisch gegebenen Engrammen fällt das Eintreten des engraphischen Reizes in die Vergangenheit. Der Organismus, wie wir ihn zur Untersuchung erhalten, befindet sich bereits im sekandären Indifferenzzustand. Nur die Latenzphase und die Manifestationsphase sind also unserer Untersuchung zugänglich. Der Schluß, daß hier anch wirklich ein Engramm vorliegt, kann sich demgemäß bei dieser Art der Beweisfuhrung nur anf zwei Momente stitzen: Erstens auf den Umstand, daß es sich um Eigenschaften der organischen Substanz handelt, die bald latent, bald manifest sind. Zweitens auf die Art und Weise, wie der Übergang aus der Latenzphase in die Manifestationsphase ansgelöst wird, $d_{s} h_{\text {. }}$ auf den Nachweis, daß diese Auslösung den Charakter einer Ekphorie trägt.

Nun besitzen die uns hier beschäftigenden ererbten Eigenschaften sämtlich ein Latenzstadium, aus dem sie bei jeder Wiederkehr des auslösenden Einflusses in den zugehörigen Erregungszustand verfallen. 
Die Reaktion, durch die ein Engramm für uns manifest wird, unterscheidet sich natiurlich als solche nicht von irgendeiner anderen durch Originalreiz bewirkten Reaktion. Ein Unterschied findet sich nur in dem was die Reaktion hervorruft. Können wir es aber einem solchen Einfluß ansehen, ob seine Wirkung eine ekphorische ist, oder ob er als Originalreiz wirkt? Hier hat unser Wahrscheinlichkeitsbeweis einzusetzen.

Wie wir im Anfang unserer Untersuchungen gesehen haben, erkennen wir das Vorhandensein eines Engramms aus dem Umstande, daß zur Auslösung der zugehörigen Reaktion nicht mehr das Auftreten des unveränderten Originalreizes erforderlich ist, sondern entweder des quantitativ veränderten Originalreizes, oder des qualitativ veränderten Originalreizes, oder eines Reizes, der auf ein assoziiertes Engramm ekphorisch wirkt, oder der Ablauf eines bestimmten Zeitabschnittes (chronogene Ekphorie), oder endlich das Auftreten einer bestimmten Entwicklnngsphase in der kontinuierlichen Reihe der aufeinander folgenden Generationen (phasogene Ekphorie).

Nun begegnen wir bei allen Organismen: Protozoen, Pflanzen und Tieren, einer außerordentlich großen Anzahl von Erregungsdispositionen, deren zugehöriger Reiz mit größter Wahrscheinlichkeit in eine der erwähnten Kategorien einzureihen ist.

Die beiden erstgenannten Kategorien ekphorischer Einflisse, bei denen es sich um ejne bloße quantitative oder qualitative Veränderung des Originalreizes handelt, sind nicht unwichtiger und nicht ungewöhnlicher als die drei letztgenannten. Da sie aber den Originalreizen mehr oder weniger ähnlich sind, so liegt es auf der Hand, daß wir ihnen bei der uns jetzt beschäftigenden Beweisfihrung viel weniger 
schlagende Argumente entnehmen können, als den Fällen der assoziativen, chronogenen und phasogenen Ekphorie. Immerhin kann man auch erstere Fälle ins Feld fuhren. Bei vielen Vogelarten ist die Reaktion, beim Anblick von Körnern und anderen kleinen Gegenständen nach diesen zu picken, angeboren. Daß es sich dabei um ein ererbtes Engramm handelt, auf das der optische Reiz des betreffenden Gegenstandes ekphorisch wirkt, erscheint mir schon an und für sich sehr wahrscheinlich. Es kommt nun aber vor, daß der optische Reiz zur Auslösung der Reaktion nicht genügt, und bei manchem Huhner- und Fasanenkuicken, das im Brntapparat ausgebrtitet ist, dauert es lange, bis auf den bloßen optischen Reiz der ruhig daliegenden Körner die Reaktion des Pickens eintritt. Diese Reaktion kann aber eingeleitet werden durch das Beispiel etwas älterer Kticken oder anch dadurch, daß man in Nachahmung der Henne vor den Augen der Tierchen mit dem Fingernagel oder einem Stifte auf das Futter tupft. Besonders die jungen Strauße, die im Brutofen ausgebrütet sind, picken nach Claypole ${ }^{1}$ die ihnen vorgeworfene Nahrung nicht auf, ohne daB man vor ihnen auf den Boden tupft, auf dem das Futter liegt. Von allen Erklärungen dieses Vorganges scheint mir weitaus die wahrscheinlichste die, darin die Ekphorie eines ererbten Engramms zu erblicken, und zwar: Engramm, dessen zugehörige Reaktion das Picken ist; ekphorischer Reiz die Wiederkehr des qualitativ etwas veränderten Primärreizes (statt Vorpicken der Matterhenne, Tupfen mit dem Fingernagel oder einem Stifte auf das Futter: vikariierende Ekphorie).

Beobachtangen, die vielleicht noch beweisender für den

1 Siehe L. Morgan, Instinkt und Gewohnheit, Leipzig und Berlin, B. G. Tenbner, 1909, S. 43. 
engraphischen Charakter vieler ererbter Dispositionen and für den ekphorischen Charakter der sie auslösenden Einfltusse sind, betreffen Fälle, in denen junge Vögel durch den bloßen Kontakt ihres Schnabels mit Wasser, mit dem sie zum ersten Male in Bertihrung kamen, veranlaßt wurden, alle Zeremonien eines Vogelbades im Troekenen durchzumachen. Morgan berichtet im vierten Kapitel seines eben zitierten Buchs mehrere solche Beobachtungen, von denen ich eine von Charbonnier angestellte hier wiedergebe: >Einer etwa funf Wochen alten Elster, die von dem Beobachter von klein auf aufgezogen worden war, wurde in ihrem Käfig eine Schtissel mit Wasser vorgesetzt. Sie pickte ein paarmal nach der Oberfläche des Wassers und fing dann an, außerhalb der Schussel, and ohne uberhaupt ins Wasser gegangen zu sein, alle die Gesten durchzunehmen, die ein Vogel beim Baden auszufuhren pflegt; sie duckte ihren Kopf, flatterte mit den Flügeln und dem Schwanze, hockte sich hin und spreizte sich. Später und ganz allmählich nahm sie die Gewohnheit des wirklichen Badens an und schien ihr Bad bei regnerischem Wetter kaum erwarten zu können.* Auch dieser Fall verliert das Befremdende, das ihm anhaftet, sobald man annimmt, daß es sich um ein ererbtes Engramm handelt, auf das der Kontaktreiz des Wassers, selbst wenn er bloß einen kleinen Bezirk der Körperoberfläche trifft, ekphorisch wirkt.

In den bisher angefthrten Fällen handelte es sich um mehr oder weniger unmittelbare Ekphorien. Nicht minder zahlreich finden sich aber bei den Organismen ererbte Dispositionen, zu deren Auslösung Einfltisse erforderlich sind, die wir den mehr mittelbar ekphorischen zuzurechnen haben. Ich iühre zunächst einen Fall für viele anf, der sich leicht 
durch die Annahme mehrerer assoziativ verbundener Engramme erklären läßt. P. Huber ${ }^{1}$ berichtet von einer Raupe, welche mittels einer Reihe von Prozessen ein sehr kompliziertes Gewebe fuir ihre Verpuppung herstellt. Er fand nun, daß, wenn er eine Raupe, welche ihr Gewebe etwa bis zur sechsten Stufe seiner Vollendung fertig hatte, in ein solches setzte, welches nur bis zur dritten Stufe vollendet war, die Raupe durchaus nicht in Verlegenheit geriet, sondern die vierte, fünte und sechste Stufe des Gespinstes wiederholte. Wenn er aber eine Raupe aus einem Gewebe der dritten Entstehungsstufe in ein solches brachte, das bis zur neunten Stufe fertig war, so daß das Tier also eines großen Teils seiner Arbeit iiberboben gewesen wäre, so war es ihm nicht möglich, unter Überspringung der vierten bis achten Stufe bei der neunten Stufe fortzufahren; es mußte vielmehr von der dritten Stufe, die es vorher verlassen hatte, wieder ausgehen, so daß an dem Gewebe, an welchem es fortspann, die vierte bis, achte Stufe doppelt gesponnen wurde. Dieser Fall findet seine ungezwungene Erklärung durch die Annahme, daß der komplizierte Spinnakt die Manifestation einer Kette von sukzessiv assoziierten (ererbten) Engrammen ist. Die Ekphorie des einen wirkt ihrerseits wieder ekphorisch auf das nächste sukzessiv assoziierte ${ }^{2}$.

$1 \mathrm{Vgl}$. G. J. Romanes, Die geistige Entwicklnng im Tierreich, Leipzig 1885, S. 192.

2 Die Ekphorie der betreffenden Engramme findet bei der Raupe, die noch nie gesponnen hat, lediglich als sukzessive Ekphorie sukzessiv assoziierter Engramme statt. Setzt man eine solche Raupe in ein angefangenes Gespinst, oder eine andere, die zu spinnen begonnen in ein Gespinst, das weiter fortgeschritten ist als ihr eigenes, so wirkt Anblick oder Berührung dieses im individnellen Leben des Tieres noch nie vorgekommenen Objekts nicht ekphorisch auf den entsprechenden Punkt der ererbten Engrammkette. Wohl aber wirkt er so, wenn das 
Die bisher erörterten Engramme waren solche, deren Reaktionen sich in Muskelkontraktionen (Picken, Fltigelspreizen eines jungen Vogels, komplizierte Spinntätigkeit einer Raupe) äußern. Wie ich schon oben betont habe und jetzt nachdrticklich wiederholen möchte, ist es für die uns beschäftigenden prinzipiellen Fragen vollkommen gleichgültig, ob die von uns beobachteten Reaktionen, durch welche die Erregungszustände der reizbaren organischen Substanz für uns manifest werden, in Muskelkontraktionen, oder Veränderungen des Turgors der Zellen, oder Sekretionsvorgangen und anderen Stoffwechselprozessen; oder in Zellteilungen und anderen Wachstumsvorgängen, oder endlich in Empfindungen, die uns direkt nur bei uns selbst manifest werden, bestehen.

Wir wenden uns jetzt zu ererbten Dispositionen, deren zugehörige Reaktionen durch zeitliche Einflüsse (Ablauf eines bestimmten Zeitabschnitts) ausgelöst werden, deren Auslösung sich mithin als chronogene Ekphorie (vgl. S. 61) darstellt. Ererbten Dispositionen, die durch chronogene Ekphorie manifest werden, begegnen wir in sehr großer Anzahl im Tier-

Tier in seinem individuellen Leben mit dem Spinnen bereits so weit gekommen ist, also bereits frische, individuell erworbene Engramme des Objekts besitzt. In dem vorliegenden Falle ist also nur die Sukzession derjenigen Engramme, die sich in den Spinnreaktionen manifestieren, ererbt; nicht ererbt sind die Engramme des Aussehens oder der dem Tastsinn zugänglichen Eigenschaften des Gespinstes.

Die Raupe befindet sich, um die Sache durch einen unserer Erfahrung näher liegenden Vergleich zu illustrieren, in einer ähnlichen Lage, wio wir selbst, wenn wir ein seit sehr langer Zeit nicht repetiertes Gedicht aufsagen sollen. Wir können es wohl von Anfang bis zu Ende herunterschnurren, sind aber nicht imstande, auf ein herausgegriffenes Stichwort hin, an einer beliebigen Stelle zu beginnen und fortzufahren. Wenigstens nicht beim ersten Male. Haben wir aber erst einmal einen Teil hersagend wiederholt, so können wir innerhalb dieses jetzt wieder aufgefrischten Stückes an beliebiger Stelle anfangen und weitersagen. 
und Pflanzenreich. Ich erinnere nur an die periodische Eireifung beim menschlichen Weibe, an die Brunstperioden der meisten Tiere. Die Reaktionen, durch die diese Engramme manifest werden, bestehen in erster Linie aus Wachstumsvorgängen. Der vielen Vogelarten angeborene -Wandertrieb ist die motorische Reaktion eines ererbten Engramms, die ebenfalls durch chronogene Ekphorie ausgelöst wird.

Die sogenannten Vegetationsperioden der Pflanzen sind Phänomene, bei denen chronogene Ekphorie eine sehr wichtige Rolle spielt. Besonders tritt dies bei denjenigen Pflanzen hervor, die sich nicht *treiben (assen, $d$. h. bei denen der Eintritt der Wachstumsreaktion durch einen anderen Einfluß nicht oder doch nur sehr schwer zu erzielen ist. Wenn eine Buche, die bei gleichbleibender Temperatur im geheizten Zimmer gehalten wird, im November ihre Blätter welken läßt und abwirft, obgleich der direkte Reiz, der sonst diese Reaktion auslöst, die Einwirkung niederer Temperatur, in diesem Fall nicht eingewirkt hat, so liegt die Erklärung auf der Hand, daß hier ein chronogenes Engramm vorliegt, das durch chronogene Ekphorie, anch bei Ausbleiben des für gewöhnlich die Reaktion des Blattabwurfs anslösenden Kältereizes, sich im Blattabwurf manifestiert. Daß dieses Engramm ererbt ist, läßt sich leicht dadurch nachweisen, daß man zu solchen Versuchen ein direkt aus Samen gezogenes, immer bei gleicher Temperatur gehaltenes Exemplar verwendet; das also in seinem individuellen Leben in dieser Beziehung noch wicht engraphisch beeinflußt worden ist.

Freilich wird dieser Fall insofern etwas kompliziert, als bei der starren Fixierung der Jahresperiode derjenigen Pflanzen, die sich nicht oder nur sehr schwer treiben lassen, 
die naturliche Auslese mitgewirkt hat. Denn es muß für frostempfindliche Gewächse sehr wichtig sein, sich nicht durch die Wärme eines vorzeitigen Fruhlings verlocken zu lassen, ihre Knospen verfrüht zu entfalten und sie dadurch den mit Wahrscheinlichkeit eintretenden späteren Frösten auszusetzen. Der Fall der Jahresperiode ist deshalb kein so reiner Fall als der gleich zu besprechende der Tagesperiode, bei deren erblicher Fixierung, wie ich anderwärts gezeigt habe ${ }^{1}$, die natlirliche Anslese offenbar nicht mitgewirkt hat.

Auch die Blattbewegungen der Tagesperiode werden bei Aufhören des normalerweise auslösenden Lichtreizes noch längere Zeit hindurch chronogen ekphoriert. Den Nachweis, daß es sich bei diesem Nachwirken der Tagesperiode, die man bei in koustanter Dunkelheit oder in konstanter Helligkeit gehaltenen Pflanzen beobachtet, mit um ererbte Dispositionen und nicht, wie Pfeffer $^{2}$ gemeint hat, aussehlie Blich um individuell erworbene handeit, habe ich folgendermaßen geführt. Keimlinge von Albizzia (Acacia) lophantha, die bis dahin in vollkommener Dunkelheit gehalten worden waren, wurden intermittierender künstlicher Beleuchtung und Verdunkelung ausgesetzt, und zwar wurde in einer Reihe von Fällen ein 6stundiger, in einer anderen ein 24stindiger Turnus gewählt. Wurde nach mehrwöchiger Einwirkung dieser Belichtungsart mit der intermittierenden Beleuchtung anfgehört und die Pflanzen entweder in dauernder Helligkeit oder in dauernder Dunkelheit gelassen, so setzten sie eine

1 R. Semon, Beweise für die Vererbung erworbener Eigenschaften Archiv für Rassen- ond Gesellschafts-Biologie, 4. Jahrg, 1. Heft 1907.

2 W. Pfeffer, Die periodischen Bewegungen der Blattorgane. Leipzig 1875, und Pflanzenphysiologie, Bd. II, 1904. Vgl. bes. S. 491. 
Zeitlang ihre Blattbewegung fort, aber nicht in dem Turnus, den ich zu induzieren versucht hatte, also nicht in 6- bzw. 24 stündigen, sondern in 12 stundigen Intervallen, wodurch als bewiesen anzusehen ist, daß die Tendenz zu diesem 12 stuindigen Turnus ihnen angeboren ist ${ }^{1}$. Keimlinge, die

1 Ausführlicher habe ich meine Experimente in dem Aufsatz >Über die Erblichkeit der Tagesperioder, Biol. Centralblatt, Bd. 25, 1905, dargestellt und durch Kurven illustriert. Neuerdings hat W. Pfeffer sehr eingehende >Untersuchungen über die Entstehung der Schlafbewegungen der Blattorganer; im 30. Bd. d. Abhdlg. d. Mat.-Phys. Kl. d. Kgl. Sächs. Ges. d. Wissensch. Nr. III, Leipzig 1907, veröffentlicht. Die tiefwurzelnde Disposition zu 12 stiindigem Bewegungsturnus, die ich bei Albizzia (Acacia) entdeckt habe, wurde später von Pfeffer auch bei Phaseolus und etwas weniger ausgeprägt bei Mimosa Speggazzinii wiedergefunden. Seine Befunde stehen überhanpt in der denkbar größten Ửbereinstimmung mit meinen oben mitgeteilten Ergebnissen und ihrer Deutung, wie ich in einem zweiten Artikel im Biologischen Centralblatt (28. Bd. 1908, S. 225-243) ausgeführt habe. In seiner Erwiderung (Biol. Centralblatt, 28. Bd. 1908, S. 389-415) hat Pfeffer eine formelle Bestätigung seiner Übereinstimmung mit meiner Auffassung in dem uns hier beschäftigenden Hauptpunkt mit den Worten gegeben: sDie Mög lichkeit, daß den schlaftäigen Organen ein Reaktionsvermögen zukommt, vermöge dessen sie während eines andersartigen Beleuchtungshythmus und ferner bei den Nachschwingungen eine tagesperiodische Bewegungstätigkeit anstreben oder erreichen, habeichniebestritten, auch habe ich neuerdings (1907) in diesem Pnnkte keinen prinzipiellen Widerspruch gegen Semon erhoben. Vielmehr habeichdie Existenzeinessolchen durch die Eigenschaften der Pflanze bedingten Strebens in evidenter Weise für die Blätter von Phaseolus fes tgestellt (1907, S. 357, 424, 441) und somit Semons Auffassung für einen konkreten Fall bestätigt.ء Die neusten Forschungen von R. Stoppel (Zeitschr. f. Botanik, 2. Jahrg., 6. Heft, 1910, S. 418, 427, 431, 444) machen es übrigens beinah sicher, daß bei gewissen Blüten (Calendula, Bellis) eine Vererbung der Tagesperiodizität in einer spontanen Bewegungstätigkeit, nicht bloß, wie ich für die Schlafbewegungen nachgewiesen habe, in der Vorstufe zu einer solchen, nämlich in einer bloßen Disposition, zu Tage tritt. Eine weitere wichtige Ergänzung meiner Feststellungen. 
von Anfang an in vollkommener Dunkelheit oder in dauernder Helligkeit gelassen wurden, zeigten uberhaupt keine periodischen Bewegungen. Die in Dunkelheit belassenen entfalteten ihre zusammengelegten Blätter gar nicht; die konstant beleuchteten entfalteten sie, nahmen eine Winkelstellung ein, die bei verschiedenen Individuen zwischen $135-180^{\circ}$ schwankte, und verharrten so. Aus diesen Beobachtungen geht hervor, daß zur Ekphorie des Engramms, dessen zugehörige Reaktion sich in periodischen Blattbewegungen von 12 stundigem Turnus äuBert, periodische Belichtung und Verdunkelung gehürt. Diese letztere ist zur Ekphorie des Engramms erforderlich. Daß nicht sie es ist, die bei dem betreffenden Individuum dieses Engramm (Tendenz, die Bewegung in 12 stündigem Turnus auszuführen) selbst erzeugt hat, wird dadurch bewiesen, daß nach ihrem Aufhören die Öffnung und Schließung der Blätter nicht in ihrem Turnus (6- oder 24stündig) erfolgt, sondern in einem anderen, nämlich dem 12 stündigenTurnus, dem das betreffende Individuum niemals ansgesetzt worden ist, wohl aber seine Vorfahren durch viele Generationen hindurch, und der mithin als ererbt anzusehen ist.

Das Gebiet derjenigen mnemischen Periodizität, deren engraphische Faktoren ohne weiteres erkennbar sind, ist mit den eben gegebenen Beispielen natürlich nicht erschöpft. Eine Tagesperiode unzweifelhaft mnemischen Charakters ist z. B. von Gamble und Keeble ${ }^{1}$ bei Crustaceen nachgewiesen und bei einer Garneele, Hippolyte varians, genau untersucht worden. Gewisse Beobachtungen derselben Forscher ${ }^{2}$ an

1 P. W. Gamble and F. W. Keeble, Hippolyte varians. Quarterly Journ. Microscop. Science, N. S. Vol. 43, 1900.

${ }^{2}$ P. W. Gamble and F. W. Keeble. Philosoph. Transact. Roy-Soc. London (B) Vol. 196, 1904. 
Palaemon squilla sprechen daftir, daß bei den Crustaceen auch bereits eine erbliche Fixierung dieser Periodizität stattgefunden hat. Noch bei vielen anderen Tieren ließ sich eine mnemische Tagesperiodizität feststellen, das heißt eine Periodizität, die auch nach Ausschaltung des periodischen Beleuchtungswechsels andauert; wieweit dieselbe aber bereits erblichen Charakter angenommen hat, ist in den betreffenden Fällen bisher noch nicht festgestellt worden. Ich hebe hier besonders bervor die Beobachtungen ron Bohn ${ }^{\mathrm{C}}$ an Actinien, Würmern and Mollusken und die kurzlich erschienene eingehende Untersuchung von Schleip ${ }^{2}$ an einer Gespenstheuschrecke, Dixippus morosus, wo man auch ausführliche Literaturangaben findet.

Das Gebiet der Tagesperiodizität ist nur ein kleiner Ausschnitt der mnemischen Periodizität überhaupt. So zeigte z. B. Bohn, daß der Wechsel von Ebbe und Flut bei strandbewohnenden Meerestieren (Actinien, Strudelwlirmern, Ringelwlirmern, Schnecken) Periodizitäten von 6stündigem Turnus schafft. Sehr viele hierher gehörige Beobachtungen ließen sich noch anreihen. Ich muß es mir aber für eine andere Gelegenheit versparen, das Problem der engraphischen beziehungsweise erblich engraphischen Fixierung von periodischer Reizwirkung in umfassender Weise zu behandeln.

Bei den Auseinandersetzungen des vorigen Kapitels haben wir unter den ekphorischen Einflissen noch die phasogene Ekphorie (S. 62) kennen gelernt. Wir bezeichneten damit die Erscheinung, daß mit Erreichung einer bestimmten

1 G. Bohn, Ball. Institut gén. psycholog. 3, 1903; 7, 1907; vgl. ferner desselben Autors > Entstehung des Denkvermögens <. Leipzig 1910.

2 W. Schleip, Der Farbenwechsel bei Dixippus morosus. Zool. Jahrb., Abt. f. allg. Zool. u. Physiol., 30. Bd., 1. Heft, 1910. 
Entwicklungsphase ein Züstand der erregbaren Substauz geschaffen ist, der auf ein bestimmtes Engramm ekphorisch wirkt. Ererbte Dispositionen, die durch phasogene Ekphorie manifest werden, finden sich in jedem Organismus des Protisten-, Pflanzen- und Tierreichs in außerordentlich großer Anzahl. So erfolgt, um ein beliebiges Beispiel heranszagreifen, nach Selenka die Furchung eines Echinodermeneies, des Eies von Synapta digitata, in 9 Phasen, indem sich neunmal hintereinander alle jeweilig vorhandenen Zellen äqual teilen. Ist anf diese Weise ein Stadium von 512-Zellen erreicht, so erfclgt regelmäßig ein Vorgang, der als Gastrulation bezeichnet wird. Derselbe besteht darin, daß an einem Eipol eine rasche Zellvermehrung durch Teilung anhebt, und dieser Teil sich in die Furchangshöhle einstulpt. Gleichzeitig entwickeln sämtliche Zellen auf ihrer Außenseite Wimpern und der Organismus beginnt innerhalb der Eihant zu rotieren. Wir können also sagen, die Erreichnng des 512Zellen-Stadiums oder die energetische Situation des 512-ZellenStadiums bei Synapta wirkt ekphorisch anf eine ererbte Disposition, die fur uns durch eine Anzah! plastischer Reaktionen (Gastrulation, Ausbildung von Wimpern) und motorischer Reaktionen (Wimperbewegung) manifest wird.

Wir müssen uns jedoch von vornherein bewußt sein, daß der Ausdruck phasogene Ekphorie einen Begriff bezeichnet, der in jedem einzelnen Falle einer genæueren Analyse zugänglich ist. Unter einer bestimmten Entwicklungspùase einez Organismus verstehen wir seinen morphologisehen und physiologischen Gesamtzristand in dem gegebenen Augenblicke. Die Entwickiung der Organismen verläuft nun zwar bei Angehörigen derselben Art mit einer grewissen Regelmäßigkeit, keineswegs aber in absolut identischer Weise. Die ent- 
sprechenden Phasen oder Stadien oder Gesamtzustände sind daher selbst bei Zwillingen zwar ähnlich, aber nicht identisch, und wir werden es deshalb immer unmöglich finden, eine Gesamtphase uber den einzelnen konkreten Fall hinans in absolut gemeingültiger Weise $z \mathbf{z}$ definieren. Indessen ergibt sich daraus für unsere Auffassung der phasogenen Ekphorie keine ernstere Schwierigkeit. Für jede Ekphorie ist es ja gerade charakteristisch, daß die partielle Wiederkehr einer bestimmten energetischen Situation gentigt, um das Engramm aus seinem latenten Zustand zu erwecken. Jedem Eintritt in eine neue Entwicklungsphase entspricht nun naturlich physikalisch die Wirksamkeit einer neuen (inneren) energetischen Situation, und leichte Veränderungen der Phase werden in der uberwiegenden Mehrzahl der Fälle für die ekphorische Wirkung ohne Bedeutung sein, da ja die partielle Wiederkehr der energetischen Situation ausreicht.

Freilich werden wir uns mit dieser allgemeinen Feststellung nicht begnuigen. Innerhalb der großen Symphonie von Einzelkomponenten, die eine jede organische Entwicklung darstellt, gibt es anßer der allgemeinen Abhängigkeit jeder folgenden Gesamtphase von ihrer Vorgängerin, noch zahllose speziellere innerbalb der einzelnen sich entwickeinden Organsysteme.

Es sei mir hier ein Vergleich gestattet. Bei der Reprodaktion eines mehrstimmigen Musikwerks schreitet zwar das Ganze von Phase zu Phase fort, und jeder neue Takt des Ganzen wächst sozusagen aus seinem Vorgänger heraus und gibt ablaufend den AnstoB zam Auftreten seines Nachfolgers. Daneben bestehen aber ebensoviele speziellere Abhängigkeiten innerhalb der einzelnen Stimmen als es solche Stimmen gibt. Jede dieser Stimmen steht in Abhängigkeit vom 
Ganzen, schreitet aber auch wieder in einer gewissen Selbständigkeit in ihrer eigenen Sukzession fort, und einem nicht sehr musikalischen Klavierspieler kann es begegnen, daB, wenn er z. B. mit der rechten Hand einen anderen Rhythmus zu spielen hat, z. B. Triolen, als mit der linken, die beispielsweise Vierundsechzigstel-Passagen zu spielen hat, die erstere mit einem Takt etwas fruher fertig wird als die letztere. Freilich pflegen sich unter solchen Umständen die beiden anf eigener Spur wandelnden Stimmen immer bald wieder zusammenzufinden, besonders bei Eintritt einer neuen Phase, das heißt hier eines neuen Takts.

Ganz ähnlich gibt es in der wundervollen Symphonie einer organischen Entwicklung außer der allgemeinen Abhängigkeit der sukzedierenden Simultankomplexe noch zahllose speziellere, die doch wiederum dem Ganzen untergeordnet sind. Auch hier kann es zu leichten Schwankungen im Znsammenspiel der Einzelablänfe kommen, die ihren Ausdruck in dem finden, was man in der Embryologie als Heterochronie zu bezeichnen pflegt. Gewöhnlich zwingt aber auch hier bald die gemeinsame Assoziation aller einzelnen Komponenten innerhalb der Simultankomplexe die einzelnen Spezialabläufe in den allgemeinen Takt zurlick ${ }^{1}$. Wir werden unten im zweiten Teil (S. 126) noch Gelegenheit haben, auf die innigere und weniger innige Beziehnng der einzelnen Komponenten von aufeinander folgenden Simultankomplexen näher einzugehen.

1 Von diesen Gesichtspunkten aus ergibt sich von selbst ein tieferer Einblick in das Wesen desjenigen, was man in der entwicklungsphysiologischen Forschung nach Roux als Selbstdifferenzierung und abhängige Differenzierung zu bezeichnen pflegt. Da jedem mit diesen Begriffen Vertrauten dies ohne weiteres klar sein wird, darf ich hier wohl auf eine ausführlichere Darlegung verzichten. 
Von dem eben entwickelten Standpunkt aus ist es daher gerechtfertigt und notwendig, innerhalb der Gesamtphasen nach Einzelmomenten zu forschen, an deren Auftreten die spezielleren Ekphorien gekntipft sind, oder die besonders stark in dieser Richtung wirken. So sprachen wir oben von der Gastrulation eines bestimmten Echinodermeneies und kamen zu dem Resultat, daß bei demselben diese Reaktion durch die Erreichnng des 512-Zellen-Stadiums ausgelöst würde. Ist es hier nun möglich, innerhalb des Gesamtzustandes der Phase Einzelmomente anfzufinden, an deren Auftreten diese Ekphorie geknüpft ist? Die Beobachtungen und Schlüsse einer ganzen Reihe von Forschern, unter denen ich vor allen Th. H.Morgan, Driesch und Boveri nenne 1 , geben uns hierfür einen Fingerzeig. Es ergab sich, daß wenn man statt vollständiger unversehrter Echinodermeneier Fragmente solcher oder auch isolierte Blastomeren sich furchen ließ, die Gastrulation eintrat, nicht nachdem die für das normale Ei charakteristische $\mathrm{Zahl}$ von Zellen erreicht war, also nicht schlechthin nach der so urd so vielten Teilungsphase, sondern nachdem die Zellen durch fortgesetzte Teilungen bis anf ein gewisses $\mathrm{MaB}$ verkleinert waren. Das eigentlich ekphorierende Moment war also hier nicht lediglich die Absolvierung einer gewissen Zahl von Zellteilungen oder die davon abhängige Erreichung einer bestimmten Gesamtzahl von Zellen, sondern in erster Linie die Erreichung einer bestimmten Kleinheit der Einzelzellen bei der Teilnng, das Eintreten eines bestimmten wenn auch innerhalb gewisser

1 Über diese Frage existiert eine ganze Literatur. Ich greife nur heraus Th. H. Morgans erste Arbeit, Studies of the Partial Larvae of Sphaerechinus. Archiv f. Entw.-Mech., Bd. 2, 1896; ferner H. Driesch, Neue Antworten und neue Fragen der Entwicklungsphysiologie. Ergebn. d. Anat. u. Entw.-Gesch., Bd. 11, 1902 und Th. Boveri, Zellenstadien, Heft 5, Jena 1905. 
Engraphische Wirkung der Reize auf die Deszendenz.

Grenzen beweglichen Verhältnisses zwischen Chrowininmenge und Protoplasmamenge (Kernplasmarelation) innerhalb der Einzelzellen.

Noch ein Fall, in dem wir die wichtigste Komponente einer speziellen phasogenen Ekphorie genauer bestimmen können. Wenn ein Wirbeltierembryo eine gewisse Entwicklungsstufe erreicht hat, so erfolgt die Bildung der Linse. Nun haben aber Herbst ${ }^{1}$ und Spemann ${ }^{2}$ unabhängig roneinander dargelegt, da $B$ nicht der Eintritt in diesen oder jenen Gesamtzustand, sondern vor allen Dingen der Reiz, der auf das Ektoderm durch die sich an dasselbe anlegenden Augenblasen (und zwar die Retinalschicht derselben) ausgettbt wird, die Wachstumsreaktion der Linsenbildung auslöst. Spemann konnte beim Grasfrosch, Rana fusca, experimentell nachweisen, daß, wenn der Augenbecher die Haut nicht erreicnt, überhaupt keine Linsenbildung erfolgt. Auch bleibt die Hant dunkel pigmentiert und hellt sich nicht zum Cornealepithel auf. Sowie aber der Augenbecher die Epidermis berïhrt, beginnt an der Bertihrungsstelle die Wucherung der Linse.

Es könnte unter diesen Umständen wohl gerechtfertigt erscheinen, in diesem Falle den Begriff der phasogenen Ekphorie auf das stärkste einzuengen nnd die Ekphorie auf eine einzige Komponente zu beschränken, auf den Berührungsreiz, den der Augenbecher in entsprechenden Stadien anf die Epidermis ausubt. Es hat sich aber in der Folgezeit herausgestellt, daß es Fälle gibt, in denen die Linsenbildung beim Eintritt in die Gesamtphase erfolgt, selbst wenn

${ }^{1} \mathrm{C}$. Herbst, Formative Reize in der tierischen Ontogenese. Leipzig 1901, S. 59.

2 H. Spemann, Sitzungsber. d. Phys-med. Ges. Würzburg 1901. S. ferner Anat. Anz., Bd. 23, 1903, Zool. Anz., Bd. 28, 1905. 
bei dieser Wiederkehr der inneren energetischen Situation die Hauptkomponente, der Berührungsreiz, den der Augenbecher auf die Epidermis ausubt, fehit. Mencl ${ }^{1}$ fand, daß beim Lachsembryo Linsenbildung bei vollkommener Abwesenheit des Augenbechers erfolgen kann. Spemann ${ }^{2}$ selbst ermittelte, daß während beim Grasfrosch (Rana fusca), bei der Unke (Bombinator igneus) und wobl auch bei Triton taeniatus der Berührungsreiz unerläßlich zu sein scheint, beim Wasserfrosch (Rana esculenta) die Linsenbildung regelmäßig auch ohne diese Berlihrung erfolgt, sobald die betreffende Gesamtphase erreicht ist. Die amerikanische Rana palustris scheint sich nach den Versuchsergebnissen von King ${ }^{3}$ nahe an Rana esculenta anzuschließen.

Wir können also in bezug auf diese Frage zusammens fassend sagen: Es giebt eine Komponente der betreffenden Entwicklungsphase, die eine besonders kräftige ekphorische Wirkung auf den Engrammkomplex besitzt, dessen Ekphorie sich durch die Reaktionen der Linsenbildung manifestiert. Es ist dies der durch die Berthrung des Augenbechers mit der Epidermis bedingte Reiz. Wie zuerst Lewis ${ }^{4}$ bei Rana silvatica gezeigt hat, vermag dieser Berthrungsreiz, den die Augenblase auf die Haut auslibt, auch an anderen Stellen der Epidermis als den bei normaler Entwicklung dafür prädestinierten eine Linsenbildung zu ekphorieren. Spemann bezeichnet es auf Grund seiner Nachprufung an Bombinator als wahrscheinlich, daß bei diesem Organismus zwar nicht

1 E. Mencl, Archiv f. Entw.-Mech., Bd. 16, 1903; Bd. 25, 1908.

2 H. Spemann, Zool. Anz., Bd. 31, 1907; Verhandl. d. deutsch. Zool. Gesellschaft in Rostock and Lübeck 1907; Verhdlg. d. Zool. Ges. in Stattgart 1908.

3 H. D. King, Archiv f. Entw.-Mech., Bd. 19, 1905.

4 W. H. Lewis. Amer. Journ. Anat., Vol. 3, 1904 und Vol. 7, 1907. 
die Haut des Bauchs oder Rumpfs, wohl aber die des Kopfs hinter dem Auge befähigt ist, unter dem Einfluß des Augenbechers eine Linse zn bilden. Im Vergleich za der ekphorischen Wirksamkeit dieses Reizes treten die anderen Komponenten der energetischen Situation jener Phase in ihrer ekphorischen Wirksamkeit auf diesen Engrammkomplex zwar sehr zurtick, ganz wirkungslos sind sie aber in der Regel nicht, wie die anderen Fälie (Rana esculenta, R. palustris) beweisen, in denen sie bei Ausschaltung jenes Beruhrungsreizes zur Ekphorie gentigen. Bei unserer Auffassung des Vorgangs als einer phasogenen Ekphorie, veracbwindet also die scheinbare Regellosigkeit und das Widerspruchsvolle, das ihm sonst anhaften wirde. Grade diese neuen, erst seit Erscheinen der ersten Auflage der Mneme bekannt gewordenen Tatsachen lehren auf das deutlichste, daß ein Verständnis dieser Vorgänge sich nur im Lichte einer Ekphorie gewinnen läßt.

Als wichtiges Resultat ergibt sich aus unseren bisherigen Betrachtungen folgendes: wir finden an der reizbaren Substanz der Protisten, Pflanzen und Tiere Eigenschaften, \Erregungsdispositionen «, die, wie die letztgenannte Bezeichnung schon andeutet, dadurch charakterisiert sind, daß sie für gewöhnlich latent sind. Durch bestimmte Einflusse werden sie ganz ebenso wie die individuell erworbenen Engramme aus diesem Latenzstadinm aktiviert, um uber kurz oder lang wieder latent zu werden. Jede Wiederkehr des ekphorischen Einflusses bewirkt den Wiedereintritt des betreffenden Erregungszustandes, der fur uns durch die zugehörige Reaktion manifest wird.

Was endlich drittens einen Ausschlag für die Auffassang gibt, daß wir in ihnen ererbte Engramme zu erblicken 
haben, ist die Natur der sie aktivierenden Einflïsse. Dieselben tragen, wie wir soeben kurz dargelegt haben, den deutlichen Charakter der Ekphorie, und zwar teils der unmittelbaren, teils der assoziativen, chronogenen oder phasogenen Ekphorie.

Als Schlußergebnis können wir aufstellen, daß die in Frage stebenden ererbten Erregungsdispositionen sich in jeder Beziehung verhalten wie Engramme. Als fernere Übcreinstimmung ließe sich noch anführen, daß sie nicht etwa etwas unveränderlich Gegebenes, sondern wie jene durch Reize ebenfalls engraphisch veränderbar sind.

Problematisch als Engramme sind sie also nur ibrer Herkunft, nicht ihrem Wesen nach.

Wir sehen uns jetzt noch vor die Frage gestellt, das Vorkommen derjenigen ererbten Erregungsdispositionen, die unserer Ansicht nach als Engramme aufzufassen sind, schärfer zu umgrenzen und ihre Unterscheidungsmerkmale gegenüber anderen ererbten Dispositionen, die nicht als Engramme anzusehen wären, zu bestimmen. Es liegt nahe genug, diese Unterscheidungsmerkmale da zu suchen, wo das für die Engrammnatur Charakteristische der ererbten Engramme überhaupt liegt, also: erstens im Besitz eines Latenzstadiums; zweitens in dem Umstand, daß jede Wiederkehr des auslösenden Einflusses den Wiedereint itt des betreffenden Erregungszustandes bewirkt; drittens in den Eigentümlichkeiten der auslösenden Einflüsse, die dieselben als ekphorische kennzeichnen; endlich in der Möglichkeit, die Funktion der ererbten Dispositionen durch neu hinzugefugte engraphische Einflüsse zu verändern.

Je nach dem Besitz oder Nichtbesitz dieser Merkmale könnten wir die ererbten Erregungsdispositionen als ererbte 
Engramme auffassen oder ihnen den Engrammcharakter absprechen.

Was das erste Merkmal, den Besitz oder Nichtbesitz eines Latenzstadiums anlangt, so ist dasselbe als Unierscheidungsmerkmal deshalb nicht $z u$ gebranchen, weil wir die sämtlichen hier zu betrachtenden Eigenschaften der organischen Substanz als Dispositionen oder Prädispositionen bezeichnet haben. In dieser Bezeichnung ist bereits die Eigentiumlichkeit ausgedrickt, daß es sich in dieser ganzen Frage überhaupt aur um Vermögen handelt, die für gewöhnlich latent sind.

Als zweites Charakteristikum warde angegeben, daß jede Wiederkehr des auslösenden Einflusses den Wiedereintritt des betreffenden Erregungszustandes bewirke. Gibt es nun ererbte Dispositionen, bei denen dies nicht der Fall ist? Es wäre sehr wohl denkbar, dal die Disposition nach einmaliger oder einige Male wiederholter Auslösung allmählich verschwände. Dispositionen der organischen reizbaren Substanz, die sich allein durch wiederholten Eintritt in den zugehörigen Erregangszustand erschöpften, ohne daß sonstige Zustandsänderungen - z. B. Eintritt in ein ganz anderes Entwicklungstadium - erfolgt wären, sind mir jedoch nicht bekannt.

Es kann ja bei rascher Wiederholung und langer Dauer der Erregung eine Art Ermüdungszastand eintreten, der zur Abschwächung der Erregung und der durch sie verursachten Reaktionen flihrt. Läßt man aber dem Organismus gentugend Zeit zur Erholung, so tritt, wenigstens solange er sich im jugendkräftigen Zustande befindet, keine Erschöpfung, meist sogar umgekehrt eine Zunahme der Disposition ein. Manche Dispositionen werden im individuellen Leben des Organismus 
nur einmal aktiviert, ich erinnere an das Durchlaufen der verschiedenen Entwicklungsphasen bei der Ontogenese oder an verschiedene Instinkte, die normalerweise nur einmal im individuellen Leben manifest werden. $\mathrm{Da}$ aber auch in diesen Fällen keine Erschöpfung der Disposition eintritt, sondern nur ein Aufhören der Konstellation, die auf diese Disposition ekphorisch wirkt, wird dadurch bewiesen, daß, wenn ich künstlich einen Organismus anf einen frtiheren, bereits durchlaufenen Zustand zurückwerfe, die bereits einmal aktivierte Disposition wiederum aktiviert wird. Ich brauche nur an die zahllosen Fälle von Regeneration bei Embryonen und ausgebildeten Tieren hinzuweisen, um zu zeigen, daß die Disposition, auch wenn sie normalerweise nur einmal im individuellen Leben aktiviert wird, deshalb noch keineswegs als erloschen anzusehen ist. Dasselbe ist der Fall mit Erregungsdispositionen, deren zugehörige Reaktionen in der motorischen oder sekretorischen Sphäre liegen. So wurde schon oben (S. 90) mitgeteilt, wie man Raupen, die normalerweise nur einmal in ihrem Leben ein Gespinst machen, veranlassen kann, Teile oder das ganze mehrmals zu spinnen.

Es kommt also allen ererbten Dispositionen der Besitz eines Latenzstadiums sowie die Eigentülichkeit zu, durch Inanspruchnahme nicht abgeschwächt und allmählich aufgebraucht, sondern viel eher gefestigt zu werden.

Vielleicht haben wir mit dem dritten Merkmal mehr Gluck und können ererbte Dispositionen herausfinden, die sich auf Grund ihrer Aktivierung durch ekphorische Einflusse von solchen unterscheiden, bei deren Aktivierung von einer Ekphorie nicht geredet werden kann.

Eine exakte Beantwortang dieser Frage ist nicht möglich, denn mit Sicherheit läßt sich ein auslösender Einfluß nur 
dann als ein ekphorischer bezeichnen, wenn wir den engraphischen Reiz kennen, und demnach durch Vergleichung imstande sind, den ekphorischen Einfluß von ihm zu unterscheiden. Der Kern aller uns gegenwärtig beschäftigenden Schwierigkeiten liegt aber darin, da $B$ uns die engraphischen Reize bei der großen Mehrzahl der ererbten Dispositionen unbekannt sind, und wir deshalb, besonders wo es sich um unmittelbare Aktivierungen handelt, nur in besonders gtinstigen Fällen imstande sind, den ekphorischen Charakter einer solchen A'stivierung wahrscheinlich zu machen. Ich erinnere z. B. an das elaborierte Vogelbad im Trockenen, das bei einer jungen Elster durch Beruhrung des Schnabels mit Wasser in Gang gesetzt wurde (S. 89). Andererseits aber sind wir nicht berechtigt, solche Fälle, bei denen der ekphorische Charakter des aktivierenden Moments weniger augenfällig ist, auszusondern und die Engrammnatur der betreffenden Reaktionen in Abrede zu stellen.

Unter den ererbten Dispositionen ist natürlich die Reizbarkeit an sich nicht mit zu verstehen. Denn sie ist die Voraussetzang des Erwerbs von Engrammen, die sich erst auf dieser Grundlage aufbauen können. Aber die spezifische Ausbildung dieser Reizbarkeit ist erfolgt durch die eine Grundeigenschaft derselben, sich engraphisch beeinflussen zu lassen. Die Reizbarkeit, wie sie uns heutzutage in dem einzelnen Organismus nach einer Geschichte von vielen Jahrmillionen vorliegt, ist mit unzähligen Engrammen durchsetzt und durch dieselben verändert.

Schon als wir im Anfange unserer Untersuchung den primären Indifferenzzustand definierten, sagten wir, da $B$ wir darunter einfach den Zustand des betreffenden Organismus bei Beginn unserer jeweiligen Beobachtangen und Versuche 
verstehen wollten. Selbst wenn wir als Objekt einen Organismus wählen, der sich soeben vom Mutterorganismus losgelöst hat, ist derselbe nur in bezug anf individuelle Mneme ein unbeschriebenes Blatt. Wenn wir einen solchen Organismus zum erstenmal einem Reiz unterwerfen und dessen Wirkung als eine einfache synchrone Reizwirkung bezeichnen, ist der Charakter dieses Reizes als Originalreiz nur ein relativer, kein absoluter. In der Mehrzahl der Fälle wird es sich auch bei dieser Versuchsanordnung zum Teil um Ekphorien ererbter Engramme handelu, oder werden solche Ekphorien sich der Wirkung auf die primäre, sozusagen präengraphische Reizbarkeit beimischen. Wir sind deshalb uberhaupt nicht imstande, bei irgendeiner Reizwirkung jeden ekphorischen $\mathrm{Zu}$ satz mit Sicherheit auszuschließen. Könnten wir frisch durch Urzeugung hergestellte organische Sabstanz untersuchen, dann, aber nur dann würden wir Reizwirkungen kennen lernen, die wir als rein synchrone bezeichnen dürten, bei denen sich jeder ekphorische Zusatz ansschließen ließe. An dieser Schwierigkeit muß notgedrungen auch der Versuch scheitern, auf Grund des ekphorischen oder nicht ekphorischen Charakters der aktivierenden Einflisse ererbte Dispositionen engraphischer Natur von eventuell vorhandenen nichtengraphischen zu unterscheiden.

Wir wenden uns endlich zar Prüfung des vierten noch zurtickbleibenden Merkmals: welche ererbten Dispositionen lassen sich durch neue hinzutretende Engramme beeinflussen, welche nicht? Die Möglichkeit, eine solche Disposition engraphisch zu beeinflussen, legt allerdings den Schluß nahe, in ihr ein ererbtes Engramm zu erblicken. Die Unmöglichkeit ist aber deshalb nicht für das Gegenteil beweisend, weil sie von der Unvollkommenheit unserer Experimente mitbedingt ist. Jede neue Versuchs- 
anordnung kann einen derartigen Schluß umsttirzen. Die Schwierigkeit, ererbte Dispositionen engraphisch zu beeinflussen, ist gradweise sehr verschieden.

Besonders diejenigen ererbten Dispositionen höherer Tiere, zu deren Ekphorie eine besondere Konstellation des Zentralnervensystems notwendig ist, sind leichter engraphisch zn beeinflussen, als weniger spezialisierte Dispositionen. Doch kenne ich keine Kategorie von ererbten Dispositionen, die sich jeder engraphischen Beeiuflussung tiberhaupt entzöge, ebensowenig eine Organismengruppe, die ausschließlich starre, unmodifizierbare ererbte Dispositionen besäße. Viele ererbte Dispositionen der Bakterien lassen sich sehr wohl engraphisch verändern, ja selbst eine erblich fortwirkende engraphische Beeinflussung ist bei ihnen verhältnismäßig leicht zu erzielen. Ebenso verhält es sich mit manchen ererbten Dispositionen, z. B. dem Heliotropismus anderer einzelliger Lebewesen, wie der Flagellaten, ebenso mit vielen Tropismen, periodischen Bewegungen, dem Vegetationstempo und anderen Dispositionen der Pflanzen.

$\mathrm{DaB}$ man endlich bisher nur eine immerhin beschränkte wenn auch schon recht stattliche Anzahl von ererbten Dispositionen so energisch zu beeinflussen vermocht hat, daß das hinzugekommene Engramm nicht nur im individuellen Leben des betreffenden Organismus in Kraft bleibt, sondern sich auch auf die Nachkommenschaft überträgt (ich erinnere an die S. $68-80$ mitgeteilten Fälle, liegt einerseits an der Unvollkommenheit und zu karzen Dauer unserer bisherigen Experimente, andererseits zum Teil wohl auch daran, daß die Keimzellen vieler, vielleicht aller Organismen, nur eine kurze > sensible Periode e besitzen, während welcher allein sie in ausgiebigerem Maße engraphisch zu beeinflussen sind. Deshalb 
trägt die erbliche engraphische Veränderbarkeit einen Charakter, den man von unserem kurzsichtigen menschlichen Standpunkt aus fast als einen launenhaften bezeichnen könnte 1 .

Es erscheint mir nach alledem unmöglich, die ererbten Dispositionen in zwei Kategorien zu teilen: solche, die als Engramme aufzufassen sind, und solche, die nicht. Wenn wir demnach jede spezifisch ausgebildete Form der Reizbarkeit als engraphisch kompliziert ansehen, haben wir Rede zu stehen anf die Frage: Wie weit kommen wir mit dieser Auffassung, d. h. läßt sie sich in konkreten Fällen folgerichtig durchfuhhren? Ist mit ihr etwas für unser Verständnis, für ein - vollständiges und auf die einfachste Weise Beschreiben * im Kirchhoffschen Sinne erreicht? Wenn sich der Nachweis fuhren läßt, daß keine Tatsachen unserer Auffassung der ererbten Dispositionen als Engramme widersprechen, und daß durch eine solche Annahme neues Licht auf diese Seite organischen Geschehens fällt, so ist damit dem Wahrscheinlichkeitsbeweis, in dessen Führung wir stehen, ein neues wichtiges Glied hinzugefügt.

Dieser Aufgabe werden wir uns im dritten Teil des vorliegenden Werkes unterziehen, in dem die Wirksamkeit mnemischer Prozesse bei der Ontogenese untersucht und gezeigt werden soll, wie gerade die rätselhaftesten Erscheinungen des normalen and des durch Eingriffe modifizierten ontogenetischen Geschehens ebenso wie die Regenerationserscheinungen unserem Verständnis näher gertickt werden, wenn wir sie als eine Funktion der Mneme aufassen.

Ehe wir uns aber dieser Aufgabe zuwenden, wollen wir in einem vorangestellten zweiten Teil die Grundlage, auf der

1 Vgl. Stand der Frage S. $61,75-78$. 
wir bauen, vertiefen und ansdehnen, indem wir die mnemischen Grundphänomene einer systematischen Durcharbeitung unterwerfen.

Nachschrift zu diesem Kapitel bei Gelegenheit der dritten Auflage.

Seit dem Erscheinen der ersten Auflage (1904) hat sich das empirische Material außerordentlich vermehrt, auf Grund dessen sich der Wahrscheinlichkeitsbeweis für den engraphischen Ursprung der historisch gegebenen Dispositionen fuhren läßt. Es hat sich aus den neuen Versuchen von Blaringhem, Klebs, Bordage, Kammerer, Pictet, Tower, Przibram, Sumner, um nur die hauptsächlichsten za nennen, in voller Übereinstimmung mit den älteren, wie denen von Schubeler, Chauvin, Standfuß, Fischer, Schröder usw. aufs deutlichste ergeben, daß sich bei geeigneter Versuchsanordnung sowohl eine Neuschaffung von Dispositionen aller Art, als auch - was sich davon kaum scharf trennen läßt - eine Veränderung in der Manifestationsweise der bereits vorhandenen unschwer erzielen läßt, und daß diese neuen Erwerbungen der Organismen sich ausnahmslos als Produkte einer wie immer zustande gekommenen Reizwirkung oder Induktion darstellen. Sie sind also als Engramme aufufassen, and sie erweisen sich, wenn unter Umständen zustande gekommen, in deren Gesetzmäßigkeit wir ebenfalls bereits einen Einblick zu erhalten beginnen (z. B. während der sensiblen Periode der Keimzellen) als erblich. Auch darin verhalten sie sich wie die historisch gegebenen Dispositionen, daß sie, wie die Kreuzungsversuche Towers und Kammerers lehren, unter Umständen alternativ vererbt werden, daß sie den Mendelschen Spaltungsregeln folgen. Anf Grund aller dieser zahlreichen Übereinstimmungen, denen keine einzige 
Nichtubereinstimmang gegentibersteht, er eheint der Schluß durchans gerechtfertigt, $\mathrm{daB}$ auch die historisch ge sebenen Dispositionen auf engraphischem Wege entstanden sind. Auf einer Engrammlehre haben wir unter allen Umständen zu faßen ${ }^{1}$. Es wird unsere Aufgabe sein, in den folgenden $\mathrm{Ab}$ schnitten des vorliegenden Werkes zn zeigen, was mit dem Ausbau dieser Lehre fur unser allgemeines Verständnis des organischen Geschehens gewonnen ist.

1 Vgl. über alles dies besonders die Ausführungen in Stand der Frage, S. 70-73. 


\section{Zweiter Teil}

\section{Systematische Darstellung der mnemischen Grundphänomene}





\section{Viertes Kapitel.}

Die gegenseitigen Beziehnngen der Engramme; simultane und sukzessive Assoziation.

In einflihrenden Teil haben wir die Entstehung der Engramme und die verschiedenen Phasen ihres Daseins kennen gelernt. Wir gelangten auf Grund unserer analytischen Betrachtungen zu folgender Definition: Das Resultat der engraphischen Wirkung (das Engramm) besteht in einer veränderten Disposition der reizbaren Substanz in bezug auf die Wiederholung des seinerzeit durch den Originalreiz ausgelösten Erregungszustandes. Die organische Substanz zeigt sich alsdann gegen fruher in einer eigentiimlichen und durchaus gesetzmäßigen Weise dafür prädisponiert, sowohl durch den Originalreiz als auch durch anderweitige Einflitsse, die im Grunde immer auf einer partiellen Wiederkehr einer bestimmten energetischen Situation beruhen, wieder in jenen Erregungszustand versetzt zu werden. "

Indem wir diese Definition auch fernerhin zugrunde legen, haben wir zunäcbst die Begrenzung der in demselben Orga nismus entstehenden und aufbewahrten Engramme untereinander einer schärferen Prüfung zu unterziehen. Wie wir schon oben sahen, wird der Organismus nur ganz ausnahmsweise von einem wirklich einfachen Reiz, etwa einem einzigen Lichtstrahl von bestimmter Wellenlänge getroffen und beein- 
flußt. Fast immer ist der Reiz, auch wenn er nur einer Reizkategorie, z. B. den photischen Reizen, angehört, zusammengesetzter, meist sehr zusammengesetzter Natur; man braucht nur an die verschiedenen Komponenten der meisten Gesichtseindrücke, der meisten Klänge zu denken, die auf die Organismen einwirken, um das zu erkennen. Sehen wir eine Landschaft, beruhren wir mit dem Finger einen Körper, so wird in beiden Fällen unser Organismus gleichzeitig von einer größeren Anzahl von Reizen erregt, die aber nicht jedesmal zu etwas Homogenem zusammengeschmolzen werden, sondern sich zu einem Nebeneinander ${ }^{1}$ ordnen. So empfinden wir das Nebeneinander der photischen Reize, die unsere Retina treffen, als das Nebeneinander, das wir als Bild bezeichnen, das Nebeneinander von polyphonen akustischen Reizen als das Nebeneinander des harmonischen oder disharmonischen Akkordes. Eine Erklärung dieser Tatsache versuchen wir nicht, sondern uehmen sie als gegeben hin. Entsprechend dieser koordinierten Aufnahme der im gleichen Moment wirkenden Reize von seiten des Organismus, die wir als koordinierten synchronen Reizungseffekt bezeichnen können, ist auch der engraphische Reizungseffekt ein koordinierter, d. h. bei einer späteren Ekphorie des betreffenden Zustandes durch irgendeinen ekphorischen Einflaß tritt ein Erregungszustand ein, der dem koordinierten Reizungazustand der ehemals in einem gewissen Moment synchron nebeneinander wirkenden Reize entspricht.

Diese Erkenntnis, die zunächst nur die Umschreibung der gemeinplätzlichen Tatsache ist, daß das Nebeneinander der

1 In den Mnemischen Empfindungen S. 33-81 habe ich inzwischen das Nebeneinander der Empfindungen in eingehender Weise behandelt. 
Beziehungen der Engramme; simultane u. sukzessive Assoziation. 117

Reize vom Organismus als ein Nebeneinander aufgenommen und ebenso mnemisch reproduziert wird, eröffnet uns in ihren weiteren Konsequenzen überraschende Einblicke in den tieferen Zusammenhang verschiedener, von uns bisher auf analytischem Wege gewonnener Tatsachen.

Schon bei dem Einwirken eines komplexen Reizes einer bestimmten Reizqualität findet bei der Aufnahme ein Nebeneinander, kein diffuses Zusammenfließen statt.

Ein koordinierter synchroner Reizungseffekt kommt nun aber nicht nur bei der gleichzeitigen Einwirkung von verschiedenen Reizen derselben Reizkategorie, sondern auch von Reizen verschiedener Kategorien 'zustande.

Wenn ein Eisenbahnzug an uns vorïbersaust, baben wir ein absolut deutlich ausgesprochenes Nebeneinander von optischen und akustischen Eindrücken, und wir sind imstande, dieses Nebeneinander nach Aufhören der Reize selbst als ein ebensolches Nebeneinander auch mnemisch zu reproduzieren, wenn die letzteren nur hinreichend stark gewesen sind, um engraphisch zu wirken.

$\mathrm{Da}$ bei der Aufnahme von Reizen, die verschiedenen Reizkategorien angehören, seitens des Organismus verschiedene Rezeptionsorgane (z. B. Sinnesorgane) in Tätigkeit treten, ist für die uns hier beschäftigenden Fragen vollkommen gleichguiltig. Das koordinierte Sehen ist ja auch durch die Erregung zahlreicher besonderer Rezeptionselemente (in diesem Falle Stäbchen und Zapfen) bedingt, ebenso wie das koordinierte Tasten, Hören usw. Was uns hier interessiert, ist die Tatsache, daß der Organismus als Ganzes verschiedene Reize gleichzeitig nebeneinander aufzunehmen vermag und immer aufnimmt, deren Wirkung sich dabeizu etwas Kontinuierlichem verbindet, ohne sich zu etwasHomogenemzu vermischen. 
Es besteht also in jedem gegebenen Augenblick im Individuum ein festrerbundenes koordiniertes Totale von Erregungszustäuden, die sich für das eigene Ich durch die Bewußtseinstatsache des Nebeneinander der Empfindungen sowie durch zahlreiche objektiv wahrnehmbare Reaktionen, die sich uns an fremden Organismen aber nur durch die letzteren manifestieren. Dieses Totale wollen wir als den simultanen Erregungskomplex bezeichneu. Ans dem zusammenhängenden Ganzen des simultanen Erregungskomplexes können wir nun allerdiugs die Wirkung eines einzelnen Reizes oder einer Reizkategorie begrifflich herausschälen und uns damit die Übersicht uber dieses wogende Meer von gleichzeitigen Erregungszuständen erleichtern. Wir mlissen uns aber bewußt sein, daß wir damit den eigentlichen Beobachtungstatsachen Zwang antun und den Zusammenhang eines Ganzen willkuirlich lösen.

Dasselbe ist der Fall, wenn wir nicht die synchrone, sondern die engraphische Wirkung der im gegebenen Augenblick wirkenden Reize ins Auge fassend von einem Engramm reden. Nicht ein einzelner Reiz hat außer synchroner auch engraphische Wirkung, sondern der simultane Erregungskomplex als solcher zeigt sich nach Ablauf der synchronen Reizwirkungen in seiner Totalität engraphisch fixiert, er hinterläßt einen simultanen Engrammkomplex.

Wenn wir aus diesem letzteren das Produkt eines speziellen Originalreizes als »Engramm * herauslösen, um uns die Übersicht zu erleichtern, so mlissen wir uns doch klar darüber bleiben, daß wir dabei zu unserer Bequemlichkeit da eine rein begriffliche Trennung vornehmen, wo der $\mathrm{Zu}$ sammenhang, nicht aber eine Trennung das durch die Tatsachen Gegebene ist. Ein Verkennen dieser begrifflichen 
Wiilkur hat dann folgendes sonderbare Ergebnis. Weitere Tatsachen lehren uns den Zusammenhang aller im gleichen Augenblick erzeugten Engramme, bzw. der durch Ekphorie dieser Engramme entstandenen mnemischen Erregungen, diè, wenn sie sich in Emptindungen nanifestieren, wie schon erwähnt, bei Menscheri und höheren Tieren bisher gewöhnlich als $\triangleright$ Erinnerungsbilder bezeichnet worden sind. Diesen Zusammenhang bezeichnen wir dann als Assoziation, sehen in ihm etwas höchst Merkwürdiges und bescnderer Erklärung Bedurftiges und verkennen ganz, daß diese Assoziation der Ergramine anf der fundamentalen Tatsache der koordinierten und sich zil etwas Kontinuierlichem verbindenden Erregungswirkung der simultanen Reize auf den Organismus beruht.

Folgerichtig milssen wir dagegen sagen: Der simultane Erregungskomplex wird engraphisch fixiert. Ihm entspricht dann ein Engrammkomplex, der als solcher ekphoriert wird und in diesem Zustande eine Reproduktion des simultanen Erregungskomplexes darstellt, der ehemals anf Grund originaler Reizwirkungen bestanden hat. Bei dieser Betrachtungsweise bedarf die Tatsache der simultanen Assoziation keinel besonderen Erklärnng. Sie liegt in der Natur der Sache. Als zu lösendes Problem bleibt dann also nicht die - Assoziation der Erinnerngsbilder*, sondern die viel tiefere Grundfrage, wie hei den aus verschiedenen Pforten einströmenden and in topographisch verschiedenen Teilen des Organismus kulminierenden simultanen Erregungen der simultane Erregungskomplex als ein geordnetes zusammenhängendes. Ganzes, also, soweit er sich in Empfindingen manifestiert, als ein geschlossenes Nebeneinander von Linpfindungen zustande kommt. Ausfuhrlicher babe ich dieses Problem im zweiten Kapitel der Mnemischen Empfindungen behandelt. 
Verweilen wir noch etwas länger bei dem simnltanen Erregungskomplex und der engraphischen Wirkung, die sein Vorhandensein auf den Organismus ausübt. Den simultanen Erregungshomplex können wir als das Produkt der Erregungex bezeichnen, welche aus der gesamten energetischen Situation resutieren. Unter energetischer Situation haben wir nicht nur die ron außen auf den Organismus wirkenden Einflüsse, sondern auch, wie oben (S. 8) auseinandergesetzt, seinen inneren energetischen Zustand im weitesten Sinne zu verstehen. Der letztere ist mindestens ebenso wichtig wie die von außen auf ihn wirkenden Energien, was ohne weiteres klar wird, wenn man z. B. den Organismus eines höheren Tieres im Schlafen und im Wachen unter dem Einfluß derselben Reize, also unter annähernd gleicher äußerer energetischer Situation beobachtet.

Aber auch im Wachen ist der innere energetische Zustand des Organismus za verschiedenen Zeiten oft so verschieden, daß die annähernd gleiche äußere energetische Situation in einem Moment einen ganz andern simultanen Erregungskomplex bewirkt als in einem anderen Moment. Diesem verschiedenen Erregungskomplex entspricht dann natürlich auch eine verschiedene engraphische Wirkung.

Da die mnemische Reproduktion eines simultanen Erregungskomplexes gewöhnlich schwächer ist, als er selbst als originaler Erregungskomplex es seinerzeit war, kann es uns nicht wundern, daß bei der Ekphorie des betreffenden Engrammkomplexes eine große Anzahl von Einzelkomponenten jenes Komplexes gar nicht manifest wird, $d$. h. sich durch keine Reaktionen erkennen läßt. So kommt das Resultat zustande, daß scheinbar von jedem Zeitmoment nur einige wenige Engramme aufbewahrt werden. Die meisten dieser Engramme 
Beziehungen der Engramme; simultane u. sukzessive Assoziation. 121

sind aber, wie gesagt, schon an sich nichts Einfaches, sondern Produkte höchst zusammengesetzter Erregungskomplexe, wie das in der Natur des Reizes jedes Landschaftsbildes, jedes charakteristischen Tones oder Geräusches begründet ist.

Deshalb, weil bei der mnemischen Reproduktion eines simultanen Erregung:skomplexes nur ein kleiner Bruchteil deutlich wieder in Erscheinung tritt, haben wir bei oberflächlicher Beobachtung der mnemischen Vorgänge bei uns selbst den Eindruck nicht einer Wiederholung einer ehemaligen geschlossenen energetischen Situation, sondern einzelner, scheinbar scharf umgrenzter Ausschnitte aus derselben. Wir stehen am Golf von Neapel, vor uns sehen wir Capri liegen, neben uns spielt ein Leiermann auf einem großen Pianoforteleierkasten, aus einer benachbarten Trattorie dringt ein eigentlimlicher Ölgeruch zu uns herüber, die Sonne brennt uns heiß auf den Rticken, und unsere Schuhe, in denen wir stundenlang herumgelanfen sind, dricken uns. Nach Jabren ekphoriert ein ähnlicher Ölgeruch wieder auf das lebhafteste das optische Engramm des damals gesehenen Capri. Wir beobachten an ans, daß wir uberhaupt jenen Geruch nie wieder wahrnehmen können, ohne gleichzeitig das damals geschante Bild vor Augen zu haben. Die übrige damalige Situation braucht aber nicht so kräftig engraphisch mitfixiert zu sein, um in manifester Weise gleichzeitig mit ekphoriert zu werden. Die Melodie des Leierkastens, der Sonnenbrand, der Druck der Schuhe werden weder durch den Ölgeruch noch durch den erneuten Anblick Capris ekphoriert und wirken; wenn sie selbst wieder als Originalreize auftreten, auch ihrerseits nicht ekphorisch auf jene beiden Engrammkomplexe. Dies ist aber keineswegs ein Beweis dafür, daß sie tuberhaupt nicht engraphisch gewirkt haben. Wenn uns in unserem 
Falle z. B. ein Freund an unsere damaligen, durch Hitze und enge Stiefel verursachten Leiden erinnert oder uns die $\mathrm{Me-}$ lodie des Leierkastens wiedier auf dem Klavier vorspielt, so entdecken wir, daß in vielen Fällen auch jene Teile der energetischen Situation engraphisch gewirkt haben, daß zu ihrer manifesten Ekphorie aber der Eintritt ganz besonderer Nachhilfen notwendig sein kann.

Dieser Fall ist auch eine gute Illustration fur die Tatsache, daB keineswegs immer der am deutlichsten bewuBt empfundene Reiz am ansgeprägtesten engraphisch wirkt. Der Druck der Stiefel war in seiner Art vielleicht viel hervortretender ais die eigentimlichen Geriiche der Ölkuiche; dennoch ist dieser Teil des Erregungskomplexes viel besser engraphisch fixiert als jener. Ich will nicht näher auf diese spezielleren Fragen eingehen und nur als allgemeine Regel hervorheben, daß beides, sowohl die Natur des Reizes als auch der momentane Zustand des Organismus von größter Bedeutung fiir den größeren oder geringeren engraphischen Effekt sind, und daß je nach den Umständen der Einfluß des einen oder des anderen Faktors uberwiegt. Oft finden wir in einem simultanen Engrammkomplex, den wir bewahrt haben, neben für uns bedeutsamen ganz banale, gleichgültige Eindricke mnemisch fixiert. Eine meiner frthesten Erinnsrungen ist das Bild eines Gartens in Kreuznach, in dem ich als etwa dreijähriges Kind von einer Wespe gestochen wurde. Noch heute könnte ich die Lage der Beete und die Verteilung der Rosenstämme und meine Stellung zu denselben im Moment, als ich gestochen wurde, aufzeichnen. Darwin ${ }^{1}$ berichtet in seiner Autobiographie, daß die Lösung

${ }_{1}$ Leben und Briefe von Charles Darwin. Bd. I, S. 75. Stuttgart 1887. 
Beziehungen der Engramme; simultane u. sukzessive Assoziation. 123

eines wichtigen Problems, die ihm den Schliussel zu vielem bisher Rätselhaften bot, ganz plötzlich bei einer Spazierfahrt gekommen sei, und macht dazu die Bemerkung: "Ich kann mich selbst noch der Stelle auf der Straße erinnern, wo mir, während ich in meinem Wagen saß, die Lösung einfiel; und dies geschah lange Zeit nach meiner Übersiedelung nach Down*. Es wäre leicht, noch viele andere Beobachtungen anzuftuhren, aus denen hervorgeht, daß in Momenten einer starken freudigen oder schmerzlichen Erregung neben den Haupteindricken auch ganz schwache und nebensächliche Partien des simultanen Erregangskomplexes erstaunlich stark engraphisch wirkten, wobei sie sich nattirlich mit den betreffenden Haupteindrücken unlöslich assoziiert zeigen und auch ihrerseits auf dieseiben ekphorisch wirken.

Unsere bisherigen Untersuchungen haben, wie ich glaube, gezeigt, daß sich alle Tatsachen der simultanen Assoziation von selbst aus der an sich als gegeben hinzunehmenden Grundtatsache ergeben, daß die organische Substanz auf eine Anzahl gleichzeitig auf sie als Reize wirkender Einflisse mit einem gesetzmäßig geordneten zusammenhängenden Nebeneinander von Erregungen antwortet, und daß dieser simultane Erregungskomplex als solcher engraphisch wirkt.

Jeder einzelue simultane Erregangskomplex stellt ein geordnetes Nebeneinander von Einzelerregungen innerhalb des Organismus dar. Unter sich finden wir die einzelnen simultanen Erreguugskomplexe in einer anders beschaffenen Verteilung geordnet, die wir als zeitliche Anordnung oder Sukzession bezeichnen, und an der wir gewisse Eigentumlichkeiten beobachten könuen, die sich aus ihrer Entstehungsart erklären lassen. Diese Anordnung nämlich ist eine stetige, $d . h$. ein Erregungskomplex geht unmittelbar in einen anderen liber, 
bzw. grenzt unmittelbar an einen anderen an. Eine Unterbrechung in dem Sinne, daß zwei Erregungskomplexe durch einen Abschnitt getrennt wären, in dem tuberhaupt keine Erregungskomplexe vorhanden wären, findet nicht statt, auch nicht im Schlafe oder in den verschiedenen anderen Ruheperioden der Organismen, in denen bloß Unterbrechungen in der Kontinuität des Oberbewußtseins in Erscheinung treten.

Ferner ist diese Anordnung eine einreihige, d. b. jeder Simultankomplex beruhrt sich nur mit zwei anderen, demjenigen, der seiner Entstehung vorausging, und demjenigen, der ihm folgt: dem nächstfruheren und nächstspäteren. $\mathrm{Da}$ kein Komplex einem anderen völlig gleich ist, obwohl eine periodische Wiederkehr einzelner Komponenten der Komplexe furr viele Lebensvorgänge charakteristisch ist, ist die Reihe auch eine einsinnig geordnete, $d$. $h$. es macht einen fundamentalen Unterschied, ob sie im Sinne ihrer Entstehung, also vom Fruheren zum Späteren oder umgekehrt vom Späteren zum Frtheren, betrachtet wird.

Stellt sich nun ein simultaner Engrammkomplex bei seiner Ekphorie als das getreue, wenn auch meist abgeschwächte Abbild des simultanen Erregungskomplexes dar, dem er seine Entstehung verdankt, d. h. zeigt er dasselbe geordnete Nebeneinander der verschiedenen Reizwirkangen, so gilt das gleiche fuir eine Sukzession von Engrammkomplexen. Dieselbe stetige, einreihige, einsinnige Anordnung, in der sich die originalen Erregungskomplexe aneinander gereiht haben, zeigt sich engraphisch fixiert und tritt bei jeder Ekphorie der Sukzession wieder zutage.

Wir sahen, daß jeder einzelne simultane Engrammkomplex ein geordnetes Nebeneinander der verschiedenen Reizwirkungen vorstellt, und daß sein ebenso gearteter Nachfolger 
Beziehungen der Engramme; simultane u. sukzessize Assoziation. 125

kontinuierlich auf ihn folgt. Hierdurch ist notwendigerweise ein Rahmen gegeben, in den jedes neu hinzutretende Engramm an einer ganz bestimmten Stelle eingeordnet werden muß, indem ihm von vornherein nähere Beziehungen zu diesen, entferntere za jenen simultanen Engrammen angewiesen werden. Daraus ergibt sich, daß nicht nur innerhalb eines Simultankomplexes eine Komponente allein schon durch ihre Zugehörigkeiten enger mit gewissen Mitkomponenten assoziiert ist als mit anderen, sondern daß gleiche Beziehungen anch fur die sukzessive Assoziation Geltung haben. Freilich können besondere Umstände auch nähere Assoziationen zwischen Engrammen herstellen, die ihrer Einordnung im Simultankomplex nach keinerlei nähere Beziehungen zueinander aufweisen. Dies kann allein durch die besondere Stärke der engraphischen Wirk ung erzielt werden, die diesen beiden Engrammen bei ihrer Entstehung im Gegensatz zu allen ihren Mitkomponenten zuteil geworden ist. Stärke der Reize, Hüufigkeit der gleichzeitigen Reiznng, Fokuswirkung der Aufmerksamkeit sohlägt dann Assoziationsbrücken zwischen ganz heterogenen Engrammen, verbindet z. B. einen Ölgeruch mit dem Bilde von Capri enger als mit anderen Komponenten desselben Simultankomplexes. Für gewöhnlich aber, oder besser gesagt ceteris paribus, beobachten wir, daß sowohl innerhalb eines simultanen Engrammkomplexes als auch innerhalb zweier sulkzessiv assoziierter Engramnkomplexe eine innigere Assoziation zwischen Engrammen gleicher Reizqualität besteht als zwischen Engrammen verschiedener Reizqualität, und daß innerhalb einer Reizqualität Engramme verwandten Ursprungs enger assoziiert sind als solche entfernterer Verwandtschaft. Enger assoziiert bedeutet dabei stärker aufeinander ekphorisch wirkend. 
Was den Ausdruck nähere oder entferntere Verwandtschaft der Engramme anlangt, so ist er so wenig mißverständlich, daß ich von einer strengeren Definition wohl absehen kann. Einige Beispiele mögen aber zur Lrläuterung dienen. Wens ich einen tanzenden Menschen sehe, der nach einer leicht faßlichen Melodie einen eindrucksvollen Tanz ausführt, so prägt sich mir wohl erstens eine Sukzession von akustischen und zweitens eine Sukzession von optischen Engrammen ein, die sich leicht, jede Reihe fuir sich, ekphorieren lassen. Auch wirkt im allgemeinen die eine Reihe auf die andere ekphorisch. Wenn ich die Melodie höre, sehe ich auch die Bilder des Tanzenden, und umgekehrt. Dabei pflegt sich aber zunächst, wenn nicht häufige Wiederholung stattgefunden hat, nicht das optische mit dem akustischen Einzelengramm so eng assoziiert zu haben, daß nun auch jedem Takt der Melodie genau die simultane Bewegung des Tanzenden entspräche.

Daß selbst bei Sukzessionen von Engrammkomplexen einer und derselben Reizqualität zwischen gewissen Komponenten der Sukzessionen innigere Verbindungen bestehen als zwischen anderen, beweist sehr deutlich folgendes Faktum. Ein wirklich musikalischer Mensch, dem ein polyphones Musikstuck wiederholt vorgespielt oder vorgesungen worden ist, vermag nach einiger Zeit den Ablauf jeder einzelnen Stimme für sich innerlich zu reprodnzieren oder auch singend oder spielend wiederzugeben. Diese Fähigkeit, zu der gar keine anderweitige musikalische Schulung erforderlich ist wenn es sich um zweistimmigen Gesang handelt, so ist ein Kind dazu imstande -, ist nur unter der Voraussetzung erklärlich, daß die Tonfolgen innerhalb jeder Stimme enger assoziiert sind als von einer Stimme zur anderen. Wäre dies 
Beziebungen der Engramme; simultane u. sukzessive Assoziation. 127 nicht der Fall, so whirde bei dem Versuch, eine einzelne Stimme wiederzugeben, besonders wenn es nicht die führende ist, der Reproduzierende hilflos zwischen den nebeneinander hergehenden Sukzessionen umberirren.

Die Verbindungen zwischen vier sukzessiven Engrammkomplexen lassen sich demnach, wenn wir einen natürlich ungemein vereinfachten Fall wiedergeben, bei dem nur die akustischen Komponenten etwas eingehender bericksichtigt sind, folgendermaßen schematisch andeuten:

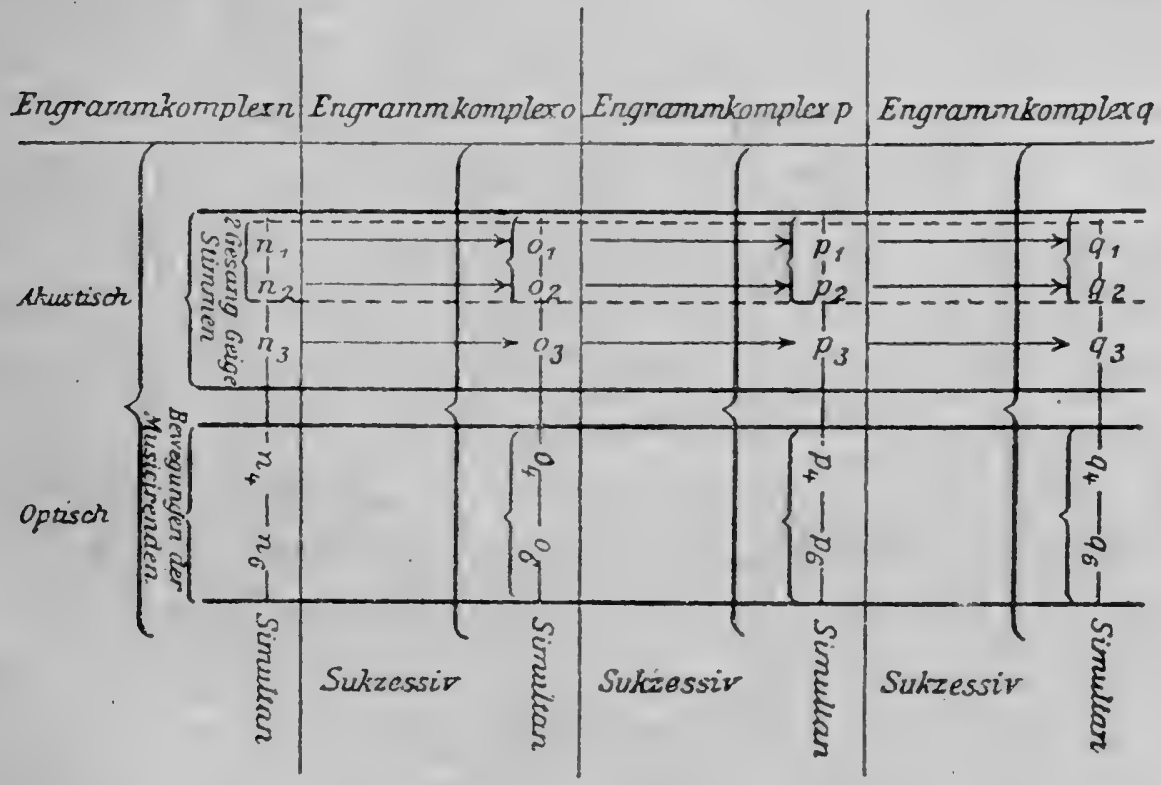

Als Resultat unserer bisherigen Betrachtungen ergibt sich folgendes: Die simultan und sukzessir auf den Organismus wirkenden äußeren und inneren Reize erzeugen in ihm Erregungskomplexe, die in ihrer simultanen Wirkung ein bestimmt geordnetes Nebeneinander, in ibrer Sukzession ein stetiges. einreihig und einsinnig geordnetes Nacheinander darstellen. Da nun das Auftreten dieser Erregungskomplexe eine beandere bleibende Wirkung auf den Organismus aus- 
tibt, die wir als engraphische jezeichnet haben, das heißt da sie eine gesteigerte Disposition des Organismus, jene Erregungskomplexe zu wiederholen, hervorruft, so ist es selbstverständlich, daß bei der Wiederholung alles wieder so stattfindet wie beim ersten Auftreten, nämlich als ein bestimmt geordnetes Nebeneinander und ein stetiges, einreihig und einsinnig geordnetes Nacheinander. Jede Abweichung, nicht aber die vorliegende Übereinstimmung, würde besonderer Erklärnng bedtirfen.

Wir haben die Zusammenordnung der simultanen Erregungs- und an sie anschließend der Engrammkomplexe als eine stetige, einreihige and einsinnige bezeichnet. In dem Ausdruck "stetig " ist bereits die Erkenntnis ausgedriickt, daß es sich um eine Kontinuität handelt, die in sich keine Teilung wahrnehmen läßt, deren Teilung wir also nur aus Gründen, die in unserem Denkvermögen, nicht in dem Phänomen selbst liegen, vollzogen haben. Dies wird sofort klar, wenn wir der Teilungsgröße gegenïber Stellung zu nehmen suchen. Wenn wir von simultanen oder gleichzeitigen Erregungen sprechen, also Erregungen, die zu gleicher Zeit vorhanden sind, so kann die Awwort auf die Fringe: wie lange dauert solch eine Gleichzeitigkeit? bei der ungeheuren Anzahl der in jedem Angenblick auf den Organismus wirkenden Einflisse, deren jeder zu eigener Zeit beginnt und endet, nur lauten: unendlich kurz. Da nun jeder Erregungsvorgang der organischen Substanz, auch der kürzeste, eine meßbare Zeitdauer besitzt, also niemals unendlich klein ist, so ist bei der Aneinanderreihung simultaner, in unserem Falle unendlich kurzer Zustände ein rein logisches, von außen in die Dinge hineingetragenes Teilungsprinzip angewendet. Dennoch ist uns dasselbe unentbehrlich, weil es in der Natur unseres 
Beziehungen der Engramme; simultane u. sukzessive Assoziation. 129

Denkvermögens liegt, daß uns eine Übersicht ther die Welt der Erscheinungen nur durch das Hilfsmittel der Teilnng und Neuzusammenordnung möglich ist. Indem wir die Erregungszustände eines Organismus in zeitlichem Sinne in simultane und sukzessive teilen und anordnen, gewinnen wir unter $\mathrm{Za}$ grundelegung einer willkturlichen, rein logischen Teilnng eine doch sachlich begrtindete Anordnung. Untersuchen wir nun zwei anfeinander folgende simultane Erregungskomplexe I und $\Pi$ eines Organismus, so finden wir, daß dieselben sich in einzelnen Komponenten wesentlich unterscheiden können. Die Erregungskomponenten $a, b, c$ von I können verschwunden, die Komponenten $x, y, z$ von II können dagegen neu aufgetreten sein. Eine Anzahl von Komponenten wird aber regelmäßig von I auf II hinubergenommen. Selbst wenn sich einmal die änßere energetische Situation plötzlich von Grund aus ändert: ich springe z. B. aus der heißen, hellen Sonne kopfuber in die dunkele Tiefe des kublen Flusses, so findet erstens diese Änderung der änßeren energetischen Situation fur meinen Gesamtorganısmus nicht in einem unendlich kleinen, sondern in einem meßbaren Zeitraum statt; zweitens bleiben auch dann in der inneren energetischen Situation des Organismus viele Komponenten unverändert.

Aus diesen Betrachtungen folgt, daß auch die simultanen Engrammkomplexe nur begriffliche, nicht naturliche Einheiten darstellen und an sich ohne Begrenzung ineinander ubergehen, wenn auch einzelne ihrer Komponenten zirkumskript anfangen und endigen. Nun zeigen sich in einer Snkzession simultaner Erregungskomplexe nicht etwa nur die kontinuierlich fortdanernden, sondern auch die zirkumskript anfangenden und endigenden Komponenten sukzessiv assoziiert. Dies wird ohne weiteres klar, wenn man 
an eine Sukzession von Tönen (Melodie) oder Geräuschen (Trommelrhythmus) oder sinnlos zusammengestellten Worten (Genusregeln) denkt. Eine einfache Überlegung zeigt, daß man bei den kontinuierlich fortdauernden, also gleichbleibenden Komponenten der sukzessiven Engrammkomplexe tiberhaupt nicht wohl von einer Assoziation reden kann. Nur die neuauftretenden and verschwindenden Komponenten einer Sukzession von Engrammkomplexen zeigen sich bei Introspektion im Bewußtsein, bei Verwendung der objektiven Methode, durch Auftreten und Verschwinden objektiv wahrnehmbarer Reaktionen verknuipft oder assoziiert, da der Begriff der Verkntipfung oder Assoziation Diskontinuität des zu Verkntipfenden zur Voranssetzung hat.

Die direkte Beobachtung lehrt uns nun, daß die Engramme der diskontinuierlichen Komponenten von aufeinander folgenden Erregungskomplexen sukzessiv assoziiert sind, auch wenn der sie trennende Zeitabschnitt nicht unendlich klein ist, sondern eine meßbare Größe darstellt. Eine Melodie wird ebensogut engraphisch fixiert, wenn ihre Töne staccato in längeren Zeitintervallen aufeinander folgen, wie wenn sie ineinander tibergezogen werden. Freilich durfen die Intervalle auch nicht zu groß werden, wenn sich die Engramme noch sukzessiv assoziieren sollen. Tonfolgen, deren Intervalle mehrere Minuten betragen, werden als solche beim Menschen nicht mehr engraphisch assoziiert. Es wird Aufgabe späterer experimenteller Forschung sein, die maximale Länge der Intervalle zu bestimmen, bei der noch im Einzelfall eine sukzessive Assoziation zustande kommt. Nichtnur die akustischen, auch alle anderen Engramme, wie die optischen, taktischen nsw., dürfen nicht durch zu lange Intervalle voneinandergetrenntsein, soll die Aktivierung des frtheren ekphorisch auf die des späteren wirken. 
Beziehnngen der Engramme; simultane u. sukzessive Assoziation. 131

Der Grund fur diese zeitliche Beschränkung der sukzessiven Assoziation wird uns sofort klar, wenn wir untersuchen, wie sich die sukzessive Assoziation zur simultanen verhält, ob sich vielleicht die erstere von der letzteren ableiten läßt. $\mathrm{Da}$ ergibt sich in der Tat, daß die sukzessive Assoziation nur eine Konsequenz der simultanen ist. Wie wir oben (S. 11) ausgefuihrt haben, entspricht jedem Originalreiz eine bestimmte synchrone Erregung. Mit dem Aufhören des Reizes hört die Erregung aber nicht plötzlich, nicht scharf abgeschnitten auf, sondern sie klingt allmählich ab, im Abklingen manchmal noch ein ein- oder mehrmaliges Anschwellen (man denke an die Nachbilder) zeigend. Wir haben die Erregung in dieser Phase des Abklingens als akoluthe Erregung bezeichnet. Schließlich sei noch hervorgehoben, daß die Erregung nicht nur während ihrer an sich stärkeren synchronen, sondern auch während ihrer schwächeren akoluthen Phase engraphisch wirkt.

Bei einer Sukzession diskontinuierlicher Reize besteht nun allerdings keine Simultaneität der synchronen Erregungen, die wir als $C(s y n), D(s y n), E(s y n), \quad F(s y n)$ bezeichnen wollen; wohl aber besteht eine Simultaneität der synchronen Erregung $D(s y n)$ mit der abklingenden, akoluthen Phase ihrer Vorlänferin, die wir in dieser Phase mit $c(a k)$, oder um ihr Abklingen von einem Augenblick zum anderen anzudeuten $c_{1}(a k)-c_{2}(a k)-c_{3}(a k)-\mathrm{C}$ bezeichnen wollen. Das folgende Schema gibt Auskunft über diese simultanen Beziehungen der synchronen Phase einer Erregung mit den akoluthen ihrer Vorgängerinnen. 
Viertes Kapitel.

\begin{tabular}{|c|c|c|c|c|c|c|c|}
\hline Phase & 1 & 2 & 3 & 4 & 5 & 6 & 7 \\
\hline & \multicolumn{7}{|c|}{$\begin{aligned} & C(s y n)-c_{1}(a k)-c_{2}(a k)- c_{3}(a k)-0 \\
& \mid \mid \\
& D(s y n)-d_{1}(a k)- d_{2}(a k)-d_{3}(a k)-0 \\
& E(s y n)-e_{1}(a k)-e_{2}(a k)-e_{3}(a k)-0 \\
& \mid \\
& F(s y n)-f_{1}(a k)-f_{2}(a k)-f_{3}(a k)-0\end{aligned}$} \\
\hline
\end{tabular}

Wie wir sehen, besteht Simultaneität zwischen der synchronen Erregung $D(s y n)$ und der akoluthen $c_{1}(a / k)$, ebenso zwischen der synchronen $E(s y n)$ und der akoluthen $d_{1}(a k)$ sowie der schon sehr schwach gewordenen $c_{2}(a k)$; endlich zwischen der synchronen $F(s y n)$ und der akoluthen $e_{1}(a k)$, der schwächeren akoluthen $d_{2}(a k)$ und der erlöschenden $c_{3}(a k$.) Aus dieser Simultaneität der Erregungen ergibt sich natirlich eine Simultanassoziation der von diesen Erregungen zurückgelassenen Engramme und damit die Möglichkeit, jede sukzessive Assoziation auf simultane Assoziation zweier Engramme zurtickzuftihren, von denen das eine durch eine synchrone Erregung, das andere durch die akoluthe Phase ihrer Vorgängerin zurlickgelassen worden ist.

Ein Blick auf unser Schema erklärt aber ferner auch auf demselben Wege die wichtige von Ebbinghaus experimentell festgestellte Tatsache, daß eine sukzessive Assoziation nicht nur zwischen unmittelbar aufeinanderfolgenden Gliedern einer Reihe besteht, sondern, daß jedes Glied anch, wiewohl schwächer mit dem zweitfolgenden und noch schwächer mit dem drittfolgenden, eventuell auch viertfolgenden usw. assoziiert ist. Eine Grenze der. Ausbildung solcher entfernterer Assoziationen ist nur durch das unaufhaltsame Schwächerwerden und schließlich völlige Erlöschen aller akoluthen Erregungen gegeben. Daraus erklärt sich aber auch, daß eine Folge von Erregungen tiberhaupt nur dann assoziierte En- 
Beziehungen der Engramme; simultane u. sukzessive Assoziation. 133

gramme liefert, wenn bei der Originalerregung die Zeitintervalle zwischen den einzelnen Gliedern nicht so lang waren, daB die akolnthe Erregung des frtheren Glieds bereits erloschen war, als die synchrone Erregung seines Nachfolgers einsetzte. - In den Mnemischen Empfindungen sind diese hier $\mathrm{bloB}$ angedeuteten Gedanken weiter ausgefuhrt und eingehender begrindet worden.

Trotzdem, wie wir sahen, die sukzessive Assoziation sich aus der simultanen ableiten läßt, ist und bleibt das Endresultat in beiden Fällen ein erheblich verschiedenes. Dies änßert sich unter anderem auch in sehr angenfälliger Weise in bezug auf die Ekphorie einerseits simultan, andererseits sukzessir assoziierter Engramme. In einer Hinsicht besteht da allerdings Übereinstimmung. Auch bei der Eksphorie simultan assoziierter Engramme muß das eine zeitlich ein wenig vor dem anderen ekphoriert werden, um auf dieses andere ekphorisch $\mathrm{zu}$ wirken.

Ein Hauptunterschied besteht nur darin, daß simultan erzeugte Engramme doppelsinnig gleichwertig verkntupft sind, sukzessiv erzeugte Engramme aber polar ungleichwertig. Wir mussen dies aus dem Umstand schließen, daß, wenn Engramm $a$ mit Engramm $b$ simultan assoziiert ist, die Ekphorie von $a$ ebenso stark, aber nicht stärker ekphorisch auf $b$ wirkt, wie die von $b$ auf $a$, was allerdings nur dann unverhtillt zutage tritt, wenn in beiden Fällen die Manifestationschancen die gleichen sind ${ }^{1}$. Sinả aber $a$ und $b$ sukzessir assoziiert, so wirkt ansnahmslos die Ekphorie ron $a$ ungleich stärker ekphorisch anf $b$, als umgekehrt.

1 In den Mnemischen Empfindungen (S. 198-202) habe ich gezeigt, wie auf dem Empfindungsgebiet dieses Verhältnis bei Ungleichheit der Manifestationschancen verschleiert wird. 
Die polare Ungleichwertigkeit der sukzessiven Assoziation läßt sich am leichtesten an akustischen Engrammen demonstrieren. Selbst der musikalischste Mensch ist unfähig, eine ihm noch so bekannte Tonfolge wiederzuerkennen, wenn sie ihm in umgekehrter Reihenfolge vorgespielt wird. Dasselbe gilt von den Lautfolgen, aus welchen sich die Wörter unserer Sprache zusammensetzen. Wenn ich jemandem etwas sage, und er antwortet in fragendem Ton darauf: ^muraw *, so habe ich keine Ahnung dáron, daß er "warum\& in umgekehrter Lautfolge gesagt hat. Dasselbe gilt für eine Folge von Worten. Auch sind wir nicht imstande, ein Gedicht in umgekehrter Wortfolge herzusagen oder eine an sich sinnlose Kombination von Worten, z. B. eine Genusregel. Wenn man einmal bei einer Rezitation etwas umstellt, so ist dies nur ein Beweis dafür, entweder daß man die Engramme gleich in falscher Reihenfolge in sich aufgenommen hat, oder daß man bei der Aufnahme noch mit dem Hilfsmittel der Simultanassoziation operiert hat, was oft genug geschieht. Wenn z. B. ein Schüler, der die Regel: „Die Männer, Völker, Flüsse, Wind a lernen soll, sich zu diesem Behufe das Bild vorstellt, wie die Männer eines seefahrenden Volkes bei guinstigem Wind in die Mündung eines Flusses einfahren, so wird naturlich durch Zuhilfenahme solcher simultaner Assoziationen leicht die Reihenfolge verwirrt, weil die Komponenten der Simultanassoziation eben doppelsinnig gleichwertig verbunden sind.

Wird durch Mitwirkung von simultanen Assoziationen die Evidenz der Fundamentalregel: sSukzessiv rerknlipfte Engramme wirken weit stärker in der Reihenfolge ihrer Entstehung aufeinander ekphorisch als umgekehrt gelegentlich schon bei Sukzessionen akustischer Engramme verschleiert, 
so ist dies noch mehr bei Sukzessionen von Engrammen der Fall, die durch die Pforte anderer Sinne in den Organismus Eingang gefunden haben. Man denke beispielsweise an die Sukzession von optischen Eindrücken bei einem Spaziergang. Hier erfolgt oft die Sukzession von optischen Erregungskomplexen und damit die Erzeugung ron sukzessiven optischen Engrammen so langsam, so viele Komponenten gehen kontinuierlich von den fruheren in die späteren Stadien über, daß die Prävalenz der Sukzession gegentiber der Antezession in der Verknüpfung durch das Hineinspielen zahlreicher simultaner, also in sich doppelsinniger Verknüpfungen in hohem Maße unkenntlich werden kann.

Einen gaten experimentellen Beweis von der polar ungleichwertigen ekphorischen Wirkung optischer Engrammsukzessionen kann man folgendermaßen erbringen. Das Bild einer Bewegung setzt sich fur den Organismus aus einer Sukzession optischer Erregungen zusammen, die, wenn mnemisch fixiert, eine Sukzession optischer Engramme darstellen. Dreht man nun die Sukzession einer Bewegung um, was sich mit Hilfe von Photographien kurzer Phasen dieser Bewegung, die mittels Stroboskop oder Kinematograph rasch in umgekehrter Folge an unserem Auge vorubergefuihrt werden, leicht bewerkstelligen läßt, so wirkt diese Umdrehung genau so fremdartig auf uns wie eine umgekehrte Tonfolge oder das Wort smaraw « für warum. Ihre Zugehörigkeit zu der betreffenden Bewegung wird tiberhaupt nicht erkannt.

Engramme des Geruchssinns - für den Geschmackssinn gilt dasselbe - zeigen sich beim Menschen zwar vielfach simultan mit Engrammen anderer Provenienz assoziiert, viel seltener aber mit Engrammen ihrer eigenen Sphäre, da sich mehrfache gleichzeitige Geruchs- und Geschmackserregungen 
nicht so scharf nebeneinander ordnen wie mehrfache gleichzeitige Gesichts -, Gehörs- und Tasterregungen, sondern häufig zu Mischerregungen verschmelzen oder sich auch gegenseitig in ihrer Wirkung aufheben. Ebenso bilden sie sukzessiv keine aus wohlumschriebenen Einzelelementen bestehende, etwa mit den Tonfolgen vergleichbare Reihen. Forel ${ }^{1}$ hat sehr gut auseinandergesetzt, daß dieser Mangel zum größten Teil anf die sozusagen regellose Art und Weise zurückzuftihren ist, in welcher die betreffenden Reize in unserem Organismus Eingang finden. Vornehmlich bedingt die Beschaffenheit der diese Reize aufnehmenden Sinnesorgane, daß hier die Reizsukzessionen meist nicht rasch und ungemischt genug einwirken können, um sukzessiv assoziierte Engramme zu erzeugen.

In viel vollkommnerer Art als bei uns zeigen sich die durch die Pforte des Geruchssinns in den Organismus eingetretenen Engramme bei vielen Insekten simultan und sukzessiv assoziiert. Wie Forel in dem oben zitierten Werke uiberzeugend nachgewiesen hat, beruht diese Differenz zwischen Insekt und Mensch nicht sowohl in der größeren oder geringeren Sinnesschärfe, als vielmehr in dem verschiedenen Modus der Aufnahme dieser Erregungen seitens der verschiedenen Organișmen. Eine Ameise, deren Geruchsorgane sich in den Fühlhörnern befinden, die alle Gegenstände, denen sie auf ihrem Weg begegnet, geruchlich sozusagen abtasten kann, erhält durch ein solches Organ ganz ähnlich simultan und sukzessiv assoziierte synchrone Erregungen und in der Folge entsprechende Engramme, wie wir Menschen

1 A. Forel, Sensations des Insects; 1900 . Übersetzt unter dem Titel: Das Sinnesleben der Insekten, München 1910, vgl. bes. S. 111, $284-286,292$. 
Beziehungen der Engramme; simultane u. sukzessiveAssoziation. 137

und unter uns Menschen besonders die Blindgeborenen sie in der Sphäre des Tastsinns durch die tastenden Fingerspitzen erhalten. Forel bezeichnet deshalb auch den durch dieses Vermögen der genauen ränmlichen Lokalisation ausgezeichneten Geruchssinn der Insekten sehr treffend als topochemischen Geruchssinn.

Wie dann ferner Forel and sich ihm anschließend Wasmann ${ }^{1}$ gezeigt haben, bietet der genaue Einblick in die besondere Beschaffenheit dieses topochemischen Sinnes und die Erkenntnis, daß die durch ihn aufgenommenen Eindricke im Gedächtnis der Tiere aufbewahrt werden, daß sie, wie ich mich ausdrücke, engraphisch wirken, den Schlüssel zu vielen Erscheinungen der Ameisenbiologie. Überall lehrt eine genauere Prüfung aber auch, daß die sukzessiven Geruchsengramme in bezug auf ihre gegenseitige ekphorische Wirkung polar ungleichwertig verknuipft sind ${ }^{2}$. Naturlich kann jede Reihe von Engrammen auch in doppelsinniger Verkntupfung erworben werden. Ich kann die Regel:' panis, piscis, crinis, finis auch noch in der Folge: finis, crinis, piscis, panis erlernen, d. h. durch häufige Wiederholung als in dieser Sukzession assoziierte Engramme meinem Organismus einprägen. Damit habe ich aber nichts anderes getan, als eine zweite

1 E. Wasmann, Die psychologischen Fühigkeiten der Ameisen. Stuttgart 1899.

${ }^{2}$ Die Tatsachen, ans denen Bethe (Dürfen wir den Bienen und Ameisen psychische Qualitäten zuschreiben? Bonn 1896; Die Heimkehrfähigkeit der Bienen and Ameisen. Biol. Zentralbl., Bd. 22, 1902) anf eine Polarisation der (von den Ameisen hinterlassenen) chemischen Spur schließt, erklären sich in der Hauptsache aus dem Umstande, daß die Sukzessionen der topochemischen Engramme bei den Ameisen ebenso polar ungleichwertig verknüpft, also, um mit Bethe zu reden, spolarisierte sind, wie bei uns Menschen die Sukzessionen der optischen Engramme einer Bewegung oder der akustischen einer Melodie. 
Sukzession von Engrammen aufgenommen. Wenn also eine Ameise von der Gattung Lasius denselben Weg mehrfach hinund zurückzagehen hat, so prägen sich ihr allmählich auf Grund der häufig wiederholten, in zwei bestimmten Reihenfolgen wirkenden chemischen Reizkomplexe zwei Sukzessionen von topochemischen Engrammkomplexen ein, die voneinander aber nahezu ebenso unabhängig sind, als wenn für den Hinund Ruckweg eine verschiedene Straße gewählt worden wäre, was ja auch zuweilen vorkommt.

Äußerst interessante und wichtige Feststellungen tiber die Art der Verkntipfung, d. h. die gegenseitige ekphorische Wirkung sukzessiver Engramme sind Ebbinghaus ${ }^{1}$ auf einem sinnreichen experimentellen Wege gelungen. Die von Ebbinghaus erdachte Methode besteht aus Auswendiglernen sinnlos kombinierter Silbenreihen bis zum fehlerlosen Hersagen, Bildung neuer Kombinationen aus den fruher gelernten Reihen nach bestimmten Gesichtspunkten, neues Auswendiglernen dieser neuen Kombinationen, schließlich Vergleichung der Zahl der Wiederholungen bzw. der Zeiten, die zum Auswendiglernen der verschieden vorbereiteten Kombinationen erforderlich sind. Ebbinghaus fand nun mit Hilfe dieser Methode, deren nähere Beschreibung im Original nachzusehen ist, erstens folgendes: $*$ Bei wiederholter Erzengung von

1 H. Ebbinghaus, Über das Gedächtnis. Untersuchungen zur experimentellen Psychologie. Leipzig 1885 . Vgl. auch die zusammenfassende Darstellung in desselben Autors > Grundzüge der Psychologies 2. Aufl. Leipzig 1905, Bd. I, S. $644 \mathrm{ff}$. Es liegt für uns kein Bedürnis vor, hier näher auf die Einzelheiten einzugehen. Soweit dies für unsere Probleme von Natzen ist, ist es in den Mnemischen Empfindungen, der speziell dem Empfindungsgebiet gewidmeten Fortsotzung des vorliegenden Werkes geschehen. Dort bin ich auch auf die umfangreiche Literatur eingegangen, die sich an die bahnbrechende Ebbinghanssche Arbeit angeschlossen hat. 
Silbenreihen assoziierten sich nicht nur die einzelnen Glieder mit ihren unmittelbaren Folgegliedern, sondern es bildeten sich Verknulpfungen zwischen jedem Glied and mehreren ihm zunächst folgenden tiber die Zwischenglieder hinweg. * - Die Stärke der Verknüpfung . . . ist eine abnehmende Funktion der Zeit oder der Anzahl der Zwischenglieder, welche die betreffenden Silben in der ursprünglichen Reihe voneinander trennen. Sie ist ein Maximum fur die unmittelbar aufeinander folgenden Glieder. Die nähere Beschaffenheit der Funktion ist unbekannt, nur nimmt sie für wachsende Entfernungen der Glieder zuerst sehr schnell und allmählich sehr langsam ab.« Als zweites Hauptresultat der Ebbinghausschen Experimentaluntersuchungen ergab sich folgende fundamentale Feststellung, die ich ebenfalls mit den Worten des Autors wiedergebe: "Es bildeten sich also in der Tat durch das Lernen einer Reihe gewisse Verkntipfungen der Glieder untereinander nach rïckwärts ganz ebenso wie nach vorwärts. ₹ — Die Stärke der so geschaffenen Prädispositionen war wiederum eine abnehmende Funktion der Entfernung der Glieder voneinander in der ursprünglichen Reihe. Nur war sie bei gleichen Entfernungen für die Verknüpfungen rückwärts erheblich geringer als für diejenigen vorwärts. Bei durchschnittlich gleich hänfiger Wiederholung einer Reihe warde jedem Glied das ihm unmittelbar vorangegangene nicht sehr viel fester verbunden als das zweitfolgende, das zweitvorangegangene - soviel sich aus den wenigen Versuchen uberhanpt schließen läßt - kaum so fest als das drittfolgende. *

Da Ebbinghaus an anderer Stelle die Stärke der Verknüpfung eines Gliedes mit dem zweitfolgenden auf ein Drittel der Stärke seiner Verknuipfung mit dem unmittelbar folgenden 
Glied berechnet hat, so kann man nach seiner eben zitierten Angabe diese Verhältniszahl auch für das Verhältnis von sukzedierendem $z u$ antezedierendem. Gliede einsetzen und sagen, die Ekphorie eines Engramms habe in dem von ihm untersuchten Fall dreimal stärkere ekphorische Wirkung auf das ihm sukzedierende als auf das ihm antezedierende Engramm.

Hier haben wir also ein genaueres Maß derpolaren Ungleichwertigkeit sukzessiver Assoziation. Wie weit diese Maßbestimmung freilich über den von Ebbinghaus studierten besonderen Fall hinaus allgemeinere Gültigkeit hat, wird sich erst durch weiter ausgedehnte Experimentaluntersuchungen feststellen lassen.

Der Leser wird mit Recht von mir erwarten, daß ich, nachdem ich oben die sukzessive aus der simultanen Assoziation abgeleitet habe, nun auch, auf dem betretenen Wege fortschreitend, zeige, worin der eigentliche Grund der polaren Ungleichwertigkeit der sukzessiven Verkntipfung zu suchen ist. Denn darauf möchte ich aufmerksam machen, daB sie ans unserem Schema S. 132 keineswegs als selbstverständlich hervorgeht. Waram wirkt z. B. die Ekphorie von $E(s y n)$ uber $d_{1}(a k)$ nicht ebenso stark ekphorisch auf $D$ (syn), als sie uber $e_{1}(a k)$ ekphorisch auf $F($ syn) wirkt? Ich bin dieser Frage in den Mnemischen Empfindungen (S. 205-216) weiter nachgegangen und glaube eine befriedigende Lösung derselben gefunden zu haben. Da aber zar Darstellnng dieser Lösung eine Kenntnis des Prinzips der Homophonie gehören würde, auf die wir erst in einem späteren Absc'nnitt des vorliegenden Buchs eingehen, eine verständliche Wiedergabe des Resultats in kurzen Worten hier deshalb nicht möglich ist, so lasse ich es an dieser Stelle bei der Verweisung auf die Behandlung des Problems in den Mnemischen Empfindungen bewenden. Umsomehr als ich 
Beziehungen der Engramme; simultane u. sukzessive Assoziation. 141

mich dort nicht auf das Empfindungsgebiet beschränkt sondern alle, auch die nicht durch Empfindungen manifestierten Sukzessionen berücksichtigt habe.

Eine ganz ähnliche polare Ungleichwertigkeit, wie die von uns bisher behandelten individuell erworbenen Engrammsrkzessionen, zeigen nun auch die sukzessiv verknüpten ererbten Dispositionen. Daß wir viele Grtinde haben, diese ererbten Dispositionen ebenfalls für Engramme anzasehen, habe ich schon oben ausgefthrt. Eine ausfuhrlichere Begrtindung dieser Ansicht soll aber erst im dritten Teile des vorliegenden Buches gegeben werden.

Jedenfalls finden wir die Sukzessionsreihen aller derartigen ererbten Dispositionen, was die Art und Wertigkeit ihrer Verknüpfung anlangt, genau denselben Regeln unterworfen, wie die Snkzessionen der individuell erworbenen Engramme. Eine Umkehr im Ablauf der Reihe ron Rüaktionen, durch die jene Dispositionen manifest werden, findet nicht statt. Auch bei ihnen ist die Stärke der Verkntipfung eine abnehmende Funktion der Zwischenglieder und ist maximal für die unmittelbar aufeinander folgenden Glieder. Glied $a$ wirkt deshalb stärker ekphorisch auf $b$ als auf $c ; b$ stärker ekphorisch auf $c$ als auf $d$. Deshalb ist $a$ nicht fähig, $c$ mit Überspringung von $b$ zu ekphorieren; $b$ nicht tähig, $d$ mit Überspringung von $c$ zu ekphorieren.

Ein äußerst frappantes Beispiel von der Wirksamkeit der letzterwähnten Grandregel bietet eine Beobachtung von J. H. Fabre ${ }^{1}$, wobei ich hervorhebe, daß es sich dabei um eine

1 J. Fabre, Souvenirs entomologiques, Paris 1879-82. Deutsche Übersetzung unter dem Titel: Bilder aus der Insektenwelt, Zweite Serie, Stuttgart 1911, S. 41. Auf S. 98 berichtet übrigens Fabre über einen ähnlichen ebenso frappanten Fall, den er bei einer anderen Grabwespe, Bembex rostratus beobachtet hat. 
ererbte, nicht um eine individuell erworbene Sukzession von Lebensänßerungen handelt. Eine Grabwespe (Sphex) macht eine Höhle, fliegt nach Beute aus, die, durch einen Stich wehrlos gemacht, an den Eingang der Höhle gebracht wird, und dringt, bevor sie die Beute hineinschleppt, stets zuerst in die Höhle, um zu sehen, ob hier alles in Ordnung ist. Während die Wespe in ihrer Höhle war, brachte Fabre die Beute auf eine kurze Entfernung bei Seite. Als die Wespe wieder herauskam, fand sie bald die Beute und brachte sie wiederum an den Eingang der Höhle, worauf jedoch der instinktive $Z_{w a n g}$ eintrat, die eben untersuchte Höhle abermals zu untersuchen, und so oft Fabre die Beute entfernte, so folgte auch das Weitere aufeinander, so daß die ungliickliche Grabwespe im gegebenen Fall ihre Höhle vierzigmal untersuchte.

Analysieren wir diesen Fall genauer und bezeichnen wir die aufeinander folgenden Reaktionen des Heranschleppens der Bente mit a, des Ablegens derselben vor der Höhle mit $b$, des Untersuchens der Höhle mit $c$, des Eintragens in die Höhle mit $d$, die diesen Reaktionen entsprechenden ererbten Dispositionen aber mit $\alpha, \beta, \gamma, \delta$, so ergibt sich tibersichtlich angeordnet folgende Sukzession:

Heranschleppen - Ablegen - Untersuchen - Eintragen

$\alpha$

Das Fabresche Experiment besagt nun, daß, wenn man das Tier nach Aktivierung der Dispositionsreihe $\alpha-\beta-\gamma$ in eine Lage versetzt, die die Neuaktivierung von Disposition $\alpha$ notwendig macht, diese Aktivierung wieder die Aktivierung von $\beta$, diese die von $\gamma$ nach sich zieht, sie, wenn wir die Dispositionen als Engramme auffassen, ekphoriert. Dis- 
Beziehungen der Engramme; simultane u. sukzessive Assoziation. 143

position (oder Engramm) $\alpha$ ist um so viel schwächer mit $\delta$ assoziiert als mit $\beta$ und $\gamma, \mathrm{da} \beta$ selbst eine vierzigmal fruchtlose Arbeit des Tieres nicht eine direkte Ekphorie von $\delta$ durch $\alpha$ unter Überspringen der Ekphorien von $\beta$ und $\gamma$ zu bewirken vermag. Naturlich soll damit nicht gesagt werden, daß damit die Sukzession für Sphex und seine fernsten Nachkommen in alle Ewigkeit unverrtickbar feststeht und unter dem Einfluß synchron und engraphisch wirkender Reize nicht allmählich umgestaltet werden kann. Wir kennen im Gegenteil bei den Hymenopteren ebenso wie bei den Wirbeltieren viele Beispiele einer gewissen Umbildungsfähigkeit mancher ererbter Engrammreihen durch neu hinzutretende individuell erworbene Engramme.

Ganz dieselben Gesetze der Assoziation beobachten wir an den Sukzessionen ererbter Dispositionen, deren zugehörige Reaktionen sich als Wachstumserscheinungen manifestieren ${ }^{1}$. Diese Beobachtungstatsache ist von großer Bedeutung fur. das Verständnis der normalen und der durch Eingriffe veränderten Ontogenese der Organismen. Da dieses Thema jedoch später noch ausfỉhrlich erörtert werden wird, so gehe ich hier nicht näher darauf ein, sondern will zum Schluß nur noch eine besondere Eigentümlichkeit der sukzessiven Assoziation behandeln.

1 Auf die scheinbaren Ausnahmen, die sogenannten Heterochronien, die sich in Ontogenese wie Regeneration nicht selten zeigen und die, wenn durch häufige Wiederholung erblich fixiert, zu feststehenden scänogenetischen* Verschiebungen der Entwicklung führen können, gehe ich hier nicht näher ein. Ich habe bereits oben (S. 99) in großen Zügen gezeigt, daß solche zeitlichen Schwankungen mit der grundlegenden Gesetzmäßigkeit der mnemischen Abläufe, mit der wir uns hier beschäftigen, nicht in Widerspruch stehen, sondern sich ihr ebenfalls unterordnen. Ich gedenke diese Heterochronien (ebenso wie die Heteromorphosen) in der zweiten Fortsetzung der Mneme ausführlich zu behandeln. 
Nicht immer braucht sich eine Sukzession einreihig fortzusetzen, sondern in vielen Fällen gabelt sich die eine Reihe von Erregungen an einem bestimmten Punkt in zwei (eventuell auch drei oder mehr) Äste Ich erinnere, nm ein einfaches Beispiel za bringen, an die Engrammverteilung eines mnemisch bewahrten Musikstücks, das einstimmig beginnt und sich zweistimmig fortsetzt:

\begin{tabular}{l|c|c|c|c}
\hline Phase 1 & 2 & 3 & 4 & 5 \\
\hline \multirow{2}{*}{$c-$} & $d-$ & $e<$ & $g-$ & $c-$ \\
& & & $d$ & $e-$
\end{tabular}

$\mathrm{Es}$ ist klar, daß in allen derartigen Fällen die gleichphasigen Glieder der beiden Äste der Dichotomie simultan assoziiert sind. Wir können eine derartige Dichotomie einer Engrammsukzession deshalb als eine simultan assoziierte Dichotomie bezeichnen.

Es gibt aber auch Dichotomien (und Trichotomien usw.) von Engrammsukzessionen, deren gleichphasige Glieder nicht simultan assoziiert sind, und bei denen die Ekphorie an der Gablungsstelle nur in dem einen Ast der Dichotomie (oder Trichotomie) weitergeht. Oft beruht diese Beschränkung nur auf dem Umstande, daß bisher noch keine Simultanassoziation eingetreten ist, so z. B., wenn ich von dem oben skizzierten Tonstuck die erste und die zweite Stimme einzeln studiere, ohne sie je zusammen zu hören, zu lesen oder zu spielen. Zunächst ist dann die Dichotomie nicht simultan assoziiert und deshalb auch nicht simultan ekphorierbar, sondern sie ist nur alternativ ekphorierbar. Schaffung von simultanen Assoziationen durch eine einmalige simultane Originalerregung verwandelt aber diese alternative in eine 
Beziehungen der Engramme; simultane u. sukzessive Assoziation. 145

simultan assoziierte Dichotomie. Es gibt indessen auch zahlreiche Fälle, wo eine derartige Umwandlung aus Grinden, die sehr verschiedenartiger Natur sein können, nicht möglich ist. Gewöhnlich beruhen diese Grinde auf der Unfähigkeit des Organismus, gleichzeitig die Reaktionen beider Erregungsreihen auszufuhren. Dann bleibt danernd eine alternative Dichotomie bestehen. Höre oder lese ich z. B. das berihmte Goethesche Gedicht: „Über allen Gipfeln ist Rub \& zuweilen in der ersten, zuweilen in der zweiten Fassung, so prägt es sich mir in folgender alternativ dichotomischer Form ein :

, Über allen GipfeIn ist Ruh, in allen $\left\{\begin{array}{l}\text { WäIdern hörest du } \\ \text { Keinen Hauch -c } \\ \text { Wipfeln sptirest du } \\ \text { Kaum einen Hauch -c }\end{array}\right.$

Diese alternative Dichotomie läßt sich nicht durch gleichzeitiges Hören oder andere engraphische Einflüsse, wie diejenigen des obenerwähnten zweistimmig werdenden Musiksticks, in eine simultan assoziierte rerwandeln ${ }^{1}$. Wo aus irgendeinem Grund eine Simultanassoziation der Äste einer Dichotomie (oder Trichotomie) unmöglich ist, da bleibt dieselbe dauernd eine alternative.

In das Wesen der alternativen Dichotomie können wir erst tiefer eindringen, wenn wir den Begriff der Homophonie kennen gelernt haben. Hier möchte ich nar darauf aufmerksam machen, daß an der Gablungsstelle jeder Dichotomie ein Engrammkomplex statt an einen an zwei oder mehr sukzedierende Komplexe angrenzt, in dem zitierten Gedicht also das Wort »allen* sowohl an , Wäldern c als auch an $\times$ Wipfeln $*$. Da es sich in dem gegebenen Fall um

1 Über die Gründe dieser Unmöglichkeit vgl. Mnemische Empfindungen S. $357-361$. 
eine nur alternativ ekphorierbare Dichotomie handelt, fragt es sich, ob das Engramm *allen* auf sWäldern * oder auf -Wipfeln* ekphorisch wirken wird. Dies hängt in erster Linie davon ab, welche von den beiden Assoziationen enger, das heißt von stärkerer ekphorischer Wirkung ist. Oft ist es lediglich die verschiedene Hänfigkeit der Wiederholung bzw. die verschiedene zeitliche Nähe der Wiederholung, die dem einen Ast einer Alternative das Übergewicht uber den anderen verleiht. Dies ist z. B. der Fall bei unserem Beispiel von den zwei Fassungen des Goetheschen Gedichts.

In ubrigen können sehr verschiedenartige Nebeneinflüsse dahin wirken, daß der Ausschlag einmal nach der einen, das andere Mal nach der anderen Seite hin erfolgt. Wir gehen hierauf noch näher im zwölften und dreizehnten Kapitel ein.

Bei unseren bisherigen Betrachtungen haben wir immer nur die Assoziation von Engrammen berücksichtigt, die sich als die Hinterlassenschaft von durch Originalreize erzengten Erregungen, also von Originalerregungen darstellen. Wir haben also bisher der Einfachheit halber die Sache so dargestellt, als ob der jeweilige simultane Erregungskomplex, der bei seinem Verschwinden einen entsprechenden simultanen Engrammkomplex zurlickläßt, nur aus Originalerregungen bestünde. Dies war aber eine willkürliche Vereinfachung. Die simultanen Erregungskomplexe enthalten anßer zahlreichen Originalerregungen aller Art in der Regel auch noch mnemische Erregungen, und diese bilden genau ebenso einen an sich aufs neue engraphisch wirkenden Bestandteil des betreffenden simultanen Erregungskomplexes wie die durch Originalreiz erzeugten Originalerregungen. $\mathrm{Zn}$ jedem simultanen Erregungskomplex gehören also, außer den jeweiligen Originalerregungen auch noch alle momentan gerade ekpho- 
rierten mnemischen Erregungen und entfalten genau ebenso wie erstere eine engraphische Wirksamkeit.

Eine ausfuhrliche Behandlung dieses Themas findet man im neunten Kapitel der Mnemischen Empfindungen, wo die Beschaffenheit des individuell erworbenen Engrammschatzes und seine schichtweise Entstehung aus den von Augenblick zu Augenblick wechselnden simultanen Erregungskomplexen dargestellt ist, während man eine Übersicht uber die Komponenten der einzelnen Engrammschichten ebenda am SchluB des elften Kapitels (S. 216, 217) findet. Indem ich auf jene spezielleren Ausfuhrungen verweise, verzichte ich hier auf eine Darstellung dessen, was ich in den frtheren Auflagen des vorliegenden Buchs als kombinatorische Assoziation bezeichnet habe. Ich habe diese Bezeichnung in den Mnemischen Empfindungen (S. 165) durch den schwerfälligeren aber weniger mißverständlichen Ausdruck Assoziation von Komponenten verschiedenerEngrammschichten * ersetzt und dort diesen wichtigen aber für uns angenblicklich etwas abseits liegenden Vorgang genau analysiert.

Ich habe dort ferner gezeigt, daß auch diese Assoziation wie jede andere nur das Produkt einer einmal eingetretenen gemeinsamen Anwesenheit der betreffenden Komponenten in demselben simultanen Erregungskomplex ist und sich mithin wie jede andere Assoziation anf Simultanassoziation zurtickfuhren läßt. Wie die Zuruckfuhrung der Sukzessivassoziation auf Simultanassoziation zu erfolgen hat, wurde oben (S. 130-132) kurz ausgeftihrt. Für die Zuruickfübrung der anderen Assoziationsarten, die von den Psychologen seit Aristoteles unterschieden warden und zum Teil beate noch werden, muß auf das zehnte Kapitel der Mnemischen Empfindungen verwiesen werden. 


\section{Fünftes Kapitel.}

\section{Die Lokalisation der Engramme.}

Bei unseren bisherigen Betrachtungen haben wir keinen Versuch gemacht, tiefer in das innerste Wesen der Veränderungen einzudringen, die die reizbare Substanz beim Auftreten und Verschwinden der Erregung erleidet, und die in besonderer Modifikation im Engramm zurickbleibt. Nur soviel können wir sagen, daß es sich bei diesen Veränderungen der reizbaren Substanz selbstrerständlich um substanzielle, materielle Veränderungen handelt. Indem wir uns darauf beschränken, die gesetzmäßigen Zusammenhänge zwischen Reiz und Reaktion festzustellen und keinen Versuch machen, in das *Wesen * der Erregung im Sinne molekularmechanischer Hypotbesen einzudringen, sind wir noch keineswegs der Aufgabe tiberhoben, zu untersuchen, ob die reizbare Substanz innerhalb desselben Individuums uberall dieselben Eigenschaften besitzt, und nach Entscheidung dieser Frage, die bekanntlich in negativem Sinne längst erfolgt ist, das sich unmittelbar anschließende Problem in Angriff za nehmen, wie sich die reizbare Substanz entsprechend ihrer verschiedenartigen Ligenschaften im Individuum verschieden verteilt zeigt.

Diese Aufgabe, deren Lösung von physiologischer Seite schon seit langer Zeit und von den verschiedensten Ausgangs- 
punkten her unternommen worden ist, soll uns im folgenden nach Möglichkeit nur insoweit beschäftigen, als es sich um das Verhältnis der reizbaren Substanz zur engraphischen Reizwirkung, also um die Lokalisation der mnemischen Phänomene innerhalb des Individuums handelt. Indem wir das Lokalisationsproblem von der mnemischen. Seite her in Angriff nehmen, werden wir imstande sein, es in besonderer Beleuchtung zu zeigen, und werden gleichzeitig unseren Einblick in das Wesen der mnemischen Phänomene vertiefen.

Einleitende Betrachtungen über das Problem der Lokalisation ererbter Engramme.

(Die Fortfïhrung dieser Untersuchung erfolgt erst im dritten Teil, Kapitel XI.)

Schneidet man eine Planarie, also einen Wurm, der, wenn auch auf der Stufenleiter der Tiere ziemlich tief stehend, doch schon ein differenziertes Zentralnervensystem (Gehirn und Längsnervenstämme), zwei Augen, ein kompliziertes Darm-, Exkretions- und Genitalsystem besitzt, kreuz and quer in beliebige Teilstücke, so ist jedes Stlick, ganz gleich, ob es von vorn oder von hinten oder von einer Seite stammt', imstande, sich wieder za einem vollständigen Wurm mit allen seinen morphologischen und physiologischen Eigentümlichkeiten, natürlich auch mit allen seinen sogenannten Instinkten, zu ergänzen, falls der Ausschnitt nur nicht allzu winzig genommen worden ist. Dasselbe vermögen bei Hydra Teilstücke, die irgendeinem beliebigen Körperabschnitt mit Ausnalime der Tentakel entnommen sind, wenn sie nur nicht

1 Ausgenommen sind nur Teilstücke aus dem äußersten Vorderende des Wurmes vor den Angen (Th. H. Morgan) und dünne Abschnitte der änßersten Seiten, die keine Spur der Seitennervenstämme enthalten (H. Barde $: n)$; ob letztere Ausnahme eine unbedingte ist, ist übrigens strittig. 
unter $1 / 6 \mathrm{~mm} \mathrm{bzw}$. $1 / 9 \mathrm{~mm}$ Durchmesser, d. h. etwa $1 / 200$ des Gesamtrolumens einer Hydra, heruntergehen. Beliebige Ausschnitte aus den,Wurzeln mancher Pflanzen (z. B. Scorzonera, Leontodon usw.) vermögen das ganze Pflanzenindividuum wieder aufzubauen, ebenso wie ein beliebiger Blattausschnitt einer Begonie, auf feuchten Sand gelegt, sich zu einer vollständigen Pflanze regeneriert. Auch Infusorien, wie z. B. Stentor, kann man in beliebige Teilstucke zerlegen; / sind diese Teilstticke nicht allzu klein und enthalten sie wenigstens Bruchstucke des Kerns, so wird aus jedem derselben ein vollständig verkleinerter Stentor. Wir können also unter Zagrundelegung der Auffassung, daß die Mehrzahl der ererbten Dispositionen Engramme sind, für die noch im dritten Teil dieses Buchs weitere Belege gebracht werden sollen, sagen: Die betreffenden Bruchstticke der Planarie, der Scorzonera, Begonie und des Stentors besitzen den gesamten ererbten Engrammschatz des vollständigen Individuums. Diese beliebig hergestellten Ausschnitte verhalten sich also in dieser Beziehung wie die entwicklungsfähigen Keimprodukte der betreffenden Organismen.

An dieser Stelle möchte ich einige Worte sagen tiber die Bedeutung des Satzes, die Keimprodukte und Ausschnitte aus dem Körperverbande bei gewissen Formen befänden sich im Besitz des gesamten ererbten Engrammschatzes. Im Besitz dieser oder jener Engrammkomplexe sein, bedeutet nicht etwa, sie zu jeder Zeit und unter allen Umständen ekphorieren können, sondern nur, sie bei Eintritt ganz bestimmter änßerer und innerer Bedingungen oder, besser gesagt, bei Eintritt einer bestimmten energetischen Situation ekphorieren können. Deshalb sind wir allerdings berechtigt, zu sagen, die Keimzellen besäßen ebenso wie Ausschnitte aus dem 
Körperverbande anch jene Engramme, die erst bei dem ausgebildeten tierischen oder pflanzlichen Organismus bei den bloß dann vorhandenen Zustandsmöglichkeiten ekphoriert werden können.

Aus dem Umstande, daß ganz beliebige herausgeschnittene Teilstlicke gewisser Organismen im Besitze des ganzen ererbten Engrammschatzes sind, können wir entnehmen, daß wenigstens bei diesen Formen dieses Erbteil nicht in besonderen Bezirken des Organismus lokalisiert ist, sondern uberall der reizbaren Substanz des Organismus zu eigen gehört. Zerschneide ich einen solchen Organismus in immer kleinere Teilstticke, so komme ich allerdings schließlich an einen Punkt, uber den hinaus eine Verkleinerung nicht mehr möglich ist, ohne die Lebensfähigkeit und damit auch die Regenerationsfähigkeit des Bruchstlicks anzutasten. Wir mlissen aber dabei bedenken, daß ein Bruchstuck, das zur Nahrungsaufnahme von anßen untauglich ist, bei zu kleiner Zuschneidung gar nicht genug Material besitzt, um anßer den Ausgaben für die Fortfuhrung seiner Lebensprozesse auch noch das Betriebskapital zur Ausfuhrung der Regeneration zu liefern. Unsere bisherigen Zerschneidungsversuche klären uns deshalb keineswegs tuber die wirkliche Minimalgröße der Bruchstlicke auf, die noch im Besitz des gesamten ererbten Engrammschatzes sind. Stitzen wir uns auf die Beobachtungen, die wir bei der Fortpflanzung der Organismen machen, so sehen wir in diesen Fällen einzelne Zellen, nämlich die Keimzellen, im Besitz des gesamten ererbten Engrammschatzes. Der Umstand, daß man Protozoenzellen (Stentor) in mehrere beliebige Teilsticke zerschneiden kann, aus deren jedem sich ein ganzer Stentor regeneriert, wenn es nur ein Bruchstick des Kernes miterhalten hat, spricht 
stark dafür, daß wenigstens in diesem und in ähnlichen Fällen der Besitz des gesamen ererbten Engrammschatzes einer noch kleineren biologischen Einheit zukommt, als sie uns in dem Element der Zelle entgegentritt.

Auf die Frage, ob innerhalb jeder Zelle die engraphische Veränderung sich vorwiegend oder ausschließlich in der Substanz des Kernes and seiner Äquivalente lokalisiert, ob wir also die Kernsubstanzen als Träger der Engramme aufzufassen haben, wofür eine Reihe von bedeutsamen Tatsachen spricht, will ich hier nicht näher eingehen, weil ich sie noch nicht fur spruchreif halte.

Als gesichertes Resultat unserer bisherigen Betrachtungen können wir vorläufig folgendes hinstellen. Erstens: Der gesamte ererbte Engrammschatz ist bei Beginn jeder durch Keimzellen eingefuhrten Individualitätsphase im Rahmen einer Zelle oder eines Zelläquivalents enthalten. Höchstwahrscheinlich ist das Element der Zelle (oder vielleicht auch nur des Kernes dieser Zelle) noch nicht die kleinste Einheit, die ihn zu umschließen imstande ist.

Jene kleinste Einheit, deren nähere Umgrenzung, ob Zelle, ob subordinierte morphologische Einheit, wir zukunftiger Forschung ubberlassen, wollen wir lediglich um den Begriff nicht immer durch längere Ausfuihrungen umschreiben zu mussen, als mnemisches Protomer bezeichnen.

Als zweites Resultat hat sich uns ergeben: Im späteren Verlauf einer Individualitätsphase, $d . h$. wenn das pflanzliche oder tierische Individuum mehr-oder vielzellig geworden ist, zeigen aus beliebigen Teilen der Organismen entnommene Ausschnitte sich in zahlreichen Fällen im Besitz des gesamten ererbten Engrammschatzes. Auch in diesen Fällen sind wir vorläufig noch nicht imstande, die kleinsten muemischen 
Einheiten oder Protomere, d. h. die Minimalansschnitte von reizbarer Substanz, die sich noch im Besitz dieses ererbten Engrammschatzes zeigen, morphologisch zu umgrenzen. Wir können bei diesen Versuchen nicht auf zu kleine organische Partikel heruntergehen, weil solche beliebigen Ausschnitte der doppelten Aufgabe, den Lebenshaushalt weiterzufubren und die Extraausgabe der Regeneration zu leisten, sehr viel ungtinstiger gegenuberstehen als die diesen Anfgaben angepaßten Keimzellen. Wir sind deshalb noch nicht einmal imstande, die Frage zu beantworten, ob unter Umständen ein einzelliger Ausschnitt eines ausgebildeten vielzelligen Organismus genlugt, das Ganze zu regenerieren, also ob er den gesamten ererbten Engrammschatz besitzt. Fur den Anfang der Keimesentwicklung, speziell während der Furchung der tierischen Keimzellen läßt sich dieser Nachweis allerdings in vielen Fällen fübren.

Ich gehe indessen an dieser Stelle auf die mit der Einschränkung und Nichteinschränkung der Regenerationsfähigkeit verknüpften Fragen nicht näher ein, sondern warte mit dieser Erörterung, bis wir weiter in unserer Untersuchung fortgeschritten sind, vor allem bis wir uber das Wesen der Homophonie und die Wirksamkeit der Prozesse bei der Ontogenese näher orientiert sind. Im elften Kapitel des dritten Teils werden wir an den hier fallen gelassenen Faden wieder anknupfen und vor allem zu untersuchen baben, ob die hänfig mit Fortschreiten der Ontogenese zunehmende Einschränkung der Regenerationsfähigkeit für eine gewisse lokalisierte Verteilung des ererbten Engrammschatzes spricht oder nichi. 
Lokalisation der individuell erworbenen Engramme.

Wenn wir am Schlusse unserer bisherigen Ausführungen die Frage, ob jede Zelle oder besser jedes mnemische Protomer des sich entwickelnden wie des fertigen Organismus im Besitz des gesamten ererbten Engrammschatzes ist, vorläufig noch offen gelassen haben, so können wir unser jetziges Thema mit der Erklärung beginnen, daß sicherlich nicht jede Zelle oder jedes mnemische Protomer derjenigen Individuen, die wir in hervorragendem Maße zum individuellen Erwerbe von Engrammen befähigt finden, im Vollbesitz des gesamten individuellen Engrammschatzes des ganzes Organismus ist.

Wir können dies deshalb mit solcher Bestimmtheit behaupten, weil wir ausnahmslos beobachten, daß die Keimzellen eines Organismus, welche sich ja stets im Vollbesitz derjenigen Engramme befinden, die der Organismus von seinen Vorfahren ererbt hat, von den Engrammen, die er im individuellen Leben erworben hat, meist nichts oder doch nur verschwindend wenig in der nächsten Individualitätsphase manifest werden lassen. Weder Vater noch Mutter sind imstande, in manifestationsfähiger Stärke die Fülle der zahllosen Engramme, die der höhere tierische Organismus rom ersten Atemzug an in sich aufgenommen hat, aufihre Nachkommen zu übertragen, oder alle die vielen Fertigkeiten, die sie im Laufe ihres Daseins erlernt haben, ihren Kindern mitzugeben. In einem friheren Kapitel (S. 69-80) haben wir nun aber gesehen, $\mathrm{da} ß$ die Übertragung individuell erworbener Engramme von der einen Generation auf die andere sich allerdings in günstigen Fällen nachweisen läßt, besonders, wenn es sich um in verschiedenen Generationen wiederholte Eindrticke 
handelt. Häufig sind wir aber nicht imstande, eine derartige Übertragung mit den uns zu Gebote stehenden Beobachtungsmitteln zu konstatieren, und aus beiden Tatsachenreihen zusammengenommen ergibt sich die Wahrscheinlichkeit einer zwar vorhandenen, aber gewöhnlich nur in starker Abschwächung wirkenden Übertragung von individuell erworbenen Engrammen auf die reizbare Substanz der Keimzellen und durch diese auf die Nachkommen.

Ganz besonders stark ist diese Differenz in der engraphischen Wirkung eines Reizes auf verschiedene Teile desselben Organismus, wenn wir bei höheren Wirbeltieren die Wirkung einmaliger, rasch vortibergehender, schwacher Reize auf die nervös differenzierte reizbare Substanz mit der Wirkung derselben Reize auf die reizbare Substanz der Keimzellen vergleichen. Da könnte es wohl den Anschein haben, als ob die engraphische Wirkung solcher Reize auf die reizbare Substanz der Keimzellen einfach gleich Null sei. Da aber andere Reize, ich erinnere an die an zitierter Stelle mitgeteilten Beispiele, nachweisbar engraphisch auf die reizbare Substanz der Keimzellen wirken, so haben wir keinesfalls das Recht, aus den negativen Ergebnissen anderer Versuche ohne weiteres die Abwesenheit jeder engraphischen Wirkung zu folgern 1.

1 Nenes Licht fällt auf dieses ganze Problem durch die wichtige Entdeckung Towers (Evolution of Leptinotarsa, Washington 1906), daß bei manchen Organismen (Insekten) die Keimzellen eine ssensible Perioder besitzen, während welcher ihre Empfänglichkeit für Reize außerordentlich gesteigert ist. Bis zu einem gewissen Grade erklärt diese Eigentümlichkeit, die wahrscheinlich durchaus nicht auf die Keimzellen der Insekten beschränkt ist, sondern eine viel allgemeinere Verbreitung besitzt, die scheinbare Launenhaftigkeit im Auftreten von erblich fixierten Abänderungen nach Einwirkung äußerer Reize (vgl. Stand der Frage S. 45, 50, 60-64, 75). 
Wir lassen aber diese Frage vorderhand beiseite und konstatieren zunächst nur die Grundtatsache: die reizbare Sabstanz der Keimzellen befindet sich zwar im Vollbesitz des ererbten Engrammschatzes eines Organismus und ist imstande, denselben so auf ihre Teilungsprodukte, d. b. den sich entwickelnden und voll ausgebildeten Organismus, zu übertragen, $\mathrm{da} B$ er in allen zugehörigen Reaktionen ungeschwächt zutage tritt; sie besitzt aber von den individuell erworbenen Engrammen des Organismus verschwindend wenige, so daß in ihren späteren Produkten, d. h. dem sich entwickelnden und ausgebildeten Organismus, nahezu nichts von diesen erworbenen Engrammen des elterlichen Organismus zatage tritt.

Gibt es nun abgesehen von der mangelnden oder doch jedenfalls stark abgeschwächten Übertragung der individuellen Engramme auf die reizbare Substanz der Keimzellen noch andere Tatsachen, die für eine lokal verschiedene Verteilung dieser Engramme auf die reizbare Substanz der Organismen sprechen? Es ist natürlich, daß wir uns zur Entscheidung dieser Frage an diejenigen Organismen wenden, die besonders befähigt sind, Reize engraphisch auf sich einwirken $z \mathfrak{u}$ lassen und die dadurch bedingte Zustandsänderung durch Reaktionen za manifestieren. Es sind dies in erster Linie die höheren Wirbeltiere, in der höchsten Steigerung der Mensch. In zweiter Linie auch manche Insekten, besonders eine Anzahl von Hymenopteren (Bienen, Wespen und Ameisen) und endlich auch einige Cephalopoden. Eine zirkumskripte Lokalisation der individuell erworbenen Engramme od̉er, wie die Physiologen und Psychologen sich in diesem Falle meist auszudricken pflegen, der Erinnerungsbilder * wurde bisher von einer großen An- 
zahl von Forschern als erwiesen angenommen und für den Menschen und die höheren Wirbeltiere in die Großhirnrinde verlegt. Die Haupttatsache, auf die sich diese Anschaung griindet, besteht in der immer aufs neue zu machenden Beobachtung, daß bei allen Krankheiten des »Gedächtnisses «, die uns in mannigfachen Formen beim Menschen entgegentreten, als einzige konstante körperliche Veränderang eine Herderkrankung oder ein sonstiger zirkumskripter Insult oder ein mehr diffuser Degenerationsprozeß der Großhirnrinde nachweisbar zu sein pflegt. Ja, wir sind wenigstens in einem Falle imstande, noch genauer zu lokalisieren, und können mit größter Bestimmtheit vorhersagen, daß, wenn sich ein rechtshändiger Mensch plötzlich der Erinnerang an einen großen Teil seines Wortschatzes beraubt zeigt (amnestische Aphasie), eine Läsion seines Großhirns in der Gegend der linken Insel mit den anstoßencien Partien des Stirn- und Schläfenlappens stattgefunden hat.

Viele Hirnphysiologen und -pathologen gingen nun ehemals noch erheblich weiter in einer Lokalisation der Erinnerungsbilder. Sie lokalisierten die optischen Erinnernngsbilder an einer bestimmten Stelle hinter der Fissura parieto-occipitalis. $\mathrm{Je}$ in einem besonderen Felde befände sich in konsequenter Weiterbildung dieser Auffassung der Speicher der Erinnerungsbilder von Landschaften, von Personen, von Zahlen und von Schriftzeichen. Ja schließlich hätte jedes Buchstaben-, jedes Zahlzeichen, jeder einmalige Gesichtseindruck sein besonderes »Erinnerangsfeld oder Schubfach, das man sich dann am bequemsten in Gestalt viner Zelle vorstellen würde. In ähnlichem Sinne wurde das Zentrum für die akustischen Erinnerungsbilder und zwar speziell furr die Erinnerung an den Klang der Worte, in den ersten linken Temporallappen 
(3. und 4. Füftel desselben) zu verlegen sein. Auch hier wieder stellte man sich die Zelle wie ein Schubfach vor, das die Erinnerung an den Klang eines bestimmten Wortes anfbewahrt, eine naive Auffassung, die jetzt zwar durchans im engeren Kreise der Hirnspezialisten, keineswegs aber im weiteren der Biologen und Mediziner als tiberwunden zu bezeichnen ist, sondern vielfach noch nachwirkt ${ }^{1}$.

Wir befinden uns also in dem Dilemma, eine Lokalisationslehre, die sich jedes einzelne Engramm in einer Zelle oder in einem Zellkomplex des Großhirns wie in einem besonderen Schubfach verwahrt denkt, auf das entschiedenste ablehnen zu mlissen, andererseits aber zu dem Zugeständnis gezwungen zu sein, daß im menschlichen Organismus ein besonderes Abhängigkeitsverhältnis besteht zwischen räumlich abgrenzbaren Teilen der Großhirnrinde und dem Vorhandensein oder vielleicht richtiger der Mögliehkeit der Ekphorie von bestimmten Gruppen gewisser individuell erworbener Engramme. Letzteres Zugeständnis bedeutet aber doch immerhin die Anerkennung ener gewissen Lokalisation, wenngleich es nicht eine Lokalisation zu sein braucht, die in jederNervenzelle einer bestimmten Hirnregion ein Schubfach für ein besonderes Engramm erblickt.

Wir haben bei allen unseren bisherigen Untersuchungen voransgeschickt und immer wieder betont, daß wir von dem innersten Wesen des Erregungsvorgangs ebensowenig eine

1 Ich komme darauf unten im 16. Kapitel bei Besprechung der mir gemachten Einwände noch einmal zurtick. Eine ausgezeichnete kritische Darstellung der Lokalisationsprobleme, die sich in wesentlichen Punkten mit den hier von uns vertretenen Auffassungen berührt, findet man in der vor kurzem erschienenen Schrift eines besonders kompetenten Beurteilers dieser Probleme, C. v. Monakow, Über die Lokalisation der Hirnfunktionen, Wiesbaden, E. F. Bergmann 1910. 
Vorstellung haben können, die mehr wäre als ein trügerisches Gleichnis, wie uber das $>$ Wesen $\propto$ irgendeines anderen energetischen Vorgangs. Wir können aber unter Verzicht auf ein Eindringen in das Wesen der Erregung sehr wohl die Gesetze ihres Auftretens und Verschwindens, ihrer Fortleitung und ibrer Nachwirkungen feststellen oder, wenn man will, beschreiben. Und da ergibt sich sofort eine für die uns jetzt beschäftigenden Fragen sehr wichtige Tatsache, nämlich, daß der Erregungsvorgang den Organismus, am ausgeprägtesten den höheren, mit einem wohldifferenzierten Nervensystem ausgestatteten Organismus, nicht diffus, sondern auf dem Wege bestimmter, im ganzen gut isolierter Bahnen durchläuft. $\mathrm{Daß}$ eine solche Erregung höchst wahrscheinlich kein einheitlicher Vorgang ist, sondern auf seinem Wege durch den Organismus regionär wechselnde Modalitäten besitzt, ist zwar sehr wahrscheinlich, entzieht sich aber vorläufig der näheren Analyse.

Wir sehen also hierdurch schon den originalen synchronen Erregungsvorgang in gewisser Weise lokalisiert, und da die engraphische Veränderung der reizbaren Substanz ein unmittelbares Produkt dieses synchronen Erregungszustandes ist, so ist eine gewisse Lokalisation der individuell erworbenen Engramme innerhalb der reizbaren Substanz eines Organismus von vornherein gegeben. Wäre die Isolation der einzelnen Bahnen, in denen die Erregungen verlaufen, eine vollkommene, so würden wir auch vollkommen scharfe Lokalisation erwarten dirfen. Viele Erfahrungen lehren uns aber, daß die Isolation der Leitung zwar eine den funktionellen Bedürfnissen entsprechende, aber keineswegs absolute ist. Bei "Leitung." denke ich nicht etwa bloß an die Teilstrecken, die durch Nervenfasern repräsentiert werden, sondern an den ganzen 
Weg, den die synchrone Erregung von ihrem Auftreten bis zu ihrem Erlöschen zurücklegt, mag dieselbe durch Nervenzellen, -fasern oder -grau oder and̉ere Formen von reizbarer Substanz fuhren. Ich bezeichne die ganze dabei von der Erregung durchlanfene Strecke von reizbarer Substanz als den primären Eigenbezirk einer bestimmten Erregung.

Auf ein Übergreifen der Erregung uber die fur gewöhnlich innegehaltenen Grenzen des Eigenbezirks hinaus hat man sogenannte Reflexkrämpfe zurẗckzufuhren, die entweder bei erhöhter Irritabilität des Zentralnervensystems (Strychninvergiftung, Tetanus, Hydrophobie) durch gewöhnliche sensible Reize ansgelöst werden können oder auch bei normaler Irritabilität der Nerven durch Steigerung der Reizgröße. Man bezeichnet diese Krämpfe auch als ungeordnete Reflexe, eine nicht sehr glickliche Bezeichnung, denn wie Pfluger gezeigt hat, folgt das Übergreifen der Erregung im Zentralorgan einer durchaus bestimmten Ordnung. Zunächst manifestiert es sich in einer Kontraktion der Muskeln, deren motorische Nerven im Ruickenmark anf derselben Seite und im gleichen Niveau entspringen wie diejenigen, die allein bei gewöhnlichem Reflex auf die Reizung einer bestimmten Hautstelle durch Zusammenziehung geantwortet hätten. Erst bei weiterer Ausdehnung des Übergreifens werden auch Nervenkomplexe der anderen Seite ergriffen, aber stets nur solche, die symmetrisch sind mit ergriffenen Nerven der primären Seite, und nie stärker als diese. Weiterhin werc̉en auch Nervenkomplexe anderer Niveans affiziert, und zwar nach der Medulla oblongata hin fortschreitend.

In einem ganz ähnlichen Verhältnis wie die Reflexkrämpfe zu den gewöhnlichen Reflexen stehen manche der sogenannten - Mitbewegungen ₹ zu den automatischen Bewegungen. Wäh- 
rend es z. B. keine Mühe kostet, bei gemäßigten Bewegungen des einen Arms den anderen ruhig zu halten, so muß dies bei heftigen Bewegungen, wie man sich bei Beobachtung der studentischen Fechtubungen, besonders beim Hiebfechten überzengen kann, von dem Anfänger erst allmählich gelernt werden, falls er den unbeschäftigten Arm frei herabhängen läßt und ihn nicht durch Anklammern an der Kleidung fixiert. Ein Mensch, dessen Irritabilität durch gewisse Einwirkungen (Affekte, Intoxikationen) erhöht worden ist, macht aber solche Mitbewegungen selbst bei schwachen Innerrationen, bewegt z. B. den linken Arm auch bei schwachen Bewegungen des rechten Arms mit. Auch sonst läßt sich bei den automatischen Bewegungen fur das Übergreifen der Erregung im allgemeinen die Geltung der für die Reflexkrämpfe angefuihrten Regeln nachweisen.

In der sensiblen Sphäre beruhen die sogenannten Irradiationen optischer und sensibler Erregungen ebenfalls auf einem Übergreifen der Erregung tuber ihren primären Eigenbezirk hinaus. Fur eine besonders unvollkommene Isolation der Leitung spricht es, wenn bei Berlihrung des änßeren Gehörgangs nahe dem Trommelfell ein Kitzel im Kehlkopf empfunden wird. (Bekanntlich werden beide Regionen von Vagusfasern versorgt.)

Wir sehen aus allen diesen Beispielen, daß die Isolierung aller nervöser Leitungen nur eine durchaus relative und von einer absoluten weit entfernte ist. Eine relative Isolierung findet ja insofern statt, als bei schwächeren Reizen und bei nicht gesteigerter Irritabilität das Übergreifen der Erregung uber den Eigenbezirk hinaus nicht manifest wird. Sie wird es aber sofort bei Verstärkung des Reizes oder bei Steigernng der Irritabilität, und hieraus ist zu schließen, daß 
das Nichtmanifestwerden durchaus nicht mit einem Nichtvorhandensein identisch ist.

Es liegt überhaupt im Wesen des Erregungsvorganges, daß er erst eine gewisse Stärke (Schwellenwert) erreicht haben $\mathrm{muB}$, ehe er sich durch Reaktionen für uns manifestiert. Die Erfahrungen bei der Reizsummation (vgl. S. 28) lehren uns, daß ein äußerst schwacher Reiz sehr wohl Erregung hervorrufen kann, ohne daß die letztere sioh fur uns in einer Reaktion zu manifestieren braucht.

Die Erregung also, deren Wirkungskreis zwar in der Regel auf einen bestimmten, mit dem Reiz wechselnden primären Eigenbezirk beschränkt erscheint - wie das geschieht, ist besonders im Hinblick auf die grane Substanz, die nicht im entferntesten mit den Isoliervorrichtungen der weißen Substanz und peripherer Nerven ausgestattet ist, ganz unbekannt -, läBt den Rest der reizbaren Substanz des Organismus keineswegs unberihhrt, sondern verteilt sich zunächst tiber direkt anschließende, von dort über entlegenere Linien der den ganzen Körper durchziehenden reizbaren Substanz. Wie uns die Beobachtungen bei Reflexkrämpfen, bei gewissen Mitbewegungen and bei sensiblen Irradiationen belehren, erfolgt auch dieses Fortwirken der Erregung ther ihren naturlich von Fall za Fall verschiedenen primären Eigenbezirk hinaus in ganz bestimmten Bahnen unter fortdauernder $\mathrm{Ab}$ schwächung der Erregung, und zwar ist die Abschwächung um so größer, je weiter sich die auf Nebenleitungen abströmende Erregung von ihrem primären Eigenbezirk entfernt. So setzt sich schließlich die Erregung auf die gesamte ${ }^{1}$ reizbare Substanz des Organismus fort, in abnehmender

1 Bezüglich einer etwaigen Einschränkung vgl. Anmerkung S. 164. 
Stärke freilich, aber doch so, daß wohl auch die von dem Eigenbezirk der betreffenden Erregung am weitesten abliegen- den oder mit ihr nur ganz indirekt verbundenen Teile der reizbaren Substanz von ihrem Einfluß bertihrt werden können. Warum wir letztere Annahme machen müssen, wird weiter unten noch näher auseinander gesetzt werden.

Wir haben jetzt die Basis gewonnen, auf der sich ein Verständnis der mnemischen Lokalisationsphänomene gewinnen läßt, und vergegenwärtigen uns noch einmal die beiden Grundroraussetzungen, die das Zustandekommen einer gewissen mnemischen Lokalisation innerhalb des Organismus bedingen.

Erste Voraussetzung ist natürlich die engraphische Wirkung der Erregung, d. h. die eigentlimliche Veränderung, die nach Ablauf einer synchronen Reizwirkung in der reizbaren Substanz zurückbleibt. Der engraphische Effekt steht dabei in einem bestimmten Verbältnis znr Stärke der synchronen Erregung. Sehr schwache Erregungen hinterlassen scheinbar keine engraphischen Effekte. Aber nur scheinbar. Denn da bei häufiger Wiederholung solcher schwacher Erregungen eine engraphische Wirkung manifest werden kann, ist bewiesen, daß jeder einzelne Faktor für sich nicht engraphisch wirkungslos geblieben ist.

Als zweite Voraussetzung hat sich uns ergeben, daß jede Originalerregung innerhalb eines höher differenzierten Organismus, speziell bei einem Wirbeltier mit hoch differenziertem Nervensystem, nicht die ganze reizbare Substanz dieses Organismus gleichmäßig beeinflußt, sondern seine größte Stärke in einem Ausschnitt derselben hat, den wir als den primären Eigenbezirk dieser Erregung bezeichnet haben. Von dort strahlt sie mit abnehmender Stärke, bestimmten Bahnen 
folgend, in immer entferntere Bezirke der reizbaren Substanz aus, wahrscheinlich auch die entferntesten noch als verklingender Nachhall beruhrend, und vielleicht nur von solchen ganz ausgeschlossen, die durch allzu spezifizierte Ausbildung für die betreffende Erregung unzugänglich gemacht sind. Aus diesen beiden Voraussetzungen ergibt sich, daß jede im Organismus vor sich gehende Erregung bei hinreichender Stärke jede Zelle oder besser jedes mnemische Protomer mit der eben als möglich zugegebenen Ausnahme - engraphisch beeinflussen wird, aber entsprechend der Lage dieses Protomers innerhalb des Organismus in verschieden starker Weise. Ein Protomer zum Beispiel, das in jenen Gebieten liegt, die die Eigenbezirke der Geschmackserregungen umfassen, wird von den eigentlichen Geschmacksreizen, die den Organismus treffen, sehr stark, von anders gearteten Reizen dagegen nur viel schwächer engraphisch beeinflußt werden 1 .

1 Natürlich ist Vorbedingung für diese Auffassung, daß man keine Gleichartigkeit des Erregungsprozesses in allen Nervenfasern voraussetzt, sondern die Möglichkeit qualitativ verschiedener Erregungszustände innerhalb desselben Neurons zugibt. Dazu aber ist man, wie Hering in seiner klassischen Abhandlung zurTheorie der Nerventätigkeit (Leipzig 1899) gezeigt hat, nicht bloß berechtigt, sondern geradezu genötigt. Hering nimmt gleichzeitig an, die Fähigkeit, qualitativ verschiedene Erregungszustånde durchzumachen, sei durch eine gewisse angeborene Spezifikation mehr oder weniger aller, besonders aber der Sinnesneurone, beschränkt, die sie verhindert, auf allzu heterogene Reize anzaklingen and mit allzu heterogenen $\mathbf{E r}$ regungen mitzuklingen (spezifische Energie). Dann wird also bei einem Erregungsvorgang in einem höheren Organismus immer ein gewisser, dieser Erregung spezifisch allza entrückter Teil der reizbaren Substanz nicht mitklingen, also auch nicht engraphisch beeinflußt werden, und es wird nur der spezifisch prädisponierte und der uiberhaupt nicht ausgesprochen spezialisierte Rest der reizbaren Substanz synchron miterregt and engraphisch beeinfußt werden. Die Entscheidung, in welchem Umfange wir genötigt sind, diese Ein- 
Wenn also in einem bestimmten Augenblick nicht ein einzelner Reiz, sondern, wie das unter natürlichen Bedingungen fast immer der Fall ist, ein ganzer Komplex von an sich schon komplexen photischen, akustischen, sensiblen usw. Reizen auf den Organismus einwirkt, wird dieser Simultan. komplex von Reizen zwar als solcher jede Zelle oder jedes mnemische Protomer (betreffs Einschränkungen vgl. die Anmerkung) beeinflussen, aber entsprechend der Topographie jedes einzelnen Protomers in sehr verschiedenem Grade.

Um dies noch anschaulicher zu machen, möchte ich mich eines Vergleichs bedienen. Ich betone dabei aber ansdrticklich, daß, wenn ich hier ausnahmsweise einmal die phonographische Reproduktion heranziehe, ich damit keine, auch nicht die entfernteste Analogie zwischen der Entstehung einer engraphischen Veränderung der organischen Substanz mit dem Zustandekommen eines Phonogramms andeuten will. Meiner Ansicht nach verhält sick ein organisches Engramm zu einem Phonogramm, wie ein Pferd, das einen Wagen zieht, zu einer Lokomotive, die das auch tut. Die Leistung

schränkung zu machen, möchte ich einer späteren Untersuchung vorbehalten. Jedenfalls aber diurfen wir die Annahme einer angeborenen spezifischeu Beschränkung der Resonanz der Neuronen nur insoweit durchführen, als sie den Spielraum des Anklingens für jedes Neuron nicht za sehr einengen. Sonst kommen wir wieder auf die von Hering so erfolgreich bekämpfte Auffassung, da $\beta$ der Erregungsproze $B$ in einer und derselben Faser immer qualitativ derselbe und nur nach Intensität und zeitlichem Verlauf verschieden sei. Auch W. Nagel kommt in seiner zusammenfassenden Betrachtung uiber die Lehre von den spezifischen Sinnesenergien (Handbuch der Physiologie des Menschen, 3. Bd. 1. Hälfte, 1904) zu einem ähnlichen Resultat: »Bei dem jetzigen Stande unseres Wissens dürfen wir die Möglichkeit nicht bestreiten, daß die einzelne Sinnesnervenfaser je nach der Art ihrer Erregung qualitativ verschiedene Empfindungen zar Auslösung im Zentralnervensystem bringen kann.\& 
kann unter Umständen eine gewisse Ähnlichkeit haben, die Mittel, durch die sie zustande kommt, sind fundamental verschieden. Wie es aber deshalb nichts Unstatthaftes hat, die Arbeitsleistung einer Maschine mit der eines Pferdes zu vergleichen, kann ich wohl auch, ohne Mißverständnisse befürchten zu miissen, die topographischen Eigentimlichkeiten der Wirkung komplexer Einflusse auf organische Substanz an den topographischen Eigenttumlichkeiten der Wirkung komplexer akustischer Einflisse auf Phonographen anschaulich machen.

Denken wir uns in einem Opernhaus von der gewöhnlichen Bauart während des Spiels eines großen Orchesters eine größere Anzahl von möglichst gleichartigen Phonographen an verschiedenen Stellen des Parketts und der Ränge und Logen, ferner auf und hinter der Bühne, endlich im Orchesterraum zwischen den Sitzen der Orchestermitglieder verteilt! Läßt man nun nach Aufhören des Orchesterspiels die einzelnen Phonographen ihre Phonogramme reproduzieren, so wird sich ergeben, daß die Reproduktionen der einzelnen so ähnlichen Apparate keineswegs tibereinstimmen. Nicht nur wird sich je nach dem Standort eine größere Dentlichkeit und Kraft der Gesamtwiedergabe unterscheiden lassen. Unter den Apparaten, die im Orchesterraum selbst verteilt gewesen sind, werden die, die in der Nähe der Bässe gestanden haben, die Leistungen dieser Stimmen mit solcher Macht wiedergeben, daß alle anderen Stimmen dagegen ganz zuriucktreten. Ehenso werden die Phonographen, die zwischen den Celli verteilt gewesen sind, durch ihre Reproduktion den Eindruck erwecken, die Celli hätten während der Vorführung immer die fuhrenden Stimmen gehabt, und seien von den anderen Instrumenten nur ganz pianissimo begleitet worden. 
So himmelweit verschieden nun allerdings das Wesen der mnemischen Aufnahme und Wiedergabe von dem Wesen der phonographisehen ist, so ist die Resultante zwischen Placierung und Aufnahme der komplexen Einflusse bei Phonograph und mnemischem Protomer eine sehr ähnliche. Naturlich handelt es sich für das letztere nicht allein um die Einwirkung durch akustische Einflusse, sondern auch durch photische, thermische, elektrische, kurz durch allen möglichen Energiearten angehörige Reizkomplexe.

Ein mnemisches Protomer nimmt naturgemäß nur von denjenigen Erregungen eines simultanen Engrammkomplexes kräftige Engramme in sich auf, in deren primärem Eigenbezirk es liegt. Von allen anderen Erregungen, die gleichzeitig im Organismus vor sich gehen, empfängt es nur mehr oder weniger abgeschwächte Beiklänge und kann sie auch nur in dieser Abschwächung engraphisch aufbewahren.

Innerhalb des Eigenbezirks einer Erregung ist ubrigens höchstwahrscheinlich die Stärke dieser Erregung regional ebenfalls recht verschieden. Bestimmte Daten daruber lassen sich aber zurzeit noch nicht geben. Wenn wir wohl berechtigt sind, zu sagen, der Eigenbezirk einer bestimmten optischen Erregung dehne sich aus tuber Retina, Sehnerven, Chiasma, äußere Kniehöcker und Thalamus, obere Vierhtigel nebst Verbindungen zu den Augenmuskelnerven, endlich bestimmte Rindenbezirke des Occipitallappens des Großhirns, and dazu noch vieles addieren, was uns als in die engere Sehsphäre fallend zurzeit noch unbekannt ${ }^{1}$ ist, so haben wir

1 v. Monakow sagt darüber a. a. 0. 1910, S. 25: >Über die Anordnung, Organisation und Ausdehnung derjenigen Innervationswege im Kortex, welche von der Stelle des deutlichen Sebens (Macula lutea) bedient werden, auf denen sich auch die bewußte Licht- 
zur Beantwortung der Frage, ob innerhalb dieses Eigenbezirks quantitative oder qualitative Verschiedenheiten des betreffenden Erregungsvorgangs angenommen werden dürfen oder mulssen, nur sehr wenige tatsächliche Handhaben. Ich will nun nicht so vorgehen, daß ich aus einzelnen Beobachtungstatsachen die Wahrscheinlichkeit von lokalen Intensitätsdifferenzen einer Erregung innerhalb ihres Eigenbezirks nachzuweisen suche, sondern will gleich von einer bestimmten Annahme ansgehen und zeigen, daß bei ihrer Zugrundelegung die einschlägigen Beobachtungen eine vollkommene Erklärung finden.

Wenn wir die Annahme machen, daß die Stärke einer Erregung innerhalb ihres Eigenbezirks jedesmal in der reizbaren Substanz der Großhirnrinde ihr Maximum erreicht, so finden durch diese Annahme ganze Gruppen von Tatsachen eine neue Beleuchtung.

Unter Zugrundelegung der Auffassung, daß sich die Großhirnrinde in der Wirbeltierreihe allmählich zu einer Art von »Multiplikator* der Erregungen entwickelt hat, verstehen wir die Sonderstellung, die sie nach den Erfahrungen der vergleichenden Anatomie und vergleichenden Physiologie ebensowohl als der Pathologie in folgenden Beziehungen einnimmt:

1. Zum Bewaßtsein oder, besser ausgedrlickt, zum Oberbewußtsein. Nur denjenigen Erregungen, die in die Großhirnrinde eingetreten sind und die dort ihre maximale Stärke er-

empfindung aufbaut, wissen wir noch außerordentlich wenig genaueres. Sicher ist nur soviel, da $B$ der seinur beiden Sehsphären beraubte Mensch ... wie einige Fälle in der Literatur zeigen, von einem kleinsten zentralen Gesichtsfelde, welches gesucht werden muß, aus, nicht nur Lichtempfindungen haben, sondern auch noch Schrift erkennen und lesen kann«: 
reicht haben, entsprechen, introspektiv betrachtet, oberbewußte Empfindungen.

2. Zum individuell erworbenen Engrammschatz. In der Großhirnrinde, wo die Erregungen innerhalb ihres Eigenbezirks ihre maximale Stärke erreichen, hinterlassen sie anch die deutlichsten und am leichtesten ekphorierbaren Engramme.

Da also die Erregungen aus einem Sinnesgebiet entsprechend der ans den zugehörigen Sinnesorganen zuführenden Leitung in einer bestimmten Region der Großhirnrinde den höchsten Grad ihrer Entwicklung erreichen, befinden sich in dieser Region auch die präzisesten Engramme aus diesem Sinnesgebiet. Entfernter ${ }^{1}$ von dieser Region zeigen sich diese Engramme mehr und mehr abgeschwächt, während die Engramme aus anderen Sinn€sgebieten an Bestimmtheitzunehmen, ähnlich den Phonographen, die im Orchesterraum in der Nähe der Celli nur die Cellostimmen deutlich, die Stimmen der anderen Instrumente bloß als schwache Beiklänge aufgenommen hatten.

Unsere Annahme erklärt auch durchaus das Verbältnis, das wir bei vergleichender Betrachtung der Wirbeltierreihe zwischen Entfaltung der Großhirnrinde einerseits und $\mathrm{Zu}$ nahme der Aufnahmefähigkeit für Reize und der engraphischen Fixierung der Erregungen andererseits finden. Von der Vervollkommnung der letzteren beiden Faktoren ist im wesentlichen das bedingt, was wir als Zunahme der Intelligenz zu bezeichnen pflegen.

Wo immer in der Biologie der Tiere der individuelle Er-

1 -Entfernt< hier natïrlich nicht im Sinne der Luftlinie, sondern im Sinne der Leitung, also des von der Erregung zurückzulegenden Weges. 
werb von Engrammen und deren Verwertung eine so große Rolle spielt wie bei den Warmblutern, und zwar in einer ihrer Großhirnentwicklung entsprechenden Proportion, da fuhrt auch der völlige Verlust dieses » Multiplikators \& der Erregungen und demzufolge Festhalters selbst flichtiger Eindruicke zu einer je höher in der Reihe aufwärts um so merklicheren Schädigung der Persönlichkeit, wie diè großhirnlosen Tauben und Falken Schraders ${ }^{1}$, der Goltzsche ${ }^{2}$ großhirnlose Hund beweisen. Diese Zitate sollen naturlich ans dem ungeheneren Beobachtungsmaterial, das vorliegt, nur ein paar besonders vollständig durchgefuhrte Versuchs- und Beobachtungsreihen herausgreifen.

Daß aber auch bei Warmblutern das individuell erworbene Gedächtnis zwar vorwiegend, aber keineswegs ansschlieBlich im Großhirn lokalisiert ist, wird ebenfalls durch jene großhirnlosen Tauben, Falken und Hunde bewiesen, die nach der Operation ihre Artgenossen, Pfleger and Feinde nicht mehr wieder erkennen, obwohl sie sie noch sehr gut sehen und hören können, die aber noch sehr wohl zn fliegen und za laufen verstehen. Da letztere Fähigkeiten ihnen keineswegs angeboren sind, so haben wir sie als Reaktionen zu betrachten, die das Vorhandensein von individuell erworbenen Engrammen auch bei Abwesenheit des Großhirns beweisen.

In den letzterwähnten Fällen sind die individuell erworbenen Engramme, deren Ekphorie sich in den komplizierten Reaktionen des Fliegens und Laufens manifestiert, infolge der häufigen Wiederholung dieses Erregungskom-

1 M. E. G. Schrader, Zur Physiologie des Vogelhirns. Pflügers Archiv, Bd. 44, 1889.

2 F. Goltz, Der Hand ohne Großhirn. Pfligers Archiv, Bd. 61 1892. 
plexes in subkortikalen Teilen des Zentralnerrensystems mit hinreichender Schärfe fixiert, um auch bei Abwesenheit des Großhirns ekphoriert werden zu können und die zugehörigen Reaktionen zu liefern.

Was nun die Lokalisation im Großhirn selbst anlangt, auf die wir ans der "Lokalisation der Symptomes schließen müssen, die genau festgestellt ist und zu den großen Triumphen der modernen Hirnchirurgie gefuhrt hat, so liegen zur Erklärung dieser Lokalisation der Symptome zwei Möglichkeiten vor. Entweder es kommt in der Tat zu einer glied- und sinnestopographischen Lokalisation ${ }^{1}$ der 'Engramme selbst, oder aber es handelt sich bloß um ein Abhängigkeitsverhältnis zwischen räumlich abgrenzbaren Teilen der Großhirnrinde und der Möglichkeit der Ekphorie von bestimmten Gruppen individuell erworbener Engramme, worauf ich bereits oben (S. 158, 1. Aufl. S. 149, 2. Aufl. S. 159) aufmerksam gemacht habe. Sollte sich das Vorhandensein einer gewissen topogenen Lokalisation der Engramme bei weiterer Vertiefung unserer Kenntnisse bewahrheiten, so könnte eine solche Lokalisation höchstens eine graduelle, keinesfalls eine exklusive sein, wie man bisher vielfach angenommen hat. Eine solche graduelle Lokalisation wurde sich dann ebenfalls ganz im Sinne des oben ausgefuhrten Bildes von räumlich verschieden verteilten Phonographen erklären. Vielleicht ist sie bis zu einem gewissen, allerdings viel beschränkteren Grade vorhanden, als man gemeiniglich annimmt, und liefert zusammen mit einer Lokalisation der Ekphorie, d. h. der Schaffung der anatomischen Grundlage

1 Ich habe dies in den Mnemischen Empfindungen (S. 282, 378) im Gegensatz zur chronogenen Lokalisation als topogene Lokalisation bezeichnet. 
für die Ekphorie der Engramme, die Gesamterscheinung, die uns in der Lokalisation der Symptome entgegentritt. Ein tieferes Eingehen auf diese Fragen sei der zweiten Fortsetzung der Mneme vorbehalten. Ich möchte aber zum Schluß dieser Auseinandersetzung noch durch einige Zitate wiedergeben, wie sich $\mathrm{V}$. Monakow ${ }^{1}$ in seiner neuesten, hochbedeutsamen Schrift uber die Lokalisation der Hirnfunktionen zu dieser Frage stellt: sIn weiterer Ferne steht vor uns das schwierige Problem, das örtliche Moment bei den unzähligen aufgespeicherten Eindrücken, den Engrammkomplexen - die je nach Beduirfnis manifest werden zu bestimmen (mnestische Leistangen). Hier verfluchtigt sich zweifellos die Örtlichkeit Schritt für Schritt auf ein Minimum* (S. 22) ... . Die Fähigkeit, Schalleindrücke nach ihrer Natur and näheren Bedentung (für den nervösen Haushalt) zu unterscheiden und die hierauf sich aufbauenden Klangengramme haben aber ihre eigentlichen Werkstätten im gesamten Kortex, wenn auch die in der Peripherie der sog. Heschlschen Windung (I. Temporalwindung; Hörsphäre) liegenden Abschnitte eine bevorzugte Stellung einnehmen* (S. 25). „... müsssen sich die Werkstätten für die später erworbenen Engrammkomplexe (Semon), also das, was wir als ,Wahrnehmungen', ,Vorstellungen', ,Erinnerungsbilder' usw. bezeichnen - weit über die eigentlichen somatischen Kortexfelder hinans auf die ganze Hirnoberfläche (wenn auch verschieden verteilt) im Sinne eines enorm kompliziert ausgespannten Faserzeltes ausdehnen (S. 27). „... Ein gewisses örtliches Moment bleibt aber selbst den höchsten Verrichtungen erhalten, näm-

1 C. v. Monakow. Über Lokalisation ảer Hirnfunktionen. Wiesbaden 1910. 
lich dasjenige, welches der unmittelbaren Realisation, resp. der ,Ekphorie' (Semon) vierschiedener Akte zur anatomischen Grundlage dient* (S. 27).

Die Frage, ob Erregungen von der Körperoberfläche zentripetal zum Zentralnervensystem, ron dort aus zentrifugal uber die gesamte reizbare Substanz des Individuums, auch die nicht nervös differenzierte, mit hinreichender Kraft fortgeleitet werden können, um selbst noch in den äußersten Endstationen Engramme zu liefern, die - eventuell durch häufige Wiederholnng an Zahl vermehrt und dadurch bei der Ekphorie in ihrer Wirkung verstärkt - Manifestationsfähigkeit erreichen, ist eine schwierige. Das beste Versuchs- und Beobachtungsobjekt werden für diese Frage wohl immer die Keimzellen sein. Der in Frage stehende Experimentalbeweis kann nur so gefuhrt werden, daß man die erste Generation einer Reizeinwirkung aussetzt, die die Keimzellen nicht unmittelbar, sondern bloß auf dem Wege oder, wenn man will, Umwege der organischen Reizleitung treffen kann. Zeigt sich dann die aus diesen Keimzellen entwickelte nächste Generation, ohne ihrerseits je dem Reiz ausgesetzt worden zu sein, in der betreffenden Richtung verändert, so ist damit bewiesen, daß der engraphische Reiz die Keimzellen der Elterngeneration erreicht hat, und $z$ war, da er sie nicht direkt treffen konnte, daB er sie auf dem Wege der Ausstrahlung der organischen Reizleitung im Sinne unserer obigen Darlegungen erreicht hat.

Diesen Anforderungen genügt die folgende ron uns oben schon kurz erwähnteBeobachtungsreihe, die durch Frl. v. Chanvin $^{1}$ an mexikanischen Molchen, dem vielfach auch in Europa

1 Marie von Chaurin, Über die Verwandlungsfähigkeit des mexikanischen Axolotl. Zeitschr. f. wissensch. Zoologie, Bd. 41, 1885. 
geziichteten und aus Liebhaberei in Aquarien gehaltenen Axolotl, Siredon (Amblystoma) angestellt worden sind. Diese Molche sind vor ihren europäischen Verwandten, den allbekannten Tritonen und Salamandern, dadurch ansgezeichnet, daB sie am Ende ihrer Embryonalentwicklung nicht das Wasser verlassen and sich nicht unter Rlickbildung der Kiemen zu Landmolchen umwandeln, sondern daß sie unter gewöhnlichen Verhältnissen im Wasser bleiben, die Kiemen behalten und als mit allen Attributen des Wasserlebens versehene Wasserformen, sagen wir kurz als Larven geschlechtsreif werden und sich fortplanzen. Das ist die Norm. Es mag ja wohl auch in Mexiko Lokalrassen von Axolotln geben, bei denen ähnliche Einwirkungen im Freileben eingetreten sind, wie die, denen Frl. v. Chauvin ihr Material experimentell ausgesetzt hat, und die, erblich fixiert, auch im Freileben Rassen mit veränderten Instinkten erzengt haben. Das Material jedoch, mit dem Frl. v. Chauvin experimentiert hat, und von dem wir hier reden, war so beschaffen, daß die jungen Tiere auf keinem Stadium der Entwicklung die Tendenz zeigten, spontan von der Kiemen- zur Lungenatmung überzugehen und sich in die Landform umzuwandeln. Bei einmal geschlechtsreif gewordenen Tieren ist die Verwandlung ohnehin ausgeschlossen.

Dagegen war Frl. v. Chanvin imstande, durch Anwendung besonderer Reize die Larven in einer bestimmten kritischen Entwicklungsphase zur Lungenatmung, Rtickbildung der Kiemen, Verlassen des Wassers, schließlich vollkommener Metamorphose zum kiemenlosen Landmolch (Amblystoma) zu. veranlassen. Die ersten Schritte auf diesem Wege, der zu tiefgreifenden morphologischen und Instinktänderungen führt, sind immer das Außerfunktiontreten der Kiemen und das In- 
funktiontreten der Lunge, und der Reiz, durch den diese ersten Schritte hervorgerufen werden, ist die Erschwerung: der Kiemenatmung, die leicht dadurch za erzielen ist, daß man die Tiere in derbetreffendenZeit in nicht hinreichend luftreichem oder überhaupt in zu spärlich zugemessenem Wasser hält.

Die auf diese Weise zur Metamorphose gebrachten Molche wurden dann weiter am Leben erhalten, bis sie als Landtiere geschlechtsreif wurden und sich fortpflanzten. Auch sie legen ihre Eier ins Wasser ab, und die ausschlüpfenden Larven durchlaufen wie ihre Eltern ihre eigentliche Entwicklung im Wasser. Haben sie aber die Stufe erreicht, in der der Beginn der Metamorphose überhaupt erst möglich wird - die Tiere besitzen dann eine Länge von 14-16 cm -, und in welcher man ihre Eltern, wollte man die Metamorphose einleiten, in Verhältnisse hätte bringen mttssen, die der Kiemenatmung ungünstig gewesen wären, so ist letzteres bei den Nachkommen nicht mehr notwendig. Trotzdem Frl. v. Chauvin viele solche Larven in reichlichem luftreichem Wasser hielt, skamen sie hänfig an die Oberfläche, um Luft zu schöpfen und hielten sich hier oft stundenlang auf, ein Benehmen, welches der Axolotl nur bei vorgeschrittnerem Alter und in luftarmem Wasser zu zeigen pflegta.

Auch der weitere Verlauf ihrer Umwandlung, den Frl. v. Chauvin bei derartigen Individuen sich vollziehen ließ, war nach Art und Tempo trotz jeden Fortfalls einer äußeren Nötigung ein wesentlich anderer, viel rapiderer, als er bei Abkömmlingen von unmetamorphosierten Axolotln in den Chauvinschen Zuchten je eingetreten war. Frl. v. Chauvin kommt daher zu dem Schluß, daß es wohl anßer Zweifel sei, >daß dieser ausgeprägte Hang zur Fortentwicklung durch Vererbung auf diese Individuen übergegangen war *. 
Das steht für mich ebenfalls fest'. Ich behaupte aber auch, daß in diesem Falle eine uberwältigende Wahrscheinlichkeit daftir spricht, daß die engraphische Beeinflussung den Keimzellen der Elterngeneration auf dem Leitungswege übermittelt ist, und daß eine direkte Reizung der Keimzellen durch die betreffenden engraphischen Reize auszuschließen ist. Ich sagte daruber in einer fruheren Arbeit: s Ebenso unzuiössig wäre hier aber auch der Einwand der direkten Beeinflussung der Keimzellen. Bei ihrer Lage tief im Innern des Körpers, wo sie nicht wie die Zellen der änfleren Haut je nach dem Medium, in dem das Tier lebt, einem Wechsel der Feuchtigkeit ausgesetzt sind, uberhanpt allen unmittelbaren Reizen entzogen, die der Übergang vom Wasserleben zum Landleben mit sich bringt, können die Keimzellen nur durch Leitungsreize von der veränderten Situation Kande erhalten und beeinflußt werden.*

Dazu kommt noch, daß sich die Keimzellen anch der landlebenden Wirbeltiere schon an und für sich in einem feuchten Medium befinden. Sie liegen in einer großen serösen Höhle, der Leibeshöhle, und werden steta von der Flüssig-

1 v. Hansemann, Deszendenz und Pathologie, Berlin 1909, S. 313, hat geglaubt, dieser Fall ließe sich durch Zuchtwahl erklären, Frl. v. Chauvin habe ganz unbewaßt eine Auslese getroffen, denn es sei eine -Beobachtungstatsache $₫$, daß bei dem Versuch die Axolotl in Amblystomen üherzufübren, das durchaus nicht bei allen Tieren gelinge, ja da $B$, wenn man dieselben zwinge, aufs Trockene zu gehen, eine Anzahl Axolotl dabei zu Grunde gehe. Diese Behauptung $\nabla$. Hansemanns widerspricht dem Wortlaut der Chauvinschen Angaben und der von dieser gewissenhaften Forscherin mitgeteilten Tabelle. Bei den 24 Exemplaren entsprechenden Stadiums, über die Frl. v. Chauvin in ihrer Arbeit berichtet (S. 368-371, Tab. S. 369) gelang a us nahmslos die Erzwingung der Metamorphose und ni cht ein einziges Tier ging dabei zu Grunde.

2 R. Semon, Beweise für die Vererbang erworbener Eigenschaften. Archiv f. Rassen- u. Gesellschaftsbiologie, 4. Jahrg, 1907, S. 25. 
keit dieses mächtigen Lymphraums umspultt. Es scheint mir deshalb ausgeschlossen za sein, daß für die Keimzellen osmotisch ein einschneidender Unterschied daraus resultiert, ob ihr Träger als Axolotl im Wasser oder als Amblystoma auf dem Lande lebt, wo er wie alle Landmolche sich tibrigens auch stets vor zu großer Trockenheit des Mediums zu schützen sucht. Auch die Möglichkeit, daß etwa bei den wasserlebenden Amphibien normalerweise Wasser durch Kloake and Ovidukt bis zu den Keimzellen vordringt, ließ sich durch Tatsachen ausschließen, und so hat denn auch Kammerer, der anfangs diese Möglichkeit offen halten zu mässen glaubte, auf meine Grinde hin seinen Widerspruch zurickgenommen ${ }^{1}$.

Noch mehr aber liegt eine solche direkte physikalische Beeinflussung der Keimzellen bei einigen der Kammererschen Salamandraexperimente außerhalb der Grenze des Denkbaren, ganz besonders bei denen ${ }^{2}$, wo eine Vererbung der Färbung durch komplexe Licht- und Feuchtigkeitswirkung erzielt wurde, z. B. stärkere Gelbfärbung der Jungen durch Halten der Eltern auf gelber Erde. Daß das verhältnismäßig nur äußerst geringe Plus an Feuchtigkeit, dem das auf gelber Erde lebende Tier im Vergleich zu dem auf schwarzer Erde lebenden ansgesetzt ist, eine Einwirkung auf die der äußeren Luft unmittelbar exponierte Hant hervorbringt, ist sehr verständlich; daß aber dieser an sich doch nur minimale Feuch-

1 P. Kammerer, Vererbung erzwungener Fortpflanzangsanpassungen 3. Mitteil. Archiv f. Entw.-Mech., 28. Bd., 1909, S. 526, sowie ferner Zeitschr. f. induktive Abstammangs- und Vererbungslehre, 1. Bd., 1909, S. 139.

2 P. Kammerer, Direkt induzierte Farbanpassungen und deren Vererbung, Zeitschrift f. induktive Abstammungs- und Vererbungslehre, 4. Bd., Heft 3 u. $4,1911$. 
tigkeitsunterschied durch die Körpergewebe hindurch auf die in den stets feuchten Lymphranm der Leibeshöhle eingebetteten Keimzellen einen bestimmenden Einfluß ausüben soll, erscheint durchaus unglaublich. In noch höherem Grade gilt alles dieses für die Lichtwirkung, insofern ja der Einfluß des Lichts auf die Haut gar kein direkter ist, vielmehr der Vermittlung des Anges bedarf. Schaltet man nämlich diese Reizpforte, diesen Rezeptor aus, indem man das Tier beiderseitig blendet, so reagiert das Tier nicht mehr durch Verändernng seiner Hautfärbung auf die verschiedene Farbe seiner Umgebung.

Es ließen sich noch eine ganze Anzahl von Experimentaluntersuchungen anfuhren, bei denen eine direkte Beeinflussung der Keimzellen durch den unmittelbar zu ihnen dringenden physikalischen Reiz meiner Ansicht nach ausgeschlossen ist. Was für ein physikalischer Reiz ist es, der bei der Raupe von Gracilaria stigmatella, die Schröder ${ }^{1}$ durch Abschneiden der Blattspitzen der von ihnen bewohnten Weidenbäume zu einer Änderung bei der Anlage ihres Gespinstes gezwungen hat und die diese neue Gewohnheit anf einen Teil ihrer Nachkommenschaft, denen unverstlimmelte Weidenblätter zur Verftigung gestellt waren, vererbten, was fur ein physikalischer Reiz ist es, der hier die Keimzellen getroffen hat? Fast alle Tiere, die man in der Gefangenschaft hält, werden mit der Zeit zahmer. Przibram ${ }^{2}$ beobachtete nun bei der von ihm gezüchteten Gottesanbeterin (Sphodromantis)

1 F. C. Schröder, Über experimentell erzengte Instinktvariationen. Verhandl. d. Zool. Ges., Leipzig 1903.

2 H. Przibram, Aufzucht, Farbwechsel und Regeneration der Gottesanbeterin (Mantidae) III. Archiv f. Entw. -Mech., 28. Bd., 1909, vgl. auch desselben Autors experimentelle Zoologie, Bd. 3, Phylogenese, Leipzig and Wien 1910, S. 161. 
eine zunehmende Zahmheit mit jeder in der Gefangenschaft unter vollkommenem Ausschluß von Selektion gezlichteten Generation. Wo steckt hier der physikalische, die Keimzellen direkt treffende Reiz? Eine Zusammenstellung der übrigen für diesen Punkt besonders beweisenden Fälle habe ich im achten Abschnitt meiner Arbeit uber den Stand der Frage nach der Vererbung erworbener Eigenschaften gegeben.

In zahlreichen Fällen ist natürlich die Möglichkeit nicht in Abrede zu stellen, daß viele physikalische und chemische Reize als solche durch die Gewehe des Körpers hindurch bis zu den Keimzellen durchzudringen vermögen. Wenn man z. B. eine Pflanze oder einen Kaltblüter abkuhlt, so werden auch seine Keimzellen direkt von der Temperaturerniedrigung betroffen. Ein chemischer, den Körpersäften einverleibter Stoff kann als solcher direkt bis zu den Keimzellen gelangen usw. Derartige Reize nun wirken nach Weismann und seinen Anhängern nicht nur gesondert auf den eigentlichen Körper, das „Soma und die Keimzellen, sondern sie entfalten bei diesem gesonderten Eintritt hier and dort auch eine korrespondierende Wirkung. Im Soma bewirken sie, durch spezifizierte Reizpforten eindringend und sich bei ihrer weiteren Ausgestaltung uberall spezifizierter Apparate und Systeme bedienend, ganz bestimmate morphologische und dynamische Veränderungen. Ganz unabhängig davon sollen sie an den Keimzellen ohne die Vermittlung solcher Apparate eine korrespondierende Abänderung der entsprechenden Determinanten im Keimplasma bewirken Detto ${ }^{1}$ hat diese hypothetisch angenommene gleichartige Beeinflussung einerseits des Somas mit seinen komplizierten Ap-

1 C. Detto, Die Theorie der direkten Anpassung. Jena 1904. 
paraten zur Reizaufnahme und Ausgestaltung, andererseits der Weismannschen »Determinanten * des Keimplasmas treffend als -parallele Induktion * bezeichnet. Trotz dieser seiner Patenschaft steht er übrigens dieser Hypothese in der Hauptsache kritisch gegentuber. Die Beeinflussung der Keimzellen durch das Soma auf dem Leitungswege, wie sie in unseren obigen Ausführungen vertreten worden ist, wird von Detto als $\gg$ somatische Induktion * bezeichnet.

$\mathrm{Zu}$ der Lehre von der Parallelinduktion wurde Weismann durch die aprioristische Annahme gefuhrt, daß jede Beeinflussung des Keimplasma durch das Soma ausgeschlossen werden musse. Es hängt, so sagt er tiber das Keimplasma, * seine Beschaffenheit, also vor allem seine Molekularstruktur, nicht von dem Individuum $a b$, in dem es zufällig gerade liegt, sondern dies ist gewissermaßen nur der Nährboden, auf dessen Kosten es gerade wächst; seine Struktur aber ist von vornherein gegeben ${ }^{1}$. Schon diese Vorstellung von der reizphysiologischen Isolierung des Keimplasmas vom Soma steht im Widerspruch mit dem anatomischen Tatbestand, denn die Histologie hat unzweifelhaft festgestellt, daß die Keimzellen mit dem übrigen Soma organisch zusammenhängen und von ihm durch keinerlei isolatorische Apparate geschieden sind.

Was nun die physiologische Grundlage der Lehre von der Parallelinduktion anlangt, so habe ich dieselbe in Stand der Frage ausfuhrlicher untersucht und kann mich deshalb hier darauf beschränken, an einem einzelnen Beispiel zu zeigen, daß fundamentale physiologische Schwierigkeiten diese Annahme, soweit es sich um spezifische Reizwirkungen handelt,

1 A. Weismann, Aufsätze über Vererbung, Jena 1892, S. 323. 
unmöglich machen. Przibram ${ }^{1}$ and Sumner ${ }^{2}$ haben unabhängig voneinander gefunden, $\mathrm{daB}$ bei Ratten und Mänsen, die man bei ungewöhnlich hohen Temperaturen hält, der Haarpelz düner wird, während gleichzeitig die peripheren Organe wie Ohren, Fủße, Schwänze, änßere Geschlechtsorgane an Größe zunehmen; bei Tieren, die bei ungewöbnlich tiefen Temperaturen gehalten werden, tritt das umgekehrte ein. Diese Veränderungen erweisen sich unter Umständen als erblich, d. h. sie treten bei den Nachkommen auch dann wieder auf, wenn dieselben in mittleren Temperaturen ansgetragen, geboren und aufgezogen werden. Was können wir aber diesen Experimenten für die physiologische Seite der Frage entnehmen?

Nicht allzu extreme Temperatureinflìsse auf Säugetiere wirken als solche beinahe ausschließlich auf ihre äußere Haut ein, da die Wärmeregulation des Tiers die anderen Organe diesen Einflussen so gut wie gauz entzieht. Dementsprechend lassen sich denn auch fast alle morphologischen Reaktioneu, die sich auf solche Einwirkungen hin einstellen, auf Reaktionen der Haut zurückführen. Bei länger dauernder Wärmeeinwirkung vergrößern sich die peripher freien Teile wie Ohren, Schwänze, Hände und Fủe, Hautfalten und Hauthüllen der Geschlechtsorgane; gleichzeitig findet ein Dunnerwerden der Behaarung statt. Alles dies sind ganz vorwiegend Reaktionen des einzigen von der Hitzewirkang direkt betroffenen Organs, der Haut. Einen Hauptanstoß zu diesen Veränderungen gibt dabei wohl die durch die Wärmewirkang

1 Vortrag auf der 81. Versammlung deatscher Naturforscher und Ärzte im September 1909 in Salzburg.

2 F. B. Sumner, An experimental Study of Somatic Modifications and their Reappearance in the offspring. Arch. f. Entw. Mechanik, 30. Bd., II. Teil, 1910. 
bedingte mächtige Entwicklung der Schweißdrlisen und ihrer Ausfuhrgänge, die eine Oberflächenzunahme der gesamten Haut bedingt und andererseits ein teilweises Verdrängen der Haarbälge und ihrer Talgdrusen mit sich bringt. Die stärkste Ausbildung der Schweißdrusen hat, wio uns die vergleichende Anatomie lehrt, an den Sohlenflächen von Händen und Füßen stattgefunden; bei vielen Tieren wie auch dem Menschen ist hier völlige Haarlosigkeit bei gleichzeitiger stärkster Ausbildung der Schweißdrtisen aufgetreten. An Händen und Fußen erfolgt denn auch bei längerer Wärmeeinwirkung besondere Größenzunahme, und bei klimatischen Wärmevarietäten, wo noch Sohlenbehaarung vorhanden ist, Enthaarung, während sich bei den entsprechenden Kältevarietäten eine Haarbedeckung der Sohlenflächen vorfindet. Bei Kälteeineinwirkung machen sich die entgegengesetzten Reaktionen bemerkbar, wobei tubrigens nicht nur eine Reduktion der Schweißdrüsen, sondern auch eine direkt anregende Wirkung der Kälte anf das Haarwachstum in Frage kommt.

Wir finden hier also bei näherer Analyse (abgesehen von den mehr allgemeinen Wirkungen auf Körpergröße und Entwicklungstempo) eine Menge durchaus lokalisierter und spezifizierter Wirkangen der Reize. Und bei dieser Sachlage sollen wir annehmen, daß eine Erwärmung der Keimzellen in toto durch eine leichte (wenn tiberhaupt vorhandene ${ }^{1)} \mathrm{Er}$ -

1 Eine solche leichte Erhöhung der Körpertemperatur war wahrscheinlich bei den Experimenten Przibrams in den Fällen vorhanden, in denen er die Ratten in den Hitzegraden von $30^{\circ}-35^{\circ} \mathrm{C}$ hielt. Bei den Sumnerschen Experimenten (mittlere Temperatur der Wärmeräume 26,3 $3^{\circ}$ C) kommt eine Erhöhung der Körpertemperatur, wie aus seinen neusten Mitteilungen (Some Effects of Temperature upon growing Mice Amer. Naturalist, V.45, Febr. 1911, S. 93) hervorgeht, überhaupt nicht in Frage. 
höhung der Gesamttemperatur, die das >Keimplasma * direkt ohne Vermittlung der lokalisierten and differenzierten Rezeptoren der Haut trifft, dennoch eine genan korrespondierende, auch beim Nachkommen im Grunde wieder organologisch ausschließlich auf die Haut beschränkte Wirkung hervorgebracht haben soll! Diese Spezifikation der Reizwirkang, besonders aber ihre Lokalisation a uf die Haut läßt die physiologische Hinfälligkeit des Gedankens der Parallelinduktion in besonderer Deutlichkeit hervortreten.

In Stand der Frage habe ich diese fundamentalen physiologischen Schwierigkeiten fur die Annahme einer Parallelinduktion noch an zahlreichen anderen Beispielen erläutert. Andererseits ist es klar, daß solche Schwierigkeiten bei der Annahme einer somatischen Induktion, d. h. bei der einzig naturgemäßen Auffassung des Individuams mit seinem Soma und seinen Keimzellen als eines organischen Ganzen vollkommen fortfallen. Das ^Somak liefert hier eben die unentbehrlichen Apparate zur Rezeption und Transformation der Reize in die spezifischen Erregungen für den Gesamtorganismus mit Einschluß der Keimzellen und damit der Erregungswirkungen sowohl bei den Eltern wie bei den Kindern. Voraussetzung ist dabei nur die hinreichende Empfindlichkeit der reizbaren Substanz der Keimzellen, anf die so ubermittelten Erregungen auch anzusprechen. Die Tow er sche Entdeckung einer Periode gesteigerter Empfindlichkeit, einer s sensiblen Periode * der Keimzellen ist geeignet, manche Rätsel and bisher unverständliche Launen der Reizubertragung der Erklärung näher zu bringen.

Als Endresultat anserer Untersuchungen tiber die Lokalisation einerseits der erblich libertragenen, andererseits der individuell erworbenen Engramme innerhalb des Organismus 
ergibt sich folgendes: Die Tatsachen der Regeneration und der experimentell beeinflußten Embryogenie lehren uns, daß jede Zelle oder, besser noch, jedes mnemische Protomer eines sich entwickelnden sowie eines ausgebildeten Organismus sich im Besitz aller derjenigen Engramme befindet, die der Organismus als Ganzes von seinen Vorfahren ererbt hat. Natülich ist damit nicht gegeben, daß jedes Teilstuck oder mnemische Protomer imstande ist, jedes dieser erblichen Engramme jederzeit zur Ekphorie kommen zu lassen (d. h. jederzeit den zugehörigen Erregungszustand zu reproduzieren). Dazu ist der Eintritt einer ganz bestimmten energetischen Situation erforderlich.

Die engraphischen Einwirkungen, die den Organismus in seinem individuellen Leben treffen, wirken zwar anf jedes einzelne Protomer des Körpers, aber sie wirken je nach der Art, wie der Reiz in den Organismus eintritt, und wie sich die Erregung in diesem fortpflanzt, in verschiedener Stärke anf die versehiedenen Protomere entsprechend der topographischen Verteilung derselben. Die ansgeprägtesten Unterschiede in der lokal verschiedenen Beeinflussung der Protomere desselben Individuums ergeben sich dabei bei Organismen mit einem hochdifferenzierten Nervensystem, von dem gewisse Abschnitte bei Wirbeltieren, Insekten, Cephalopoden zu einer Art >Multiplikator \& der Erregungen werden können. In diesen Regionen werden die Protomere auch besonders stark engraphisch beeinflubt. Wie sich anf dieser Basis die bei höheren Wirbeltieren und dem Menschen beobachteten mnemischen Lokalisationsphänomene erklären, ist oben ausfuhrlicher auseinandergesetzt worden. Wir kommen zu dem Schlnßergebnis, daß jedes Protomer des Körpers in den Besitz auch der meisten im individuellen Leben vom Organismus aufgenommenen En- 
gramme gelangt, aber je nach seiner topographischen Lage die eine Gruppe von Engrammen stärker, die andere schwächer aufnimmt, als es die in anderen Regionen des Körpers gelegenen Protomere tun. Besonders durch ihre Lage bevorzugt erweisen sich die Protomere, die bei den höheren Wirbeltieren in der Großhirnrinde gelegen sind. Auf mehr indirektem Wege können wir aus verschiedenen Tatsachen der vergleichenden Anatomie und Physiologie schließen, daß die Protomere der Rindenschicht des oberen Schlundganglions bei Insekten (besonders Hymenopteren) und der Rindenschicht der Cerebralganglien der Cephalopoden eine ähnliche bevorzugte Stellung einnehmen. Eine einmalige Erregung kann bei Protomeren, die sozusagen im jeweiligen Brennpunkt dieser Kondensoren liegen, schon ein kräftiges Engramm erzeugen. Ganz außerhalb dieser Brennpunkte liegt die reizbare Substanz der Keimzellen. Gerade die nerrösen Erregangen gelangen nur auf vielerlei Umwegen und in der Regel sehr stark abgeschwächt bis zu ihnen. Häufige Wiederholung im individuellen Leben und Wiederholung dieser Wiederholung in der Folge der Generationen ist aber imstande, schlieBlich aus dieser zunächst sublimalen engraphischen Wirkung supraliminale, d. h. manifestationsfähige erbliche Engramme zu erzeagen.

Meiner Ansicht nach stehen mit den so von uns gewonnenen Anschauungen über die Lokalisation der individuell erworbenen Engramme and tiber die Art, wie dieselben den Keimzellen mitgeteilt werden können, sowohl alle die zahlreichen Tatsachen der Hirnphysiologie und Hirnpathologie als anch alle die Erfahrangen in vollem Einklang, die iiber das Erblichwerden von erworbenen Eigenschaften gemacht worden sind. Im Plane der vorliegenden Arbeit liegt es 
aber bloB, dem mnemischen Lokalisationsproblem gegentiber einen Standpankt zu gewinnen, der alle Seiten des Gebiets beherrscht. Dies ist uns, wie ich glaube, gelungen. Von diesem Standpunkt aus das ungeheure Tatsachenmaterial der cerebralen Lokalisation sowie der Vererbungsphänomene im einzelnen zu analysieren, würde zu einer zu großen Belastung des vorliegenden Buches fuhren. Da ich aber eine Durchfuhrung dieser Aufgabe auf der von uns gewonnenen Basis fur möglich halte, hoffe ich Gelegenheit zu haben, in späteren Arbeiten ausfuhrlicher darauf zurtickzukommen. 


\section{Sechstes Kapitel.}

\section{Die Ekphorie der Engramme. Die beiden mnemischen}

Hauptsätze.

Unter Ekphorie eines Engramms verstehen wir die Versetzung eines Engramms aus seinem latenten in seinen manifesten Zustand oder, anders ausgedrickt, die Aktivierung einer Erregungsdisposition, die als bleibende, aber für gewöhnlich latente Veränderung im Organismus zurtickgeblieben ist. Das manifest gewordene Engramm oder die Erregang, die sich auf dem Boden jener Erregungsdisposition entwickelt, haben wir als $\mathrm{mnemisch}$ e Erregung bezeichnet. Wir haben keinerlei Grund, anzunehmen, daß sich die mnemische Erregung als solche in ihrem Wesen von ihrer Vorläuferin und Vorarbeiterin, der Originalerregung, unterscheidet ${ }^{1}$. Außer dem Umstand, daß die mnemische Erregung zu ihrem Zustandekommen uberhaupt des Vorangehens der Originalerregung bedarf, daß also zwischen beiden das Verhältnis einer einseitigen, nicht reziproken Determinierung besteht, unterscheiden sich beide durch das, was zu ihrer Auslösung erforderlich ist.

Der originale Erregungskomplex wird hervorgerufen und aufrecht erhalten durch die mit der Erregung synchrone

1 Bzgl. näherer Ausführungen dieses Satzes bei Betrachtang von der Empfindungsseite her vgl. das 12. Kapitel der Mnemischen Empfindungen: 
Einwirkung eines Reizkomplexes, den wir als originalen Reizkomplex bezeichnen. Der entsprechende mnemische Erregungskomplex bedarf za seiner Auslösung nicht der Wiederkehr dieses Reizkomplexes, sondern nur eines meist viel kleineren Anstoßes, den wir als den ekphorischen bezeichnet haben. Derselbe besteht in der partiellen Wiederkehr derjenigen energetischen Situation, die vormals engraphisch gewirkt hat. Indem wir uns die endgultige Formulierung für den Schluß des Kapitels vorbehalten, wollen wir zunächst einmal die Unterschiede zwischen der Hervorrufung eines originalen und der Ekphorie eines mnemischen Erregungsablaufs an der Hand der beiden folgenden Schemata klar machen, von denen das erste einen originalen, das zweite

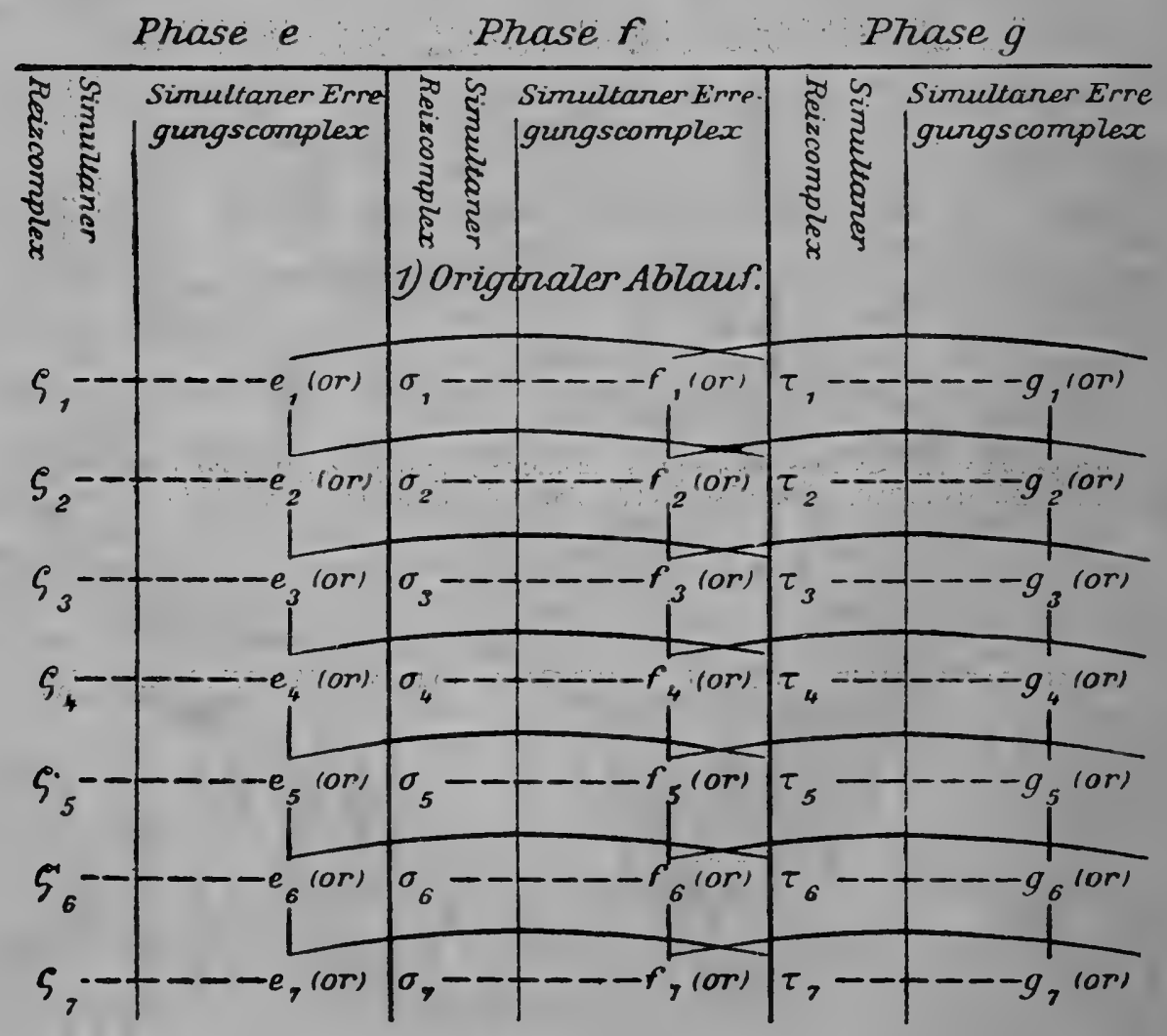


Die Ekphorie der Engramme. Die beiden mnemischen Hauptsätze. 189

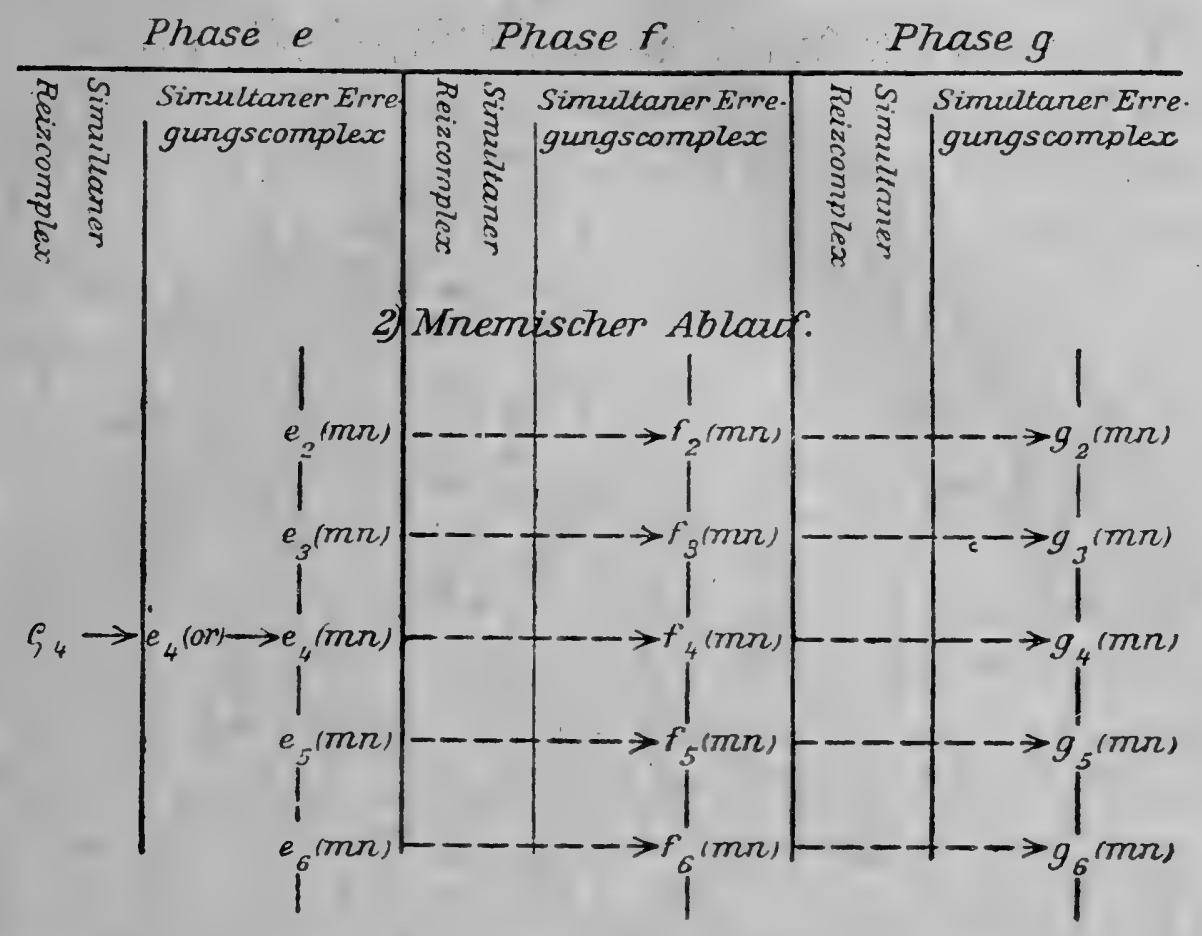

einen mnemischen Ablauf in den drei Phasen $e, f$ und $g$ wiedergibt.

Bei dem originalen Ablauf löst in der Phase $e$ der Reizkomplex $\varrho_{1-7}$ den originalen Erregungskomplex $e_{1-7}$ (or) ans; in der Phase $f$ der Reizkomplex $\sigma_{1 \rightarrow}$ den originalen Erregungskomplex $f_{1-7}$ (or); in der Phase $g$ der Reizkomplex $\tau_{1-7}$ den originalen Erregungskomplex $g_{1-7}$ (or). Nun nehmen wir an, daß von den drei sukzessiven Erregungskomplexen $e_{1 \rightarrow}$ (or), $f_{1 \rightarrow 7}$ (or), $g_{1-7}$ (or) die Komponenten mit gleichen Vorzeichen wie $e_{1}, f_{1}, g_{1}$ oder $e_{2}, f_{2}, g_{2}$ oder $e_{3}, f_{3}, g_{3}$ usw. innigere Beziehungen zueinander haben, wie die mit ungleichen, also etwa $e_{1}$ zu $f_{2}$ oder $f_{4}$ zu $g_{5}$. Dann werden, wie wir S. 125 gesehen haben, die von den gleich vorgezeichneten Komponenten erzengten Engramme fester untereinander assoziiert, d. h. wirken bei der Aktivierung stärker sukzessiv ekphorisch aufeinander als die ungleich vorgezeichneten. Dies ist im Schema 
für den originalen Ablanf durch die horizontalen gebogenen Bindungslinien angedeutet, während die Entstehung der simultanen Assoziation durch die vertikalen geraden Bindungslinien zum Ausdruck gebracht ist. Man könnte vielleicht die Anbringung dieser Verbindungslinien bei den Originalerregungen beanstanden and sagen, daß die Anwesenheit solcher Bindungen von uns bisher nur fur die von den Originalerregungen erzengten Engramme bewiesen worden sei.

Die Engramme sind indessen lediglich und ohne jede sonstige Zutat die Produkte der Originalerregungen, und deshalb sind anch die Eigentumlichkeiten ihrer Bindungen auf die entsprechenden Eigenschaften ihrer Erzenger: der Originalerregungen zurtickzufuhren. Die Richtigkeit dieses logischen Schlusses findet durch die Beobachtung unmittelbare Bestätigung. Am deutlichsten ergibt die introspektive Methode die engere Bindung der originalen sukzessiven Komponenten in genau derselben Weise, wie sie später bei Ekphorie der entsprechenden Engrammkomplexe zutage tritt. So nehmen wir z. B. bei Anhörung eines Musikstücks die engere Bindung der sukzessiven Erregungen innerhalb der einzelnen Stimmen durch unmittelbaren Bewußtseinsvorgang wahr, oder bei melodramatischer Vorfuhrung die engere Bindung der Worte einerseits, der Musik andererseits, oder endlich beim Anblick zweier gleichzeitig, aber getrennt voneinander tanzenden Figuren die engere Bindung der Bewegungen der einen und der Bewegungen der anderen Figar.

Nach Ablauf jeder einzelnen originalen Simultanphase verschwindet der betreffende Erregungskomplex, bzw. er tritt; soweit er engraphisch gewirkt hat, in ein Latenzstadium.

1 Vgl. das daruber oben (S: 126) Gesagte. 
Die Ekphorie der Engramme. Die beiden mnemischen Hauptsätze. 191

Sind alle drei Phasen abgelaufen, so sind, wenn wir eine stärkere engraphische Wirkung aller Komponenten voraussetzen, folgende drei Engrammkomplexe in folgender Anordnung und Bindung zurtickgeblieben:

\begin{tabular}{|c|c|c|}
\hline $\begin{array}{c}\text { Simultaner } \\
\text { Engrammkomplex } \\
e\end{array}$ & $\begin{array}{c}\text { Simultaner } \\
\text { Engrammkomplex } \\
f\end{array}$ & $\begin{array}{c}\text { Simultaner } \\
\text { Engrammkomplex } \\
g\end{array}$ \\
\hline
\end{tabular}

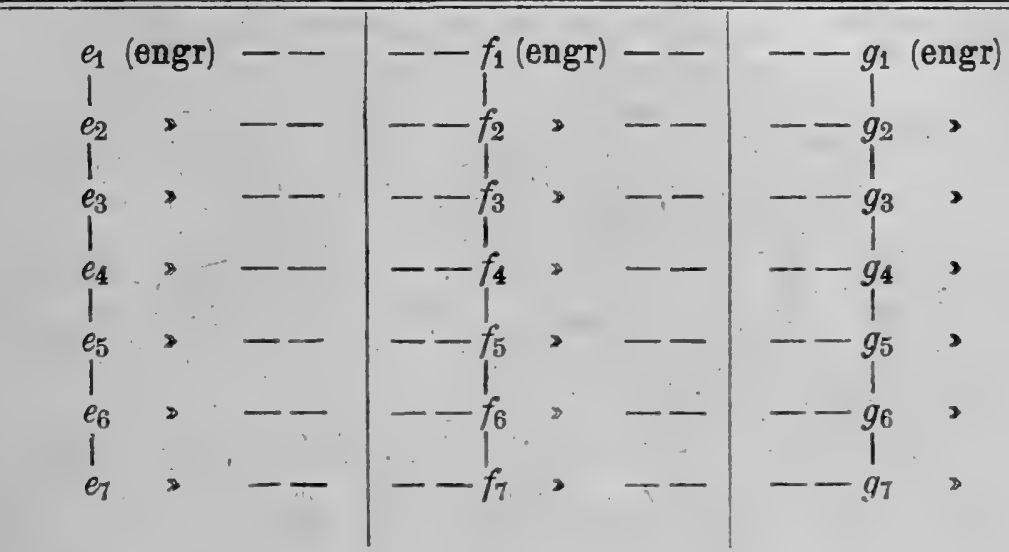

Ekphoriert werden können diese drei sukzessiv assoziierten Engrammkomplexe vom Simultankomplex $e$ aus durch Auftreten der originalen Erregungen $e_{1-7}$ (or) oder eines Einzelkomponenten dieses Komplexes. Wir haben in unserem Schema S. 189 die Einzelkomponente $e_{4}$ (or) gewählt, und diese ihrerseits durch die Reizkomponente $\varrho_{4}$ ausgelöst sein lassen. Man könnte fragen, warum ich nicht einfach sage, die Ekphorie erfolge durch den Reiz $\varrho_{4}$. Die von mir gewählte Ansdrucksweise hat folgenden Grund. Wie die sukzessive Ekphorie (im Schema z. B. in Phase $f$ und $g$ ) lehrt, bedarf es zur Aktivierung einer mnemischen Erregung gar nicht der Originalreize, auch nicht eines Bruchteils derselben, sondern bloß der entsprechenden Erregungen. Bei der Ekphorie, wie ich sie im Schema 
des mnemischen Ablaufs in Phase $e$ zum Ausdruck gebracht habe, ist jedenfalls, wie noch im nächsten Kapitel bei Besprechung der mnemischen Homophonie auseinandergesetzt werden wird, nach Eintritt des Reizes $\varrho_{4}$ nicht nur die mnemische Erregung $e_{4}(\mathrm{mn})$, sondern neben ihr auch die Originalerregung $e_{4}$ (or) nachweisbar. Wir sind in Anbetracht des Umstandes, daB die Engramme $e_{2}, e_{3}, e_{5}, e_{6}, f_{2-6}$ und $g_{2-6}$ nicht durch die originalen Reizkomponenten, sondern durch die von diesen ausgelösten Erregungen ekphoriert werden, durchaus berechtigt, anzunehmen, daß auch das Eugramm $e_{4}$ (engr) nicht direkt durch den Reiz $\varrho_{4}$, sondern durch die von diesem ansgelöste Originalerregung $e_{4}$ (or) ekphoriert wird.

Der im Schema S. 189 eingetragene mnemische Ablauf ist also folgender. Der Reiz $\varrho_{4}$ löst die Originalerregung $e_{4}$ (or) aus. Der Eintritt dieser Erregung wirkt ekphorisch zunächst auf das Engramm $e_{4}$ (engr) und aktiviert es zu der mnemischen Erregung $e_{4}(\mathrm{mn})$. Das Auftreten der Erregung $e_{4}$ (or) $+e_{4}(\mathbf{m n})$ wirkt aber weiter ekphorisch auf alle oder einen Teil der mit dem Engramm $e_{4}$ simultan assoziierten Engramme. Wir haben im Schema angenommen, daß er hinreichend stark ekphorisch nur auf einen Teil, nämlich die Engramme $e_{2}, e_{3}, e_{4}$ und $e_{6}$, nicht aber auf $e_{1}$ und $e_{7}$ wirkt. An die Ekphorie des Teilkomplexes $e_{2-6}$ schließt sich dann durch sukzessive Assoziation in der im Schema angedeuteten Weise die Ekphorie der Teilkomplexe $f_{2-6}$ und $g_{2-6}$. Beim mnemischen Ablauf hat also in unserem Falle die Auslösung der Originalerregung $e_{4}$ durch den Reiz $\varrho_{4}$ dieselbe oder nahezu dieselbe Wirkung gehabt wie beim originalen Ablanf das Zusammenwirken der Reize $\varrho_{2-6}, \sigma_{2-6}, \tau_{2-6}$.

Wir haben nun zunächst noch eine besondere Eigentum- 
Die Ekphorie der Engramme. Die beiden mnemischen Hauptsätze. 193

lichkeit der Ekphorie zu erörtern, auf die in unserem Schema S. 189 beim mnemischen Ablauf bereits Rucksicht genommen worden ist. Die Wiederkehr eines Bruchteils derjenigen energetischen Situation, die engraphisch gewirkt hat, kann den ganzen oder doch den größten Teil des entsprechenden simultanen Engrammkomplexes ekphorieren, sie braucht es aber nicht za tun. Tatsächlich ekphoriert sie sogar fast immer nur Bruchstuicke, die zwar die ekphorisch wirkende Erregung an Menge der Komponenten weit tibertreffen können, sich aber doch so gut wie nie auf alle Komponenten des Engrammkomplexes erstrecken. In unserem Schema ist dies so ausgedruckt, daß die durch $\varrho_{4}$ ausgelöste Originalerregung $e_{4}$ (or) zwar die mniemischen Erregungen $e_{2-6}(\mathrm{mn})$ ekphoriert, aber nicht mehr die Fähigkeit hat, auch die Engramme $e_{1}$ (engr) und $e_{7}$ (engr) mit zu ekphorieren. Um ein Beispiel anzufuhren, greife ich auf den im Kapitel über die Entstehung der Engramme (S. 121) erwähnten Fall zurlick. Eine bestimmte, durch den Duft von siedendem Olivenöl ausgelöste Geruchserregung ekphoriert mit Sicherheit bei mir das assoziierte Engramm: Bild Capris von einem bestimmten Punkte Neapels aus gesehen. Dagezen vermochte diese Erregang nicht andere Teile des zugehörigen Simultankomplexes, z. B. das Engramm der Leierkastenmelodie, zu ekphorieren. Diese Ekphorie war nur dadurch möglich, daß mir die Melodie später wieder einmal rorgespielt wurde. Um in der Sprache unseres Schemas zu reden, war, wenn $e_{1}$ (engr) das Engramm des einleitenden Akkordes jenes Leierkastenliedes vorstellt, die Ekphorie dieses Engramms nur durch Wiederkehr der Originalerregung $e_{1}$ (or) möglich

Wir können uns leicht überzeugen, daß dasjenige, was Somon, Mnsme.' 3. Aufi. 
wir bei uns selbst und unseren Mitmenschen als gates Gedächtnis bezeichnen, nur zum Teil auf der Leichtigkeit und Dauerhaftigkeit beruht, mit welcher die Reize auf den Organismus engraphisch wirken.

Fast ebenso wichtig als der Besitz zahlreicher und gut fixierter Engramme ist die leichte Ekphorierbarkeit derselben auf dem Wege der simultanen and sukzessiven Assoziation in all ihren mannigfachen Abarten und Kombinationen. Durch sie ist eine weit ausgiebigere Inbetriebnahme der Engramme ermöglicht, als wenn die Ekphorie bloß durch die Wiederkehr des Originalreizes, der frtiher zur Erzeugung dieses Engramms gedient hat, zu erzielen wäre. Letzterem Fall entspricht das Vorspielen der Melodie, anf die man sich nicht besinnen kann, oder das Vorsagen des Wortes, das dem •Gedächtnisschwachen $\approx$ nicht einfallen will. Erkennt er es auch dann nicht wieder ${ }^{1}$, so liegt die Vermutung nahe, daß es therhaupt nicht engraphisch fixiert worden ist. Ganz sicher ist dieser Schluß aber auch nicht, denn wenn im übrigen die energetische Situation sehr verändert ist, in Aufregungszuständen, bei Intoxikationen, bei manchen vortibergehenden Amnesien gentugt auch die Wiederkehr des Originalreizes noch nicht zur Ekphorie des zugehörigen Engramms. Das heißt: der Aufgeregte, Betrunkene, Geisteggestörte vermag nicht, ihm sonst wohlbekannte Dinge wiederzuerkennen. Sehr lehrreich sind in dieser Beziehung die sogenannten periodischen Amnesien, unter denen die Fälle von Bildung zweier selbständiger Gedächtnisse oder »doppelter Persönlichkeit « für uns besonders wichtig sind.

1 Auf die Reaktion des $>$ Wiedererkennens sten Kapitel näher ein. 
Die Ekphorie der Engramme. Die beiden mnemischen Hauptsätze. 195

Ich zitiere hier einen beruhmten Fall von Macnish (Philosophy of Sleep) nach Ribot 1 .

-Eine junge Amerikanerin verlor nach einem langen Schlafe die Erinnerung von allem, was sie gelernt hatte. Sie konnte weder buchstabieren, noch lesen, nicht schreiben, noch rechnen und erkannte auch die Gegenstände und Personen ihrer Umgebung nicht mehr. Einige Monate darauf fiel sie wieder in einen tiefen Schlaf, und als sie erwachte, war sie wieder im Besitz all ihrer Kenntnisse and Jugenderinnerangen, befand sich uberhaupt so, wie sie vor ihrem ersten Schlaf gewesen war, hatte dagegen nun alle Vorfälle während ihres ersten Anfalls vergessen. Vier Jahre und daruber ist sie abwechselnd ron einem Zustand in den anderen ubergegangen, regelmäßig nach einem langen und tiefen Schlafe... Von ihrer doppelten Persönlichkeit hat sie nicht das geringste Bewußtsein. In ihrem ailen Zustand besitzt sie z. B. alle ihre ursprünglichen Kenntnisse, in dem neuen Zustand nur diejenigen, welche sie seit ihrer Krankheit hat erwerben können; im alten Zustand hat sie eine schöne Handschrift, im neuen schreibt sie schlecht und ungeschickt, da sie wenig Zeit zur Übung gehabt hat. Es genligt nicht, daß ihr Personen in einem der beiden Zustände vorgestellt sind; wenn sie dieselben hinlänglich kennen soll, so muß sie sie in beiden Zaständen gesehen haben. Dasselbe gilt für alle anderen Sacheri. *

Ganz ähnliche Zustände kommen bei manchen Fällen von

1 Th. Ribot, Das Gedächtnis und seine Störungen. Deutsche Über. setzung. Hamburg und Leipzig 1882. Die letzten Jahrzehnte haben unsere Kenntnisse in dieser Richtung noch außerordentlich bereichert und uns in Besitz eines imposanten Beobachtungsmaterials gesetzt. Ein näheres Eingehen darauf soll in der zweiten Fortsetzung der Mneme erfolgen. 
Hysterie vor, und ein ähnliches • Alternieren des Gedächtnisses s beobachten wir bei Hypnotisierten, die sich der Vorgänge während einer Hypnose zwar nicht beim Wiedererwachen, wohl aber in der nüchsten Hypnose zu erinnern vermögen. Auch durch Intoxikation, z. B. mit Alkohol, läßt sich unter Umständen eine energetische Situation schaffen, deren Engramme erst bei der nächsten Intoxikation, nicht im Zustande der Nichternheit, ekphorierbar sind. Sehr lehrreich ist in dieser Beziehung das von Ribot (a. a. 0. S. 72) berichtete Beispiel von dem irischen Gepäckträger, der in der Betrunkenheit ein Paket verloren hatte, und sich erst während eines neuen Rausches zu erinnern vermochte, wo er es liegen gelassen hatte. In allen diesen Fällen ist im Zustande $b$ (Zustand des Schlafs oder der pathologischen Störung oder der Hypnose oder der Intoxikation oder des Fiebers) eine vom Zustande $a$ (Zustand des Wachseins, der Abwesenheit von Störungen, der Nüchternheit) so verschiedene energetische Situation geschaffen, daß die Ekphorie der im Zustande $a$ erworbenen Engramme im Zustand $b$ nur sehr liuckenhaft, in ausgeprägten Fällen nur in bezug auf sehr gut ekphorierbare Engramme gelingt and umgekehrt. , Gut ekphorierbar « pflegt dabei mit tief eingeprägt und häufig ekphoriert, weil von Jugend an in Gebrauch gewesen, gleichbedeutend zu sein.

Za ganz ähnlichen Resultaten ist Ribot gekommen, der in bezug anf die periodischen Amnesien (a. a. O. S. 71) sagt: -In Summa, zwei physiologische Zustände bestimmen durch ihren Wechsel zwei Gemeingefthle, diese wieder bestimmen zwei Assoziationsformen und folglich zwei Gedächtnisse.

Im allgemeinen werden wir nunmehr in bezug auf die simultane Ekphorie eines bestimmten Engramms wohl fol- 
Die Ekphorie der Engramme. Die beiden mnemischen Hauptsätze. 197

gende Stufenleiter der ekphorisch wirkenden Einflissse aufstellen dürfen:

1. Am stärksten ekphorisch wirkt die möglichst vollståndige Wiederkehr der energetischen Situation, die sich bei der Erzeugung des Engramms vorfand.

2. Kehren nur Bruchteile dieser Situation wieder, so wirkt von diesen am stärksten ekphorisch die Wiederkehr der speziellen Originalerregung, die das betreffende Engramm erzeugt hat. Unter Umständen (beđeutende Änderung der übrigen energetischen Situation) kann aber selbst diese Partialwiederkehr unwirksam bleiben.

3. Befindet sich diese Originalerregung nicht unter den wiederkehrenden Bruchsticken, so wirken von den übrigen simultan assoziierten Engrammen des gemeinsamen Komplexes nicht alle in gleicher Weise, sondern sie wirken in Abstufungen ekphorisch.

Auch die beiden besonderen Arten von Ekphorie, die wir bereits in unserer vorläufigen Orientierung kennen gelernt und mit den Namer chronogene und phasogene Ekphorie bezeichnet haben, sind im Grunde nur besondere Fälle, für die unsere allgemeine Definition des ekphorischen Einflusses ohne Einschränkung und Zusatz gilt.

In beiden Fällen wirkt die totale oder partielle Wiederkehr and der Ablanf einer bestimmten energetischen Situation ekphorisch, und zwar im Falle reiner chronogener wie reiner phasogener Ekphorie die Wiederkehr einer inneren energetischen Situation.

Chronogene Ekphorie beobachteten wir sowohl individuell erworbenen als auch ererbten Engrammen gegentiber in Wirksamkeit. Was individuell erworbene Engramme an- 
langt, so erinnere ich an die S. 52 erörterten Beispiele. Wenn wir gewohnt sind, täglich unsere erste Mahlzeit um 8 und unsere zweite um $1 \mathrm{Uhr}$ einzunehmen, so versptiren wir in der Zwischenzeit keinen Hunger. Schieben wir aber aus irgendeinem Grunde einige Zeit lang um 11 eine Zwischenmahlzeit ein, so meldet sich, auch wenn wir mit ganz anderen Dingen beschäftigt sind, bald regelmäßig und pünktlich um 11 Uhr ein eindringlicher Appetit. Ebenso geht es uns mit unserem Schlafbedürfnis, wenn wir plötzlich anfangen, unser Tagewerk durch ein eingeschobenes Schlafstïndchen zu unterbrechen; auch bier tritt nach einiger Zeit die Müdigkeit auf Grund rein chronogener Ekphorie auf.

Ein prachtrolles Beispiel von chronogener Ekphorie bei Axolotln wird von Frl. v. Chauvin (a. a. O. S. 382) berichtet. Verschiedene dieser Tiere waren $v 0 \mathrm{n}$ ihr in einem dauernden Zwischenzustande zwischen Kiemenmolch and Landmolch dadurch erhalten worden, dals sie während 3 Jahren und 2 Monaten am Tage auf dem Lande und in der Nacht im Wasser gehalten wurden. Eins der Tiere, Nr. 4, mußte, um mit den Worten Frl. v. Chauvins zu berichten, »behufs seiner Verwandlung zum Landtier einige Zeit lang ganz auf das Wasser verzichten, und ward ihm erst nach erfolgter Häntung wieder gestattet, dasselbe aufzusuchen. Sobald das Tier nun die freie Wahl hatte, ging es zu meinem Befremden jeden Abend in das Wasser und jeden Morgen auf das Land, ungefähr zu derselben Zeit, wie es ihm durch die Gewohnheit eingeprägt worden war. Dieses fur ein Amblystoma sehr auffällige Benehmen erhielt sich vom 20. Januar bis zum 25. April ohne Unterbrechung. Von da ab blieb das Tier auch Nachts im Moos verborgen und kehrte nur noch in das Wasser zurück, wenn durch den Häutangsprozeß das Be- 
Die Ekphorie der Engramme. Die beiden mnemischen Hauptsätze. 199

dürfnis nach größerer Feuchtigkeit in ihm geweckt wurde ${ }^{1}$.

Als Beispiel der rein chronogenen Ekphorie eines ererbten Engramms haben wir oben das Öffnen und Zusammenfalten der Blätter bei Mimosen und Akazien in 12stündigem Turnus bei gleichbleibender Beleuchtung kennen gelernt; ebenso verhält es sich mit der Winterruhe unserer Buchen, kurz der Tages- und Jahresperiode vieler Pflanzen.

Die partielle Wiederkehr der inneren energetischen Situation erklärten wir uns in allen diesen Fällen mit dem Ablauf einer bestimmten Summe von Stoffwechselvorgängen, anf deren Zeitdauer, wie wir oben ausgefuhrt haben, die chronometrische Fähigkeit der Organismen beruht. Natïlich ist dieses Chronometer ebensowenig unfehlbar wie eine ron Menschenhand gefertigte Uhr, und wird vorgehen oder nachgehen, sobald es gelingt durch äußere Einflüsse irgendwelcher Art das Tempo der betreffenden Stoffwechselabläufe zu verändern. Unter Umständen ist es aber sehr schwer, auf dieses Tempo einzawirken, wie z. B. das Verhalten der Buchen während ihrer Winterruhe beweist, deren Chronometer auch durch dauernde Erwärmung, die doch, wie man annehmen sollte, das Stoffwechseltempo beschleunigen müßte, nicht merklich zum Vorgehen zu bringen ist. Wahrscheinlich sind aber gerade die hier in Frage kommenden winterlichen Stoffwechselvorgänge von der Außentemperatur in hohem Grade unabhängig. Wie wir oben (S. 80) gesehen haben, bedarf es einer Einwirkung von 20 Jahren, um den Pfirsichbaum auf

1 Auf eine briefliche Anfrage hin hat Frl. v. Chauvin die Giute gohabt, mir mitzuteilen, $d a B$ kein einziges anderes Exemplar aus der sehr großen Zahl von Axolotin, deren Umwandlung zu Landmolchen sie beobachtet hat, auch nur eine Andeutung eines solchen Verhaltens zeigte. 
Réunion aus einem sommergrünen zu einem immergrünen Baum za machen.

Auch phasogene Ekphorie ist im Grande nichts anderes als der Wiedereintritt einer bestimmten inneren energetischen Situation, und zwar genïgt gleichfalls, wie uns zahlretche Tatsachen der experimentellen Entwicklungsgeschichte und der Statistik chronologischer Variationen lehren, oft bloß der partielle Wiedereintritt derselben. Man vergleiche auch das oben bei Erörterung derjenigen Momente, die die Linienbildung in der Embryonalentwicklung auslösen, Gesagte. Selbst starke Alterationen der inneren energetischen Situation, wie sie z. B. durch die Rouxschen Anstichexperimente bei Froscheiern bedingt sind; beeinträchtigen in der unverletzten Hälfte des sich entwickelnden Organismus nicht den ungestörten Eintritt der phasogenen Ekphorien und der sich an sie anschließenden Wachstumsreaktionen. Da wirim folgenden Abschnitt auf die phasogene Ekphorie und ihre Besonderheiten noch ausführlich zurijckkommen müssen, gehen wir an dieser Stelle, um Wiederholungen zu vermeiden, nicht näher auf diese Fragen ein.

Die Hauptresultate, za denen wir in dem vorliegenden Kapitel sowie seinen beiden Vorgängern gelangt sind, fassen wir in den beiden folgenden Sätzen zusammen, zu deren Formulierung ich zwar erst in den Mneinischen Empfindungen geschritten bin, die aber durch das bereits hier Gesagte voll begründet sind und die in ihrer Vereinigung die Quintessenz der mnemischen Grundgesetzmäßigkeit enthalten. Ich habe sie deshalb als die beiden mnemischen Hauptsätze bezeichnet.

Erster mnemischer Haptsatz (Satz der Engraphie): Alle gleichzeitigen Erregungen innerhalb eines Orga- 
Die Ekphorie der Engramme. Die beiden mnemischen Hauptsätze. 201

nismus bilden einen zusammenhängenden simultanen Erregungskomplex, der als solcher engraphisch wirkt, das heißt: der einen zusammenhängenden und insofern ein Ganzes bildenden Engrammkomplex hinterläßt.

Zweiter mnemischer Hauptsatz (Satz der Ekphorie): Ekphorisch auf einen simultanen Engrammkomplex wirkt die partielle Wiederkehr derjenigen energetischen Sitaation, die vormals engraphisch gewirkt hat. In engerer Fassung: Ekphorisch auf einen simultanen Engrammkomplex wirkt die partielle Wiederkehr des Erregungskomplexes, der seinerzeit den Engrammkomplex hinterlassen hat, und zwar eine Wiederkehr sei es in Gestalt von Originalerregungen, sei es ron mnemischen Erregungen.

Diesen beiden Sätzen, aus denen sich, wie bereits im Laufe der letzten drei Kapitel angedeutet und wie noch näher im 10. Kapitel der Mnemischen Empfindungen nachgewiesen worden ist, die Gesetze der Assoziation in einfacher Weise ableiten lassen, fügen wir deshalb noch folgenden erläuternden Zusatz bei: Assoziation ist die Verbindung von einzelnen Engrammen, die sich bei ihrer relativ isolierten Ekphorie herausstellt, und rührt lediglich von der gemeinsamen Anwesenheit der betreffenden Komponenten in demselben Simultankomplex her. Sie ist deshalb im Grunde stets Simultanassoziation. 
Siebentes Kapitel.

Der mnemische Erregungszastand and die Homophonie.

In unserem ersten, einleitenden Kapitel sind wir zu dem Ergebnis gelangt, daß jede Originalerregung in ihrem Auftreten, ihrer Daner and in ihrem Verschwinden von Auftreten, Dauer and Verschwinden einer elementarenergetischen Bedingung, die wir Reiz nennen, abhängig ist.

Für die mnemische Erregung besteht eine solche $A b-$ hängigkeit von einer elementarenergetischen Bedingung nicht; die beiden notwendigen Voraussetzungen fur das Auftreten einer mnemischen Erregung sind: Erstens das Vorhandensein eines entsprechenden Engramms, dessen Beschaffenheit das für die Beschaffenheit und Dauer der mnemischen Erregung in erster Linie Bestimmende ist. Zweitens das Auftreten eines ekphorischen Einflusses.

Jeder mnemische Erregungszustand ist somit sozusagen der Abkömmling eines originalen und verhält sich zu ihm wie eine Reproduktion zum Original. Er verhält sich dabei in den meisten Fällen wie eine abgeschwächte, nur die stärksten Lichter wiedergebende Reproduktion zum Original, und es bedarf eines besonders güntigen Zustandes des Individums zur Zeit der Ekphorie, wenn der mnemische Erregungszustand dem originalen an Vividität ${ }^{1}$ gleichkommen oder ihn gar tubertreffen soll.

1 Über die Unterscheidung zwischen Vividiät und Intensität im engeren Sinne vgl. Mnemische Empfindungen S. 19, 94-96, 232, 238, 
Der mnemische Erregungszustand ist eine Wiederholung des originalen in allen seinen extensiven Wertverhältnissen, auch seinen zeitlichen. Dieser Grundsatz ergibt sich aus dem Studium mnєmischer Sukzessionen, die, falls keine störenden Momente eingreifen, in genau demselben Rhythmus erfolgen wie die Sukzessionen der Originalerregungen, die engraphisch gewirkt haben. Auf den Umstand, daß die mnemischen Erregungen in bezug auf ihre.Intensitäten und auf die Tempi ihrer Abläufe nur in ihren Wertverhältnissen, nicht in ihren absoluten Werten eine Wiederholung der Originalerregungen darstellen, soll erst im 14. Kapitel bei Besprechung der proportionalen Veränderbarkeit der mnemischen Erregungen näher eingegangen werden.

Während also die Dauer der Hauptphase einer Originalerregung genan der Dauer des sie hervorrufenden Reizes entspricht, ist im Gegensatz dazu die Dauer einer mnemischen Erregurg nicht durch die Dauer eines gleichzeitigen, sondern durch die Dauer eines fruheren Reizes (desjenigen, der engraphisch gewirkt hat) bestimmt. Sie ist also im wesentlichen von vornherein zeitlich determiniert. Dasselbe gilt für die Intensität im engeren Sinne (nicht für die Viridität) der mnemischen Erregungen.

Die mnemische Erregung braucht übrigens nicht notwendig als Glied einer Sukzession aufutreten, sondern kann, durch simultane Ekphorie ausgelöst, auch isoliert auftreten und, ohne

385. Dort ist übrigens immer nur von der Unterseheidung zwischen Vividität and Intensität (im engeren Sinne) von Empfindungen die Rede. Es ist aber selbstverständlich, daß diesen beiden verschiedenen Eigenschaften der Empfindungen bei Betrachtung von der energetischen Seite her ein Äquivalent in der Beschaffenheit der Erregungen entspricht, deren Bewußtseinsmanifestation die betreffenden Empfindungen darstellen. 
sukzessiv ekphorisch zu wirken, wenigstens ohne manifest so zu wirken, wieder erlöschen. Ich erinnere an das Bild einer Landschaft, das bei Wahrnehmung eines Ölgeruchs auftauchte and bald wieder verschwand, ohne notwendig immer in merklicher Weise eine Reihe weiterer mnemischer Erregungen auszulösen.

Ich glaube nun, daß auch in diesem Falle die mnemische Erregung von der Zeitdauer der Originalerregung in einem gewissen Abhängigkeitsverhältnis steht; denn der Umstand, daß sich an sie keine sukzessiven mnemischen Erregungen anschließen, ist doch nur mehr oder weniger ein Zufall, der durch Verschiedenes bedingt sein kann: entweder dadurch, daß die späteren Engramme sehr viel weniger gut ausgeprägt sind als ihr ekphorierter Vorgänger, oder daß bei der Ekphorie neue Originalreize oder neuauftauchende Assoziationen den Ablauf der mnemischen Sukzession stören.

Derartige Störungen bewirken es auch, daß wir nur verhältnismäßig selten längere Reihen von individuell erworbenen Engrammen durchlanfen, ohne, neuen synchronen Eindrücken folgend oder auf assoziative Seitenbahnen abgelenkt, abzuschweifen und immer wieder neue Reihen zu beginnen. Nur Sukzessionen von Tönen zu Melodien oder von Worten zu Gedichten, also gewisse Arten akustischer Reize, geben bei uns so fest verbundene Sukzessionen von Engrammen, daß bei ihrer Ekphorie das ungestörte Durchlaufen der ganzen Kette weit häufiger erfolgt als bei anderen Arten von Engrammreihen.

Die erwähnten Störungen und Ablenkungen bewirken aber auch oft eine Abkürzung einer bestimmten mnemischen Erregung im Vergleich mit ihrer Originalerregung. Werden mnemische Erregungen retardiert, so findet die Re- 
Der mnemische Erregungszustand und die Homophonie. 205

tardation doch bei Sukzessionen von Erregungen so genau. proportional fur jedes Glied statt, daß stets der Rhythmus, in dem die Originalerregungen aufeinander folgten, gewahrt bleibt.

Wenn wir oft eine mnemische Erregung beliebig lange als ununterbrochene Erregung festzuhalten meinen, so beruht dies wohl meistens auf einer Selbsttäuschung, und es handelt sich in Wirklichkeit um wiederholte Ekphorie desselben Engramms. Wenn z. B. ein Maler stundenlang ununterbrochen an einem Portrait malt, dessen Original ihm nicht leibhaftig yor Augen sitzt, sondern von ihm nur als ekphoriertes Engramm, als ^Erinnerungsbild «, wahrgenommen wird, so ist offenbar dieses sein mnemisches Modell während der vielstündigen Arbeit nicht das Resultat einer einzelnen, sondern einer vielfach wiederholten Ekphorie, die späterhin, nachdem seine Arbeit weiter fortgeschritten ist, von dieser selbst ausgeubt wird, und zwar um so leichter, je mehr sie dem Original, von dem der Originalreiz ausging, zu gleichen beginnt.

Hier kxommen wir bereits auf ein äuBerst häufig auftretendes Zusammentreffen, das die mnemischen Phänomene in eigentümlicher Weise beeinflußt und genauere Analyse erfordert. Zur Inbetriebsetzung eines mnemischen Ablaufs bedarf es stets eines ekphorischen Anstoßes. Dieser Anstoß kann, wie unser zweiter mnemischer Hauptsatz besagt, in der Wiederkehr von bestimmten Erregungen, sei es in Gestalt von Originalerregungen, sei es von mnemischen Erregungen, bestehen. Ich bitte den Leser hier auf unser Schema S. 189 zurückzugreifen. Der mnemische Ablauf wird hier durch. Wiederkehr der Erregung $e_{4}$ in Betrieb gesetzt und zwar kehrt im Schema diese Erregung als Originaler- 
regung $e_{4}$ (or) (ausgelöst durch den Reiz $\varrho_{4}$ ) wieder, sie ekphoriert zunächst die mnemische Erregung $e_{4}(m n)$ und darauf erfolgt der weitere mnemische Ablanf. Wie das Schema zeigts sind dann also in Phase $e$ die Originalerregung $e_{4}$ (or) und die mnemische Erregung $e_{4}(\mathrm{mn})$ gleichzeitig vorhanden. In den späteren Phasen $f, g \ldots$ fehlt die Anwesenheit von entsprechenden Originalerregungen. Ein Beispiel mag dies erläntern. Rafe ich Jemandem za: Rezitiere innerlich die Schillersche Ballade: Zum Kampf der Wagen und Gesänge! so ekphorieren die durch die sechs Reizworte: Zum Kampf der Wagen und Gesänge! ausgelösten Originalerregungen die entsprechenden mnemischen Erregungen und sind mit ihnen gleichzeitig vorhanden. Während des ganzen dann folgenden inneren Ablaufs der aus nahezu 1000 Worten bestehenden Ballade folgt nur mnemische Erregung auf mnemische Erregung; entsprechende Originalerregungen fehlen währecid dieser Zeit.

Uns interessiert jetzt aber weniger der letztere rein mnemische Ablauf rom siebenten Worte an als vielmehr der Zustand, in dem die Bedingungen fur das gleichzeitige Vorhandensein der durch die sechs Reizworte erzengten Originalerregungen nnd der durch die ekphorierten mnemischen Originalerregungen $\left[e_{4}\right.$ (or) und $\left.e_{4}(\mathrm{mn})\right]$ in Phase $e$ des Schemas gegeben sind. Wenn mannun auch das Vorhandensein dieser Bedingungen ohne weiteres zugeben maß, so ist damit noch nicht bewiesen, daß̣ bei dem Zusammenwirken beider Bedingungen jede ihre ungestörte selbständige Wirkung bewahrt. Thre Wirkungen könnten zu einer einheitlichen Summe verschmelzen, sie könnten sich auch, sofern sie nicht ganz gleichartig sinả, durch eine Art Interferenz teils schwächen, teils verstärken, aber dabei ein einheitliches Produkt liefern, sie 
könnten endlich zusammen nur denselben Effekt haben, als wenn-jede einzeln für sich tätig wăre.

Wie wir nun bei Untersuchung der originalen synchronen und der engraphischen Reizwirkung (S. 116-128) gesehen haben, liegt es schon an sich in der Natur der synchronen Reizwirkung auf organische Substanz, daß die aus verschiedenen Reizen resultierenden Erregungen sich nicht diffus mischen, sondern selbständig nebeneinander bestehen und ablaufen. Nicht anders verhält sich aber der gleichzeitige Ablauf einer mnemischen und einer dieser verwandten, neuen Originalerregung.

Ohne weiteres können wir dies bei uns selbst durch Introspektion nachweisen, am deutlichsten in allen jenen äußerst zahlreichen Fällen, in denen der nene Originalreiz, der gleichzeitig mit der mnemischen Erregung einwirkt, nur ähnlich, aber nicht identisch ist mit dem friheren Originalreiz, der engraphisch gewirkt, den Boden für jene mnemische Erregung geschaffen hat. Die aus dieser Inkongruenz resultierenden Differenzen $\mathrm{zwischen}$ der muemischen nd der mit ihr gleichzeitigen neuen Originalerregung werden mit großer Schärfe, oft bis in die kleinsten Details von uns wahrgenommen. Erblicken wir eine uns bekannte Landschaft wieder, so reagieren wir auf kleine Veränderungen, z. B. die Abwesenheit eines mittlerweile abgeholzten Wäldchens, die Anwesenheit eines neuen Bauwerks, mit großer Bestimmtheit. Ein guter Kapellmeister, der auswendig ein großes Orchesterwerk dirigiert, nimmt das Ausbleiben der einen Stimme, den zu früben Einsatz einer anderen, jede leichte Variante des Sängers. kurz jede Inkongruenz des mnemischen Prozesses mit dem gleichzeitig ablaufenden originalen mit erstaunlicher Schärfe wahr.

Fur diesen Prozeß, bei dem mnemische Erregung und 
neue Originalerregung sozusagen zur Deckung gebracht̂ wird und jede Inkongruenz eine Empindungsreaktion erzeugt, weitere Beispiele aus den anderen Sinnesgebieten vorzufuhren, hat keinen Sinn. Dies sind Erfahrungen, die jeder täglich hundertfach an sich selbst macht 1 .

Aber selbst in dem Falle, daß die mnemische Erregung und die neue Originalerregung miteinander so übereinstimmen, daß keinerlei Unterschiedsreaktion anftritt, beweist eine andere Reaktion auf das unzweideutigste, daß beide Arten von Erregungen nebeneinander selbständig vorhanden sind und ablaufen, nicht etwa sich zu einem einheitlichen Ganzen summieren, also immer wie $f\left(a_{1}\right)+f\left(a_{2}\right)$ und nicht wie $f(2 a)$. Diese andere Reaktion ist das Wiedererkennen. Im Fall vollkommener Übereinstimmung ron mnemischer und neuer Originalerregung tritt sie rein, im Fall nicht vollkommener Übereinstimmung tritt sie gemischt mit der Reaktion des Unterschiedempfindens auf. Damit die Reaktion des Wiedererkennens bzw. Unterschiedempfindens als deutlicher Bewußtseinsvorgang eintritt, ist notwendig, daß die mnemische Erregung eine gewisse Vividität besitzt. Zwischen den verschiedenen Gefublen 1. beim ersten Auftreten einer Originalerregung, 2. der unbestimmten Empindung, etwas bereits Gesehenes wiederzusehen, wiederzuhören, wiederzufublen bei schwacher mnemischer Miterregung, and 3. dem bestimmten Wiedererkennen bei starker mnemischer Miterregung gibt es unzählige Übergänge. Für die uns hier beschäftigenden Grundfragen ist es von geringer Bedeutung, ob die Reaktion des Wiedererkennens eine mehr oder weniger kräftige ist.

1 Näher bin ich auf diese Dinge, die Unterschiedsempfindung wie das Wiedererkennen, auf das, was ich als sEmpfindungsdifferentials bezeichne, im 17. Kapitel der Mnemischen Empfindungen eingegangen. 
Der mnemische Erregnngszastand und die Homophonie. 209

Den gleichzeitigen selbständigen Ablauf der mnemischen nnd der neuen Originalerregung haben wir demnach auf dem Wege der Introspektion durch zwei sehr charakteristische Reaktionen erkannt: die Reaktion des Wiedererkennens nnd die Reaktion des Unterschiedempfindens. Bei der wichtigen Rolle, den die Erscheinung dieses gleichzeitigen selbständigen Ablanfs der beiden Erregungen in der Biologie der Organismen spielt, ist es zweckmäßig, sie mit einem besonderen Namen zu benennen. Reifliche Überlegung hat mich dazu gefuhrt, für diesen Vorgang des Zusammenklingens einer mnemischen und einer nenen Originalerregung bzw. auch des Zusammenklingens zweier mnemischer Erregungen oder zweier Originalerregungen die Bezeichnung $*$ Homophonie ${ }^{1}$ zu wählen. Natürlich ist dieser Ausdruck nur dann buchstäblich zutreffend, wenn die Erregungen der akustischen Sphäre angehören. Für alle anderen Erregungen, optische, sensible, olfaktorische usw. ist sie nur im tibertragenen Sinne anwendbar. Aber eine Metapher, die sich deutlich als solche zu erkennen gibt und zweifellos unserem Vorstellungsvermögen zu Hilfe kommt, ist wohl dann auch in der wissenschaftlichen Terminologie berechtigt, wenn ein ebenso sinnfälliger und dabei für alle Fälle buchstäblich za nehmender Ausdrack nicht zur Verfugung steht. Einen solchen zu finden ist mir aber nicht gelungen.

$1 \mathrm{Da}$ sich ein tieferes Eindringen in die Grundlagen der Homophonie als ein unumgängliches Erfordernis erwiesen hat, ist dieser Aufgabe der größere Teil der ersten Fortsetzung der Mneme, der Mnemischen Empfindungen, gewidmet worden. Es wurde dort auch (Kap. 5) gezeigt, daß bei bestimmter Konstellation Homophonie von Originalerregungen unter sich auf den verechiedensten Sinnesgebieten nachgewiesen werden kann, in besonderer Reinheit auf dem Gebiet des Gesichts-, Gehörs- und Geruchssinns. Auf die Homophonie von Originalerregungen gehe ich bier nicht weiter ein.

Sem on, Nneme, 3. Aufl. 
Weit schwerer als durch Introspektion mittels der Empfindungsreaktion des Wiedererkennens oder des Unterschiedempfindens ist der Vorgang der Homophonie bei anderen Geschöpfen aus objektiven Reaktionen zu erkennen. Die durch die menschliche Sprache sich ansdrückenden Reaktionen sind unzweidentig genug, um uns in bezug auf unsere Mitmenschen das Vorhandensein der mnemischen Homophonie ebenso unzweifelhaft zu demonstrieren, wie wir ihr Vorhandensein an uns selbst durch die besprochenen Bewußtseinsreaktionen erkennen.

Schwieriger ist dieser Nachweis dagegen bei allen den Organismen za erbringen, die sich uns durch keine artikulierte Sprache verständlich machen können, und die uns bei aller Übereinstimmung in den Grundzigen ihres Banes und ihrer Lebeneprozesse doch nicht nahe genug stehen, um Beobachtungen an uns ohne weiteres auf sie zu übertragen. Vor allem gilt dies für die kritiklose Homologisierung unserer Bewußtseinszustände mit denen anderer Geschöpfe. Zwar bin ich nattirlich der größte Gegner eines Standpunkts, der das Genus homo in dieser Beziehung den tibrigen Organismen prinzipiell gegentiberzustellen strebt. Andererseits halte ich es beim gegenwärtigen Stande unserer Kenntnisse und Beobachtungsmittel methodisch für das einzig Richtige, in der Reizphysiologie sich bei anderen Organismen möglichst ansschließlich an die Reaktionen zu halten, die der unmittelbaren Beobachtung zugänglich sind, und mit Analogieschltussen anf die Bewußtseinsreaktionen äußerst vorsichtig zu sein, ja sie bei der grundlegenden Beweisführungen ganz zu vermeiden. Ich hoffe, daß mir dies in meinen bisherigen Ausführungen durchweg gelungen ist, und ich will versuchen, auf dieser Bahn fortzufahren. 
Der mnemische Erregungszustand und die Homophonie. 211

Wir hatten durch Introspektion aus der Art unseres Wiedererkennens und Urterschiederkennens auf den Vorgang einer Homophonie, des Nebeneinanderbestehens der mnemischen Erregung und der neuen Originalerregung geschlossen. Wollten wir unvorsichtig vorgehen, so könnten wir sagen: »der Hund, nachdem er einmal mit einer Peitsche geztichtigt ist, > erkennt < das Strafinstrument *wieder" und äußert dies durch unzweideutige Reaktionen. Hierdurch wird das Vorhandensein von Homophonie durch objektive Reaktionen deutlich bewiesen $*$ Dies wäre ganz falsch. Bewiesen wird in diesem Falle nur die Ekphorie von Engrammkomplexen durch einen bestimmten Reiz. Der Anblick der Peitsche wirkt ekphorisch auf einen Engrammkomplex, in dem das Engramm der Schmerzempfindung eine große Rolle spielt, wie aus dem Auftreten der zugehörigen Reaktionen mit Recht zu schließen ist. Ein mnemischer Vorgang liegt also allerdings vor, aber ob derselbe mit dem Bewußtseinsvorgang des Wiedererkennens verbunden ist, wie wir ihn durch Introspektion bei uns kennen, ist noch keineswegs ohne weiteres ausgemacht. Man mủßte also erst die Identität der Bewußtseinsvorgänge beweisen, ehe man aus diesen auf das Vorhandensein einer solchen Homophonie auch bei niederen Geschöpfen schließen durfte.

Indem wir aber wie gesagt auf diese Form der Beweisführnng verzichten, suchen wir in den objektiv zu beobachtenden Reaktionen nach Kriterien, die fur das Vorhandensein der uns jetzt beschäftigenden Homophonie, $d$. h. des ungemischten Nebeneinanderklingens einer mnemischen und einer neuen Originalerregung beweisend sind. Soweit ich das Tatsachenmaterial bis jetzt uberschaue, ist es am leichtesten, auf solchem objektivem Wege die Homophonie in den Fällen nachzuweisen, 
in denen die mnemische Erregung und die neue Originalerregung sich nicht vollkommen decken. Es treten dann nämlich Reaktionen auf, die man nicht anders deuten kann, wie als Reaktionen auf die Inkongruenz der mnemischen und der Originalerregung. Spielen wir mit einem Hunde, dem das Apportieren großes Vergniigen macht - am besten eignen sich für diesen Versuch die temperamentvollen Foxterrier, die für das Apportierspiel eine wahre Leidenschaft besitzen - , und schleudern kleinere, beim raschen Fliegen nicht leicht erkennbare Gegenstände, z. B. Steinchen, mit kräftigem Schwunge in ziemliche Entfernung fort, so stellt sich der Hund mit gespannten Muskeln und erhobenem Kopfe vor uns anf und beobachtet genau jede Bewegung unseres Armes and anserer Hand. Sobald unsere Schleuderbewegung ausgeführt ist, und das Steinchen seinen Flug begonnen hat, dreht sich das Tier, so schnell es kann, um und sturzt in der Richtung des fliegenden Steines diesem uach. Haben wir dies einige Male wiederholt und führen dann die Schleuderbewegung aus, ohne den Stein fliegen zu lassen, ao reagiert zunächst der Hund auf die bloß markierte Bewegung unseres Armes genau wie vorhin. Da aber in jener Richtung kein Stein auf den Boden fällt, den er aufnehmen und apportiereu kann, verdoppelt er, nachdem er einige Male getäuscht worden ist, seine Aufmerksamkeit. Er fixiert noch genauer als vorher, und dadurch wird das Detail des originalen Erregungskomplexes vervollständigt. Die Reaktion des Sichumdrehens und in der Wurfrichtung Fortstürzens erfolgt nur noch, wenn er das Steinchen wirklich fortliegen gesehen hat, also nur bei vollkommener Kongruenz der Homophonie von mnemischem und neuem originalem Erregungskomplex. Bei Inkongruenz: Schleuderbewegung ohne Wurf, reagiert er anders. Er bleibt 
Der mnemische Erregungszustand und die Homophonie.

entweder ruhig stehen oder antwortet in seiner Aufregung mit einem kurzen Zusammenfahren, das aber gleich wieder der früheren gespannten Ruhe Platz macht. Dies verschiedene Verhalten des Tieres in den beiden Fällen können wir geradezu als Reaktionen darauf bezeichnen, ob Kongruenz oder Inkongruenz bei der Homophonie der mnemischen und der neuen Originalerregung vorhanden gewesen ist.

Eine andere sehr deutliche Reaktion auf die Kongruen's oder Inkongruenz der Homophonie kann jeder Jäger beobachten, der es unternimmt, Tiere, besonders höhere Säugetiere, durch bestimmte Töne und Tonfolgen zu locken. Wer nicht ein besonderes Talent fur die Nachahmung von Tierstimmen besitzt, bedient sich dazu besonderer Instrumente: der Hirschlocke, um durch den täuschend nachgeahmten Brunstschrei des Hirsches die Eifersucht der Brunsthirsche zu erregen und sie so in den Hinterhalt zu locken; der Rehblatte, die das lockende Fiepen des Schmalrehs wiedergibt, um den Rehbock zu betören; der Hasenquäke, um durch den Klageton des kranken oder in Not befindlichen Hasen die Geluste seiner Feinde zi reizen und auf diese Weise selbst den vorsichtigen Fuchs in die Nähe des Jägers zu ziehen. In allen diesen Fällen ist ceteris paribus die Reaktion der anzulockenden Tiere eine verschiedene, wenn die Locktöne das Vorbild verhältnismäßig vollkommen nachahmen, oder wenn sie ihm nur im allgemeinen ähnlich sind. Auch im letzteren Falle verhält sich das Wild nicht indifferent gegen die Töne, reagiert auch auf sie nicht so, wie auf unbekannte Schrecktöne, die es zur Flucht reizen Es interessiert sich vielmehr fur diese Laute, reagiert auf sie ähnlich wie auf die wirklichen Lockrufe, zeigt also, daß der Ton auf bestimmte Engramme ekphorisch gewirkt hat, rea- 
giert aber doch nur ähnlich, nicht genau so. Daß es einen Unterschied wahrgenommen hat, zeigt es dadurch, daß es sich nicht in größere Nähe des Ortes wagt, von dem die rätselhaften Laute herkommen. Natürlich ist hier immer voransgesetzt, daß das Wild sonst keine Witterung vom Jäger hat. Nimmt dann der erfahrene Jäger dem Anfänger die Locke aus der Hand und bringt die Töne besser, d. h. naturwahrer zum Ausdruck, so ändert sich das Verhalten des Wildes, es reagiert dann oft auf die Nachahmung wie auf die Naturlante, um so vollkommener, je weniger hänfig es die letzteren bis dahin gehört hat, je weniger bestimmt deshalb die mnemische Erregung bei ihm ist, mit einem Worte je junger es ist. Ein sehr alter und erfahrener Rehbock, auch wenn seine Paschageltiste sich sonst noch nicht im mindesten verringert haben, reagiert auf die Inkongruenz, die bei der Homophonie der in diesem Falle sehr deutlichen mnemischen und der neuen Originalerregung auch bei bester Nachahmung vorhanden zu sein pflegt, meistenteils durch scheues Herumschleichen und Spionieren und benimmt sich uberhaupt, wie man sich leicht durch Beobachtungen auf dem Anstand uberzeugen kann, ganz anders, als wenn die echten Töne des Schmalrehs sein Gehör treffen.

Es wäre mir leicht, noch zahlreiche verwandte Beispiele von deutlichen Reaktionen auf die Inkongruenz der Homophonie von mnemischer und erneuter Originalerregung anzufuhren. Ich begnuge mich aber zum Schluß mit Beibringung eines Beispiels, bei welchem es sich bei der mnemischen Erregung um ererbte, nicht wie in den bisher aufgeftuhrten Beispielen um in der Hauptsache individuell erworbene Engramme handelt. Es ist bekannt, daß anch im Brutapparat erbrutete Vögel, die in ibrem individuellen Leben nie ein Vogelnest 
gesehen haben, wenn ihnen Gelegenheit zur Paarung gegeben wird, ein Nest zu bauen beginnen und dasselbe annähernd, wenn auch nicht ganz so vollkommen herstellen, wie Artgenossen, die bereits verschiedene Bratperioden hinter sich haben.

Die betreffende Reaktionsfolge, die wir als Manifestation eines bestimmten Komplexes von mnemischen Erregungen aufzufassen haben - sie tritt periodisch im Zusammenhang mit der Brunst ein und fehlt bei kastrierten Tieren -, gelangt mit der Fertigstellung des Nestes zum Abschluß. Man könnte nun denken, dieser Abschlaß sei dadurch bedingt, daß die innere energetische Situation der Tiere in eine andere Phase getreten sei, oder daß die Disposition durch den natïrlichen Ablauf der Erregangen, der sich durch den Ablauf der Reaktionen manifestiert, erschöpft sei. Dies ist aber nicht der Fall, wie leicht bewiesen werden kann. Es genügt, den Tieren das eben fertige Nest wegzunehmen, am dieselbe Reaktionsfolge zweimal, dreimal herrorzurufen. Anderseits kann man dieselbe aber auch schon oft im Beginn abschneiden, indem man den Tieren, ehe sie noch zu bauen angefangen haben, gleich ein fertiges Nest zur Verfügung stellt.

Diesen Einfluß auf die phasogenen ekphorischen Nestbaureaktionen thbt aber nur die Verfugung tuber ein Nest von bestimmter Form, Größe and Konsistenz. Weicht die Form sehr erheblich von derjenigen ab, die der betreffenden Vogelari erbeigentumlich ist, ist das Ganze viel zu groB oder viel zu klein, besteht es aus zu harten oder nicht hinreichend trockenen Stoffen, so tht es, nachdem es eingehend von den brütelustigen Vögeln untersucht worden ist, entweder keinen weiteren Einfluß auf ibre Nestbaureaktionen; das zu ihrer 
Verfugung gestellte Gebilde wird dann nicht weiter beachtet und der Bau eines eigenen Nestes begonnen. Oder aber es wird grtindlich umgebant, das Unpassende entfernt, das Fehlende ergänzt. Und zwar dies in unserem Falle von Organismen, die in ihrem individuellen Leben niemals ein Nest ihrer Art erblickt haben und keine individuelle Erfahrung über die Eier und Jungen besitzen, die sie bald darauf zur Welt bringen, ansbriten und großziehen werden. Ganz ähnlich verhalten sich auch Bienen, die selbst noch nie natiirliche Waben gesehen oder an ihnen mitgebaut haben, angefangenen Kunstwaben gegenüber, die der Mensch ihnen zur Verfigung stellt. So korrigieren sie z. B. die kunstliche Wabe, wo sie von der scharfen Senkrechten abweicht.

Das Charakteristische bei diesen Vorgängen ist, daß, um bei den Vögeln zu bleiben, der normale Gang der Reaktionen durch den originalen Reizkomplex, den die Verftigung uber das dargebotene Nest ausübt, in einer Weise modifiziert wird, die zu der Differenz zwischen diesem originalen Reizkomplex und dem Endeffekt der mnemischen Erregung (Erzeugung einer bestimmten Art von Nest) in einem ganz bestimmten Verłältnis steht. Oder anders ausgedrückt: solange der originale Reizkomplex des zur Verfugung gestellten Nestes wesentliche Inkongruenzen zeigt mit dem normalerweise durch mnemische Reaktionen erzeugten Neste, erfolgen von seiten der Organismen allerlei Reaktionen, um diese Inkongruenz zu beseitigen. Ist das geschehen, so hören alle hierher gehurigen Reaktionen auf, um sofort wieder aufzutreten, wenn die Kongruenz durch irgendeinen Eingriff gestört wird.

Vielleicht wird mir hier der Einwand gemacht werden, um Kongruenz oder Inkongruenz der Homophonie könne es 
sich in diesem Falle nicht handeln, weil die mnemische Erregung hier sicher eine unbewußte sei oder, anders ausgedrückt, den zum ersten Male brütenden Vögeln beim Bau ihres Nestes mit allergrößter Wahrscheinlichkeit kein deutliches Bild des Endprodukts ihrer Handlungen vorschwebe. Ich gebe nun vollkommen zu, daß im gegebenen Falle höchstwahrscheinlich kein solches deutliches Bild im Oberbewußtsein anftritt. Zur sicheren Entscheidung derartiger Bewußtseinsfragen fehlen uns, wie schon mehrfach betont, alle Kriterien, weshalb wir sie nur da berïcksichtigen, wo die introspektive Methode anwendbar ist. Zur Widerlegung des Einwandes genügt es aber nachzuweisen, daß auch bei uns selbst die Existenz und der Nachweis der Homophonie von dem Vorhandensein oberbewußter Empfindungen unabhängig ist.

Wenn jemand, während wir intensiv geistig beschäftigt sind, im Nebenzimmer uns bekannte Stucke auf dem Klavier oder der Geige spielt, können wir oft zeitweilig die schwierigsten Operationen in unserem Oberbewußtsein vornehmen, ohne den Klängen bewußt zu folgen. Wenigstens solange die Kongruenz der Homophonie nicht gestört wird, d. h. der Spieler sein Stlick so spielt, daß seine Wiedergabe und unsere mnemische Kenntnis ubereinstimmt. Tritt Inkongruenz ein, so reagieren wir bald durch ein Zusammenfahren, Stirnrunzeln, Reaktionen, die hänfig noch unter der Schwelle des klaren Oberbewußtseins erfolgen können; bei längerer Dater der Inkongruenz pflegt unser Oberbewußtsein dann endlich deutlich auf dieselbe zu reagieren.

Fälle von Homophonie, ohne daß eine der beiden Erregungen, mnemische oder originale, im Oberbewußtsein zum Ausdruck kommt, sind unendlich häufig im täglichen Leben 
eines jeden Menschen. Wenn wir einen einmal gemachten Weg das zweite oder dritte Mal gehen, sind wir uns der dabei in Frage kommenden Homephonien meist klar bewußt. Bei häufigerer Wiederholung können dann die Homophonien ganz unbewußt ablaufen, wenn man jenen Weg z. B. in tiefe anderweitige Gedanken versunken oder in eifrigem, alles absorbierendem Gespräch verfolgt. Das Vorhandensein der Homophonien auch in letzteren Fällen muß dann nattirlich durch andere Reaktionen als durch Bewußtseinsreaktionen nachgewiesen werden. Dieser Nachweis ergibt sich leicht aus der Tatsache, daß der ganze Vorgang nur möglich ist, wenn mnemische und Originalerregungen wirklich tibereinstimmen. Bei Auftreten von Inkongruenzen, etwa verursacht durch mittlerweile vorgekommene Straßenänderungen, hört die Fähigkeit auf, das Ziel ohne Mitwirkung des OberbewuBtseins zu erreichen. So spielt die unbewußte mnemische Homophonie eine mindestens ebensogroße Rolle im Leben eines jeden menschlichen Organismus wie die bewaßte, and die Frage, ob eine Homophonie im Oberbewaßtsein eines Organismus zur Wahrnehmung gelangt oder nicht, ist keineswegs die wichtigste Frage, die wir bei Untersuchung der betreffenden Homophonie zu stellen haben, sie ist für uns uberhaupt keine Hauptfrage.

Zusammenfassend können wir sagen: die Anwesenheit und Wirksamkeit der Homophonie wird für uns durch besondere Reaktionen manifestiert. Experimentieren wir mit dem eigenen Ich, und handelt es sich um mnemische und Originalerregungen, die auch in unserem Oberbewußtsein zur Wahrnehmung kommen, so manifestiert sich die Homophonie durch die Empfindungsreaktionen des bewußten Wiedererkennens und des bewußten Unterschiedempfindens. Kommen 
dagegen beim eigenen Ich die Erregungen nicht im Oberbewaßtsein zur Wahrnehmung, so kann die Homophonie auf mehr indirektem Wege durch das Auftreten oder Ausbleiben objektiv wahrnehmbarer Reaktionen nachgewiesen werden, und dies gilt strenggenommen fur den Nachweis jeglicher Homophonie bei einem anderen Organismus als dem eigenen Ich. Hier können wir auf Homophonie nur ans dem Auftreten objektiv wahrnehmbarer Reaktionen schließen, deren Charakteristikum darin liegt, daß sie sich genau entsprechend der Kongruenz oder Inkongruenz des originalen Erregungzustandes mit einem fruher einmal bei demselben Organismas (oder seinen Vorfahren) vorhanden gewesenen Erregungszustand modifizieren, für dessen Ekphorie als mnemischer Erregungszustand jetzt wieder die Bedingungen vorhanden sind. Dieser letztere Erregungszustand kann sich bei der gleichzeitigen Gegenwart der entsprechenden Originalerregung dem außenstehenden Beobachter am leichtesten durch Reaktionen manifestieren, die an eine etwaige Inkongrnenz anknüpen. Von diesen Reaktionen sind am beweisendsten für die Anwesenheit und Wirksamkeit von Homophonie diejenigen, die bewirken, daß die Inkongruenz beseitigt wird.

Was die Natur der Reaktionen anlaugt, so haben wir bisher bei der Erörterung der Homophonie - außer den nur durch Introspektion wahrzunehmenden Empfindungsreaktionen - bloß solche als Beispiel herangezogen, äie sich als Resultate von Muskelbewegungen ergaben. Es ist klar und ron uns auch schon mehrfach hervorgehoben worden, daß die Reaktion fur uns nur das Mittel ist, eine Erregung, ganz gleich ob eine originale oder eine mnemische, zu erkennen. Dieselbe Erregung kann sich oft durch Reaktionen in ver- 
schiedenen Gebieten biologischen Geschehens: Protoplasma- oder Muskelbewegungen, Stoffwechselphänomenen, Wachstumsphänomenen, äußern, die ich, die ersteren als motorische Reaktionen, die zweiten als Stoffwechselreaktionen, die dritten als plastische Reaktionen bezeichnen will. Nun liegt offenbar nicht der Schatten eines Grundes vor, die Erregungszustände, die sich uns vorwiegend oder ausschließlich durch motorische Reaktionen manifestieren, anders zu beurteilen und von denen abzusondern, die flir uns durch plastische oder Stoffwechselreaktionen in Erscheinung treten. Ein Beispiel wird das klarmachen. Allgemein bekannt sind bei Pflanzen wie bei Tieren die Erscheinungen des Heliotropismus und der Heliotaxis, Phänomene, die sich auf die Reizwirkung zurlickfuhren lassen, die das Licht auf die organische Substanz austubt, und die sich unter durchaus einheitliche Gesichtspunkte fur alle Organismen bringen lassen. Die Reaktionen aber, durch welche jene zusammengehörigen Reizwirkungen und Erregungen für uns manifest werden, können, um einmal nur das Pflanzenreich ins Auge zu fassen, sowohl motorische sein (amöboide Bewegung, Cilienbewegung), oder auf osmotischen Prozessen (Turgorschwankungen) in der Pflanze beruhen, oder endlich plastische Reaktionen sein (Wachstumskriummungen). Es wird keinem Pflanzenphysiologen einfallen, bei seinen Stadien der Reizwirkung des Lichts auf die organische Substanz der Pflanzen Erregungen, die sich durch osmotische Reaktionen manifestieren, als prinzipiell von denen verschieden anzusehen, die dies durch motorische oder plastische Reaktionen tun. Was aber den Originalerregungen recht ist, ist auch den mnemischen Erregungen billig, und dieser Gesichtspunkt ist auch fur uns in den fruheren Abschnitten dieses Werkes maßgebend gewesen, als wir die plastischen Reaktionen des 
Laubabwurfs und der Wiederbegrünnng usw. und die osmotischen der sogenannten Schlafbewegungen der Pflanzen ebensogut als Manifestationen mnemischer Erregungen auffaßten, wie irgendeine motorische Reaktion.

Sobald wir aber in einem bestiminten Falle das Vorhandensein mnemischer Erregungen anerkennen, ist jedesmal wenigstens die Möglichkeit des Auftretens von Homophonie gegeben. Zu ihrem Nachweis gehört dann folgendes: Erstens die Darlegung, daß unter den in Frage stehenden Verhältnissen die Bedingungen fur das Auftreten bestimmter mnemischer und gleichzeitig der ihnen entsprechenden Origiualerregungen vorhanden sind. Zweitens der Nachweis des unter solchen Bedingungen erfolgenden regelmäßigen Auftretens von Reaktionen, die sich je nach der Kongruenz oder Inkongruenz dieser möglichen, aber erst zu beweisenden Homophonie modifizieren, gauz besonders das regelmäßige Auftreten von Reaktionen, die eine Beseitigung der Inkongruenz zur Folge haben.

Nun kennen wir eine große Gruppe vou plastischen Reaktionen, die die Beseitigung einer bestimmten Inkongruenz zur Folge haben, ich will noch nicht sagen der Inkongruenz bei einer Homophonie, soudern zunäehst formulieren: einer Inkongraenz zwischen dem normalen Entwicklungszustande oder normalen ausgebildeten Zustande und einem in dem betreffenden Einzelfall erzeugten tatsächlicheu plastischen Zustande. Diese Reaktionen pflegen wir als Regenerationen im weitesten Sinne (d. h. mit Einschluß der Begriffe der Postgeneration, Reparation, Restitution nsw.) und als Regulationen zu bezeichnen. Um aus diesen Reaktionen auf Homophonie schließen zu dürfen, müßte zunächst der Nachweis gefuhrt werden, daß in den gegebenen Fällen die 
Bedingungen fur das Auftreten bestimmter mnemischer und gleichzeitig der ihnen entsprechenden Originalerregungen gegeben sind, und daß die betreffende Reaktion eine Inkongruenz bei der Homophonie dieser beiden Erregungen beseitigt.

Diesen, wie ich gleich betonen will, nicht schwer zu erbringenden Nachweis verspare ich aber, um Wiederholnngen za vermeiden, auf die folgenden Abschnitte, die der Analyse des mnemischen Falktors bei der Ontogenese, der Regeneration und den Regulationsvorgängen gewidmet sein sollen.

In unseren bisherigen Betrachtangen ther die Homphonie haben wir den mnemischen Erregungszustand immer als etwas bei aller Kompliziertheit doch Einheitliches betrachtet. An dieser Anschauung wollen wir auch nichts ändern, wenn dieser Zustand der Reproduktion einer einmaligen vorhergegangenen Erregung entspricht. Wie aber, wenn er eine hänfiger wiederholte Erregung reproduziert?

Zur Lösung dieser Frage bieten sich nns zwei Wege: Einmal können wir synthetisch untersuchen, wie sich bei der jedesmaiigen Wiederholung der mnemische Besitz vermehrt. Zweitens können wir versuchen, eine auf mehrfacher Wiederholung basierende mnemische Erregung analytisch zu zergliedern.

Beschreiten wir zunächst den zweiten Weg, und suchen wir eine auf wiederholter engraphischer Einwirkung basierende mnemische Erregung zu analysieren! Wir wählen einen Fall von mnemischer Erregung, deren Vorhandensein wir an uns selbst durch Introspektion wahrnehmen können, und suchen uns einmal das körperliche Bild anseres nächsten Anverwandten in dessen Abwesenheit za ekphorieren, haben damit also einen rein mnemischen Vorgang vor uns. Zunächst 
Der mnemische Erregungszustand und die Homophonie.

mag es uns wohl scheinen, daß ein bestimmtes, ganz konkretes Bild in uns manifest wilide, aber gerade, wenn es sich um eine Person handelt, mit der wir immerfort verkehren, werden wir finden, daß das ekphorierte Bild etwas sozusagen Verallgemeinertes hat. Es gleicht ein wenig jenen amerikanischen Photographien, die das Allgemeine eines Typus dadurch heranszubringen versuchen, daß sie eine große, sich deckende Anzahl ron Aufnahmen verschiedener Köpfe auf ein und dieselbe Fläche projizieren.

In unserem Falle geschieht die Verallgemeinerung durch homophone Wirksamkeit verschiedener Bilder desselben Antlitzes, das uns in den verschiedensten Zuständen und Situationen, einmal bleich, das andere Mal gerötet, einmal heiter, das andere Mal ernst, einmal in dieser, das andere Mal in jener Beleuchtung entgegentritt. Sobald wir nicht die große Reihe von Wiederholungen gleichmäßig in uns erklingen lassen, sondern unter den vielen einen bestimmten Moment, der engraphisch gewirkt hat, bei der Ekphorie des Gesichtsengramms in den Brennpunkt unserer Aufmerksamkeit rücken, iiberwiegt sogleich diese bestimmte mnemische Erregung ibre mitklingenden Vorgängerinnen und Nachfolgerinnen, und wir erblicken das betreffende Antlitz in konkreter Schärfe in dieser bestimmten Situation.

Im Falle, daß es sich um Personen handelt, mit denen wir fortdauernd zusammen sind, bewirkt gerade die Fülle der für gewöhnlich miteinander klingenden mnemischen Erregungen die sonderbare Unschärfe und Verallgemeinerung, mit denen sich ibre Züge in uns mnemisch reproduzieren. Bei Personen, mit denen wir seltener zusammentreffen, wird häufig bei der mnemischen Reproduktion ihres Gesichts ein einzelner Moment, in dem das Gesicht auf uns besonderen 
Eindruck gemacht hat, und besonders stark engraphisch gewirkt hat, in den Brennpunkt der Aufmerksamkeit gerlickt, und durch diese Hervorhebung erscheinen uns dann die Züge greifbarer, konkreter, als die viel häufiger und in den verschiedensten Situationen gesehenen unserer nächsten Verwandten.

In dem Falle, daß bei der Ekphorie eines hänfig wiederholten Engramms kein Vorklingen einer einzelnen Komponente (einer einzigen der miteinander klingenden mnemischen Erregungen) stattfindet, bemerkten wir, wie erwähnt, ein Verschwimmen, sozusagen Abstraktwerden des Erinnerungsbildes, ähnlich dem Verschwimmen der Konturen, wenn man eine Anzahl voneinander nicht genau entsprechenden Pausen übereinander legt. Das Resultat ist - wenigstens beim Menschen, wahrscheinlich aber auch bei höheren Tieren die Entstehung einer Art von Abstraktion, die ich in den fruheren Auflagen dieses Buchs als physiologische Abstraktion bezeichnet habe, die ich aber nunmehr, seit ich sie in den Mnemischen Empfindungen S. 304-309 noch genauer analysiert und den Phänomenen der nicht differenzierenden Homophonie untergeordnet habe, als $\otimes$ Abstraktion durch Homophonie bezeichne. Die mnemische Homophonie liefert uns ohne das Hinzutreten sonstiger Denkprozesse ein in gewissem Sinne abstraktes Bild unseres Freundes X, nicht das konkrete in irgendeiner situation, sondern $\mathrm{X}$ losgelöst von einem bestimmten Zeitpunkt. Wird der Kreis der ekphorierten Engramme noch weiter gezogen, so treten abstrakte Bilder höherer Ordnung auf: etwa ein weißer Mann oder ein Neger. Meiner Ansicht nach basiert anf solchen abstrakten Bildern die erste Bildung von abstrakten Begriffen tiberhaupt. Die auf dem oben bezeichneten Wege bloß durch Homo- 
phonie zustande gekommene Abstraktion ist Vorläuferin der rein logischen ${ }^{1}$. Sie ist durchans kein Monopol des menschlichen Geschlechts, sondern manifestiert sich auf verschiedenartigem Wege auch bei allen höher organisierten Tieren.

$\mathrm{DaB}$ es sich bei den erwähnten Homophonien tibrigens nie um vollkommene Verschmelzungen der mnemischen Erregungen handelt, wird durch den Umstand bewiesen, daß eine Zerlegung in alle oder doch viele der Einzelkomponenten durch verschiedene Einstellung der Aufmerksamkeit auf dieselben meist unschwer gelingt.

Wir wollen nunmehr die Richtigkeit unserer auf analy-

1 Andeutungen einer gleichen Auffassung bezüglich der Zurückführung der ersten Anfänge des Abstraktionsvermögens auf das $\mathrm{Zu}$ sammentreten vieler konkreter Erinnerangsbilder finden sich bereits bei Hume und schärfer ausgesprochen in dem geistreichen Buche Th. Huxleys über Hume (London 1879). Auch der Vergleich mit den Typenphotographien ist bereits von Huxley gemacht worden. Viel unbestimmter äußerte sich später W. Roux in einer entfernt an diese Vorgänger erinnernden Bemerkung seines bekannten Buchs: Der Kampf der Teile im Organismus, Leipzig 1881, S. 234. Während er auf jedes weitere Eindringen in die Frage als Nichtfachmann verzichtet, ist Huxley bereits zu einer verhältnismäßig klareu Anschauung des Problems vorgedrungen, aber auch dem englischen Biologen fehlt zur eigentlichen Lösung d9sselben die Erfassung und Durcharbeitung des Homophoniebegriffs. Ich selbst bin ohne Kenntnis dieser Huxleyschen Vorgängerschaft zu meinen oben und besonders in den Mnemischen Empfindungen ausführlich dargelegten Gedankengängen gelangt, als ich mein eigentiches, bisher wohl noch nie ernstlich ins Ange gefaßtes Ziel verfolgte: Die Aufstellung des Begriffs der Homophonie, seine Ausdehnung von dem Bereich der mnemischen auch auf das Bereich der originalen Erregungen; das Studium der Kombinationen der Homophonie, ihrer verschiedenen Erscheinungsformen, unter denen die Abstraktion durch Homophonie nur einen besonderen Fall darstellt. Dadurch ist diese urspruinglichste Form der Abstraktion erst auf eine feste Basis gestellt und, wie die auf S. 302 der Mnemischen Empfindungen mitgeteilten Versuche zeigen, anch der experimentellen Untersuchung zugänglich gemacht worden.

Semon, Mnome. 3. Aufl. 
tischem Wege gewonnenen Auffassungen prufen, indem wir synthetisch das Ergebnis der mehrmaligen Wiederholnng einer engraphischen Einwirkung unter Zugrundelegang der allgemeinen Gesetze konstruieren, die wir aus unseren fruheren Untersuchungen gewonnen haben.

Für den Fall, daß eine erstmalige Ekphorie eines Engramms durch eine Wiederholnng des Originalreizes stattfindet, haben unsere bisherigen Untersuchnngen uns bereits eine Lösung gegeben. Bezeichne ich die mnemische Erregung bei ihrer ersten Ekphorie als $p_{1}(\mathrm{mn})$ und die Originalerregung, die durch die erste Wiederholung des Originalreizes auftritt, als $p_{2}$ (or), so findet ein Miteinanderklingen oder eine Homophonie, nicht aber eine Verschmelzang dieser beiden Erregungen statt; das Resultat ist $p_{1}(\mathrm{mn})+p_{2}$ (or). Wir haben nun schon fruher (S. 116-119) als ein allgemeines mnemisches Gesetz erkannt, daß, wenn zwei Erregungen koordiniert in einem Organismus auftreten, sie auch koordiniert engraphisch anfgenommen und fixiert werden. Es ist selbstrerständlich, daß die Erregungen $p_{1}(\mathrm{mn})$ und $p_{2}$ (or) hiervon keine Ausnahme machen, wenn sie nach ihrem Ablauf als Engramme in das Latenzstadinm ein- bzw. zurlicktreten. Werden sie durch eine erneute Wiederholung des Originalreizes wiederum ekphoriert, so müssen sie natirlich auch wiederum koordiniert and nicht homogen verschmolzen als eine homophone mnemische Erregung $p_{1}(\mathrm{mn})+p_{2}(\mathrm{mn})$ manifest werden und sich in dieser Form zu der neu aufgetretenen Originalerregung $p_{3}$ (or) gesellen. Es findet also jetzt die dreifache Homophonie $p_{1}(\mathrm{mn})+p_{2}(\mathrm{mn})+p_{3}$ (or) statt. Dasselbe findet bei der dritten, vierten bis $n$ ten Wiederholung statt. Bei der $n+1$ ten Wiederholung findet dann z. B. eine mnemische Homophonie der mnemischen Er- 
regungen $p_{1}(\mathrm{mn})+p_{2}(\mathrm{mn})+p_{3}(\mathrm{mn}) \ldots p_{n}(\mathrm{mn})$ mit der Originalerregung $p_{n+1}$ (or) statt. Oder in Worten ausgegedrückt: Bei der Ekphorie einer Engrammkombination, die mehrfach wiederholten engraphischen Einwirkungen ihre Entstehung verdankt, tritt keine unentwirrbar verschmolzene mnemische Erregung auf, $k$ eine $>$ Verwachsung c, wie manche Psychologen das genannt haben, sondern es erfolgt ein entwirrbares Miteinanderklingen der einzelnen in ibrer zeitlichen Entstehung getrennten Komponenten dieser scheinbar einheitlichen Engrammkombination.

Dabei ist auch noch zu berücksichtigen, daß in den meisten Fällen die einzelnen Komponenten gar nicht so unerheblich voneinander verschieden sein werden, und zwar aus folgenden Grüden. Erstens wird nur selten der Fall eintreten, daB ein Originalreiz bei seiner Wiederholung seinem Vorgänger vollkommen gleich ausfällt. Zweitens greift er nie in genau dieselbe, ja nur selten in eine durchans ähnliche energetische Situation des Organismus, wie sein Vorgänger sie vorfand. Er wird deshalb stets mit anderen Engrammkomplexen assoziiert, und ist daher simultan und sukzessiv, also kurz gesagt zeitlich, anders determiniert als letzterer.

Analytische wie synthetische Untersuchung fuhrt uns demnach zu dem ubereinstimmenden Resultat, daß bei jeder Ekphorie einer auf wiederholter Reizwirkung beruhenden Engrammkombination ein ungemischtes Miteinanderklingen der jeder einzelnen Reizung entsprechenden Einzelkomponenten stattfindet.

Von der jetzt gewonnenen Basis aus sind wir nun auch imstande, tiefer in das Wesen der nur alternativ ekphorierbaren Dichotomien von Engrammsukzessionen einzudringen, als dies vorher möglich war. 
Wir gehen wieder ans von dem Falle der zwei Fassungen des Goetheschen

sÜber allen Gipfeln ist Ruh, in allen $<$ Wäldern hörest -:

and nehmen an, sowohl die erste wie die zweite Fassung sei uns dreimal vorgetragen worden. Bezeichnen wir dann die einzelnen, durch die gesprochenen Worte erzeugten Engramme mit Buchstaben und geben dem Buchstabenzeichen den der Nummer ihrer Wiederholung entsprechenden Index, so erhalten wir, wenn wir nur die Sukzession der ersten 9 Engramme ins Auge fassen, folgendes Engrammschema:

$\begin{array}{llllllllll}\text { Phase } 1 & 2 & 3 & 4 & 5 & 6 & 7 & 8 & 9\end{array}$

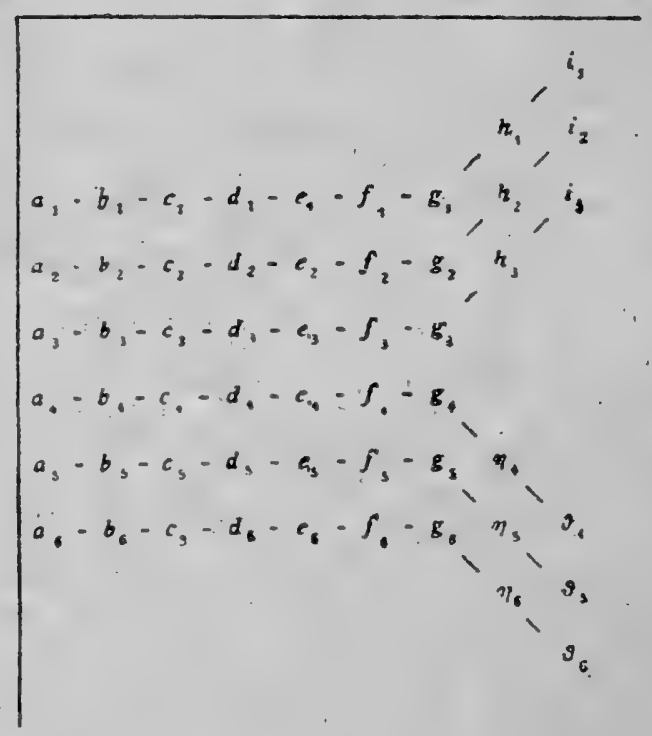

Tritt Ekphorie ein, so besteht die mnemische Erregúng in Phase 1 ans der Homophonie der Erregungen $a_{1-6}$ oder in Phase 7 ans der Homophonie der Erregungen $g_{1-6}$. In Phase 8 aber tritt die Alternative ein: entweder werden die Engramme $h_{1-3}$ oder die Engramme $\eta_{4-6}$ ekphoriert. Warum aber die Alternative? Weil, wie ich in den Mnemischen Empfindungen (S. 356) näher ausgeftihrt habe, in diesem 
Der mnemische Erregungszustand und die Homophonie.

Falle simultane Manifestation der aus Wortengrammen bestehenden Äste der Dichotomie unmöglich ist.

Etwas ganz anderes als die gleichzeitige Ekphorie der beiden Äste einer nicht alternativ, sondern simultan ekphorierbaren Engrammdichotomie, wie wir es oben in dem zweistimmig werdenden Musikstick

\begin{tabular}{c|c|c|c|c}
\hline Phase 1 & 2 & 3 & 4 & 5 \\
\hline \hline \multirow{2}{*}{$c-$} & $d-$ & $e<$ & $g-$ & $e-$ \\
& $d-$ & 1 \\
& & & $d-$ & $e-$
\end{tabular}

kennen gelernt haben, ist bei einer nur alternativ ekphorierbaren Dichotomie das Überspringen der Ekphorie von einem Engrammast auf den anderen. Im ersteren Fall ergeben sich einfach simultane Doppelreaktionen, in zweiten dagegen alternierend kombinierte oder, wie wir sie abgekurzt nennen wollen, Mischreaktionen. Eine solche Mischreaktion haben wir z. B. vor uns, wenn wir, was ja sehr leicht geschehen kann, die beiden Alternativen folgendermaßen kombinieren: - Über allen Gipfeln ist Ruh, in allen Wipfeln hörest du kaum einen Hanch . Solche Mischreaktionen sind weder bei den Äußerungen der individuell erworbenen Mneme eine Seltenheit, noch fehlen sie bei der Manifestation von ererbten dichotomischen Engrammsukzessionen. Wir kommen darauf noch ausfuhrlicher in dem Kapitel uber die Bedeutung der alternativen Dichotomie auf ontogenetischem Gebiet zurtick. Immerhin folgt sowohl bei ererbten als auch bei individuell erworbenen alternativen Dichotomien in der Mehrzahl der Fälle an der Gabelungsstelie die Ekphorie nur entweder der einen oder der anderen Bahn, in dem S. 228 erörterten Falle werden also entweder die homophonen Engramme $h_{1-3}$ oder $\eta_{4-6}$ ek- 
phoriert. Wie diese mnemische Alternative beantwortet wird, hängt davon ab, ob der ekphorische Einfluß auf $h_{1-3}$ oder $\eta_{4-6}$ iberwiegt, und Faktoren der mannigfachsten Art können die Wagschale nach der einen oder der anderen Seite hin zam Sinken bringen. In der Mehrzahl der Fälle besteht schon von vornherein dadurch ein Übergewicht nach der einen Seite hin, daß die Zahl der Wiederholungen gewöhnlich nicht für beide Gabeläste eine so ganz gleiche sein wird, wie wir sie in unserem Schema angenommen haben. Habe ich z. B. das Gedicht in der zweiten Fassung viel öfter gehört als in der ersten, so wird ceteris paribus die Ekphorie in der Richtung dieses Gabelastes vor der anderen ein entschiedenes Übergewicht haben. Ein weiteres Übergewicht kommt derjenigen Seite zugute, auf der die zeitlich späteren, noch weniger verblaßten Wiederholungen liegen. Infolge dieses Moments wird auf morphogenetischem Gebiet, wie wir später sehen werden, das Einschlagen atavistischer Bahnen für gewöhnlich vermieden. Ferner können aber noch neu hinzutretende Originalreize aller Art der einen oder der anderen Ekphorie ein Übergewicht verleihen und dadurch ein bereits bestehendes Übergewicht der Gegenseite iiberkompensieren. Wenn ich einem Rezitator, der zwei Fassungen seines Vortragsgedichts kennt, aber gewohnt ist, es in der zweiten Fassung vorzutragen, an der Gabelungsstelle das Stichwort der ersten Fassung souffliere, in unserem Goetheschen Gedicht also Wäldern statt Wipfeln*, wird es zuweilen gelingen, durch Hinzufügung dieser Originalerregung ihn in die andere Babn zu lenken. Daß unter Umständen auch hemmende Einflusse das Einschlagen oder Verfolgen des einen Astes der Weggabelung verhindern und dadurch die Bahn der Ekphorie nach der anderen Seite lenken können, wird später im 
Kapitel uber die morphogenetischen Dichotomien noch ausfuhrlicher erörtert werden.

Eine allgemeine Formel, durch deren Anwendung sich vorher bestimmen ließe, in welchem Sinne die mnemische Alternative in jedem einzelnen Falle beantwortet werden wird, läßt sich also nicht aufstellen. Wohl aber läßt sich in zahlreichen Fällen yon Ekphorie dichotomischer Sukzessionen individuell erworbener Engramme und in manchen Fällen ebensolcher ererbter Engramme nachträglich erkennen, welche Einflusse bei der Alternative einmal dieser, das andere Mal jener Ekphorie das Übergewicht verliehen haben.

Am Schlusse unserer Betrachtungen ther die Homophonie möchte ich noch darauf aufmerksam machen, daß sich uns auf Grund der gewonnenen Resultate ein neuer Einblick eröffnet in das eigentumliche Verhältnis, in dem die Wiederholung eines Reizes zu seiner engraphischen Wirkung steht. Man sollte denken, und denkt wohl auch gewöhnlich, daß man durch einmalige, doppeltkräftige Reizwirkung ein genau ebenso wirksames Engramm erhalten müßte, wie durch zweimalige, halb so starke. Jeder von uns hat aber wohl schon an sich selbst erfahren, daß dies keineswegs immer der Fall ist, daß man z. B. beim Auswendiglernen durch häufiges fluchtiges Überlesen oft sehr viel mehr erreicht als durch selteneres angespanntes und aufmerksames. Die Zauberkraft der Wiederholung auf mnemischem Gebiet könnte noch an vielen anderen Beispielen demonstriert werden. Sie wird uns verständlich durch die Einsicht, daß das engraphische Resultat bei wiederholter Reizwirkung grundsätzlich verschieden ist von dem durch einmalige entsprechend stärkere Reizung herbeigeführten. Der fundamentale Unterschied besteht darin, daB bei der Wiederbolung eines Reizes 
nicht ein bereits vorhandenes Engramm verstärkt, sondern ein neues Engramm geschaffen wird. Die Ekphorie dieses Engramms fuhrt dann zu einer zweiten mnemischen Erregung, diehomophon neben der ersten mitklingt. So schafft jede neue Wiederholung ein neues Engramm oder eine neue Engrammsukzession. 


\section{Dritter Teil}

\section{Die Wirksamkeit mnemischer Prozesse}

\section{bei der 0ntogenese}



Achtes Kapitel.

Nachweis des mnemischen Faktors bei den ontogenetischen Reproduktionen.

Betrachten wir die normale Ontogenese eines beliebigen Organismus, so scheint zunächst kein Anlaß vorzuliegen, das ontogenetische Geschehen anf etwas anderes zuruckzuftuhren, als auf die Wirkung von Originalreizen, die Originalerregungen hervorrafen. So könnte man z. B. sagen: die Befruchtung wirkt wie ein Originalreiz, der als Reaktion die erste Kernund Zellteilung bedingt. Der Positionsreiz, den das Nebeneinanderliegen der beiden ersten Furchungszellen austibt, wirkt original auslösend auf die nächste Teilung, usw. In einem gewissen Entwicklangsstadinm kommt bei den Wirbeltieren das freie Ende der Augenblase mit dem Ektoderm in Beruhrung. Diese Beruhrung wirkt gleich einem Originalreiz (vielleicht mittels einer spezifischen Thigmomorphose), der eine plastische Reaktion, die Linseneinstilpung des Ektoderms, bedingt.

Alle diese Vorgänge sind als Wirkungen reiner Originalerregungen durc: aus vorstellbar. Wenn wir auch naturlich noch weit entferut sind, die Kette der inneren Veränderungen von der ersten durch den Reiz gesetzten Veränderung bis zur endlichen Reaktion analysieren zu können, scheint jedenfalls zunächst kein zwingender Grund vorzuliegen, der hier auf 
die Wirkung oder Mitwirkung mnemischer Erregungen hinwiese. Denn die Wiederholung an sick, als welche das ontogenetische Geschehen in den aufeinander folgenden Generationen sich darstellt, bedarf zu ihrer Erklärung keineswegs der Heranziehung mnemischer Erklärungsprinzipien. Unsere gesamte Erfahrung basiert auf dem Satze, daß gleiche Ursachen gleiche Wirkungen hervorrufen, oder anders ansgedrlickt, daß bei Herstellung derselben Voraussetzungen auch derselbe Ablauf eintritt. Nach diesem Grundsatz lassen sich aber, zunächst im Groben betrachtet, die Wiederholungen des ontogenetischen Geschehens ebensogut verstehen, wie viele sich wiederholenden Erscheinungen in der unbelebten Natur, deren Erklärung ohne jede Heranziehung mnemischer Prozesse restlos durchgefuhrt werden kann. Ich brauche nur an den Wechsel der Jahreszeiten, an Ebbe und Flut, an die intermittierenden Eruptionen der Geiser und ähnliche Erscheinungen zu erinnern.

Futr alle diese Wiederholungen ist aber eins charakteristisch: genau die gleichen oder doch in der Hauptsache die gleichen Voraussetzungen müssen auftreten, um die Wiederkehr der gleichen Abläufe zu ermöglichen. Allerdings sind auch in der unbelebten Natur leicht Fälle konstruierbar, in denen durch eine Gesamtheit von Ursachen keine andere Wirkung hervorgebracht wird, wie durch einen Bruchteil dieser Gesamtheit. Lasse ich einen Wagen mit 5 Pferdekräften nach vorn und mit 4 Pferdekräften nach hinten ziehen, so wirkt das ebenso, wie wenn ich ihn durch 4 Pferde nach vorn und durch 3 nach hinten ziehen ließe. In diesem Falle habe ich aber nur zwei sich ohnehin ausgleichende Ursachen eliminiert. Der Bruchteil der Ursachen wirkt nur dann ebenso, wie die Gesamtheit, wenn die Wirkung des 
Nachweis des mnem. Faktors bei den ontogen. Reproduktionen. 237

tortfallenden Restes sich gegenseitig kompensiert. Wo das nicht der Fall ist, hat eine Gesamtheit von Ursachen eben in der uberwältigenden Mehrzahl der Fälle eine andere Wirkung als ein Bruchteil and besonders als ein beliebig herausgehobener Bruchteil.

Nur eine Gruppe von Erscheinungen sahen wir von dieser Regel eine Art Ausnahme machen: es sind dies die mnemischen Erregungen mit den aus ihnen resultierenden Reaktionen. Wir sind durch unsere frtheren Untersuchungen za dem Resultat gefuhrt worden, daß ein wesentliches Unterscheidungsmerkmal $\mathrm{zwischen}$ originaler und entsprechender mnemischer Erregung darin besteht, daß die erstere nur durch einen ganz bestimmten originalen Reizkomplex ausgelöst werden kann, die letztere aber durch einen Teil, oft einen beliebig zu wählenden Teil desselben. So mußten, um auf unser altes Beispiel zurtickzugreifen, der optische Reiz von Capri, der akustische des Leierkastens, der eine Geruchsempfindung auslösende der Ölktuche als Originalreize vorhanden sein and gleichzeitig einwirken, um den entsprechenden originalen Erregungskomplex herrorzurufen. Die Ekphorie des entsprechenden mnemischen Erregungskomplexes konnte hingegen beliebig durch Wiederkehr eines einzigen dieser Reize unter Fortfall der anderen herbeigefuhrt werden. Gewisse Reize (Wärme, Feuchtigkeit, Darbietung von Wasser) rufen bei dem Alpensalamander, der unter normalen Verhältnissen zwei metamorphosierte Junge zur Welt bringt, Fruh- und Massengeburten hervor. In jedem Wiederholungsfalle wirken dieselben Reize auf dasselbe Individuum in dieser Beziehung stärker und stärker. Ja man kann die Reize schlieBlich ganz fortlassen, und nichtsdestoweniger tritt nicht nur in der betreffenden Generation selbst, sondern auch 
bei der nächsten Generation bei Eintritt von Schwangerschaft, Frth- und Massengeburt von neuem ein. Ebenso mutatis mutandis verhält es sich mit den habituellen und ererbten Spätgeburten des Feuersalamanders (vgl. oben S. 69).

In letzterem Beispiel haben wir bereits ein entwicklungsgeschichtliches Phänomen, das sich als ein zweifellos mnemisches erweisen läßt, und zwar durch das für diese Prozesse sicherste Kriterium: durch die experimentelle Prufung der engraphischen Einwirkungen. Dasselbe gilt für die von Standfuß und von Fischer, sowie ihren Nachfolgern festgestellten ontogenetischen Phänomene der Schmetterlingsfärbung und uberhaupt dem reichen Schatz der experimentellen Zuchtergebnisse, die wir Blaringhem, Bordage, Chauvin, Kammerer, Klebs, Pictet, Przibram, Schröder, Sumner, 'Tower und vielen anderen verdanken ${ }^{1}$.

Aber bei der ungeheueren Mehrzahl der ontogenetischen Erscheinungen, bei denen eine experimentelle Prüung der etwaigen engraphischen Reizwirkungen nicht möglich ist, läßt sich doch experimentell ein anderer Nachweis erbringen, der uns bestimmen muß, diese Erscheinungen in die Klasse der mnemischen einzuordnen: wir können bei ihnen in ziemlich freier Weise bald diesen, bald jenen Teil der Voraussetzungen eliminieren, und dennoch wird der Ablauf zunächst nur insoweit verändert, als der Eingriff das Eintreten gewisser Reaktionen unmöglich macht - in dem Sinne, daß eine nicht vorhandene Zelle sich eben nicht mehr teilen kanu -. Soweit die Organe fur die Reaktionen tuberhaupt noch da sind, geht der Ablauf in ungestörter oder nahezn

1 Vgl. meine Zusammenstellung in Stand der Frage S. 30-64 und besonders die Ausführungen auf S. 70-72. 
Nachweis des munem. Faktors bei den ontogen. Reproduktionen. 239

ungestörter Weise weiter, trotz sehr großer Beeinträchtigung der Voraussetzungen.

Dieser experimentelle Nachweis ist bereits für die Ontogenese aller möglichen Gruppen ron Metazoen erbracht worden. Es ist klar, daß wir die Voraussetzungen eines Ablaufs in außerordentlich starker Weise verändern, wenn wir von dem System, in dem sich dieser Ablauf vollzieht, ansehnliche Teile, $1 / 2$ oder $3 / 4$ oder gar $7 / 8$ des Ganzen, entfernen. Und zwar ist die Änderung der Voraussetzungen dann eine besonders große, wenn der Ablauf sich nicht auf Grund von äußerlich hinzutretenden Ursachen vollzieht, sondern lediglich oder doch ganz wesentlich durch innerhalb des Systems sich vollziehende Veränderungen bedingt ist.

Alles dies trifft zu, wenn wir die Bedingungen eines tierischen Keims während der Ontogenese durch operative Eingriffe verändern, wenn wir z. B. ein aus acht Zellen bestehendes Furchungsstadium einer Ctenophore halbieren, oder vierteilen oder gar achtteilen. Wir sehen dann den Ablanf in dem ibriggebliebenen Rest des Systems fast genau so weitergehen, als hätte keine so außerordentliche Veränderung der Voraussetzungen, d. h. der den ganzen Ablauf bedingenden energetischen Situation, stattgefunden. Ich brauche den Leser wohl nicht erst darauf aufmerksam zu machen, daß, wenn man in solchen Fällen aussagt, der Rest entwickele sich durch »Selbstdifferenzierung " weiter, man die Tatsache nur umschreibt, ohne fur ihre Anffassung einen neuen Gesichtspunkt einzufuhren. Auch wir betrachten es nicht als unsere Aufgabe, die letzten Ursachen der Erscheinung zu erklären. Wir versuchen sie aber in eine größere Gruppe ron Erscheinungen einzuordnen, und bei diesem Bestreben tun wir am besten, von Beschreibungen 
and Benennungen der Vorgänge, die von anderen Gesichtspunkten aus geschaffen worden sind, vorläufig keine Notiz za nehmen.

Auch an den sich entwickelnden Eiern der Echinodermen, Anneliden, Ascidien, Mollusken usw. kann man in ähnlicher Weise wie an denen der Ctenophoren durch operative Eingriffe in ziemlich freier Weise anßerordentlich starke Veränderungen der Voraussetzungen hervorrufen, ohne zunächst den Ablauf innerhalb des Restes des Systems in wesentlichen Punkten zu verändern. Daß dann später wesentliche $\mathrm{Ab}$ weichungen von dem gewöhnlichen Ablauf eintreten, beschäftigt uns vorlänfig nicht. Wir haben auf diesen Umstand, dessen große Bedeutung wir noch erkennen werden, später ausfubrlich zuriickzukommen.

Es wurde gesagt, daß man die Veränderung der Voraussetzungen, in unserem Falle das Verstiummeln der Systeme durch operative Eingriffe, in ziemlich freier Weise vornehmen könne, ohne den Ablauf innerhalb des Restes zu stören. Bei aller Freiheit, mit der wir bei unseren Eingriffen schalten, und nach Belieben bald diese, bald jene Teile des Systems entfernen können, hat dieses Belieben doch gewisse Grenzen, die je nach den Spezies, dem der untersuchte Organismus angehört, und dem Entwicklungsstadium, auf dem er sich befindet, verschieden ist. Ich komme hierauf im elften Kapitel noch ausführlicher zurtick.

Wenn wir also frtiher gefunden haben, $\mathrm{da} B$ es ein Charakteristikum der mnemischen Phänomene (mnemische Erregungen manifestiert durch bestimmte Reaktionen) ist, daß sie zu ihrer Hervorrufung nur eines Teils und, mit gewissen Einschränkungen gesagt, nur eines beliebig zu wählenden Teils der Voraussetzungen bedtirfen, der zur Hervorrufang der ent- 
Nachweis des mnem. Faktors bei den ontogen. Reproduktionen. 241

sprechenden Originalerregungen erforderlich war, so ist es klar, daß die ontogenetischen Phänomene sich ihnen insofern angliedern, als bei ihrer Hervorrufung ebenfalls ron den gewöhnlich vorhandenen Voraussetzungen große, bis zu einem gewissen Grade beliebig große Abstriche gemacht werden können. Es ist hervorzuheben, daß es sich hierbei um ein allgemeines Merkmal der ontogenetischen Prozesse bei allen Arten von Organismen und für alle Entwicklungsstadien handelt; nur das Maß der Veränderungen, die wir in den Volaussetzungen anbringen dürfen, obne den Ablauf unmöglich zll machen, schwankt nach Art und Entwicklungsstufe.

Allerdings geht nur bei einer Anzahl von Tierklassen der Ablauf eine Weile nach Eintritt der Veränderung der Voraussetzungen ebenso weiter, wie bei ungestörten Voraussetzungen. Bei anderen - hierher gehören z. B. die Hydromedusen, Amphioxus, Teleostier, Amphibien - wird zwar auch der Ablauf nicht unmöglich gemacht, aber er wird fast unmittelbar nach Eintritt der Änderung modifiziert. Die Art dieser Modifikation ist jedoch eine derartige, daß sie als weiteres starkes Argument für den mnemischen Charakter der Erregungen gelten kann, die sich in den plastischen Reaktionen der Ontogenese manifestieren. Diese Modifikation des Ablaufs tritt übrigens auch häufig in denjenigen Fällen auf, in denen der Ablauf zunächst noch eine Zeitlang ebenso weitergeht, als ob keine Veränderung der Voraussetzungen eingetreten wäre, z. B. bei den Echinodermen.

Worin besteht nun diese Modifikation des Ablaufs?

Wir haben, wenn wir von ungestörtem Ablauf nach Elimination eines Teils der Voraussetzungen durch operativen Eingriff sprachen, dies sungestört " immer nur in dem Sinne gebraucht, daß wir es in bezug auf die Reaktionen des zurtick- 
gebliebenen Restes des Systems, nicht aber in bezug auf die Reaktionen der eliminierten Teile des Systems aufgefaßt haben. Daß mit jenen Teilen auch die an ihnen auftretenden Reaktionen fortfielen, ist ja selbstverständlich. Nun sehen wir aber an dem tibriggebliebenen Rest entweder nach einiger Zeit oder in selteneren Fällen sogleich neben den gewöhnlichen Ablaufsreaktionen neue plastische Reaktionen auftreten, die bei aller von Fall zu Fall vorhandenen Verschiedenheit das eine Gemeinsame haben, daß sie schließlich eine Wiederherstellung der durch den Eingrifí gestörten Voraussetzungen bewirken. Oder anders ausgedruickt, sie stellen eine Kongruenz her zwischen dem Zustand - zunächst denken wir dabei nur an den morphologischen Zustand - des operativ veränderten Restes des Systems und demjenigen Zustand, den das System erreicht haben würde, wenn kein Eingriff stattgefunden hätte.

Nun haben wir bereits im vorigen Kapitel (S. 216) bei Untersuchung der mnemischen Homophonie Reaktionen kennen gelernt, die bewirkten, daß eine Inkongruenz zwischen zwei Zuständen beseitigt wird. Es waren das zwei Erregungszustände, ein originaler und ein entsprechender mnemischer. In den uns jetzt beschäftigenden Fällen handelt es sich allerdings zunächst um morpholc ;ische Zustände. Wenn wir also die besprochenen ontogenetis hen Beobachtungen mit unseren bei Untersuchung der mnemischen Homophonie gewonnenen Resultaten in irgendwelche direktere Beziehung bringen wollen, so müssen wir folg'endes nachweisen. Erstens: auch bei den ontogenetischen Phänomenen werden wir von den zunächat der Beobachtang vorliegenden morphologischen Zuständen auf Erregungszustände gefuhrt. Zweitens: in den betreffenden Fällen sind die Bedingungen ge- 
Nachweis des mnem. Faktors bei den ontogen. Reproduktionen. 243

geben sowohl für das Vorhandensein eines Originalerregungszustandes, als auch fur das Vorhandensein eines entsprechenden mnemischen Lrregungszustandes. Drittens: die beobachteten neu hinzutretenden Reaktionen bewirken ganz oder teilweise die Beseitigung von Inkongruenzen bei der Homophonie jener beiden Erregungszustände.

Die Frage, ob den morphologischen Zuständen, die in der Ontogenese als klare Beobachtungstatsachen vorliegen, Erregungszustände entsprechen, ist leicht zu beantworten. Dabei wollen wir aber die Frage weiter fassen und sie auf alle morphologischen Zustände, auch die des ausgebildeten Organismus nach Abschluß der Ontogenese, ausdehnen. Es ist klar, daß durch den morphologischen Zustand eines Systems seine energetische Situation, and zwar seine innere energetische Situation mitbedingt ist. Nur mitbedingt! Denn außer dem morphologischen $₹$ ustand spielt natlirlich anch der chemische, thermische, elektrische usw., der ja von ersterem nur teilweise abhängig zu sein braucht, ebenfalls eine bedeutende Rolle. Alle diese Teile der energetischen Situation wirken neben dem morphologischen Zustand mitbestimmend auf den jeweiligen Erregunģzustand eines Organismus, und zu diesen Originalerregungen kommen ferner noch die mnemischen, die im gegebenen Augenblicke gerade im Organismus ekphoriert sind. Somit bestimmt der morphologische Zustand eines Organismus nur zum Teil den äußerst komplexen Erregungszustand, der im gegebenen Augenblick im Organismus abläuft. Er ist einer von mehreren Faktoren, aber er ist ein sehr wichtiger uud eiu in keinem Augenblick außer Wirksamkeit tretender Faktor. Sowie er sich ändert, muß sich anch der Erregungszustand ändern. Ein Teil dieses komplexen Erregungscustandes befindet sich also stets in einem 
bestimmten Abhängigkeitsverhältnis rom jeweiligen morphologischen Zustande des Organismus. Wir wollen diesen in sich wieder komplexen Teil des Erregungszustandes als den morphogenen Teil des Erregungskomplexes bezeichnen.

Diese Abtrennung eines morphogenen Teils von der Gesamtheit eines simultanen Erregungskomplexes betrachte ich nicht als eine begrifflich tiefer begründete und schärfer durchfubrbare. Sie erleichtert uns aber die Verständigung und mag deshalb als ein provisorischer Notbehelf in der gegenwärtigen Phase anserer Untersuchung ibre Dienste tun. Wenn wir den morphogenen Teil eines simultanen Erregungskomplexes als die Summe derjenigen Erregungen betrachten, die durch die $\gg$ Positionsreize * der Entwicklungsphysiologen ausgelöst werden, so dürfen wir nicht vergessen, daß damit sein Inhalt nur summarisch angedeutet, nicht erschöpfend definiert ist. Diese Positionsreize werden sich bei weiterer Analyse in Reize verschiedener Reizkategorien auflösen lassen. Für unsere gegenwärtigen Zwecke dürfte aber ein derartiger Sammelbegriff gentigen:

Wir beantworten demnach die erste der von uns aufgeworfenen Fragen dahin, daß dem morphologischen Zustande eines sich entwickelnden oder ausgebildeten Organismus ein bestimmter Teil seines jeweiligen Erregungszustandes entspricht, den wir summarisch den morphogenen Teil dieses Erregungszustandes genannt haben.

Die zweite Frage, die wir zu beantworten hatten, lautete: Waren in denjenigen Fällen, in denen wir die Voraussetzungen durch einen operativen Eingriff verändert hatten und darauf einen eigentumlich modifizierten Ablauf eintreten sahen, die Bedingungen vorhanden nicht nur fur das Vorhandensein 
Nachweis des mnem. Faktors bei den ontogen Reproduktionen. 245

eines originalen, sondern auch für das Vorhandensein eines entsprechenden mnemischen Erregungszustandes?

Die Bedingungen jedenfalls. Für den Eintritt einer mnemischen Erregung sind zwei Voraussetzungen erforderlich: das Vorhandensein eines Engramms und die Ekphorie desselben. Dieses Engramm mußte in den uns vorliegenden Fällen, da es eine dem morphogenen Erregungsteil entsprechende Erregung liefern soll, das Produkt der wiederholten Einwirkung einer ähnlichen morphogenen Erregung sein. Nun ist es klar, daß, wenn es sich um ontogenetische Vorgänge handelt, die Positionsreize eines vorübergehenden Stadiums für das vorliegende Individuum jedesmal zum erstenmal und nur einmal erregend einwirken. Wohl aber haben dieselben oder äußerst ähnliche Reizkomplexe auf unzählige Aszendenten dieses Individuums erregend gewirkt. DaB diese Einwirkungen auch engraphisch gewirkt und die Engramme sich auf die Nachkommen übertragen haben, ist das, was wir beweisen wollen. Wir können dies aber nicht durch direkte experimentelle Nachprüfung, $d$. h. experimentelle Neuschaffung dieser Engramme - etwa ähnlich den Experimenten von Kammerer, Chauvin, Standfuss, Fischer, Tower, Bordage usw. - beweisen, soudern müssen an fest gegebenen Zuständen die mnemische Natur bestimmter Erregungen darlegen ( $\nabla$ gl. S. 83). Wir wollen im gegenwärtigen Augenblick das za Beweisende einmal als bewiesen ansehen und annehmen die morphogenen Erregungen hätten in jeder Generation engraphisch gewirkt, und die Engramme hätte n sich auf die Nachkommen tibertragen. Unsere Frage lautet dann weiter: Sind die Voraussetzungen vorhanden, daB diese erblich ubertragenen morphogenen Engramme im entsprechenden Augenblick auch bei den Nachkommen ekphoriert werden? 
Eine einfache Überlegung zeigt, daß in jeder Generation die morphologischen Zustände, deren energetische Einwirkung jene morphogenen Engrammkomplexe hervorgebracht hat, eine kontinuierliche Sukzession bilden. Hieraus folgt ohne weiteres, daß die morphogenen Engrammkomplexe sukzessiv assoziiert sein muissen, daß also die Ekphorie des ersten fortlaufend die Ekphorie der ganzen Engrammkette bewirken maß. Wird daher beim Beginn einer Ontogenese - und dies ist, wie wir später zeigen werden, der Fall - das erste Engramm ekphoriert, so ist damit eine Voraussetzung gegeben, daß mit der Zeit alle seine Nachfolger in einer Weise, deren Abhängigkeiten wir noch näher studieren werden, zur Ekphorie gelangen.

$\mathrm{Zu}$ dieser einen Voraussetzung tritt aber noch eine zweite, die auf einer Ekphorie der einzelnen Glieder der Engrammsukzession durch Originalreize beruht. Auf diese zweite Voraussetzung wollen wir aber erst später eingehen, und uns jetzt den konkreten Fällen operativ gestörter ontogenetischer Entwicklung wieder zawenden, von denen wir aúsgegangen sind.

Wir sahen, daß bei operativer Entfernung von Teilen des sich entwickelnden Organismus im ïbrigbleibenden Rest nach einiger Zeit (oder in selteneren Fällen sofort) neben den ihm zugehörigen Ablaufsreaktionen neue plastische Reaktionen auftreten, die bei aller von Fall zu Fall vorhandenen Verschiedenheit das eine Gemeinsame haben, daß sie schließlich eine Wiederherstellang der durch den Eingriff gestörten Voraussetzungen bewirken, d. h. eine Kongruenz herstellen zwischen dem morphologischen Zustand des operativ veränderten, dabei aber in der Entwicklung fortfahrenden Restes des Organismus und dem morphologischen Zustand desselben Stadiams, wie ihn 
Nachweis des mnem. Faktors bei den ontogen. Reproduktionen. 247

seine Vorfahren und unoperierten Geschwister durchlaufen und den er selbst erreicht haben wurde, wenn kein Eingriff stattgefunden hätte. Letzterer Zustand ist uns aus dem Studium der normalen Ontogenese bekannt.

Nun haben wir erkaunt, daß der morphologische Zustand des operativ veränderten Restes des Organismus ein bestimmender Faktor des jeweiligen originalen Erregangszustandes dieses Restes ist. Dell morphologischen Zustande aber, den der Organismus erreicht haben würde, wenn kein Eingriff stattgefunden hätte, extspricht als Erregungsustand der muemische morphogene Erregungszustand, dessen Vorhandensein wir zwar bisher nur in hypothetischer Form angenommen haben, für dessen Zustandekommen aber, wie nunmehr gezeigt worden ist, alle Bedingungen vorhanden sind. Es ist selbstverständlich, daß dieser mnemische morphogene Erregungszustand durch den operativen Eingriff nicht rerändert wird, da er ja aus dem Bestande des ererbten Engrammschatzes stammt, der, wie wir (S. 152) angedeutet " `ben und im elften Kapitel noch ausfuhrlicher nachweisen werden, jedem mnemischen Protomer eines Individuums in gleicher Weise zukommt, also auch durch Fortnahme von morphologischen Teilen aus dem Verbande des Ganzen nicht angegriffen werden kann:

Der Ausdruck: ^der morphologische Zustand, den der Organismus erreicht haben würde, wenn kein Eingriff stattgefunden hätte* gewinnt Realität erst dadurch, daß wir das Abhängigkeitsverhältnis dieses Zustandes von dem entsprechenden, im operierten wie nicht operierten Organismus real vorhandenen muemischen Erregungszustande feststellen.

Wenn wir also nicht mehr die beiden morphologischen Zugtände, von denen der eine in den gegebenen Fällen keine 
Realität besitzen kann, sondern die realisierbaren Erregungszustände ins Auge fassen, so fallen die plastischen Ausgleichsreaktionen (plastischen Regulationen), die bei der Störung der Entwicklung neben den gewöhnlichen, die Entwicklang fortfubbrenden Reaktionen auftreten, in eine Kategorie uns bereits bekannter Reaktionen. Wir haben oben (S. 211) gezeigt, daß wir auf objektivem Wege auf mnemische Homophonie nur aus dem Auftreten objektiv wahrnehmbarer Reaktionen schließen können, deren Charakteristikum darin liegt, $\gg \mathrm{daB}$ sie sich genau entsprechend der Kongruenz oder Inkongruenz eines originalen Erregungszustandes mit einem fruher einmal bei demselben Organismus (oder seinen Vorfahren) vorhanden gewesenen Erregungszustand modifizieren, fur dessen Ekphorie als mnemischer Erregungszustand jetzt wieder die Bedingungen vorhanden sind. - Von diesen Reaktionen sind am beweisendsten für die Anwesenheit und Wirksamkeit von Homophonie diejenigen, die bewirken, daß die Inkongruenz beseitigt wird * (S. 219).

Wir können unsere Schlußfolgerung demnach jetzt folgendermaßen formulieren. Bei experimentellen oder zufälligen Störungen der Ontogenese treten Reaktionen auf, die sich entsprechend der Inkongruenz zwischen einer morphogenen Originalerregung und einer früher einmal bei den direkten Vorfahren des Organismus vorhanden gewesenen morphogenen Erregung modifizieren, und zwar in der Weise modifizieren, daß sie mit der Zeit diese Inkongruenz beseitigen. Aus diesen Reaktionen dürfen wir auf Homophonie schließen, d. h. es als bewiesen ansehen, daß gleichzeitig neben der morphogenen Originalerregung der früher einmal bei den Vorfahren vorhanden gewesene morphogene Erregungszustand jetzt als mnemische Erregung wieder aufgetreten ist. 
Ehe wir uns nunmehr das ontogenetische Geschehen unter dem Einflusse dieser Homophonie genauer in seinen einzelnen Phasen vor Augen führen, wollen wir noch auf einen vorher nur kurz berührten Punkt zurlickkommen.

Wir hatten gesehen, daß die morphogenen Engrammkomplexe sukzessiv assoziiert sind, daß also die Ekphorie des ersten fortlaufend die Ekphorie der ganzen Engrammkette bewirkt. Wir hatten aber gleich bemerkt, daß dazu eine zweite Möglichkeit der Ekphorie der einzelnen Glieder tritt, und zwar einer Ekphorie auf Grund von Originalreizen. Wir wollen diesen Punkt jetzt einer näheren Betrachtung unterziehen, and verfolgen dazu die Kette der Erregungen und morphologischen Veränderungen, die bei einem beliebigen ontogenetischen Ablauf tätig sind, indem wir als Ausgangspunkt den Eintritt eines mnemischen morphogenen Erregungskomplexes wählen. Dieser Erregungskomplex wird fur uns durch den Eintritt eines Reaktionskomplexes manifest, und die dadurch geschaffene energetische Situation wirkt als Originalreiz und erzeugt als solcher einen originalen Erregungskomplex, der im Falle ungestörter Ontogenese dem mnemischen Erregungskomplex, von dem wir ausgegangen sind, im ganzen entspricht (Kongruenz der Homophonie). Es ist nun klar, daß in diesem Falle jeder der beiden homophonen Erregungskomplexe ekphorisch auf den nächsten sukzessiv assoziierten Engrammkomplex wirken muß.

Von ihrer gemeinsamen Wirksamkeit können wir uns eine Vorstellung verschaffen, indem wir einen analogen, uns mittels Introspektion zugänglichen Fall untersuchen. Wenn uns eine altbekannte Melodie auf einem Instrument vorgespielt wird, so wirken auch mnemische und originale Erregungen zusammen ekphorisch auf die sukzedierenden En- 
grammkomplexe. Verstummt das Instrument plötzlich, so läuft doch der mnemische Vorgang noch eine Zeitlang weiter. Ist er dann nach einiger Zeit am Stillstehen, so kann er durch ein paar von neuem vorgespielte Takte wieder einen neuen Anstoß erhalten. Was das Tempo anlangt, in dem die Sukzessionen ablaufen, so dominieren bei seiner Bestimmang entweder die mnemischen oder die originalen Erregungen. Jedenfalls wird auch darin mit der Zeit immer eine Kongruenz der Homophonien hergestellt. Bei einem Kapellmeister zum Beispiel, der sich durch ein za lebhaftes Tempo, in das sein Orchester verfallen ist, ins Schlepptau nehmen läßt und einen Satz übermäßig schnell abdirigiert, überwiegen bei der Ekphorie die originalen Erregungen über die mnemischen. Ein anderer dagegen, dessen mnemische Erregungen eine größere Kraft besitzen, uberwindet die Gewalt der originalen Einwirkungen und weiß dieselben durch sein hemmendes Taktieren der Herrschaft der mnemischen Gewalten unterzuordnen. Jedenfalls sieht man, daß in beiden Fällen beide Arten von Erregungen ekphorisch wirksam sind. Bei ihrer Wirksamkeit gilt auch wieder die Regel, daß, wenn keine Kongruenz bei der Homophonie vorhanden ist, dieselbe auf dem einen oder dem anderen Wege mit der Zeit hergestellt wird.

Bei der Ontogenese wird nun wohl das Tempo der Abläufe der Sukzessionen ganz vorwiegend von dem Tempo der originalen Reizkomplexe beherrscht, die ihrerseits von dem Tempo abhängig sind, das die plastischen Reaktionen zu ibrem Ablauf brauchen. Denn das Tempo der mnemischen Abläufe kann leicht akzeleriert und retardiert werden; dasjenige der von den plastischen Reaktionen abhängigen originalen Erregungen ist durch diese morphologischen Vorgänge

1 Diese Regel hat indessen auch Ausnahmen. Vgl. die Anm. S. 265. 
Nachweis des mnem. Faktors bei den ontogen. Reproduktionen. 251

bestimmt, die von vielen änßeren, besonders thermischen, Bedingungen abhängig sind.

An dem Satze, daß bei den ontogenetischen Abläufen die Ekphorie eines Engramms durch die gemeinsame Wirkung des präzedenten mnemischen und des mit ihm homophonen originalen Erregungskomplexes erfolgt, wird in der Hauptsache nichts geändert, wenn infolge operativer Eingriffe der originale Erregungskomplex verkleinert, sozusagen verstümmelt wird. Denn, wie wir wissen, ist es ein allgemeines mnemisches Gesetz, daß schon die Wiederkehr eines bloßen Teiles eines Reizkomplexes ekphorisch auf einen Engrammkomplex wirkt.

Indem wir uns vorbehalten, später noch auf einige speziellere Fälle der Ekphorie der ontogenetischen Engramme zurückzakommen, geben wir im folgenden ein Schema, das die Abläufe bei der normalen Ontogenese, und ein zweites, das die Abläufe bei der experimentell gestörten Ontogenese darstellt, wobei wir zunächst nur die Abläufe solcher Erregungen ins Ange fassen, die sich in plastischen Reaktionen manifestieren.

$\mathrm{Za}$ den beiden umstehenden Schemata haben wir noch folgende Bemerkangen hinzazufugen, die für ihre richtige Auffassung von Bedeutung sind. Es ist selbstrerständlich, daB diese Schematisierungen nur dadurch ihrer Anfgabe gerecht werden können, uns den Überblick uber das ungeheuer verwickelte Getriebe des Naturgeschehəns zu erleichtern, daß sie durch mehr oder weniger willkürliche Trennung, Weglassung und Zusammenziehung eine Vereinfachung herbeiftihren.

Eine willkürliche Trennung ist zunächst die Phaseneinteilung der Ontogenese, mögen wir die Dauer der Phase nun durch ein siderisches oder durch ein aus dem organischen Ablauf selbst gewonnenes Zeitmaß bemessen. Wählen wir bei einem bestimmten ontogenetischen Prozeß, z. B. einer 
Achtes Kapitel.

Schema der Abläufe bei der normalen Morphogenese.

\begin{tabular}{|c|c|c|}
\hline Phase $a$ & Phase $b$ & Phase $c$ \\
\hline $\begin{array}{l}\text { Mnemischer Erre- } \\
\text { gungskomplex } \\
a \text { (mn) } \\
\downarrow \\
\text { Plastische Reak- } \\
\text { tionen: } \\
\text { Morphologischer } \\
\text { Zustand } a \text { (z) } \\
\downarrow \\
\text { Originaler Erre- } \\
\text { gungskomplex } \\
a \text { (or) - . . } \\
\text { [Homophonie zwi- } \\
\text { schen } \\
a \text { (mn) und } a \text { (or)] }\end{array}$ & $\begin{array}{l}a \text { (or) und } a \text { (mn) } \\
\text { wirken gemeinsam } \\
\text { sukzessiv ekpho- } \\
\text { risch auf Engramm- } \\
\text { komplex } b \text { (engr). Es } \\
\text { resaltiert der mne- } \\
\text { mische Erregungs- } \\
\text { komplex } \\
b \text { (mn) } \\
\downarrow \\
\text { Plastische Reak- } \\
\text { tionen: } \\
\text { Morphologischer } \\
\text { Zustand } b \text { (z) } \\
\downarrow \\
\text { Originaler Erre- } \\
\text { gungskomplex } \\
b \text { (or) - } \\
\text { [Homophonie zwi- } \\
\text { schen } \\
b \text { (mn) und } b \text { (or)] }\end{array}$ & 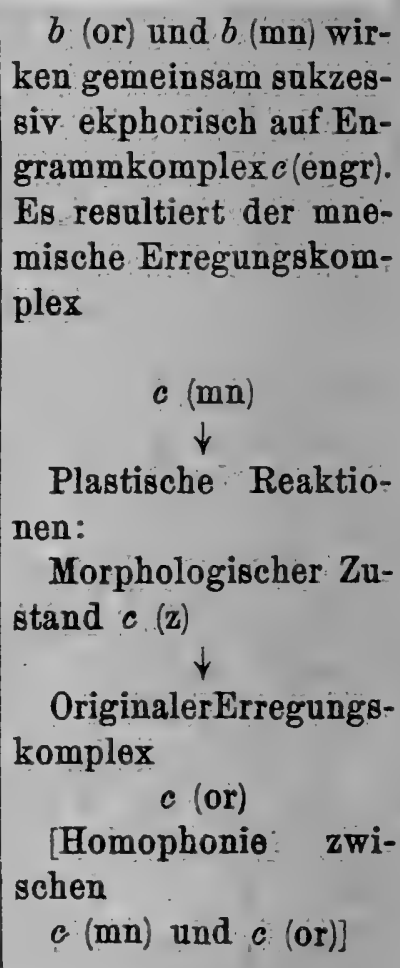 \\
\hline
\end{tabular}

totalen adäqualen Eifurchang, den Zeitranm, der zum vollständigen Ablauf einer Kernteilung erforderlich ist, als Zeiteinheit für die Phaseneinteilung, so befinden wir uns doch gleich dadurch wieder in Verlegenheit, daß dieses Zeitmaß selbst für den gerade vorliegenden Organismus ein keineswegs konstantes ist, sondern je nach äußeren und inneren Bedingungen and zudem noch von Kern zu Kern innerhalb ziemlich weiter Grenzen schwankt. Immerhin wäre es vielleicht nicht unpraktisch, die mittlere Zeitdaner der Kernteilungen eines Organismus als Zeitmaß für die Phaseneinteilung der Furchung dieses Organismus zu verwenden, wenn man sich der Willktir dieser Kontinuitätstrennung bewußt bleibt and der 
Nachweis des mnem. Faktors bei den ontogen. Reproduktionen. 253

Schema der Abläufe bei der gestörten Morphogenese.

(In Phase $a$ sei durch einen Eingriff der morphologische Zustand a in den Zustand $\alpha$ verwandelt worden.)

\begin{tabular}{|c|c|c|}
\hline$e: a$ & se $b$ & ase $c$ \\
\hline $\begin{array}{l}\text { Mnemischer Erre- } \\
\text { gungskomplex } \\
a(\mathrm{mn}) \\
\downarrow \\
\text { Plastische Reak- } \\
\text { tionen: } \\
\text { Morphologischer } \\
\text { Zustand } \alpha \text { (z), } \\
\text { [welcher anstatt } a \\
\text { (z) infolge einer Stö- } \\
\text { rung eingetreten ist] } \\
\downarrow \\
\text { Originaler Erre- } \\
\text { gungskomplex } \\
\quad \alpha \text { (or) -.... } \\
\text { [Homophonie zwi- } \\
\text { schen } \\
a \text { (mn) und } \alpha \text { (or)] } \\
\downarrow \\
\text { Eventuell: Pla- } \\
\text { stische Reaktionen } \\
\text { in der Richtung des } \\
\text { Ausgleichs der In- } \\
\text { kongruenz } a: \alpha\end{array}$ & $\begin{array}{c}\downarrow \\
\text { Originaler Erre- } \\
\text { gungskomplex } \\
\beta \text { (or) -.... } \\
{[\text { Homophonie zwi- }} \\
\text { schen } \\
b \text { (mn) und } \beta \text { (or)] } \\
\downarrow \\
\text { Eventuell: Pla- } \\
\text { stische Reaktionen } \\
\text { in der Richtung des } \\
\text { Ausgleichs der In- } \\
\text { kongruenz } b: \beta\end{array}$ & 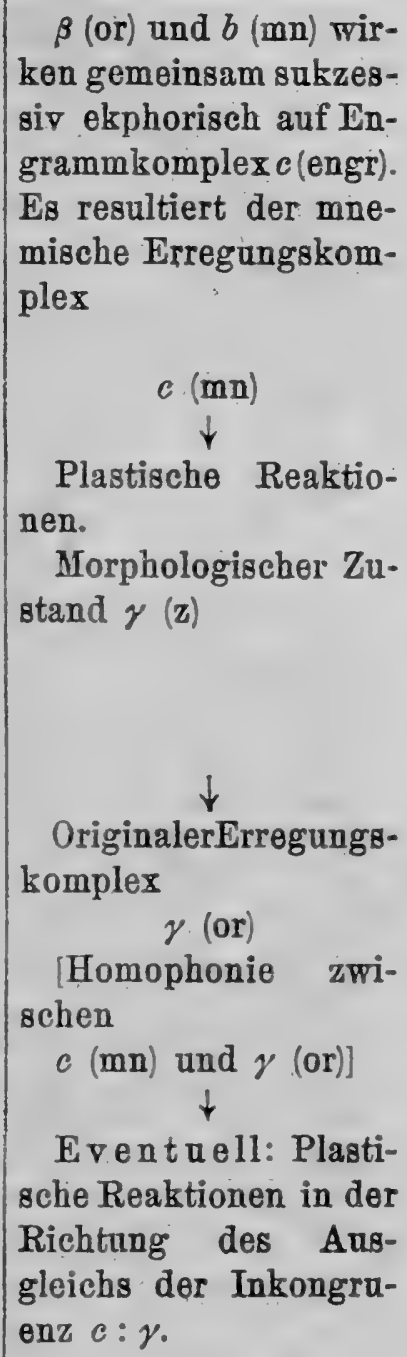 \\
\hline
\end{tabular}

In bezug auf die Phase $c$ des zweiten Schemas bemerke ich noch, $\mathrm{da} B$, wenn die plastische Reaktion in der Richtung des Ausgleichs der Inkongruenz zwischen $c$ und $\gamma$ diesen Ausgleich herbeiführt, die Ontogenese von $d a$ an als normale weiter verläuft, $d$. h. die dann folgende mnemische Erregung $d$ ruft den morphologischen Zustand $d$ (z), nicht $\delta(\mathrm{z})$ hervor. 
Phaseneinteilung keine tiefere Bedeutung beilegt als etwa der Einteilung einer fortlaufenden Melodie in Takte. Wie in einem polyphonen Musikstück können sich innerhalb eines solchen Takts sehr viele verschiedene Ablänfe in sehr verschiedenen Einzeltempi vollziehen und die Kontinuität der Einzelkomponenten, hier Töne, ebensowohl innerhalb der Takte unterbrochen werden als zwischen zwei Takten.

Somit ist es ferner anch als eine willkürliche Vereinfachung in unseren Schemata anfzufassen, wenn sich in denselben die komplizierten Abläufe in ihrer Totalität scheinbar genau in die Phaseneinteilung einordnen. In konkreten Fällen ist die Möglichkeit einer solchen glatten Einordnung wohl so gut wie ausgeschlossen. Auch ist die Ausdrucksweise, Erregungskomplex $a$ wirke ekphorisch auf Engrammkomplex $b$, nattirlich eine ganz summarische. Betreffs der Verbindung der Engrammkomplexe untereinander bitte ich

Phase $a$ Phase $b$ Phase $c$ Phase $d$

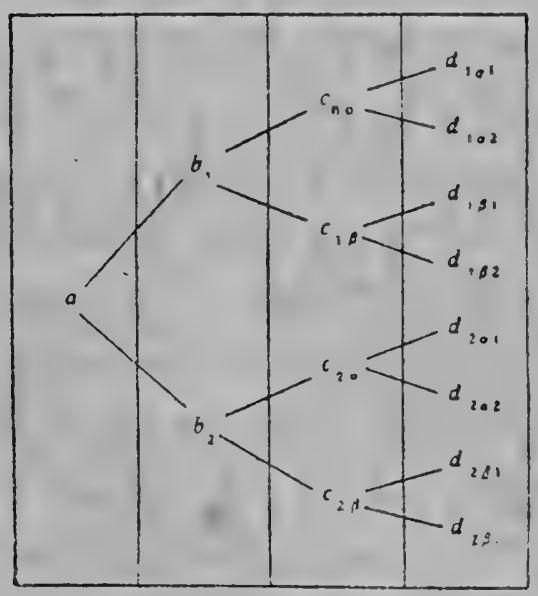

der Ontogenese.

die allgemeinen Ausfuhbrungen auf S. 125 noch einmal durchzulesen und das Schema auf S. 127 anzusehen. Die dortigen Ausfübrungen tuber die näheren und ferneren Verbindungen $z w i-$ schen den einzelnen Komponenten der simultanen and sukzessiven Engrammkomplexe gelten auch durchaus für die Verbindungen der Komponenten morphogener Engrammkomplexe bei

So wiirden in einem sehr vereinfachten Schema nach Art des anf S. 127 wiedergegebenen die Vsrbindungen der 
Nachweis des mnem. Faktors bei den ontogen. Reproduktionen. 255

Komponeuten, kürzer gesagt, die Komposition des morphogenen Engranunkomplexes bei einer adäqualen Eifurchung sich wie im roranstehenden Schema (N. 254) gestalten.

Wie wir sehen, stellt sich uns aus diesem Schema der Charakter der Verknlipfung der Engramme als der einer simultan ekphorierbaren (weil in ihren Komponenten simultan assoziierten) Dichotomie dar (rgl. S. 144). Von den Verbindungen der Engrammkomponenten sind in unserem Falle die sukzessiven inniger als die simultanen. Dies geht aus der Tatsache herror, daB bei der Ontogenese die Simultankomplexe lange nicht so fest gebunden sind als die Komposition der Sukzessionen.

Dieses eigentimiiche Verhalten erklärt sich folgendermaBen. Die Ekphurie gewisser zusammengehöriger Komponenten eines simultanés Engrammkomplexes kann durch allerlei Einflusse so beschlenuigt oder verzögert werden, daß sie in einer frulueren oder einer späteren Phase erfolgt, als die der mit ihnen simultan assoziierten Komponenten. Es ergibt sich dies schon aus der statistischen Tatsache, daß die Entwicklungshöhe der Organe in den einzelnen »Stadien* normalerweise innerhalb gewisser, meist allerdings relativ enger Grenzen schwankt. Gehen wir hierron als von etwas ron vornherein Gegebenem ans, so ergibt sich weiter, daB, da bei jeder Wiederholung in der Folge der Generationen die Zusammensetzung der Simultankomplexe eine innerhalb einer bestimmten Breite schwankende ist, dies auch mnemisch in einer gewissen Ferwischung der ekphorischen Kraft der Simultanassoziationeu mum Ausdruck kommen snaß. Die ekphorische Bedtutng der sukzessiren Assoziationen dagegen, die bei jeder Tiederholung annähernd dieselben sind, steigert sich eben aus diesem Grunde durch jede neue Wiederholung, und 
übertrifft an Wirksamkeit weit die verwischteren Simultanassoziationen.

Wir können den ontogenetischen Ablauf in dieser Beziehung mit der ebenfalls unter der Herrschaft der Mneme ablaufenden Reproduktion eines Musikstucks vergleichen, bei dem zwar jede einzelne Stimme an sich korrekt durchgefuhrt wird, bei dem aber das Zusammenspiel der Stimmen leichten Schwankungen unterliegt, die sich gerade so weit in Schranken halten, daß der Totalablauf nicht zerstört wird. Menschen ron geringer musikalischer Begabung produzieren auf dem Klavier besonders dann eine solche Musik, wenn die Baßstimme einem anderen Rhythmus zu folgen hat als die Diskantstimme, oder wenn beim Selbstakkompagnement zum Gesang Gesangstimme und Begleitung verhältnismäßig selbständigen Bahnen folgen.

Größere Abweichungen in dieser Richtung werden freilich sowohl beim morphogenetischen Geschehen als auch bei der musikalischen Reproduktion durch regulierende Reaktionen zum Verschwinden gebracht, die sich einstellen, wenn die Inkongruenz zwischen den Originalerregungen und den mnemischen Erregungen ein gewisses $\mathrm{MaB}$ überschreitet.

Noch auf eins möchte ich aufmerksam machen. Nicht die Zahl der Schritte von Anfang der individuellen Entwicklung an wirkt in erster Linie sukzessiv ekphorisch auf ein bestimmtes Engramm, sondern die Erreichung eines bestimmten Zustandes. Wie wir schon im dritten Kapitel (S. 100) ausgeführt haben, ist der Eintritt der Gastrulation bei Echinidenkeimen nicht lediglich abhängig von der Zahl der vorhergegangenen Zellteilungen. Sondern sie erfolgt in erster Linie, sobald die Größe der einzelnen Zellen bis auf ein bestimmtes Maß herabgemindert ist, also bei Volleiern nach einer größeren, bei Eifragmenten oder isolierten Blastomeren 
nach einer ihrer Kleinheit entsprechend geringeren Zahl von Teilungen. Zwingt man, wie Driesch es getan hat, zwei sich entwickelnde Keime, sich zu einer einzigen, doppelt so voluminösen neuen Individualität zu vereinigen, so ist eine größere Anzahl von Teilungen bis zum Eintritt der Gastrulation erforderlich als bei gewöhnlichen Volleiern.

Endlich haben wir noch auf einen Punkt einzugehen, um einen naheliegenden Irrtum auszuschließen. Auf S. 254 haben wir ein Schema der Komposition der morphogenen Engramm- bzw. Erregungskomplexe bei einer adäqualen Eifurchung gegeben. Entwirf man nun ein zweites Schema, das nicht die Verbindungen der Engramme bzw. Erregungen, sondern die Verbindungen der auseinander hervorgehenden Zellen wiedergibt, so könnte man aus den Übereinstimmangen dieser graphischen Darstellungen auf den Gedanken kommen, in jeder Phase entspräche je eine Engramm- bzw. Erregungslromponente derart einer bestimmten Zelle, daß diese Komponente nun auch in dieser Zelle lokalisiert sei. Die Unmöglichkeit dieser Vorstellung ergibt sich aber schon aus unseren Auseinandersetzungen über das Ausstrahlen der Erregungen tiber den ganzen Organismus (S. 162), und dies wäre in der Tat nur denkbar, wenn jede Zelle gegen ihre Nachbarschaft in bezug auf Reizleitung isoliert wäre, wovon naturlich keine Rede sein kann.

Jeder morphogene Erregungskomplex spielt sich also nicht innerhalb des Organismus in einer morphologiseh streng lokalisierten Verteilung ab, dergestalt, daß die eine Erregungskomponente nur in dieser, die andere in jener Zelle abläuft, sondern sein Ablauf erfolgt als ein solcher, der jedes mnemische Protomer in Mitleidenschaft zieht. 


\section{Neuntes Kapitel.}

Das ontogenetische Initialengramm und der: ontogenetische Ablauf.

Die Entwicklung einer Organismenreihe stellt sich, wie wir S. 65 gesehen haben, als eine Kontinnität dar, die zeitlich und räumlich in Phasen verläuft. Jeder Zeitphase entspricht als räumliche Phase ein Individuum. Während die zeitliche Kontinuität eine absolut ununterbrochene ist, kann die räumliche Kontinuität insofern unterbrochen sein, als sich bei Beginn einer jeden solchen Individualitätsphase eine ränmliche Trennung auszubilden pflegt. Dieselbe ist bei geschlechtlicher Fortpflanzung die Regel; bei ungeschlechtlicher kann sie ganz ausbleiben oder sich doch erst sehr spät einstellen. Trotz dieser Kontinuitätstrennung dürfen wir nie vergessen, daß die eigentliche Entwicklung sich ansnahmslos als fortlaufende Linie darstellt, deren Unterbrechungen durchweg sekundärer Natur sind, das heißt an einem Punkte stattfinden, der von der Fuhrungslinie bereits durchlaufen ist.

Die Kontinuitätstrennung ist für unsere jetzigen Betrachtungen deshalb noch von besonderer Bedeutung, weil durch dieselbe zwischen elterlichem und kindlichem Organismus anch mnemisch eine Trennung vollzogen wird. Erst nach 
Vollzug dieser Treniung ist fur den kindlichen Organismus die Möglichkeit gegeben, Engramme zn erwerben, an denen der elterliche Organismus keinerlei Anteil hat; er erhält dadurch auch mnemisch seine eigene Individnalität.

Wenn der kindliche Organismus sich vom elterlichen abgelöst hat, tritt nun in der tiberwiegenden Mehrzahl der Fälle der neae ontogenetische Ablauf nicht ohne weiteres ein. Wenn wir von den männlichen Keimen absehen, die aus äußeren Grinden unvermögend sind, nach ihrer Ablösung ohne weiteres den Entwicklungszyklus zr wiederholen, und nur die gtinstiger gestellten weiblichen Keime berícksichtigen, so inden wir auch diese nach Ablauf gemisser Veränderungen, die wir als tireifung bezeichnen, meist nnvermögend, den netien Entwickingsszjklus zu beginnen, wenn nicht ein äußerer Ansto hinzutritt. Obme diesen verharrt gewöhnlich das Ei im Ruhegustande und stirbt, wenn der AnstoB sehr lange Zeit ansbleibt; endlich ab.

Wenn wir dieses Stadium als Ausgangspunkt der Ontogenese wählen, wie dies $j a$ 'anch bisher von seiten der deskriptiven und experimentellen Entwicklungslehre stets geschehen ist, so bedare es, nm den Organismus in Phase $a$ unseres Seliemas S. 254 eintreten zu lassen, in den meisten Fällen eines bosonderen yon außen hinzutretenden Reizes, um die Ekphorie des Engranms, das wir das ontogenetische Initialengramm nennen wollen, zu bewirken und die mnemische Erregung a zu aktivieren.

Der Reiz, der normalerweise ekphorisch auf das ontogenetische Initialengramm wirkt, ist ein mit dem Befruchtungsvorgange verbundener Reiz., Welcher von den zahlreichen energetischen Einflissen, die beim Befruchtungsvorgang in Tätigkeit gesetzt werden, im speziellen die ekphorische Wir- 
kung ausibt, wollen wir jetzt nicht untersuchen, so interessant und wichtig diese Frage an sich auch ist.

Es ist nun aber besonders lehrreich und spricht seinerseits sehr fur den mnemischen Charakter der die Ontogenese eröffnenden Erregung, daß der auslösende Reiz gar kein spezifischer zu seir braucht, sondern daß an Stelle des normal auslösenden Reizes eine ganze Reihe, anderer, ganz verschiedenen Reizkategorien angehörige Reize treten köonen, die kunstlich eine Parthenogenese oder jungfräuliche Zengung, das heißt Entwicklung ohne Befruchtnng durch das männliche Element, auszulösen vermögen. Ich verweise hier auf das tiber vikarierende Ekphorie S. 47 und 88 Gesagte.

Loeb, der diese Frage in einer Reihe ron vorzllglichen Untersuchungen bearbeitet hat, erblickt in der Membranbildung, der Abbebung der Dotterhaut, der ersten entscheidenden Schritt zum Beginn der Fientwicklung. Es gelang ihm sowohl durch Einwirkung von Fettsäuren (Essiggäare, Propionsäure, Buttersäure, Valerłansäure) also auch, wiewohl weniger sicher, von Mineralsäeren (z. B. Salzsäure) die Membranbildung hervorzurufen. Es stellte sich ferner heraus, daß Saponin, Solanin, Digitalin, gallensaure Salze, ferner die spezifisch fettlösenden Kohlenwasserstoffe wie Amylen, Benzol, Toluol, Choroform, sodann Äther und Aikohole, ferner bei Gegenwart von freiem Sauerstoff Basen nnd endlich unter Umständen sogar bloße Temperaturerhöhung die Membranbildung anslösen kann. Auch durch die Einwirkung von artfremdem Blut oder von Extraikt aus Organen fremder Tiere läßt sich dasselbe Ziel erreichen. Freilich kommt es bei einer großen Zahl dieser Einwirkungen vor, daß die eingeleitete Entwicklung abnorm verläuft und vorzeitig zum Stillstand kommt. Dies liegt höchstwahrscheinlich an einer 
Das ontogenetische Initiaiengramm und der ontogenet. Ablauf. 261

gleichzeitig hervorgernfenen schädlichen Nebenwirkung. Loeb fand zwei Mittel, die so entstandene giftige Sabstanz za beseitigen: entweder Nachbehandlung mit einer hypertonischen Lösung bei Anwesenheit von freiem Sauerstoff, wobei das Gift durch Oxydation unschädlich gemacht wird; oder Sanerstoffentziehung bzw. Unterdrückung der Oxydationstorgänge durch Zyankalium, wobei wahrscheinlich der bypothetische schädliche Stoff durch Hydrolysen beseitigt wird. Den eigentlichen Anstoß zur Bildung der Membran und damit zur Auslösung der Entwicklung - freilich findet auch unter Uinständen Entwicklung ohne Membranbilinung statt - gibt nach Loeb die zytolytische Wirkung aller der gensnnten Säuren, Kohlenwasserstoffe, Basen, artfremden Organextrakte und Blute sowie des im arteigenen Sperma enthaltenen Lysins auf die Rindenschicht des Eies. Auch die mechanischen Einflisse wirken nach Loebs Áuffassung mittels Zytolyse. Fruher ${ }^{1}$ sträubte sich dieser Forscher dagegen, alle diese Einwirkungen als Reize zn bezeichaen. Nenerdings rechnet er sie selbst anter die formativen Reize?

An dieser Stelle sehe ich mich za einem Exkurs genötigt. In Einleitung und Vorwort seiner neuesten Zusammenstellung uiber künstliche Parthenogenese ${ }^{3}$ sagt Loeb: > Gerade der Umstand, daß die Entwickingserregung des Eies an die ,Reizung' erinnert, war mit Schuld daran, daß ich so viele Arbeit an dieses Problem gewandt habe. Es war mir bei meinen Versachen uber Tropismen sowic uber Gehirn, Nerrund Muskelphysiologie klar geworden, daß hier kein entS. 171.

1 J. Loeb, The Dynamics of Living Matter. New York 1906,

2 J. Loeb, J̛̉bar das Wesen der formativen Reizung, Berlin 1309.

3 J. Loeb, Dio chemische Entwicklungserregung des tierischen Eies. (Künstliche Parthenogenese), Berlin 1909. 
scheidender Fortachrit zu machen sel, bis wir wn tuber das Wesen des Nolzrorganges klar seien. Trot wehr als houdertjähriger Yromohwag sind wir von dlesern Ziel noch weis entfernt, and cen Grund hierfü sehe ich in dem Umstand, daß wir nich nach Wunsch direkt sehen künnen, was im Nerv und in geiner Endigungen bei der Reizung vorgeht. Beim Ei Krinnen wir die Vorgänge der Erregung direkt mit dem Auge rerfolgen, und was mehr ist, vir können dieselbe Tatsache gleichzeitig an Millionen von Individuen bestätigen. Das fuhrte mich anf den Gedanken, daR gerade das Studium der Entwicklungserregung berufen sein könne, uns die bis jetzt fehlender Analogien fur die erfolgreiche Ánalyse der Vorgänge im Muskel und Nerven und vielleicht in allen Zellen zu geber.:

Stellen wir nun aber die Frage, ob es Loeb bis jetzt relungen ist, auf diesem Wege tiefer in das Wesen des Erregnngsvorganges einzudringen, so mlissen wir diese Frage, selbst wenn wir uber alles Hypothetische in den theoretischen Ergebnissen Loebs hinwegsehen, uneingeschränkt mit Nein beantworten. Ganz abgesehen davon, aaß die Behauptung: wir könaten beim Fi »dic Vorgänge der Erregung \& direkt rait dem Ange becbachten, viel zu weit gefaBt und deshalb irrefuihrend ist, gewährt uns weder die Ermittlung, daß die Membranbildung in der Regel die erste sichtbare Reaktion der eingeleiteten Entwicklung ist, noch auch die gewiß sehr dankenswerte Feststellung, daß diese Membranbildung durch eine oberfächliche Zytolyse des Eies angeregt wird, einen eigentlichen Einblick in das "Wesen dieser formativen Reizung, das heiBt in die Kette der sich dabei abspielenden chemischen and physikalischen Vorgänge. Dazn kommt, daß die Membranbildung, die nach Loeb *der wesentliche 
Sehritt bei dex Entwicklungserregung seiv soll, unter Umständen auch gand unterbleiben kann, daß aber die Eier sich dennoch entwickeln. Und wenn Loeb trotz dieses augenscheinlichen MiRerfolgs, in dem vorliegenden von ihm als besonders guinstig angesehenen Einzelfall in die eigentlichen Zusammenhänge einzudringen, den generellen Vorschlag macht, die Worte Reizung und Reizwirkung ganz aus dem Wortschatz der Physiologie zu streichen ${ }^{1}$, so bedarf es kaum eines besonderen Nachweises, daß ein solches Vorgehen bei dem gegenwärtigen Stande unseres Wissens auf dem Gebiet der Muskel-, Nerven- und Sinnes-Physiologie zu einem voliständigen Chaos fularen wirde.

Zweifellos ist die Erregung im Grunde ein physikalischchemischer Vorgang und nichts als ein solcher, und das Engramm ist nichts anrieres als eine von ihm zuriickgelassene physikalisch-chemische Veränderung. Solange wir aber ron einem tatsächlichen Einblick in die Physik and Chemie dieser Vorgänge so weit entfernt sind wie heute, wäre es der größte Febler, das erprobte Tnventar der biaherigen Reizphysiologie uber Bord zu werfen und uns dariber zu tåuschen, wie weit wir von dem Endziel rein physikalisch-chemischer Begriffsbestimmung noch entfernt sind. Eine solche Selbstiäuschung mit der ihr unausbleiblich folgenden Enttäuschung würde nur neues Wasser auf die Mühlen der Vitalisten liefern.

Während wir in den Fällen experimentell erzeugter Parthenogenese die Reize kennen, die ekphorisch auf das ontogenetische Initialengramm wirken, befinden wir uns bis jetzt noch in Unkenninis tiber die ekphorischen Reize in den seltenen Fällen, in denen die Parthenogenese als normale Er-

1 J. Loeb. Die chemiache Entwicklungserregung des tieriachen Eies. Berlin 1909, S. 10, ferner S. 207. 
scheinung bei einer Organismengruppe auftritt, wie z. B. bei Rotatorien, Crustaceen, Insekten, als Ausnahmeerscheinung auch bei Seesternen (Asterina). In manchen Fällen ist vielleicht ein äußerer Reiz chemischer oder mechanischer Natur bei der Ablage der Eier, die aus der Leibesflüssigkeit in die Luft oder das Wasser gelangen, wirksam. In anderen Fällen aber, z. B. bei den parthenogenetisch viviparen Aphiden, kommt ein solcher äußerer Reiz nicht in Frage. An die Reifung des Eies schließt sich gleich seine Teilung an. Hier wirken höchstwahrscheinlich die Prozesse der Reifung ekphorsch anf das in diesem Falle sukzessiv assoziierte ontogenetische Initialengramm ${ }^{1}$.

Bei der asexuellen Entwicklung der aus den Sporen ent-

1 Der Wortlaut des obenstehenden Absatzes befindet sich bereits in der ersten Auflage der Mneme (1904). Neuerdings hat sich Loeb (Chemische Entwicklungserregung 1909, S. 200) zu dieser Frage in ganz ähnlichem Sinne geänßert: $>$ Der Umstand, daß gewisse Eier sich ohne äaßere Hilfsmittel und ohne Spermatozoen zu entwickeln vermögen, hat Morphologen oft verleitet, anzunehmen, daß dieser Vorgang der natürlichen Parthenogenese keiner weiteren Erklärung bedürfe. Für diejenigen Naturforscher aber, die chemisch zu denken imstande sind, bedarf dieser Vorgang ebenso der Analyse wie die Keimung der Samen, die ja auch, von selbst' erfolgt. Wir sind geneigt, anzunehmen, daß die Entwicklungserregung bei ,spontan parthenogenetischen ${ }^{*}$ Eiern entweder durch eine im Ei nach der Ablage derselben gebildete Säure eingeleitet wird: etwa $\mathrm{CO}_{2}$ oder Milchsäure, die ja, wie es scheint, in allen lebenden Zellen zu entstehen vermögen, oder aber, daß ein im Blut resp. im Seewasser enthaltener Stoff, z. B. Hydroxylionen, diese Einleitung der Entwicklung besorgen. Bei einigen parthenogenetischen Formen findet die spontane Entwicklungserregung des Eies im Körper der Matter statt: z. B. bei den Aphiden, bei denen das Ei sich in der Mutter entwickelt. Bei den meisten Formen aber beginnt die parthenogenetische Entwicklung des Eies erst nach der Ablage desselben. Man muß in diesen letzteren Fällen vermuten, daß im Körper der Matter ein die Entwicklung hemmender Stoff oder Umstand vorhanden ist, oder daß nach der Eiablage ein die Entwickłung beguinstigender Umstand hinzukommt.s 
stehenden Generation der Farne wirkt die Befeuchtung der Sporen ekphorisch auf das ontogenetische Initialengramm der letzteren.

Ist durch einen ekphorischen Reiz irgendwelcher Art das ontogenetische Initialengramm aktiviert, so findet der weitere Ablauf der Ontogenese in der Hauptsache nach den im vorigen Abschnitt entwickelten Prinzipien statt. Indessen ist der Ablaufauch von den äußeren Bedingungen abhängig, die dabei bald eine mehr passive, bald eine mehr aktive Rolle spielen.

Eine gewöhnlich mehr passive, dabei aber immer sehr wichtige Rolle spielt die Temperatur, in der die Entwicklung abläuft. $\mathrm{Da}$ das Tempo des ganzen Stoffwechsels und im Zusammenhang damit der plastischen Reaktionen von ihr abhängig ist, beherrscht sie das Tempo des Eintritts der Originalerregungen und damit auch, wie wir S. 250 auseinandergesetzt haben, das Tempo (nicht den Rhythmns) der ganzen Ablänfe sowohl der originalen als auch der mnemischen Erregungen. Durch Herabsetzung der Temperatur können wir den ganzen Ablauf außerordentlich verlangsamen. Ob wir ihn zum vollständigen Stillstand bringen können, ohne den Organismus dauernd za schädigen, ist durch neuere Untersuchungen von 0 . Schultze an Eiern von Rana fusca fraglich geworden 1 . Wie dem auch sei, nach Eintritt normaler Bedingungen, im vorliegenden Falle normaler Temperaturen, geht der Ablauf in gewöhnlichem Tempo weiter,

1 Bei der Entwicklung des Rehes tritt ebenfalls nicht, wie neuerdings von F. Keibel (Archiv f. Anat. u. Physiol., Anat. Abt, 1902) gegen Bischoff festgestellt worden ist, ein vollkommener Stillstand des Entwicklungsganges ein, sondern nur eine außerordentliche Verlangsamung seines Tempos. Diese Verlangsamung ist aber hier natiurlich nicht, wie bei der sogenannten Kälteruhe, durch den änßeren Faktor der Temperatur bedingt. Höchstwahrscheinlich steht in diesem besonderen Falle das Tempo des Ablaufs unter der Vorherrschaft eines mnemisch fixierten Rhythmus. 
obne daB ein neuer, yon auRen herkommender Originalreiz erforderich wäre, ihn wieder in Betrieb zu setzen.

Ahuliche, fir gewöhnlich mehr passive Rollen spielen beim Ablauf der Ontogenesen, Belichtung, Beschaffenheit des Mediums, Nahrungszufuhr. Doch kann jeder dieser Faktoren auch inter Umständen in einer bestimmten Phase einer Ontogenese eine aktive Bedeutung erlangen, indem die Ekphorie gewisser Engramme nicht auf dem gewöhnlichen Wege dersukzessiven Assoziation erfolgt, sondern ausbleibt, wenn nicht bestimmte äuBere Reize als ekphorische hinzutreten.

So treten z. B. gewisse Veränderangen an Kiemen, Haut und Schwanz bei den Larven vieler Salamandrinen erst dann auf, wenn man den jungen Tieren Gelegenheit gibt, mit der atmosphärischen Luft auf irgendeine Weise in direkte Beribrung za kommen. Verhindert man diese Beruhrung, beispielsweise dadurch, daB man die Tiere durch ein unterbalb der.Wasserobertäche angebrachtes Drahtnetz ganz von der Luft absperrt, so können bei manchen Formen diese Veränderungen uberhaupt völiig ausbleiben, und die Tiere in diesem $\mathrm{Zu}$ stande weiterleben, weiterwachsen und geschlechtsreif werden.

Es handelt sich in diesem und ähnlichen Fällen bei Ausbleiben der auf äußere Reize gestellten Ekphorien nicht um einen gänzlichen Stillstand der Entwicklung - die Tiere wachsen ja und werden unter Umständen geschlechtsreif sondern nur um Ausfall gewisser Teile der mnemischen Erregungskomplexe, die einer stärkeren Ekphorie durch Originalreize bedürfen, um aktiviert zu werden. Eine nähere Untersuchung solcher nicht gerade häufigen Fälle lehrt uns, daß diese Abhängigkeit der Ekphorie von einem äußeren Reiz meist eine ganz besondere biologische Bedeutung hat, eine Bedeatung, die diese Ausnahmefälle als nutzliche Anpassungen erschei- 
nen läRt. Fis encheint uns "zweckmëBig *, dab der Axoloti oder Tritos cret dawn aeine Eiemen verliert und sich zum Landtier umbildet, wenn er Gelegenbei hat, das trockene Land zu erreichen. Ioh will an dieser Stelle nicht versuchen, in diege Tragen tiefer einzudringen, und mich nicht anf abseits fuhronds: Wege begeben, inder ich das große Problem, wie wir una solche zweckm haben, in irgendeiner. Form diskutiere. Es wird Aufgabe einer besonderen Untersuchung sein, die Darwinsche Lehre im Lichte der allgemeinen, in dem porliegenden Werke gewonnenen Anchauungen zu betrachten. Ich möchte hier nur vorwegnehmend bemerken, daß̉ diese zuktinftige Auseinandersetzung keinesweg` zu einer Belämpfung, höchstens in Einzelfällen zu einer Einschränkung der neuerdings so leidenschafilich angegriffenen Selektionslehre fuhren wird.

Zuribklwelrend wu den Fällen, in denen zur Ekphorie eines morphogenen Engramms der gewöhnliche, S. 252 gekennzeichnete Weg nicht zum Ziele fuhrt, sondern das Hinzutreten eines äußeren Reizes erforierlich ist, wollen wir auBer dem Hinweis, daB es sich in diesen Fällen um besondere Anpassungen handelt, noch bervorheben, daß wir in den meisten Frlien nachweisen können, daß dieser äußere ekphorische Nuir wenigstens ein Bruchtei eines ehemaligen engraphischen Reizes ist, der die Forfahren der betreffenden Orgarismen in den entsprechenden Stadien beeinflußt hat. Tritonlarven Ferlieren gewöhnlich ihre Fiemen, wenn man ihnen nur gestattet, an die Oberflache des Wassers zu kommen und Luft zu schlucken, auch wenn sie keine Gelegenheit baben, sich aufs Trockne zu begeben und die Kiemen

1 Ich hoffe dies in einer späteren, abschließenden Fortsetzung der Mneme tun zi kðnnen. 
selbst der atmosphärischen Luft zn exponieren. Phylogenetisch haben ohne Zwoifel der gänzliche Verlust der Kiemen and die Umwandlungen an Haut and Schwanz nnter viel direkterem und intensiverem EinAuß der atmosphärischen Luft und des Lebens im Trockenen stattgefunden. Jetzt gentigt ontogenetisch ein Brachteil diezer Reize, am bei den Nachkommen eine Ekphorie der anf jene zurickzufithrenden Engramme za erzielen.

Wir sagten vorhin, daß es sich bei Ausbleiben der durch äußere Reize repräsentierten Ekphorien nicht um einen gänzlichen Stillstand der Entwicklang, sondern nur um Ausfälle gewisser Teile der Erregungskomplexe handle. Hier mulssen wir uns aber der Frage zuwenden, wie dieses möglich ist. Wird denn nicht immer ein ganzer simultaner Engrammkomplex in seiner Totalität ekphoriert, sondern bedarf es unter Umständen noch spezieller Ekphorien für seine einzelnen Teile? Wir greifen hier auf unsere die Ekphorie im allgemeinen behandelnden Ausfuhrungen S. 101 zurück und erinnern uns, daß die Wiederkehr eines Bruchteils eines originalen Erregungskomplexes durchaus nicht immer imstande ist, den zugehörigen Engrammkorplex als Ganzes zu ekphorieren (vgl. auch das Schema S. 189). In manchen, gar nicht besonders seltenen Fällen kanz dies oder jenes Engramm eines Engrammkomplexes tiberhaupt nicht auf dem Wege simultaner oder sukzessiver Assoziation, sondern nur durch Wiederkehrderihm entsprechenden Originalerregung ekphoriert werden. Der Reiz, der diese Wiederkehr auslöst, kann dabei ein auBerordentlich abgeschwächter sein, wenn z.B. zwar keine Beschreibung, keine Zurtickrufung von Situationen and Vorgängen, bei denen ein lange nicht gesehener Bekannter eine Rolle gespielt hat, seine Zuge in unserem Gedächtnis zu ekphorieren vermögen, während hingegen eine Aluchtige Blei- 
Das ontogenetische Initialengramm und der ontogenet. Ablauf. 269

stiftskizze seines Gesichts dies sofort tut. Oder wenn ein nur gelegentlicher und kurzer Kontakt mit der atmosphärischen Luft bei vielen Gattungen der Salamandrinen einen Erregungskomplex ekphoriert, der sich in Reaktionen wie: Resorption der Kiemen, Veränderungen an der Fant und am Schwanze manifestiert, eine Ekphorie, die bei den Larven mancher Gattungen, auch wenn sie dariber heranwachsen ind gesehlechtsreif werden, unterbleibt, falls jeder Kontakt mit der atmosphärischen Luft unmöglich gemacht wird.

In unserem Schema der Abläufe bei der normalen Morphogenese haben wir also noch für g'ewisse Ansnahmefälle folgenden Zusats anzubringen:

Ergånzungsschema zu S. 252.

\begin{tabular}{|c|c|}
\hline Phase $r$ & Phase $s$ \\
\hline 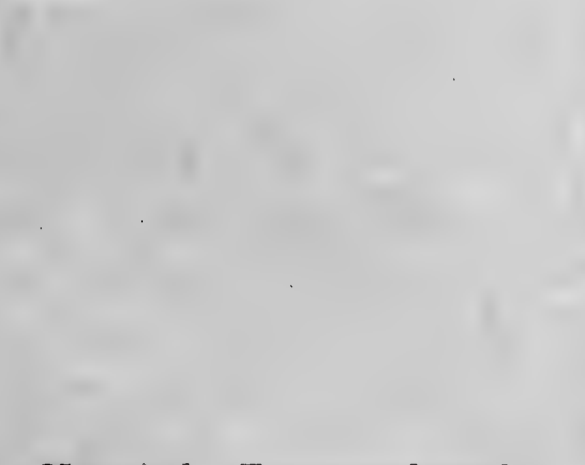 & $\begin{array}{l}r \text { (or) }+r \text { (mn) allein vormögen } \\
\text { in diesem Spozialfall nicht den } \\
\text { vollen Engrammkomplez s (engr) } \\
\text { auf dem. Wege der sukzessiven } \\
\text { Assoziation zu ekphorieren. Zur } \\
\text { Ekphorie oines bestimmten Bruch- } \\
\text { teils, nämlich siz (engr), dieses Kom- } \\
\text { plexes bedarf es noch des Binzt- } \\
\text { tretens oiner durch einen äußeren } \\
\text { Roiz ausgelösten Originalerregung }\end{array}$ \\
\hline Mnemischer Erregungskomplex & en (or). Dann ekphorieren $r$ (or) + \\
\hline$r(m) \longrightarrow$ & $\begin{array}{l}r(\mathrm{mn})+\rho_{n} \text { (or) zusammon } s \text { (engr). } \\
\text { Es resultiert der mnemische Er- } \\
\text { regungskomplex } s(\mathrm{mn})\end{array}$ \\
\hline $\begin{array}{l}\text { Plastische Reaktionen: Mor- } \\
\text { phologischer Zustand } r(z)\end{array}$ & $\begin{array}{l}\text { Plastische Reaktionen: Morpho- } \\
\text { logischer Zustand s (z) } \\
\downarrow\end{array}$ \\
\hline $\begin{array}{l}r \text { (or) } \\
\text { [Homophonie zrischen } r \text { (mn) }\end{array}$ & $\begin{array}{l}\text { Originaler Erregungskomplex } \\
\qquad \begin{array}{l}s \text { (or) } \\
\text { [Eomophonis zwischen } s(\mathrm{~m}\end{array}\end{array}$ \\
\hline
\end{tabular}
nud $r(o r)$. and $(s$ or) ]. 
In dem folgenden ergänzenden Schema wollen wir die Ekphorie eines Engrammkomplexes $s$ (engr) den wir der Einfachheit halber bloß aus den Engrammen $s_{1}$ (engr), $s_{2}$ (engr), $s_{3}$ (engr), $s_{4}$ (engr), $s_{5}$ (engr) bestehen lassen, durch die morphogenen, sukzessiv assoziierten Erregungen $r_{1-4}$ und die durch einen äußeren Reiz ausgelöste Erregung $\varrho_{5}$ uns graphisch noch etwas anschanlicher vor Angen fuhren, wobei wir auf

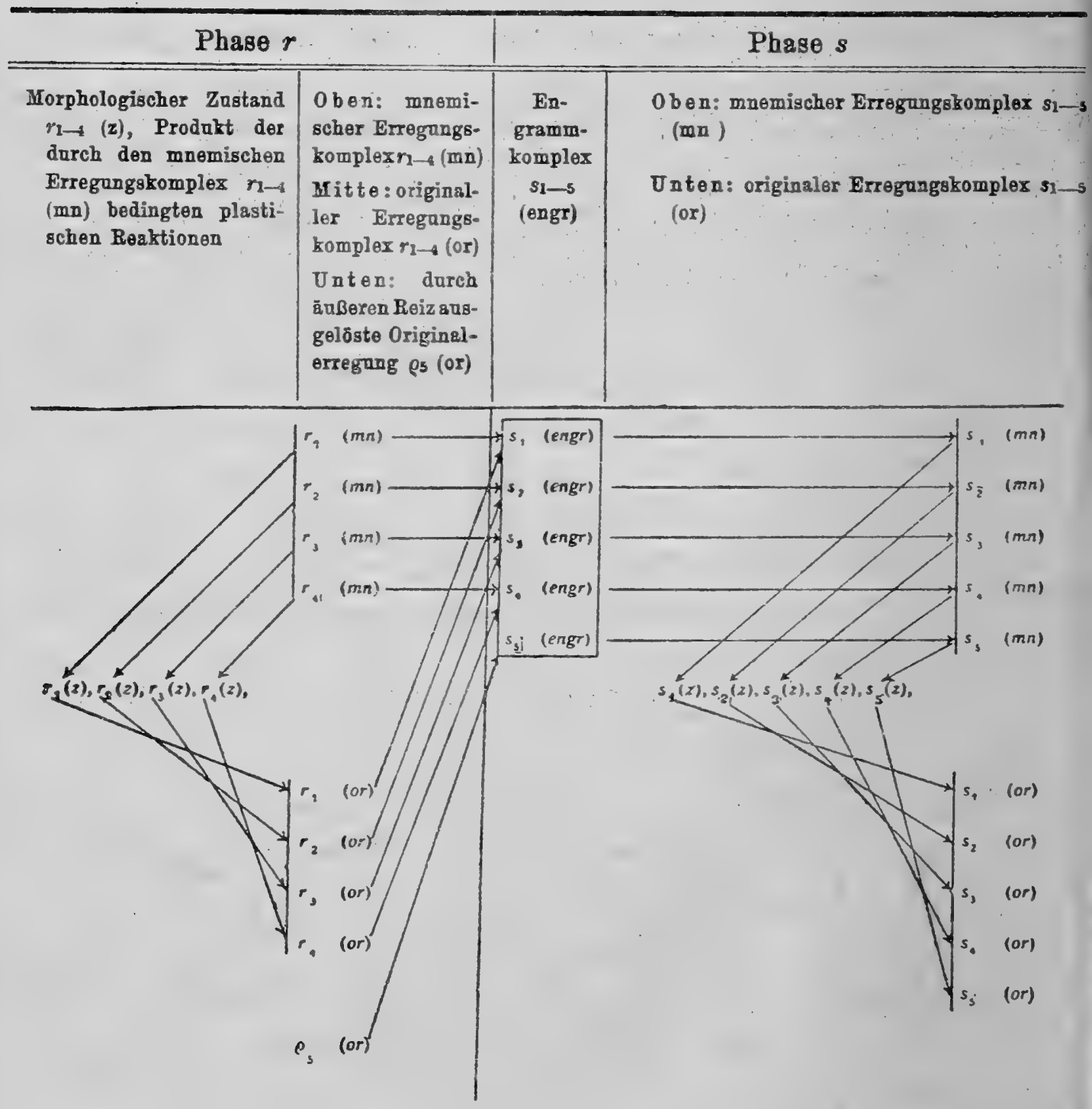


Das ontogenetische Initialengramm und der ontogenet. Ablauf. 271

die Auseinandersetzungen über die spezielleren Biudungen $z$ wischen den einzelnen Komponenten zweier sukzedierender Engrammkomplexe (S. 126) and auf die damit zusammenhängenden Eigentumlichkeiten der Ekphorie (S. 189) verweisen.

Man könnte bei oberflächlicher Musterung dieses letzteren Schemas zu der Ansicht gelangen, die in diesem Buche niedergelegten Untersuchungen hätten, was ihre Anwendung auf die Ontogenese anlangt, zu nichts Weiterem gefihrt, als zu einer neuen Umschreibung bekannter Vorgänge. Den Prozeß des Hervorgehens von Teil aus Teil, den wir direkt beobachten können, bätten wir dann nicht besser analysiert und tiefer erkannt als bisher, sondern nur bei der Beschreibung durch Verquickung mit einem Begriffsschematismus belastet. Solche umschreibende Theorien der Vererbung besitzen wir ja schon zur Genüge. Indessen lehrt genaueres Studium unseres Schemas unmittelbar die Ungerechtigkeit dieses Verdachts.

Infolge der Einfuihrung unserer mnemischen Terminologie in unser Schema und der dadurch bedingten Unterordnung der ontogenetischen Verknuipfungen unter die mnemischen Gesetze besitzen nämlich diese Verknüpfungen einen anderen, viel freieren Sinn als alle auf gewöbnliche originale Reizwirkung basierten Verknüpfungen. Wie unsere Schemata zeigen, erfolgen die ontogenetischen Verknüpfungen wenigstens an den Knotenpunkten durch Ekphorie ron Engrammen und Engrammkomplexen. Diese Ekphorien unterseheiden sich aber von gewöhnlichen originalen Reizwirkungen durch die Eigentümlichkeit, daß ein vollständiger Engrammkomplex auch durch einen Bruchteil des für gewöhnlich wirksamen Erregungskomplexes ekphoriert werden kann. So kannz. B., 
wenn in unserem Schema S. 270 das Zeichen $\varrho_{5}$ (or) eine rom Kontakt mit der äußeren Laft hervorgerufene Originalerregung bei Salamandrinenlarven bedentet, bei gewissen Formen der Engrammkomponent $s_{5}$ (engr) auch ohne Hinzutritt von $\varrho_{5}$ (or) ekphoriert werden, entweder auf dem Wege der Simultanassoziation durch die Ekphorie von $s_{1-4}$ (engr), oder auch orst später durch andere ekphorische Einflisse. In anderen Fällen dagegen ist die Ekphorie völlig rom Eintritt der Criginalerregung $\varrho_{5}$ (or) abhängig. So erfolgt bei Salamandra die Ekphorie des Engramms $s_{5}$ (engr) ohne Hinzutreten der Originalerregung $\varrho_{5}$ (or) fast sicher, wenn anch nicht selten etwas verspätet, während sie bei Siredon ohne das Finzutreter von $\varrho_{5}$ (or) ebenso sicher unterbleibt.

Unser Scheria bedeutet also nur eine, allerdings die vollkommenste Möglichkeit der Verknlipfung bei dem dort dargestellten ontogenetischen Ablauf. Der Ablauf kann aber ack stattfinden und zu demselben Ziele führen, wenn verschiedene Einzelkoraponenten nicht in Betrieb gesetzt werden. Ich erinnere hier an unsere oben (S. 101) gegebene Darstellung der verschiedenen Möglichkeiten, die fur die Auslösung der Entwicklung der Augenlinse nachweisbar sind, vor allem an die zahlreichen Fälle, in denen es anch bei Ausschaltung des scheinbar allein ausschlaggebenden Berithrungsreizes doch zur Linsenbildung kommt. Bei der Darstellung der Ablänfe ist es deshaib ein notwendiges Erfordernis, dieser Freiheit in den Verkntipfungen Rechnung zu tragen, die neben einer vollkommeren noch vielen anderen minder vollkommenen, aber zum gleichen Ziele ruhrenden Auslösungsmöglichkeiten Ran gibt. Diesem Erfordemis aber genügt in ausgedehntestem Maße unsere auf die mnemische Grundlage gestellte Darstellung der Ontogenese. 
Ein zweiter, ebenso wichtiger Vorzug ist aber ferner noch durch die Einfuhrung des mnemischen Prinzips in die Verknüpfung der ontogenetischen Abläufe bedingt nnd geht unmittelbar aus unseren schematischen Darstellungen (S. 252, 253, $269,270)$ hervor. Wir sehen den ganzen ontogenetischen $\mathrm{Ab}$ lauf in Gegenwart und unter der Kontrolle ron mnemischer Homophonie vor sich gehen, die sich von selbst als notwendige Folge der von uns beobachteten Verknupfungen ergibt. In der Erkenntnis dieser Homophonie eröffnet sich uns aber ein Weg, auf dem wir tiefer in das Wesen der rätselhaften Regnlations- und Regenerationserscheinungen einzudringen vermögen, als dies bisher möglich war. Nattirlich bleiben auch hier noch die letzten Rätsel nngelöst. Jedenfalls aber ist anch in dieser Beziehung unsere Darstellung das Gegenteil, von einer bloßen Umschreibung der Probleme. 


\section{Zehntes Kapitel.}

Vorhandensein und Wirksamkeit morphogener mnemischer Erregungen im ansgebildeten Organismus.

Wenn wir das in der Kapiteltuberschrift gestellte Thema behandeln wollen, so haben wir uns zunächst dartiber klar zu werden, was unter sausgebildetem . Organismus zu verstehen ist. Sollen wir ein Individuum dann ausgebildet nennen, wenn seine Keimprodukte sich zum ersten Male zur Reife entwickeln, oder sollen wir es tun, wenn der Organismus seine Wachstumsgrenze erreicht hat? Das letztgenannte Kriterium erweist sich als unbrauchbar bei allen Organismen mit unbegrenztem Wachstum, also bei den meisten Pflanzen, and auch bei Organismen mit begrenztem Wachstum ist es kaum durchfuhrbar. Bei vielen findet ein Dickenwachstum, beim Menschen z. B. eine Volumenzunahme der Knochen, Muskeln und anderer Organe noch viele Jahre nach Aufhören des Längenwachstums statt und hört erst auf, wenn der Höhepunkt der Entwicklung in bezug anf andere Organe längst uberschritten ist. Ebenso unbrauchbar zur Bestimmung des Zeitpunktes, wann wir von einem ausgebildeten Zustand des Organismus sprechen dirfen, erweist sich das Kriteriuu der ersten Produktion von Keimzellen. Es genuigt, auf die zahlreichen Fälle hinzaweisen, in denen morphologisch noch ganz unentwickelte Jugendformen zur Geschlechts- 
Morphogene mnem. Erregungen im ausgebildeten Organismus. 275

reife gelangen (sogenannte Pädogenese), um die Unzalänglichkeit auch dieses Merkmals bei allgemeinerer Anwendung zu erweisen.

Die beschreibenden Embryologen pflegen einen Organismus dann auggebildet $\mathrm{z}$ nennen, wenn die uberwiegende Mehrzahl seiner Organe so weit in der Entwicklung fortgeschritten ist, $\mathrm{da} B$ die noch eintretenden Veränderangen mehr eine bloße Volumenzunahme als eine weitere Differenzierung dieser Organe betreffen. Diese Definition erweist sich fur deskriptive $\mathrm{Z}$ wecke im ganzen brauchbar. Aber schon in der von mir angedeuteten Fassung * Mehrzahl der Organe* und smehr Volumenzunahme als Differenzierung druckt sich das rein Konventionelle dieser Einteilung des Lebenslaufs eines Organismus klar genug aus, und es bedarf keiner weiteren Beweise, daß in $\mathrm{zweifelhaften} \mathrm{Fällen} \mathrm{diese} \mathrm{Definition}$ ebenso versagen wird wie die auf einzelne Merkmale, Geschlechtsreife, Erreichnng der Wachstumsgrenze, gegründeten Definitionen. Solange das Individuum lebt, treten in ihm unausgesetzt physiologische und morphologische Veränderungen auf, und wenn wir auch das Recht haben, den Lebensablauf in summarischer Weise in zwei Abschnitte zu teilen, in einen, in dem der Ablauf der morphologischen Veränderungen sehr lebhaft ist, und einen zweiten, in dem das Tempo sich außerordentlich verlangsamt, so gibt es doch keine scharfe Grenze zwischen den beiden Abschnitten. Der Übergang des einen in den anderen ist ein ganz allmählicher.

Untersuchen wir nun den Ablauf in jener Übergangszeit, so ergibt sich, wenn wir wieder auf unser Schema S. 252 zurluckgehen, als einziger Unterschied der, daß die Dauer der einzelnen Phasen sich sehr verlängert. Innerhalb jeder Phase verlangsamt sich dabei weniger das Tempo der plastischen 
Reaktionen als der Übergang von einer Phase zur anderen, also die Exphorie neuer Engrammkomplexe, bzw. Engramme. Immer länger währen die Zeitabschnitte, in denen nach Erreichung eines morphologischen Zustandes $t(\mathbf{z})$ sowohl die mnemische Erregung $t(\mathrm{mn})$ als auch die Originalerregung $t$ (or) homophon wirksam sind, bis endlich die Ekphorie des nächsten morphogenen Engramms $u$ zustande kommt. Für Organismen mit begrenztem Wachstum tritt dann endlich eine Zeit ein, in der es zar erstmaligen Ekphorie nener morphogener Engramme tiberhanpt nicht mehr kommt, in der das Endglied der Sukzession ererbter morphogener Engramme ekphoriert ist. Nennen wir dieses Engramm $w$ (engr), so fuhrt seine Ekphorie zur mnemischen Erregung $w(\mathrm{mn})$, deren zugehörige plastische Reaktionen den morphologischen $\mathrm{Zu}$ stand $w(\mathbf{z})$ herbeifuhren. In diesem Zustand und der durch inn bedingten Originalerregung $w$ (or) wird dann der Organismus bis zu seinem Ende verharren. Der Organismus bleibt ganz einfach morphogenetisch jetzt in der Phase $w$ stehen, innerhalb der er nur noch zyklische Veränderungen durchlärft. Es erhebt sich dabei eine Frage. Bei Beginn der Phase $w$ herrscht, gleich nachdem der morphologische $\mathrm{Zu}$ stand $w(\mathbf{z})$ erreicht ist, die bekannte. Homophonie zwischen der mnemischen Erregung $w(\mathrm{mn})$ und der Originalerregung $w$ (or). Die letztere Erregung dauert natirlich an, solange der morphologische Zustand $w(\mathrm{z})$ andauert. Ist dasselbe aber auch mit der mnemischen Erregung $w(\mathbf{m n})$ der Fall? Es wäre ja denkbar, daß, nachdem die ganze morphogene Sukzession mnemischer Erregungen durchlaufen ist, das Endglied mit der Zeit erlischt. Diese Annahme ist aber hinfällig, denn die Gegenwart der Originalerregungen $w$ (or) muß fort und fort ekphorisch auf die mnemische Erregung 
Morphogene mnem. Erregungen im ausgebildeten Organismus. 277 $w(\mathrm{mn})$ wirken. Am sichersten wird aber die Andauer der Homophonie $\mathrm{H}\left(\begin{array}{l}w \text { (or) } \\ w(\mathrm{mn})\end{array}\right)$ durch die Andauer der dieser Homophonie eigentumlichen Reaktionen bewiesen. Bei Kongruenz der Homophonie treten diese Reaktionen allerdings nicht hervor. Bei jeder Inkongruenz treten aber regelmäßig, wenn auch mit von Art zu Art verschiedenem Erfolge, die uns schon so gut bekannten Reaktionen auf, die die Inkongruenz entweder beseitigen oder doch abschwächen. Handelt es sich bei Herstellung der Homophonie um Ersatz operativ entfernter oder sonstwie verloren gegangener Teile, so bezeichnet man diese Reaktionen gewöhnlich als Regeneration. Viele Entwicklungsphysiologen wenden den Ausdruck Regeneration nur bei ausgebildeten Organismen an und belegen die entsprechenden Phänomene bei jüngeren Entwicklungsstadien mit anderen Ausdruicken.

$\mathrm{Zu}$ den ausgebildeten Zuständen rechnen sie aber dabei allgemein die Zustäude mit, in denen das Tempo des ontogenetischen Ablaufs sehr verlangsamt, in denen aber die Sukzession morphogener Engramme noch keineswegs dnrchlaufen ist. Der Ausdruck »ausgebildeter Zustand « wird in diesem Zusammenhange also in einer sehr schwankenden und willkürlichen Weise gebraucht.

Aus diesem Grunde, und weil ein tieferes Bedurfnis flir die Unterscheidung der Regenerationsprozesse in den verschiedenen ontogenetischen Phasen nicht vorzuliegen scheint, sehen wir ron einer verschiedenen Benennung ab und bezeichnen alle derartigen Ersatzreaktionen als Regeneration.

Wir behalten es uns vor, anf die Einschränkung der Regenerationsfähigkeit in den späteren Lebensstadien der 
Organismen im nächsten Abschnitt ausfuihrlich zurückzukommen. Jetzt gentigt uns der Hinweis, daß das bei allen Einschränkungen unzweifelbafte Vorbandensein der Regenerationsfähigkeit auch in den spätesten Stadien als eine Reaktion anzusehen ist, die die Wirksamkeit der morphogenen mnemischen Homophonie und mithin das Vorhandensein einer morphogenen mnemischen Erregung in allen Lebensstadien beweist.

Wir hatten vorhin von einem Zustand gesprochen, den man als *ausgebildeten * $z u$ bezeichnen insofern berechtigt ist, als es, wenn er erreicht ist, zur erstmaligen Ekphorie ererbter morphogener Engramme uberhaupt nicht mehr kommt. Dieser Zastand bedeutet deshalb aber noch kein Aufbören jeden morphogenetischen Ablaufs. Der dann eintretende, bzw. von fruber her sich fortsetzende Ablauf ist aber ein zyklischer, dessen Phasen periodisch wiederkehren. Dabei zeigen sich die Phasen gewöhnlich in einer gewissen Abhängigkeit von dem periodischen Wechsel der siderischen Erscheinungen, von den Tages- und Jahreszeiten und selbst den Mondphasen (Palolowurm). Das periodische Reifen der männlichen und weiblichen Keimstoffe gehört vor allem hierher, dem häufig noch sekundäre morphogenetische Prozesse (periodisches Auftreten mancher sekundärer Sexualcharaktere) folgen. Noch zahlreicher finden sich bei den Pflanzen derartige zyklische morphogenetische Prozesse im Zusammenhang mit der Tagesund besonders der Jahresperiode. Daß diese periodischen Abläufe nicht lediglich durch die periodische Veränderung der Anßenbedingungen ausgelöst und reguliert werden, sondern daß mnemischen Prozessen bei dieser Regulierung eine ebenblirtige Rolle zukommt, ließe sich leicht dadurch beweisen, daß ihre Periodizität noch lange Zeit andauert, 
Morphogene mnem. Erregungen im ausgebildeten Organismus. 279

nachdem man die periodische Veränderung der Außenbedingungen ausgeschaltet hat, indem man die betreffenden Organismen unter kunstlichen Bedingungen kultiviert'

Wir haben S. 59 anseinandergesetzt, wie wir uns das Zustandekommen der dann eintretenden "chronogenen* Ekphorie vorzustellen haben. Unter normalen Verhältnissen gesellt sich zu dieser chronogenen Ekphorie die ekphorische Wirkung der sich periodisch ändernden Außenbedingungen. Bei den Pflanzen, die sich schwer oder gar nicht streiben * lassen, wirkt der erstere Faktor weit mächtiger als der zweite, bei anderen ist das gerade umgekehrt. Ich komme hierauf an dieser Stelle nicht ausftihrlicher zurtick, hielt es aber für angebracht, knrz diese zyklischen Prozesse zu erwähnen, die vielfach in die eigentliche Ontogenese hineinspielen und sie bei Organismen von begrenztem Wachstum, bei denen eine Möglichkeit vorliegt, von ausgebildetem Zustand zu sprechen, um vieles tiberdauern.

1. Vgl, oben S. 58 und 93. 


\section{Elftes Kapitel.}

\section{Spricht die Einschränknng des Regenerationsvermögens}

fir eine Lokalisation des ererbten Engrammschatzes?

\section{Lokalisation der Ekphorie.}

Wir sind in unseren einleitenden Betrachtungen tiber die Lokalisation der ererbten Engramme (S. 152) zu folgenden vorläufigen Resultaten gelangt: Der gesamte ererbte Engrammschatz ist bei Beginn jeder sexuell oder parthenogenetisch eingefuhrten Individualitätsphase im Rahmen einer Zelle oder eines Zelläquivalents enthalten. Höchstwahrscheinlich ist das Element der Zelle (oder auch nur des Kerns dieser Zelle) noch nicht die kleinste Einheit, die ihn zu umschließen imstande ist. Wir bezeichneten die kleinste morphologische Einheit, die dies zu tun vermag, als mnemisches Protomer, machten aber keinen Versuch, diese Einheit morphologisch schärfer zu umgrenes. Als zweites Resultat hat sich uns ergeben: Im späteren Verlaufe einer Individualitätsphase, d. h. wenn das pflanziche oder tierisehe Individuum mehr- oder vielzellig gevorden ist, zeigen aus beliebigen Teilen der Organismen entrommene Ausschnitte sich in zahlreichen Fällen im Besitze des gesamten ererbten Engrammschatzes .

Schon in den vinleiteuden Betrachtungen babe ich aber

1 Über die Bedeutung des Ausdrucks ssich in Besitz des gesamten erer then Engrammschatzes befinden vgl. die Ausführungen S. 150. 
Einschränkung des Regenerationsvermögens 匹. Lokalisation. 281

erwähnt, daß die Regenerationsfähigkeit, selbst bei besonders regenerationsfähigen Formen wie z. B. Planaria und Hydra, am Ende der Ontogenese im Vergleich mit dem Anfange derselben eine Einbuße erlitten hat. Bei Planaria bestand diese Einbuße darin, daß zwar Teilsticke vom ganzen ubrigen Körper, nicht aber solche vom äußersten Vorderende vor den Augen oder Abschnitten der äußersten Seiten, die keine Spur der Seitennerren enthalten, das ganze Individuum regenerieren können. Bei Hydra vermag wohl jeder sonstige beliebige Körperabschnitt von mehr als $1 / 6 \mathrm{~mm}$ Durchmesser die ganze Hydra zu regenerieren, aber nicht vermag dies ein ebenso großer oder selbst größerer Tentakelabschnitt. Die in diesen beiden Fällen beobachtete Einschränkung der Regenerationsfähigkeit ist eine sehr geringe, bei anderen Formen ist sie aber schon ausgeprägter, und manche höhere Tiere, z. B. die warmblutigen Wirbeltiere, sind im ausgebildeten Zustande uberhaupt nur noch in sehr beschränktem Maße zur Regeneration von ganzen Organen befähigt, während allerdings Gewebsregenerationen auch bei ihnen noch in ausgedehntem Maße stattfinden können.

Wir dirfen aber die Frage nicht auf sich beruhen lassen, ob diese Einschränkung des Regenerations- and Regulationsvermügens, die wir regelmäßig, wenn auch gradweise sehr verschieden während des Fortschreitens der Ontogenese beobachten, auf einer Veränderung bzw. besonderen Lokalisierung der muemischen Eigenschaften der Organismen beruht, oder auf andere, sich während der Ontogenese vollziehende Veränderungen zurickzufibren ist.

Indem ich mir die Untersuchung der Frage nach der Lokalisation der ererbten Mneme flir eine apätere Fortsetzung des vorliegenden Werkes vorbehalte, wo sie auf 
einer breiten Basis zu erfolgen hat, will ich jetzt hier nur zeigen, daß keinerlei Tatsachen, vor allem auch nicht die in manchen Fällen so auffallenden Einschränkungen des Regenerations- und Regulationsvermögens während der Ontogenese mit unserer Anschauung in Konflikt geraten, daß jede lebenskräftige Zelle, ja jedes mnemische Protomer, welchem Teile des sich entwickelnden ebenso wie des ausgebildeten Organismus es auch entnommen sein mag, sich im - Besitz des gesamten ererbten Engrammschatzes befindet.

Von den hier in Betracht kommenden Fällen von Einschränkung des Regenerations- und Regulationsvermögens können wir gleich alle diejenigen ausschalten, in denen von seiten des Teilsticks eines Organismus die Regeneration zwar sehr verspätet eingeleitet wird, aber schließlich doch noch erfolgt. Denn in allen diesen Fällen steht das eine doch anßer Zweifel, daß das Teilstück im Besitz der sämtlichen ererbten Engramme gewesen ist; sonst würde es nicht befähigt sein, den ganzen Organismus mit all seinen morphologischen und physiologischen Eigenschaften wiederherzustellen. Nachträgliche, häufig sehr verspätete Regulationen und Regenerationen sind nun etwas ung'emein Häufiges bei Teilstiucken von Eiern oder jungen Entwicklungsstadien von Echinodermen und Amphibien, während bei entsprechenden Teilstucken von Medusen, Amphioxas, Kuochenfischen die Regulation nicht zögernd, sondern unmittelbar einsetzt. Auch solche Fälle von Regeneration bei ausgewachsenen Tieren, wie die von Przibram, Archiv f. Entwicklungsmech. Bd. XI, 1901, S. 326, bei Crustaceen (Portunas, Porcellana, Galathea usw.) beobachteten gehören hierher, bei denen ein zunächst unvollkommenes Regenerat des dritten Kieferfußes nach jeder Häutung durch eine immer vollkommnere Neubildang ersetzt 
Einschränkung des Regenerationsvermögens u. Lokalisation. 283

wurde. Wir brauchen auf alle diese Fälle nicht näher einzugehen, weil sie, wie gesagt, für die Gegenwart des gesamten ererbten Engrammschatzes in den regulationsfähigen Teilstlucken beweisend sind, nicht für das Gegenteil.

Sie sind aber immerhin für die uns jetzt beschäftigenden Fragen insofern interessant, als sie zeigen, wie durch Eingriffe und Störungen, auch bei Vorhandensein sämtlicher ererbter Engramme, den morphogenetischen Regulationsprozessen so ernste Hindernisse in den Weg gelegt werden können, daß sie erst sehr spät zum Ziele fuhren. Schon darans geht hervor, daß, wenn in anderen Fällen die Hindernisse noch ein wenig größer sind, und die Regeneration oder Regulation überhaupt nicht ihr Ziel erreicht, der Schluß, ein mnemisches Manko sei Schuld daran, ein voreiliger wwäre.

Definieren wir nach unseren fruheren Untersuchungen den Regenerations- und Regulationsvorgang als eine Summe von plastischen Reaktionen, die den Ausgleich einer Inkongrnenz bei einer Homophonie bewirken, so kann offenbar das völlige Ausbleiben oder die unvollkommene Vollendung eines solchen Regenerationsvorganges ebensowohl dadurch bedingt sein, daß die plastischen Reaktionen in irgendeiner Weise gehemmt oder unmöglich gemacht sind, als dadurch, daß die Homophonie infolge eines Mankos der entsprechenden Engrammkomplexe nicht vorhanden ist.

Die Sachlage ist in diesen Fällen ganz dieselbe, wie weun wir ein Paar Webervögel in der Gefangenschaft keine Spur ihres gewöhnlichen Webevermögens betätigen sehen. Auf ein Erlöschen oder kongenitales Fehlen dieses Vermögens werden wir selbstverständlich erst dann schließen, wenn wir sicher sind, daß den Tieren das zu ibrer Webetätigkeit notwendige 
Material ${ }^{1}$ zur Verfugung gestanden hat und auch die sonstigen Vorbedingungen (ausreichende Ernährung, Abwesenheit von Störungen, passender Raum) erfüllt gewesen sind.

Nun handelt es sich beim Ausbleiben von Regenerationen und Regulationen in einer großen Reihe von Fällen einfach um Mangel oder Unzugänglichkeit eines bestimmten Materials für die neoplastische Tätigkeit des Organismus; in einer zweiten Reihe von Fällen fällt die Abnahme des Regenerationsvermögens zusammen mit einer Abnahme der neoplastischen Fähigkeiten des Organismus im allgemeinen, d. b. mit Abnahme der plastischen Fähigkeit auch da, wo mnemische

1 Ich möchte übrigens bei dieser Gelegenheit einem Einwande begegnen, den man gegen eine meiner früheren Ausfïhrungen (S. 57) erheben könnte: Wir haben aus dem Umstand, daß die meisten mehrjährigen Pflanzen der temperierten und kalten Zonen, selbst bei Ausschaltung der winterlichen Abkühlung, eine Ruheperiode durchmachen und erst nach Ablauf eines bestimmten Zeitabschnitts in einen $\mathrm{Zu}$ stand gelangen, in dem sie von neuem austreiben bzw. sgetrieben. werden können, den Schluß gezogen, daß sich iu dieser Erscheinung eine chronogene Ekphorie bestimmter Engramme manifestiert. Vielleicht läßt sich aber der ganze Vorgang einfach darauf zuriickführen, daß vor einem bestimmten Zeitablauf die Bildung oder Umlagerang des Materials, das zur Knospenentfaltung notwendig ist, woch nicht weit genug gediehen ist? (Vgl. Alb. Fischer, Beitrïge zur Physiologie der Holzgewaichse, Pringsheims Jahrb. f. wiss. Botanik, Bd. 22, 1891, S. 126 u. 160). Aber in diesen Fillen ist doch das Rohmaterial, die Stärke, bereits im Organismus vorhanden, und eine im Dezember und Januar kühl gehaltene und dann im Februar und Anfang März auf natürlichem Wege getriebene Rotbuche Campaniens hïtte an und fuir sich Zeit genug, die zur Knospenentfaltung notwendigen Stoflumlagerungen zu vollziehen, wenu der Zustand ihrer reizbaren Substanz das gestattete. Dennoch begrünen sich auch diese Buchen erst nach Ablauf der ersten Aprilwoche, also nur etwa zwei Wochen frither als ihre nordischen Artgenossen. Eben der Jinstand, daß sich die Stoffumlagerung nicht früher zu vollziehen begiunt, kann nur mnemisch erkliirt werden, und eine lediglich auf das Fehlen eines bestimmten Materials basierte Erklärung versagt in diesen Fällen bei jeder genaueren Prüfung. 
Einschränkung des Regenerationsvermögens u. Lokalisation. 285

Prozesse gar nicht mit in Frage kommen. Auch diese Fälle scheiden nattirlich als Beweise fiur ein Manko von ererbten Engrammen oder, anders ausgedrückt, für eine Lokalisation des ererbten Engrammschatzes aus. Nach ihrer Besprechung werden wir zu untersuchen haben, ob etwas übrigbleibt, was sich ohne die Annahme einer solchen Lokalisation nicht erklären läßt.

Was den Mangel oder die Unzugänglichkeit eines bestimmten Materials anlangt, die unter Umständen die Ausführung einer Regeneration oder Regulation unmöglich machen, so gehört die Mehrzahl der einschlägigen Fälle in die-Kategorie der Anfangsstadien der betreffenden Individnalitätsphasen. Wir machen nämlich die Beobachtung, daß das Material, das der kindliche Organismus von dem elterlichen Organismus mit auf den Lebensweg erbält, außerordentlich häufig in einer Weise gesichtet und in ordnungsmäßiger Verteilung aufgespeichert ist, daß für die späteren Differenzierungsprozesse alles bequem bei der Hand ist. Würde es doch anch keinem menschlichen Baumeister einfallen, vor Beginn des Baues das Material beliebig durcheinandergew ürfelt bereit zu stellen. Wie Boveri ${ }^{1}$ sehr richtig bemerkt, ist es s eine Vereinfachung der Entwicklung, wenn schon im Ei eine solche Sonderung verschiedener Substanzen eintritt, daß jedes Primitivorgan direkt gerade diejenigen erhält, die ihm zur Ansbildung seiner weiteren Differenzierung am dienlichsten sind. * Boveri fand am Ei von Strongylocentrotus lividus eine unmittelbar wahrnehmbare Schichtung des Eiplasmas zu mindestens drei differenten Zonen; die eine derselben dient - normale Entwicklung vorausgesetzt - zur Bildung des Mesenchyms,

1 Th. Boveri, Über die Polarität des Seeigel-Eies. Verhandl. d. Phys.-Med. Ges. Würzburg. N. F. Bd. 34. 1901. 
die zweite zur Bildung des Urdarms, der Rest wird zu Ektoderm.

Mindestens ebenso deutliche Sonderungen des Materials lassen sich bei den Eiern der Anneliden (Nereis, Myzostoma, Lanice) und Mollusken (Dentalium, Patella, Ilyanassa) nachweisen. Auch hier sehen wir bei der normalen Entwicklung das verschiedene Material zu jeweilig bestimmten plastischen Aufgaben, also zu bestimmten plastischen Reaktionen verwendet. Entnahme gewisser Teile aus diesen Stadien ist also in vielen Fällen gleichbedeutend mit Kassierung eines bestimmten, sonst nicht mehr im Organismus enthaltenen and für gewisse Bauzwecke nnabweislich notwendigen Materials. Es kann 'uns also nicht wundern, daß eine solche Entnahme bestimmte plastische Reaktionen entweder ganz unmöglich macht oder ihre Ausfuhrung hinausschiebt, bis die Stoffwechselprozesse des Organismus den Stoff neu produziert haben. Vielfach scheint aber zu dieser Produktion nicht der sich entwickelnde jugendliche Organismus, sondern nur der ausgebildete mütterliche Organismus fähig zu sein.

So unterbleibt z. B. nach Crampton bei der Schnecke Ilyanassa die ganze Mesodermbildung, wenn man den sogenannten Dotterlappen vor Beginn der Furchung oder bald nach Eintritt derselben von dem übrigen Ei ablöst. In allen diesen Fällen liegt allerdings eine Lokalisation der $\gg$ Anlagen * vor, aber offenbar bloß eine Lokalisation des Baumaterials für diese Anlagen, eine * cytoplasmic localisation $*$ um einen Wilsonschen Ausdruck zu gebrauchen, keine Lokalisation der baufuhrenden Kräfte, d. h. des ererbten Engrammschatzes. Einen ähnlichen Gedanken drickt in Beziehnng auf einen bei Echiniden vorkommenden Spezialfall H. Driesch aus, wenn er sagt: , Wenn 
Einschränkung des Regenerationsvermögens u. Lokalisation. 287

wahrhaft animale Achter und Sechzehner so oft nicht gastrulieren, so liegt das offenbar - das eben auszusprechen erlauben uns Boveris Forschungen - an einem gewissen Mangel ihrer stofflichen Natur, nicht, wie ich friher vermutete, an einem Mangel ihrer Regulierbarkeit «1.

Es ist nun durchaus nicht schwer, noch in einer großen Anzahl, vielleicht der Mehrzahl von anderen als * Einengung der prospektiven Potenz" beschriebenen Fällen die Abnahme der Regenerations- und Regulationsfähigkeit der Teilstúcke anf eine Lokalisation des Baumaterials zuriuckzufuhren. Dạ in manchen Fällen diese Lokalisation, die in einer bestimmten plasmatischen Sonderung oder besonderen Schichtung: bestehen kann, nicht optisch wahrnehmbar zu machen ist, gibt uns keineswegs das Recht, ihr Vorbandensein in Abrede zu stellen, und die Abnahme des Regulationsvermögens in solchen Fällen einfach einer Lokalisation der ererbten Engramme zuzuschreiben. Wir müssen uns vielmehr Boveri anschließen, wenn er (a. a. O. S. 161) sagt: "Wir können mit voller Bestimmtheit behaupten, daB diese Schichtung in allen Seeigeleiern mit gleichem Furchungstypus vorhanden ist, ohne daß wir eine Spur daron sehen. Dies führt natürlich auf den Gedanken, daß auch im Strongylocentrotusei eine noch feinere Schichtung besteht, als die drei Zonen, die wir unterscheiden können - . *

Daß bei den Ctenophoren die Dinge mutatis mutandis ebenso liegen, scheint mir schon aus dem zurzeit vorliegenden experimentellen Beobachtungsmaterial hervorzugehen, wenn schon der optische Nachweis einer Sonderung oder Schichtung des Baumaterials bisher nicht hat gefuhrt werden

${ }^{1} \mathrm{H}$. Driesch, Neue Ergänzangen zar Entwicklungsphysiologie des Echinidenkeimes. Archiv f. Entwicklungsmechan., Bd. 14, 1902. 
krönnen, vielleicht aber durch einen Sonderfall in Zukunft ebenso erbracht werden wird, wie durch Strongylocentrotus für die Echiniden. Jedenfalls liegt auch heute nicht der Schatten eines Grundes vor, den Mangel des Regulationsvermögens unter Negierung der Lokalisation des Baumaterials bei diesen Formen als Beweis für eine lokalisierte Verteilung des ererbten Engrammschatzes anzusehen.

Wir haben oben gesagt, in der Mehrzahl derjenigen Fälle, in denen in ersichtlicher Weise das Ausbleiben von Regenerationen oder Regulationen mit Defekten des Baumaterials zusammenhänge, handle es sich um ontogenetisch sehr junge Stadien. Immerhin kann derselbe Grund fur das Ausbleiben von Regeneration anch dann in älteren Stadien oder bei erwachsenen Organismen wirksam sein, wenn man in diesen Fällen nicht die Regeneration eines Organs durch das Ganze, sondern die Regeneration des Ganzen durch ein Organ erwartet, also wenn man den Fall diskutiert, daß ein abgeschnittener Tentakel nicht eine ganze Hydra zu regenerieren imstande ist. In diesem Falle kann es sich sehr wohl um Abwesenheit gewisser Baustoffe im Tentakel handeln, die zum Aufbau des ganzen Tieres notwendig sind, und die der isolierte, zur Nahrungsaufnahme nicht befähigte Tentakel nicht zu produzieren vermag. In der therwiegenden Mehrzahl der hierher gehörigen Fälle kommt aber nur die Regeneration eines kleineren Teils oder eines einzelnen Organs (Extremität, Auge usw.) durch den im tubrigen intakten Hauptteil des Organismus in Frage, und da kann es sich beim Ausbleiben der Regeneration kanm um die Abwesenheit eines bestimmten Baumaterials handeln. Denn es ist nicht einzusehen, warum der sonst vollständige und in seinen Funktionen ungehemmte Organismus nicht imstande sein soll, die nőtigen 
Einschränkung des Regenerationsvermögens u. Lokalisation. 289

Baumaterialien zu produzieren, wenn sie nicht gleich vorrätig da sind.

Wir haben uns demnach mit folgender Frage zu beschäftigen. Es besteht bei allen Metazoen ${ }^{1}$ eine zwar bei den verschiedenen Formen verschieden ausgeprägte, aber doch uberall unverkennbare Abnahme des Regenerationsvermögens mit zunehmendem Alter des Individuums, und zwar eine Abnahme, die sich nicht auf den Mangel eines bestimmten Baumaterials zuruckführen läßt, wie wir sie in den soeben besprochenen Fällen kennen gelernt haben. Haben wir nun das Recht, aus dieser Abnahme auf eine Hand in Hand mit dem Fortschreiten der Ontogenese vor sich gehende lokalisierende Aufteilung des ererbten Engrammschatzes zu schlieBen? Diese Frage durfen wir, wie ich glaube, mit einem runden Nein beantworten, obwohl wir noch keineswegs in der Lage sind, alle Gründe für die Abnahme der Regenerationsfähigkeit im Verlaufe des individuellen Lebens zu ubersehen. Denn vor allen Dingen erfolgt in sehr vielen Fällen die Abnahme der Regenerationsfähigkeit in bezug auf ein bestimmtes Organ gar nicht in gleichem Schritt mit der Entwicklung und geweblichen Differenzierung dieses selben Organs. Die eine Kaulquappe vermag, wie uns die Barfurthschen Untersuchungen gelehrt haben, nur die eben hervor-

1 Aus den neusten Untersuchungen von 0. Maas (Archiv f. Entw Mech. 30. Bd. (Fest-Band f. Roux) 1. Teil 1910 geht doch auch für die Spongien ein ausgeprägtes Regenerationsvermögen hervor. Nur solche Stiucke, die ausschließlich aus Rinde bestehen, vermögen nicht zu regenerieren. Bei den Pflanzen ist eine eigentliche Regeneration nur in verbältnismäßig seltenen Fällen zu beobachten. Regulationsvorgänge anderer Art (Adventivbildungen) führen hier meist zur Beseitigung von Inkongruenzen bei der Homophonie, leisten also funktionell dasselbe, wie die Regenerationsprozesse bei den Tieren. 
Elftes Kapitel.

sprossende Extremität, ein anderes Individuum derselben Art vermag eine bereits ziemlich differenzierte, ein drittes - allerdings ein seltener Fall - eine schon hoch differenzierte zu regenerieren, ja der sehr zuverlässige Spallanzani fand sogar in Ausnahmefällen die jungen Frösche und Kröten zu Regeneration abgeschnittener Gliedmaßen befähigt. Wir sehen hier also das Vermögen, die Extremitäten zu regenerieren, bei Individuen derselben Art zu ganz verschiedenen Zeiten und ohne eine konstante Beziehung zur geweblichen Differenzierung des Organs erlöschen. Ein Forellenembryo vermag vor Resorption des Dottersacks den zu dieser Zeit schon wohl entwickelten und differenzierten Schwanz mitsamt dem After und der sogenannten Urethra zu regenerieren; ein wenig später aber, aur Zeit wenn der Dottersack resorbiert ist, vermag er dies nicht mehr.

Verfolgen wir das erstgenannte Beispiel noch etwas weiter und wenden wir uns von den Anuren, wo die Fähigkeit, eine Extremität zu regenerieren, im ausgebildeten Zustande stets erlischt, zu den Urodelen, wo diese Fähigkeit auch dem geschlechtsreifen und ausgewachsenen Tier erhalten bleibt. Auch bei den Schwanzlurchen begegnen wir bei höher differenzierten Formen einer beträchtlichen Einschränkung dieser Fähigkeit. Beim Brillensalamander, Salamandrina perspicillata, ist sie zwar nicht, wie man glaubte, beim ansgebildeten Tier völlig erloschen. Doch fand Kammerer (Zentralblatt f. Physiologie, Bd. 19, 1905), daß schon die Larven und Jungen dieser Gattung zur Regeneration der Beine and Schwänze viel längere Zeit brauchen als alle anderen daraufbin untersuchten Urodelenlarren, und daß bei den erwachsenen Brillensalamandern der Prozeß mit außerordentlicher Langsamkeit vor sich geht. 
Einschränkung des Regenerationsvermögens u. Lokalisation. 291

Vergleichen wir aber selbst bei Urodelen mit gut entwickelter Regenerationsfähigkeit das Verhalten der Individuen in verschiedenem. Lebensalter, so finden wir regelmäßig mit dem Fortschreiten des Lebens eine Verlangsamung der Regenerationsprozesse. Ich habe über diesen Punkt, um greifbare Anhaltspunkte geben za können, eine Anzabl von Versuchen angestellt, auf die ich nicht genauer eingehen will. Hier sei nur erwähnt, daß ältere Larven von Triton alpestris von $25-32 \mathrm{~mm}$, die schon vollkommen ausgebildete Extremitäten besitzen, zur Regeneration eines abgeschnittenen Arms bis zur deutlichen Ausbildung aller vier Finger durchschnittlich 4 Wochen brauchen, unter gleichen Verhältnissen gehaltene ausgewachsene Tiere aber bis zum gleichen Stadium der Regeneration durchschnittlich $7 \frac{1}{2}$ Wochen. Die Vollendung der Regeneration bis zur Ausgleichung jedes Größenunterschieds bedurfte bei den Larven 5 Wochen, bei den ausgewachsenen Tieren 4-5 Monate. Zu ganz demselben Resultat kam Kammerer in einer seither erschienenen Arbeit ${ }^{1}$, anf die ich hier besonders verweise, weil sie die Abhängigkeit des Regenerationsvermögens der Amphibienlarven von Alter, Entwicklungsstadium and spezifischer Größe in umfassender Weise behandelt. Auch er sagt: "Die Urodelen regenerieren sämtliche regenerationsfähige Körperteile im ausgebildeten Formenzustande langsamer als im Larrenzustande. *

Wir haben also hier einen Faktor vor uns, der in einer mit zunehmendem Alter steigenden Progression hemmend anf die Ausfuhrung von Regenerationen wirkt. Worin dieser Faktor im Grunde besteht, wollen wir vorläufig nicht unter-

1 P. Kammerer, Archiv f. Entw.-Mech., Bd. 19, 2. Heft, 1905. 
suchen, und uns mit der negativen Bestimmung begnugen, $\mathrm{daB}$ er mit einem mnemischen Defekt nichts zu tun hat. Ist nun aber dieser Faktor, der die Ausfuhrung der Regenerationsreaktion so häufig verlangsamt, identisch mit demjenigen, der sie bei anderen Formen gänzlich aufhebt und zum Verschwinden bringt? Wenn wir uns zunächst auf Betrachtung der Reihe Siredon, Triton, Salamandra, Salamandrina, Anuren beschränken, so werden wir wohl diese Frage unbedenklich bejahen. Und wenn wir bei weiterer Umschan ähnliche Verhältnisse bei allen möglichen anderen Tiergruppen wiederfinden, so werden wir nicht zögern, dieser Bejahung eine allgemeinere Gultigkeit zuzusprechen, ohne damit die Behanptung zu vertreten, die Erschwerung und gänzliche Aufhebung der Regeneration sei immer und unter allen Umständen auf ein und dieselbe Grundursache zurïckzuführen.

Überhaupt ist es ja hier nicht unsere Aufgabe, die Ursachen der Abnahme der Regenerationsfähigkeit während des individuellen Lebens aufzudecken - so wichtig und interessant eine solche Erklärang an sich auch sein wiurde -, sondern nar za zeigen, daß sie nicht auf einer lokalisierenden Aufteilung der ererbten Engramme beraht. Erwähnen möchte ich aber doch im Vortibergehen, daß mir die $A b-$ nahme jener Fähigkeit, zum Teil wenigstens, auf einer im Laufe jedes individuellen Lebens zu beobachtenden allmählichen Erlahmung der Fähigkeit zu beruhen scheint, größere neoplastische Leistungen zu erfullen. Wenigstens bei Organismen mit begrenztem Wachstam. Je höher organisiert und komplizierter gebaut ein solcher Organismus ist, nm so dentlicher tritt dies zutage und erreicht seinen Hohepunkt in der höchst auffallenden Tatsache, daß beim Genus Homo das Weib schon in der Mitte seines normalen individuellen Da- 
Einschränkung des Regenerationsvermögens u. Lokalisation. 293

seins, also gegen Ende der vierziger Jahre, unfähig wird, eine Kardinalfunktion des Organismus, die Produktion von Keimzellen; weiter zu erfüllen. Und ebenso sehen wir die pathologischen neoplastischen Reaktionen (Geschwalstbildung) mit zunehmendem Greisenalter progressiv gehemmt und schließlich nahezu aufgehoben (Carcinome von Greisen haben bekanntlich nur ein uberaus langsames Wachstum).

Zn diesem Faktor, den wir als die Abnahme der Energie der neoplastischen Prozesse mit fortschreitendem Alter bezeichnen können, mögen sich noch andere gesellen. Wenn wir also auch nicht behaupten, alle Gründe zu tibersehen, die in jedem einzelnen Falle der Abnahme der Regenerationsfähigkeit bei zunehmendem Alter zugrunde liegen, so können wir doch behaupten, daß kein einziger Fall bekannt ist, der uns nötigte, den Grund in einer mit der Ontogenese fortschreitenden lokalisierenden Aufteilung der Engramme za suchen.

Vielleicht wird man hier einwenden, aus dem Umstande, daß das Vorhandensein und die ungestörte Leitung des Zentralnervensystems für das Zustandekommen mancher Regenerationen notwendig ist, könne man folgern, gewrisse ererbte Engramme würden im Laufe der Ontogenese im Zentralnervensystem deponiert. So erkläre es sich, daß bei Ausschaltung dieses Organs auch die Engramme ausgeschaltet würden, und die Regeneration nicht ausgefuhrt werden könne.

Dieser Einwand basiert auf einer falschen Vorstellung von der Stellung, die das Zentralnervensystem gegenüber den plastischen Reaktionen der anderen Gewebe eianimmt.

Zunächst haben die bisherigen, auf diese Frage gerichteten Experimente, wie mir scheint, mit größter Klarheit ergeben, daß in frühen Entwicklungsstadien sich sämtliche Organe unabhängig vom bereits vorhandenen Zentralnerven- 
Elftes Kapitel.

system entwickeln und auch gegebenenfalls regeneratorische Fähigkeiten entfalten (Versuche Loebs, anenzephale amyelitische Froschlarve Schapers, Versuche Raffaeles, Harrisons, Barfurths, Rubins, Fortfuhrung der Schaperschen Untersuchungen durch Goldstein ${ }^{1}$ ). Selbst das Muskelsystem entwickelt sich und regeneriert sich in diesen jungen Stadien, wie die Versuche von Harrison und Schaper-Goldstein lehren, unabhängig von Zentralnervensystem und Spinalganglien. In älteren Stadien ändert sich dies allerdings insofern, als nach neueren, sehr eindringenden Untersuchungen von Rubin (Archir für Entwicklungsmech., Bd. 16, 1903, S. 71) zwar die Ausschaltung des Nervensystems bei Siredon pisciformis nicht den rechtzeitigen Eintritt und die ersten Stadien der Regeneration hindert. Später aber äußert sich der Mangel der Innervation oder anch der fehlenden Funktion in einer zunehmenden Verzögerang und in einem allmählich erfolgenden Stillstand der Regeneration. Zum richtigen Verständnis ist diesem Satze allerdings noch hinzuzufugen, daß der Stillstand der Regeneration bei Ausschaltung des nervösen Einflusses in späteren Stadien zwar in der Gesamtgröße des Regenerats zum Ausdruck kommt, wie aber genauere Untersuchung lehrt, die verschiedenen Gewebe in sehr verschiedonem Maße betrifft. Wie Rubin fand, >trat am Muskelsystem der fehlende Einfluß des Zentralnervensystems am meisten hervor. Hier hörte die Regeneration schon am zehnten bis zwölften Tage vollständig auf,

1 Vgl. die gute kritische Darstellang des gegenwärtigen Standes der Frage nach dem Einflu $B$ des Zentralnervensystems auf die em= bryonale Entwicklung nnd die Regeneration in dem Aufsatz von K. Goldstein, Archiv f. Entw.-Mech., Bd. 18, 1904, S. 57. Ferner die seither erschienene Übersicht in Przibram, Experimentalzoologie, 2. Bd., R日generation, Leipzig and Berlin 1909, bes. S. 58, 103, 142, 169-172. 
Einschränkung des Regenerationspermögens u. Lokalisation. 295

noch bevor es zar Bildung spezifischer Muskelstubstanz gekommen war." Bleiben wir zunächst bei diesem Befund, so haben wir zu seiner Wurdigung die Frage zu untersuchen: Wie verhält sich denn die Muskulatur bei Ausschaltung jedes Nerveneinflusses an einem Organ, dem nicht durch einen weiteren Eingriff eine regeneratorische Leistung zugeschoben ist? Die Antwort darauf lantet: die Muskulatur wird atrophisch. Ob diese Atrophie lediglich eine Inaktivitätsatrophie ist, eine Ansicht, die sich trotz entgegenstehender $\mathrm{Be}-$ denken sehr wohl verfechten läßt, oder ob bei ihrem Zustandekommen auch noch der Fortfall einer $>$ trophischen Wirkung des Nervensystems eine Rolle spielt, dies zu untersuchen wurde uns hier zu weit fuhren und ist auch fur die uns beschäftigenden Fragen nicht von grundlegender Bedeutung. Die Tatsache an sich gentigt aber, um uns dartiber aufzuklären, warum eine gelähmte Maskulatur zu regeneratorischen Leistungen nicht befähigt ist. Ganz einfach, weil sie sich nach der Nervendurchschneidung in einem anomalen Zustande befindet, weil ihre energetische Situation in eingreifender Weise verändert ist.

Wenn hier etwas wunderbar ist, so ist es allein der Umstand, daß sich nach Rubin an einer solchen Muskulatur tiberhaupt Regenerationserscheinungen im allerersten Beginn beobachten lassen, nicht aber, daß sie bald aufhören und zu nichts fuhren.

An den anderen Geweben eines Regenerationsstumpfs, an dem durch Nervendurchschneidung der nervöse Einfluß ausgeschaltet ist, hören nach Rubins Untersuchungen die Regenerationserscheinungen erst viel später auf, als an der Muskulatur. Das Wachstum der Cutis dauerte noch längere Zeit an, bis der ganze Regenerationskegel umwachsen war, doch 
unterblieb ein weiteres Dickenwachstum. Das Bindegewebe zeigte nur noch ein geringes Wachstum. Die Regeneration des Knorpels begann zu einer Zeit, als die der Muskulatur bereits aufghört hatte, blieb aber eine äußerst beschränkte. Am GefäBsystem erweiterten sich die während der ersten zehn Tage gebildeten Kapillaren und fullten sich mit Blut. Eine Neubildung von Gefäßsprossen fand dann nicht mehr statt.

Was hier die Regenerationsfähigkeit auch der tubrigen Gewebe allmählich zum Stillstand bringt, ist nicht die Abwesenheit des Nerreneinflusses, sondern höchst wahrscheinlich die durch das Aufhören der Muskelregeneration gesetzte allgemeine Störung der energetischen Situation.

Durch die Unmöglichkeit, die Muskelregeneration durchzufuhren, ist es ja tiberhaupt ausgeschlossen, die Inkongruenz der Homophonie in den gegebenen Fällen wirklich zu beseitigen, was nur geschehen könnte, wenn der komplizierte Ersatzbau in einigermaßen harmonischer Weise ansgefuhrt wtirde. Die dahin zielenden Reaktionen erlahmen deshalb sehr verständlicher Weise nach einiger Zeit. Daß die Abwesenheit des Nerveneinflasses kein Hindernis fir die Regeneration kleinerer, bald diese bald jene Gewebsart betreffender Defekte ist, ist eine durch zahlreiche Beobachtungen und Experimente festgestellte Tatsache. Wunden aller Art heilen ebensogut an den dem Nerveneinfluß entzogenen Gliedern als an solchen mit intakten Nerven; bei Knochenbrüchen tritt eine ebenso- vollkommene Regeneration an gelähmten als an ungelähmten Extremitäten ein.

Kturzer kann ich mich über die bekannten Herbstschen Versuche an Crustaceen fassen, die ergaben, daß eine Regeneration des Anges nur dann stattfindet, wenn die Angenganglien des amputierten Auges nicht mit entfernt worden 
waren. Es scheint mir, daß man in diese an sich gewiß sehr interessanten Versuche mehr hineingetragen hat, als in ihnen liegt1. Es herrscht unter den deskriptiven Embryologen darliber Übereinstimmung, daß bei der Entwicklung der paarigen zusammengesetzten Augen der Crustaceen das eigentliche Ange und das Ganglion opticum aus einer gemeinsamen Ektodermanlage hervorgehen. Daraus folgt, daß man also das zusammengehörige Ganze nur dann radikal exstirpiert, wenn man auch das Ganglion opticum mit fortnimmt. Nebensächlich ist dabei, daß dieser Teil des Sehorgans durch sekundäre Wachstumsprozesse bei manchen Formen räumlich eine gewisse Sonderstellnng erlangt, dem naiven Beschauer sich also als etwas Selbständiges präsentiert. Daß nun ein Organ leichter regeneriert wird, wenn ich noch Teile davon im Organismus zuricklasse, als wenn ich es radikal entferne, daß in letzterem Falle bei Formen mit nur mäßig erhaltenem Regenerationsvermögen oft tuberhaupt keine Regeneration erfolgt, ist eine der bekanntesten Tatsachen der Regenerationslehre. So regenerieren z. B. nach Philippeaux die so regenerationsfähigen Urodelen nur dann ihre Extremitäten, wenn wenigstens Teile des Schulterblatts bzw. Beckens im Körper zurlickgeblieben sind. Auch vermögen sie nur kleinere Defekte am Auge durch Regeneration auszugleichen, nicht aber den ganzen Bulbus zu regenerieren. In alledem spricht sich doch nur die allgemeine Regel aus, $\mathrm{da} B$ das Regonerationsvermögen besonders der höheren Tiere und bei diesen besonders in späteren Lebensstadien ein mehr und mehr begrenztes wird. $\mathrm{DaB}$ die Crustaceen einen Teil

1 Ähnlich urteilt, wie ich sehe, anch 0 . Maas, Einfuhrung in die experimentelle Entwicklungsgeschichte, 1903, S. 122. 
des Sehorgans, d. h. das Auge abzliglich des Ganglion opticum, regenerieren können, ist schon eine im Vergleich mit anderen hochorganisierten Tieren sehr respektable Leistung. Daß sie nicht das radikal, d. h. zusammen mit dem ontogenetisch zugehörigen Ganglion opticum exstirpierte Auge regenerieren können, beweist nur, daß auch ihr Regenerationsvermögen seine Grenzen hat, beweist aber noch nicht einen spezifisch »formativen * Einfluß des Ganglions beziehungsweise des Zentralnervensystems, umsoweniger als das eigentliche Zentralnervensystem, nämlich das Gehirn (obere Schlundganglion), bei allen den betreffenden Versuchen ja intakt und funktionsfähig geblieben ist.

Herbst hat festgestellt, daß eine große Anzahl Crustaceen bei nicht radikaler Fortnahme des Auges (Zurticklassung des Ganglion opticum) das Organ regenerieren, bei radikaler Fortnabme dies aber niemals tun, und $\mathrm{da} B$ sie in letzterem Falle, also im Unvermögensfalle, das Auge zu regenerieren, manchmal an der Amputationsstelle ein antennenähnliches Organ hervorsprossen lassen.

Noch verschiedene andere derartige "Heteromorphosen sind in letzter Zeit nicht selten bei Crastaceen und Arthropoden beobachtet worden. Es kann sich dabei um Ersatz eines Gliedes durch ein weniger differenziertes handeln, welches fur ein davor oder dahinter gelegenes Segment typisch ist; außerdem kommen aber auch noch weniger einfach einzuordnende Ersatzbildungen vor ${ }^{1}$. Ich werde auf dieses Thema in einer späteren Fortsetzung der Mneme näher eingehen und dort zu zeigen versuchen, daß auch diese schein-

1. Vgl. H. Przibram: Experimentalzoologie, Bd. II, Regeneration, Leipzig und Berlin 1909, S. 117-119, sowie: Die Homoeosis bei Arthropoden, Archiv f. Entwicklungsmechanik, 29. Bd. 1910. 
Einschränkung des Regenerationsvermögens u. Lokalisation. 299

bar so rätselhaften Erscheinungen bei mnemischer Betrachtungsweise der Ontogenese und Regeneration, besonders bei entsprechender Berucksichtigung der Homophonie sowie der Zusammensetzung des ererbten Engrammschatzes einer Erklärung oder doch einer Zurtickfluhrung anf allgemeinere Gesetzmäßigkeiten zugänglich sind. Hier würde uns dies zu weit fluhren, and ich möchte nur hervorheben, daß ich einen bestimmten Einfluß des Nervensystems in diesen Fällen ebensowenig leugne als in jenen anderen, in denen $z$ : B. das Tempo der Regeneration nach Nervendurchschneidung auffillig verlangsamt wird. Was ich aber auch durch diese Fälle nicht für bewiesen halte, ist ein spezifisch formativer Einfluß des Nervensystems.

Przibram ist im zweiten Bande seiner eben zitierten Experimentalzoologie, der die Regeneration behandelt und eine erschöpfende Wiedergabe des einschlägigen umfangreichen Tatsachenmaterials enthält, S. $224 \mathrm{zu}$ einem Schlußergebnis gelangt, das sich mit meiner Auffassung sehrnahe beruhrt, und das ich hier wörtlich wiedergebe: "Halten wir daran fest, daß einerseits die Regeneration nur von wachstumsfähigen Teilen geleistet, andrerseits die Regenerate aus den fortwacbsenden Geweben selbst entstehen, so liegt es nahe, den gunstigen EinfluB der Nerven vorwiegend auf ihre Begthstigung des Wachstums, nicht auf ihre spezielle formbildende Kraft zurlickzuftihren. Die Förderung des Wachstums durch die Nerven ist für die Säugetiere allbekannt. Auch bei der Heterochelie der Krebse trifft dies auffallend zu c.

Ich glaube in dew vorliegenden Kapitel gezeigt zu haben, erstens: Die im Laufe der Ontogenese auftretenden Beschränkungen des Regulations- und Regenerationsvermögens finden nicht ihre Erklärung in einer lokalisierenden Aufteilung des 
ererbten Engrammschatzes während der Ontogenese. Zweitens: die Tatsachen, aus denen manche Autoren auf einen spezifisch »gestalteten * oder »formativen * EinfluB von Teilen des Zentralnervensystems auf die Regeneration schließen, erfordern diese Deutung nicht und finden ihre Erklärung ebenfalls nicht in einer solchen lokalisierenden Aufteilung.

Wir werden demnach allen Tatsachen gerecht, wenn wir annehmen, daß sich jede Zelle, ja jedes mnemische Protomer im Besitz des gesamten ererbten Engrammschatzes des betreffenden Organismus befindet. Andererseits aber möchte ich doch noch einmal, um ja keine Mißverständnisse aufkommen zu lassen, daran erinnern, daß die Ekphorie eines jeden ererbten Engramms, wie die eines jeden individuell erworbenen, an ganz bestimmte lokale Bedingungen gekntipft, also sozusagen lokalisiert ist.

Die Reaktion desPickens nach Körnern und anderen kleinen Partikeln bei eben ausgekrochenen Kucken ist als Manifestation der Ekphorie eines ererbten Engramms aufzufassen. Diese Ekphorie ist aber nur bei Anwesenheit wenigstens eines intakten Auges und seiner nervösen Verbindungen möglich. Der photische Reiz des Korns löst zanächst eine Erregung in der reizbaren Substanz der Retina, diese fortstrahlend eine Erregung in anderen Teilen des Zentralnervensystems aus, die zuerst in diesen Teilen, den Eigenbezirken dieser Erregung, auch ekphorisch wirkt, also, wenn man will, hier in einem gewissen Sinne lokalisiert ist. Aber dieso Lokalisation der Ekphorie, das Vorhandensein eines Eigenbezirks der ekphorischen Reizwirkung, von dem aus sie über den ubrigen Organismus ausstrahlt, hat nichts mit einer lokalisierenden Aufteilung der ererbten Engramme zu tun. Denn die dominierende Stellung des „Eigenbezirks« bei der 
Einschränkung des Regenerationsvermögens u. Lokalisation. 301 Ekphorie erklärt sich ganz einfach daraus, daß hier zuerst der zur Ekphorie notwendige Zustand der energetischen Situation realisiert wird, und daB dieser Zustand uberhaupt nicht realisiert werden kann, wenn der Eigenbezirk fehlt oder schwer geschädigt ist. 


\section{Zwölftes Kapitel.}

Die Bedentung der alternativ ekphorierbaren Dichotomien auf ontogenetischem Gebiet.

Wir sind schon an verschiedenen Stellen (S. 145, 228, 255) bei unseren Betrachtungen der Tatsache begegnet, daß die Engrammsukzessionen, die durch eine stetige, einreihige und einsinnige Anordnung charakterisiert sind, doch auch hie und da eine gablige Teilung (Dichotomie, Trichotomie usw.) dieser einreihigen Anordnung zeigen können. Wir unterschieden nach der Ekphorierbarkeit zwei Arten solcher Dichotomien: simultan ekphorierbare und alternativ ekphorierbare. Simultan ekphorierbare Dichotomien sind sebr häufige Vorkommnisse bei der Gruppierung von ontogenetischen Engrammsukzessionen. Ich verweise z. B. auf die Gruppierung der Engramme bei einem teilungsfähigen Ei (S. 254). Näher haben wir aber hier noch auf die nur alternativ ekphorierbaren Dichotomien in bezug auf ontogenetische Engrammreiken einzugehen.

Das Konstruktionschema solch einer alternativen Dichotomie haben wir ansgehend von dem konkreten Fall der zwei Fassungen des Goetheschen Gedichts: ,Über allen Wipfeln ist Ruh* graphisch wiedergegeben (S. 228). Im wesentlichen hat dieses Schema furr jede alternative Dichotomie Geltung, auch für eine alternative Dichotomie von 
Die Bedeutung der alternativen Dichotomien in der Ontogenese. 303

Sakzessionen solcher Engramme, deren Reaktionen auf plastischem Gebiet liegen. Indem wir hier jetzt ron der Entsteh angsweise der alternativen Dichotomien auf ontogenetischem Gebiet absehen und die Erörterang derjenigen, die durch Krenzung entstehen, auf das nächste Kapitel versparen, wenden wir uns zunächst zur Untersuchung solcher Fälle, bei denen die Entscheidung der Alternative auf Grund äußerer Einflüsse erfolgt.

Zunächst ein Fall bei unserer Honigbiene, Apis mellifica. Für das befruchtete Bienenei sind bekanntlich zwei Entwicklnngsmöglichkeiten gegeben. Entweder es entsteht aus ihm ein geschlechtsreifes Weibchen, eine sogenannte Königin, oder aber eine Arbeiterin. Beide Formen unterscheiden sich voneinander durch ihre Körperbeschaffenheit und ihre Instinkte in der ausgesprochensten Weise. Bei der Arbeiterin kommt es zu keiner vollen Ausbildung der Geschlechtsorgane. Diesem Bildungsdefekt stehen eine ganze Reibe von positiven Merkmalen gegentuber: Ausbildung des Sammelapparats (Körbchen und Bürste) an den Hinterfußen, der Wachstaschen, des Mittelkiels am Abdomen. Bei der Königin findet sich dagegen einerseits volle Ausbildung der Geschlechtsorgane, andererseits Fehleu aller der zuletzt genannten Merkmale sowie eine im Vergleich zur Arbeiterin geringere Ausbildung des Rüssels, der Kauorgane; der Speicheldruisen, der Flügel, eine andere Form des Stachels usw. Auch fehlen ihr alle die mit der Brutpflege zusammenhängenden Instinkte (Ban-, Fütterungs-, Sammelinstinkte usw.). Sie ist in ihren Instinkten verarmt und wesentlich $z u$ einer Eierlegmaschine geworden. Man könnte das ganze Verhältnis auch in der Weise darstellen, daß man sagt, die körperlichen und dynamischon Eigenschaften, die sich bei 
den ungesellig lebenden Apiden, den Hummeln, noch in jedem weiblichen Individuum vereinigt finden, seien bei den gesellig lebenden Apiden je nach der vollständigen oder mangelhaften Ausbildung der Geschlechtsorgane auf zwei scharf unterschiedene Formen der Weibchen verteilt: die Vollweibchen oder Königinnen und die geschlechtlich verklummerten Weibchen oder Arbeiterinnen.

Verfolgen wir nun die individuelle Entwicklang oder Ontogenese dieser beiden Formen, so finden wir, daß, wie gesagt, jedes befruchtete Bienenei befähigt ist, je nach Umständen entweder die eine oder die andere Form aus sich hervorgehen zu lassen. Schon seit langer Zeit weiß man, daß einerseits eine ans einer Königinzelle (Weiselzelle) stammende Larve mit Arbeiterfutter ernährt eine Arbeiterin ergibt und andererseits eine aus einer Arbeiterzelle stammende aber mit Königinfatter ernährte Larve eine Königin.

Die Entwicklung innerbalb der Eihullen dauert bei der Honigbiene 3 Tage. Die darauf aus dem Ei auskriechende Larve wird von den Arbeiterinnen gefütert; diese Periode dauert 6 Tage. Daran schließt sich dann das Einspinnen, eine längere oder kürzere Ruheperiode und endlich die Verpuppung. Klein ${ }^{1}$ hat nun experimentell nachgewiesen und จ. Buttel-Reepen ${ }^{2}$ hat diese Versuche bestätigt, daß, wenn man eine Larve während der ersten $1 \frac{1}{2}$ Tage ihrer Larvenentwicklung mit Arbeiterfutter ernähren läßt, von dann an aber mit Königinfutter - auf die chemische Zusammensetzung der Futtersorten kommen wir unten zurück -, die

1 Klein, Futterbrei und weibliche Bienenlarve. In $>$ Die Bienenpfleger, 26. Jahrg., Ludwigsburg 1904, S. 80.

2 H. . Buttel-Reepen. Atavistische Erscheinungen im Bienenstarat C. R. d. I. Congrès Internat. d'Entomologie à Bruxelles 1910. Brüssel 1911. 
Die Bedeutung der alternativen Dichotomien in der Ontogenese. 305

kurze und fruhe Einwirkung des Arbeiterfutters keine merkliche Veränderung, keine Ekphorie der sArbeiter *-Engramme hervorruft, vielmehr das Endprodukt der Entwicklung eine typische Königin liefert. Anders verhält es sich aber, wenn man $21 / 2-31 / 2$ Tage lang mit Arbeiterfutter und and dann erst mit Königinfutter füttern läßt. Man erhält dann eine Königin mit deutlichen Andeutungen gewisser Arbeitermerkmale. Larven endlich, die $4 \frac{1}{2}$ Tage lang in Arbeiterzellen gewesen und mit Arbeiterfutter ernährt worden sind, dann erst umgelarvt werden und somit nur kurze Zeit am Ende dieser kritischen Periode dem Einflusse des Königinfutters unterliegen, zeigen neben den Königinmerkmalen sehr ausgeprägte Arbeitermerkmale.

Ließ Klein andererseits $1 / 2-1 \frac{1}{2}$ tägige Arbeiterlarven während der folgenden 2 Tage mit Königinfutter ernähren und dann wieder 1-11/2 Tage lang mit Arbeiterfutter, so erhielt er Arbeiterformen mit nur ganz schwach angedeuteten Königinmerkmalen.

Aus diesen Experimenten geht mit Sicherheit hervor, daß hier die Entscheidung der Alternative, welcher der beiden Engrammäste ekphoriert werden wird, durch äußere Reize (Nahrungsreize) erfolgt. Zur Erläuterung möge das Schema auf der folgenden Seite dienen.

In dem Schema ist angedeutet, die in Phase 4 beginnende Dichotomie der betreffenden Engrammkomplexe sei derart, daß noch bis Phase 9 ein Übergang von der einen auf die andere Bahn möglich und erst von Phase 10 an ausgeschlossen ist. Ein solches Pendeln der Ekphorie zwischen zwei Bahnen beziehungsweise eine gleichzeitige Ekphorie von Teilen beider Reihen manifestiert sich dann durch das Auftreten von Mischreaktionen. In unserem Falle er- 


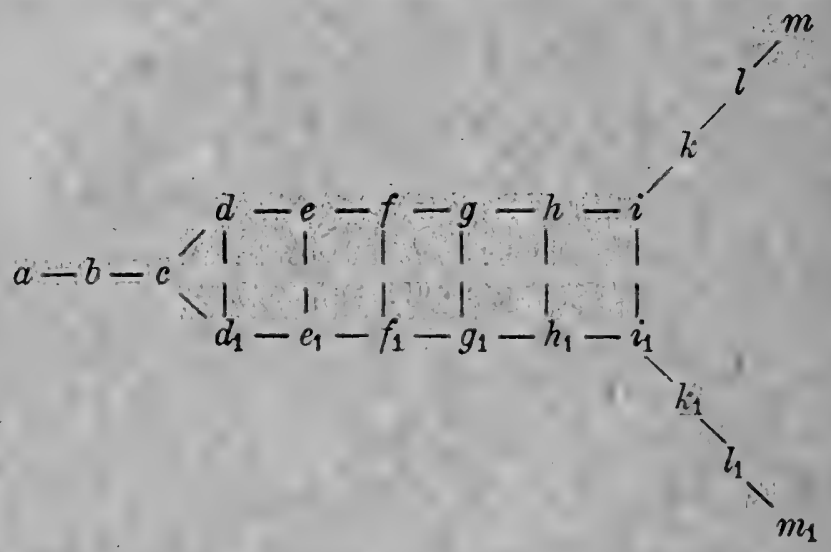

balten wir unter solchen Umständen „Übergangstiere , Königinnen mit Arbeitercharakteren oder Arbeiter mit Königincharakteren, wie sie sich in den oben zitierten Schriften von Klein und $\nabla$. Buttel-Reepen beschrieben und abgebildet finden. Ähnliche Mischformen werden wir gleich unten auch bei den Ameisen kennen lernen.

Vorher will ich aber erst uber die Natur der Reizung einige Worte sagen, die in unserem Beispiel die Entscheidung der Alternative herbeifuhrt. Der Erfolg hängt, wie fur die Honigbiene sicher festgestellt worden ist, ausschlieBlich von der Beschaffenheit des dargereichten Futters ab, die Reize um die es sich handelt, sind also unzweifelhaft chemische. Das Königinfutter ist nach Planta durchschnittlich um $5 \%$ reicher an Eiweiß und um $7 \%$ reicher an Fett aber um 11\% ärmer an Zucker als das Arbeiterfutter 1. Es ist aber sehr wohl denkbar, daß nicht sowohl diese quanti-

1 Die Arbeiterlarven erhalten nach Klein die ersten 3 Tage ausschließlich vorverdautes Futter, am 4. Tage Honig mit nur teilweise verdantem Pollen; dieses Futter geht am 5. und 6. Tage in Honig und Pollen über. Die Königinlarve bekommt die ganzen 5 Tage ihres Larvenlebens vorverdaute Nahrung und dazu etwas Honig, ungerechnet die Säure, die aller Larvennahrung beigemischt ist. 
Die Bedeutang der alternativen Dichotomien in der Ontogenese. 307

tative Dosierung als vielmehr die Beimischung von spezifischen Stoffen, vielleicht Ausscheidungsprodukten der Ernährer, die eigentlichen Entwicklungsreize, die ekphorischen Reize für den einen oder den anderen Ast der Engrammdichotomie bedingen. Bei den gleich zu besprechenden Ameisen, wo bei vielen Formen nach Janet und Wheeler eine qualitative Dosierung der Nahrung kaum möglich ist, durfte es sich wohl ausschließlich um die Darreichung solcher spezifischer Reizstoffe handeln.

Ganz ähnlich nämlich wie bei den Bienen liegen die entsprechenden Verhältnisse bei den Ameisen. Freilich besitzen wir für die letzteren keine so vollständigen Experimentaluntersuchungen, sondern sind mehr auf aus vergleichenden Beobachtungen und aus Naturexperimenten zu ziehende Schlüsse angewiesen. Dieselben harmonieren aber vollständig mit den bei den Bienen gewonnenen experimentellen Ergebnissen.

Schon im Jahre 1874 hat Forel ${ }^{1}$ Zwischenformen zwischen Weibchen und Arbeiterinnen bei den verschiedensten Ameisen beschrieben. Wasmann ${ }^{2}$ hat später eine plausible Erklärung dafür gegeben, warum in gewissen Nestern ein massenhaftes Auftreten von Zwischenformen, sogenannten Pseudogynen, in Erscheinung tritt.

Er hat nämlich durch langjährige Beobachtungen nachgewiesen, daß in diesen Fällen das Auftreten der Pseudogynen mit der Anwesenheit gewisser Ameisengäste, Lomechusa, Xenodus, Atemeles ursächlich zusammenhängt. Jene

1 A. Forel, Les Fourmis de la Suisse, Neue Denkschr. d. allg. Schweiz. Ges. f. d. allg. Naturw., 26. Bd., 1874.

2 E. Wasmann, Ergatogyne Formen bei den Ameisen. Biologisches Centralblatt, 15. Bd., 1895. 
von den Gattungen Formica wie Myrmica geduldeten Käfer dezimieren nämlich die Eier und Larven ihrer Wirte. $>$ Dadurch entsteht ein sehr fühlbarer und plötzlicher Ausfall in der Entwicklung der Arbeitergeneration, und diesen Ausfall suchen die Ameisen dadurch zu ersetzen, daß sie alle noch disponiblen ursprünglich zu Weibchen bestimmten Larven der unmittelbar vorhergehenden Generation (welche regelmäßig zu den Geschlechtsindividuen erzogen zu werden pflegt), zu Arbeiterinnen umztuchten.* Die Richtigkeit dieser Erklärung konnte Viehmeyer ${ }^{1}$ bei einem Kontrollversuch dadurch feststellen, daß er eine Königin, die in einer mit Lomechusa infizierten Kolonie gelebt und dort 4 Jahre lang Psendogynen erzeugt hatte, in ein nicht infiziertes Nest versetzte. Von Stund an verschwanden die Psendogynen aus der Nachkommenschaft dieses Weibchens, und nur noch reine Vollweibchen und reine Arbeiterinnen wurden aufgezogen. $\mathrm{Ob}$ und inwieweit die Entwicklung der Verschiedenheiten der Arbeiterinnen da, wo es innerbalb derselben wieder verschiedene Formen gibt wie bei so vielen Ameisen und bei den Termiten, lediglich durch Ernährungsreize während der Aufzucht-ausgelöst wird, kann nur durch weitere Untersuchungen festgestellt werden.

Nur einer Schwierigkeit möchte ich hier noch einige Worte widmen. Sowohl bei den Bienen und Ameisen als auch bei den Termiten handelt es sich in den eben besprochenen Beispielen um Fälle, bei denen der eine Ast der Dichotomie bzw. Trichotomie zur Ausbildung von Individuen führt, die in ihrer Fortpflanzungsfähigkeit beeinträchtigt

1 H. Viehmeyer. Experimente zu Wasmanns Pseudogynen-Lome. chusa-'Theorie. Allgem. Zeitschr. f. Entom., 9. Bd., 1904. 
Die Bedeutung der alternativen Dichotomien in der Ontogenese. 309 sind. Dürfen wir trotzdem diesen Ast der Sukzession von Erregungsdispositionen als eine Sukzession von ererbten Engrammen ansehen, obwohl diejenigen individuen, in denen diese Erregungsdispositionen aktiviert werden, aus dem Zeugungskreis der Art ausgeschlossen erscheinen? Diese Frage wäre fủr alle diejenigen Fälle zu verneinen, in denen angenommen werden müßte, daß der ausgeprägte Dimorphismus oder Polymorphismus erst $\mathrm{n}$ ach Auftreten der vollkommenen Sterilität der einen Reihe zur Ausbildung gelangt sei.

Es sprechen aber, worauf schon Herbert Spencer hingewiesen hat, starke Gründe dafür, daß für die Hauptdivergenzen der Reiben gerade das umgekehrte Zeitverhältnis maßgebend gewesen ist.

Am schönsten läßt sich dies bei den Apiden nachweisen, wo sich wie erwähnt, die meisten anatomischen Unterscheidungsmerkmale zwischen Königin und Arbeiterin bei den einfacher organisierten Hummeln noch in einem und demselben Individuum vereinigt finden. Ganz ähnlich verhält es sich mit den Instinkten. Sehr bezeichnend ist, was v. Buttel-Reepen ${ }^{1}$ tiber die Verschiedenheit der Instinktentwicklung bei Königin- und Arbeiterinform sagt: $\gg \mathrm{Die} H$ a uptveränderung liegt a uf seiten der Königin, die von ihrer Höhe als fruhere Allesschafferin herabsinkt, fast alle ihre eigentlimlichen Instinkte verliert, und nur noch Eierlegmaschine ist, während die Arbeiterinnen alle Instinkte ihres friberen Weibchentums behalten, also die Bau- und Futter- bzw. Sammelinstinkte usw. und

1 H. v. Buttel-Reepen, Die stammesgeschichtliche Entstehung des Bienenstaates. Biol. Centralblatt, Bd. 23, 1903, auch separat mit $\mathrm{Zu-}$ sätzen erschienen bei G. Thieme, Leipzig 1903. 
Zwölftes Kapitel.

nur den Begattungstrieb einbüßen, dafür aber einige neue Instinkte hinzugewinnen, z. B. die sogenannte ,Anhänglichkeit an die Stockmutter und die besondere abweichende Pflege derselben.:

Natürlich läßt sich nicht leugnen, daß außer diesem Bewabren bereits bestehender Merkmale in der angeblich sterilen Reihe doch auch noch neue körperliche Eigenschaften und Instinkte hinzu erworben worden sind. Darin liegt aber durchaus nicht eine besondere Schwierigkeit für unsere Auffassung, denn die Arbeiter- und Soldatenkaste ist keineswegs rollständig von dem Zeugungskreis der Art ausgeschlossen. Schon im Jahre 1874 machte Forel a. a. O. die Mitteilung von dem Eierlegen der Ameisenarbeiter und diese Beobachtungen sind seitdem von ihm selbst, Lubbock, Wasmann, Viehmeyer, Tanner, Reichenbach, Wheeler, Miß Fielde und anderen bestätigt worden. Ähnliches geht für die Arbeiter der Termiten aus den Beobachtungen von Silvestri und für ihre Soldaten aus denen von Grassi hervor, und der Termitenforscher Escherich bezweifelt nicht, daß solche Fälle sich stark mehren werden, wenn man diese Fragen einmal eingehender studieren wird. Was endlich die Bienen anlangt, so herrscht vollständige und ausnahmslose Sterilität der Arbeiterinnen nur bei einer Form, nämlich unserer Honigbiene, Apis mellifica, und selbst bei ihr wird fur die ägyptische Varietät (Apis mellifica fasciata) angegeben, daß sich häufig in den Stöcken neben der Königin eierlegende Arbeiterinnen vorfinden. Bei den ubrigen Varietäten derHonigbiene, bei denen die Arbeiterinnen normalerweise nicht Eier legen, schreiten dieselben doch bei Mangel einer Königin und Fehlen nachzuchtfähiger Brut zur Ablage parthenogenetisch sich entwickelnder Eier. Man nennt solche Völker 
Die Bedeutung der alternativen Dichotomien in der Ontogenese. 311

bekanntlich afterdrohnenbritig. Aus allem dem geht hervor, daß die Arbeiterinnen nur in den seltensten Ausnahmefällen vollständig oder so gut wie vollständig aus dem Zeugungskreis der Art ausgeschlossen sind. Der Umstand, daß ihre parthenogenetischen Eier bei den Bienen stets, bei den Ameisen gewöhnlich ${ }^{1}$ nur männliche Nachkommen hervorgehen lassen, ist, wie jeder Kundige weiß und wie ich hier deshalb nicht näher zu erläutern braache, kein Hinderungggrund.

Bisher haben wir alternative Dichotomien bericksichtigt, deren beiden Äste insofern gleichwertig sind, als beide, der eine bei diesem, der andere bei jenem Vertreter der betreffenden Spezies unter den gewöhnlichen Lebensbedingungen dieser Spezies zur Ekphcric zu gelangen pflegen, wobei der Ausschlag nach der einen oder der anderen Seite hin durch das Hinzutreten oder Wegbleiben eines bestimmten Originalreizes erzielt werden kann.

Man kann solche Dichotomien als äquilibre bezeichnen und ihnen als nichtäquilibre diejenigen gegentiberstellen, bei denen die beiden Äste richt gleichwertig sind. Die Ekphorie bewegt sich bei letzteren normalerweise nahezu ausschließlich in dem einen Sukzessionsast, während der andere nur noch von wenigen Vertretern der Art und Rasse unter besonderen, in güstigen Fällen von uns kontrollierbaren Verbältnissen durchlaufen wird.

Ich erinnere an das Beispiel, an dem wir in einem fruheren Kapitel (S. 230) die Dicbotomie von Sukzessionen

1 Tanuer, Reichenbach, Wheeler berichten ron Fällen, in denen aus (natuirlich unbefruchteten) Arbeiterinneneiern sowohl Männchen als auch Arbeiterinnen hervorgegangen sind. Diese Frage bedarf noch weiterer Untersuchung. 
individuell erworbener Engramme erläutert haben, an das Beispiel eines in zwei Fassungen gelernten Gedichts. Wenn wir die eine Fassung nach der anderen erlernen und aus irgendeinem Grunde bevorzugen und ausschließlich benutzen, so wird mit der Zeit die zweite Bahn zur Hauptbahn, in die die Ekphorie an der Gablungsstelle selbstverständlich einlenkt. Der andere Ast ist immer noch da, es bedarf aber eines ganz besonderen Anstoßes, um die Ekphorie an der Gablungsstelle in seine Bahn zu drängen. Diesem alten und neuen Aste von Sukzessionen individuell erworbener Engramme entspricht, wenn es sich um ererbte Sukzessionen handelt, ein Ast der bei den entfernteren Vorfahren, den "Atavi « der gangbare gewesen ist, und ein jungerer Ast, der bei den näheren und nächsten Vorfahren gangbar geworden ist. Wir können diesen jüngeren frequentierten Engrammast als den rezenten von dem älteren obsolet gewordenen, aber immer noch vorhandenen als dem atavistischen unterscheiden.

Über den Begriff des Atavismus oder des Ruckschlages im allgemeinen muß ich hier ein paar karze Bemerkungen einschieben. Ich gebe ohne weiteres $\mathrm{zu}, \mathrm{daB}$ es in vielen Fällen schwer, ja unmöglich sein kann, za entscheiden, ob diese oder jene ontogenetische Abnormität - dies Wort ist im weitesten Sinne zu verstehen - als atavistische Erscheinung aufzufassen ist, oder nicht. Vor allem ist dies dann der Fall, wenn die Vorfahrenreihe der Form, um die es sich handelt, nur ungenugend oder gar nicht bekannt ist, im besonderen der Teil der Reihe, der die mutmaßlich atavistische Eigentümlichkeit als normales Charakteristikum besessen haben soll. Der Schluß: diese Abnormität dürte wohl atavistiseher Natur sein, folglich haben äie unbekannten Vor- 
Die Bedeutung der alternativen Dichotomien in der Ontogenese. 313

fahren der die Abnormität aufweisenden Form diesen morphologischen Charakter besessen, ist nicht selten ein trugerischer und fast nie ein völlig beweisbarer. Eine Kritik, die hier ansetzt, hat ihre volle Berechtigung. Nur darf sie nicht tiber das Ziel hinausschießen, und nach einigen billigen Siegen über einige falsche oder nicht genügend begründete Anwendungen des Begriffs diesen Begriff selbst als anfechtbaren, problematischen, als ein veraltetes Schlagwort hinstellen.

Wenn beispielsweise bei hornlosen Rinderrassen, wie dem Galloway- oder Suffolk-Rind ${ }^{1}$, die während der letzten 100 bis 150 Jahre hornlos gewesen sind, die aber nachweislich von hörnertragenden Vorfahren abstammen, gelegentlich gehörnte Kälber geboren werden, deren Hörner oft nur lose anhangen, so fällt dieses Phänomen gewiß restlos unter den Begriff des Atavismus. Dasselbe gilt für den ähnlichen Fall bei der hornlosen Southdown-Schafrasse, bei welcher nicht selten männliche Lämmer mit kleinen Hörnern geboren werden. Solche Hörner wachsen entweder bis zur vollen Größe oder sind in merkwurdiger Weise nur der Haut angeheftet und hängen lose herab, oder fallen ganz ab.

Diese Beispielé von unzweifelhaftem Atarismus ließen sich beliebig vermehren. Um das Prädikat s unzweifelhaft zu verdienen, ist es bei allen erstes Erfordernis, daß man die Vorfahren, deren Eigentumlichkeiten in der betreffenden atavistischen Abnormität wieder zum Vorschein kommen,

1 Die folgenden Beispiele sind sämtlich dem dreizehnten Kapitel von Ch. Darwins sDas Variieren der Tiere und Pflanzen im Zustande der Domestikation = entnominen. Eine interessante kritische Zusammenstellung von Atavismus bei Pflanzen, unter Ausscheidung von unsicheren oder fälschlich dazu gerechneten Fällen, findet man bei de Vries, Die Mutationstheorie, Leipzig 1901, Bd. I, S. 482, Bd. II, S. 374. 
wirklich kennt und nicht bloß hypothetisch konstruiert. In letzterem Falle muß dann auch der Atavismus mehr oder weniger hypothetisch bleiben, er kann aber naturlich durch vergleichend anatomische und entwicklungsgeschichtliche, sowie durch allg emen biologische Argumente sehr wahrscheinlich gemacht werden.

In dem Falle des Wiederanftretens von Hörnern bei einer seit langem hornlos gewordenen Rinder- oder Schafrasse handelt es sich um das Wiedererscheinen eines in den jungeren Generationen verloren gegangenen Charakters. Kann man nun in solchen Fällen auch von einer Dichotomie der Engrammsukzessionen sprechen? $\mathrm{DaB}$ dies korrekterweise geschehen darf, lehrt uns das folgende Schema. In demselben bezeichnen in der kritischen Periode, in der die Anlage von Hörnern eintritt oder unterbleibt, $k, l, m, n$ die Engrammkomplexe als Inbegriffe sämtlicher während der betreffenden Phase vorhandener ererbter Engramme minus der auf die Hornentwicklung bezliglichen Engramme. Diese letzteren drücken wir durch die Engrammsukzession $\alpha, \beta, \gamma, \delta$ aus. Wir erhalten dann folgendes Engrammschema:

$$
k\langle\langle l+\alpha)-(m+\beta)-(n+\gamma)-(o+\delta)-
$$

Wie wir sehen, besteht auch in diesen Fällen eine klar ansgeprägte Dichotomie der Engrammsukzessionen. Wenn dagegen nicht eine plastische oder motorische Errungenschaft einfach aufgegeben wird, sondern nur verändert, zu etwas Neuem umgemodelt wird, nimmt das Schema folgende Gestalt an:

$$
k \begin{aligned}
& (l+\alpha)-(m+\beta)-(n+\gamma)-(o+\delta)- \\
& \left(l+\alpha_{1}\right)-\left(m+\beta_{1}\right)-\left(n+\gamma_{1}\right)-\left(o+\delta_{1}\right)-
\end{aligned}
$$


Die Bedeutung der alternativen Dichotomien in der Ontogenese. 315

Eine Reihe besonderer Fälle kann man als ausgesprochenste Vertreter jener ersterwähnten Gruppe auffassen, bei der es sich um das Wiedererscheinen von Merkmalen bandelt, die in den jüngeren Generationen für gewöhnlich nicht mehr zur Entwicklung gelangen. Es gibt Fialle, in denen ein solcher Entwicklungsstillstand nicht einige wenige Komponenten der Engrammkomplexe, sondern die große Mehrzahl der Komponenten dieser Komplexe betrifft, so daB auf einem gewissen Entwicklungsstadium ein nahezu rollkommener Entwicklungsstillstand eintritt. Auf diesem Stadium verharrt dann, von bloßer Volumenvergrößerung und unbedeutenden sonstigen Veränderungen abgesehen, der Organismus dauernd und wird auch in diesem Zustande geschlechtsreif. Man bezeichnet diese Erscheinung als Neotenie, und da wir gerade auf diesem Gebiet ein gut durchbeobachtetes und lehrreiches Beispiel von Atavismus und seiner experimentellen Hervorrufung besitzen, will ich hierbei etwas länger verweilen.

Wie wir schon oben S. 173 ausführlich auseinandergesetzt haben, werden die weiblichen und männlichen Exemplare der amerikanischen Molchart Amblystoma (Siredon) tigrinum für gewöhnlich im Larvenzustande (als Axolotl) geschlechtsreif und verharren dann dauernd in diesem Zustande. Erst seit den Beobachtungen von Duméril im Akklimatisationsgarten von Paris im Jahre 1865 wissen wir, daß gelegentlich jungere Exernplare ans Land gehen, die Verwandlung vom Kiemenmolch zum kiemenlosen Amblystoma durchmachen und sich in diesem Zustande fortpflanzen können. Vollkommen geklärt wurde der Gegenstand aber erst durch Marie von Chaurins ${ }^{1}$ eingehende Experimentaluntersuchungen,

1 Marie von Chauvin, Zeitschr. f. wissenschaftl. Zoologie, 1875, 1876,1885 . 
auf Grund derer dann Weismann erkannt hat, daß es sich beim Geschlechtsreifwerden im Axolotlstadium um einetypische Neotenie handelt. Wollen wir diese Neotenie auf der Basis unserer bisherigen Untersuchungen als Engrammsukzession ausdrücken, so werden wir sagen: Bedeuten in der folgenden Reihe:

\begin{tabular}{l|c|c|c|c|c|c|c|c|c|c}
\hline Phasen & 1 & 2 & 6 & 3 & 4 & 5 & 7 & 8 & 9 & 10 \\
\hline $\begin{array}{c}\text { Engramm- } \\
\text { komplex }\end{array}$ & $a-$ & $b-$ & $c-\mid$ & $d-$ & $e-$ & $f-$ & $g-$ & $h-$ & $i-$ & $k-$
\end{tabular}

\begin{tabular}{|c|c|c|c|c|c|c|c|c|c|c|}
\hline Phasen & 11 & 12 & 13 & 14 & 15 & 16 & 17 & 18 & 19 & 20 \\
\hline $\left.\begin{array}{c}\text { Engramm- } \\
\text { komplex }\end{array}\right\}$ & $l-$ & $m-$ & $n-$ & $0-$ & $p-$ & $q-$ & $q_{1}-$ & $q_{2}-$ & $q_{3}-$ & $q_{4}-$ \\
\hline
\end{tabular}

die Buchstaben das Totale der ontogenetischen Engrammkomplexe bis zum Abschluß der Verwandlung in die Landform in Phase 16, so sind mit dem Engrammkomplex $q$ dieser Phase sukzessiv nur noch die keine großen Veränderungen mehr in sich schließenden Engrammkomplexe $q_{1}-q_{2}-q_{3}-q_{4}$ assoziiert. Damit diese ganze Engrammreihe aber ekphoriert werde und sich in den entsprechenden plastischen und motorischen Reaktionen manifestieren kann, bedarf es im Lanfe der Phase 10, wie schon oben S. 174 auseinandergesetzt, eines besonderen äußeren Anstoßes: Mangel an Sauerstoff im Wasser, das die Larven bewohnen, so daß sie neben der Kiemen- auch die Lungenatmung zur Anwendung bringen mitssen; wenn dies nicht genügt, direkter $\mathrm{Z}$ wang, zeitweilig außerhalb des Wassers im feuchten Moose oder Schlamm zu verweilen. Unterbleiben diese äußeren Anstöße, so tritt auf Phase 10 keine Ekphorie des Engrammkomplexes $l$ ein ${ }^{1}$, der

1 Wenigstens war dies bei dem gesamten Chauvinschen Material der Fall, soweit es nicht durch äußere auf die Eltern geübte Anstöße bereits erblich engraphisch verändert war. Vgl. oben S. 174. 
Die Bedeutang der alternativen Dichotomien in der Ontogenese. 317

im Engrammkomplex $k$ versinnbildlichte Zustand wird zum permanenten oder annähernd permanenten, was wir durch die Bezeichnungen $k_{1}, k_{2}, k_{3}$ usw. des folgenden Schemas ausdrucken wollen, die nur unbedeutende Veränderungen nach Ekphorie des Engrammkomplexes $k$ andeuten sollen. Wir erhalten also folgendes dichotomische Engrammschema:

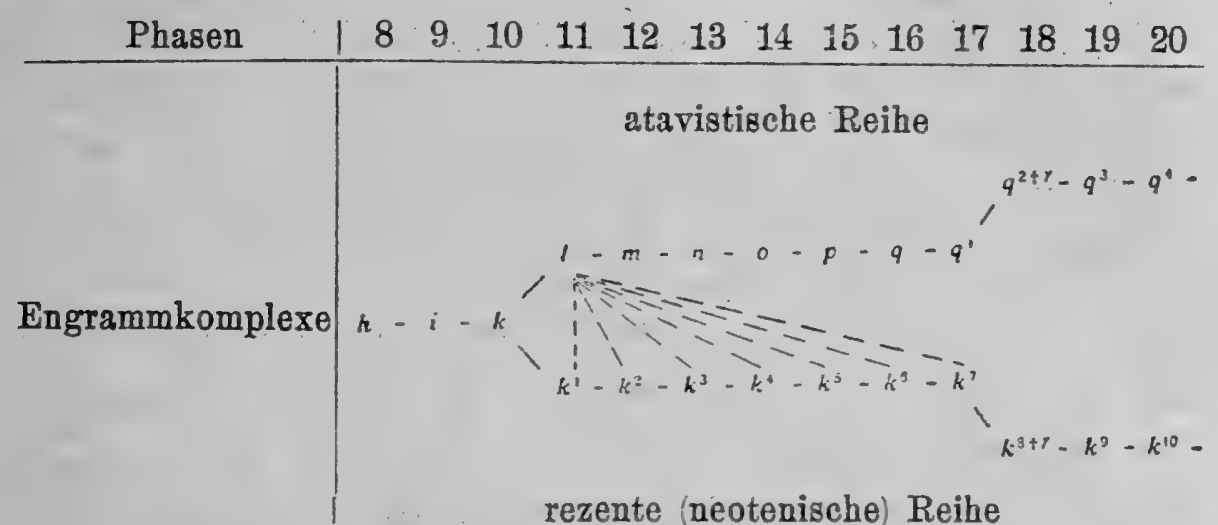

In Phase 10 befindet sich, wie schon hervorgehoben, die Dichotomie, die wir im Schema durch $k<_{l_{1}}^{l-}$ ausgedrückt haben.

Nach den Untersuchungen Frl. F. Chauvins kann aber nach Entscheidung der eigentlichen Alternative bei Hinzutreten geeigneter Originalreize die Ekphorie auch noch während der folgenden Phasen (in unserem Schema 11-17) von der neotenischen zur atavistischen Reihe ubergehen, was wir durch die Verbindungslinien zwischen $l$ einerseits, $k_{1}, k_{2}$, $k_{3}, k_{4}, k_{5}, k_{6}, k_{7}$ andererseits ausgedriuckt haben. Durch sie soll die Beobachtungstatsache zum Ausdruck gebracht werden, đaß auch in diesen älteren Stadien noch die Entwicklung von der neotenischen in die atavistische Bahn einlenken kann, wenn auch mit proportional dem Alter fortschreitender Schwierigkeit. Unmöglich wird dieser Übergang 
erst bei Eintritt der Geschlechtsreife, die wir für beide Reihen in Phase 18 angenommen und durch den Vermerk $+\gamma$ zum Index des Engrammkomplexes $\left(q_{2+\gamma}\right.$ der atavistischen, $k_{8+\gamma}$ der neotenischen Reihe) gekennzeichnet haben. Wir hätten nach den Chauvinschen Beobachtungen auch noch Engrammkomplex $m$ mit $k_{2}-k_{7}, n$ mit $k_{3}-k_{7}$, auch wohl noch 0 mit $k_{4}-k_{7}$ durch ein ähnliches System verbinden können wie $l$ mit $k_{1}-k_{7}$, denn nachdem die Ekphorie in der atavistischen Reihe schon ziemlich weit fortgeschritten ist und sich durch eine Reihe von Reaktionen bereits manifestiert hat, ist gerade beim Amblystoma immer noch der Übergang in die neotenische Bahn möglich, wird aber allerdings immer schwieriger, je weiter die Ekphorie sich bereits vom Eugrammkomplex $l$ entfernt hat:

Die äußerst interessanten Beobachtungen Marie von Chauvins $m a ß$ ich den Leser bitten, im Original ihrer Arbeit von 1885 nachzulesen. In unser Schema habe ich im Interesse der Einfachheit und Klarheit des Drucks diese Komplikation nicht eingetragen und bitte, sie in Gedanken unter Zubilfenahme des Schemas S. 306 zu ergänzen, wo es sich ja um in dieser Beziehung ähnlich liegende Verhältnisse handelt. In der atavistischen Reihe denken wir uns auf Phase 16 nach Ekphorie des Engrammkomplexes $q$ und Eintritt der zugehörigen Reaktionen die Verwandlung in die Landform beendigt. Diese Landform unterscheidet sich bekanntlich nieht nur durch die Abwesenheit der Kiemen und die bedentende Entwicklung der Lunge von der Wasserform, sondern auch durch die Abwesenbeit des Kamms auf Rücken and Schwanz, die Umwandlung des Ruderschwanzes in einen gerundeten Schwanz, die Form des Kopfes und der Beine, die histologische Beschaffenheit und die Zeichnung der Haut. Nach 
Die Bedentung der alternativen Dichotomien in der Ontogenese. 319

Abschluß aller dieser Veränderungen ist eine Rückkehr in die neotenische Form nicht mehr möglich.

Sehr interessant ist auch der von Frl. v. Chauvin beobachtete Umstand, daß, so lange man die Ekphorie der Engrammkomplexe zwischen der atavistischen und neotenischen Reihe sozusagen in der Schwebe hält, so daß anf der einen Seite weder die Engrammkomplexe $q-q_{1}-q_{2}$ noch auf der anderen der Engrammkomplex $k_{8}$ ekphoriert wird, auch der Eintritt der Geschlechtsreife ausbleibt. Offenbar ist die Engrammkomponente, deren Ekphorie sich durch Eintritt der Geschlechtsreife manifestiert, mit diesen am Ende der beiden Sukzessionsäste befindlichen Engrammkomplexen assoziiert and kann erst mit letzteren ekphoriert werden; ihre Ekphorie wird also hintangehalten, wenn der Ablauf der Sukzession gehemmt wird.

Ich habe eben elwähnt, đaß es Frl. v. Chaurin gelungen ist, nicht nur von Phase 11, sondern auch noch von den folgenden Phasen aus durch Zuhilfenahme äußerer Einwirkungen einen Übergang der Ekphorie ron der atavistischen in die neotenische Bahn zu erzielen, also sagen wir einmal: von Engrammkomplex $n$ zu $k_{3}$ (auf einer im Schema nicht eingetragenen Bahn).

Manifest wird für ans dieser Wechsel erstens dadurch, daß der Ablauf in der atavistischen Bahn alsdann zum Stillstand kommt, und zweitens dadurch, daß die bereits eingetretenen, den Engrammkomplexen $l-m-n$ zugehörigen plastischen und motorischen Reaktionen wieder ruckgängig gemacht werden. So wachsen nicht nur die bereits stummelförmig gewordenen Kiemen von neuem ans, sondern die Kämme, deren Schrumpfung bereits begonnen hat, richten sich wieder auf, der Ruderschwanz stellt sich wieder her und 
wird entsprechend gebraucht, was während des Ablaufs der atavistischen Reihe aufgehört hatte. Es werden eben nach Ekphorie des Engrammkomplexes $k_{3}$ die Inkongruenzen wieder beseitigt, die bei der Homophonie zwischen dem damit zur Herrschaft gelangten mnemischen Erregungskomplex $k_{3}$ und dem zunächst noch vorhandenen originalen Erregungskomplex $n$ auftreten müssen.

Beim Amblystoma bedarf es meist einer relativ starken äußeren Einwirkung, um den Ablauf der Ekphorie von der neotenischen nach der atavistischen Seite zu wenden. Ohne solche Einwirkung erfolgt bei der Mehrzahl der Individuen, deren Eltern der neotenischen Reihe angehört haben, einfach der Ablauf in der neotenischen Reihe. Bei denjenigen Salamandrinen dagegen, bei welchen eine neotenische Engrammreihe uberhaupt nicht ansgebildet ist, erfolgt der Ablauf in der gewöhnlichen Engrammsukzession, und werden meist die Engrammkomplexe der Umwandlungsstadien (im Amblystomaschema $l-q)$ ekphoriert, auch wenn die äußeren Reize ansbleiben, deren Wirkung als Originalreize bei den Vorfahren zur Ausbildung der Engramme der Umwandlungsphasen den Ansto $B$ gegeben haben. So machen die Larven von Salamandra maculosa die Umwandlung, wenn auch verspätet, selbst dann durch, wenn man sie in äußerst sauerstoffreichem Wasser hält und durch ein Drahtnetz verhindert, mit der atmosphärischen Luft überhaupt in Berlihrung zu kommen, und die umgewandelten Tiere würden ersticken, wenn man sie nicht aus dieser Situation befreite (vgl. Chauvin a. a. 0. 1885, S. 385).

Die Macht der sukzessiven Assoziation ist hier stärker als die Gegenwart oder Abwesenheit von äußeren Reizen. Bei Tritonen dagegen kann durch besondere Umstände eine ori- 
Die Bedeutung der alternativen Dichotomien in der Ontogenese. 321

ginale, nicht mnemische Neotenie hervorgerufen werden, so daß dieseMolcheim kiementragendenZustande zurGeschlechtsreife gelangen können. Wurde man die Nachkommenschaft solcher Individuen weiterzlichten, so würde man wahrscheinlich imstande sein, die originale Neotenie mit der Zeit in eine mnemische umzuwandeln. $\mathrm{Da}$ dies bisher noch nicht ausgeführt ist, so handelt es sich vorläufig bloß um eine Vermutung. Keine Vermutung, sondern sichere Tatsache ist aber, wie wir oben S. 175 gesehen haben, die Chanvinsche Beobachtung, daß die Abkömmlinge von Amblystomen, die in der atavistischen Reihe geschlechtsreif geworden sind, auf viel geringere äußere Beeinflussung hin in die atavistische Bahn einlenken und viel rascher die atavistische Sukzession durchlaufen als die Abkömmlinge von neotenischen Eltern. Das Auffischen der atavistischen Engrammreihe bei den Eltern bewirkt also eine kräftigere Ausprägung bzw. leichtere Ekphorierbarkeit dieser Engrammsukzession auch bei der Nachkommenschaft.

Zum Schluß wende ich mich noch zu einem erst kürzlich experimentell ermittelten Fall, der dadurch merkwurdig ist, daß das durch äußere Einflüsse bewirkte Einlenken in die ataristische Engrammreihe bei den Eltern insofern eine besonders frappierende Wirkung auf die Nachkommen ausuibt, als zwar noch nicht bei der ersten wohl aber in steigendem Maße bei späteren Generationen Merkmale wieder auftreten, die bei der betreffenden Art und jedenfalls bei der betreffenden Rasse, mit der experimentiert wurde, spurlos verschwunden schienen.

Bekanntlich suchen die meisten unserer Frösche und Kröten, wenn sie sich fortpllanzen wollen, das Wasser auf. Hier umklammert das Männchen sein Weibchen und preBt 
ihm in vielstibndiger Arbeit die Eier vermittels des Drucks der Vordereztremitäten aus dem Körper. Bei ihrem Austritt werden die kleinen, nach hunderten zählenden Eier vom Männchen befruchtet; ihre klebrige Gallerthtille quillt dann im Wasser sofort anf und bildet um jedes einzelne Ei eine kugelige, elastische und nicht mehr klebrige Hulle. Die Eiermassen, zu Klumpen vereinigt oder schnurförmig aneinandergereiht bleiben darauf im Wasser liegen, ohne daB die Eltern sich weiter um sie kummern. Aus den Eiern schlupfen dann nach einiger Zeit die mit Ruderschwanz versehenen, wasserlebenden Larven, die allbekannten Kaulquappen, aus.

Eine bemerkenswerte Ausnahme von dieser Regel macht in Europa eine Krötenart: die eiertragende oder Geburtshelferkröte, Alytes obstetricans. Bei ihr erfolgt Umklammerung, Befruchtung der Eier und Ablage derselben auf dem Lande. Die Zahl der Eier ist eine viel kleinere, dafür sind die einzelnen durch ihren Dotterreichtum ausgezeichnet, groß und hellfarbig. Das Männchen begntigt sich nicht wie bei den ubrigen Kröten damit, dem Weibchen die Eier herauszupressen, sondern es unterstlutzt ihr Heranstreten durch Ziehen und Stemmen mit den Hinterbeinen. Da die Laichschnur nicht ins Wasser geiangt, können die Gallerthullen nicht aufquellen und verlieren deshalb zunächst nichts von ihrer Klebrigkeit, sondern bleiben an den Hinterschenkeln des Männchens haften und wickeln sich infolge der Bewegungen, die das Männchen unausgesetzt mit seinen Beinen vollfuhrt, eng um diese herum. Einige Stunden später verliert die Gallerthtllle ihre Klebrigkeit, sie schrumpft aber unter gleichzeitiger Erhärtung und legt sich eng den Schenkeln des Männchens an, so daß die Laichschntire ron 
Die Bedeatung der alternativen Dichotomien in der Ontogenese. 323

diesem bis zum Ausschlupfen herumgeschleppt werden können, ohne herunterzugleiten. Haften die Laichschnüre beim Anlegen nicht sofort, so bemüht sich das Männchen durch wiederholtes Herumschlingen, ihnen die richtige Lage zu geben.

Es gelang nun Kammerer ${ }^{1}$ auf einem einfachen Wege, durch äußere Beeinflussung die Geburtshelferkiöten zu den ursprtunglicheren Fortptlanzungsgewohnheiten der ubrigen Kröten und Frösche zurlickzufuhren. Hält man nämlich die Tiere in Räumen mit hohen Temperaturen $\left(25-30^{\circ} \mathrm{C}\right)$, so werden sie durch die ungewohnte Hitze veranlaRt, in dem ihnen zur Verfugung stehenden Wassergefäß Kublung zu suchen. Die Geschlechter finden sich dann auch im Wasser, und hier findet die Umklammerung, Befruchtung und Eiablage statt. Unter diesen Umständen aber kommt die Gallerthulle mit dem Wasser in Berthrung, sie quillt auf, verliert sofort ihre Klebrigkeit, und dies macht es dem Männchen unmöglich, die Laichschnur an seinen Hintergliedmaßen zu befestigen. Nach einer Anzahl von vergeblichen Versuchen lassen sie die Männchen im Wasser liegen, wo die Eier ebenfalls zur Entwicklung zu kommen vermögen.

Wiederholt man dies Verfahren während mehrerer Brutperioden, so gewöhnen sich die Tiere allmählich daran, sich im Wasser zu begatten und die Fier dort ohne weitere Versuche, sie um die Schenkel za schlingen, einfach abzulegen; sie tun dies schlieBlich auch dann, wenn man den Zwang der hohen Temperatur ganz fortfallen läßt und die Tiere bei

1 P. Kammerer, Vererbung erzwungenerFortpflanzungsanpassungen. III. Mitt. Die Nachkommen der nicht bratpflegenden Alytes obstetricans. Archiv f. Entwicklungsmechanik, 28. Bd., 1909. 
gewöhnlichen Temperaturen hält. Die Zahl der Eier, die sie ablegen nimmt zu; dafür werden aber die Eier kleiner, dotterärmer und dunkler, den Eiern der gewöhnlichen Frösche und Kröten ähnlicher.

In dem Maße nun als diese Veränderung der Fortpflanzungs- und Bratpflegeinstinkte bei den Eltern feste Norm geworden sind, in dem Maße tritt sie auch bei den Nachkommen der so veränderten Eltern auf. Die geschlechtsreif gewordenen Kinder solcher Eltern suchen bei Eintritt ihrer ersten Brunst auch dann, wenn sie bei gewöhnlichen Temperaturen gehalten werden, das Wasser auf und setzen dort ihre aus zahlreichen, kleinen dunklen Eiern bestehenden Laichschnüre $a b$, ohne den Versuch zu machen, ihnen eine weitere Brutpflege zuteil werden zu lassen. In der ontogenetischen Entwicklung dieser und in steigendem Maße der folgenden Generationen treten außerdem noch Rückschläge in die Ontogenie der primitiveren übrigen Froschlurche auf, auf die wir nicht näher eingehen wollen.

Nur dem in sebr eigentumlicher Weise erfolgenden Auftreten einer scheinbar völlig verschwundenen Merkmalsgruppe beim ausgebildeten Tier wollen wir hier unsere Aufmerksamkeit noch zuwenden. Bekanntlich besitzen die Männchen der im Wasser kopulierenđen Frösche und Kröten eigentümliche sekundäre Geschlechtsmerkmale, die Brunstschwielen, die sich während jeder Brunst vergrößern und so charakteristisch sind, daß ihre Topographie und Konfiguration in der Systematik besondere Verwertung findet. Sie haben funktionell die Bedeutung, dem Männchen das Anklammern im Wasser za ermöglichen und parallel damit geht eine ebenfalls morphologisch sehr deutliche Hypertrophie der Vorderarmmuskulatur beim Männchen, durch die die ganze Glied- 
Die Bedeutung der alternativen Dichotomien in der Ontogenese. 325

maße eine sehr charakteristische einwärts gekrümmte Stellung erhält. Diese sekundären Geschlechtsmerkmale nun fehlen bei den auf dem Lande kopulierenden Alytesmännchen. Wenigstens fehlten sie total bei der nach vielen hunderten von Exemplaren zählenden Rasse, mit der Kammerer experimentiert hat. Zwang nun dieser Forscher in der von uns geschilderten Weise die Tiere zur Kopulation und Eiablage im Wasser, so trat bei der betreffenden Generation, auch wenn dieser Fortpflanzungsmodus bei ihr allmählich zur festen Norm wurde, noch keine Andeutung von Brunstschwielen auf; dasselbe war bei der ersten unter gleichen Verhältnissen weitergezlichteten Nachkommengeneration der Fall. Bei der zweiten Generation dagegen traten am Daumen und Daumenballen bereits Rauhigkeiten auf, und in der dritten waren die brünstigen Männchen sämtlich mit typischen, schwarzgrau verfärbten Schwielen an der Oberseite des Daumeng und am Daumenballen versehen. Ebenso zeigte sich bei ihnen die Hypertrophie der Vorderarmmuskulatur, derzafolge die Extremität mehr nach einwärts gekrümntwird, und die Handflächen näher der Medianlinie auf den Boden aufgestemmt werden.

Hier haben wir also ein besonders schönes und beweisendes Beispiel dafür, daß unter dem Einfluß von durch vier Generationen hindurch fortgesetzten Erregungswirkungen ein obsolet gewordener Ast einer Engrammsukzession wieder befahren, alte morphogene Engramme wieder erweckt, neit ekphoriert werden. Auf morphologischem Gebiet handelt es sich dabei um das Wiederauftreten eines verschwundenen, atavistischen Merkmals, auf dem Instinktgebiet um den Ersatz des rezenten Geburtshelferinstinkts durch den atavistischen der Kopulation und Eiablage im Wasser. 
326 Zwölftes Kapitel. Die Bedeutung der altern. Dichotomien usw.

Zum Schluß mache ich daranf aufmerksam, daß in allen den in diesem Kapitel vorgefubrten Fällen die Entscheidung der ontogenetischen Alternativen, mag es sich dabei nun um Di- oder Polymorphismus, um neotenische oder atavistische Bahn oder endlich um ein sonstiges Einlenken in atavistische Bahnen handeln, lediglich und ausschlieBlich auf Grund äußerer Einflusse erfolgt, die einer genaueren Analyse zugänglich sind. Von diesem Gesichtspunkt habe ich mich bei der Auswahl der Beispiele in diesem Kapitel jetzt im Gegensatz zu den fruheren Auflagen des vorliegenden Buchs leiten lassen. 
Dreizehntes Kapitel.

Der Bau der ontogenetischen Engrammsakzessionen und seine rerschiedenen Entstehnngsweisen.

1. Entstehung von alternativen Dichotomien durch Reizwirkung.

Wenn zu einer bereits vorhandenen Sukzession von Engrammen $c-d-e$ durch eine Reizeinwirkang ein nenes Glied $f$ hinzukommt, so kann dieses sich je nach den besonderen Umständen seiner Entstehung und der Natur der von ihm bedingten Erregungen in zweierlei Art an die bereits vorhandene Reihe angliedern: entweder als weiteres fortsetzendes Glied, so daß ans dem bisherigen Endglied $e$ das vorletzto Glied der einreihig bleibenden Sukzession wird, also $c-d-$ $e \rightarrow f$. Oder aber im Sinne einer dichotomischen Gabelung, dergestalt daß das neue Glied $f$ zu dem bisherigen Endglied $e$ in eine alternative Beziehung $c-d K_{f}^{e}$ tritt. Auf derartige Dichotomien im Gebiet der individuell erworbenen Engramme ohne Rlicksichtnahme auf ihre Erblichkeit sind wir bereits oben im vierten Kapitel eingegangen. Ausfuhrlicher habe ich die alternativen Dichotomien auf dem Gebiet des höheren Gedächtnisses im 18. Kapitel der Mnemischen Empfinäungen untersucht.

Es liegt im Wesen der engraphischen Reizwirkung, daß 
niemals die alten bereits vorhandenen Engramme umgemodelt werden, sondern daß sie als solche unverändert erhalten bleiben, die neuen Engramme aber als Neuschöpfungen gesondert deponiert werden. Diese Eigentümlichkeit der engraphischen Wirkung eröffnet uns erst das richtige Verständnis in die Art der Zusammensetzung des Engrammschatzes und bildet die Grundlage fur das ganze große Gebiet der Alternativen sowohl im Bereich der individuellen Erwerbungen als auch da, wo es sich um erbliche engraphische Wirkungen handelt. Fur die individuell erworbenen Engramme habe ich dies besonders im 15. Kapitel der Mnemischen Empfindungen zum Teil auf experimenteller Basis begrindet.

Was die erblichen Engramme anlangt, so geht diese Tatsache aus solchen Erscheinungen des Atavismus, wie wir sie im zweiten Teil deঞ vorigen Kapitels näher betrachtet haben, anf das unzweideutigste hervor. Die alten, scheinbar spurlos verschwundenen Dispositionen sind immer noch vorhanden, es bedarf nur eines besonderen äußeren Anstoßes, um die alten Engramme wieder aufleben zu lassen, die alten Bahnen wieder wegsam zu machen. Eins der schönsten Beispiele hierfür ist das Wiederauftreten der verschwundenen Brunstschwielen in der dritten und vierten Generation der Geburtshelferkröten, das wir im vorigen Kapitel kennen gelernt haben, ferner das Unterdricken von zur Norm gewordener Neotenie und das Wiedereinschlagen der verlassenen friheren Bahnen auf Grund äußerer Reize.

Auch auf anderen Gebieten lassen sich Riuckschläge oder Atarismen experimentell hervorrufen; so treten sie z. B. unter Umständen gesetzmäBig im Anschluß an Regenerationserscheinungen auf. Ich will hier nur auf einen besonders 
klaren Fall hinweisen, dessen genaue Feststellungen an einer sehr großen Reihe verschiedener Formen wir Przibram ${ }^{1}$ verdanken. Entfernt man bei den kurzschwänzigen Krebsen (Krabben) den dritten Kieferfuß, so treten bei der Regeneration zunächst Bildungen auf, die in jeder Beziehung den Schreitbeinen entsprechen. Erst in Laufe weiterer Häutungen erfolgt die allmähliche Umwandlung in einen typischen Kieferfuß. In der normalen Ontogenese der Krabben kommt ein derartiges schreitbeinähnliches Entwicklungsstadium nicht vor. Hingegen finden sich zeitlebens schreitbeinähnliche Kieferfuße bei der Stammgruppe der kurzschwänzigen Krebse, nämlich den langschwänzigen Krebsen. Ganz analoge atavistische Erscheinungen treten, wie Fritz Muiller bereits im Jahre 1880 festgestellt hat, bei der Regeneration der Scheere und besonders des fünften Beins der Garneele Atyoida zu Tage, auch in diesen Fällen ubrigens in Gestalt von vorübergebenden, bei späteren Häutungen allmählich wieder korrigierten Regenerationsstadien.

Andere Fälle, die man als Zeugnisse für das Auftreten von Atavismen herangezogen hat, sind in ihrer Dentung nicht ebenso einwandsfrei wie die genannten. Bei einigen von ihnen wird sich bei weiterem Eindringen die Richtigkeit dieser Deutung voraussichtlich bestätigen, bei anderen handelt es sich dagegen um handgreifliche Mißgriffe. Die mißbräuchliche Anwendung einer Deutung durch einen beliebigen Forscher in diesem oder jenem Falle erschiittert aber natürlich nicht die Richtigkeit derselben Deutung in einem anderen, ganz anders gelagerten Falle und gibt uns

1 H. Przibram, Experimentelle Studien iiber Regeneration. Archiv f. Entw.-Mech., 11. Bd., 1901. Ferner: Experimental-Zoologie. 2. Regeneration. Leipzig, und Wien 1909, S. 108. 
keineswegs das Recht, tiber einen wohlbegrindeten und durch unzweidentige Experimente gestutzten Begriff zur Tagesordnung tuberzugehen.

Ich will an dieser Stelle hervorheben, daß in allen den bisher besprochenen Fällen das Auftreten des Rlickschlags absolut nichts mit Kreuzung zu tun hat, sondern daß die Ekphorie der alten, normalerweise nicht mehr aktivierten Dispositionen, das Einlenken in die atavistischen Bahnen, lediglich im Anschluß an die Einwirkung ¿ußerer Reize erfolgt.

Bei den sogenannten Kreuzungsrïckschlägen erfolgt dagegen das Einlenken in die alte, sonst nicht mehr aktivierte Entwicklungsbahn im Anschluß und auf Grund einer Krenzung. Neuerdings ist es der so erfolgreich arbeitenden Bastardforschung gelungen, gewisse Zusammenhänge bei dem Auftreten dieser Kreuzungsruckschlage etwas näher zu analysieren. Aber die Grundlage aller dieser Erklärungen beruht doch immer auf der Tatsache des Vorhandenseins von sanzestralen Faktorenci von denen nachgewiesen wird, daß sie einzeln für sich inaktiv sind. Bei der Kreuzung werden eben in einer bestimmten Anzahl von Fullen die besonderen Kombinationen wieder hergestellt, welche jene Faktoren befähigen, zur aktiven Wirksamkeit und damit zur Manifestation zu gelangen.

Übrigens sei daran erinnert, $\mathrm{daB}$ auch bei reingezuchteten, ungekreuzten Formen Ruckschläge auf seit vielen Generationen verlorene oder veränderte Charaktere schon seit langer Zeit festgestellt worden sind2. Besonders wichtig,

1 Vgl. zum Beispiel C. B. Davenport, The new Views about Reversion. Proc. Americ. Philosoph. Soc., Vol. 49, Nr. 196, 1910.

2 Vgl. besonders Ch. Darwin, Das Variieren der Tiere und Pflanzen im Zustande der Domestikation, 2. Bd., 13. Kap., Stuttgart. Ferner H. de Vries, Arten und Varietäten, Berlin 1906, 6. Vorlesung. 
weil besonders genau verfolgt, sind in dieser Beziehung die in Svalöf schon in den neunziger Jahren gemachten Beobachtungen uber spontane atavistische Ruckschläge bei Pedigreestämmen von Hafer nach dem Wildhafer. Neuerdings hat H. Nilsson-Ehle ${ }^{1}$ mit völliger Sicherheit festgestellt, daß die betreffenden Atavisten in keinem Zusammenhang mit Krellzungen entstehen, sondern sich als durchaus spontane* Abänderung darstellen.

Indem wir uns vorbehalten, auf die Frage, ob die hier in Frage kommenden $\gg$ Faktoren stehen oder nicht, im nächsten Kapitel näher einzugehen, wenden wir uns jetzt zunächst zur Unterbrechung der Kreazungsdichotomien.

2. Entstehung ron alternativen Dichotomien durch Krenzung.

Kreuzt man zwei Varietäten oder Rassen, die sich durch ein gut definiertes Merkmal voneinander unterscheiden, etwa eine weißbluhende mit einer rotbluhenden Pflanzenvarietät oder ein rauhaariges mit einem glatthaarigen Meerschweinchen oder eine Geburtshelferkröte aus einer sich auf dem Lande begattenden Rasse mit einer solchen, die sich im Wasser fortpflanzt2, so ist die Alternative gestellt: der Ent-

1 H. Nilsson-Ehle, Über Fälle spontanen Wegfallens eines Hemmungsfaktors beim Hafer. Zeitschr. f. induktive Abstammungs- und Vererbungslehre. 5. Bd., 1. Heft, April 1911.

2 Derartige Merkmale, die sich nach einer Krenzung antagonistisch gegenüberstehen, d. h. die eine Alternative bedingen, bezeichnet man als Allelomorpha. In sehr vielen Fällen ist es möglich, die Verschiedenheit solcher Allelomorphen durch positive Kennzeichnung des einen, negative Kennzeichnung des anderen zum Ausdruck zu bringen: Behaartheit nnd Fehlen der Behaarung (= Glattheit). Buntblütigkeit nnd Fehlen derselben (= Weißblütigkeit); Bänderung bzw. Scheckung und Fehlen derselben (=Einfarbigkeit) usw. Für die Aufstellung von Erb- 
wicklungsbahn welches der beiden Eltern wird das Kind folgen? Oder um uns unserer schon öfter benutzten schematischen Ausdrucksweise zu bedienen: werden bei der durch die Kreuzung bedingten alternativen Dichotomie $d<_{f}^{e}$ die Kinder der Bahn $d-e$ oder $d-f$ folgen?

Ich spreche in den jetzt zunächst folgenden Ausfübrungen nur von den Kindern, die ans einer solchen Kreuzung hervorgehen, also der ersten Generation von Nachkommen oder ersten Filialgeneration, die man in der neueren Vererbungslehre als die $F_{1}$-Generation zu bezeichnen pflegt, während die zweite Nachkommengeneration (Enkel) als $F_{2}$ Generation, die dritte (Urenkel) als $F_{3}$-Generation usw. bezeichnet wird.

Es ist klar, daß bei einer solchen Kreuzung an und fur sich nicht vorhergesagt werden kann, welche von den beiden zu Gebote stehenden Bahnen, ob $d-e$ oder $d-f$, die größten Chancen hat, von den Produkten der Kreuzung, der $\boldsymbol{F}_{1}$ Generation eingeschlagen zu werden. Ja, nach Analogie der von uns oben (S. 229) erwähnten und in den Mnemischen Empfindungen (S. 362) näher behandelten Mischreaktionen auf dem Gebiete des höheren Gedächtnisses ist auch die Möglichkeit gegeben, daß die Alternative tiberhaupt nicht

formeln ergeben sich aus dieser Formulierung, die das Fehlen und Vorhandensein (Batesons Presence-andAbsence-Theorie) zur Ausdrucksform wählt, bedeutende Vereinfachungen, und ist sie deshalb sehr zweckmäßig. Bei einer allgemeinen Darstellung der Kreuzungsphänomene würde aber diese Ausdrucksform entschiedene Übelstïnde haben, sie würde anch zu eng sein und könnte endlich leicht in gewisser Richtung präjudizierend wirken. Ich habe deshalb von ihrer Anwendung Abstand genommen, obwohl es nicht schwer gewesen wäre, die alternativen Dichotomien auch mittels dieser Ausdrucksform darzustellen, was sich ohne weiteres aus einer Betrachtung des ersten Schemas S. 314 ergibt. 
in exklusiver Weise entschieden wird, sondern daß Mischreaktionen stattfinden, aus denen auf eine Ekphorie der Engramme beider divergierender Äste zu schließen ist.

Die Erfahrung lehrt, daß in einer Anzahl von Fällen die eine, in einer anderen die andere Möglichkeit realisiert wird. Wenn die Alternative in dem Sinne entschieden wird, daß die Entwicklung in ausgesprochener Weise, das heißt ausschließlich oder nahezu ausschließlich der einen Bahn folgt, so sagt man im Anschluß an Mendel, daß das durch das Verfolgen dieser Bahn bedingte strukturelle oder funktionelle Merkmal uher das der anderen Bahn entsprechende Merkmal dominiert. Letzteres wird dann als das rezessive bezeichnet.

Häufig kommt es aber auch vor, daß die Alternative gar nicht entschieden, sondern durch einen Kompromil, das heißt Beteiligung beider divergierender Entwicklungsbahnen, beigelegt wird. Das Resultat ist dann das Auftreten einer Mischreaktion, das Erscheinen eines intermediären Merkmals bei allen Vertretern der $F_{1}$-Generation. Nicht immer braucht dasselbe aber gerade intermediär zu sein. Aus der Mischung kann vielmehr auch ein in manchen Beziehungen eigenartiges Produkt hervorgehen. So verhält es sich mit dem metallschimmernden Blau der sogenannten Andalusierhühner, das regelmäßig und ausschließlich bei der Kreuzung eines Vertreters der weißen Varietät dieser Hühner mit einem Vertreter der schwarzen Varietät auftritt. Dagegen ist im genauen Wortsinne intermediär das Merkmal in solchen Fällen, in denen z. B. eine rotblühende und eine weißbluhende Varietät gekreuzt eine rosablühende $F_{1}$-Generation ergeben, wie bei Lychnis and der Wunderblume, Mirabilis Jalapa. 
Zwischen den Extremen einer vollständigen Dominanz, so $\mathrm{daB}$ von dem rezessiven Merkmal auch bei genauester Untersuchung nicht die geringste Spur zu entdecken ist (Beispiele: Dominanz der Buntblutigkeit tiber die Weißbltitigkeit bei Lathyrus und Matthiola, der Haarigkeit uber die Glattheit bei Matthiola) und dem anderen Extrem, dem Auftreten eines genau intermediären Merkmals gibt es alle möglichen Übergänge.

Werfen wir die Frage auf, was bei dieser vollständigen oder teilweisen Entscheidung der Hybridisationsalternative den Ausschlag gibt, so mussen wir gestehen, daß wir daruber vor der Hand noch herzlich wenig wissen. Die Vermutung, daß die phylogenetisch ältere über die phylogenetisch jüngere Bahn eine mehr oder weniger vollkommene Dominanz besitzt, hat sich nicht als der Ausdruck eines gesetzmäßigen Verhaltens bestätigen lassen, weil gar nicht selten auch das Gegenteil vorkommt. Ebensowenig läßt sich als Gesetz aufstellen, daß bei Kreuzungen von Rassen, deren eine ein Merkmal besitzt, das der anderen fehlt, das Vorhandensein stets tiber das Fehlen des Merkmals dominiere.

Im allgemeinen ist die Dominanz, das heißt das völlige oder vorherrschende Überwiegen der einen Bahn da, wo sie bei Hybridisationsalternativen auftritt, insofern eine recht konstante Erscheinung, als sie meist bei sämtlichen Kindern der gekreuzten Eltern in Erscheinung tritt. Doch kommen ausnahmsweise auch Unregelmäßigkeiten in dieser Richtung vor. Licht in dieses Gebiet kann erst durch weitere planvoll darauf gerichtete Experimente gebracht werden.

$\mathrm{Daß}$ es unter Umständen durch änßere Einwirkungen gelingt, die Dominanz nach der einen oder der anderen Richtung hin zu verschieben, haben die Experimente von Tscher- 
mak $^{1}$ mit Getreiderassen, diejenigen von Vernon ${ }^{2}$, Doncaster ${ }^{3}$, Herbst ${ }^{4}$ und Tennent ${ }^{5}$ bei Kreuzang verschiedener Seeigelgattungen, sowie die von Tower ${ }^{6}$ bei Kreuzungen von Kartoffelblattkiefern bewiesen. Obwohl besonders die Arbeiten der drei letztgenannten Autoren Einblicke in die Art dieser Einflusse eröffnen, und die Herbstschen Arbeiten sogar den ersten Schritt tun, ihre Wirkungsweise etwas näher zu analysieren, befinden wir uns hier doch erst an der Eingangspforte der Erkenntnis und mussen es der weiteren Forschung tuberlassen, die Ergebnisse in bestimmter Weise zu formulieren.

Als Resultat unserer bisherigen Betrachtungen ergibt sich, daB in der Generation, die als erstes Produkt einer Kreuzung auftritt (erste Filialgeneration, $F_{1}$ ) eine Kombination der abweichenden Entwicklungsbahnen in Form einer Dichotomie geschaffen ist. Die Entwicklung bei den Vertretern dieser Generation folgt dann entweder ausschließlich der einen Bahn: vollständige Dominanz

oder hauptsächlich der einen Bahn, der Einfluß der anderen macht sich aber doch bemerklich: unvollständige Dominanz

oder sie verläuft unter gleichzeitiger anュähernd gleich starker Aktivierung beider Engrammreihen, so daß eine Misch-

1 E. v. Tschermak, Über Züchtung neuer Getreiderassen mittels künstlicher Kreuzung, II. Mitt. Zeitschr. f. d. landw. Versuchswesen in Österreich, 1906.

2 Archiv f. Entw.-Mech., Bd.. 9, 1900.

3 Philosoph. Transact., Vol. 196, 1903.

4 Vererbungsstudien IV, V, VI. Archiv f. Entw.-Mech., Bd. 22, 1906; Bd. 24, 1907; Bd. 27, 1900.

5 Archir f. Entw.-Mech., Bd. 29, 1910.

${ }^{6}$ Biological Bulletin, Vol. 18, Nr. 6, 1910. 
reaktion, gewöhnlich in Gestalt eines intermediären Merkmals, herauskommt: intermediäre Vererbung.

Dabei ist die Regel, daß die einzelnen Vertreter der $F_{1^{-}}$ Generation unter sich ein gleiches Verhalten zeigen. Diese Übereinstimmung aller Vertreter der $F_{1}$-Generation findet sich fast ausnahmslos in allen den Fällen, in denen die $F_{2^{-}}$ Generation nach den gleich zu besprechenden Mendelschen Regeln spaltet.

Wir wenden uns nun zu dem Schicksal der Kreuzungen in den folgenden Generationen und fassen zunäcbst die Enkel- oder zweite Filialgeneration $F_{2}$ ins Auge. Um eindeutige Resultate zu erhalten, ist es dabei nötig, kein fremdes Element mehr einzumischen, vielmehr strenge Inzucht zu üben und zwar zunächst in der Art, daß zur Erzielung der $F_{2}$-Generation ausschließlich die Produkte der Kreuzung, das heißt die Vertreter der $F_{1}$-Generation verwendet werden. Dies ist der Weg, den bekanntlich vor 50 Jahren Gregor Mendel beschritten hat und auf dem er zu seinen bahnbrechenden Entdeckungen gelangt ist,

Je nachdem in der $F_{1}$-Generation das eine Merkmal tiber das andere dominierte, so daß also bei jedem Vertreter nur dies dominierende Merkmal in Erscheinung trat, oder aber, daB in Abwesenheit einer Dominanz der mittlere Weg beschritten und jeder Vertreter der $F_{1}$-Generation Träger des intermediären Merkmals wurde, je nachdem machen sich in der $F_{2}$-Generation gewisse Unterschiede geltend, die sich bei näherem Zusehen nur als eine verschiedenartige aber leicht zu durchschauende Einkleidung derselben Gesetzmäßigkeit erweisen. Wir betrachten zunächst den ersten Fall, den der vollständigen oder nahezu vollständigen Dominanz des einen Merkmals über das andere und wählen als Bei- 
spiel den klassischen Fall, von dem Mendel seinerzeit ausgegangen ist. Mendel paarte zwei Rassen der Saaterbse, Pisum sativum, und fand, daß wenn die beiden gekreuzten Rassen durch das gut ausgesprochene Merkmal der Gelbsamigkeit und Grinsamigkeit voneinander unterschieden waren, die Gelbsamigkeit über die Grünsamigkeit dominierte, so $\mathrm{da} B$ in der $F_{1}$-Generation bei allen Vertretern Gelbsamigkeit herrschte. In der folgenden, der $F_{2}$-Generation, die in diesem Falle durch Selbstbefruchtung aus der $F_{1-}$ Generation gewonnen wurde, streten nebst den dominierenden Merkmalen auch die rezessiven in ihrer vollen Eigentümlichkeit wieder auf und zwar in dem entschieden ausgesprochenen Durchschnittsrerhältnisse $3: 1$, so daß unter je vier Pflanzen aus dieser Generation drei den dominierenden und eine den rezessiven Charakter erhalten ${ }^{1}$. Was nun die dritte aus der Kreuzung herrorgegangene und durch Selbstbefruchtung weitergezuchtete Generation anlangt, so stellte Mendel von ihr Folgendes fest: Jene Formen, die in der vorigen Generation den rezessiven Charakter haben, variieren in der zweiten Generation in Bezug auf diesen Cbarakter nicht mehr, sie bleiben in ibren Nachkommen kons tant. Anders verhält es sich mit jenen, welche in der ersten Generation das dominierende Merkmal besitzen. Von diesen geben zwei Teile Nachkommen, welche in dem Verhältnisse $3: 1$ das dominierende und rezessive Merkmal an sich tragen, somit genau dasselbe Verhalten zeigen wie die Hybridformen; nur ein Teil bleibt mit dem dominierenden Merkmale konstant $\times$ (a. a. O. S. 14).

1 Gregor Mendel, Versuche über Pflanzen-Hybriden. Verhdl. d. Natnrf. Vereins in Brünn, Bd.10, 1865. Nenausgabe in Ostwalds Klassikern der exakten Wissenschaften, Leipzig 1911. 
Entwerfen wir uns von diesem Verhalten ein Schema, in dem wir das dominierende Merkmal mit $d$ und das rezessive mit $r$ bezeichnen, so zeigt dieses Schema folgende Anordnung einer typisch spaltenden Mendelschen Bastardform.

Kreuzung von $d$ mit $r$ ( $d=$ dominant, $r=$ rezessiv).

Kreuzungsprodukte $F_{1}$-Generation $F_{2}$-Generation $F_{3}$-Generation $F_{4}$-Generation $d^{\prime} d^{\prime} \widehat{d d \vec{d} r} r$.

Nur scheinbar anders liegen die Dinge, wenn es sich um die Kreuzung von Merkmalen handelt, von denen nicht das eine uber das andere dominiert, sondern die in der $F_{1}$ Generation etwas Intermediäres oder auch scheinbar Neues (Andalusierhuhner) ergeben. Kreuzt man z. B. ein weißblühendes Exemplar der Wunderblume Mirabilis Jalapa mit einem rotbltihenden, so erhält man eine $F_{1}$-Generation, deren sämtliche Vertreter rosabluhend sind. Die durch Selbstbefruchtang oder Inzucht aus diesen erzogene $F_{2}$-Generation enthält nun aber neben $1 / 2$ rosabluhenden $1 / 4$ rein weißbluhende und $1 / 4$ rein rotbluhende Vertreter. Jede dieser letzteren beiden Gruppen erhält sich bei Reinzucht konstant, das heißt liefert immer nur wieder rein weiße bzw. rein rote Exemplare. Die ubrig bleibende rosabluhende Hälfte der $F_{2}$-Generation liefert unter sich gepaart in der nächsten, der $F_{3}$-Generation, wiederam $1 / 4$ reinzlichtende weiBbluhende, $1 / 4$ reinziichtende rotbluhende und $1 / 2$ rosabltihende Exemplare. Letztere spalten sich dann in der nächsten Generation nach derselben Regel weiter. Bezeichnen wir die weißbluhenden Exemplare mit $a$, die 
rotbluhenden mit $b$, die intermediären rosa mit $\widehat{a b}$, so erhalten wir folgendes Schema:

Kreuzung von $a$ und $b$.

Kreazungsprodukte $F_{1}$-Generation

$\mathrm{F}_{2}$-Generation

$F_{3}$-Generation

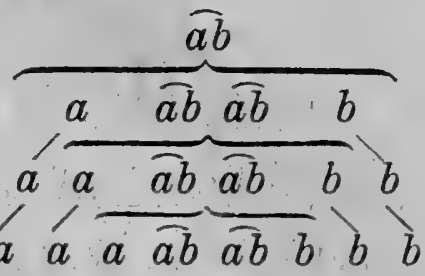

Es ist ohne weitere Erklärung klar, daß dieses Schema unmittelbar in das Schema auf der vorigen Seite ubergeht, sobald es sich um einen Fall handelt, in $\operatorname{dem} a$ über $b$ dominiert, statt mit ihm ein intermediäres Merkmal $\widehat{a b}$ zu ergeben.

Worin ist nun die in beiden Schemata so deutlich hervortretende Abweichung des Verhaltens der $F_{2-}, F_{3}-, F_{4}$ - usw. Generation von dem Verhalten der $F_{1}$-Generation begründet? Dem Scharfblick Gregor Mendels ist es geglückt, die Grundlage zu entdecken, auf der die Erklärung zu fußen hat. Auf diese Grundlage werden auch wir uns stellen. Inwieweit wir dabei in einem Punkt von grundlegender Bedeutung, von der gewöhnlich bedingungslos §ngenommenen Mendelschen Erklärung abweichen oder uns wenigstens dazu durchaus skeptisch stellen, werden wir später noch genauer auszuftihren haben.

Wir gehen am besten von unserem zuletzt erörterten Fall aus und lesen aus dem ihn darstellenden Schema $a b$, da $B$ in der $F_{1}$-Generation in jedem Individun die vereinten Merkmale $\widehat{a b}$ zu Tage treten. In der nächsten, der $\mathrm{F}_{2}$-Generation aber ist das anders: Es treten nur bei der Hälfte der Vertreter dieser Generation beido Merkmale zu Tage. Von der anderen Hälfte zeigt die eine Hälfte $1 / 4$ der ganzen Generation) nur das Merkmal $a$, die andere nur das 
Merkmal $b$. Da nun bei reiner Weiterziichtung dieser letzteren beiden Viertel das jeweils verschwundene Merkmal in der Deszendenz nie wieder auftritt, können wir es als ausgeschaltet ansehen. Auf die Frage, wie wir uns diese *Ausschaltung * vorzustellen haben, werden wir unten noch ausführlich einzugehen haben.

Wann erfolgt nun diese Ausschaltung? Auch dies hat Mendel sofort vollkommen richtig erkannt. Es geschieht bei der Bildung der Keimzellen oder Gameten. Pflanzt man nämlich einen Vertreter der $F_{1}$-Generation auf rein vegetativem Wege (z.B. durch Auslänfer, Brutknospen, Knollen usw.) fort, so kann man dies in der Regel unbegrenzt fortsetzen, ohne daß Spaltungen erfolgen. Spaltungen auf regetativem Wege sollen allerdings zuweilen vorkommen; sie sind aber jedenfalls als recht seltene Ansnahmen anzusehen.

In fast allen den Fällen, in welchen bei Kreuzung von Varietäten aus der $F_{1}$-Generation durch Bildung von Keimzellen oder Gameten eine $F_{2}$-Generation entsteht, erfolgt dagegen regelmäßig in dieser Generation bei $50 \%$ ihrer Vertreter eine Spaltung der Merkmale, und schon die Konstanz dieser Erscheinung weist gegenüber dem Verhalten der $F_{1}$-Generation mit großer Bestimmtheit darauf hin, daß es die Keimzellen sind, auf die dieses abweichende Verhalten zurïckzuführen ist, da aus ihnen ja die $F_{2}$-Generation hervorgeht. Wir haben daher anzunehmen, daß in den Keimzellen die Faktoren, die später das Auftreten der alternativen Merkmale im Laufe der ontogenetischen Entwicklung bestimmen, die determinierenden Faktoren oder Determinanten sich endgtiltig so miteinander abfinden, daß jedesmal nur der eine Faktor seine Wirksamkeit behält, sein Antagonist aber in irgendeiner Weise entweder entfernt oder in 
seiner Wirksamkeit lahm gelegt, kurz als $\$$ Faktor ausgeschaltet wird.

Bezeichnen wir den Faktor, der das Auftreten des Merkmals $a$ determiniert, mit $A$ und den, welcher $b$ determiniert, mit $B$, so können wir sagen: in der Hälfte der Gameten der $F_{1}$-Generation ist Faktor $A$ ansgeschaltet, in der anderen Hälfte Faktor $B$. Diese Zahlenverhältnisse lassen darauf schließen, daß dieser gegenseitigen Ausschaltung die Gesetze der Wahrscheinlichkeitsrechnung zu Grunde liegen. Wenn wir nämlich die naheliegende Annahme machen, daß die beiden Antagonisten, uber deren Schicksal bei der Keimzellenbildung entschieden wird, an und für sich gleiche Gewinncliancen haben, so wird nach den Gesetzen der Wahrscheinlichkeit in der Hälfte der Fälle $A$ über $B$ obsiegen, in der anderen Hälfte $B$ ủber $A$.

Nehmen wir pun diese Keimzellen eines Individuums der $F_{1}$-Generation. (z. B. einer zwittrigen Pflanze) und paaren sie untereinander, was wird dann geschehen? Wie wir sahen, besitzen unter 50 weiblichen Gameten 25 den Faktor $A, 25$ den Faktor $B$ und ebenso verhält es sich mit 50 männlichen Gameten. Nach den Regeln der Wahrscheinlichkeit werden nun in einem Viertel der Fälle männliche Gameten, die den Faktor $A$ besitzen, auf weibliche treffen, bei denen dasselbe der Fall ist: Resultat $A A$. In einem zweiten Viertel der Fälle werden männliche Gameten, die den Falstor $B$ besitzen, auf weibliche mit $B$ treffen: Resultat $B . B$. In einem dritten Viertel der Fälle werden männliche Gameten mit Faktor $A$ auf weibliche mit Faktor $B$ treffen: Resultat $A B$; und im letzten Viertel werden männliche Gameten mit Faktor $B$ auf weibliche mit Faktor $A$ treffen: Resultat $B A$. Berücksichtigen wir nun, daß es in der 
ungeheuren Mehrzahl der Fälle - einige wenige Ausnahmen sind allerdings bekannt - dasselbe ist, ob ein Faktor durch die männliche oder die weibliche Gamete eingefuhrt wird, so ist $A B$ gleichbedeutend mit $B A$. Die Kopulationsprodukte in unserem Beispiel ordnen sich alsdann in folgender Weise zusanmen:

$$
25 A A \quad 25 A B \quad 25 B A \quad 25 B B .
$$

Dies entspricht der oben mitgeteilten Verteilung der Merkmale in der $F_{2}$-Generation

$$
\begin{array}{llll}
a & \overline{a b} & \overline{a b} & b .
\end{array}
$$

Diejenigen Kopulationsprodukte oder Zygoten, die nur den Faktor $A$ als aktiven Faktor besitzen, ergeben naturlich unter sich gepaart nur wieder Individuen mit dem Merkmal $a$; dasselbe gilt für die Zygoten mit dem alleinigen Faktor $B$ in bezug auf das Merkmal $b$. An diesen Kopulationsprodukten ist die Bastardierung, wenigstens in bezug auf die hier ins Auge gefaßten Merkmale ohne einen bleibenden Einfluß vorubergegangen, sie sind in bezug auf diese Merkmale nicht Hybride, nicht gekreazt gepaart, sondern gleich gepaart, oder, wie man dies neuerdings bezeichnet, homozygot:

Da aber, wo Gameten mit Faktor $A$ sich mit Gameten mit Faktor $B$ vereinigt haben, also in den von uns mit $A B$ und $B A$ bezeichneten Fällen, ist eine neue Bastardierung eingetreten, die so entstandenen, in bezug auf diese Merkmale hybriden Zygoten, bezeichnet man als gekreuzt gepaart oder heterozygot. Während die Homozygoten $A A$, unter sich gepaart, rein weiterzlichten, und ebenso die Homozygoten $B B$, tritt, wenn man die Heterozygoten $A B$ und $B A$ unter sich paart, nach den eben dargelegten Gesetzen der 
Entstehnng der ontogenetischen Alternativen.

Wahrscheinlichkeit in der nächsten Generation wiederum Spaltung nach dem Typus

$$
A A \quad A B \quad B A \quad B B
$$

ein, und dies wiederholt sich in jeder neuen Generation, woraus sich ohne weiteres unser Scbema S. 339 ableitet.

Wenden wir dieselbe Betrachtungsweise auf diejenigen Fälle an, in denen gekreuzte antagonistische Merkmale bei den Hybriden (Heterozygoten) nicht ein intermediäres Merkmal ergaben, sondern in denen ein Merkmal (d) über das andere Merkmal $(\boldsymbol{r})$ dominierte und bezeichnen wir die entsprechenden Faktoren oder Determinanten mit $D$ and $R$, so zeigt sich, daß bei Paarung der aus der $F_{1}$-Generation hervorgegangenen Gameten je hundert Kopulationsprodukte sich in folgendem Zahlenverhältnis zusammenordnen:

$$
25 D D \quad 25 D R \quad 25 R D \quad 25 R R \text {. }
$$

Da Merkmal $d$ über Merkmal $r$ dominiert, entspricht dem (vgl. auch oben das Schema S. 338) folgende Merkmalsanordnung:

$$
d \quad d \quad d \quad r
$$

Das heißt also: Von den 75 Individuen mit dem dominanten Merkmal $d$ sind nur $1 / 3$ homozygot $(D D)$, die ubrigen $2 / 3$ aber sind heterozygot $(D R$ und $R D)$. Es besteht also hier im Grunde genau dasselbe Verhältnis von Homozygoten und Heterozygoten wie in den Fällen, in denen keine Dominanz vorhanden ist. Der zunächst so in die Augen fallende Unterschied erklärt sich daraus, daß man bei Dominanz eines Merkmals uber das andere die homozygoten Dominanten $D D$ von den Heterozygoten $D R$ und $R D$ nicht oder doch nur bei genauerer Untersuchung unterscheiden kann.

Bekanntlich rerdanken wir nicht nur die Kenntnis der 
dieser Darstellung zugrunde liegenden Tatsachen, sondern auch ihre geistige Durchdringung dem genialen Scharfblick Gregor Mendels. Seine Entdeckung ist durch alle späteren Untersuchungen nur bestätigt und auf immer weitere Gebiete ausgedehnt worden. Auch ist soviel sicher, daß eine Erklärung der Zahlenverhältnisse bei der Bastardspaltung auf einer anderen als der von Mendel angegebenen Grundlage unmöglich ist. In der zweiten Auflage der Mneme (1908, S. 349-351) habe ich noch die Anschauung vertreten, daß die Zahlenverhältnisse sich zwar ebenfalls auf Grund der Wahrscheinlichkeitarechnung aber im tibrigen noch auf einem anderen Wege erklären ließen als demjenigen, den Mendel eingeschlagen bat. Von dieser Auffassung bin ich aber zurückgekommen.

Nur ein Punkt bleibt noch zweifelhaft, ein Punkt, der die Mendelsche Erklärung des zahlenmäßigen Verhaltens nicht berührt, der aber in seinen letzten Konsequenzen von größter Bedeutung für die Auffassung der Struktur der organischen Substanz sein muB. Es ist die Frage, in welcher Weise bei der Gametenbildung die - Ausschaltung « des einen der antagonistischen Faktoren vor sich geht. Handelt es sich dabei um eine körperliche Trennung der beiden durch die Hybridisation zusammengefuhrten und vereinten Faktoren, um » Segregation *, wie die englisschen und amerikanischen Autoren sich auszudrïcken pflegen, um eine Verteilung dieser Faktoren auf zwei verschiedene Gameten? Oder erfolgt die unzweifelhaft festgestellte Ausschaltung des einen Antagonisten auf eine andere Weise, wird er nicht ausgestoßen, sondern nur in eine Lage versetzt, in der er seine Wirksamkeit einbüßt?

Mendel entschied sich unbedingt für die, wie zugestanden 
werden muß, naheliegende und einfache Annahme einer Segregation der durch die Paarung vereinigten Antagonisten und eine Verteilung auf je zwei verschiedene Keimzellen bei einer Zellteilung, und hierin sind ihm die meisten seiner Nachfolger am so unbedenklicher gefolgt, als manche Schwierigkeiten, die sich dieser Auffassung entgegensetzen, im Laufe der weiteren Untersuchungen in der Tat beseitigt worden sind.

Immerhin bleibt eine Anzahl von großen, nicht gering zu veranschlagenden Schwierigkeiten nach wie vor bestehen. Vor allem gegen eine Konsequenz, die sich unmittelbar aus der Annahme einer solchen Segregation ergibt, lassen sich von verschiedenen Gesichtspnnkten aus die größten Bedenken geltend machen, es ist die Notwendigkeit, dann jeden mendelnden Faktor (Determinante, Gen) als ein morphologisch verbältnismäßig selbständiges, isolierbares Substanzpartikelchen aufzufassen. Mir erscheint jedenfalls diese Konsequenz viel zu weittragend, als daß ich sie als bewiesen hinnehmen könnte, nur weil die Segregation der mendelnden Faktoren bei der Gametenbildung eine einfachere und bequemere Vorstellung ist als die Annahme einer bloßen Labmlegung des einen Antagonisten durch den anderen bei der Gametenbildung.

Vielleicht ist es nur irgendein Lagevorteil, der unter gewöhnlichen Bedingungen nach den Gesetzen der Wabrscheinlichkeit in der einen Hälfte der Fïlle dem einen Antagonisten zufällt, in der anderen dem anderen, der aber unter Umständen, wie die neuesten, mit größter Sorgfalt nach neuen Gesichtspunkten angestellten Versuche Towers ${ }^{1}$ lehren,

1 W. L. Tower, The Determination of Dominance and the Modification of Behaviour in Alternative (Mendelian) Inheritance by Conditions Surrounding or Incident upon the Germ Cells at Fertilization. Biological Bülletin, Vol. XVIII, Nr. 6, 1910. 
durch äußere Einwirkungen in gesetzmäßiger Weise zugunsten des einen oder des anderen Antagonisten verschoben werden kann. Hieraus $m u B$ sich dann eine so starke Verschiebung der Zahlenverhältnisse der Spaltungen gegentuber der gewöhnlichen Mendelspaltung ergeben, wie sie Tower durch seine Variierung der äußeren Bedingungen tatsächlich geglïekt ist. Diese Towerschen Versuche sind die ersten, in denen in systematischer Weise eine Beeinflussung der Bastardiernngsergebnisse durch äußere Einwirkungen unternommen worden ist, und die gewonnenen Resultate sind so unerwartet und merkwtirdig, daß sie zu einer weiteren Bebaunng dieses bisher ganz vernachlässigten Feldes der Untersuchung mahnen und uns warnen in der Segregationsfrage ubereilt Stellung zu nehmen. Führt uns doch die Annahme einer buchstäblichen Segregation zu der Konsequenz, daß der determinierende Faktor des Zwergwuchses, der geringen Fruchtbarkeit, der Empfänglichkeit gegen Rostkrankheit, der Farbenblindheit, des Katarakts, der Kurzfingrigkeit, der Scheckung ${ }^{1}$ usw. in einem isolierbaren Substanzpartikelchen besteht. So nutzlich sich auch solche Abstraktionen als Symbole bei Analyse und Bezeichnung in der Bastardforschung erwiesen haben, so gewagt erscheint mir andererseits eine Personifiziernng der Symbole in Gestalt von morphologisch isolierbaren Einheiten; eine solche bedarf zu ihrer Rechtfertigung weit stärkerer Beweise als es der ist, daß man sich die Ausschaltung bestimmter Potenzen bei

1 Mit Recht sagt in dieser Beziehung Th. H. Morgan in seinem Aufsatz, Chromosomes and Heredity: sThe humor of the situation grows when one thinks that the spotting factor may produce a few white hairs on the tip of the tail or a coat nearly entirely white. To be logical there should be as many spotting factors as there are hairs on the body. American Naturalist, Vol. 44, Nr. 524, 1910. 
der Gametenbildung der Bastarde am einfachsten und bequemsten im Bilde von Segregation und Verteilung der Allelomorphen auf die beiden Teilprodukte einer Zelle bei der Gametenbildung vorstellen kann.

Nur nebenbei möchte ich darauf hinweisen, daB die Ausschaltung des einen Antagonisten bei der Gametenbildung, also das, was man als mendelnde Vererbung bezeichnet, keineswegs ein in allen Fällen von Krenzung auftretender Vorgang zu sein scheint. Das heißt, es erfolgt durchaus nicht nach jeder Art von Kreuzung eine Spaltung der Merkmale bei einem Teile der $F_{2}$-Generation. Es unterbleibt vielmehr eine solche Spaltung in der Regel dann, wenn die beiden gekreuzten Formen in ihrem Gesamtbau so stark voneinander abweichen, daß ein Systematiker sie als verschiedenen Arten oder gar Gattungen, nicht aber verschiedenen Rassen zugehörig klassifizieren würde. Bei der Kreuzung von verschiedenen Arten zeigt sich im Gegensatz zu den Erfahrungen der Rassenkreuzung in der $F_{1}$-Generation in der Regel keine Dominanz, auch gewöhnlich nicht das Auftreten eines einheitlichen intermediären Typus, sondern etwas, was man als Pleiotypie bezeichnet, nämlich das Auftreten von zablreichen Schattierungen der Mischung beider elterlicher Typen. Da Artbastarde in der Regel unfruchtbar sind, ist das Verhalten der späteren $\left(F_{2}, F_{3}\right.$ - usw. $)$ Generationen nur in besonders günstigen Fällen festzustellen. Immerhin ist es in einer Anzahl von Fällen gelungen, fruchtbare Artbastarde zu erhalten, die bei Inzucht in den folgenden Generationen intermediäre Merkmale erkennen ließen, so bei Kreuzungen von Schmetterlingen, ferner von Fäsanen sowie bei Kreuzung von Kaninchen mit Hasen. Die beiden Silberfasanenarten, Euplocamus nycthemerus und E. albo- 
cristatus ergaben bei Kreuzung und Inzucht der Bastarde durch funf Generationen eine konstante Bastardrasse. Bastarde von Hasen und Kaninchen (die sogenannten Leporiden) wurden von Conrad in der landwirtschaftlichen Versuchsstation zu Jena in reiner Inzucht bis in die sechste Generation weitergeztichtet und behielten eine Anzahl von intermediären Merkmalen konstant bei. Eine Anzahl von reinziehenden Artbastarden sind ferner aus dem Pflanzenreich bekannt. Auch diese Fälle bedürfen übrigens wie die erwähnten aus dem Tierreich noch genauer Analyse und durch längere Generationsreihen fortgesetzter Nachprüfung.

In seiner neuesten, oben (S. 345) zitierten Arbeit berichtet Tower unter anderem über Kreuzungsversuche, die er unter verschiedenen äußeren Bedingungen mit drei Arten des Kartoffelblattkäfers Leptinotarsa, L. decemlineata, L. oblongata und L. multitaeniata vorgenommen hat. Auf einer Insel im Balsas-Fluß sich selbst überlassen, ergaben diese 3 Formen schließlich eine neue Bastardrasse, die eine intermediäre Mischung aller ihrer drei Vorfahrentypen zeigte, wobei die oblongata-decemlineata Merkmale die multitaeniata-Merkmale tiberwogen. Diese Form lieB sich rein fortzitchten, obne Spaltungen und Rückschläge zu zeigen; nur traten von Zeit zu Zeit in den Zuchten spontane Variationen auf, die in jeder Beziehung an die Mutationen von Oenothera Lamarckiana in den de Vriesschen Zuchten erinnerten. Unter anderen äußeren Bedingungen entstanden aus der gleichen dreifachen Mischung Bastardrassen, die nur die intermediären Merkmale zweier ihrer Vorfabrenrassen (decemlineata-oblongata bzw. decemlineata-multitaeniata) aufwiesen und sich ebenfalls, von vereinzelten Mutationen abgesehen, konstant weiterztichten ließen. 
Es wird von Vorteil sein, hier zum SchluB eine kurze Zusammenfassung der Ausfuhrungen des letzten Abschnitts dieses Kapitels zu geben. Durch Kreuzung von zwei Individuen, die sich durch ein bestimmtes Merkmal voneinander unterscheiden, werden in der ersten Nachkommengeneration $\left(F_{1}\right)$ Dichotomien der oben gekennzeichneten Art geschaffen. In der Ontogenese dieser $F_{1}$-Generation dominiert dann entweder die eine Entwicklungsbahn uber die andere mehr oder weniger vollständig oder aber es kommen beide zur Geltung und letzterer Kompromiß manifestiert sich in Mischreaktionen, im Auftreten eines intermediären Merkmals oder des Äquiralents eines solchen. Wie die Entscheidung der durch die Dichotomie gestellten Alternative ausfallen wird, hängt hauptsächlich von der spezifischen Beschaffenheit der antagonistischen Bahnen, unter Umständen aber auch, wie neuere Untersuchungen gelehrt haben, von einer Einwirkung äußerer Einflüsse ab.

Bei der Gametenbildung dieser $F_{1}$-Generation wird dann der labile Zustand, in dem sich die Alternative in der $F_{1}$ Generation befindet, in einen stabilen Zustand verwandelt. In der überwiegenden Mehrzahl der Fälle (besonders bei Rassenhybriden) geschieht dies durch Außerbetriebsetzung je eines Astes der Dichotomie, wobei Gewinn- und Verlustchancen für beide konkurrierende Äste an sich gleich sind, weshalb nach den Regeln der Wahrscheinlichkeit in der einen Hälfte der Fälle der eine, in der anderen der andere außer Betrieb gesetzt wird. Durch äußere Einwirkungen läßt sich allerdings dieses Zahlenverhältnis unter Umständen verschieben (Tower), aber normalerweise ist es das herrschende, und daraus erklären sich, wie Mendel gezeigt und die weitere Forschung durchaus bestätigt hat, alle die ein- 
facheren wie die komplizierteren Zahlenverhältnisse der mendelnden (spaltenden) Vererbung.

In sehr viel seltneren Füllen erfolgt bei der Gametenbildung der $F_{1}$-Generation keine Außerbetriebsetzung des einen Astes der Dichotomie, sondern es wird ein Zustand stabilisiert, in dem beide nebeneinander in Wirksamkeit bleiben; was sich durch das konstante und ausschließliche Auftreten der intermediären Merkmale auch in der $F_{2}$-Generation und in allen folgenden Generationen zu erkennen gibt. Diese intermediären Bastardmerkmale lassen sich alsdann konstant weiterzüohten; durch die Kreuzung ist eine reinziehende Bastardform entstanden.

Unentschieden lassen wir die Frage, auf welche Weise bei der mendelnden Vererbung die Außerbetriebsetzung oder Ausschaltung je eines der Antagonisten bei der Gametenbildung vor sich geht. Mendel und die Mehrzahl seiner Nachfolger nehmen hier eine Segregation, eine Trennung und Verteilung der beiden antagonistischen Faktoren auf die zwei Teilungsprodukte der Mutterzellen der Gameten (wahrscheinlich bei der Reduktionsteilung) an. Indessen lassen sich gegen diese scheinbar höchst einfache Auffassung, die notwendigerweise zur Annahme von isolierbaren Substanzpartikelchen als Vertreter der Merkmale in den Gameten fuhren muB, gewichtige Bedenken geltend machen. Einfach ist diese Lösung des Rätsels vor allem nur so lange, als man sich nicht um das ungekeuer komplizierte, aufs feinste abgestimmte und harmonisierte Zusammenwirken jener vermeintlich isolierbaren Substanzpartikelchen kümmert.

Obwohl die Frage nach der Segregation und der sich aus letzterer ergebenden Partikel-Natur der Determinanten an sich von fundamentaler Bedeutung ist, ist es doch im 
Hinblick auf die uns im vorliegenden Buch beschäftigenden Probleme nicht notwendig, sie ausführlich zu erörtern; wir lzönnen ihre Entscheidung ruhig offen lassen. Von unmittelbarer Bedeutung fur uns ist dagegen die Frage nach der Provenienz der Determinanten oder Gene, mit denen die Erblichkeitsforschung arbeitet. Der Erörterung dieser Frage wird das nächste Kapitel gewidmet sein. 


\section{Vierzehntes Kapitel.}

Engraphische Herkunft der determinierenden Faktoren.

Dem Nachweis, daß die jeweilig neu auftretenden Potenzen der Keimzellen als Reizprodukte oder Erregungsresidnen, kurz auf engraphischem Wege entstehen, und daß sie mit den somatischen Engrammen, das heißt denen, die sich im Leben des Individuums dessen übriger reizbarer Substanz aufgeprägt haben, in allen ihren Eigenschaften ubereinstimmen, war ein großer Teil unserer bisherigen Betrachtungen gewidmet. Ich verweise auf die mannigfachen, im Laufe der fruheren Kapitel mitgeteilten Beispiele, denen sich noch zahlreiche andere anreihen ließen, die ich im Stand der Frage zusammengestellt habe, und deren Menge um so bemerkenswerter ist, als die systematische experimentelle Forschung in dieser Richtung erst seit wenigen Jahren begonnen hat. Die Versuche von Chauvin, Kammerer, Standfuß, Fischer, Schröder, Pictet, Tower, Sumner, Przibram, Blaringhem, Klebs, Bordage und vielen Anderen haben in völliger Übereinstimmung za dem Ergebnis gefthrt, daß die neuen Potenzen durch Reiz- bzw. Erregungswirkung entstehen.

Eine andere Frage ist die, ob diese Engramme durch direkte Einwirkung äußerer Reize anf die Keimzellen oder aber auf dem Wege organischer Reizleitung durch Ver- 
mittlung der reizbaren Substanz des tubrigen Körpers (Soma)

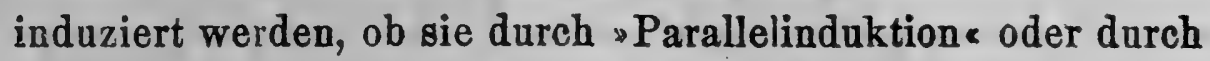
^somatische Induktion * entstehen. Ich habe diese Frage oben im 5. Kapitel (S. 173-183) erörtert, viel eingehender aber in einem besonderen Kapitel meiner Arbeit tuber den Stand der Frage geprift und glaube dort die physikalische und physiologische Undurchführbarkeit der Hypothese von der Parallelinduktion nachgewiesen zu haben. Wie man sich aber auch dazu stellen, welche Art der Induktion man annehmen mag, daß es sich um eine Induktion, um eine Reizwirkung handelt, darüber sind Alle einig, und somit kann liber die Engrammnatur jener neuen Potenzen kein $\mathrm{Z}$ weifel obwalten.

Soweit man solche neuerzeugten Determinanten oder erblichen Engramme daraufhin untersucht hat, was sowohl durch Tower' ${ }^{1}$ als auch durch Kammerer ${ }^{2}$ geschehen ist, hat sich herausgestellt, daß, wenn man ihre Träger mit Individuen kreuzt, die sie nicht besitzen, sie alternativ vererbt werden, daß sie mendelnk, und sich also in dieser Beziehung ebenso verhalten wie diejenigen, die man als historisch gegeben vorfindet und mit denen bei den Kreuzungsexperimenten in der Regel operiert wird. Hier herrscht also vollkommene Übereinstimmung.

$\mathrm{Daß}$ ein Reiz, der die reizbare Substanz eines Organismus trifft und in ihr Erregungen hervorruft, zwar in einer Reihe von Fällen auch die Keimzellen in wirksamer Weise be-

1 W. L. Tower, An Investigation of Evolution in Chrysomelid Beetles of the Genus Leptinotarsa. Carnegie Institution, Washington 1906.

2 P. Kammerer, Vererbung erzwungener Fortptlanzungsanpassungen 3. Mitt. Archiv f. Entwicklungsmechanik, 28. Bd., 1909. Ausführlichere Angaben in dem späteren Aufsatz: Mendelsche Regeln und Vererbung erworbener Eigenschaften, Verhandl. d. naturf, Vereines in Brün, 49. Bd. 1911 . 
einflußt, in ihnen nachweisbare Engramme hinterläßt, in anderen Fällen aber nicht; wurde schon oben (S. 183) ron uns erörtert. Diese scheinbare Launenhaftigkeit einer derartigen Vererbung ist wohl auf verschiedene Ursachen zuruckzuführen. Erstens natürlich auf die Art und die Stärke des angewandten Reizes. Neuerdings ist aber durch Tower noch ein zweiter hier mitsprechender Faktor entdeckt und mit aller wünschenswerten Exaktheit bestimmt worden, der in manchen Fällen von ausschlaggebender Bedeutung ist1. Bei den Kartoffelblattkäfern (Coloradokäfern Leptinotarsa) hat dieser Forscher eine kurzdauernde Periode außerordentlich gesteigerter Reizbarkeit der Keimzellen festgestellt, die man als ihre sensible Periode bezeichnet. Erfolgt während dieser Zeit eine entsprechende Reizung, so kommt es zur Entstehung manifestationsfähiger Engramme; dieselbe Reizung zu einer Zeit angewandt, in der sich die Keimzellen nicht in ihrer sensiblen Periode befinden, erweist sich fuir ihre engraphische Beeinflussung als unwirksam. Es ist naturlich sehr wohl möglich, daß in anderen Fällen bei dem Gelingen einer engraphischen Veränderung der Keinuzellen noch andere Umstände mitsprechen oder auch ausschlaggebend sind. Bisher sind eben blob die ersten Schritte getan, um tiefer in dies Problem einzudringen.

In diesem Zusammenhange will ich auch kurz auf das scheinbar spontane Auftreten von neuen Potenzen eingehen, wie es sich in dem plötzlichen mehr oder weniger

1 In dieser bewunderungswïrdigen auf der vorigen Seite zitierten Arbeit glaubte Tower auch den Beweis gefuhrt zu haben, daß es sich in seinen Fällen nur um Parallelinduktion, nicht um somatische Induktion handeln könne. In meiner Arbeit über den Stand der Frage habe ich gezeigt, $d a ß$ Tower sich in dieser Beziehung im Irrtum befindet, und $\mathrm{da} ß$ seine in so vielen anderen Richtungen entscheidenden Befunde grade liber diesen Punkt nicht das geringste aussagen. 
Engraphische Herkunft der determinierenden Faktoren.

vereinzelten Auftreten ron Sports * (Sprungrariationen, spontane Mutationen) manifestiert. Dieser Erscheinung hat Darwin schon im Beginn seiner deszendenztheoretischen Forschungen ${ }^{1}$ seine Aufmerksamkeit zugewandt, und später hat de Vries in seiner Mutationstheorie ${ }^{2}$ in diesen scheinbar spontanen $\mathrm{Mu}$ tationen, die er besonders bei Oenothera Lamarckiana verfolgt hat, die eigentliche Quelle der Bildung "neuer Arten $z \mathfrak{u}$ finden geglaubt. Wichtige Beiträge in dieser Richtung haben neuerdings 3 die Zuchtexperimente Towers geliefert. Das Rätsel dieser scheinbaren Spontaneität - eine wirkliche Spontaneität gibt es naturlich nicht für den kausal denkenden Naturforscher - wird sich voraussichtlich in einer Anzabl von Fällen auf eine unter bestimmten Umständen auftretende besonders verstärkte Sensibilität der Keimzellen zurückfuibren lassen, die die Keimzellen bestinmter Individuen für engraphische Beeinflussung besonders empfänglich macht, zumal wenn zufällig einmal ein stärkerer Reiz die besonders sensibilisierten Keimzellen trifft. Bastardierungen scheinen in dieser Richtung besondere Prädispositionen zu schaffen, was seinerzeit schon Darwin aus den Erfahrungen der Züchter geschlossen hat. Die neusten Versuche Towers scheinen dies zu bestätigen. Natürlich ist besonders bei solchen Bastardierungen die Möglichkeit nicht aus den Augen zu lassen, daß manche Sprungvariationen nur Neugruppierungen bereits vorhandener Engramme und nichts wirklich neues darstellen, besonders in solchen Fällen, in denen sie regres-

1 Ch. Darwin, Die Fundamente zur Entstehung der Arten. Zwei Essays aus den Jahren 1842 and 1844, herausgegeben von seinem Sohne Francis Darwin. Deutsche Übersetzung, Leipzig 1911.

2 H. de Vries, Die Mutationstheorie, Leipzig 1901-1903.

3 W. L. Tower, The Determination of Dominance, Biological Bulletin, Vol. XVIUI, Nr. 6, 1910. 
siver, atavistischer Natur sind ${ }^{1}$. Es muß der weiteren Forschung uberlassen bleiben, sowohl die reizphysiologischen wie die genotypischen Bedingungen dieser scheinbaren Spontaneitait näher zu analysieren.

Wenn wir von einer Entstehung der Determinanten durch Reizwirkung, also auf engraphischem Wege sprechen, so soll damit keineswegs gesagt sein, daß im konkreten Falle immer dasjenigc, was der Bastardforscher als einzelnen determinierenden Faktor, als einzelnes * Gen in Rechnung setzt, genau einem cinzigen Einzelengramm entspricht. Die neuere Erblichkoitsforschung hat in einer großen Anzahl von Fällen die komplexe Natur dessen nachgewiesen, was man zunächst als einzelne Determinante aufzufassen geneigt ist. Solche komplexen Faktoren sind natirlich nicht als Einzelengramme sondern entweder als Engrammkomplexe (in dem von uns darunter verstandenen Sinne) oder in anderen Fällen auch als zusammenwirkende Engramme verschiedener Herkunft aufzufassen.

Was uns als ein einzelner Reiz erscheint, ist häufig, ja in der Regel bereits ein komplexer energetischer Vorgang. Der scheinbar einheitliche Sonnenstrahl z. B., der unser Gesicht trifft, setzt sich aus chemisch, optisch, thermisch wirksamen Strahlen zusammen, die durch verschiedene Reizpforten aufgenommen gleichzeitig verschiedenartige Erregungen erzeugen und verschiedenartige Engramme hinterlassen. Derselbe Strahl wirkt auch, wie oben (S. 31) ausgefuhrt, verschiedenartig erregend und verschiedenartige Engramme hinterlassend auf die Pflanze, die er trifft. Zieht man junge

$1 \mathrm{H}$. Nilsson-Ehle, Kreuzungsuntersuchungen an-Hafer und Weizen. Lunds Universitets Arsskrift, N. F, Afd. 2, Bd. 5, Nr. 2, Lund 1909, S. 109 (ferner S. 15): 
Mäuse oder Ratten in ungewöhnlich hoher Temperatar auf, wie Sumner ${ }^{1}$ und Przibram ${ }^{2}$ dies getan haben, so wirkt die Wärme in erster Linie auf ihre äußere Haut ein, da die Wärmeregulation dieser Tiere die anderen Organe diesem Einfluß so gut wie ganz entzieht. Die Entfaltung der Haut, ihre Drüsen und vor allem ihre Behaarung verändern sich unter dieser Einwirkung, und daß entsprechende erbliche Engramme in den Keimzellen erzeugt werden, manifestiert sich dadurch, daß die Nachkommen dieser Tiere, auch wenn in normaler Temperatur aufgezogen, die entsprechenden Veränderungen erkennen lassen. Die höhere Temperatur wirkt, außer auf das Organ Haut, auch auf den gesamten Stoffwechsel der Tiere, sie beschleunigt die Entwicklung, erzeugt Frühreife und wirkt hemmend anf die Größenentwicklung der Tiere. Auch die diese Reaktionen bedingenden Erregungen hinterlassen erbliche, in den Keimzellen aufbewahrte Engramme, die entsprechende Veränderungen bei den Nachkommen bedingen. Derselbe thermische Reiz erzeugt also den komplexen Organismus treffend verschiedenartige Erregungen und hinterläßt verschiedenartige erbliche Engramme, die als solche zwar simultan assoziieri sind, bei denen aber die Möglichkeit rorliegt, daß diese Assoziation oder Korrelation durch entsprechend angeordnete Kreuzungen sich wird trennen lassen, wie ja die Kreuzung sich in vielen Fällen als Mittel erwiesen hat, Korrelationen zu brechen. Wir kommen darauf unten noch einmal zuriuck.

1 F. B. Sumner, An experimental Study of Somatic Modifications and their Reappearance in the Offspring. Archiv f. Entwicklungsmechanik, 30. Bd., II. Teil, 1910.

2 H. Przibram, Versuche an Hitzeratten. Verhdlg. d. Ges. deutscher Naturforscher und Ärzte. Versammlung Salzburg 1909. 
$\mathrm{Ob}$ dies auch in dem eben besprochenen Falle gelingen wird, $\mathrm{muß}$ durch weitere Untersuchungen festgestellt werden.

Andererseits können aber auch Faktoren ganz verschiedener Herkunft (Engramme, die zu ganz verschiedenen Zeiten im Individuum oder in der Generationsreihe induziert worden sind, also nicht in unserem Sinne als Engrammkomplexe bezeichnet werden durfen) Merkmale bedingen, die durchaus einheitlicher Natur zu sein scheinen, für die sich aber - besonders auf dem Wege der Analyse durch Kreuzungen - nachweisen läßt, daß sie durch das Zusammenwirken von verschiedenen determinierenden Faktoren zustande kommen. Ich möchte hier besonders auf eine neuere Errungenschaft der Erblichkeitsforschung eingehen, weil sie gewisse Eigentümlichkeiten der erblichen determinierenden Faktoren aufgedeckt hat, die in frappierender Weise denen entsprechen, die ich für die individuell erworbenen Engramme festgestellt habe.

Ich habe schon oben (S. 231) darauf hingewiesen und habe dies in den Mnemischen Empfindungen (S. 270, 280) noch genauer ausgeführt, daß, wenn der Reiz, der ein Engramm erzengt hat, später noch einmal auf das Individuum einwirkt, nicht das alte bereits vorhandene Engramm verstärkt, sondern daß ein neues gesondertes und isoliert ekphorierbares Engramm gleicher Art aber in anderer Determination ${ }^{1}$ geschaffen wird. Werden zwei (oder mebr) derartige im wesentlichen gleiche aber gesonderte Engramme ekphoriert, so erfolgt Homophonie der entsprechenden mnemischen Erregungen. Manifestieren sich diese homophonen Erregungen durch Empfindungsreaktionen, so zeigt sich die aus der Homophonie resultierende Empfindung nicht sowohl 1 Vgl. Mnemische Empfindungen S. 281. 
in ihrer Intensität (im engeren Sinne) als in ihrer Vividität verstärkt.

Was uns hier besonders interessiert, ist der Umstand, $\mathrm{daB}$ in einem Individuum durch Wiederholung desselben Reizes eine größere Anzahl qualitativ im wesentlichen gleicher Engramme erzeugt wird, die nicht miteinander verschmelzen sondern dauernd gesondert bleiben, wenn sie auch eine gemeinschaftliche (homophone) Wirksamkeit entfalten können.

Wie nun Nilsson-Ehle ${ }^{1}$ neuerdings in seinen außerordentlich interessanten Kreuzungsuntersuchungen an Hafer und Weizen nachgewiesen hat, verdankt in vielen Fällen ein Merkmal der Kooperation einer größeren Anzahl yon qualitativ gleichen Determinanten oder $\gg$ Einheiten $<$ seine Entwicklung. So argaben sich aus seinen Untersuchungen (S. 66) - fur die braune Ährenfarbe, ebenso wie für die schwarze Spelzenfarbe beim Hafer mehrere Einheiten (oder wenigstens mehr als eine), die auch hier qualitativ voneinander nicht unterschieden werdèn können*. Ferner zeigte er (S. 71) - daB die rote Kornfarbedes schwedischen Sammetweizens durch drei voneinander unabhängige und je fur sich selbständigspaltende Einheiten bedingt ist, und daB jede einzelne von diesen Einheiten imstande ist, für sich allein die rote Farbe zu bewirken.* >Mit Sicherheit kann behauptet werden, daß die Differenzen in der äuBerlich sichtbaren Wirkung der verschiedenen Einheiten fur die rote Kornfarbe ganz unbeträchtlich sind, und $d a B j e d e n f a l l s$ nicht von einer qualitativen Verschiedenheit derselben die Rede sein kann, ebenso wie bei der schwar-

$1 \mathrm{H}$. Nilsson-Ehle. Kreazungsuntersuchungen an Hafer und Weizen, Lands Universitets Ärsskrift, N. F. Afd. 2, Bd. 5, Nr. 2, Lund 1909. 
zen Spelzenfarbe des Hafers oder bei der Äbrenfarbe des Weizens. Die Einheiten bewirken nur etwas verschieden tiefe rote Farbe, nichts mehre (S. 72). Das Gleiche gilt für andere Merkmale, wie Rispen- und Ährentypus, ferner für das Ligulamerkmal beim Hafer: Die beiden unabhängigen Ligulaeinheiten der Sorte 0353 bewirken also of fenbarkaum verschiedene Beschaffenheit der Ligula, und aus ihrer äußeren Wirkung kann man daher durchaus nicht ersehen, $d a B$ sie verschiedene Einheiten darstellen * (S. 89).

Nielsson-Ehle hat in seiner Arbeit gezeigt, wie wichtige deszendenztheoretische Konsequenzen sich aus diesem eigentümlichen Verhalten ergeben, wie sich darauf sowohl das Auftreten gewisser Sprungvariationen als auch das von erblichen $A b$ s tufungen gewisser Eigenschaften bei Kreuzungen zurïckführen läßt. Es ist nicht unmöglich, daß sich auch manche Fälle von anscheinend konstanter intermediärer Vererbung von diesen Gesichtspunkten aus erklären lassen ${ }^{1}$. Ein sicherer Beweis hierfur ist aber bisher noch nicht erbracht.

Was uns aber in dem uns jetzt beschäftigenden Zusammenhang besonders interessiert, ist der sichere Nachweis des Nebeneinanderbestehens der gleichen bzw. in ihrer Manifestation gleichen Determinanten in demselben Individuum. Hier ist also Nilsson-Ehle durch Kreuzngsversuche in bezug a af die erblichen Faktoren zu genaudemselben Ergebnis gekommen, za dem ich in bezug

1 Vgl. z. B. den Versuch von A. Lang, die Erblichkeitsverhältnisse der Ohrenlïnge der Kaninchen und das Problem der intermediären Vererbung und Bildung konstanter Bastardrassen auf diese Weise zu erklären. Zeitschr. f. induktive Abstammungs- und Vererbungslehre, Bd. IV, Heft 1, 1910. 
auf die individnell erworbenen Engramme auf einem ganz anderen Wege gelangt bin: das anvermischte Nebeneinanderbestehen gesonderter aberqualitativ im wesentlichen gleicher Potenzen, deren jedes fur sich bei Ekphorie die betreffende Reaktion hervorzarufen imstande ist, darch deren homophones Zusammenwirken aber andererseits unter Umständen eine gewisse Steigerung der Wirkung bewerks telligt. wird.

In diesem wie in allen anderen Punkten steht die von uns in diesem Buche durchgefuhrte Betrachtungsweise in keiner Weise in Widerspruch mit den Ergebnissen der Variations- und Bastardforschung, sie liefert nur eine von ganz anderen Ausgangspunkten aus gewcnnene Ergänzung derselben. Die Fortschritte, die wir diesen modernen Forschungszweigen verdanken, sind außerordentlich groß. Sie sind durch eine auf biologischem Gebiet sonst kaum zu erzielende zahlenmäßige Exaktheit ausgezeichnet, was das Verfolgen der von ihnen eingeschlagenen Wege geradezu zu einem ästhetischen Genuß macht. Dabei darf man aber nicht aus den Angen verlieren, daß diese Forschung sich damit begnugt, mit ihren determinierenden Faktoren oder Genen als mit gegebenen Größen zu rechnen, mit Symbolen, die man aus den Merkmalen abstrahiert, und die man nicht nur als solche sondern auch mit ihrer wunderbaren Fähigkeit, jederzeit zur rechten Zeit und am rechten Ort das Vorgeschriebene zu tun, als gegeben hinnimmt.

Daß die Variations- und Bastardforschung so vorgegangen ist, war methodisch das einzig Richtige und hat dazu gefuhrt, gewisse Probleme bis zu einem hohen Grad der Vollendung zu lösen. Unberechtigt aber wåre es, unter Nicht- 
beachtnng dieser im engeren Rahmen voll berechtigten Einseitigkeit, in den Schlußfolgerungen die der Bastardforschung hierdurch gesteckten Grenzen zu uberschreiten. Dies aber geschieht, wenn man, ohne sich um die physiologische Frage zu ktummern, wie denn nun die sdeterminierenden Faktoren* ihre Aufgabe lösen, wie sie funktionieren, ganz bestimmte Schltisse auf ihre speziellere Beschaffenheit und ihre Verbindungen bzw. Nichtverbindungen zieht, Schlisse, deren Grundlage lediglich darauf beruht, daß man dergestalt unter gewissen sehr einfachen aber in dieser Form schwer lich zutreffenden Voraussetzungen die Spaltungsphänomene an bequemsten darzustellen vermag. Bei diesen Voraussetzungen bleibt das ganze Tatsachengebiet der Entwicklungsmechanik, der Regulations- und Regenerationserscheinungen, der Periodizität, kurz der Kooperation der Determinanten unberlicksichtigt.

In dieser Beziehung geht meiner Ansicht nach schon der Schluß zu weit, daß die Determinanten isolierbare Substanzpartikelchen sind. Immerhin ist die Entscheidung dieser Frage vorderhand zu schwierig, um ihr hier näher zu treten, und obwohl ich mich persönlich ${ }^{1}$ zu einer ganz anderen Ansicht bekenne, ziehe ich es, wie oben mehrfach betont, vor, sie hier offen zu lassen.

1 Ich stehe hier ganz auf dem Standpunkt von W. Roux, der (Archiv f. Entw.-Mech., 25. Bd., 1908, S. 723) sagt: >Da nach meiner Auffassung die Ontogenese vielmal mehr Epigenese als Evolution ist, so entsprechen die Determinationsfaktoren meiner Distinktion keineswegs den auf evolutionistischer Basis erschlossenen ,Determinanten ${ }^{6}$ A. Weismanns, welche diskrete körperliche Gebilde darstellen, während die Determinationsfaktoren der Epigenesis z. B. auch in bestimmten Konfigurationen von Faktoren bestehen liönnen s Eine gleiche Anschaung vertritt auch 0. Hertwig, vgl. z. B. seine Schrift: Der Kampf um Kernfragen von Entwicklungs- und Vererbungslehre, Jena 1909, S. 15 . 
Ganz unberechtigt erscheint mir aber der noch viel weitergehende, von manchen Biologen gezogene Schluß, daß über diese immerhin diskutable Isolierbarkeit der Einzelstruktur hinaus, welche man als determinierenden Faktor bezeichnet, ein Mangel des Zusammenhanges dieser Strukturen unter sich bewiesen sei, daß mit einem Wort anzunehmen sei, jene Faktoren lägen in der Erbmasse unverbunden und ohne bestimmte Anordnung nebeneinander. $\mathrm{Zu}$ diesem Schluß werden die betreffenden Forscher durch die Tatsache gefuhrt, daß man Kreuzungskorrelationen von Merkmalen zu brechen, scheinbar unlöslich miteinander verbundene Merkmale zu trennen vermag. Man könnte hiergegen zunächst einwenden, daß es Korrelationen gibt, dereu Lösung durch Kreuzung bisher noch nicht geglückt ist. Ich erinnere an die merkwürdigen Erscheinuugen der sogenannten Gametenkupplung (gametic coupling); umgekehrt gibt es auch Fälle, in denen sich zwei Faktoren miteinander durch Kreuzung uicht vereinigen lassen, sich sozusagen gegenseitig abstoßen (spurious allelomorphism) ${ }^{1}$. Es erscheint jedoch nicht ausgeschlossen, daß solche Fälle noch ihre besondere Erklärung finden. So hat z. B. Nilsson-Ehle ganz kürzlich gezeigt ${ }^{2}$, daß unter Umständen ein Hemmungsfaktor die Wirkung mehrereranderer selbständiger Faktoren auf einmal anfhebt. Es werden dadureh Merkmale korrelativ verbunden, die von Faktoren bedingt werden, welche als solche nicht in besonderer Weise verbunden zu sein brauchen.

Aber selbst gesetzt den durchaus nicht unwahrscheinlichen, wiewohl bisher noch nicht feststehenden Fall, es sei

1 W. Bateson, Mendels Principles of Heredity, Cambridge 1909 Kap. IX.

2 H. Nilsson-Ehle. Über Fialle spontanen Wegfallens eines Hemmungsfaktors beim Hafer. Zeitschr. f. induktive Abstammungs- und Vererbungslehre, 5. Bd., I. Heft, 1911. 
möglich, mittels der Kreuzung jeden Faktor von jedem anderen zu trennen; damit wäre noch keineswegs eine von vornherẹin bestehende Zusammenhangslosigkeit dieser Elemente bewiesen. Man hat in letzter Zeit häufig die Analysen der Bastardforscher mit den Analysen der Chemiker verglichen, ein Vergleich, gegen den sich manches einwenden läßt. Aber seine Berechtigung angenommen, auch in einer chemischen Verbindung wird doch eine ganz bestimmte Anordnung der betreffenden Einheiten und eine ausgesprochene Verbindang im Bilde von fester und weniger fest zusammengefügten subordinierten Komplexen angenommen - ich erinnere z. B. an die Bindungen im Benzolring und den eingetretenen Seitenketten - und niemandem fällt es ein, aus der Möglichkeit der Trennung auf ein zusammenhangloses Nebeneinanderliegen der chemischen Einbeiten zu schließen.

Die durch die Bastardierungen bewerkstelligten Spaltungen sind meiner Ansicht nach etwas wesentlich anderes als die Trenuungen der chemischen Analyse. Aber selbst wenn ich mich in dieser Ansicht durchaus irren sollte, wiirde daraus doch keineswegs folgern, daß kein verschiedenartig abgestufter, bestimmt geordneter Zusammenhang der genetischen Determinanten * vorliegt, da ein solcher in der dann zu Recht bestehenden chemischen Parallele ja allgemein angenommen wird, und da, was ausschlaggebender ist, die physiologischen Tatsachen der Entwicklung, Regulation, Regeneration, Periodizität ihn unbedingt erfordern.

Die individuell erworbenen Engramme fanden wir ebenfalls in einer ganz bestimmten Zusammenordnung, die sich bei ihrer Ekphorie in den Erscheinungen der simultanen und sukzessiven Assoziation manifestiert. Wir haben nun gesehen, 
daß die simultanen Engrammkomplexe zwar ein zusammenhängendes Ganzes bilden, daß man aber dennoch imstande ist, mit Hilfe der einzelnen Komponenten neue Kombinationen dieser Komplexe herzustellen. Ich habe dies oben (S. 147) als $\gg$ Assoziation der Komponenten verschiedener Engrammschichten * bezeichnet und babe den Gegenstand in den Mnemischen Empfindungen S. 165-171 ausführlicher behandelt. Die Art und Weise, wie hierbei im individuellen Leben die Komponenten der Engrammkomplexe zur Erzengung neuer Komplexe in anderer Kombination verwendet werden, ist allerdings eine durchaus andere wie diejenige, um die es sich bei der Neukombination der Komponenten bei den Bastardkreuzungen handelt. Das tertium comparationis liegt aber darin, daß in beiden Fällen eine Lösung der ursprïnglichen Zusammenhänge und eine neue Kombination der Komponenten möglich ist, und $d a \beta$ in beiden Fällen aus der Tatsache dieser Lösung in keiner Weise der Schluß gezogen werden darf, daß von vorn herein keine gesetzmäßige Zusammenordnung der Komponenten vorgelegen habe.

Die Frage nach der Verbindung der erblich ubermittelten "Faktoren «, das Problem ihrer Kooperation, der zeitlichen und örtlichen Lokaliwationen ihrer Leistungen ist ein solches, das sich mit den Methoden der Variations- und Bastardforschung allein nicht lösen läßt. Mit Recht sagt Tower ${ }^{1:}$; to say that together they direct the development of one part after another in orderly succession puts upon these determiners a burden of great responsibility, almost intelligence, and makes necessary some coordinating mechanism behind it all.

1 W. L. Tower, The Determination of Dominance, Biological Bulletin, Vol. XVIII, Nr. 6, 1910, S. 324. 
Geht man, wie wir es getan haben, und wie es für viele Fälle experimentell bewiesen ist, von der engraphischen Entstehung der Determinanten* aus und nimmt man die Gesetzmäßigkeiten, die wir in unseren beiden mnemischen Hauptsätzen ausgedrïckt haben, zur Grundlage aller der durch die Ekphorie der Engramme bedingten Abläufe, indem man das Tatsachenmaterial, das man tiber die Eigenschaften sowohl der erblichen als auch der individuell erworbenen Engramme besitzt, unter gemeinsamen Gesichtspunkten zusammenfaßt, so erhält man einen Einblick in den $*$ koordinierenden Mechanismus«, von dem Tower spricht, und man tut es, ohne den streng physiologischen Boden zu verlassen und ohne den Determinanten etwas wie Intelligenz zuschreiben zu missen. Dieses unser Vorgehen liefert also die notwendige Ergänzung zu demjenigen der zunächst ganz andere Ziele verfolgenden Variations- und Bastardforschung, indem es die räumliche und zeitliche Ordnung der ontogenetischen Abläufe aus einer allgemeineren Gesetzmäßigkeit ableitet, welche mit der Entstehung und dem Wesen der engraphisch erzeugten Determinanten zusammenhängt. Damit schlägt es eine Brücke vom Forschungsgebiet der Variations- und Bastardierungslebre zu demjenigen der Entwicklungsphysiologie, und da es das, was die Wirksamkeit der determinierenden Faktoren beherrscht, in einer rein physiologischen Gesetzmäßigkeit, einem koordinierenden Mechanismus findet, sind seine Wege ausgesprochen mechanistische und seine Ergebnisse machen die Zuhilfenahme irgendeines vitalistischen Prinzips tiberflüssig. 


\section{Fünfzehntes Kapitel.}

\section{Die proportionale Veränderbarkeit der mnemischen Erregungen.}

In dem Kapitel über die mnemische Homophonie haben wir ausgefuhrt, daß der mnemische Erregungszustand eine Wiederholung des originalen in allen seinen Wertverhältnissen ist. Aber, so wollen wir jetzt betonen, nur in seinen WertVerhältnissen, nicht in seinen absoluten Werten. Je nach dem energetischen Zustand, der zur Zeit der Wiederholung herrscht, kann die Intensität der mnemischen Erregung oder Sukzession von Erregungen eine schwächere oder auch eine stärkere sein als diejenige ihrer originalen Schöpferin es war. Und ferner kann aus demselben Grunde oder unter dem Einfluß neuer Originalreize der Ablauf einer Sukzession von mnemischen Erregungen in einem absolut rascheren oder langsameren Tempo erfolgen, als ehemals der Ablauf der Originalerregungen erfolgte. Nur wird immer das Verhältnis der Zeitfolge, kurz gesagt der Originalrhythmus, in der mnemischen Wiederholung erhalten bleiben.

Findet durch Änderung der inneren oder äußeren energetischen Situation zur Zeit der Reproduktion eine proportionale Veränderung der mnemischen Erregungen statt, so kann diese Verïnderung alle Werte betreffen, die sich in quantitativ verschiedenen Reaktionen ausdrïcken können. 
Gehen wir von Bewußtseinsreaktionen aus, so weiß jeder, daß er die räumliche Projektion seiner mnemischen Erregungen in jeden beliebigen Rahmen einspannen kann. Das Engramm jedes räumlichen Gebildes kann um ein Vielfaches vergrößert oder verkleinert ekphoriert werden, je nach der Natur des ekphorischen Einflusses oder einer eventuellen homophonen Originalerregung oder endlich je nach dem Mitwirken begleitender Assoziationen. Ein ktinstlerisch Veranlagter kann dies auch in jedem beliebigen Falle durch objektive Reaktionen einem Dritten manifestieren, indem er das proportional veränderte Erinnerungsbild wie einen originalen Anblick in den veränderten Dimensionen, aber mit vollkommener Treue der Proportionen zeichnerisch oder plastisch reproduziert. Aber auch bei Nichtkunstlern gelingt dieser objektive Nachweis. Zwischen engeren Linien schreiben die meisten Menschen ganz unbewuBt kleiner als zwischen weiten, tuberhaupt kleiner, als sie es fur gewöbnlich tnn, wobei jeder Buchstabe das korrekt in allen seinen Proportionen verkleinerte Abbild des furr den betreffenden Menschen normalen Schriftzeichens ist. Proportionale Verkleinerung oder Vergrößerung der Handschrift kann auch als vorwiegend motorische Reaktion beim Schreiben mit geschlossenen Augen erfolgen.

Ebenso vermag man eine Sukzession von mnemischen Erregungen in viel langsamerem oder in viel rascherem Tempo ablaufen zu lassen, als bei früheren Gelegenheiten die Folge der Originalerregungen ablief, wobei aber die urspringliche Proportion in der Aufeinanderfolge der Erregungen gewahrt bleibt. Man denke an ein Musikstuck, das man unter dem Einfluß eines den Takt Schlagenden oder eines Mitsängers oder der Klavierbegleitung oder der durch Alkoholgenuß ge- 
Die proportionale Veränderbarkeit der mnem. Erregungen. 369

steigerten Stimmung - noch vieles andere ließe sich heranziehen ${ }^{1}$ - bewußt oder unbervußt in einem viel lebhafteren Tempo singt, als man es je zuror getan hat ${ }^{2}$.

Die letzten beiden Fälle sind besonders auch dafür charakteristisch, daß die proportionalen Veränderungen der mnemischen Prozesse von Bewnßtseinsreaktionen begleitet sein können, es aber durchaus nicht zu sein brauchen. Ebenso ist es durchaus nicht eine Eigentümlichkeit des im individuellen Leben erworbenen Engramms, daß seine mnemische Erregung durch die energetische Situation zur Zeit der Ekphorie proportional verändert werden kaun, bzw. in einer proportional veränderten Weise wirkt. Wir begegnen vielmehr derselben Eigentlimlichkeit auch da, wo es sich um ererbte Engramme handelt, und zwar in besonders eklatanter Weise.

Ebenso wie das Tempo eines Musiksticks durch die oben aufgezählten Einflisse, vermag man auch das Tempo der ontogenetischen Abläufe unter Wahrung des oft äußerstkomplizierten Rhythmus, also proportional, durch Herabsetzung oder Steigerung der Temperatur zu retardieren und akzelerieren. Ist doch das Tempo der morphogenetischen Abläufe z. B. beim Froschei ein mehr als viermal so rasches, wenn der Ablauf bei $24^{\circ} \mathrm{C}$ und nicht bei $10^{\circ} \mathrm{C}$ vor sich geht. Und doch ist in beiden Fällen der Rhythmus der Abläufe ganz derselbe. Oder vermindert man bei einem sich entwickelnden Organismus

1 Im Fieberzustand träamen wir leicht von riesenhaft vergrößerten Gesichtern.

2 Ausfubrlicher bin ich auf diese Tatsachen, soweit sie sich im Empfindungsgebiet manifestieren, in den Mnemischen Empfindungen (13. Kap. S. 247-257) eingegangen und habe dort gezeigt,. daß die Gesetze der proportionalen Veränderbarkeit nicht nur für die extensiven Werte (räumliche Ausdehnung, Zeitdauer) aondern auch in genau gleicher Weise für die intensiven Werte (Empfindungsintensitäten im engeren Sinne) Geltung haben.

Semon, Mneme. 3. Aut. 
die Menge des für die plastischen Prozesse zur Verfügung stehenden Materials oder hemmt man die Produktion von neuem Material, so findet der ganze plastische Aufbau in proportional verminderten Dimensionen statt, und es resultiert ein gegen die Norm in durchaus richtigen Dimensionen verkleinerter Organismus; vermehrt man umgekehrt die Menge des vorrätigen Materials oder steigert die Produktion von neuem Material über die Norm, so erfolgt alles in proportional vergrößerten Dimensionen, und es resultiert ein gegen die Norm in durchaus richtigen Proportionen vergrößerter Organismus.

Die Materialverminderung ist experimentell leicht zu erzielen durch Zerschneiden der Furchungsstadien bei vielen Tieren (z. B. Medusen, Echinodermen, Acraniern usw.) oder dadurch, daB man Pflanzen und manche Tiere während ihrer Entwicklung dürftig ernährt oder sonst in ungünstige Lebensverhältnisse versetzt.

Dię Materialvermehrung läßt sich umgekehrt dadurch erreichen, daß man zwei korrespondierende Furchungs- bzw. Blastulastadien zur Verschmelzung zu einem Organismus bringt, was Metschnikoff bei Medusen, Driesch bei Echinodermen geglüekt ist ${ }^{1}$. Auch dadurch, daß man die Organismen unter sehr gitnstigen Lebensbedingungen kultiviert, besonders sie sehr reichlich ernährt, gelingt es, zumal bei Pflanzen, in vielen Fällen obne weiteres, eine proportionale Vergrößerung des ganzen Organismus oder einzelner Teile, z. B. der Blätter und Blüten, um ein beträchtliches der normalen Dimensionen zu erzielen.

1 Ein ähnlicher Vorgang liegt wohl als Ergebnis eines Naturexperiments bei den von zur Straßen untersuchten Rieseneiern von Ascaris megalocephala vor. 
Die proportionale Veränderbarkeit der mnem. Erregungen. 371

Daß es sich bei dieser Erscheinung also um eine allgemein jedem mnemischen Erregungskomplex sowie jeder Sukzession solcher Komplexe zukommende Eigentumlichkeit handelt, dürfte durch die angefuhrten Beispiele, die sich ohne jede Schwierigkeit vervielfachen und auf alle Gebiete mnemischen Geschehens ausdehnen ließen, bewiesen sein.

Bei Organismen mit begrenztem Wachstum, bei denen alle Proportionen der Teile engraphisch genau bestimmt sind, also bei den meisten Tieren im Gegensatz zu den meisten Pflanzen, wirkt in ihrer Morphogenese zwar nicht Veränderung der absoluten Werte, wohl aber Störung der Proportionen als Inkongruenz der mnemischen Homophonie und hat Reaktionen zur Folge, die diese Inkongruenz beseitigen.

Wenn z. B., um an einen bekannten, ron Th. H. Morgan näher studierten Fall anzukntupfen, von einer Planarie ein so kleiner Ausschnitt gemacht wird, daß dieser Ausschnitt nur das Material zum Aufbau eines um das Funfache kleineren Tieres enthält, als der ursprüngliche Wurm es war, so werden Organe des letzteren, wie der Pharynx, selbst wenn sie unverletzt rom Ganzen in den Ausschnitt hintibergelangen, sobald dort die Regenerationsprozesse beginnen, nicht gelassen wie sie sind, sondern sozusagen eingeschmolzen und entsprechend den veränderten Proportionen des Ganzen neu aufgebaut. Es ist klar, daß in dem proportional verkleinerten Ganzen die Originalerregung, die die Anwesenheit des unverkleinerten alten Pharynx hervorruft, bei der Homophonie mit der dem verkleinerten Ganzen entsprechenden mnemischen Erregung eine starke Inkongruenz ergeben maß, eine Inkongruenz, die durch die Reaktionen des Abbaus des 
alten und Aufbaus eines neuen Pharynx beseitigt wird. Auch dieses merkwürdige Phänomen, eins der wunderbarsten Beispiele von Regulation, das wir kennen, ordnet sich bei Kenntnis der proportionalen Veränderbarkeit der mnemischen Erregungen ein in die große Gruppe der Reaktionen, die eine Inkongruenz bei der mnemischen Homophonie beseitigen.

Zusammenfassend können wir sagen: Das Engramm, dessen Charakter als Erregungsdisposition wir hier allein ins Auge fassen, bedingt nicht die absolute Größe der aus seiner Ekphorie resultierenden mnemischen Erregung, sondern nur ihre Qualität und ihr Größenverhältnis zu anderen simultan oder antezedent assoziierten mnemischen Erregungen.

In den Mnemischen Empfindungen habe ich eine nähere Untersuchnng daruber augestellt, was denn nun die absoluten Werte der bei der jeweiligen Ekphorie einer Engrammsukzession aktivierten mnemischen Erregungen bedingt, wenigstens soweit dieselben durch Empfindungsreaktionen zur Manifestation gelangen. Ich bin dabei zu dem Ergebnis gelangt, daß infolge von engraphischer Mitfixierung gewisser Merkzeichen die Reproduktion unter gewöhnlichen Umständen in denselben Raum-, Zeit- und Intensitätswerten erfolgt, wie sie die engraphisch wirksam gewesenen Originalempfindungen besessen hatten, und daß die proportionale Vergrößerung oder Verkleinerung dieser Werte infolge dessen einen gewissen, wenn auch nicht sehr starken, Widerstand zu überwinden hat. Für das weitere muß ich auf das 13. Kapitel der zitierten Arbeit verweisen.

Bei den mnemischen Erregungen, die sich durch plastische Reaktionen manifestieren, liegen die Dinge prinzipiell ganz ebenso. Auch auf diesem Gebiete beruht die Bestim- 
Die proportionale Veränderbarkeit der mnem. Erregungen. 373

mung der absoluten Werte in erster Linie auf der Mitwirkung gewisser engraphisch mitfixierter Faktoren. Vor allem scheint die Zahl der Zellteilungen, die zu erfolgen hat, bis eine bestimmte neue Entwicklungsphase eintritt (vgl. oben S. 97) engraphisch bestimmt, und damit ist eine gewisse Norm für die absolute Größe der Organe auf den verschiedenen Entwicklungsstadien gegeben. Allerdings haben wir bereits oben (S. 100) gesehen, daß dieses Moment nicht das alleinausschlaggebende ist, daß vielmehr unter Umständen andere Faktoren (im obigen Beispiel die Erreichung einer bestimmten Kernplasmarelation) eine noch entscheidendere Rolle spielen können. Das beweist aber nur, daß auch auf diesem Gebiet die Willerstände gegen Vergrößerung oder Verkleinerung gegenüber der Norm durch verschiedene andere Momente innerer und äuBerer Natur überwundeu werden können. Allerdings nur innerhalb bestimmter mnemisch fixierter Grenzen.

Die absoluten Werte fur die aus der mnemischen Erregung resultierenden Reaktionen werden also in erster Linie bestimmt durch andere mitfixierte engraphische Komponenten erblicher oder individueller Herkunft, die gleichzeitig ekphoriert werden und die ihrer Natur nach gewisse absolute Maße bedingen. In zweiter Linie aber auch durch zur Zeit der Ekphorie wirksame originale Einflüsse. Die Homophonie wirkt, wie wir gesehen haben, auch in diesem Falle beim Auftreten von stärkeren Inkongruenzen als das regulierende Moment. 



\section{Vierter Teil}

\section{Schlußbetrachtungen}




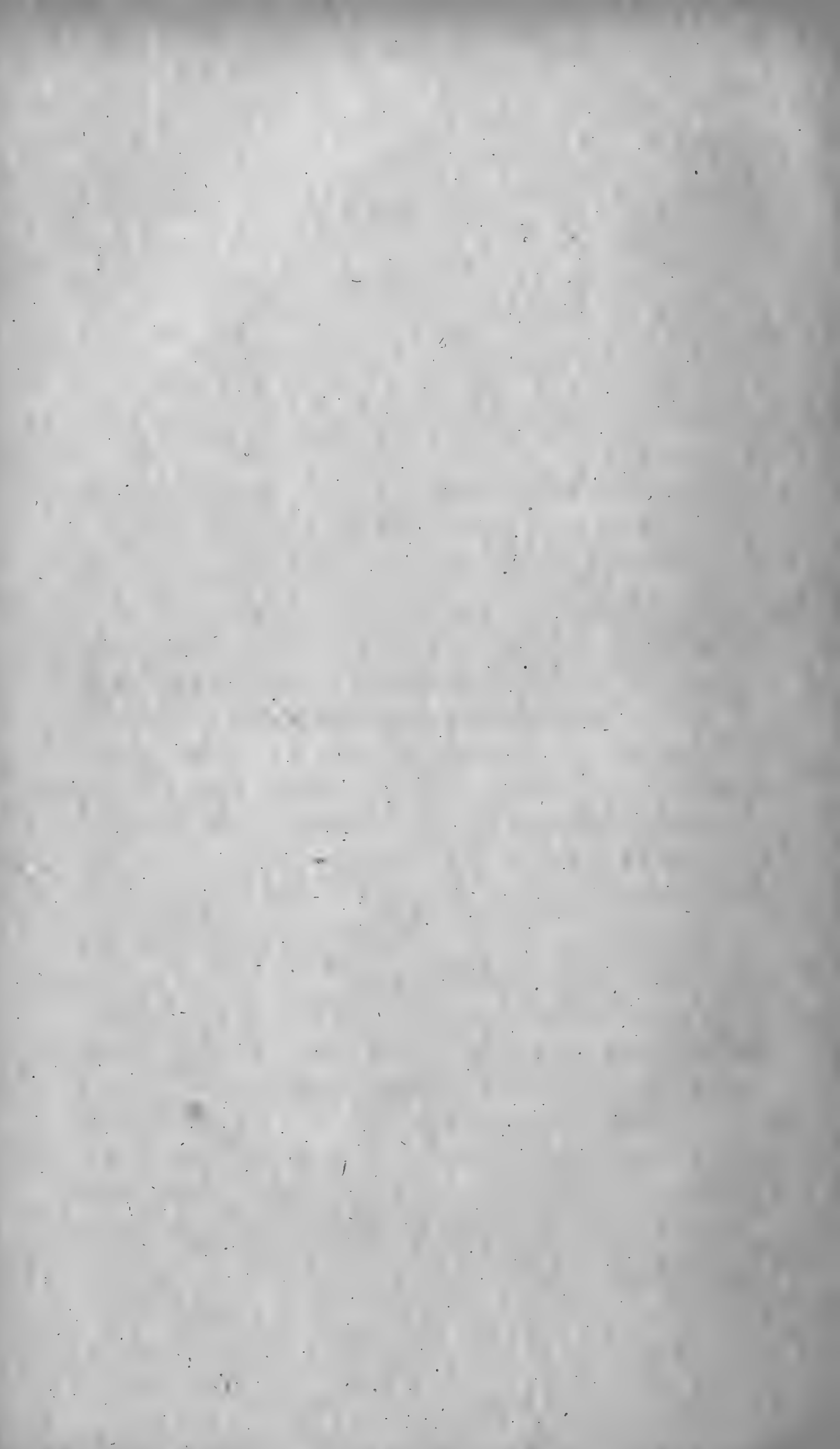




\section{Sechzehntes Kapitel.}

\section{Rückblick. Einwände.}

Ich habe es in den vorstehenden Untersuchungen unternommen, das Vorhandensein und die Bedeutung einer gemeinsamen reizphysiologischen Grundlage für die scheinbar so ganz heterogenen organischen Reproduktionsphänomene nachzuweisen. Die beiden Pfeiler dieser Grundlage sind crstens die Tatsache des primären Zusammenhanges aller gleichzeitiger Erregungen im Organismus und zweitens die Tatsache, daß die Reizwirkung weder mit der synchronen noch auch mit der akoluten Phase restlos abgetan ist, sondern $\mathrm{da} ß$ nach dem Ausklingen der letzteren eine dauernde materielle Veränderung der reizbaren Substanz, das Engramm, zurückbleibt, das als solches latent ist, jeden Augenblick aber auf einem gesetzmäßig vorgezeichneten Wege zur Manifestation gebracht werden kann. Da die Keimzellen durch keinerlei isolatorischen Apparate von dem ubrigen Körper des Organismus geschieden sind, können die in der ubrigen reizbaren Substanz ablaufenden Erregungen auch bis zu ihnen gelangen und, zumal während ihrer sensiblen Periode, auch in ihnen manifestationsfähige Engramme hinterlassen.

Die Quintessenz der mnemischen Gesetzmässigkeit habe ich folgendermaßen in den beiden zusammengehörigen Sätzen ansgedruickt: 
Erster mnemischer Hauptsatz (Satz der Engraphie): Alle gleichzeitigen Erregungen innerhalb eines Organismus bilden einen zusammenhängenden simultanen Erregungskomplex, der als solcher engraphisch wirkt, das heißt einen zusammenhängenden und insofern ein Ganzes bildenden Engrammkomplex hinterläßt.

Zweiter mnemischer Hauptsatz (Satz der Ekphorie): Ekphorisch auf einen simultanen Engrammkomplex wirkt die partielle Wiederkehr derjenigen energetischen Situation, die vormals engraphisch gewirkt hat. In engerer Fassung: Ekphorisch auf einen simultanen Engrammkomplex wirkt die partielle Wiederkehr des Erregungskomplexes, der seinerzeit den Engrammkomplex hinterlassen hat, und zwar. eine Wiederkehr, sei es in Gestalt von Originalerregungen, sei es ron mnemischen Erregungen.

Aus unserem Satz der Engraphie leitet sich unmittelbar das ab, was wir als Assoziation bezeichnen; es ist der Zasammenhang der einzelnen Komponenten eines Engrammkomplexes. Assoziation ist ein Ergebnis der Engraphie, das bei Gelegenheit der Ekphorie in Erscheinung tritt.

Dazu gesellt sich als drittes Hauprergebnis unserer Untersuchungen der Einblick in das Wesen der Homophonie, das heißt des Zusammenwirkens gleichzeitiger im wesentlichen übereinstimmender Erregungen. Je nach der größeren oder geringeren Vollständigkeit dieser Übereinstimmung und je nach der Beschaffenheit der begleitenden Umstände kommt es zu einer nicht differenzierenden oder einer differenzierenden Homophonie 1.

Von der so geschaffenen Grundlage aus habe ich dann

1 Vgl. bezüglich dieser Unterscheidungen das 16. und 17. Kapitel der Mnemischen Empfindungen. 
im dritten Teil des vorliegenden Buchs die Wirksamkeit der mnemischen Prozesse bei der Ontogenese untersucht und glaube gezeigt $\mathrm{zu}$ haben, $\mathrm{da} B$ die strenge räumliche and zeitliche Ordnung der ontogenetischen Abläufe, das Auftreten jedes der zahllosen Einzelprozesse am gegebenen Ort und zur gegebenen Zeit, die Abhängigkeit aller gleichzeitigen Prozesse von einander (abhängige Differenzierung) und andererseits auch eine in gewissen Grenzen realisierbare Unabhängigkeit (Selbstdifferenzierung) sich aus den mnemischen Gesetzmäßigkeiten ohne weitere Hilfsannahmen ebenśo ableiten läßt, wie die Phänomone der erblichen und nicht erblichen Periodizität. Ferner habe ich gezeigt, daß die Gesetze der Homophonie uns den Schltissel zu einem physiologischen Verständnis der sonst ganz mystischen Regenerationsund Regulationsvorgänge geben.

Ehe ich nun daran gehe, die Einwände näher zu untersuchen, die gegen die Richtigkeit der hier vertretenen Theorie vorgebracht worden sind, will ich mich zunächst mit einem Hauptbedenken beschäftigen, das sich nicht gegen die Richtigkeit des Ganzen oder einzelner seiner Teile, wohl aber gegen seinen klärenden Wert und seine wissenschaftliche Frnchtbarkeit richtet. Dieses Bedenken lautet: Die Richtigkeit aller der vorausgehenden Auseinandersetzungen zugegeben, was ist das Ganze anderes als eine neue Umschreibung alter Rätsel?

Um mich gegen diesen Einwurf zu verteidigen, den ich mir oft genug selbst gemacht habe, möchte ich so verfahren, daß ich ihn darch den Gegner weiter ausfuhren lasse, und im Kreuzverhör auf die aufsteigenden Zweifel Rede und Antwort stehe.

Bei der näheren Begrundung wird der Gegner sein erstes 
Bedenken gegen die Aufstellang der Begriffe »engraphische Reizwirkung* und *Engramm * richten und behaupten, hier beginne bereits die sich als Erklärung gebärdende Umschreibung. Denn ich hätte nicht das eigentliche Wesen der engraphischen Reizwirkung und des Engramms erklärt.

Darauf habe ich zu erwidern, daß das Verlangen, das seigentliche Wesen * irgend eines Naturgeschehens zu erklären, eine Aufgabe ist, die - von der Möglichkeit ihrer Lösung ganz abgesehen - jedenfalls bisher noch in keinem einzigen Fall von Naturwissenschaft oder Philosophie gelöst worden ist. Ich behaupte aber, daß es uns gelungen ist, einige Seiten der engraphischen Reizwirkung in ihrer gesetzmäßigen Wiederkehr zu erkennen und auf ein Minimum einfacher Grundsătze zurückzufuhbren, und zwar, soweit es sich nicht um historisch gegebene, $d$. h. nicht mehr wiederholbare Engramme handelt, unter gänzlichem Verzicht auf alle Hypothesen und durchans auf dem Boden realer, jeden Augenblick nachzuprüfender. Beobachtungen. Dadurch ist das Wesen der engraphischen Reizwirkung zwar nicht erklärt, aber seine Erklärung in naturwissenschaftlichem Sinne ${ }^{1}$ angebahnt.

Gleich in der ersten Auflage des vorliegenden Buchs habe ich gesagt, ich hätte durchaus von dem Versuche Abstand genommen, »die engraphische Veränderung auf hypothetische Umlagerungen hypothetischer Molekile zurtickzuführen $\%$.

Dieser Standpunkt, der einfach der Standpunkt vorsichtiger Zurïckhaltung ist, ist von einigen meiner Leser

${ }^{1}$ Das heißt im Sinne Robert Mayers: sIst einmal eine Tatsache nach allen ihren Seiten bekannt, so ist sie eben damit erklärt und die Aufgabe der Wissenschaft beendetc. J. R. Mayer, Bemerkungen über das mechanische Äquivalent der Wärme. 1850. 
und Kritiker durchaus mißverstanden worden, und man hat mir vorgeworfen, der Engrammlehre hafte damit etwas $\mathbf{M y -}$ stisches an. Wer meinen Gedankengängen aber wirklich gefolgt ist, wird mir zugeben, daß alles andere eher gerechtfertigt ist als dieser Vorwurf. Denn ich habe damit keineswegs die Möglichkeit offen gelassen, daß das Engramm etwas immaterielles oder mystisches sei, ich habe es vielmehr stets als eine materielle wenn auch ihrer näheren Beschaffenheit nach noch unbekannte Veränderung aufgefaßt und dargestellt. Dies geht ohne weiteres daraus hervor, daß ich es als eine Veränderung bezeichnet habe, die in der reizbaren $\mathrm{Sub}$ stanz nach Abklingen des Erregungsvorganges zurückbleibt. Als veränderter Zustand einer Substanz muß das Engramm notwendigerweise etwas Substanzielles oder Materielles sein und man kann es deshalb auch ebensogut als materielle Veränderung bezeichnen.

Übrigens habe ich einer bestimmten strnkturellen Seite der Engramme nämlich ihrer Lokalisation sowohl in dem vorliegendem Buche, als auch in den Mnemischen Empfindungen meine besondere Aufmerksamkeit zugewendet und glaube in dem letzteren Werke (S. 282, 373) durch Feststellung des Vorhandenseins einer chronogenen Lokalisation auf ein wichtiges neues Element hingewiesen zu haben, das bei der weiteren Ánalyse der Lokalisationsprobleme nicht aus den Augen zu verlieren ist.

Anf die Frage, inwieweit es notwendig and zulässig ist, die Probleme, die uns hier beschäftigt haben, mit unsichtbaren, nur indirekt auf höchst unsicherer oder ganz illusorischer Basis erschlossenen Strukturen in Beziehung zu bringen, komme ich noch unten bei Erörterung eines anderen mir gemachten Einwandes zurück. Aber zugegeben, daß 
man, so lange die feinere Struktur der Engramme nicht ergrtindet ist, mit der engraphischen Reizwirkung als mit einer Größe zu rechnen hat, die in einer wichtigen Beziehnng, der morphologischen, noch als eine unbekannte zu bezeichnen ist: ist es nicht schon ein großer Vorteil, eine ganze Anzahl von Unbekannten, wie Gedächtnis in engerem Sinne, Vererbungsfähigkeit, Regulationsvermögen, aus den biologischen Problemen auszuschalten, und durch die Funktion einer einzigen Unbekannten: »mnemische Erregung « zu ersetzen, die um so mehr ihren Charakter als Unbekannte verliert, je genauer man ihre unendlich vielseitigen Manifestationen studiert?

Und indem wir bei diesem näheren Studium gefunden haben, daB sich alle diese scheinbar so ganz heterogenen Manifestationen anf einige wenige Grundsätze zuruckfuhren lassen, die sich ihrerseits als bloße Konsequenzen der synchronen Reizwirkung ergeben: die beiden mnemischen Hauptsätze und die Gesetze der Homophonie, haben wir meiner Ansicht nach durch diese Vereinfachung unserer Anschanungen auch einen Schritt in der wirklichen Erkenntnis vorwärts getan.

Aber, so wird unser Gegner nun einwenden, wenn in unseren Ausfuhrungen die Regulationen und verwandte Erscheinungen als $\gg$ Reaktionen zur Beseitigung der Inkongruenz einer Homophonie bezeichnet worden sind, so ist jedenfalls dieses Problem dadurch nicht erklärt, sondern in eklatanter Weise nur umschrieben worden. Die Art und Weise, wie die Beseitigung dieser Inkongruenz stattindet, ist ja gerade das Wesentliche, was erklärt werden sollte, und mit der Aussage: es tritt eine Reaktion ein, die die Inkongruenz beseitigt, beschreiben wir den schönsten Zirkelschluß der Welt: 
Dem gegenuber habe ich zu betonen, daß ich mir durchaus bewußt bin, die Regulationsvorgänge keineswegs in allen ihren wesentlichen Zusammenhängen aufgeklärt zu haben. Wohl aber scheint mir ibre Erklärnng durch ein neues Erkenntnismoment auf eine völlig neue Stufe gertickt; dieses Moment beruht auf der Einführung des Begriffs der Homophonie.

Die in diesem Begriffe enthaltene Erkenntnis lehrt uns das Vorhandensein zweier real vorbandener Erregungen in dem regulierenden Organismus: einer Originalerregung als Reizprodukt des gegenwärtigen (anormalen) Zustandes und einer mnemischen Erregung, die dem zugehörigen normalen Zustande des Organismus bzw. seiner Aszendenten entspricht. Wie sich unter der gemeinschaftlichen Wirkung dieser beiden Erregungen die regulierenden Reaktionen einstellen und ablaufen, ist allerdings vorderhand noch nicht aufgeklärt, und wird es wohl auch so lange nicht werden, bis nicht der Zusammenhang zwischen Erregung und Reaktion im allgemeinen viel genauer stadiert und besser durchschaut sein wird, als dies beim jetzigen Stande unserer physiologischen Kenntnisse möglich ist.

Aber das Problem ist durch den Nachweis, daß es sich bei der Regulation um Wirkung und Gegenwirkung zweier real vorhandener Erregungen handelt, einer naturwissenschaftlichen Bebandlung erst zugänglich geworden. Es war ein metaphysisches, solange man von Regulation auf etwas Zuktinftiges hin, oder Regulation auf ein gedachtes verkleinertes oder vergrößertes Ganzes sprechen mußte. Die Beseitigang solcher außerhalb der Dinge selbst liegender Begriffe, wie es ihr zukünftiger oder ihr sonstwie sgedachter" Zustand ist, und ihr Ersatz durch das Produkt der Homo- 
phonie zweier, zwar von Phase zu Phase wechselnder aber stets real vorhandener materieller Vorgänge beweist, daß auch in diesem Falle die Einfuhrung des mnemischen Prinzips das Gegenteil einer Umschreibung bedeutet, das Problem vielmehr erst zu einem auf naturwissenschaftlichem Wege lösbaren macht.

Die Beweise fur eine Autonomie der Formbildung, fur eine Autonomie des Lebens tiberhaupt und damit für die Berechtigung des Vitalismus stlutzen sich im wesentlichen auf die angebliche Unmöglichkeit, den Phänomenen der Vererbung, der Regulation und Regeneration, der proportionalen Vergrößerung und Verkleinerung allein auf dem Wege der Kausalität und ohne Annahme eines besonderen teleologischen Prinzips beizukommen. Unsere Betrachtungsweise zeigt uns nun einen Weg, der die Annahme solch eines vitalistischen Prinzips wie Entelechie und Ähnliches unnötig macht, sie bietet uns die Angriffspunkte, um selbst diese Probleme rein kausal-mechanisch zu lösen.

Ich wende mich nun zu den Einwänden, die sich gegen die Richtigkeit unserer Auffassungen, vor allem ihres Kernes, gegen die Zulässigkeit einer Ableitung aller der scheinbar so heterogenen Reproduktionsphänomene von einer gemeinsamen reizphysiologischen Basis richten. Zwei Haupteinwände sind gegen diese Ableitung erhoben worden. Der eine derselben gründet sich auf die Behauptung, daß erworbene Eigenschaften, oder um einen präziseren Ausdruck za gebrauchen, daB im individuellen Leben erworbene Engramme sich nicht vererben. Der andere Einwurf wird auch von einigen derer erhoben, die die Möglichkeit einer solchen Vererbung zugeben; er besagt, die den Phänomenen des höheren Gedächtnisses zugrunde liegende Gesetzmäßigkeit 
besäße zwar eine gewisse Ähnlichkeit, sie habe eine entfernte Analogie mit derjenigen, die die Phänomene der Vererbung beherrscht, sei aber nicht identisch mit ihr.

Der Einwand ${ }^{1}$, daß sich im individuellen Leben erworbene Engramme nicht auf die Nachkonmen vererben, ist heutzutage widerlegt durch eine große Anzahl experimentell sicher begrtindeter Tatsachen, die wir zum Teil in den vorangegangenen Ausfïhrungen kennen gelernt haben, die man aber in einer vollständigen Zusammenfassung und kritischen Würdigung in meiner ausschließlich dieser Frage gewidmeten Abhandlung tiber den Stand der Frage nach der Vererbung erworbener Eigenschaften findet. Durch die moderne experimentelle Forschung ist mit voller Sicherheit festgestellt, daB die neuen erblichen Erwerbungen des Organismus als Produkte einer wie immer zustande gekommenen Reizwirkung oder Induktion entstehen, daß sie also als Engramme aufuufassen sind. An dieser Grundtatsache kann auch die Behauptung nichts ändern, die engraphische Veränderung der Keimzellen erfolge durch unmittelbar bis zu ihnen dringende äußere Reize in einer der Beeinflussung des tibrigen Körpers gleichsinnigen Weise (Parallelinduktion), nicht aber durch Fortleitung der sich im übrigen Körper abspielenden Erregungen auf die Keimzellen (somatische Induktion).

Denn da auch die Gegner annehmen müssen, daß die En-

1 Am ausführlichsten ist dieser Einwand begründet worden in dem Aufsatz von A. Weismann: Semons > Mneme und die Vererbung erworbener Eigenschaften, Archiv f. Rassen- und Gesellschaftsbiologie, 3. Jahrg. 1906. Meine Erwiderung findet man in der Schrift: Beweise für die Vererbung erworbener Eigenschaften, Archiv f. Rassen- und Gesellschaftsbiologie. 4. Jahrg. 1907, ferner in der schon wiederholt zitierten neueren Arbeit über den Stand der Frage, Fortschritte der naturwissenschaftlichen Forschung, 2. Bd., Berlin u. Wien 1911.

Sem on, Mneme. 3. Auf: 
gramme der Keimzellen genau die gleichen Eigenschaften besitzen wie die durch parallele Induktion entstandenen des Soma, wlirde es, soweit es sich um die Beteiligung äußerer Reize landelt, fur den Ausbau der Engrammlehre keinen fundamentalen Unterschied machen, für welche Art des Zustandekommens der Engraphie man sich entscheidet. Ich glaube aber, in der zitierten Abhandlung den Beweis geführt zu haben, daß eine große Anzahl von physikalischen und eine noch größere von physiologischen Tatsachen die Durchführung der Hypothese von der Parallelinduktion geradezu. unmöglich machen, und daß aus diesem Grunde der Ausbau der Engrammlehre unter Annahme einer somatischen Induktion der Keimzellen erfolgen muß. Auf diese Weise ist er denn auch in dem vorliegenden Werke erfolgt.

Aber selbst wer sich dem nicht anschließen will und sich auf die überaus künstliche, physiologisch höchst anfechtbare and in vielen Fällen tiberhaupt nicht durchführbare Annahme der Parallelinduktion versteift, auch er nimmt damit eine auf die Keimdrlisen ausgeubte Reizwirkung also eine erbliche Engraphie an und hat somit auf der Grundlage einer Engrammlehre zu bauen, auch er kann daher an dem in Frage stehenden Einwand als einem Fundamentaleinwand gegen die Mnemetheorie nicht festhalten.

Ich komme nun zum zweiten Einwand, der besagt, es handle sich, selbst die Vererbung erworbener Engramme zugegeben, bei der Übereinstimmung der Phänomene des höheren Gedächtnisses und der Vererbung um eine bloße Analogie, keineswegs aber um eine gemeinsame Grundgesetzmäßigkeit, eine prinzipielle Identität.

$\mathrm{Daß}$ ein Gedächtnisvorgang im Großhirn nicht mit einem Wachstumsprozeß bei der Embryonalentwicklung und dieser 
nicht mit der Schlafbewegung einer Pflanze schlechthin und als solcher identisch ist, >es braucht kein Geist rom Grabe herzukommen, um das zu sagen *.

Identisch ist auch ein Gedächtnisvorgang < im engeren Sinne nicht mit irgendeinem anderen. Ja, wenn ich mich jetzt und fünf Minuten später desselben optischen Eindrucks. erinnere, sind beide Vorgänge nicht identisch. Identisch als Vorgang ist naturlich jeder organische Ablauf, ja schlechthin jede Erscheinung nur mit sich selbst. Dessenungeachtet kann man sehr wohl sagen, daß zwei nicht identischen und vielleicht sehr verschieden aussehenden Erscheinungen ein identisches Prinzip zugrunde liegt, daß ihr Ablauf von ein und derselben Gesetzmäßigkeit beherrscht wird!

So ist ein einfaches Wasserrad, wio man es an einem Rasensprenger oder einer Gartenfontäne anzubringen pflegt, sehr unähnlich einer Turbine modernster Konstruktion und auch die in beiden Systemen ablaufenden Prozesse sind in ihren Einzelheiten verglichen durchaus nicht identisch. Dennoch wird jeder Physiker das beiden Abläufen zugrunde liegende Prinzip als identisch auffassen und nicht daran denken, es als bloß analog zu bezeichnen.

Die letztere Anschauung schien früher von O. Hertwig

1 Vgl. darüber auch die ausgezeichneten Ausführungen von B. Kern in seinem Buche, Das Problem des Lebens, Berlin 1909, S. 423--425. Vollkommen in meinem Siune fiihrt Kern dort unter anderem ans: -Sofern aber in dem Vererbungsproblem nur die Wiedererzeugung fruherer Funktionen in Betracht gezogen wird, seien es formbildende oder andere Lebensvorgänge, ist die Behauptung einer Identität als rein funktioneller Identität berechtigt. Das allein liegt auch im Sinne Semons, der keineswegs meint, den Vererbungsvorgang mit dem Prinzip der Mneme erscböpft zu haben. Sein Gesichtspunkt ist ein allgemeinerer, der vollbewaßt die Frage nach der Art der Vermittlungsvorgänge offen läßt und der weiteren Forschung vorbehält.c 
vertreten zu werden, der wiederholt ${ }^{1}$ betont hat, daß $>$ zwischen den wunderbaren Eigenschaften der Erbmasse und den nicht minder wunderbaren Eigenschaften der Hirnsubstanz eine ientfernte Analogie * (siehe S. 245) besteht. Daß diese Analogie keine Identität ist, braucht für den Einsichtigen kaum bemerkt zu werden $\approx$. Man hat sich daraufhin wiederholt auf O. Hertwig als auf einen Gegner der hier entwickelten Ansichten berufen. Wie aber mit besonderer Genugtuung bemerkt werden kann, ist er es nicht. Denn er erkennt in den inzwischen erschienenen Auflagen desselben Buches ${ }^{2}$ die Identität ausdruicklich an, indem er sagt: *Nach meiner Ansicht fallen die Erscheinungen der »Mneme«, also der Erblichkeit und die Erscheinungen des Gedächtnisses unter den allgemeinen Begriff der Reproduktion und zeigen hierbei in ihrem Wesen eine gewisse Identität, was ich weder je bestritten habe noch bestreite." 0 . Hertwig scheidet nach dieser Erklärung trotz gewisser Einschränkungen, die er macht, und auf die wir unten noch zurückkommen, aus der Reihe derer aus, die den von uns augenblicklich behandelten Einwand noch vertreten.

Was die erklärten Gegner der Identifikation der physiologischen Grundlagen aller organischen Reproduktion anlangt, so scheint die Hauptschwierigkeit fur die meisten darin zu liegen, daß die Verschiedenartigkeit der Ausdrucksform (Manifestation) zweier Erregungen ihnen das Gemeinsame der im übrigen herrschenden Gesetzmäßigkeit verdeckt. Kein Mensch wird leugnen, daß motorische Reaktionen grundverschieden sind von sekretcrischen und beide von plastischen.

1 0. Hertwig, Die Zelle und die Gewebe, 2. Buch, Jena 1898, S. 245 u. 251 .

2 0. Hertwig, Allgemeine Biologie (Neue Auflage des unter ${ }^{1}$ zitierten Buchs), 2. Aufl., Jena 1906, S. 587, 3. Aufl., Jena 1909, S. 661. 
Aber ebensowenig wie es fur den Charakter einer synchronen Erregung einen Unterschied macht, ob sie sich durch eine motorische oder sekretorische oder eine plastische Reaktion manifestiert, ebensowenig ist dies für den Charakter einer Erregung als einer mnemischen von prinzipieller Bedeutung.

Freilich behauptet Plate ${ }^{1}, \rtimes$ daß die Mneme ein psychischer Prozeß und somit, wie alle psychischen Erscheinungen, völlig rätselhaft ist, also sich auch zur Erklärung der Vererbung, d. h. zu einem wirklichen Verständnis der sich hierbei abspielenden Vorgänge nicht eignet. * Anders hatte sich derselbe Autor ein Jahr früher ausgesprochen ${ }^{2}$, indem er ganz richtig ausführte: „Den Kardinalunterschied sehe ich nicht mit Detto (1905) darin, daß es sich auf dem einen Gebiet um psychische Vorgänge, auf dem anderen um materielle handelt, denn da erstere absolut an die Substanz des Nervensystems gebunden sind, so liegen in beiden Fällen materielle Änderungen des Protoplasmas zugrunde, die direkt miteinander verglichen werden können. * Dies ist ebenso buchstäblich richtig, wie es falsch ist, die mnemischen Vorgänge, wie ich sie definiert und in ihren Gesetzmäßigkeiten festzustellen versucht babe, als psychische Vorgänge abzustempeln. Ich habe in meiner Grandlegung durchaus ihre materielle Seite ins Auge gefaßt (was Plate in seinen Sätzen von 1908 ja auch ganz richtig hervorgehoben hat), habe eine physiologische Theorie der Erregungswirkung zu begründen versucht und habe die psychische Seite der Phänomene, die Empfindungsmanifestationen, nur als eine unter vielen Arten

1 L. Plate, Archiv f. Rassen- und Gesellschaftsbiologie, 6. Jahrg., Leipzig und Berlin 1909, S. 92 (Besprechung von Fr. Darwins »President's Adress).

2 L. Plate, Selektionsprinzip und Probleme der Artbildung, 3. Aufl., Leipzig 1908; S. 334. 
von Merkzeichen benutzt, durch welche die materiellen Erregungen zu unserer Kenntnis gelangen.

Erkenntnistheoretisch habe ich zur Frage nach der Beziehung der Erregung zu ihrer Empfindungsmanifestation in der Einleitung zu den Mnemischen Empfindungen (S. 4-14) Stellung genommen, und meinen Standpunkt durch den Satz ausgedrickt: , Wir erblicken in einer Erregung und ihrer Empfindungsmanifestation nicht zwei getrennte Objekte, die sich unserer Beobachtung darstellen, sondern dasselbe Objekt von zwei verschiedenen Standpunkten aus betrachtet. Dieser meinen Standpunkt habe ich dort näher begründet. Diese erkenntnistheoretische Frage ist aber für den uns hier beschäftigenden Einwand ganz irrelevant. Denn dasjenige, was von mir unter gleichen Gesichtspunkten behandelt worden ist, bezieht sich stets ausschließlich auf die materiellen Vorgänge bei den Phänomenen des höheren Gedächtnisses und denen der Vererbung, Periodizitiat, Regulation. Und das Vorhandensein solcher materieller Vorgänge bei den Gedächtnisphänomenen wird doch von keinem Naturforscher geleugnet.

Dies ist auch der Grund, warum ich mir für meine Aufgabe eine eigene Terminologie: Originalerregung, Engramm, mnemische Erregung usw. geschaffen habe, die es gestattet, ganz davon zu abstrahieren, ob sich die betreffenden materiellen Vorgänge im gegebenen Fall durch oberbewußte Empfindungen manifestieren oder nicht, dies ist ebenfalls der Grund, warum ich sowohl bei meiner ganzen analytischen Arbeit als auch bei der sich daran anschließenden Synthese, der Aufstellung der mnemischen Hauptsätze und anderen Thesen, uberhaupt in jeder von mir gebotenen Definition die Ausdrticke Gedächtnis, Erinnerung, Erinnerungsbild usw. grund- 
sätzlich nicht verwendet habe. Ich habe dies vollbewußt getan und die Gründe dafur in der Anmerkung S. 15, die unverändert aus der ersten Auflage hintibergenommen ist, wiedergegeben. Trotzdem besteht eine fast unausrottbare Neigung, mich auf das von mir bei Analyse und Synthese geradezu perhorreszierte Wort Gedächtnis festzunageln. Dies ist mir nur ein Beweis dafür, wie recht ich gehabt habe, mir fur meine grundlegenden Begriffe eine besondere Terminologie zu schaffen, die Einwäude von vornherein gegenstandslos macht, welche wie die von Driesch ${ }^{1}$ vorgebrachten sich im Grunde nur auf das Wort Gedächtnis und darauf beziehen, »was in irgendeinem System der Psychologie ,Gedächtnis genannt zu werden pflegt*.

Was die methodologische Seite der Frage, die Berechtigung einer gleichzeitigen Verwendung der subjektiven Beobachtungsmethode (Introspektion) und der sogenannten objektiven Methode anlangt, so habe ich mich dariiber schon oben (S. 40-43) geäußert. Damit scheint mir bereits das widerlegt, was Rosenthal2 in dieser Beziehung gegen mich einwendet, wenn er sagt: > Man kann, glaube ich, mit gutem Recht die These verteiåigen, daß die logischen Folgerungen aus Tatsachen der Bewußtseinszustände immer nur auf Tatsachen derselben Art Anwendung finden können und niemals auf Vorgänge, die uns als, Wabrnehmung' von Vorgängen außerhalb unseres ,Ich' erscheinen, Licht werfen.* Wäre das richtig und zöge man daraus unerbittlich alle Konsequenzen, so gäbe es keine logische Briłcke von den eigenen

1 H. Driesch, Philosophie des Organischen, Leipzig 1909, 1. Bd. S. $220-223$.

2 J. Rosenthal, Biologisches Centralblatt, 25. Bd. 1905, S. 368 in einer kritischen Besprechung der Ilneme. 
Empfindungen zu den Empfindungen unserer Mitmenschen, und weder die psychologische noch die reizphysiologische Forschung hätte das Recht, introspektiv gewonnene Resultate mit solchen in Beziehung zu setzen, zu denen man durch -Wahrnehmung von Vorgängen anßerhalb unseres Iche gelangt ist. Ein Gebot wäre damit proklamiert, dessen Befolgung für die Arbeit unseres Verstandes im täglichen Leben ebenso unmöglich wäre wie fur die Reizphysiologie und experimentelle Psychologie einerseits, die introspektive Psychologie andererseits, Wissenschaften, die doch trotz der Nichtbeachtung dieses Verbots oder besser gerade infolge dieser Nichtbeachtung auf schöne Leistungen von dauerndem Wert zurtickblicken können.

Ich wende mich nun zu einigen spezielleren Einwänden gegen die im vorliegenden Buche vertretene Identität der reizphysiologischen Grundlage aller organischen Reproduktionserscheinungen. »Für mich «, so sagt z. B. Plate ${ }^{1}$, besteht die Hauptdifferenz darin, daß beim Gedächtnis sich die Wiederholung in demselben Gehirn abspielt, welches den Originalreiz empfing, während bei der Vererbung die Wiederholung in der nächsten Generation sich zeigt und damit erst das eigentliche Problem, nämlich die Übertragung des Reizes rom Somà auf die Keimzellen beginnt. * Hier liegt doch eine Schwierigkeit nur für denjenigen vor, der mit Weismann die Möglichkeit eines Übergreifens des Erregungsvorganges vom übrigen Körper anf die mit ihm in kontinuierlichem Zusammenhange stehenden Keimzellen leugnet. $\mathrm{Zu}$ diesen gehört aber Plate, wie seine Ausfuhrungen in demselben Buche (S. 328-330 und 344-355)

${ }^{1}$ L. Plate, Selektionsprinzip und Probleme der Artbildung. 3. Aufl. Leipzig 1908, S. 335. 
zeigen, nicht, und so ist mir dieser Einwand in seinem Munde unverständlich. Wer eine somatische Induktion, das heißt die Möglichkeit des Übergreifens von Erregungen des Soma auf die Keimzellen zugibt, für den ist auch die Möglichkeit des Zurückbleibens von Spuren dieser Erregungen also von entsprechenden Engrammen in Keimzellen und Soma eine selbstverständliche Konsequenz, vorausgesetzt daß die ubergreifende Erregung hinreichend stark ist, und die Keimzelle sich in ihrer sensiblen Periode befiudet.

Eine Schwierigkeit ist hier nur für die Anhänger einer ausschließlichen Parallelinduktion gegeben, insofern sie annehmen mussen, daß Reize, die direkt zu den Keimzellen gelangen, bei ihnen ohne Vermittlung der reizempfangenden Apparate des Soma und ohne die durch diese Reizaufnabme bedingten Transformationen dennoch Wirkungen hervorbringen und Engramme hinterlassen, die genau mit denen ubbereinstimmen, die beim Soma nur durch die Vermittlung komplizierter transformatorischer Apparate zustande kommen. Vom physiologischen Standpunkt aus erscheint dies undenkbar. Denn die Reizaufnahme von seiten des Soma ist es, durch die der betreffende Reiz auf Grund der lokalen Verteilung und spezifischen Beschaffenheit der $\gg$ Rezeptoren e eine nicht nur nach sonstiger Qualität sondern auch nach Lokalisation spezifiziorte Erregung auslöst und ein spezifiziertes Engramm hinterläßt. Hier können also erst die Einflusse denjenigen Stempel erhalten, der bei der Induktion der Keimzellen ein Wiederauftreten an demselben Ort \& der Nachkommen verblirgt 1 .

1 Näher ansgeführt und durch konkrete Beispiele illustriert habe ich dies im 8. Abschnitt meiner Abhandlung über den Stand der Frage, der von der physikalischen und physiologischen Undurchführbarkeit der Parallelinduktion handelt. 
Übrigens habe ich schon wiederholt betont, daß anch die Anhünger der Parallelinduktion eine Engraphie der Keimzellen annehmen müssen, und daß sie deshalb auch ihrerseits auf einer Engrammlehre zu fußen haben. Wenn ich die Lehre von der Parallelinduktion für richtig halten würde, hätte ich durchaus keine Schwierigkeit gehabt, auf dieser reizphysiologischen Basis die von mir vertretene Lehre auszubauen. Nur weil ich den Gedanken der Parallelinduktion für physiologisch unhaltbar halte, ist dies nicht geschehen.

Ahnlich steht es mit dem Bedenken, wwie es kommt, daß der Kern der Keimzelle Tausende von Engrammen aufspeichert, während doch die Ganglienzelle nur einen Eindruck oder nur eine geringe Zahl derselben zu beherbergen vermag « 1. Dem ist zu entgegnen, daß die Anschauung, jede Ganglienzelle vermöge nur einen Eindruck oder einige wenige zu beherbergen, das heißt also die Engramme würden so im Gehirn lokalisiert, daß jede einzelne Großhirnzelle sozusagen das Schubfach fur je ein einzelnes Erinnerungsbild * darstellte, zwar bei Beginn der hirnphysiologischen Forschung aufgetaucht, bald aber als gänzlich unmöglich verlassen worden ist, und seit wohl bald zwei Dezennien kanm noch von einem Forscher, der sich als Fachmann mit der Lokalisation der Hirnfanktionen beschäftigt, vertreten wird. Als ich mich in der ersten Auflage des vorliegenden Buchs gegen solche naive Auffassungen wandte, wurde mir

1 L. Plate bei Besprechung von Fr. Darwins President's Adress, Archir f. Rassenbiologie, 6. Jabrg., 1909, S. 92 . Plate irrt übrigens, wenn er Fr. Darwin diesen Einwand in Beziehung auf das angebliche Verhalten der Ganglienzelle in den Mnd legt. Letzterer Forscher befindet sich vielmehr in allen wesentlichen Punkten in vollkommener Übereinstimmung mit mir. Vgl. seine President's Adress, British Association for the Advancement of Science, Dublin 1908. 
von befreundeten Hirnphysiologen bedeutet, jener Standpunkt sei für die heutige Lokalisationsforschung ein so völlig uberwnndener, daß es ein Anachronismus sei, ihn zu bekämpfen. Dementsprechend habe ich es bereits in der zweiten Auflage unterlassen, mich ausführlicher gegen solche $>$ mythologische Betrachtungsweisen *, wie Rieger sie nennt, zu wenden. Ein schlimmerer Anachronismus als die Bekämpfung solcher aufgegebener Auffassungen ist aber jedenfalls ihre Verwertung gegen unseren Versuch, die organischen Reproduktionsphänomene auf eine gemeinsame physiologisohe Grundlage zu stellen 1 .

Zum SchluB noch einige Worte uber einen letzten prinzipiellen Einwand. Ich gehe dabei von folgendem Ausspruche 0 . Hertwigs aus, den ich bereits in der ersten Auflage, ansführlicher aber in der zweiten Auflage der Mneme bekämpft habe: »Denn wie die materiellen Grundlagen der Hirnsubstanz und der Erbmasse grundverschiedene sind, so sind die in beiden ablaufenden Prozesse rerschiedener Natur ${ }^{2}$. Ich habe

1 Hier finde noch folgender Einwand Plates Erwähnung: $>\mathrm{Da} B$ eine Ganglienzelle ein Engramm erleidet und dann bei Wiederholung des Reizes leichter oder auch bei veränderter energetischer Situation ännlich wie früher reagiert, ist nicht so auffallend. Sehen wir doch, daß eine solche , Gewöhnung « auch bei vielen toten Körpern sich zeigt: eine Maschine läuft sich ein, $d . h$. sie geht nach einiger Zeit leichter als am Anfang; eine Geige klingt besser, wenn sie erst eine Zeitlang gespielt wird; hat man etwas metallisches Kupfer in verdünnter Salpetersäure gelöst, so. lüst sich ein zweites Stück Knpfer schneller auf als das erste wegen der katalytischen Wirkung des gelösten Metalls. $\mathrm{DaB}$ aber ein auf die Hut ausgelibter Reiz in seiner Wirkung an der Haut der nächsten Generation wiedererscheint, ist eine total andre Sache. (Selektionsprinzip, 3. Aufl. S. 335.) Während Plate also hier die Vergleichbarkeit der Engraphie bei Keimzellen mit der bei Hirnzellen leugnet, erklürt er die letztere als wohl vergleichbar mit dem Sicheinlaufen einer Maschine oder dem Einspielen einer Geige!

2 0. Hertwig, Die Zelle und die Gewebe, 2. Buch, Jena 1898, S. 251 . 
es nun in Abrede gestellt, daß die materiellen Grundlagen der Hirnsubstanz und der Erbmasse * grundverschieden * sind. Sind diese Grundlagen doch in beiden Fällen kernhaltige Formelemente, Zellen. Hertwig hat sich in seiner Erwiderung ${ }^{1}$ anf meine hiergegen vorgebrachten Argumente uber diesen Punkt folgendermaßen näher ausgesprochen: „Die Verschiedenheit der materiellen Grundlagen besteht also darin, daß die Phänomene der Erblichkeit schon die einzelne Zelle zeigt, daß die Phänomene des Gedächtnisses dagegen erst durch einen besonderen Verband vieler Zelien, durch die Entwicklung eines hochkomplizierten Nervensystems und besonders der Großhirnrinde zustande kommen. D Damit scheint mir aber doch offenbar zugegeben, daß hier von einer Grundverschiedenheit, einer Verschiedenheit des Wesens nicht gesprochen werden kann, sondern $\mathrm{da} B$ es sich lediglich um eine Verschiedenheit der Komplikation handelt.

Eine Grundverschiedenheit der materiellen Grundlage der hier von uns ins Auge gefaßten Prozesse würde allerdings vorliegen, wenn die hypothetischen Beschreibungen und $\mathrm{Ab}$ bildungen, die H. E. Ziegler ${ }^{2}$ von der Bildung der Hirnengramme gibt, Ergebnisse wirklicher Beobachtung wären. Er stellt sie dar in Gestalt von Veränderungen an den Verzweigungen der Zellfortsätze (den Endbäumchen der Dendriten und des Neuriten) sowie als Bildung bzw. Verstärkung von Neurofibrillen. Da wir nun guten Grund zu der An-

1 0. Hertwig, Allgemeine Biologie, 3. Aufl. 1909., S. 661.

2 H. E. Ziegler, Theoretisches zur Tierpsychologie und vergleichenden Neurophysiologie. Biologisches Centralblatt, 20. Bd. 1900. Die betreffenden hypothetischen Beschreibungen and Abbildungen sind auch aufgenommen in die zweite Auflage von Zieglers Abhandlung, Der Begriff des Instinktes einst und jetzt, Jena 1910, S. 88, Fig. 8 u.9. 
nahme haben, daß die Keimzellenengramme, wenn nicht ausschließlich doch sicherlich vorwiegend im Zellkern lokalisiert sind, und es jedenfalls feststeht, daß die Keimzellen weder Endbäumchen noch eine fibrilläre Struktur des Zelleibes nach Art der Nervenzellen besitzen, so würde hier in der Tat eine Grund verschiedenheit der materiellen Grundlagen für die engraphische Veränderung der Keimzelle und der Nervenzelle vorliegen. Bisher hat aber kein menschliches Auge die engraphischen Veränderungen der Hirnzellen, die uns in der Zieglerschen Hypothese in Wort und Bild vorgeführt werden, gesehen; sie besitzen keine Realität. Meiner Ansicht nach besteht sogar die größte Wahršcheinlichkeit, daß die realen engraphischen Veränderungen von ihnen durchaus und in jeder Beziehung verschieden sind. Doch ist es ganz zwecklos uber histologische Fragen zu streiten, die so ganz jenseits der Grenze der Beobachtung liegen und zu deren Ergriindung selbst indirekte Anhaltspunkte fehlen. Wenn Ziegler (a. a. O. 1910, S. 38) mir gegenüber die Forderung aufstelit, »meiner Ansicht nach muß jede physiologische Erklärung sich auf die anatomischen und histologischen Verhältnisse gründen«, so kann ich demgegentiber meinen Standpunkt wie in den früheren Auflagen des vorliegenden Buchs nur dahin präzisieren, daß es zwar vollkommen berechtigt, ja unerläBlich ist, alle Eigenschaften der organischen Körper mit ihrer morphologischen Beschaffenheit, soweit dies ohne Zwang und willkürliche Hypothesen geht, in Beziehung zu bringen (rgl. Mneme, 2. Aufl., S. 37). Daß man aber auf eine Eryrtundung dieser Beziehang notwendigerweise solange zu verzichten hat, als eine der Beobachtung entstammende anatomische Basis uiberbaupt noch fehlt, und man es in ihrer Abwesenheit mit Strukturveränderungen zu tun hat, die wie 
es bei der Zieglersehen Darstellung der Hirnengramme der Fall ist, völlig und ohne Einschränkung der Phantasie entstammen.

Bei dieser Gelegenheit will ich anch noch kurz einen anderen Einwand berühren, der sich zwar nur auf einen einzelnen und noch dazu keineswegs wichtigen Punkt meiner Beweisfuhrung bezieht, der aber schon von mehreren Autoren ${ }^{1}$ in mißverständlicher Weise gegen mich geltend gemacht worden ist, und dem Ziegler (a. a. 0. 1810, S. 38) sogar folgende verallgemeinerte Fassung gegeben hat: >Semon stutzt seine Theorie auf einige von ihm angestellte Experimente an Pflanzen. Die Richtigkeit seiner Beobachtungen wird aber von dem bekannten Botaniker Prof. Pfeffer durchaus bestritten.* Ich glaube nicht, daß die Leser dieses Buchs den Eindruck gehabt haben, ich stutzte meine Theorie auf meine Experimente tuber die Schlafbewegungen der Pflanzen. Ist dies doch nur ein winziger Bruchteil aus einer außerordentlich großen Anzahl von Beweissticken, von denen ich stets hervorgehoben habe, daB ich rein experimentelle Beweise, wie wir sie Chauvin, Kammerer, Standfuß, Fischer, Schröder, Przibram, Sumner, Blaringhem, Klebs, Bordage und noch vielen anderen verdanken, für viel zwingender halte als meine Untersuchungen uber die Tagesperiode und andere Wahrscheinlichkeitsbeweise, die nicht in jedem einzelnen Punkte experimenteller Nachprifung zugänglich sind. Was aber das Wesentliche ist: Pfeffer hat meine Ergebnisse in bezug auf den hier einzig in Betracht kommenden Punkt nicht bestritten sondern bestätigt. (Vgl. das oben S. 94 in der Anmerkang wiedergegebene Zitat dieser Bestätigung.)

1 Vgl. Stand der Frage, S. 20. 
Man hat endlich noch gemeint ${ }^{1}$, die Mnemelehre schiene mit dem Mendelschen Gesetze in Widerspruch zu stehen. Wenn das richtig wäre, so wäre es allerdings schlecht um sie bestellt. $\mathrm{DaB}$ aber daron keine Rede sein kann, habe ich ansfuhrlich im 14, nen eingeschalteten Kapitel dieser Auflage dargetan, wo ich am Schluß gezeigt zu haben glaube, daß unsere Betrachtung der organischen Reproduktionserscheinungen auf gemeinsamer reizphysiologischer Grundlage eine notwendige Ergänzung zur Arbeit der Variations- und Bastardforschung liefert, die zunächst ganz andere Probleme ins Auge faßt, $d a ß$ sie aber in keiner Weise in Widerspruch zu ihr gerät.

Wuirde durch die Bastardforschung tatsächlich der Beweis geführt sein, daß die Ausschaltung je eines allelomorphen Faktors bei der Gametenbildung sich nur im Sinne Mendels und der meisten Bastardforscher als buchstäbliche -Segregation \&, deuten ließe, so muißte man das eben als Tatsache annehmen und die Konsequenz daraus ziehen, daß die einzelnen determinierenden Faktoren bzw. Engramme isolierbare Strukturgebilde seien. Es ist nur eine persönliche und mit den in diesem Buche vorgetragenen Gedanken

1 Vgl. z. B. H. Kranichfeld, Biol. Centralblatt, 27. Bd. 1907. Gewisse Einwände auf dem Gebiet der Psychologie, die dieser Autor vorbringt, so gegen meine Auffassung der engraphischen Aufbewahrung der simultanen Erregungskomplexe, brauchen uns hier nicht zu beschäftigen, da sie bereits durch die weitere Begründung meines Standpunkts in den Mnemischen Empfindungen erledigt werden. Noch weniger erscheint es mir erforderlich, näher auf das einzugehen, was derselbe Autor über die snkzessive Assoziation sagt, deren sUrsaches die Apperzeption sein soll! Anch gewisse Einwürfe Semi Meyers (Archiv f. Rassen- and Gesellschaftsbiologie, 3. Jahrg. 1906) kann ich hier übergehen, da ich sie bereits in meinem ebenda (3. Jahrg. 1906) erschienenen Aufsatz, Kritik und Antikritik der Ifneme, widerlegt zu haben glaube. 
nicht zusammenhängende Ansicht von mir, daß ich die bisher vorliegenden Beweisgründe für eine buchstäbliche Segregation nicht für zwingend balte und glaube, daß sich die Ausschaltung je eines Allelomorphen bei der Gametenbildung auch noch in anderer Weise erklären läßt.

Wie dem aber auch sei: die Mnemetheorie wird davon nicht berührt. Unvereinbar mit ihr wäre nicht eine bloße Isolierbarkeit sondern eine von Anfang an bestehende Isolierung, ein Mangel jeglichen Zusammenhanges und jeder weiteren Anordnung der Determinanten bzw. Engramme. Eine solche wird nun allerdings von manchen Forschern angenommen, die in ihnen nur einen Haufen zusammenhanglos zusammengewürfelter Partikelchen sehen, deren jedes seine besondere chemische Konstitution besitzt, und die, weil ein solcher Faktor unter Umständen auch zu einer Enzymbildung Veranlassung gibt, von Einigen bereits direkt als Enzyme bezeichnet werden. Wie ich indessen oben (S. 363-366) gezeigt habe, steht eine solche Anschaung mit den Erfahrungen in Widerspruch, die uns aus der Entwicklungsphysiologie, den Erscheinungen der Regulation, der Periodizität usw. zufließen; sie kann deshalb auch nicht als Argument gegen die in diesem Buche vorgetragenen Anschauungen verwertet werden.

Ich kann somit nicht finden, daß irgendeiner der bisher vorgebrachten Einwände sich als stichhaltig erwiesen hat, wobei ich übrigens ausdrücklich betone, daß auch ich es noch für ein notwendiges Erfordernis halte, die Gesetze der somatischen Induktion der Keimzelle genauer experimentell zu erforschen, als dies bisher geschehen ist. Überbaupt befinden wir uns ja erst am Anfange eines, wie ich glaube, verheißungsvollen Weges, und ich bin mir völlig klar dar- 
über, daß die Hauptarbeit noch vor uns liegt. Was ich aber gezeigt $z \mathfrak{u}$ haben hoffe, ist, daß kein Hindernis vorliegt, die von uns erkannten mnemischen Grundigesetze als einheitliche reizphysiologische Grundlage bei der Erforschung aller organischen Reproduktionsphänomene zu verwerten. 
Siebzehntes Kapitel.

Die Mneme als erhaltendes Prinzip im Weehsel des organischen Geschehens.

Anknlipfend an den SchluBsatz des vorigen Kapitels will ich jetzt von der Annahme ausgehen, es sei mir gegluckt, auf dem langen und verschlungenen Wege, den ich den Leser geführt habe, den Beweis zu erbringen, daß für alle organischen Reproduktionsphänomene dieselben reizphysiologischen Grundgesetze gelten, daß allen diesen in so verschiedenartigem Gewande auftretenden Erscheinungen ein identisches Prinzip zu Grunde liegt. Ergibt sich uns damit ein allgemeiner Gesichtspunkt für die Auffassung der gewordenen und unablässig werdenden Gestaltung der uns umgebenden organischen Welt?

Die Einflüsse der Außenwelt wirken in zwiefacher Weise verändernd auf den Organismus ein. Erstens im Sinne einer synchronen, vorubergehenden Veränderung; zweitens durch diese hindurch engraphisch verändernd, also dauernd umbildend. Die auf unserem Planeten stets wechselnde, niemals sich absolut genau wiederholende äußere energetische Situation wirkt also als Umgestalterin; die Fähigkeit der organischen Substanz, von jeder Erregung nicht nur synchron, sondern auch engraphisch beeinflußt zu werden, wirkt als 
Erhalterin dieser Umgestaltung in der Flacht der Erscheinungen.

Genügen aber diese beiden Prinzipien, um uns den $\mathrm{Zn}$ stand der organischen Welt, wie er uns bei unseren Forschungen entgegentritt, verständlich zu machen? Keineswegs! Wir finden die Organismen in einem eigentümlichen Verhältnis der Harmonie zu der umgebenden Außenwelt, das man treffend als Anpassung oder als Angepaßtsein an die Lebensbedingungen bezeichnet hat. Für diese Anpassung läßt sich weder ausschließlich die direkte Wirkung der umgestaltenden Außenwelt, noch auch das rein aufbewahrende mnemische Vermögen der organischen Substanzverantwortlich machen. Es bedarf dazu des Hinzutretens eines weiteren Prinzips.

Die Frage nach dem Wesen dieses weiteren Prinzips ist von den Forschern bisher in zweierlei Weise beantwortet worden. Erstens im Sinne der bloßen Umschreibung, indem man es auf andere undefinierte und undefinierbare Größen wie: sinnere Ursachen*, sTrieb* oder *Bediurfnis *, sich einer jeden äußeren Bedingung anzupassen, sich in dieser oder jener Richtung zu entwickeln, zurückfuhrte, und damit von vornherein auf jeden, auch den kleinsten wirklichen Einblick verzichtete. Als die hervorragendsten Vertreter dieses resignierten und jedenfalls gänzlich unfruchtbaren Standpunkts kann man Lamarck ${ }^{1}$ und Nägeli bezeichnen.

1 Es braucht wohl nicht besonders hervorgehoben zu werden daß Lamarck den umbildenden Einfluß der Außenwelt, die Bedeutung der funktionellen Reize und der Übung ganz richtig erkannt hat. Da dieses Prinzip aber nicht ausreicht, um die ganze Fülle der Anpassungserscheinungen zu erklären, und Lamarck das Selektionsprinzip nicht kannte, so half er sich mit Einführung solcher nmschreibender Ausdrücke wie Bedürfnis usw. Am klarsten tritt dies da hervor, wo er die Entstehnng neuer Organe zu erklären 
Der einzige Versuch, die Frage nach jenem Prinzip wirklich zu lösen, ist von Darwin und von Wallace unternommen worden und bedentet, indem er meiner Überzengung nach mit rollständigem Gelingen endete, eine der glänzendsten Taten des menschlichen Geistes. Das Rätsel wurde gelöst durch den Nachweis einer logisch notwendigen und tatsächlich rorhandenen auslesenden Wirkung der Außenwelt, die durch unablässige Beseitignng ron allem weniger gut Angepaßten allein dem Passenden die Gelegenheit einer dauernden, das heißt durch Generationen hindurch danernden Erhaltung gibt.

versucht. Ich verzichte hier auf eine Besprechung der Fortführnng dieser Lehre durch diejenigen >Psycholamarckisten, die die einzelnen Elementarteile der Organismen mit komplizierten psychischen Fähigkeiten, einem sozusagen menschlichen Erkennungsvermögen und Willen ausstatten. Bei solcher Behandlungsweise herrscht nicht mehr das wissenschaftliche Prinzip, die komplizierten Erscheinungen auf einfachere Gesetzmäßigkeiten zurückzuführen, alles, auch den menschlichen Intellekt und sogenannten Willen ans einfacheren Elementen abzaleiten, sondern umgekehrt die grund̈sätzlich abzulehnende Methode, das Komplizierteste unaufgelöst als einfach und gegeben in die Voraussetzung zu nehmen und als Erklärungsprinzip zu verwenden. In der Zulassung einer solchen Methode, wie sie früher von Samuel Butler, neuerdings von A. Pauly angewendet worden ist, whirde ich einen großen und gefährlichen Rückschritt erblicken. Aber selbst dann, weun man diesen Forschern jede von ihnen gew ünschte Konzession nach der Seite ihrer anthropomorphistischen Auffassung der Organismen machen wollte, bliebe es doch unmöglich, auf diese Weise die meisten der sogenannten passiven Anpassungen zu erklären. Was in dieser Beziehung beispielsweise vou den Orchideen und anderen Pfianzen in bezug auf Vorkehrungen für die Insektenbefruchtung geleistet wird, ubertrifft, wenn man es als Produkt von "Denkakte oder sUrteil < seitens der ganzen Pflanze oder ihrer Teile auffassen wollte, in Anbetracht des Fehlens höherer Sinnesorgane bei diesen Organismen bei weitem die höchste intellektnelle Leistung des größten menschlichen Ingeniums. Bis jetzt haben wir nur die Wahl, diese Art von Anpassung entweder durch das Eingreifen eines nicht etwa psychischen, sondern metapвychischen Prinzips oder aber durch natürliche Zuchtwahl zu erklären 
Dieses von Darwin gelegte Fundament hat sich als ein durchaus solides erwiesen und wird durch die Ergebnisse der neueren experimentellen Forschung zwar ergänzt und vertieft, aber wie wir gleich sehen werden selbst da, wo Berichtigungen vorzunehmen sind, nicht erschulttert.

Darwin hat die verschiedenen Arten der Variation nicht so genau zu unterscheiden vermocht, wie es heute auf Grund der ausgezeichneten experimentellen Erforschung dieses Gegenstandes möglich ist. Hier hat er nur die ersten Schritte getan und mußte die weitere Anaijsse seinen Mit- und Nacharbeitern überlassen. Daß diese Nacharbeit erst so spät mit Ernst in Angriff genommen worden ist, war nicht seine Schuld; $d a B$ sie auch fundamentale nene Tatsachen zutage gefördert hat, ist nur naturlich. Die größten Fortschritte in dieser Richtung beruhen ergtens auf der genaueren Unterscheidung der Erblichkeit und Nichterblichkeit der Variationen, auf die Darwin selbst zwar schon geachtet, die er aber nicht im eigentlichen Sinne durohgearbeitet hat. Zweitens aber auf der mittlerweile gewonnenen Erkenntnis, daß die Selektion bereits vorhandene Typen in dem Gemisch von Individuen einer »Population" zwar zu isolieren, aber. im Grunde weder qualitativ noch auch quantitativ neue Eigenschaften zu schaffen vermag:

Die Neuschaffung besorgen in letzter Linie ausschlieBlich die Reize der im steten Wechsel befindlichen Außenwelt. Auch Darwin hat ihnen diese Rolle stets zuerkannt, er hat den direkten Einfluß der Außenwelt nie geleugnet und hat sich stets von einer derartigen Überschätzung des Selektionsprinzips ferngehalten, wie sie durch Weismann unter der Devise "Allmacht der Naturzuchtung* ihre Vertretung gefunden hat. Nicht Darwin, sondern Weismann ist also durch 
die neueren Feststellungen der experimentellen Erblichkeitsforschung widerlegt worden.

Die Tätigkeit der Zuchtwahl ist in der Tat nur eine negative. Aber deshalb übt diese nichtsdestoweniger im Wechsel des organischen Geschehens eine außerordentlich wirksame und in gewissem, gleich zu erläuterndem Sinne sogar eine schöpferische Tätigkeit aus. Die Tätigkeit eines Bildhauers, der eine Gestalt aus einem Marmorblock herausmeißelt, ist

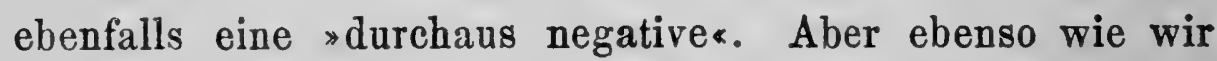
trotzdem in der Laokoongruppe eine schöpferisehe Leistang ihrer Verfertiger erblicken, dürfen wir viele der erstaunlichen Anpassungen, denen wir überall in der organischen Natur begegnen, als das Werk der Zuchtwahl betrachten, obrohl dieselbe ihr Material, die erblichen Variationen, ebensowenig geschaffen hat, wie der Bildhaver den Marmor, aus dem er seine Schöpfung herausmodelliert.

Die Zuehtwahl ist in der Tat bloß die Entfernerin alles Existenzunfähigen. Aber da sie unausgesetzt an der Arbeit ist, dürfen wir uns nicht wundern, tuberall nur Existenzfäbiges, das heißt an die gewöhnlichen Außenbedingungen Angepaßtes, vorzufinden. Dabei ist durchaus nicht alles, was wir in unserer so leicht generalisierenden Auffassung und Benennung der natürlichen Verhältnisse als >zweckmäßig * bezeichnen, ausschließlich anf Selektion zurïckzuführen. Gerade die erstaunlichen Leistungen der Regulation und Regeneration, auf die sich vielfach die Widersacher des Selektionsprinzips berufen, erklären sich, wie wir im dritten Teil dieses Buches gesehen haben, wesentlich aus den konservierenden mnemischen Prinzipien; sie sind nicht, wie z. B. Weismann fur die Regeneration behauptet hat, Kinder der von ihm für allmächtig gehaltenen Zuchtwahl. 
Das, was man als ZweckmäBigkeit in der Welt des Organischen $z \mathfrak{u}$ bezeichnen pflegt, ist demnach verschiedenartiger Herkunft und läßt sich zam mindesten ans zwei Quellen: der Wirksamkeit der natürlichen Auslese und den Manifestationen des konservierenden mnemischen Prinzips, ableiten. Beide Forschungswege, die sich hier öffnen, gestatten es, ganz in den Bahnen der sonstigen naturwissenschaftlichen Forschung zu bleiben, sie erfordern nirgends außer der gewöhnlichen Kausalität, welche zur Erforschung des anorganischen Geschehens genugt, eine besondere Finalitätc (Zielstrebigkeit, Entelechie oder wie man das nennen will), sie machen ein vitalistisches Prinzip überflussig und sind mithin antivitalistisch.

Ebensowenig wie in der Zuchtwahl erblicken wir in der Mneme ein allmächtiges Universalprinzip, das uns für sich ailein schon den Schltussel liefert zum Verständnis des organischen Geschehens. Wir erblicken aber in ihr das fur die organische Entwicklung unumgänglich notwendige erhaltende Prinzip, das die Umbildungen bewahrt, welche die Außenwelt fort und fort schafft. Ihre erhaltende Tätigkeit wird durch einen indirekten Faktor der Anßenwelt, die Auslese, insofern modifiziert, als auf die Dauer nur eine Erbaltung des Passenden zu Stande kommt.

Der Einblick in die Wirksamkeit der Mneme bei der Ontogenese liefert uns auch den Schltussel zum vollen Verständnis des biogenetischen Grundgesetzes, durch dessen Formulierung und Begrlindung Haeckel die Grundlagen der vergleichenden Morphologie in ungeahnter Weise vertieft und erweitert hat. $\mathrm{DaB}$ der von den Vorfahren eingeschlagene Weg der Entwicklung von jedem Nachkommen immer wieder in annähernd gleicher Weise gewandelt werden maß (Palin- 
genese), ist eine selbstrerständliche Konsequenz der Wirksamkeit des von uns näher definierten mnemischen Faktors bei der Ontogenese. $\mathrm{Daß}$ mit der Zeit dieser Weg, besonders in seinen ältesten und deshalb am bäufigsten zurtlckgelegten Anfangsstrecken, hie und da abgektirzt und verändert wird (Caenogenese), ist ebenso selbstrerständlich, wenn wir bedenken, $d a ß$ während jeder neuen Ontogenese neue Originalreize auf den Organismus einwirken und in gunstigen Fällen, das heißt bei ausreichender Stärke der Reize bzw. hinreichender Häufigkeit ihrer Wiederholung in der Reihe der Generationen, ihre engraphischen Wirkungen zu dem alten mnemischen Bestand hinzufügen.

Das Studium der Mneme ist aber nicht nur für die Fragen des organischen Werdens von größter Bedeutung, sondern auch für die des organischen Seins, nicht nur für genetische Probleme, sondern ebenso für eine richtige Beurteilung der Funktionen der gegenwärtig vorliegenden Organismen.

Eine Beschränkung auf das Studium der synchronen Reizwirkung allein fülht zu einer ganz einseitigen Auffassung der reizphysiologischen Erscheinungen, vor allem auch zu einer völligen Verkennung der sogenannten >formativen * Reize. Bei der Mehrzahl der letzteren handelt es sich um nichts anderes als um ekphorische Wirkung gewisser Reize auf ererbte Engramme. Weiter führt dann die Unmöglichkeit, die reizphysiologischen Erscheinungen allein auf Grund der synchronen Reizwirkungen zu verstehen, und die damit verbundene Enttäuschung so Manchen zu einer Rückkehr in die Bahnen des Vitalismus. Diese Enttäuschung und dieser Ruckschritt sind zu vermeiden, wenn die engraphischen Reizwirkungen als solche gebuihrend berïcksichtigt werden, wenn 
erkannt wird, daß die Ekphorie von ererbten und individuell erworbenen Engrammen in jedes physiologische Geschehen hineinspielt, und wenn man daron Abstand nimmt, die Physiologie des Organismus losgelöst von seinen und seiner Voreltern früheren Schicksalen ergründen zu wollen.

Noch sind wir außerordentlich weit von dem Endziel entfernt, die Lebenserscheinungen in allen ihren uns entgegentretenden $\ddot{A} u ß e r u n g e n$ auf rein physikalisch-chemischer Grundlage beschreiben zo können. Aber ich sehe eine entfernte Möglichkeit, diesem fernen Ziel näher zu kommen, wenn man die bisher jeder mechanischen Analyse widerstrebenden Regulationen als Ausgleichsprozesse zusammenwirkender originaler und mnemischer Erregungen auffaßt und weiter erforscht, wozu die ersten Schritte im siebenten und elften Kapitel des vorliegenden Werkes getan sind, und wenn man iberhaupt gewisse Haupträtsel des orgauischen Geschehens auf die mnemischen Fåhigkeiten der reizbaren Substanz zurückführt, eine Zurickführung, deren Grundlinien wir in den voraufgegangenen Darlegungen zu geben versucht haben.

Natürlich müßte gleichzeitig von der anderen Seite her, ron Physikern und Chemikern, auf dasselbe Ziel hingearbeitet und untersucht werden, $a b$ und inwieweit sich etwas der Engraphie und Ekphorie Entsprechendes auf anorganischem Gebiet nachweisen läßt. Bisher liegt etwas Brauchbares in dieser Richtung nicht vor.

Halten wir uns aber zunächst an die Erforschung des Organischen, so finden wir bei gebührender Berïcksichtigung der engraphischen Reizwirkungen das Gebiet der Reizphysiologie in außerordentlicher Weise erweitert. Wir haben gefunden, daß alle organischen Reproduktionsphänomene, ob erblichen oder nicht erblichen Charakters, von derselben 
Gesetzmäßigkeit beherrscht werden, daß sie dieselbe reizphysiologische Basis besitzen. Die Reizphysiologie hat somit dem Studium der rein historischen Engramme dieselbe Berlicksichtigung zuteil werden zu lassen, wie irgendeiner Erscheinung, die sich in allen ihren Phasen im gegenwärtigen Augenblick wiederholen läßt. Auch die Physiologie, als die Wissenschaft vom Lebenden, in der Gegenwart vor uns Ablaufenden, kann die Berücksichtigung des Gewesenen nicht entbehren. Sie gentigt dieser Anfordernng durch Erforschen der Mneme, die Vergangenheit und Gegenwart im Organismus lebendig verkntlpft. 


\section{Sachregister.}

A bhängige Differenzierung 99, 379. Abnahme des Regenerationsvermögens 284.

Abramis 51.

Absolute Werte (der Erregungen) 372.

Abstraktion (durch Homophonie) 224 , logische 225.

Acacia 93, 199.

Actinien 96.

Adventivbildungen 289.

Afterdrohnenbriitigkeit 311.

Akoluthe Erregung 12.

Aland 51.

Albinotische Aberration 77.

Albizzia 93.

Allelomorpha 331.

Allmacht der Naturzüchtung 405.

Alternative, mnemische 144, 230 , $302,327$.

Alytes 74, 322, 328.

Amblystoma 174, 198, 267, 272, 292, 294, 315-321.

Ameisen 52, 136, 307.

Ameisengäste 307.

Amnesie, periodische 196.

Amphibien 241, 282.

Amphioxus 241, 282, 370.

Analogie 386.

Axalogieschlu $B 82$.

Andalusierhuhn 333, 338.

Anneliden 240, 286.
Anpassung 403, 406.

Anstichexperimente 200.

Anuren 290, 292, 321.

Aphasie, amnestische 157.

Aphiden 64, 264.

Apiden 304, 309.

Apis mellifica 303, 306.

Arctia 74.

Artbastarde 347.

Ascaris 370.

Ascidien 240.

Assoziation 34, 48, 378; engere und entferntere 125; simultane 119, 133, 255, 272; sukzessive $125,131,133,192,246,255,364$.

Assoziation ( $\nabla$ on Komponenten verschiedener Engrammschichten) 147,365 .

Asterina 264.

Atavismus 312, 328.

Atemeles 307.

Atrophie 295.

Aufmerksamkeit 225.

Auge (Regeneration) 296.

Aurikel 55.

Ausgebildeter Zustand 274, 277.

Ausschaltung(eines Allelomorphen) $340,347$.

Autonomie (der Formbildung) 384.

Axolotl 173, 198, 267, 272, 292 294, 315-321. 
Bastardforschung 361, 366, 399. Begonia 150.

Behaarung 182.

Bellis 94.

Bembex 141.

Bienen 52, 303, 309.

Biogenetisches Grundgesetz 407.

Blei (Abramis) 51.

Bombinator 102, 103.

Branchiopoden 64 .

- Brauner Bärs 74.

Brunstschwielen 324. 328.

Buche 56, 60, 199. 284.

Bulbus (Regeneration) 297.

Caenogenese 408.

Calendula 94.

Capri 34, 121, 193, 237.

Cephalopoden 52.

Cerebralganglien 185.

Chara 64.

Chiasma 167.

Chronogene Eugramme 61.

Chronogene Ekphorie 61, 87, 91, 104.

Chronogene Lokalisation 171, 381 .

Coloradokäfer $75,155,335,348$, 354.

Crocus 55, 57.

Crustaceen 96, 264, 282, 296, 298.

Ctenophoren 239, 287.

Daphne 555.

Daphnien 22, 45, 46.

Dentalium 286.

Determinanten $179,340,353,355$, 359, 364, 366.

Dichotomie 144, 229, 302, 327.

Dionaea 29.

Disposition 86, 105.

Dixippus 96.

Dominanz 333, 336.
Doppelsinnig gleichwertige Verknüpfung 134 .

Doppelte Persönlichkeit 194.

Ebbe and Fint 96.

Echeneis 51.

Echiniden 256, 287, 335.

Echinodermen 83, 240, 241, 282, 370.

Eigenbezirk (der Erregung) 160, 163,300 .

Ekphorie 19, 186, 409; chronogene $61,87,91,104$; phasogene 62 , $72,77,87,96,101,104$; sukzessive 191 ; vikariierende 260 .

Ekphorische Einflüsse 19, 38.

Ekphorische Reize 19.

Ekphorische Wirkung Stufenleiter 197.

Elementare Energie 6.

Elementarenergetische Situation 8.

Elster 89.

Empfindungsdifferential 208.

Empfindungsmanifestation 38 .

Energetische Situation 7, 8 .

Engramm 15, 380, 390, 410.

Engrammschatz 15, 152, 169.

Engrammschichten 147.

Engraphie 409.

Engraphische Empfänglichkeit 16.

Engraphischer Reiz 27.

Engraphische Wirkung 15.

Entelechie 384, 407.

Entwicklungserregung 261.

Entwicklungsphysiologie (Entwicklungsmechanik) 362,366 . 400.

Ergatogyne Formen 307.

Erinnerungsbild 15, 119, 390.

Erregung 5.

Erregangsenergetische Situation 8.

Erregungsenergie 6 .

Erschöpfung(einer Disposition) 105 . 
Euchelia 50.

Euplocamus 347.

Fagus silvatica $56,60,199,284$. Falken 170.

Farne 265.

Fagan $49,88$.

Finalitit 407.

Fische 50, 241, 282.

Fissura parieto-occipitalis 157 .

Flagellaten 29.

Forelle 290.

Formativer Einfluß 298, 300 .

Formica 308.

Foxterrier 212.

Frühgeburt, erzwungene 73, 237.

Fuchs 213.

Futter (für Arbeiter- und Königinlarve) $304,306$.

Galonthus 55.

Galathea 282.

Galloway-Rind 313 .

Gametenbildung 340,349 .

Gametenkupplung 363.

Ganglienzelle 394.

Ganglion opticúm 297.

Garneele 95.

Gastrulation 97, 100, 256.

Geburtshelferkröte $322,328$.

Gedächtnis 15, 390, 391.

Generationsfolge 63.

Geruchssinn 135; topochemischer 137.

Gespenstheuschrecke 96.

Getreidekulturen 78.

Gleditchia 61.

Gleichzeitigkeit 128.

Goethesches Gedicht 145, 228.

Gottesanbeterin 178.

Grabwespe 141, 142.

Gracilaria 74, 178.

Grasfrosch 101, 102.

Großhirnrinde 157, 168. 西集aarwachstum 182.

Hafer 359.

Hasen 318.

Hauptsatz, erster mnemischer 200, 378, zweiter mnemischer 201 , 378.

Haut 357.

Heliotaxis 220.

Heliotropismus 109, 220.

Hemmungsfaktor 363.

Heschlsche Windung 172.

Heterochelie 299.

Heterochronie 143.

Heteromorphose 143, 298.

Heterozygoten 342.

Hippolyte 95.

Hirsch 213.

Hörsphäre 172.

Homeosis 298.

Homo 292.

Homophonie 209, 242, 283; 360, $373,378,382$; von Originalerregungen 209.

Homozygoten 342 .

Honigbiene 303, 306.

Huhn 49, 88.

Hummeln. 309 .

Fund 18, 170, 212.

Hydra 149, 281, 288.

Hydromedusen 241.

Hydrophobie 160.

Hymenopteren 185.

dentitåt 386 .

Idus 51.

Ilyanassa 286.

Inaktivitäsatrophio 295.

Indifferenzzustand 7, 14, 24, 35 .

Individualität, mnemische 259 .

Individualitätsphase 26, 258, 279. Induktion, parallele 180, 353, 385, 393 ; somatische $180,353,385$. 393. 
Infusorien $21,29,150$.

Initialengramm 259.

Inkongruenz bzw. Kongruenz (bei Homophonie) 207, 212, 214, 216. 219 ; 221, 242, 296, 371.

Insekten 264.

Intensität der Erregungen) 202.359.

Intermediäres Merkmal 333, 338, $347,350$.

Intermediäre Vererbung 347, 360 .

Intoxikation 194.

Introspektion 39, 392.

Isolation (der Leitung) 159, 161 .

Jahresperiode 54, 92, 278.

Käfer 74, 8. auch Kartoffelblattkäfer.

Kaninchen 348, 360 .

Kartoffelblattkäfer 75, 155, 335, $348,354$.

Katarakt 346.

Kaulquappe 289, 322.

Keimplasma 180.

Keimzellen 155, 179, 385, 394.

Kernplasmarelation 101, 373.

Kieferfüße 329.

Klangengramme 172.

Kniehöcker 167.

Knochenfische 50, 241, 282.

Knochenheilung (Nerveneinfluß) 296.

Körpernhr 60.

Kongruenz (bei Homophonie) 242, 246; s. auch Inkongruenz.

Konstante Bastardrassen 348, 360.

Korrelationen, Brechen derselben $357,363$.

Krabben 329.

Kreuzung 331.

Kurzfingrigkeit 346.

Lachsembryo 102.

Lanice 286.
Lasius 138.

Latenzstadium 86.

Lathyrus 334.

Launenhaftigkeit, scheinbare, der Vererbung 354.

Liebermoose 37.

Leontodon 150.

Leporiden 348.

Leptinotarsa $75,155,335,348,354$.

Leticojum .55, 57.

Lichtstimmung 23.

Ligulamerkmal 360 .

Linse (des Auges) 101, 200, 235.

Lockrufe 213.

Lokalisation 149, 154, 158, 171 , $183,186,286,289,293,299,300$, $365,381,394$.

Lomechusa 307, 308.

Lonicera' 56.

Macula Intea 167.

Mäuse 357.

Matthiola 334.

Mechanik 85.

Medulla oblongata 160 .

Medusen 282, 370.

Melanotische Aberration 77.

Membranbildung 260, 262.

Mendelsches Gesetz 111, 399.

Menstruation 53.

Mimosa 25, 42, 199.

Mirabilis Jalapa 338.

Mischreaktion 229, 305, 333, 349 .

Mitbewegungen 160 .

Mneme 15.

Mnemische Erregung 15, 187, 202 , 390.

Mnemische Hauptsätze 200, 201,378.

Mollusken 96, 240, 286.

Morphogener Erregungskomplex, 244.

Morphogener Engrammkomplex 245. 
Muschelkalk 83.

Muskulatur 295.

Mritationstheorie 355 .

Myrmica 308.

Myzostoma 286.

Nachbild 12.

Nacheinander (von Erregangen) 127.

Nachwirkung 12, 23.

Narkotisierung (von Pflanzen) 57.

Nebeneinander (von Erregungen) 116, 123, 124, 127.

Negative Schwankung 4 .

Neoplastische Fähigkeit 292.

Nereis 286.

Nestbau 215.

(1) berbewußtsein 168, 217.

Objektive Methode 41.

0ccipitallappen 167.

Ocneria 74.

Öffnungszuckung 13.

ölgerach 34, 121, 193, 204, 237.

Oenothera 348, 355 .

Ohrenlinge 360.

Originalerregung 20, 202, 390 .

Originalreiz 20.

Ovidukt 177.

Pädogenese 275.

Palaemon squilla 96.

Palingenese 407.

Palolowurm 278.

Parallelinduktion 180, 353.

Parthenogenese 64, 260.

Partielle Wiederkehr (der energetischen Situation) 98, 201, 378.

Patella 286.

Pendeln (der Ekphorie) 305.

Periodizitï 278, 362, 400.

Perlhuhn 49.

Pfirsichbaum 80, 199.
Pharynx 371.

Phaseneinteilung (der Ontogenese) 251.

Phratora 74.

Phylloxeren 64.

Pisum 357.

Planarien 149, 281.

Pleiotypie 347.

PolarungleichwertigeVerknüpfung 134, 140.

Porcellana 282.

Portunus 282.

Positionsreiz 37, 244.

Presence-and Absence-Theorie 332.

Proportionale Veränderbarkeit367. Protomer, mnemisches 152, 165.

Pseudogynen 307.

Radiumstrahlung 27.

Rana. esculenta 102, fúsca 101, 102,265 , palustris 102,103 , silvatica 102.

Rassenbastarde 347.

Ratten 357.

Raupen 106.

Reaktion 91, 220.

Reaktionsfihigkeit 14, 26.

Recessivität 333.

Reduktionsteilung 350 .

Reflexe, ungeordnete 160 .

Reflexkrïmpfe 161, 162.

Regeneration 106, 153; 277, 281, 329, 362. 406.

Regenerationsstumpf 295.

Regulation $248,282,362,400,406$, 409.

Reh 213, 265.

Reiz 1, 10, 263; formativer 261.

Reizbarkeit 107.

Reizdefinition 10.

Reizpforte 179.

Reizphysiologie 384, 410. 
Sachregister.

Reizstoffe 307.

Reizsummation $28,45,162$.

Reizwirkung 327,385 ; engraphische 27, 380, 409.

Reizworte 206.

Reproduktion 202.

Réunion 80.

Rezeptoren (der Reize) 117, 183, 393.

Rhythmus (der Abläufe) 369.

Ringelwuirmer 96.

Robinia 61 .

Rotatorien 64, 264.

Rückschlag 328 , nach Kreuzung 330 , spontaner 331 .

Saaterbse 337 .

Salamandra $69,73,177,237,272$, $292,320$.

Salamandrina $290,292$.

Salamandrinen 266, 269, $272,320$.

Scheckung 346.

Schiffshalter (Schildfisch) $\mathbf{5 1}$.

Schlafbewegungen 398.

Schlundganglion, oberes 185.

Schmetterlinge 74 .

Schnecken 96.

Schwellenwert 28, 45, 162.

Schreitbeine 329.

Sehubfach-Lokalisation 158, 394.

Schweißdrïsen 182.

Scilla 55.

Scorzonera 150 .

Seesterne 264.

Segregation 344, 346, 350, 399.

Sehsphäre 168.

Sélbstdifferenzierung 99,379 .

Selektion 176, 179, 406.

Selektionstheorie $267,404$.

Sensible Periode (der Keimzellen) $155,183,354$.

Silberfasan 347.
Simultaner Engrammkomplex 118, 129.

Simultaner Erregungskomplex 118. Siredon 174, 198, 267, 272, 292, $294,315-321$.

Soma 179.

Somatische Induktion 353 :

Southdown-Schaf 313.

Spätgeburt erzwungene 70, 237.

Spezifische Energie 164:

Sphex 142.

Sphodromantis 178.

Spongien 289 .

Spontane Mutationen 355 .

Sports 355.

Sprungvariationen 355.

s Spurious allelomorphism 363 .

Stäbchen und Zapfen 117.

Stentor 150, 151.

Sterilität 309.

Stimmung 23.

Strauß (Kilcken) 88.

Strongylocentrotus $285,288$.

Strudelwürmer 96.

Strychninvergiftung 160 .

Subjektive Methode 40.

Subkortikale Abschnitte 171.

Subliminale Reizstärke 28.

Suffolk-Rind 313 .

Synapta 97.

Synchrone Erregung 11.

Syringen 56 .

Tagesperiode $93,95,278,398$.

Tauben 170.

Teleostier 50, 241, 282.

Temporallappen 157.

Temporalwindung, erste 172.

Terminologie $15,390$.

Termiten $308,310$.

Tetanus 160.

Thalamus 167.

Thigmomorphose 235 . 
Tintenfische 52.

Topochemischer Geruchssinn 137. Transformation (der Reize) 393. Treiben (Forcieren) 55, 92. Trichotomie 144.

Triton 267, 291, 292, 320.

Typenphotographie 223.

Übergreifen der Errregung 160. Übung 47.

Unschreibung 379 .

Unke 102.

Unterschiedempfinden 208, 218 .

Unterschiedsreaktion 208.

Urodelen 290, 292, 297.

Variationsforschung $361,366,399$.

Vegetative Spaltung 340.

Vererbung 63; 'erworbener Eigenschaften 111, 179, 185, 385.

Vierhüigel 167.

Vitalismus 366, 384, 407, 408.

Vividität(der Erregungen) 202, 359.

Vorticella 21.

Wabenbau 216.

Wärmeregulation 181.
Wabrscheinlichkeitsrechning 341 , $344,349$.

Wandertrieb 92.

Warmbliiter 281.

Wasserfrosch 102, 103.

Wasserhuhn 49 .

Weberrọgel 283.

Weizen 359.

Wespen 52.

Wiedererkennen 44, 208, 218.

Wiederholbare Vorgånge 83.

Wiederholung, 222, 230, 236, 359.

Wiirmer 96.

Wunderblume 338.

Wundheilung (Nerveneinfluß) 296.

Kenodus 307.

Wahmheit, erblich erworbene 178.

Zeit, Zeitablauf 53, 59. Zellkern 397.

Zentralnervensystem, Einduß auf Regeneration 293, 298.

Zuchtivahl 176, 179, 406.

ZW eckmäßigkeit 406.

Zygoten 342.

Zyklischer Ablauf 278.

Zytolyse 261. 


\section{A utorenregister.}

Aikins, H. A. 21.

Askenasy, E. 57.

Bardeen, H. 149.

Barfurth, D. 289, 294 .

Bateson, W. 332, 363 .

Bethe, A. 137.

Biedermann, W. 28, 30.

Bischoff, I'h. 265.

Blaringhem, L. 111, 238, 352, 398.

Bohn, G. 21, 96.

Bordage, E. 79, 111, 238, 245, 352 . 398.

Butler, S. V, 404.

Buttel-Reepen, H. v. 304, 306, 309.

Boveri, Th. 100, 285, 287.

Cannon, W. B. 22, 45.46.

Charbonnier 89.

Chauvin, M. v. $73,111,173,198$, $238,245,315-320,352,398$.

Cieslar, A. 79.

Claypole 88.

Conrad 348.

Crampton, H. E. 286.

Darwin, Ch. 122, 313, 330, 355, 404, 405.

Darwin, E. III.

Darwin, Fr. 13, 21, 394.

Dayenport, Ch. B. 22, 45, 46, 330.
Detto, C. 389.

Doncaster, L. 335.

Driesch, H. 100, 257, 286, 370, 391 .

Duméril, A. M. C. 315 .

Ebbinghais, H. 132, 138 .

Edinger, L. 51.

Escherich, K. 310.

Fabre, J. 141.

Fielde, A. M. 310.

Fischer, A. 284.

Fischer, E. 74, 111, 238, 245, 352, 398.

Forel, A. VI, 136, 307, 310.

Gamble, P. W: 95 .

Ghinst, van der 21.

Goldstein, K. 294.

Goltz, F. 170.

Grassi, B. 310.

Haeckel, E. IV, VI, 407.

Hansemann, D. v. 176.

Harrieon, R. G, 294.

Helmholtz, H. 41.

Herbst, C. $101,296,335$.

Hering, E. IV-VI, 41, 164.

Hertwig, $0.27,362,387,395,396$.

Hodge, C. F. 21.

Hoffmann 79. 
Huber, P. 90.

Hume D. 225.

Huxley, $\mathrm{Th} .225$.

Janet, Ch. 307.

Jennings, H. S. 21.

Tammerer，P. $69,74,111,177$, $238,245,290,323,352,398$.

Keeble, F. W. 95.

Keibel, F. 265.

Kern, B. 387.

King, H. D. 102.

Klebs, G. 111, 238, 352, 398.

Klein 304, 306.

Kranichfeld; H. 399.

Eamarck; J. 403.

Lang, A. 360.

Laycock, F. IV.

Lewis, W. H. 102.

Loeb, J. 260-264, 294.

Lubbock; J. 310.

Mas, 0. 289, 297.

Mach, E. VI.

Macnish 195.

Mayer, R. 380.

Mayr, H. 61.

Mencl, E. 102.

Mendel, Gr. 111, 333, 336, 337, $339,344,399$.

Metschnikoff, E. 370 .

Meyer, Semi 399.

Monakow, C. v. 158, 167, 172.

Morgan, C. Lloyd 49, 88.

Morgan, Th. H. 100, 149, 346, 371.

Muller, J. 41.

Nägeli, C. 403.

Nagel, W. 165.

Nilsson-Ehle, H. 331, 356, 359, 360, 363.
Oitmanns, F. 23.

Orr, H. B. IV.

Pauly, A. 404.

Pertz, D. F. M. 13, 22.

Pfeffer, W. 36, 93, 398.

Philippeanx, J. M. 297.

Pictet, A. 73, 77, 111, 238, 352.

Planta 306.

Plate, L. 389, 392, 394, 395.

Przibram, H. 111, 178, 181, 238, 282, 294, 298, 329, 357, 398.

IRaffrele 294.

Reichenbach, H. 310, 311.

Ribot, Th. III, 195.

Rieger, K. 395.

Romanes, D. J. 90.

Rosenthal, J. 391.

Roux, W. 99, 200, 225, 362:

Rubin, R. 294.

Schaper, A. 294.

Schleip, W. 96.

Schrader, M. E. G. 170.

Schröder, Chr. 74, 111, 178, 238, $352,398$.

Schibelex, F. C. 78, 111.

Schultze, 0. 265.

Schuppe, W. 10.

Selenka, E. 97.

Silvestri, F. 310.

Spallanzani, L. 290.

Spemann, H. 101.

StandfuB, M. 74, 111, 238, 245, $352,398$.

Steinach, E. 29, 30.

Stoppel, R. 94.

Sumner, F. B. 111, 181, 238, 352, $357,398$.

Tanner 310, 311.

Tennent, D. H. 335 . 


\section{Autorenregister.}

Tower, W. L. 74, 111, 155, 183, $238,245,335,345,348,352-355$, 365.

Tschermak, E. v. 335.

Vernon, H. N. 335.

Viehmeyer, H. 308, 310.

Vries, H. de $313,330,348,355$.
Wallace, A. R. 404.

Wasmann, E. 137, 307, 310.

Weismann, A. 180, 316, 385, 405.

Wettstein, R. v: 79.

Wheeler, W. M. 307, 310, 311.

Wille, N. 78.

Ziegler, H. E. $396-398$. zur Straßen 370. 



